

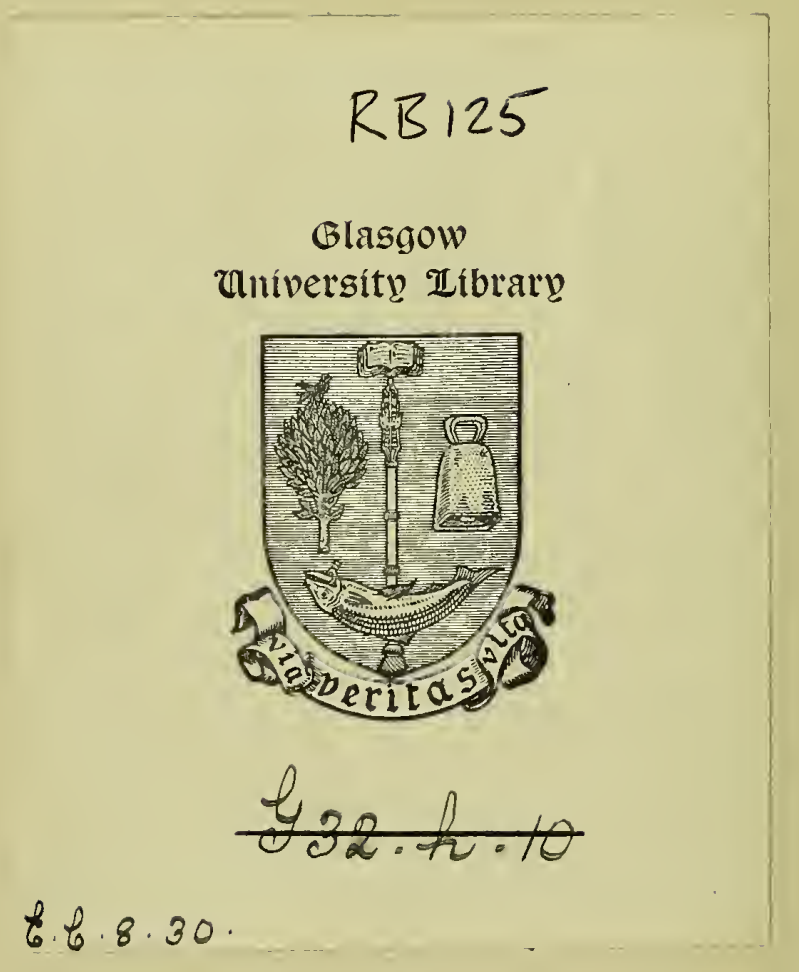


Digitized by the Internet Archive in 2016

https://archive.org/details/b24923400_0001 


SPRAT, GeOge 


\title{
FLORA MEDICA:
}

CONTAINING

\section{COLOURED DELINEATIGNS}

OF THE VARIOUS

\section{E D I C I N A L P LA N T S}

ADMITED INTO

THE LONDON, EDINBURGH, AND DUBLIN PHARMACOPEIAS;

WITH THEIR

NATURAL HISTORY, BOTANICAL DESCRIPTIONS,

MEDICAL AND CHEMICAL PROPERTIES, \&c. \&c.;

TOGE'THER WITI

A CONCISE INTRODUCTION TO BOTANY;

A COPIOUS Glossary OF

\section{BOTAN I CAL TERMS;}

\author{
AYD A LIST OF \\ POISONOUS PLANTS,
}

\&c. \&c.

EDITED BY

A MEMbER OF THE ROYAL COLLEGE OF PHYSICIANS, AND FELLOW OF THE LINNAAN SOCIETY;

WITH THE ASSISTANCE OF SEVERAL EMINENT BOTANIS'TS.

IN TWO VOLUMES.

VOL. I.

LONDON :

CALLOW AND WILSON, PRINCES STREET, SOHO. 



\section{A D D R ESS.}

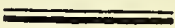

ON completing the First Volume of the Flora Medica we conceive it a paramount duty, to return unfeigned thanks to our Subscribers, and to the Profession at large, for the countenance and encouragement which they have bestowed upon our arduous undertaking.

In commencing our labours emolument was not our object, but a desire to furnish the Profession with a scientific and standard work on Medical Botany, in as small a compass as possible and at a price hitherto unprecedented.

How far we have succeeded in our endeavours is best shewn by the high patronage, and the numerous flattering testimonials which have already been bestowed upon the work; and these proofs that our efforts have been attended with some success, afford us the highest gratification which we can possibly receive. 
In every department of the work the greatest care has been taken to render it practically useful, by collecting information from the best authorities, and by sparing no expense to render the Plates correct and faithful representations of the Plants described.

We flatter ourselves also, upon comparing the early with the later numbers, that a progressive improvement will be found to have taken place, in every part of the work.

The extreme low price which we have put upon the Flora Medica, leaves us no pecuniary remuneration; but the gratification of having done our utmost to advance a Science so important to Medical Men as that of Botany is our reward; and will stimulate our exertions throughout the Second Volume, which we pledge ourselves shall in every respect equal that now presented to the public.

London, December, 1828. 


\title{
CONTENTS.
}

\author{
VOL. I.
}

\section{Dedication}

Address

Introduction

Botanical Terms and Definitions.

Acacia Catechu ......... 181

Vera 176

Aconitum Napellus ...... 18

Acorus Calamus......... 58 Esculus Hippocastanum .. 11 Althæa Officinalis ....... 26 Amygdalus Communis .... I 1 Anchusa Tinctoria ....... 220 Anthemis Nobilis ....... 73 Arbutus Uva Ursi ....... 115 Artemisia Abrotanum .... 100 Absinthium .... 96 Maritima ...... 98 Santonica ...... 99

Arum Maculatum ........ 218 Asarum Europaum ..... 45 A tropa Belladonna....... 132
PAGE

Capsicum Annuum....... 91

Carum Carui ........... 191

Cassia Sennà .......... 128

Cephälis Ipecacuanha .... 148

Citrus Aurantium ...... 53

Medica ......... 187

Cochlearia Armoracia .... 228

Officinalis...... 226

Colchicum Autumnale .... 47

Conium Maculatum ..... 143

Convolvulus Jalapa ..... 202

Scammonia .... 157

Crocus Sativus ........ 70

Croton Tiglium ......... 30

Daphne Mezereum ...., 13

Datura Stramonium ..... 125

Daucus Carota ......... 104

Delphinium Staphisagria .. 86

Dianthus Caryophyllus .... 155

Digitalis Purpurea....... 33

Fraxinus Ornus ......... 205 
CONTENTS.

\begin{tabular}{|c|c|}
\hline & \\
\hline & \\
\hline ....... 193 & Origanum Vulgare \\
\hline eum Urbanum $\ldots \ldots \ldots \ldots$ 193 & \\
\hline la Otficinalis........ 174 & Oxalis Acetosella ...... \\
\hline ..... 139 & \\
\hline & Papaver Rhœas .......... \\
\hline elleborus Fœtidus & Somniferum ....... \\
\hline _ Niger ........ & Polygonum Bistorta ...... \\
\hline lyoscyamus Niger $\ldots \ldots .22$ & enatum .... \\
\hline nula Helenium . . & Rheum Palmatum ....... 119 \\
\hline ris Florentina $\ldots \ldots \ldots \ldots 161$ & Rosa Canina...$\ldots \ldots \ldots$ \\
\hline & Rosmarinus Officinalis $\ldots$. \\
\hline Lactuca Virosa . . . . . . . 37 & Kuta Graveolens $\ldots \ldots \cdots$ \\
\hline avandula Spica $\quad \ldots \ldots \ldots .94$ & Salix Fragilis ....... \\
\hline Leontodon Taraxacum .... 59 & Salvia Officinalis $\ldots \ldots \ldots 110$ \\
\hline Catharticum ..... 109 & Sambucus Nigra........ 117 \\
\hline : & $\begin{array}{l}\text { Sinapis Alba ............ } \\
\text { Solanum Dulcamara ...... }\end{array}$ \\
\hline Ialva Sylvestris......... 15 & Spartium Scoparium ..... 147 \\
\hline Marrubium Vulgare .. & Spigelia Marilandica ..... 51 \\
\hline Melaleuca Cajuputi $\ldots \ldots \ldots 214$ & Styrax Officinale $\ldots \ldots \ldots$ \\
\hline ..... 166 & \\
\hline :...... 163 & Tussilago Farfara ....... 112 \\
\hline rdica Elaterium $\ldots . \quad 27$ & \\
\hline Morus Nigra .......... 225 & Iana Officinalis ...... 210 \\
\hline Tinction & cbunga $\ldots .213$ \\
\hline Nicotiana Tabacum $\ldots . . .195$ & Viola Odorata $\ldots \ldots \ldots \ldots 160$ \\
\hline
\end{tabular}




\section{INTRODUCTION.}

Botany, from the Grcek Bozáyn (a branch of which is to form the subject of the present work), in the more extensive signification of the term, is that science which treats of the elements, the inmediate principles, the internal and external structure, the functions, the organs, and the similitudes and dissimilitudes of the multitude of beings which constitute the vegetable kingdom : in its more limited sense, it is that science which teaches us to compare, to describe, and to name plants; and to class them according to the inutual affinities which are indicated by their external eharacters. Sil James Smith divides Botany into threc branches-lst. the physiology of plants-2dly. the systematical arrangement and denomination of their several kinds, and 3dly. their economical or medical properties. Medical Botany is the application of the science to the purposes of medicine, or in other words, it is the botanical description and chemical analysis of those plants which have been found to possess medical properties, and which are now used in the healing art. From this definition of the term, it is obvious that a knowledge of regetable chemistry is indispensable to the student, who would wish to make himself thoroughly acquainted with this important science; but as chemistry in all its branches, forms a necessary and distinct part of a medical education, we shall in the present work confine ourselves, for the most part, to the Descriptive Botany, and the sensiblc properties and action on the human frame of those plants, which are now generally received in the Plarmacopoins of the Colleges; premising, at the same time, that, when treating of plants, whose chemical analysis it may be important to give, we shall use the terms of that science with a presumption that the student is alrcady acquainted with them.

If we confue the term Medical Botany to the mere description of a plant, with a detail of its properties and actions on 
the living system, it is perhaps one of the most ancient of all the sciences; nor is this to be wondered at, when we consider that before the mineral world was explored, and its hidden stores, by the aid of chemistry, made subservient to medical purposes and the other uses of man, the vegetable productions were the only medicines known. Covered as the surface of the earth is with the spontaneous productions of nature, it was natural for its inhabitants, in the first instance, to resort to such a ready source, without seeking in its bowels the means of preserving or restoring health; and it is worthy of remark, that the virtues of many of our most active medicinal plants, were known to the common pcople of these countries long before those plants obtained a place in the Materia Medica of the Colleges : of these we may mention Digitalis, Colchicum, \&c.

In the East the greatest care was taken to acquire a knowledge of the beneficial or noxious qualities of different vegetable productions : the Chaldeans communicated their knowledge to the Egyptians, and these to the Greeks. In Greece, we are told that Fsculapius attempted, by means derived from the vegetable kingdom, to cure various diseases; his prescriptious were hung up in the temples, and finally, he was himself deified as the god of medicine, and temples erected to his lonor. Hippocrates, (styled the father of medicine,) added to the observatious of Esculapius, and in his works he makes mention of about two hundred and thirty medicinal plants, few, if any, of which are now known to us by the descriptions he has left. From the time of Hippocrates, the science of Medical Botany seems to have attracted the attention of a number of succeeding philosophers, but by all of them fable was blended with trutl, and miraculous powers, suited to the superstition of the times, were ascribed to various herbs. Thus Pythagoras, the Samiau, the first who is known to have written any treatise on Botany, absurdly affirmed that the Scilla Maratima, when preserved in vinegar, had the power of extendiug human existence; he also declared the virtues of Anise against the bite of scorpions; and eulogized the powers of Brassica, Sinapis, \&c. But it is to Aristotle we are indebted for first treating of Botany as a philosophical science, and his labours were ably followed up by his disciple Theophrastus, who flourished about 350 years 
B. C. In his "Historia Plantarum," he described all the plants which were known in his day, but without pursuing any order in the arrangement, and often applying the same name to plants extremely different. The physiology of plants, appears to have attracted the particular attention of this philosopher; the physiology of trees was tolerably well understood by him, and he distinguished between the structure of the trunks of palms and other trees, or in modern terms, between Monocotyledones and Dicotyledones. He discovered that nutrition was conveyed to plants by the leaves, but he attributed this power alike to both surfaces: the sexes of plants he likewise seemed to have some confused notion of.

Of the Roman Botanists, the first author whose writings are still considered of value, is Dioscorides, who lived under Nero, but his descriptions are very imperfect, and in many instances, he only gives the names of the plants. His catalogue however, of the plants of Greece and Italy, was the most complete which had been compiled at that time. To Dioscorides succeeded Pliny and Galen; the latter of whom, confined himsclf exclusively to Medical Botany. It would be equally tedious and unnecessary to enumerate all the botanical pretenders who existed in the middle ages, and although, after the revival of learning, several eminent names stand recorded in the history of botanical science, and from whose labours and researches, writers of a later pcriod have derived considerable assistancc, there are few of them whose works would now be of any value to the mcre student. It will, therefore, be sufficient to mention the names of Bock, Clusius, and Cæsalpinus, whose writings when they can be procured, are among the most valuable in the science; John Bauhin and his brother, natives of Lyons, whose labours were truly herculean; Boerhave and Tournefort.

But whatever fame these later writers might have hoped to gain, was entirely eclipsed by the gigantic genius of the great Linnæus, who, if we may be allowed the expression, rescned the material world from a second chaos, and laid the foundation for, if he did not actually establish, that beautiful system of scientific classification in which the animal, vegetable, and mineral kingdoms are now arranged. Before his time, it might be truly said that, natural history, as a science, was without 
form, and darkness was upon the face of it. But as the system of 'Tournefort, which appeared about the end of the seventeenth century, was cousidered at the time extremely beautiful, and was adopted in $\mathrm{F}_{\text {rance, }}$ with the greatest enthusiasm, where he probably has still some disciples, it may not be amiss to give a brief outline of it.

The first division of Tournefort was into herbs and trees, and these were again subdivided into those with a corolla, and those without. The trees with a corolla were divided into monopetalous and polypetalous, and those, regular or irregular. Herbs with a corolla had that part eitlier compound, as in the thistle, dandelion, \&c. or simple; these last were again subdivided into monopetalous and polypetalous, and both subdivisions into regular or irregular. By the fillal sections or classes of this system, herbs with a simple, monopetalous, regular corolla, were' either bell-shaped, or funnel-shaped; those with irregular corollas were, either anomalous, or labiate. Herbs with a simple, polypetalous, regular corolla, were cruciform, rosaceous, umbellate, pink-like, or libiaceous ; those with an irregular one, papilionaceous, or anomalous. The further subdivisions of his classes were founded on the fruit.

It would be uncandid not to admit that the foregoing system had much of ingenuity in it, but it was soon discovered that it could never provide for all the forms of corolla which the vegetable kingdom might present, and it soon gave way before the more comprehensive sexual system of the great Linnæus. This philosopher having proved that the stamens and pistil of a plant were the organs the most essential to its being, conceived the idea of making them subservient to a general system of classification, by reference to their number, situation, and proportion. Having decided upon this, he distinguished the vegetable as well as the animal kingdom into genera, species, and variefies. By species is to be understood those plants supposed to be established at the creation, and which have ever since continned to cover the surface of the earth ; founded on the, presumption that neither has any species been altogether lost, nor any new one permanently established. A genus includes one or more species, possessing sufficient resemblance in their nature and formation as to 
eonstitute a family or kind: thus, for example, the various speeies of roses eonstitute a well known genus, at once distinguishable to the most superficial observer. By varieties is of course understood any deviation in a partieular speeies from those external eharaeters which mark the other individuals of the same speeies, many familiar examples of whieh will occur in the eonrse of this work. Aceording to Linnæus, a plant consists of a root, trunk, leaves, props, fructifieation, infloreseence, and habit. 1. The root eonsists of two parts; the eaudex or stump, which may be either solid as in trees, bulbous, as in the lily, or tuberous, as the earrot, potatoe, \&e.; the radieula, whieh is the fibrous part of the root, by which it receives nourishment from the ground. 2. The trunk is the part which rises immediately from the eaudex, and produces the leaves, flowers, and fruit ; it is either herbaeeous, shrubby, or arboreseent. 3. The leaves are either simple or eompound, and are distinguished by their situation, insertion, \&c. 4. 'The props are those external parts whieh strengthen, support, or defend the plant, as the tendrils of some, and the thorus of others. 5. The fruetifieation or mode of fruit bearing, eronsists of the ealyx, eorolla, stanina, pistillum, periearpium, semina, and receptaeulum. 6. 'The inflorescenee, or mode by whieh flowers are joined to their several peduncles. 7 . The habit or external appearance, applied to the agreement of plants of the same genus, or natural order. 'To these may be added the hybernaenlum, or winter lodgement, which is the part of a plant that defends the embryo, or future shoot, from injury during the winter, and is either a bulb, as in the lilly, tulip, \&c., or a bud, whieh is the embryo of the plant, seated on the stem of the branches. In general there are three sorts of buds; that eontaining the flower only, as in popiar, ash, \& e. where the leaf-bud and flower-bud are distinet; that eontaining the leaves only, as in bireh; and that containing both flowers and leaves, as in the generality of plants. 'The generic charaeters of Linnæus are taken exclusively from the seven parts of fructifieation, viz. the calyx, eorolla, stamen, pistillum, pericarpium, semina, and receptaeulum.

These several parts we shall briefly describe: 1. The calyx, or cup, is the termination of the outer bark of a plant. Its chief use is to enclose, support, and protect the other 
parts of fructification; when present it is seated on the recep-tacle, and is distinguished by its figure, by the number, division, and shape of its leaves or segments, and is variously named, according to the circumstances with, which it is attended, as perianthium, involucrum, amentum, \&c., these terms are liereafter explained.

2. 'The corolla is the termination of the inner bark of the plants, and accompanies the fructification in the for'm of leaves, variously coloured, under the general name of the flower of the plant: it is generally seated on the receptacle, sometimes on the calyx. 'The leaves of the corolla are called petals, by the number, division and shape of which it is distinguished. The nectarium is usually an appendage to the petals of the corolla.

3. 'The stamina, or male parts of the flower, proceed from the wood of the plant; each stamen consisis of two parts, the filament and anthera; the filament is the threadshaped part which serves as a foot-stalk to elevate the anthera; which last is the top of the filament, and contains the impregnating pollen. The anthera is distiuguished by its shape, \&c.

4. 'The pistillum, or female part ' of the flower, proceeding from the pith of the plant, is that ercet column which is generally placed in the centre of the flower; surrounded by the stamina; it consists of three parts: the germen, style, and stigma. 'The germen is the base of the pistillum, after some time it becomes a seed vessel, when it takes the name of pericarpium; the style elevates the stigna from the germen, to receive the influence of the stamina, and to convey it down to the germen as through a tube, the stigma is generally placed like a head on the summit of the style, and covered with moisture to retain the pollen of the anthera.

5. The pericarpium, as we have said, is the germen grown to maturity; or, in other words, it is the ultimate process of fructification, and assumes a variety of forms, distinguished by as many names, as siliqua, a pod ; barra, a berry; pomun, an apple, \&c.

6. Semina, the seeds, are the essence of the fruit of every vegctable, and consist of five parts, viz. 1 . corculum, the heart, is the essence of the seed, and principle of the future plant; and this again is divided into the plumula, or part which 
shoots up into the stem, and the rostellum which forms the root. 2. The cotyledons are the thick side-lobes of the seed, and may be distinctly seen by soaking a bean in water; these aftervards come up as the seed-leaves of the plant. 3. The hilum, or black spot on a bean, is the external mark where it was fastened within the pericarpium. 4. The arillus or external coat which falls off spontaneously. 5. The corona of a seed are the feathers, hairs, down, \&c. which are found ad. hering to the top of many seeds, for the purpose of dispcrsing them, as in scabiosa, valeriana, tussilago, \&c.

7. The receptaculum is the base which receives, supports, and connects the other parts of fructification, and has various designations according to circumstances.

The flowers of plants, which are made the sole foundation of the Linnæan system of Botany, arc distinguished in respect of sex into male, female, hermaphrodite, and ncuter. Male flowers are such as have only the stamina, as in the classes Monoecia, Dioecia, and Polygamia. Female flowers are such as have only the pistilla, as in the same classes. Hermaphrodite flowers have both the stamina and pistilla in the same flowers, which is the most general mode of inflorence, and these are again distinguished into male hermaphrodites where the female is ineffectual, and female hermaphrodites where the male is ineffectual. Neuter flowers are such as have neitler stamina nor pistilla perfect.

The classes are twenty-four in number, the first eleven of which are characterized solely by the number of stamina, viz.

Class
1. Monandria, Stamen 1.
As Amomnm, Carcuma, \&c. this is a very small class, and nnly contains two orders.
2. DIANDria, Stamina
Tlis is a most numerous class, and contains the Olea, Rosmarinus, \&ce. in the 1st order, Monogynia; the $3 \mathrm{~d}$ order is the Piper.

3. TrIANDRIA.

4. Tetrandria.

5. Pentandria.

3. Contains 3 orders, in the 1 st of which we find the Valeriana: the 2d order consists of the true grasses; no poisonous plant is found among them except the Lolium Temulentuin.

4. This is also a very numerous and varions class, but contains fer, if any, medicinal plants.

5. This is one of the most important classes of the whole system; it consists of 6 orders; the 1 st of which contains many genera, as, Borago, Convolvulus, Solanum, Datura, Hyoscyamus, $\mathbf{A t r o p a , ~ N i c o t i a n a , \& c . , ~}$ and includes many active medicinal plants. In the $2 \mathrm{~d}$ order of the class (Digynia) we tind tlue Gentiana, and all the umbellifcrous plants, as Cicuta, Anthemam, 
Carum trihes, \&re. and it may be well here to remark, that the umbellifere which grow upon dry grounds are, for the most part, aromatic and cordial, while the aquatic species are among the most deadly poisons.

6. Hexandria. Stumina 6. This class comprehends 6 orders, in the first of which are included the Liliaceous plants; it contains but few medicinal plants.

7. HeptandRIA. - 7 .

A very small class; its lst order contains the two species of Esculus.

8. Octandia.

The Tropœolum, or garden nasturtium, will illustrate the Monogynia order of this class.

9. Enneandria.

9. This is an important class to the Medical Botanist ; its 1st order, including the Laurus Cinnamomum, Sassafras, and Camphora; its 2nd order has only the Rheum, or rhubarb.

10. Decandria. 10. This class is likewise deserving of attention, including in its different orders, of which there are five, Cassia, Ruta, Saxifraga, and the trihe Dianthus.

11. Dodecandria. 12 to 19. In this class we find the Asarum, the common houseleek will also illastrate it.

12. Icos A N DRIA. 20 or more, inserted into the Calyx.

The lst order of this class consists of trees bearing for the most part stone fruits, surrounded by a pulp, as the plum, peach, cherry, \&c.; in the $2 d$ order we find the apple, pear, \&c.: and in the 3rd order the Genus Rosæ. In this class, the stamens grow out of the sides of the calyx, as in the strawherry, and it is important to observe, that such a mode of insertion indicates the fruit to he wholesome; we are not aware that there is a single exception to this rnle, so that the traveller who might meet with an anknown fruit, need not scruple to eat it if he find the stamens thus inserfed. On the other hand, many other parts of such plants or trees, as the leaves, kernels, \&c. are often higlly noxious, from their containing that peculiar acid, known by the name of Prussic Acid, of which we sliall have occasion to speak hereafter. The kernels of the stone-fruits contaiu a considerable quantity of Prussic Acid. We nay further observe, that this character of the insertion of the stamina into the calyx holds good in other classes as well as in the class Icosandria; thus in the Genus Ribes, including the currant and gooseherry, which helong to the class Pentandria, (from their flowers liaving ouly 5 stamina,) the stamens grow out of the calyx, and these fruits are well known to be extremely wholesome, while many of the berries of the same class, hut whose stamens have not a like insertion, are often very deleteriuus.

13. Polyandria. Stamina numerous, inserted into the recoptacle.

14. Didynamia. Stamina 4. two long and two short.
The plants of this class are very distinct in nature as well as character, from the preceding class. Of medicinal or deleterious plants, it includes the Papaver, the Aconitum, the Anemone, Ranunculus, and Hellehorus.

This class is easily distinguishable from the 4 th class, (Tetrandria,) which lias also 4 stamina. The flowers of this class are generally lahiate, corolla, monopetalous. It is divided into two orders, Gymnospermia, with 4 naked seeds in the bottom of the calyx, and Angiospermia, the seeds numerous and 
contained in a seed vessel; and bere again we have natural characters distinguishing between noxious and innoxious plants. In the 1 st order with the naked seeds, the plants are mostly aromatic and wholesome, including Mentha, Lavendula, Kc. In the $2 \mathrm{~d}$ order, where the seeds are enclosed in a seed. vessel we lave the Digitalis and other poisonous plants.

15. Terradynamia. Stamina 6. This class is likewisc easily distingnishable from four long and two short. the 6th class, Hexandria. Tule flowers of this class are all cruciform, and consist of 4 petals. It is divided into two orders, Siliculosa, with short round pods, and Siliquosa, with long pods. In this last order of the class, we liave the different species of Brassica, or cabbage, Sinapis, \&r.

10. Monadelphia. Stamina more or less nnmnerous nnited by their filaments into onc tube.

17. Diadelphia, Stumina united in to two parcels at the base.

\section{Polyadelpila. Stamina united into more than two parcels.}

19. Syngenesia. Anthers united into a tube; the flowers compound.

20. GYNANDRIA. Stamina united with, or growing out of the pistil, and either proceeding from the germen or the style.

21. MonÆCIA. Stamina and Pistils, in separate VOL. I.
There are eight orders in ílis class, distinguished by the number of their stamens. The Malva and Altliæa are illustrations of this class.

This is a very distinct class, consisting of papilionaceons flowers. The orders are distinguished as in the preceding class. The Astragalus Tragacantlua belongs to this class. Hore familiar specimens of it will be found in the garden pea, bean, and other leguminous plants.

The orders of this class have not heen very well defined by Linnxus. The class contains the citrus tribe of fruits.

This class consists of 5 orders. 1st-Polygamia Aqualis, where each floret is perfect, being furnished with stamens and pistils, and capable of bringing its seed to mnturity. The Leoutodon will illustratc this orter of the class. 2d--I'oly jamia Superflaa. The florets of the disk perfect, those of the margin having pistils only, but botlı perfecting their seed. The Artemisia is an example of this order, but a better one will bc furnished in the Anthemis Nobilis of the fields. 3d-Polygamia Frustanea. Florets of the disk perfect or united, those of the margin neuter, or destitute of pistils as well as of stamens. This order is by no means well defined, and unight with great propricty be abolishcd. 4thPolygamia Necessaria. Florets of the disk fornished with stamens only, those of the radius only with pistils, and both being necessary for the perfecting of the sced. The Calendula, or garden marygold, is a familiar specimen of this order. 5tlı-Polygamia Segregata. Several tlowers, either simple or compoand, with united tubular antlers, and with a partial calyx, all included in one common or general calyx. The globe thistle illustrates this order.

The orders of this class are taken from the number of the pistils, but botanists are not agreed as to the admission of some of them into the class. The Aristolochia belongs to the class Gynandria.

The orders in this class depend upon the circuma stances of their male flowers, and are 9 or 10 in uum- 
flowers, but growing on the same individual plant.

22. DIECIA.

Stamina and Pistils in separate flowers, and situated oll two separate plants.

23. Polygamia. Stamina and Pistils, separate in some flowers, united in others, either on the same plant, or on two or three distinct ones.

24. Cryptogamia. Stamina and Pistils, either not well ascertained, or not to be numbered with any certainty. her, viz. Monandria, Diandria, Triandria, Tetrandria, (which order includes the different species of birch, and may be illustrated by the alder tree), Pentandria, Hexandria, Polyandria (this order includes the Quercus, or oak), Monadelphia (in this order we find the numerous species, Pinus, the Croton Tiglinm, Croton Aromaticum, the bark of which is the Eluteria and Cascarilla of commerce, the Ricinus, and several other valuahle trees).

The orders of this class are formed like the preceding, from the male flowers. In the order Pentandria, we find the Humulus, and in Monadelphia, the Juniperus.

This class only contains 3 orders, and in the opinion of many eminent botanists, the class itself miglit well he omitted.

In this class there are 5 orders easily distinguish. able, viz. 1st-Fitices, or ferns. 2d-Musci, or mosses. 3d-Hepaticæ, or liverworts. 4th-Algx, or flags; this last order compreliends the various Lichens, of which the L. Islandicus is a faniliar illustratiou, as also the numerous species of sea weeds. 5-Fungi, or mnshrooms.

To these twenty-four classes Linnæus added an appendix, for the tribe Palnæ, whieh at that time was but little understood.

\section{Of the Linnean Orders.}

We have so fully illustrated these in our description of the classes, that little more remains to be said about them : in the first thirteen classes the orders are founded on the number of the styles of the pistils, or where the styles are wanting, on the number of the stigmas. They are aceordingly named, Monogynia, 1 style; Dygynia, 2; Trigynia, 3 ; Tetragynia, 4; Pentagynia, 5; Hexagynia, 6; (this order is very rarely found) Heptagynia, 7, also very rare ; Oetagynia, 8 , which scareely oecurs; Enneagynia, 9, also extremely rare; Deeagyıia, 10 ; Dodeeagynia, about 12 ; Polygynia, styles numerous. The orders Gymnospermia and Angiospermia are referable to the 14th elass, as we have already shewn, depending on the situation of the seeds, Siliculosa and Siliquosa belong to the 15th class, and are distinguished by the form of the pods. The orders of the 16th, 17th, and 18th classes are founded on the numbers of the stamens, and are aceordingly named Monandria, Diandria, \&c. In the 19th class we have Polygamia Equalis, P. Superflua, P. Frustranea, P. Necessaria, and $\mathbf{P}$. Segregata, which have been already explained, as have the orders in the other five classes. 
The foregoing is what is termed the artificial system of Linnæus; to this it has bcen objected that notwithstanding the extreme simplicity of this artificial arrangement, it is continually nccessary to leave the organs upon which it depends out of consideration in determining the locality of plants; but it is much easier to cavil at a system, than to invent a better; Linnæus himself was awarc of the difficulties attendiug an artificial arrangement, and he therefore studied with the greatest assiduity the natural affinitics of plants, for the formation of a natural classification, depending on these affinities, resemblances, or other external characters or habits of the vegetable world. On these principles Linnæus divides vegetables into fifty-eight natural classes or orders as follows :

1. Palma. These are perennial, and mostly trees or stirubs, as the phrenix, \&ic.

2. Piperita. Peppers; mostly herbaceous and perennial, as the arum, \&c.

3. Calamaria. Reeds.

4. Gramina. Grasses.

5. Tripetaloidea, have no very striking cliaracter, but are nearly allied to the grasses, as the butomus, \&c.

6. Ensatr. Sword-like plants, as the saffron, iris, \&ic.

7. Orchidea. The orchis tribe

8. Scitaminece, are all natives of warm climates, as the amomum, or ginger ; the inusa, or plantain, \&ic.

9. Spathacea, are distinguished from the lijiaceous plants, to which they are nearly allied, by the spathra, out of which their flowers are protruded, as the atlium, amaryllis, \&c.

10. Coronaria, are herbaceous, perennial, and from one inch to fifteen feet high. The roots are either buthous, fibrous, or composed of small flesliy knobs, jointed at the top. The hyacinths and lilies belong to this order.

11. Sarmentasea, have climbing stems and branches, by which they attach themselves to other bodies for support.

12. Holeracea, contains trees, shruhs and herbs, annual and perennial; chiefly for domestic purposes, as the beet, rhubarb, \&c.
13. Succulenta. Consists of flat, fleshy, and juicy plants, most of them evergreens.

14. Gruinales. Cranelike, consists of a geranium, and a few other plants allied to it in labit

15. Inundata, aquatic plants; low, herbaceous, and mostly perennial, as hippuris, elatine, \&c.

16. Calycifiora, have the stamina inserted into the calyx, and are all of the slirub or tree kind.

17. Calycantheme, have the corolla and stamina, inserted int, the calyx, as the epilobium, lythrum, \&c.

18 Bicornes. Plants whose anthera have the appearance of two horns. Of these are the heaths.

19. Hesperidece, are of the shrub and tree kind, and mostly evergreen, as the myrtle, ctove tree, \&ic.

20 Rotacea. Plants with one wheelshaped petal witbout a tube, as the plitox, cistus, bypericuin, \&c.

21. Precia, from precius, early, the primrose and some other early flowering plants whicl agree with it in habit.

22. Caryoplyllea. The pink, carnation, and plants of that description.

23. Trihilata. Plants will three seeds, marked with an external cicatrix where they are fastened within to the fruit, as the acer, \&c.

21. Corydales, have irregular flowers somewhat resembling a helmet, as the balsam, fumaria, \&c. 
25. Putaminer," sbelled, a few genera of plants allied in liabit, wbose fruit is covered with a laard woody shell, as the caper shrub.

26. Multisiliqua. Plants which have more seed ressels than one, as the columbines and delphinums

27. Rhoadea. The poppy, and a few genera resembling it in habit and structure: when cut they emit a milky juice whicb is white in poppy, and yellow in tbe others.

28. Lurida. An order of plants whose pale appearance indicates their noxious quality: such are the atıopa, datura, \&c.

29. Campanacea, have bell shaped flowers, as the convolvulus.

30. Contoria, plants which have a single petal, twisted to one side, as the asclepias: the plants being cut, emit a juice of a milky or greenish white which is deemed poisonous.

31 Veprecula, plants resembling the daphne, but which do not constitute a true watural class.

32. Papilionacea. Plants that have papilionaceous flowers, as the garden pea.

33. Lomentacea, (from lomentum, a colour used by painters,) this order furnishes beautiful tints, as tbe sophora, \&c.

34. Cucurbitacea, (from cucurbita, a gourd,) Plants which resemble the gourd, as the cucumber, melon, \&c.

35. Senticosæ, (from sentis, a briar,) consist of the rose, bramble, and other plants resembling them in structure.

36. Pomacea. Plants which have a pulpy esculent frnit of the apple, berry, or cherry kind.

37. Columniferce, plants whose stamina and jistel have tbe appearance of a pillar in the centre of tbe flower, such are the althrea, camellia, \&c.

38. Tricocca. Plants with a single tbreecornered capsule, having three cells, each containing a single seed, as box, pliyllauthus, Sc.

39. Siliquosa. Plants which have a pod for their seed vessel, as the cahlage, mustard, \&c.

40. Personata, (from persona, a mask). Plants whose flowers are furnished witl an irregular ga. ping petal, resembling the snout of an aniural, as the snapdragon.

41. Asperifolice. Rough-leaved plants; as borage, bugloss, \&ic.

42. Verticillata, consists of herbaceous plants, having four naked seeds, and the flower's disposed in whorls round the stalk, as lavender and liyssop.

43. Dumose, (from dumus,) a busl, are all of the tree or shrub kind, rising from six to thirty or forty feet high, as the elder, huckthorn, \&c.

44. Sepiaria, (from sepes, a liedge.) Ash, privet, lilac and sucli like plants, fit from their size and other circumstances for hedges.

45. Umbellata. Plants, whose flowers grow in umbels, with five petals, and two naked seeds joined at top and separated below, such are parsley, caraway, fenuel, \&c.

46. Hederacea, herbaceous and shrubby plants, having creeping branches which attach themselves by roots and tendrils to other bodies, as the ivy, and vine.

47. Stellate, (from stella, a star.) Plants with two naked seerls, and leaves disposed round the stem in form of a star, as spigelia.

48. Aggreguta. Plants which have aggregate flowers, each floret having a proper and common calyx, as dipsacus, scabius, \&c.

49. Composita. Plants with compound flowers, as carduus, xeranthemuin, \&ic.

50. Amentrcec. Plants bearing catkins, as the tribe salix.

51. Coniferce. Plants whose female flowers, placed at a distance from the male, either on the same or distinct roots, are formed into a cone. Such are the fir, pine, cypras, \&c.

52. Coadunata. So termed from the general appeurance of the seed vessels which are numerous, and being sliglitly attached below, form altogetber a single fruit in the shape of a sphere or cone, as the mag. nolia, tulip tree. \&ic.

53. Scabrida. Plants with rougb leaves, and nearly allied to the order asperifolia, only the roughness of the former is inuch greater. 
The hemp and fig tree are examples of this order.

54 Miscellanea, consist of such genera as are not connected together by very numerous relations.

5.5. Filices, ferns, bear their flower and fruit on the back of the leaf.

56. Musci. Mosses.

57. Algre, flags, consist of marine plants whose root-leaf and stem are all one.

58. Fungi. The mushroom tribe.

Such are the natural orders of Limmus, and it now remains for us tu give some explanation of the System of $\mathbf{J}$ ussien, as it is at present used by many botanists, in preference to that of Linnæus. 'This system is saicl to have originated in Franee, with Berna:d de $\mathbf{J}$ ussieu, about the year 17.58 , , but sinee that time it has indergone many modifications. The mode of arrangement and analysis are these: the vegretable kingdom is divided into three portions, according to the strueture of the embryo and of vegetation, viz.

I. Dicotyledones which are formed with two eotyledones, and whose vegetation is produeed by the gradual superposition of internal layers beneath the bark; these constitnte the greatest part of the vegetable kingdom, and are deemed to be in a more perfeet state of developement than the other two. They are subdivided, 1st, aceording to the number or absenee of their petals, into Polypetalous, Monopetalous, and Apetalous ; 2nd, according to the insertion of their stamens which is Hypogynous or Perigynous; 3rd, aceording to the adhesion or non-adhesion of their calyx with the ovarium, which is either superior or inferior; 4th, aceording to the position of the stamens with respect to the petals; 5 th, according to the strueture of the fruit; 6th, aecording to the strueture of the seed; and 7 th, aecording to the modifieations of their vegetation, as far as they indieate a eorresponding peenliarity in the parts of fructification. 2. Monocotyledones, whose embryo has one eotyledon, rarely morc, and which in that ease, germinates from a determinate point, and whose vegetation is formed by increase at their centre, not at their circunference. This order is also subdivided like the 1st, as far as it is applicable to them, but its prineipal section is that of Cryptogamia, which is characterised by the absence of any apprarent flowers. 3. Acotyledones, which contains the plants of the simplest strueture; have no sexes, but reproduce themselves by what are called sporles, that is, seed-like bodies, but differ from seeds, by germinating from any part of their surface, and in 
not being the resuit of sexual eontaet: this group corresponds with the Cryptogamia of Limneus.

Sueh is the foundation upon whieh the natural system of Jussieu is arranged; his elasses amount to fifteen, eleven of which are included in the Dieotyledoneous plants; three in the Monoeotyledoneous; and one, in the Acotyledones: these classes are not distinguished by any particular names-each elass is again subdivided into natural orders, but the system has undergone so many revisions, and the labours of living botanists are so constantly extending or diminishing the number of these orders, that it is not very easy to aseertain their precise number; aeeording to Sir J. Smith, (see his Grammar of Botany) they only amount to one hundred, while other botanists enumerate nearly double that number. Eaeh order is defined by tolerably full definitions, taken, first from the parts of fruetification, and seeondly from secondary eliaraeters, founded on other eireumstances.

Having thus given an analysis of the two great systems by which botanists of the present day are divided, and to whieh referenee is made iu the Frora Medrcia, the limits of our undertaking will only adınit of our saying a few words on the subject of vegetable secretions, a subjeet whieh above all others sliould interest the Medieal Botanist. It is from those seeretions that lie is to draw his medieinal store, and on them that he is to exereise his ehemical and pharmaceutieal art; while as a subjeet worthy the attention of a "philosophic mind, we know of none more curious than this part of vegetable physiology. The first tling that strikes us is the variety of secretions of different plants, or families of plants, by whieh they are distinguished from each other, and differing so materially in smell, taste, sensible qualities, and medical virtues : even in the same plant, we frequently find a variety of seeretions totally different; of this the peach tree offers a familiar example; the gum of the tree being mild and mucilaginous, and agreeing very uearly, when in its purest state, with the gum of the Mimosa Nilotiea, while the bark, leaves, and flowers abound with a bitter seeretion of a dangerous quality; the fruit again is replete with acid, mucilage, and sugar, and its own peeuliar aromatie and volatile secretion, while in the kernel of the same fruit is contained a large portion of the Prussie Acid, whieh in its highest state of concentration is so noxious to animal life. 
The most distinct secretions of vegetables, we slıall class under distinct heads.

1. Gum, or Mucilage. A viscid substance of little flavour or smell, soluble in water, and exuding fiom many trees in the form of drops or lumps, as in the plum, cherry, peach, \&c. and in many species of the Mimosa, as the Mimosa Nilotica, which yields the gum arabic of the Pharmacopeais.

2. Jelly. Somewhat allied to the former, but of less consistency, being soluble by licat, and remaining fluid in a very low temperature. It is procured from ripe pulpy fruits.

3. Resin. Soluble in spirits-insoluble in water, as the turpentine of the fir and juniper, \&c.

4. Gum Resin. Vegetable exudations for the most part partake of a nature betwcen resin and gum, being partly soluble in spirits, and partly in water:

5. Milky Juice. The milky juice of the fig, spurge, \&c. is an emulsion or combination of watery fluid with oil or resin, and when cvaporated in the air becomes gum-resins, as the gum euphorbium.

6. Essential Oils. 'The volatile resinous secretions, are called essential oils, and are often highly aromatic and odoriferous, as the essential oil yielded by the bark of cilnamon, and those procured from the effluvia of flowers, as lavender, \&c.

7. Bitter Secretion. The nature of this sccretion is not very well understood, some chemical botanists suppose it to be of a resinous nature, but as it is often perfectly soluble in water, this opinion does not seem to be well founded. The Cinchona Officinalis is a familiar instance of this secretion.

8. Acid Secretions. 'These are found to be very abundant in plants, as the oxalic procured from oxalis, or wood sorrel, the malic, citric, \&c.

9. Alkaline. Of these there are two kinds, the vegetable alkali, termed Rali, and the fossil alkali or soda, procured mostly from marine plants.

10. Saccharine Secretions. Sugar more or less pure is very generally found in plants ; various roots, as the carrot, beet, parsnip, \&c. it abounds also in the Saccharum Officinarum, or sugar cane, so well known in commerce, as to need no mention here: in fruits likewise the saccharine principlc con- 
stitutes a clief part of their value in contributing to our appetite and luxury. But botanists are inclined to consider sugar not so much an original secretion, as the result of chemical change in the acid and mucilaginous secretions already formed, and we are inclined to subscribe to this opinion from the process we daily witness in the growth of fruits towards their mature or ripe state.

Besides these more obvious and general secretions, many plants are known to secrete colouring matter, while the bamboos, some species of palm, inany of the grasses, and most of the tribe of plants producing edible grain, secrete flinty matter which forms a shining coat on the outside of the stalks of the plants, and contribute to strengthen and support their reed-like and slender growth. 'These are subjects which we cannot too strongly recommend to the attention of the Botanical student, but it would be impossible for us, in the present work, to enter deeply on so curious and interesting a topic: we must content ourselves in haviug given in this introductory chapter what we think will be considered a sufficient outline of the Science of Botany, to enable the student to make considerable progress, and to prepare limself for works in which it is treated of at more length. 


\section{T A BLE}

OF

\section{BOTANICAL TERMS AND DEFINITIONS.}

A BRUPt, (Abrupte) applied to leaves; when the extremity of the leaf is, as it were, cut off by a transverse line.

A bruptly Pinnate, (Abrupte Pinnata) applied to pinnate leaves, terminated neither with a leaflet nor a tendril.

ACAules, plants wher destitute of stems, are so called.

ACEROSE, (Acerosum) leaves, (needle shaped) linear, every where of an equal breadth, mostly acute and nigid.

ACINACIFORME, cinteter shaped leaves, one edge of which is straight and thick, the other thin and curved.

AcINUS, each separate part of a compound berry containing a seed: compound berries consist of many simple acini united together, as the raspberry, \&c. \&c.

Acotyledonous, plants, whose embryos have no lobes, or seminal leaves.

ACUlEATE, (Aculeat $u$ ) applied to leaves armed with prickles.

ACULEUS, a prickle, a sharp projecting point, (arising from the bark only, having no connection with the wood.)

ACUMINATE, (Acuminatum) very sliarp pointed, ending in a taper or awl shaped point.

Acute, (Acutum) sharp, ending in a point, (applied to leaves, \&c.) Adnate, (Adnata) applied to leaves; signifies when a leaf adlieres to the stem, or branch, by the surface or disk itself; applied to stipules when they are fixed to the petioles.

AGGREGATE, flowers composed of many small florets, having a common undivided receptacle, the anthers separate and distant, the florets commonly stand on stalks, eaclı having a single or double partial calyx.

Aggregate Pedunculi, clustered flower stalks, many growing together.

ALIENATED, (Alienaium) when the first leaves of a plant give place to others very different from them, and from the natural habit of the genus.

VOL I. 
Alternate, (Alterna) applied to leaves, when they stand singly on the stem or branclies, alternately first on one side, then on the other; to branches when placed round the stem alternately one above the other; to flowers placed in regular succession one above another.

Ament, (Amentum) a species of inflirescence as well as a calyx, (also called a catkin) cousisting of a common receptacle, of a cylindrical form, beset with chaffy scales, arranged along a slender thread-like stalk, each of which is accompanied by one or more stamens or pistils, altogetler forming an aggregate flower.

Amplexicaul, (Amplexicaulia) stem clasping; when the base of a leaf surrounds the stem, but not perfectly so.

ANCEPs, vide Two-EDGED.

ANGULAR, (Angulatus) haviug angles; applied to leaves when the number of angles are not specified.

ANNual, (Annua) perishing within the year.

Anomalous, (Anomalus) corollas, (not being papilionaceous) are so called when formed of different sized petals.

ANTHER, (Anthera) that part of the flower containing the fertilizing dust, which, when mature, it scatters; situated at the top of the stamen, the anther is always present, and forms the essential part of the stamen.

APPENDAGED, (Appendiculatus) applied to flowers, furnished with some addition distinct from the tube; to petioles with leafy films at the base; to seeds furnished with looks, scales, \&c.

APPENDAGES, applied to additional organs of plants, which are not universal or essential, neither is any one plant furnished with them all; botanists distinguish seven kinds of appendages, viz. stipules, floral leaves, thorns, prickles, tendrils, glands, and hairs.

Appressed, (Adpressa) applied to leaves pressed close to the stem; also to' peduncles.

Arboreous, (Arboreus) perennial, with a simple stalk.

ARiL, (Arillus) the aril or tunic, is either a complete or partial covering of a seed, fixed to its base only, and more or less loosely or closely enveloping its other parts.

Arista, vide Awn.

ARROW-SHAPED, (Sagittatum) triangular shaped leaves, hollowed out very much at the base, sometimes the posterior angles are cut off. 
Articulated, (Articulatum) articulated or jointed is applied to leaves, when one leaflet, or pair of leaflets, grow out of the summit of another, with a sort of joint; to stems divided by joints or knots, or divided from space to space by contractions; to culm with joints.

ASCENDING, (Ascendens) applied to stems ascending without support, in an oblique direction.

Attenuated, (Atlenuatus) diminishing insensibly in thickness from the base to the summit; applied to peduncles.

AURICLED, (Auriculatum) applied to leaves when they are furnished with a pair of leaflets, generally distinct, but sometimes joined with them.

Avenium, vide Veinless.

AwL-SHAPED, (Subulatum) leaves so called, when thickish at the base, and gradually tapering towards the point.

Awn, (Arista) the awn or beard, a bristle-shaped projection, growing out from the glume or chaff, in corn and grasses.

Axillary, (Axillaris) applied to peduncles when procecding from the angle made by the leaf and stem, or branch and stem; also to flowers and to spikes of flowers, proceeding from either of the above situations.

BACCA, vide BERRT.

BANNER or STANDARD, (Vexillum) the upper large petal of a papilionaceous or pea-flower.

BARK, the covering of plants, (composed of woody fibres) situated over the wood and under the cellular integument, consisting of from one to many layers, according to the age of the plant or branch, an additional layer being added every year.

BARREN Flowers, flowers háving stamens only, and producing no fruit.

Basi Trinerve, vide ThREE-RIBBED, \&c.

$\mathrm{BEAK}$, applied to an elongation of the seed vessel ; proceeding also from the permanent style; also to naked seeds.

BEARD, vide AWN.

Bell-Shaped, vide CAMPANULATE.

BERRY, (Bacca) a pulpy pericarp, without cells, the seeds being dispersed throughout the pulp, (example Atropa Belladonna.) Biflori Pedunculi, applied to peduncles bearing two flowers. BIFID, (Bifidus) two-cleft, (but not very deeply divided.)

BigeminAte, (Bigeminatum) applied to a compound leaf, having a forked petiole, with several petioles or leaflets at the end of each division. 
Bilobum, two-loberl.

BrLocular, two-celled.

BrNa, applied to the situation of leaves, signifies only two upon a stem or plant.

Binate, (Binatum) a fingered leaf of two leaflets, inserted at the same point, precisely on the summit of the petiole.

Brpinnate, (Bipinnatum) doubly pinnate, applied to a compound leaf, having a common petiole, which produces two partial ones, upon which is inserted the leaflets.

Brternate, (Biternatum) applied to compound leaves when the common petiole divides into two, each of which bears tliree leaflets.

Buistering, (Bullatum) applied to leaves, when the upper surface rises above the veins, giving the appearance of little swelling irregularities over the surface, the under side having corresponding little cavities.

Blunt, (Obtusum) terminating in a segment of a circle.

BRACHIATE, (Brachiatus) four-ranked; applied to stems, when they divide and spread in four directions, crossing eacli other. BRACTEA, the floral leaf; small leafy appendages to the flower or its stalk, differing from the other leaves of the plant in form or colour.

Bracteated, (Bracteatus) applied to peduncles, to flowers, and to cyme having bractea.

BUDS, (Gemma) small conoid bodies, covered with scales, formed during summer on the branches of trees, containing the rudiments of a future plant, or part of a plant; some buds produce flowers and leaves, others leaves only, and some flowers only.

Bulbous Roots, (Radix Bulbosa) so called, are conical or globular roots, in substance tender and succulent; either solid, tunicate, composed of concentric layers; or scaly, consisting of fleshy scales; connected only at the base, from which issue small fibres, and the fibres constitute the true roots.*

Bunch, ('Thyrsus) applied to flowers growing in a dense or close panicle, having more or less of a conical or ovate figure, (as the lilac, \&c.)

* Sir J. Smith says, " the two latter birds, (i.e. the tunicate and scaly) have the " closest analogy with leaf buds; they are the reservoirs of the vital powers of the

"plant, during the season when those powers are torpid or latent; and in order to

"perform the functions of roots, they first produce fibres, which are the actual roots." 
Caducous, (Caducus) applied to leaves falling before the end of summer; to corollas falling off before the dropping of the stamina; to perianths falling before the corolla is well unfolded.

Calyculate, calyxes having little scales at the base, on the outside. Calyptra, the calyx of mosses.

CaLyx, (Calyx) the calyx or flower cup is the outer expanded part, or exterual covering of a flower, generally resembling the leaves in colour and texture; there are seven kinds of calyxes, viz. perianthium, amentum, spatlia, gluma, involucrum, volva, perichatium.

Campanulate, (Campanulata) a bell-shaped monopetalous flower. Canaliculatum, vide Channelled.

Capitate, (Capitulum) applied to flowers, when they are assembled so as to fornu a globular, or nearly round head.

Capsule, (Capsula) a membranous or woody seed vessel, internally consisting of one or more cells, splitting into several valves, and sometimes discharging its contents through pores or orifices, or falling off entire with the seed.

Carina, vide KeEl.

Carinatum, vide KeEled.

Carnosum, vide Fleshy.

Cartilaginous, (Cartilagineum) applied to leaves, the borders of which are liard and horny.

CATKIN, vide AMENT.

CAUDA, vide TAIL.

CA ULINE, (Caulinum) applied to leaves placed upon the stem, (leaves that grow upon the stem are called stem leaves, or cauline); applied also to flowers placed upon the stem or stock; and to peduncles arising immediately out of the main stem.

Caulis, vide Stem.

CELLS, (Loculi) hollow places in pericarps for the reception of seeds. Cellular Integument, the succulent pulpy substance, situated immediately under the cuticle; the seat of colour, mostly green, particularly in the leaves or branches; "leaves " consist almost intirely of this substance, covered on eaclı " side by the cuticle; the stems and branclies of botlı " annual and perennial plants are invested with it."

Channelled, (Canaliculatum) applied to leaves having a wide longitudinal furrow the whole length of the leaf; to stems having wide longitudinal hollow lines; also to petioles having grooves.

VOL. I. 
Ciliate, or Fringed, (Cilialum) applied to leaves, the edges of which are bordered witl soft silky parallel hairs.

Cimeter-sha Ped, vide Acinaciforme.

Cirrose, (Cirrosum) applied to leaves having a tendril growing from the tip.

Cirrus, vide Tendril.

Climbing, (Scandens) stens are called climbing when they mount up other bodies, (i.e. walls, trees, \&c.) and support themselves by means of their tendrils or adhesive fibres.

Cloven, (Fissum) leaves are called cloven, when the margins of the segments and fissures are straight.

Clubbed, (Clavatus) petioles are so called when they gradually grow thicker towards the top.

Cluster, vide Raceme.

Clustered, (Conferta) applied to leaves crowded together.

Coloured, (Coloratum) applied to leaves, is intended to express any. colour except green.

Column, (Columellu) the central point of union of the partitions in the seed-vessel, (i.e. in a capsule containing many cells) to which the seeds are usually attached.

Complete Flower, (Flos completus) a flower furnished with both calyx and corolla.

Compoun D, (Compositum) applied to leaves when they consist of two or more leaflets connected by a common foot-stalk; to flowers consisting of numerous florets, all sessile on a com-mon undivided receptacle, and enclosed in one continuous calyx or perianthiun; each floret is monopetalous and superior, $i$. e. each standing on a solitary naked seed, or the rudiments of one, though not always perfected; the stamens are (with very few exceptions) five, and the anthers almost universally united into a cylinder; the number of florets vary, and they are also of two kinds, ligulate (shaped like a ribbon or strap) or tubular, cylindrical and five-cleft. Compressed, (Compressum) leaves are so called when Hattened laterally.

Concave, vide Hollow.

Conduplicate, or Folded, (Conduplicalum) applied to leaves when the margins are brought together in a parallel direction.

Cone, (Strobilus) a catkin liardened and enlarged into a seed vessel, as in the fir, cypress, \&r.

Conferta, vide Clusterbd. 
Conjugate, or Yoked, (Conjugatum) leaves are so called that consist of one pair of pinnæ or leaflets.

Connate, (Connatum) applied to leaves, when two leaves are so united at their base as to have the appearance of one leaf.

Cordatum, vide HEART-SHAPED.

CORIACEUM, vide LEATHERY.

Corolra, (Corolla) the corolla consists of the delicate (and generally coloured) petal or petals, forming what in common language are termed the blossoms; and in polypetalous flowers, the petals are usually called the leaves of the flower. The corolla constitutes the beauty of the flower; and the odour and fragrancy of the plant frequently reside therein, as in the rose, jessamine, violet, $\&$ c.; the corolla has a diversity of forms as well as of colour, and includes two parts, the petals and the nectary, the latter is sometimes a part of the former, and sometimes separate from it.

The various forms of the corolla, as wheel-shaped, bellshaped, \&c. will be described under their appropriate names.

Corymb, (Corymurus) is a spike of flowers, whose partial peduncles take their rise from different heights upon the common stalk, but the lower peduncles being longer than the upper ones, they all form nearly a level surface at the top.

Costatum, vide Ribeed.

Cotyledons, (Cotyledones) the side lobes of seeds furushing nourishment and protection to the corculum, and which form the chief bulk of the seeds; these lobes swell and expand in the ground, and as the stem ascends they are usually raised out of the ground, assume a green colour, and perform the functions of leaves until the young leaves unfold, when they generally wither.

Crenate or Notched, (Crenatum) applied to leaves when the notches or teeth on the borders are rounded, and the notches not directed to either end of the leaf.

Creeping, (Repens) applied to stems that run along the ground putting out roots as they proceed along; to roots that branch off horizontally and throw out fibres as they go.

CRESCENT-SHA PED, (Lunulatum) leaves are so called when shaped like a lialf moon.

Crispum, vide CurLed.

Crowded, (Confertus) applied to branches when growing so close as to leave scarcely any space between them; (example, the yew.) 
CruCiform, or Regular, (Cruciformis) polypetalous flowers are so called, when the petals are placed in the form of a cross. Cucullate, or Hooded, (Cucullatum) applied to leaves when the edges meet in the lower part, and expand towards the upper; (i.e. in the form of a cone).

Culm, (Culmus) an herbaceous stem peculiar to grasses, rushes, and some other plants allied to them. Culms are either hollow or solid, joiuted or without joints, round or triangular, rough or smooth, hairy or downy, and bear both leaves and flowers.

CUNEIFORME, vide WEDGE-SHAPED.

CURLED, (Crispum) applied to leaves when the border is large in proportion to the disk, and becomes in consequence waved or twisted into many irregular plates; (this form of leaf is by many botanists considered to be caused by some disease.)

CUSPIDATE, (Cuspidatum) applied to leaves terminating in sharp rigid spines; (example, the thistle.)

Cuticle, (Cuticula) the outward covering of plants : every plant is covered by a skin or membrane analogous to the scarfskin that covers the human and other animal bodies. The cuticle or epidermis varies in thickness, being extremely delicate on some parts of a flower, (as the petals, \&c.) and very thick, hard and coarse on the trunks of many trees.

CYLINDRICAL, applied to spikes of flowers having a cylindrical form ; to the tube of monopetalous flowers; also to aments, and to leaves having the form of a cylinder.

CyME, (Cyma) a form of inflorescence, the general appearance of which resembles an umbel and agrees with it in this respect, that its common stalks all spring from one centre, but differs in having tloose stalks alternately and variously divided.

Decinuous, (Deciduum) leaves are so called when falling off at the approach of winter, as in most European trees and shrubs; applied also to stipules falling in the autumn; to calyxes falling soon after the corolla has expanded; to the corolla when falling with the stamens.

Decompound, or Doubly Compound, (Decompositum) leaves are so called when the petioles instead of bearing leaflets, branch out into other petioles to which the leaflets are attached.

DeCrined, (Declinatus) applied to stems when descending archwise, and then gradually curving upwards. 
Decurrent, (Decurrens) applied to sessile leaves when the base runs down the stem and forms a border or wing; applied also to-stipules when extending downwards along the stem.

Decuss ated, (Decussatus) applied to branches growing in pairs, and alternately crossing each other at right angles; applied also to leavès alternately opposite.

Deltoid, (Deltoides) or trowel-shaped, applied to leaves having the form of a trowel, or the Greek letter $\Delta$.

DEFENDING, (Muniens) applied to the position of leaves in sleep; a leaf is said to be defending when it takes an opposite direction from the one above, and falling down, forms a kind of cap, protecting whatever lies underneath.

Demersum, vide Submerged.

Dentate, or Toothed, (Dentalum) leaves are so called when the border is beset with horizontal projecting points or teeth, with rather a distant space between each, and of the same consistence as the substance of the leaf itself; applied also to stipules having spreading teeth about the margin, remote from each other.

Depressed, (Depressum) leaves are so called when flattened vertically; radical leaves are called depressed when they are pressed close to the ground.

Diamond-ShaPed, or Rhomboid, (Rhombeum, Rhomboideum) leaves are so called when approaching to a square, having four sides, of which those opposite are equal; the four angles are generally two obtuse and two acute.

Dichотомоus, or Forken, (Dichotomus) applied to stems dividing into two parts: example, the misletoe.

Dicotyledonous, (Dicotyledones) plants are so called that have two cotyledons or seminal leaves.

Diffusa Panicula, vide Spreading.

Diffusus Caulis, vide Spreading.

Digitate, or FingerED, (Digitatum) applied to a species of compound leaf, composed of two or more leaflets. A leaf to correspond with the name should have five leaflets; but botanists include under the name Digitate, the binate and ternate, and those leaves also which are composed of more than five leaflets; for example, the horse-chesnut, which has seven leaflets.

Diccrous, (Dicecia) applied to plants when the barren and fertile flowers grow from two separate roots. voL. I. 
Disk, (Discus) applied to the central florets of a compound flower. The disk or central florets are generally yellow.

Dipetalous, (Dipetala) corollas having two petals.

Dissectum Folium, vide Leaf.

Dissepimentum, vide Partition.

Distichous, or Two-RANKED, (Disticha) applied to leaves occupying two sides of the branch, but not regularly opposite at their insertion, as the fir, yew, \&c. \&c.; applied to branches also when they spread in two horizontal directions; and to flowers placed in two opposite ranks.

Diverging, (Divergens) applied to the position of leaves during sleep, and signifies that the leaflets approach at their base, and are open at their summits.

DOLABRIFORME, vide HATCHET-SHAPED.

DotTED, (Punctatum) applied to leaves being full of small, hollow, transparent points, or having vesicles containing an essential oil.

Down, (Lanugo) very soft, short hairs, scarcely discernible, covering various parts of a plant.

Drooping, (Cernuus) pointing directly towards the ground; this term is applied to both peduncles and flowers.

DRUPE, (Drupa) a pulpy pericarp or seed-vessel, containing a single hard and bony nut, to which it is attached; as the nectarine, plum, \&c. The nut, though sometimes divided into separate cells and containing several seeds, does not part into distinct valves like the capsule. The drupe varies in consistence, being juicy in the peach, plum, \&c. or firmer and fibrous, as in the cocoa-nut.

Dust, (Pollen) of the anther. The pollen or dust is contained in the anther. In dry and warm weather the anther contracts and bursts, when the pollen is thrown out. From microscopic observation we find each particle of dust to be generally a membranous bag, either round or angular, smooth or rough, which on meeting with any moisture instantly bursts with great force and discharges a subtile. vapour.

Elliptical, or Oval, (Ellipticum) applied to leaves of an equal breadth, and rounded at each end, the longitudinal diameter being longer than the transverse one.

Emarginate, or Notched, (Emarginatum) applied to leaves terminating in a small acute notch at the summit.

EMERGED, (Emersum) applied to the leaves of plants which are raised above water when the lower ones are under. 
EMBRyo, or GERM,* (Embryo) is the most essential part of a seed, and without which no seed is perfect, or capable of reproduction. The germ is usually situater within the substance of the seed, either central, excentral out of the centre, or external; its direction is curved or straiglit, and in some instances spiral.

Enerve, vide Ribless.

ENSIFORME, vide SWORD-SHAPED.

ENTIRE LEAF, (Folium integerrimum) this term is applied to leaves when the margins are devoid of all notclies or incisions.

\section{Epidermis, vide Cutrcle.}

EQUal Corolla. Regular corollas are called equal when all the divisions are of one size. Equal is also applied to petioles when they are of the same length as the leaf; to peduncles when of the same length as the petioles; and to calyxes when the divisions are all of the same size.

Equitant, (Equitantia) applied to leaves disposed in two opposite rows, and clasping each other by their compressed bases.

ERECT, or UpRIGHT, (Erectum) leaves are so called when they form a very acute angle with the stem. Applied also to branches rising in an upright direction; to petioles rising nearly perpendicularly; and to flowers and peduncles rising perpendicularly.

ERose, or JAGGED, (Erosum) applied to leaves very irregularly cut or notched, and having the appearance of being guawed or eaten by insects.

EvergREen, (Sempervirens) applied to leaves continuing green through one or more winters, so that the branches are never stripped: example, the ivy, bay, \&c.

EYE, or ScAR, (Hilum) is a point or scar, marking the place where the seed was affixed to the seed vessel or receptacle, and through which nourishment is conveyed for perfecting its internal parts.

Exotrc, (Exoticus) plants not natives of the countries in which they are cultivated.

Falling, vide Deciduous.

Fascicular, (Fasciculatum) applied to leaves growing in a cluster, or tuft, as the larch, and some species of pine; applied

* Named by Casalpinus, Corculum, or little beart, being the point from which the vital principle of the futare plant originates. 
also to roots, when many tubes proceed from the same centre, shooting forth in an elongated form.

FASCICLE, (Fasciculus) applied to flowers on little stalks, when many spring from one point, and are collected into a close and level bundle at the top; as the sweet-william.

Feathery, (Plumosus) applied to plants furnished with lateral hairs.

Fertile Flower. Flowers are 'so called which have a pistil, or pistils, and produce seed.

Fibrous Root, (Radix fibrosa) consisting of numerous fibres, either simple or branched; these are the most simple of all roots, and convey nourishment directly to the stem, or leaves; many annual herbs and grasses have this kind of root.

Fiddle-shaPed, (Panduriforme) applied to leaves of an oblong form, and contracted at the sides.

Filament, (Filamentum) part of the anther, the long thread-like part that supports the anther; the filament is not essential, being sometimes wanting; the form is various, being sometimes short and thick, or long and slender, or forked, one point only supporting the anther; generally smooth, sometimes hairy; the number varies from one to many.

Filiform, or Thread-LiKe, (Filiformis) applied to peduncles when very fine, resembling threads; applied also to the tube of monopetalous flowers when of a thread-like form; and to aments also.

Fingered-Leaf, vide Digitate.

Fissum, vide Cloven.

Fleshy, (Carnosum) leaves are so called when of a thick pulpy substance, as the aloe, \&c.

Flexvose, or ZigzaG, (Flexuosus) applied to stems taking a zigzag direction, $i$. e. forming angles from right to left, and from left to right.

FLINT, (Silica) this substance is supposed to be a vegetable secretion, at least, it has been found in a state of great purity in many vegetables.*

Floral Leaf, vide Bractea.

FLoRET, (Flosculus) a floret is a very small monopetalous flower,

* Sir H. Davy has discovered pure fint in the cuticle of many grasses; it is also found in the hollow stems of bamboo, and in many other plants; the ashes of wheat straw are found to contain it also. 
many of which, enclosed in one calyx or perianthium, and placed (sessile) on a common undivided receptacle, form a species of compound flower.

Flosculus, vide Floret.

Folium, vide LEaF.

Follicle or BAG, (Folliculus) "a membranons seed-vessel of one valve and one cell, bursting lengthwise, and having no apparent suture to which the seeds are attached.

Fringed, vide Ciliate.

FROND, (Frons) the term frond implies a peculiar union of the fructification with the leaf and stem; $i$. e. the flowers and fruit are produced from the leaf itself.

FUNNEL-SHAPED, (Infundibuliformis) applied to a monopetalous corolla, having a conical border placed upon a tube.

Gemma, vide Buds.

Gemmaceous, (Gemmacezs) applied to flower-stalks growing out of leaf-buds.

Geniculate, (Geniculatus) applied to culms bent like the knee; also to peduncles bent at the joints.

GENUS, in botanical language signifies a tribe or family of plants, comprehending one or more species; each of which in some particulardiffers from the others, but all agree in one or more essential characters.

GerM, vide Embryo.

GERMEN, (Germen) the germen is the swollen base of the pistil, forming the rudiment of the fruit and seed.

Gibвous, (Gibbum) applied to fleshy leaves having one or both sides convex, arising from the excessive abundance of pulp.

Glaber, vide SMootTh.

GLAND, (Glandula) à sniall transparent tumour or vesicle, discharging a fluid, either oily or watery, and situated on various parts of plants, as the stalk, calyx, leaves, ' $\&$ c.

Glandular, (Glandulosum) applied to the margin of leaves beset with glands.

Graucous, (Glaucus) this term is applied to the leaves or stems of plants, when covered with a fine mealiness of a sea-green colour.

GLUME, (Gluma) the outer husk of corn and grasses.

Granulated, (Granulata vel Articulata) applied to jointed roots of a scaly nature, agreeing very much with the scaly bulbous roots.

HaIR, (Pilus) this substance is one of the appendages to plants, VOL. I. 
and varies in consistence from a soft silky down to stiff hard bristles; its use in some plants, appears to be to serve as a protection from insects and vicissitudes of weather; in some plants the hairs or bristles are tubular and pervious, and serve the office of excretory ducts, each individual hair having a small follicle or bag situated at the base and containing a fluid; which in some plants is poisonous, as in the nettle.

Hairy, (Hirsutus vel Pilosus) stems or leaves covered with hair are so called.

HALbert-SHAPED, (Hastatum) applied to leaves hollowed out at the base and sides, but witl spreading lobes: example, the upper leaves of the Solanum Dulcamara.

Hatchet-Sha PEn, (Dolabriforme) applied to leaves cylindrical at the base and having the upper part dilated, thick on one edge and cutting on the other.

HeAD, or TUFT, vide Capitate.

HEART-SHAPED, (Cordatum) applied to leaves resembling an oval, with the base deeply hollowed out; or having the exact form of a heart, as it is usually represented.

Hirsute, vide Hairy.

HILUM, vide EYE.

HISPID, (IIispidus) HAIRY.

HoARY, (Incanus) leaves and stems are so called, when the surface is clothed with silky hairs, or a scaly mealiness of a whitish or grey colour.

Hollow, or Tubular, (Tubulosum) applied to leaves hollow within : example, the common onion.

Hooded, vide Culullate.

HoRizontAL, (Horizontale) applied to leaves spreading and forming a right angle with the stem; also to flowers, malsing a right angle with the stem; and to roots which, instead of descending in a perpendicular direction, spread horizontally.

Husk, vide Glume.

HyPocrateriformis, vide SAlver-Shaped.

IMBRICATED, (Imbricatum) applied to leaves, when lying one over the other like tiles upon a loouse; applied also to the leaves of the calyx when lying one over the other.

INCANUG, vide HoARY.

INDIGENOUS, (Indigena) plants the natural produce of any particular country, are said to be indigenous to that country. 
INCOMPLETE Flower, (Flos incompletus) flowers are so called when wanting the corolla; corollas also are called incomplete when some part appears to be wanting: as in a papilionaceous flower consisting of the vexillum only, or in a rosaceous one with a single lateral petal, as if four others had been stripped off.*

IN EQUALIS, vidP UNEQUAL.

INERME, vide UNARMED.

INFLEXED, (Inflexum vel Incurvum) applied to leaves curved inward. INFLORESCENCE, (Inflorescentia) is used by Linnæus to express the particular manner in which flowers are situated upon a plant; denominated by preceding writers modus florendi, or manner of flowering. Botanists disting uish ten different kinds of inflorescence, named Whorl, Cluster or Raceme, Spike, Corymb, Fascicle, Head or Tuft, Umbel, Cyme, Panicle, and Bunch-these are described under their respective names.

INFUNDIBULIFORMIS, vide FUNNEL-SHAPED.

INTEGERRIMUM, vide ENTIRE.

INTERNODAL, (Internodis) applied to flower-stalks proceeding from the intermediate space of a branch between two leaves.

INTERRUPTEDLY, (Interruptè) applied to compound leaves when the principal leaflets are divided by intervals of smaller ones; applied also to spikes of flowers, when the larger spikes are divided by a series of smaller ones.

INVOLUCRE, (Involucrum) a species of calyx, reinote from the flower, and bearing a great resemblance to Bractea: the involucre is composed of many small leaves placed at the foot of the general umbel; in umbelliferous plants the involucre accompanying the partial umbels, is called Involucella.

Involute, (Involutum) applied to leaves, when the margins are rolled inwards upon each other.

INvolving, (Involvens) applied to the position of leaves in sleep, i. e. during the night season; and implies that the leaves approach each other by their summits only, forming an arch or hollow underneath.

IRREgular Corolla. The term irregular is used in opposition to regular, and implies that the general figure is not uniform, 
as in the rose, pink, \&c. but that the petals are of unequal size and shape, as in the violet, \&c.

JAGGED, vide Erose.

JAGGED-PoINTED, (Pramorsum) applied to leaves extremely blunt, and with many irregular notches.

Jointed, vide Articulated:

KEEL, (Carina) the term keel is applied to two of the petals in papilionaceous flowers; the keel is composed of two petals, separate or united, and encloses the internal organs of fructification.

KEELED, (Carinatum) applied to leaves when the back is very prominent longitudinally.

KIDNEY-SH A PED, (Reniforme) applied to leaves of a broad roundish form, hollowed out at the base: example, the Asarum Europæum.

KNotTY, (Nodosa) roots are so called, when forming knots, united by a filament or thread.

KNOBBED, vide Tuberous.

LABIATE, or LIPPED, (Labiatus) calyxes are so called when the segments or divisions resemble the form of lips.

LACINIATED, (Laciniatum) applied to leaves cut into numerous irregular portions.

Lavis, vide Smooth.

LANATUS, vide WoOLLY.

LANCEOLATE, (Lanceolatum) applied to leaves of a narrow oblong form, gradually tapering towards each end.

LAteral, (Laterulis) applied to peduncles when situated on the side of the stem or branch; and to stipules when placed on each side of the petiole.

LAX, (Debilis) applied to stems which are not stiff, but pliable and easily bent.

LEATHERY, (Coriaceum) leaves are so called which are thick, tough, and somewhat of a rigid consistence.

LEAF. (Folium) Leaves are organs destined to perform various functions; as imbibing and exhaling air, light, moisture, and zarbonic acid gas, which they decompose; the carbon is added to the sap, (and affords nourishment to the plant), and they exhale the oxygen: leaves in the dark give out carbon and absorb oxygen.*

* To enter into the functions of vegetables would be foreign to our work, we must therefore refer our readers for information on this interesting subject, to those works that treat particularly on Physiological Botany. Ed. 
LEGUME, (Legumen) a seed vessel peculiar to flowers of the pea kind, formed of two oblong valves having no dissepiment or longitudinal partition; the seeds are attached to one of its margins only.

LIBER, vide BARK.

LIGULATE, (Ligulatus) applied to the radiai florets of compound flowers, when shaped like a strap or ribbon.

LIMB, (Limbus) the outer spreading portion of a monopetalous flower.

LINEAR, (Lineare) narrow leaves are so called when they are of an equal breadth from one end to the other, the two edges being straight and equi-distant from each other.

Lingulatum, vide Tongue-sha PED.

LOBED, (Lobatum) leaves are so called when the margins of the segments are rounded; according to the number of lobes the leaf is termed Bilobum, Trilobum, \&c.

Lunatum, vide Crescent-Shaped.

LXRATE, or LYRE-SHAPED, (Lyratum) applied to leaves divided transversely into several segments, the segments gradually increasing in size as they approach the extremity of the leaf.

MANY-F'LOWERED, (Multiflorus) applied to peduncles, i. e. stalks bearing many flowers.

Medulata, vide Pith.

MEMBRANOUS, (Membranaceum) applied to leaves of an extremely thin and pliable texture; also to stems of a delicate substance, composed of several thin membranes laid one over the other.

MrLx, ( Lac) a vegetable secretion either white or yellow, bearing a resemblance to animal milk, and composed of a watery fluid in combination with an oil or resin.

MoNocotyledonous, (Monocotyledones) applied to a tribe of plants, whose embryos possess one cotyledon or seed-lobe. Moncecious, (Monceia) applied to a tribe of plants having the stamens and pistils situated in separate flowers, but both flowers growing on the same individual plant.

Monopetalous, (Monopetalus) flowers are so called when consisting only of one coloured leaf or petal.

MONOPHYLLOUS, (Monophyllus) applied to calyxes consisting of not more than one leaf.

Mucronatum, vide Cuspidate.

voL. I. 
NAKED, (Nudus) applied to flowers having no calyxes; also to stems without leaves; and to leaves when perfectly smooth, and destitute of all kinds of hairiness.

NECTARY. (Nectarium) The nectary may be defined, that part of a flower which secretes and contains the honey, (an almost universal fluid in flowers) and is either a part of the corolla, or an organ distinct from it and variously formed, (as the nectaries of the monkshood, black hellebore, \&c.); or a tubular elongation of the calyx, or of a petal, as in the Delphinium tribe of plants; or an assemblage of glands, \&c. In monopetalous flowers, the honey is contained in the tube which probably secretes it.*

Nervosum, vide Ribeed.

Nicked, vide EMARginate.

Notched, vide CREnate.

Nudus, vide NAKED.

NuT, (Nux) a hard shell enclosing a kernel, which when enclosed in a pulpy covering forms the pericarp named drupe, already described.

Oblique, or Twisted, (Obliquum) applied to the position of leaves, and implies that one part of the leaf is horizontal and the other vertical.

Oblong, (Oblongum) applied to leaves several times longer than broad; an oblong leaf is not precisely of one form, but varies in length, breadth, \&c. The term oblong is chiefly used to discriminate a leaf whose form does not accurately come under the denominations, oval, linear, round, \&c.

Obovate, (Obovatum) applied to leaves having the form of an egg cut lengthwise, with the broader end uppermost and forming the extremity of the leaf.

OVATE, or EGG-SHAPED, (Ovalum) applied to leaves having the form of an egg, with the broad end forming the base and the pointed the extremity of the leaf; applied also to seeds shaped like an egg.

OвtUSUM, vide Blunt.

Oval, vide Elluptical.

\footnotetext{
* The secretion of honey is not exclusively confined to the flower : in some of the liliaceous tribe of plants it exudes from the flower-stalk, and in the passion flower it is secreted by glands situated in the peduncle.
} 
Opposite, (Oppositum) applied to the position of leaves placed exactly opposite eanh other on the stem; also to branches growing in pairs; and to peduncles placed opposite to a leaf.

Orbicular, or Circular, (Orbiculatum) leaves are so called when their lengti and breadth are equal, and their form nearly circular.

Palmate (Palmatum) applied to leaves which are divided, half or rather more than half way down the middle, into several nearly equal segneuts, having a space between each.

PANDURIforme, vide FIDDLE-SHAPED.

Panicle, (Panicula) a species of inflorescence, in which the flowers are scattered on peduncles, variously subdivided without any order, and more or less close. When the stalks are at some distance it is called Diffusa, a lax or spreading panicle; when still more spreading, a divaricated panicle; and when the flower.stalks are more together, it has the appellation of a close or dense panicle.

Papilionaceous, (Papilionacea) applied to the form of a polypetalous corolla of an irregular spreading form, somewhat resembling a butterfly and composed of four petals, distinguished by appropriate names; the two side petals, wings, (Alr); the large one at the back, banner or standard, (Vexillum); and the lower one, the keel, (Carina) - the last contains and protects the internal organs.

Papillose, (Papillosus) applied to steins covered with soft tubercles; also to leaves covered with fleshy points or dots.

PAPPUS, or SEED-Down, (Pappus) the feathery, bristly, or chaffy appendage that crowns many seeds which have no pericarpium, as in the dandelion.

Partition, (Dissepimentum) the part which divides a capsule into many separate cells is so called.

Pectinate, (Pectinatum) applied to a pinuatifid leaf, whose segments are extremely narrow, resembling the teeth of a comb.

Pepate, (Pedatum) applied to a peculiar kind of ternate leaf, its lateral leaflet being compounded in the forepart: example, black hellebore.

Pedrcel, (Pedicellus) a partial flower stalk, or a subdivision of the general one, each subdivision being denominated a pedicel. Peduncle, (Pedunculus) the stalk that bears the flower and fruit. 
Pellicle, (Pellicula) a membranous or mucilaginous covering, closely adhering to the outside of some seeds, sา as to conceal their proper surface and colour; pellicles are often downy, and when of a mucilaginous substance, not perceptible till the seed is moistened.

Peltate, (Peltatum) applied to leaves when the footstalk is inserted in the middle of the leaf : example, the common nasturtium.

Perfect Flower, (Flos perfectus) applied to flowers having both stamens and pistils.

Perfoliate, (Perfoliatum) leaves are so called when the stems run through them.

Perianth, (Perianthium) the calyx is so called when it is contiguous to and makes a part of the flower.

Pericarp, (Pericarpium) the seed vessel; this is of a pulpy, woody, or leathery texture, and encloses the seeds, but is wanting in many plants; there are ten different kinds of pericarps, viz. Drupe, Pome, Berry, Follicle, Silique, Silicle, Legume, Capsule, Nut, and Strobile.

Personate, (Personatus) applied to a monopetalous flower of an irregular form, the border of the corolla resembling the mouth with the lips closed.

Petal, (Petalum) the leaf of the corolla. In some flowers a single petal forms the whole corolla, as in the Atropa Belladonna, in whicl case it is termed a monopetalous corolla; when composed of many petals, as in the rose, \&c. polypetalous.

Petrole, (Petiolus) the stalk connecting the leaf with the stem or branch.

Pilosus, vide Hairy.

Pilus, vide Hatr.

Pinnatifid, (Pinnatifidum) applied to a species of simple leaf, cut transversely into several deep, oblong, parallel segments, not extending to the midrib; applied also to involucres, divided transversely by oblong segments.

Pinnate, (Pinnatum) applied to a species of compound leaf, composed of many leaflets, placed on each side of the petiole, and alternate, opposite, decurrent, \&c.

Pistil, (Pistillum) an organ situated in the centre of the flower, and forming the rudiments of the fruit. A perfect pistil is composed of three parts, the germen, or seed vessel in the infant state; the style, and the stigma. 
Plarted, (Plicatum) applied to leaves when the disk of a leaf lies in folds, bearing a resemblance to a fan: example, the mallow.

Plume, (Plumula) applied to the ascending part of the corculum, formed of the infant stem and leaves.

PoD, (Siliqua) a long dry seed vessel of two valves, separated by a linear receptacle, on whose edges the seeds are ranged alternately.

Pornted, (Acuminatum) applied to leaves ending in an awl-shaped or taper point.

Pollen, vide Dust.

Pouch, (Silicula) a pod of a short or rounded form.

Premorsum, vide JAGGED-POINTED.

Prickle, vide Aculeus.

Procumbent, (Procumbens) applied to stems lying or falling on the ground through weakness.

Proliferous, (Prolifer) applied to the shooting out of new branches, from the extremities of former ones.

Prostrate, (Prustracus) a stemi is so called when it trails or runs horizontally over the ground.

Pubescent, (Pubescens) when applied to the stems or leaves of plants implies that they are clothed with hairs or down.

Punctatum, vide DotTed.

Quinate, (Quinatum) compound leaves are so called when composed of five leaflets.

RACEME, (Racemus) consists of numerous flowers, rather distant, each on its own proper stalk, and all connected together by one common peduncle.

Radical Leaves, (Folia Radicalia) are such as spring from the root : example, the dandelion.

RAY, (Radius) in compound flowers consists of all the florets composing the margin.

RAMOSE, (Rameus) applied to flowers growing on the branches; to peduncles proceeding from a branch; and also to leaves growing on branclies when they differ from those on the stems.

Receptacle, (Receptaculum) the basis or point, upon which all the parts of the fructification rest; the receptacle has not always any particular figure to distinguish it, except in compound flowers, when the surface, which is either convex, concave, conical, scaly, cellular, hairy, or 
naked, forms the distinguishing character of the genus or family.

ReClined, (Reclinata) applied to leaves when the point is lower than the base; also to stems when curved towards the ground.

Rectus, vide Straight.

Recurved, (Recurva vel Reflexa) applied to leaves curved backwards.

Regular Corolla. This term is applied to the corolla when the general figure is uniform, as in the pink, rose, \&c.

RENIFORME, vide KIDNEY-SHAPED.

REPANDUM, vide WAVY.

REPENS, vide CreEPING.

Resupinate, or Reversed, (Resupinatum) applied to leaves when the upper surface is turned downwards.

Retuse, (Retusum) leaves are so called when ending in a broad, shallow notcli or sinus.

Revolute, (Revolutum) applied to leaves when the margins are rolled backwards towards the under surface.

RHOMBeum, vide Dramond-SHAPED.

Ribied, (Costatum vel Nervosum) applied to leaves when the nerves or ribs extend in simple lines from the base to the point.*

RIBLESS, (Enerve) applied to leaves without ribs or nerves.

Ringent, (Ringens) applied to a monopetalous corolla, the border of which is usually divided into two lips, which gape like the mouth of an animal.

Rosaceous, or Rose-LIKe, (Rosacea) applied to polypetalous corollas, consisting of four or more petals spreading like a rose: example, the poppy.

ROSTRUM, vide BEAK.

ROTATA, vide WHEEL-SHAPED.

Rounnish, (Subrotundum) applied to leaves approaching to a circular form, but not so round as the orbicular leaf.

RUGGED, or WRINKLED, (Rugosum) leaves are so called when the surface rises into little inequalities above the veins.

Runcinate, or Lion-Toothed, (Runcinatum) leaves are so called when cut into several transverse acute segments, pointing towards the base of the leaf: example, the daudelion.

* The larger vessels are called perves or ribs, and the smaller veins, without regard to the form they take. $-E d$. 
SagitTatum, vide ARrow-Shaped.

SALVER-SHAPED, (Hypocrateriformis) applied to a monopetalous corolla, the limb of which being placed on a tube spreads out horizontally.

Sarmentose, or Trailing, (Sarmentosum) stems are so called that are thrown out from the roots for the purpose of increase, which are barren of flowers, and creep along, putting forth roots from various points; when leafy, they are called Stolo, Sucker, or Scion.

Scasrous, (Scaber) applied to stems that are rough from any little inequalities or tubercles.

Scaly, (Squamosa) roots are so called that are covered with scales. Scandens, vide Climbing.

Scape, (Scapus) an herbaceous stalk springing from the root and bearing the flower and fruit, but not the leaves; a scape is either single flowered, as in the Leontodon Taraxacum, \&c. or many flowered, as in the cowslip; it is also either naked, as in the dandelion; or scaly, as in the Tussilago Farfara, \&r.

SCAR, vide EYE.

SCATTERED, (Sparsa) applied to leaves placed irregularly upon the stems; also to peduncles dispersed irregularly on the plant.

SeEd Vessel, vide Pericarp.

Semicylnd Drical, (Semicylindraceum) applied to leaves flat on one side and convex on the other.

Seminal Leaves, (Folia Seminalia) the first leaves of a plant, serving the office of Cotyledons.

Sempervirens, vide EvergreEN.

SERRATED, (Serratum) applied to leaves, the margins of which resemble a saw, the teeth pointing towards the extremity of the leaf; when the teeth are very fine, the term Serrulatum is used.

SESSILE, (Sessilis) applied to flowers when placed directly on the branch or stem; also to leaves when they grow directly from the stem, branch, or root, without any footstalk.

SHARP, vide ACUTE.

Sheathing, or VAgINANT, (Vaginans) applied to leaves when the base forms a cylindrical tube, which invests the stem or other leaves : example, grasses.

SIlicula, vide Pouch.

Siliqua, vide PoD. 
SIMPLE, (Simplex) as applied to leaves is used in opposition to compound, which denotes a leaf composed of more than one leaflet, whereas the simple leaf consists of a single leaf, either lobed or undivided.

SiNUATED, (Sinuatum) leaves are so called, when the margins are cut into wide rounded openings; as the oak, \&c.

Souid, (Solidus) stems are so called that have no cavity.

Solitary, (Solitarius) applied to peduncles when there is only one on a plant, or whes they stand singly in the same place.

SPADIx, an elongated receptacle: example, the Arum Maculatum. SPARSA, vide ScatTERED.

SPATHE, or Sheath, (Spatha) a calyx which forms a kind of hood or sheath, at a greater or less distance from the flower, and bursts longitudinally.

Spatulate, (Spatulatum) applied to leaves of a roundish figure on the upper part, tapering and linear at the base.

SPIKE, (Spica) a species of inflorescence, in which the flowers stand sessile along a common peduncle, and are either placed alternately and cruwded together, or in separate groups.

SPICA, vide SPIKE.

SPICULA, vide SPIKelet.

SPIKELET, (Spicula) is formed of many small florets, ranged on a little stalk in one calyx : this term is applied exclusively to grasses.

SPINA, vide Thorn.

Spinous, (Spinosum) applied to leaves, the margins of which are beset with thorns.

Stamen, (Stamen) a constituent part of a flower, situated within the corolla, and generally consisting of two parts, the filaments and the anther.

STANDARD, vide BANNRR.

STIGMA, (Sligma) an essential part of the pistillum, situated on the top of the style or germen; the stigma is variously formed, being either a fine point, a round head, or lobed; generally downy, often hollow and gaping, and always more or less moist.

STIPE, (Stipes) the stem of a frond; also applied to the fungus tribe.

Stipule, (Stipula) a membranous leafy appendage, placed at that part of the stem whence the leaf or footstalk arises. Stipules vary in number, being solitary or in pairs; in situation, being either external with regard to the leaf or foot- 
stalk, or internal, the internal stipules sometimes embrace the stens in an undivided tube; in form, linear at the base but gradually tapering towards a point, or shaped like a crescent ; in attachment, conneeted dirẹctly with the stem, or with the petal; in direction, erect, or variously reflected. STRAIGHT, (Rectus) applied to stems that are perfectly straight i.e. without any bend.

STRIATED, (Striatus) applied to stems marked with fine parallel lines.

Sмоотн, (Glaber) applied to stems is opposed to all kinds of lairiness or pubescence.

STEM, (Caulis) that part of a plant which elevates from the root the flowers and leaves, and comprehends the trunk and branches of all trees and shrubs.

STrobile, (Strobilus) a seed vessel composed of ligneous scales, which enclose the seeds: a strobile is a catkin liardened and enlarged into a seed vessel.

STYLE, (Stylus) that part of the pistillum which elevates the stigma above the germen. The style is sometimes wanting, and is not absolutely essential.

SUBGLOBULAR, is used to express a form not perfectly globular or spherical.

Submerged, (Demersum vel Submersum) applied to leaves plunged or growing under water, and never rising to the surface.

Subovate, this term is used to express a form not perfectly ovate. SUBROTUNDUM, vide ROUNDISH.

SUBSESSILE, applied to leaves having very short footstalks. Subulatum, vide Awl-Shaped.

SulCATE or FuRRowED, (Sulcatum) applied to stems marked with broad deep lines; also to leaves marked with broad deep parallel lines.

SWORD-SHAPED, (Ensiforme) applied to two-edged leaves, slightly convex on both surfaces, and gradually tapering to a point from the base to the apex.

Tall, (Cauda) an elongated appendage to many seeds, formed of the permanent style: this appendage is generally feathery. TENDRIL, (Cirrus) an appendage to nuuy plants of a spiral form; its use is to clasp and wind round other bodies, by which means weak and climbing stems support themselves, and rise to a great height.

Terminal, (Terminalis) when applied to a peduncle implies that it VOL. I. 
terminates the stem; is applied also to flowers and umbels proceeding from the extremity of the stem or branches.

Terna Folia, leaves growing three together.

Ternate, (Ternatum) applied to compound leaves, consisting of three leaflets.

THORN, (Spina) a sharp projection proceeding from the wood.*

ThREE-EDGED, (Trigonum) applied to leaves having three sides, and three angles.

ThreE-Nerved, or Ribbed, (Trinerve) leaves are so called when they have three ribs, all distinct from the base, and unconnected with the margin.

ThREE-SIDED, (Triqueter) applied to stems having three flat sides. THYRSUs, vide Bunch.

TONGUE-SHAPED, (Lingulalum) applied to leaves of an oblong, blunt, thick form, generally of a cartilaginous substance at the edges.

TOOTHED, vide DENTATE.

TrIangular, (Triangulare) apphed to leaves having three sides, and to stems having three edges.

TRIgonum, vide ThrEe-EDGED.

Trilobum, vide Lobed, \&c.

TRINERVE, vide THREE-NERVED.

Triply-RIBBED, (Triplinerve) applied to leaves when a pair of large ribs brancli off from the main rib just above the base.

TRIQUETER, vide THREE-SIDED.

Trowel-Shaped, vide Deltoid.

Truncatum, vide ABRUPt.

Tuberous, (Tuberosa) roots are so called when solid and of a round form, from such small fibrous roots often shoot out, both from beneath and laterally: example the potatoe.

TUBE, (Tubus) the round hollow part of a monopetalous flower is so called.

Tubular, (Tubulosi) applied to the florets of a compound flower, when they form a cylindrical tube, and are five-cleft.

Tubulosum, vide Hollow.

TUFT, vide CAPITATE.

* It is observed by Linnæus, that many plants in their wild state have thorns, which by cultivation disappear : example the pear. $E d$. 
Tunic, vide Arir.

Twining, (Volubilis) stems are so called that by their own spiral form twine round other plants.

Two-EDGED, (Anceps) applied to stems having two angles, or edges; applied also to leaves of the sword-shaped form.

UMBEL, (Umbella) this term is applied to a peculiar form of inflores. cence : an umbel consists of several flower stalks or rays, nearly equal in length, which spread from one common centre, and the summits of which form a regular surface, either level, convex, or globular, more rarely concave. When each stalk or ray is single flowered, it is called a simple umbel; but when each ray or stalk terminates in another set of rays, it is called a compound umbel, and these smaller umbels are called Umbellata, or partial umbels: the carrot, parsley, hemlock, \&c. are examples of the compound umbel.

UNARMED, (Inerme) applied to the margins of leaves devoid of spines or thorns.

INDULATEn, (Indulatum) applied to leaves when the margins are waved obtusely up and down.

UNEQUAL, (Inaquale) applied to leaves when the two halves are of unequal size.

UNITED, applied to flowers implies the same as perfect. Vide Perfect.

UTRICULUs, this term is applied to a species of capsule resembling a small bladder, which varies in thickness, never opens by valves, and falls with the seed; this species of pericarpium seldom contains more than one seed ; it is more frequently called the external coat of the seed, rather than a capsule. Vaginant, vide Sheathing.

VARIEGATED, (Variegatum) this term is applied to leaves when marked with white or yellow spots or lines of various forms.*

Veinless, (Avenium) applied to leaves without nerves or veins. VEINY, (Venosum) applied to leaves when the vessels which nourish the leaf are more or less prominent, branched, and subdivided, forming a network on one or both surfaces.

VERRUCOSUS, vide WARTY:

* This variety in the colour of leaves is supposed by some botanists to be a disease, $\boldsymbol{E} d$. 
VerTicillata, vide WHORLED.

VERTICILLUS, vide WHORL.

VEXILLUM, vide BaNNER.

VIllous, or SHAGGY, (Villosus) applied to stems covered with rather long soft hairs.

Vișcrd, (Viscidus) applied to stems covered with a clammy juice. Volubilis, vide T'wining.

Volva, (Volva) a species of calyx. This term is applied to a membranous wrapper or covering of the fungus tribe, which conceals their parts of fructification; in due time it bursts, and forms a ring upon the stalk.

WARTY, (Verrucosus) applied to the surface of stems, beset with hard tubercles or warts.

WAvy, (Repandum) applied to the margins of leaves, when bordered alternately with numerous minute segments of circles and angles.

WEDGE-SHAPED, (C'uneiforme) applied to leaves that are broad at the summit, gradually tapering down to the base.

WHEEL-SHAPED, (Rotata) applied to corollas of the salver-shaped form, but having scarcely any tube.

WHORL, (Verticillus) a species of inforescence, in which the flowers surround the stem, in the form of a ring; this term is also applied when the flowers are not inserted equally on all sides, but on two opposite ones only.

WhoRLED, (Verticillata) applied to leaves growing in a circle round the stem. This term has no reference to the precise number of leaves.

Wing, (Ala) a membranous appendage to some seeds, serving to waft them along in the air; applied also to the two side petals of a papilionaceous corolla.

WINGED, (Alatus) applied to stems, when the angles are extended into leafy borders; also to petioles having a leafy border on each side.

Wrapper, vide Volva.

WRINKLED, vide RUGGED.

YoKeD, vide CONJUGATE. 



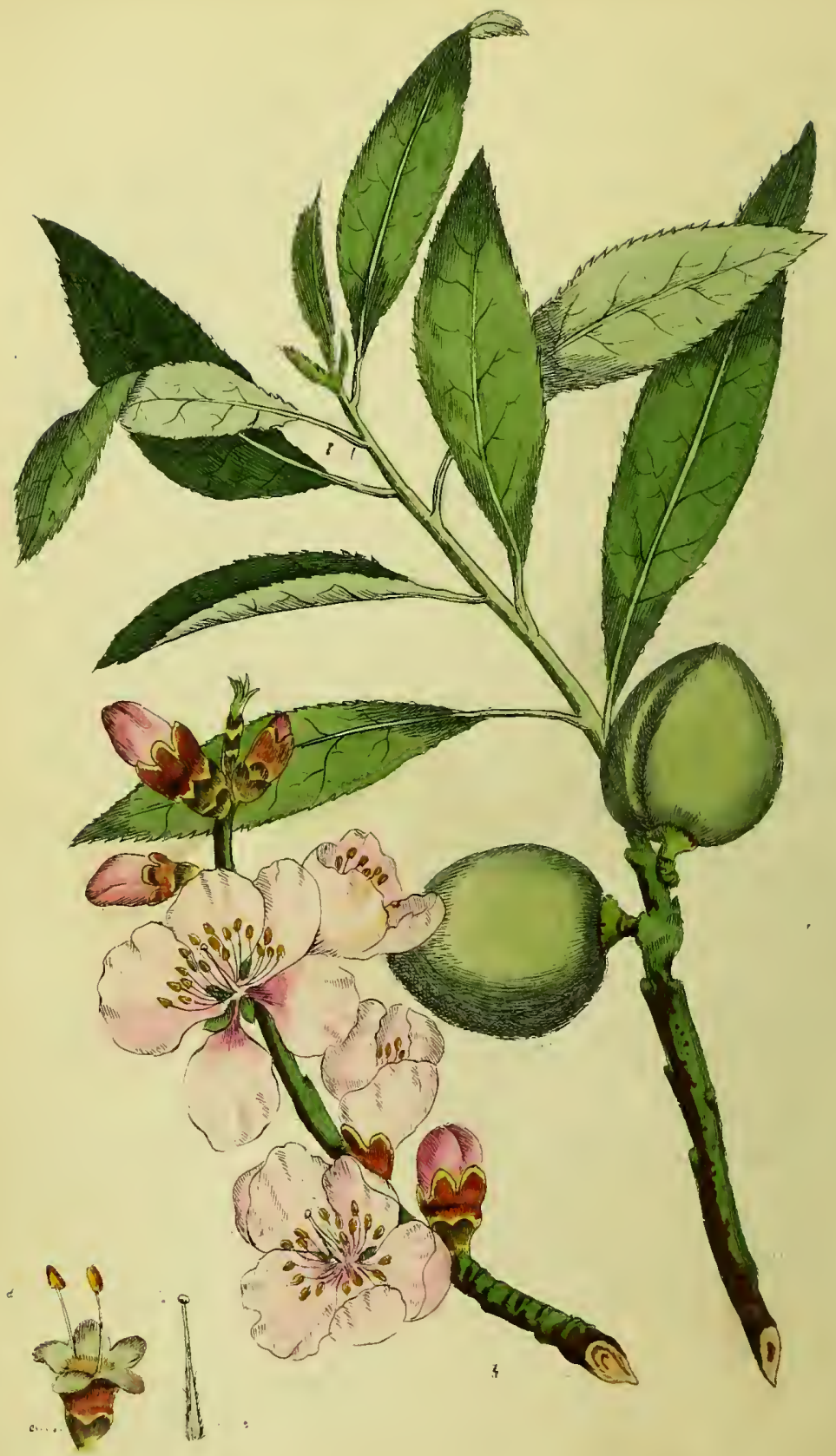

Ampadalies Commenis 


\section{AMYGDALUS COMMUNIS.}

The Almond Tree.*.

\section{Class Icosandia.-Order Monogynia.}

Nat. Ord. Pomacere, Linn. Drupacere, Juss.

Gen. Char. Calyx 5-cleft beneath. Petals 5. Drupe with nut perforated in the pores.

Spec. Char. Leaves with the lowest sawings glandular. Flowers sessile double.

The ALmond Tree, although a native of the warm climairs of Syria and Barbary, grows in great perfection in the south of Europe; where it is now much cultivated. From the writings of Hippocrates, and other ancient authors, it appears the almond tree was known in the earliest ages; hut at what period it was first introduced into Europc, their writings do not inform us; from Pliny we learn that in Italy, in the time of Cato, the fruit of the almond was known by the name of Greek nuts. $\downarrow$ Several species of the Genu's Anygdalus $\ddagger$ lave been long cultivated in Britain, as an ornament to our shrubberies. The Amygdalus Communis was first cultivated in England in the year 1570:\| of this species there are two varieties, one with sweet and the other with bitter kernels; these varieties, it is said, will often arise from iruit of the same tree, by sowing the seed, or by some accidental difference in culture. This species of almond rises to the leight of sixteen or more feet, with large spreading branches; in mild seasons it flowers early in February, when the young wood of the last year's growth is crowded with blossoms. The leaves are lanced, serrated, petioled,

* In the annexed illustration, Fig. $a$. represents a sprig, the leaves and fruit about one-third less than the natural specimen from which it was takel. $b$. A sprig representing the blossoms of the natural size. c. The pistillum (somerlat magnified.) $d$. Stamina. e. The calyx.

+ See Pliny, lib. xv. cap. 22.

$\ddagger$ In the Hortas Cantabrigiensis, there are enumerated six species.

If See Hortus Cant. 10 th ed. 
and beset with sinall glands towards the basc: the flowers are sessile, and appear before the leaves; the corolla is composed of five rose coloured petals; the calyx tubular, and divided at the brim into five obtnse segments; the filaments from twenty to thirty, spreading and of equal length, iuserted into the calyx; antheræ simple; the germen roundish and downy; style short, and crowned with a round stigma; the germen becomes a drupe, an oval compressed large fruit, with a thin tough hairy covering, marked with a longitudinal furrow where it opens; under this is a thick rough shell, perforated witl pores, containing the kernel. The kcrnel or almond is of a flat form, the skin of which is of a brown colour, covered vith an acrid powdery substance, when stripped of the skin of an ivory white; taste either sweetish or mildly bitter. The kernel of this tree is the ouly part used, either for food or medicine; and the sweet almond chiefly; although it is supposed to possess little noúrishment, and to be difficult of digestion.

Medical Uses. Almonds possess very emollient properties, softening and relaxing the solids, obtunding sharp and acrimonious humours; hence, in heat of urine, pains and inflammation, coughs, \&c. it is given with advantage. Almonds are usually prescribed in the form of emulsion, by triturating them with water; this is preferable to using the expressed oil, which is apt to become rancid, in which case it is improper in inflammatory diseases. Alnonds form a useful medium, by which many resinous and unctious substances become niscible with water. By triturating camplior, or resinous purgatives, with almonds, they are suspended in the aqueous fluid, and form a commodious and elegant mode of exhibiting those substances.

Off. Nucleus. The kernel; sweet and bitter almonds.

Off. Prep. Ol. Amygd. L. E. D. Nist. Amygd. L. D. Conf. Amygd. L. Emuls. Anygd. E.

Properties of sweet and eitter Almonds. Almonds yield by expression a large proportion of a very fine pale yellow oil, almost tasteless when recent, but soon growing rancid. Sweet almonds yield nearly half their weight of this oil ; it may also be extracted by boiling the almonds, when the oil is gradually collecied upon the surface of the water. Almonds, by trituration with water, forms a milky liquid, which soon turns sour in warm weather; this liquid yields a precipitate by acids, but not a curdy mass like milk. Almonds yield by fermentation and distillation a spirituous liquid, having the smell and taste of the fruit. The 
bitter almond, as observed, is only a variety of the sweet; it "eontains about one-third its weight of mild scentless oil, (resembling in every respect that obtained from the former, ) and about two-thirds of a farinaceous matter. When the oil is obtained by expression, the bitter prineiple remains in the cake; from which it may be extracted by digesting in water or by distillation. The distilled watcr was formerly sold under the name of black ehcrry water, and much used as an antispasmodic, eordial, and quieting medicine; but discarded on aecount of the poisonous effects sometimes produced by its use, from the Prussic Acid it contains. In consequenee of the continental experinents with Hydro-eyanie or Prussic Acid, and the applieation of it, as a remedial agent, in a variety of diseases, by Magendie on the Continent, Dr. Granville and others in this country, the distilled water of bitter alnonds is again coming into repute. A volatile oil, of a pale yellow colour, with the smell of peach blossoms is also obtained from the bitter almonds by distillation; this oil contains a considerable quantity of Prussic Acid, and is an active poison to many animals; a few drops applied to the tongue, causes almost instant death. According to the facts reported by Matthiolus, M. Deyeux, Foenisius, and othèrs, bitter almonds, in substance, in doses of a few drachms, prove poisonous to dogs, eats, foxes, birds, \&c.*

Bitter almonds may be eaten generally by man with impunity, and are daily used in cookery without any bad consequences; in a few instances they liave been known to disagree, and in some constitutions to produee urticaria, and other unpleasant symptoms. The poisonous properties of the almond seem to depend on the quantity of Prussic Acid it contains, and we may suppose that the volatile oil of the bitter almond contains this acid in a highly concentrated state; the peculiar flavour of the almond, as well the kernels of the peach, neetariue, and many other fruits, would seem to be derived from the Prussic Acid contained in them.

Properties of Prussic Acid. The existence of Hydro-cyanic or Prussic Acid, as a vegetable principle, was discovered in 1802 , by Bolm, in the distilled water of bitter almonds; in peach blossoms and leaves by Vanquelin; and in the leaves of the cherry laurel by Schrader. Schecle discovered the Prussic Acid in 1780, but we are indebted to M. Gay Lussac for a perfeet analysis of this acid; being the first chemist who obtained it in a state of purity, and who 
made knowu the eleneuts of its composition. From his experiments it appears, that the base of the Prussic Acid is a compound of azote and carbon, called by him Cyanogen, of which hydrogen is the acidifying principle, and from which lie gave it the name of Hydro-cyanic Acid. The preparation of this acid is attended with much labour and difficulty, and even when prepared in its purest state it is very rapidly decomposed, particularly when subjected to the action of light. Wc are told in a very able and very celebrated periodical woris, (the Lancet) that it is sometimes decomposed in less than lalf an hour, and can seldom be kept beyond a fortnight.

EFfects of Prussic Acid on the Animal Economy. Prussic Acid in a state of purity, is, perhaps, the most violent poison that has been yet discovered.

From the experiments of $\mathrm{M}$. Magendie, we have the following as the effects of it on the animal system. Onc drop of pure Prussic Acid being conveyed into the throat of a strong dog, the animal falls down dead, and stiffens after a few hurried inspirations. A particle of the acid applied to the eye produces equally sudden death, and when diluted with a few drops of alcohol, and injected into the jugular vein of an animal, kills it instantly, as if it were struck with lightning. In animals poisoned by Prussic Acid, scarcely any traces of irritability in the muscles can be discovered a few instants after death, and a remarkable peculiarity in this poison is, that it leaves no other traces by which it can be detected than a strong smell of bitter almonds in the dead body; this smell is cliaracteristic, and lasts for a considerable time. Pure Prussic Acid produces the same effects on man as upon animals.* And we are told that even its vapour should be avoided. If it be iuhaled, it occasions pain in the chest, and a sense of oppression which frequently lasts for several hours. (See Lancet, vol. I. p. 769.)

Medical Properties and Uses. The effects of Prussic Acid on certain diseases is, to lessen irritability in particular organs. M. Magendie tried this acid in spasmodic and nervous diseases; and especially in phthisis, and he observed, that when given in small doscs, firequently repeated, the constant effects of this acid was to lessen the cough, moderate and facilitate expectoration, and procure sleep, without exciting colliquative sweats. From a number of observations, he was induccd to believe that this acid would

* M. Scharinger, professor at Vienna, diffused some pure Prussic Acid upon his naked arm, which caused bis almost immediate death. (Vide Orfila on Poisonis.) 
furnish a complete remedy for phthisis, in its incipient stage.* M. Magendie combines one part pure Prussic Acid † with six parts water; this diluted acil he calls medicinal Prussic Acid, and prescribes according to the following formula:-

Infusion of ivy, two ounces; medicinal Prussic Acid, fifteen drops; syrup, one ounce. A dessert spoonful to be taken every nine hours, shaking the bottlc each time.

Prussic Acid may be considered as one of the most powerful sedatives we possess; and as such, has been recommended in asthma, sympathetic cough, acute pain attending abortions, pulmonary consumptions, acute and chronic pleuritis, cancer of the matrix, \&c.; as a topical remedy, it has been used for ringworm, and other cutaneous diseases. $\neq \mathbf{M}$. Haller has prescribed the Prussic Acid in very large doses, and in a variety of diseases. For the result of his success, we refer our readers to a paper on the subject. (Vide Lancet, Vol. 1.)

* We have seen the Prnssic Acid tried in various-stages of phthisis, and upon persons of different habits, and although, in some instauces, it has produced temporary good effects, chicfly we imaginc from its sedative properties, yet we bave never seen one cure effected by it. The Prussic Acid of commerce must likewise be a very uncertain medicine from the difliculty of preparing it of an uniform strength, and its tendency to decomposition, which bccomes greater the purer the acid; it is therefore a medicine, which, practitioners should use the greatest precaution in prescribing. An instance came under our own observation, where a young lady had beell for a considerable time asing the Prussic Acid, under the superintendance of an eminent physician, the dose being gradually increased; but on procuring a fresh bottle of the acid, from the druggists, and taking the same quantity as on the previous day, it produced almost iustant death; the fresh acid being uo doubt more concentrated thau what she had been previously taking.

† " Pure Prussic, or Hydro-cyanic Acid is obtained hy digesting the crystallized " deuto-cyanuret of mercury in two-thirds of its weight of liquid, and slightly fuming " Hydro-chloric Acid, in a tubulated retort, which communicates with a receiver con" taining fragments of chloruret of calcium and chalk, and which itself communicates " with a smaller receiver, destined to collect the product. These receivers must be " surrounded by a mixture of ice and salt. After the deuto-cyanuret of mercury and " the acid have been successively put into the retort, a slight heat is to be applied; a " little ebullition soon succeeds, arising in part from the evaporation of the Prussic "Acid, which is formed, and is condensed in the first receiver with a little Hydro" chloric Acid and water. When the quantity of water becomes very sensible, the " operation must be suspended, in order that the product already obtained uay be " purificd; this is performed by isolating the first receiver from the retort, taking away " the ice which surrounds it, and replacing the ice by water at 32 or 33 degrees, " (89. 6 or 91.4 Fah.) ander these circumstances, the Hydro-cyanic Acid passes alone " into the smaller receiver; for the water and the Hydro-chloric Acid, which were at " first volatilized with it, are now retained iu the first receiver; the water by the “ Chloruret of Calcium, aud the Hydro-chloric Acid by the lime." Magendie's Formulaire.

‡In impetigo, acne rosacea, and several other cutaneous diseases. Dr. A. T. Thoupsou has used the following lotion with much benefit :-

Take of Hydro-cyanic Acid...... f Jiv.

Rectified Spirit of Wiue $f \vec{z}$.

Distilled Watcr........ f $\frac{3}{3}$ sis. 
Prussic Acid is prepared for mcdicinal purposes by the London Apothecarics' Company, from cyanuret of mercury, 116j.; Hydrochloric Acid, 15j.; and water, 1bv. Four pints are drawn off and rectified through chalk.

Chemical Properties of Prussic Acid. This acid, in its most concentrated state, is a transparent colourless fluid, with a strosg smell, similar to that of peach blossoms, or bitter almond trees; its taste acrid; it scarcely reddens the tincture of turnsole; exposed to the action of caloric, it boils at $26^{\circ}{ }^{\circ} \prime$ : and congeals at $15^{\circ}$ below 0 ; it inflames on approaching a body in a state of combustion; but little soluble in water; readily dissolves in alcohol; with nitrate of silver it gives a white precipitate; combined with potash and oxyde of iron, it furnishes a double salt, of a lemon colour, which dissolves in water, and the solution of which throws down in a blue precipitate, more or less deep, the salts of iron of the second and third degree of oxydation. For a full account of the chemical properties of this acid, we refer our readers to a memoir on the subject, by M. Gay Lussac. Annales de Chimie, tom. lxxvii. p. 128.

\section{SINAPIS ALBA.}

White Mustard.*

\section{Class Tetrady namia.-Order Siliquosa.}

Nat. Ord. Siliquose, Linn. Sisymbrix, Juss.

Gen. Char. Calyx expanding. Claws of the Coral straight. Gland between the shorter stamens and pistillum and between the longer and the calyx.

Spec. Char. Siliques hispid. Beak oblique long sword form.

The white Mustard, and several species of the Genus Sinapist, are indigenous to Britain. The Sinapis Alba is chiefly cultivated for

* Fig. $a$. in the anuexed specimen, represents a spike of flowers of the natural size. b. A magnified pistillum. c. Stamina, magnified. d. Glands. e. Calyx.

t Nineteen species of the Genus Sinapis are known and caltivated in England. (Vide Hort. Cant.) 


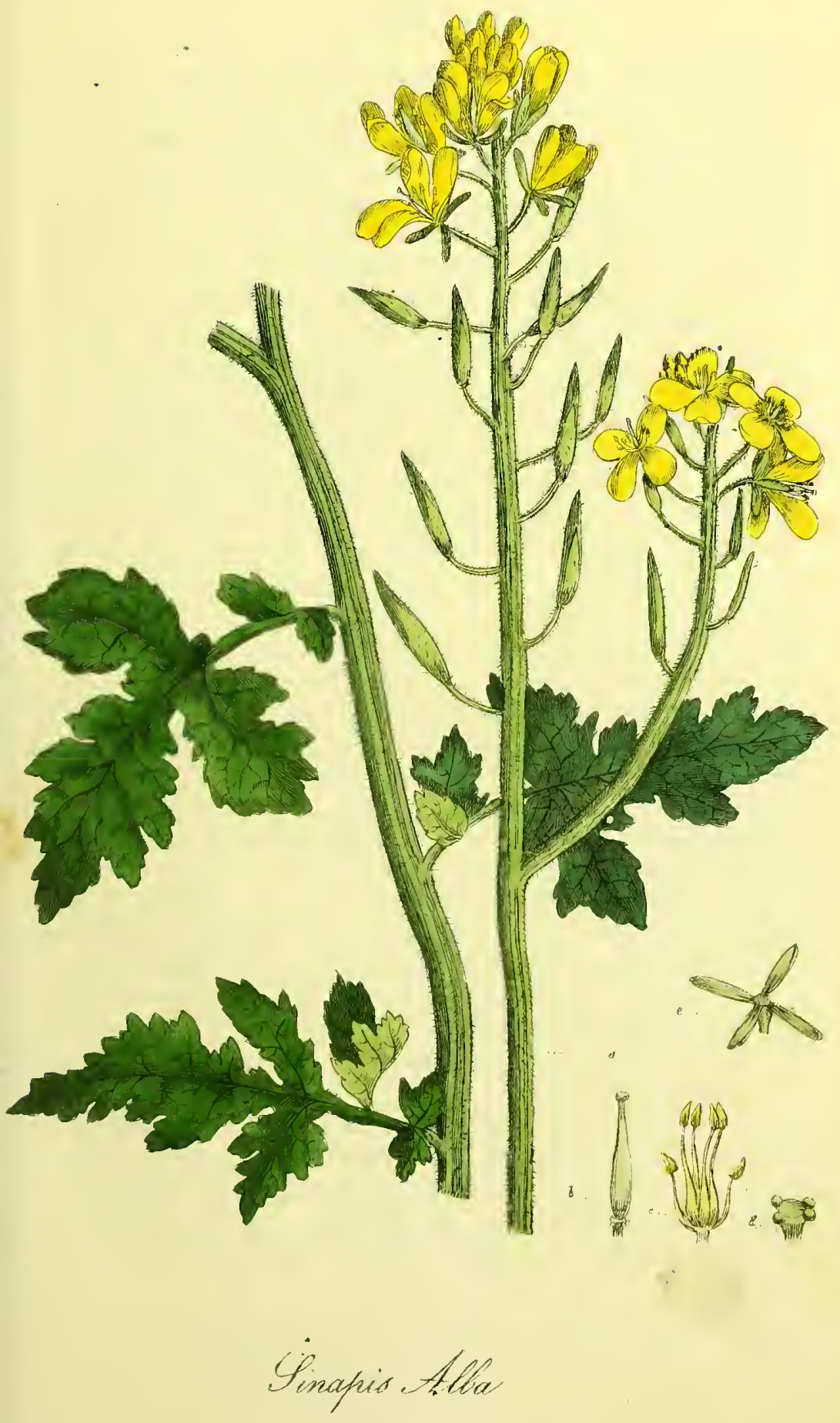

ore del. 

medicinal purposes, and as a young salad herb. In some counties it is so common in many corn fields as to become as troublesome a weed as the arvensis, or charluck, and for which it is not unfrequently mistaken. It may however be distinguished from the latter, by the leaves of the former being more jagged, and from the Sinapis Nigra, by the stalks of the former being finely grooved and strongly liaired. This anuual plant flowers in June; and rises with a branched hairy stalk, two feet in lieight; the flowers grow in loose terminal spikes: the blossoms stand on horizontal foot stalks, composed of four ycllow petals; stamina six, greenish ; anthers yellow, upright, and somewlat arrow shaped; germen inversely ovate, slightly angular, (hispid when magnified) stile tapering and two-edged; stigma obtuse; glands four; calyx perianthium, four-leaved, spread. ing, deciduous; leaves petioled, alternate, and mostly pinnated, slightly hirsute on botlı sides, composed of three or four pair of pinnæ, lowermost one very small, terminal one often three-lobed, and all of them variously indented.

Properties. Mustard seed has but little smell; taste warm and pungent, and somewhat bitter; the sifted powder is more pungent than the bruised seeds: an essential oil is obtained by distillation, heavier than water, excessively pungent and penetrating. The oil obtained from the seeds by expression, retains none of the acrid or pungent principles; it being blaud and insipid, but soon grows rauk by keeping. An infusion of the seeds las a warm, pungent, acrid, and somcwhat sweet taste; colour pale and opaline; it is not changed by sulphate of iron. Alcoliol extracts less of the pungent principle than water. The Sinapis Nigra, contains more of the pungent principle than the Sinapis Alba; the former is cultivated in large quantities, for manufacturing the flour of mustard; which lias been long in general use as a condiment.

The flour of mustard, like most-other articles of general consumption, is frequently adulterated; its pungency is increased by the addition of Caycnne pepper; and its price reduced by salt, and rye or pea flour. The cake remaining from the liulls, when the oil is expressed, is more pungent than the whole seeds, this when ground has been long in use for reducing ground pepper; and known by the dealers, under the name of P. D. (i. e. pepper-dust).

Medical Properties and Uses.** The general effects of

* The medicinal properties of the black and white mustard are the same, although the latter is generally preferred for internal use. 
mustard-seed, when taken whole, is gently to stimulate the stomach, and excite the peristaltic motion of the intestines; hence, the good effects resulting from its use, in some cases of dyspepsia, and when the bowels are in a torpid state; as in paralysis, \&c. Infused in water, and taken in small doses, it often proves diuretic and aperient; in larger quantities it creates nausea and vomiting, and is a useful remedy where opium and other narcotic poisons, have been taken. Of late years, the white mustard-seed has become a very fashionable medicine; and by some practitioners, it has been extolled in all the glittering costume of quackery, as a general specific. The flour of mustard, (as a topical remedy,) combined with bread crumband vinegar, is well known for its stimulating effects; ${ }^{*}$ an acrid oil, obtained from the seeds after the common mild oil has been expressed, is recommended as an embrocation in chronic rheumatism. The popular and well known patent medicine, called Whitehead's Essence of Mustard, is a combination of flour of mustard and other stimulating ingredients. $\dagger$

Off. Semina.

Off. Pp. Cataplasma Sinapis. Lond.

Sinapeos. Dub.

\title{
SOLANUM DULCAMARA.
}

\author{
Bitter Sweet.+
}

\section{Class Pentandria.-Order Monogynia.}

Nat. Ord. Solanacee, Linn. Juss.

Gen. Char. Corolla wheeled. Anthers subcoalescent, gaping at top, witl a double pore. Berry 2-celled.

* Dr. Underwood recommends an ointment composed of equal parts of flour of mustard, sulphur, and staves-acre, in tinea. See his Treatise on the Diseases of Children, Vol. ii.

+ Whitehead's Essence of Mustard. Ol. terebinth. camph. spt. rosmarini, to which is added farina sinapeos. (Gray's Supplement, p. 422.)

$\neq$ In the annexed illustration, Fig. $a$. represents a sprig of the natural size. $\boldsymbol{b}$. A magnified anther. c. The pistillum magnified. 


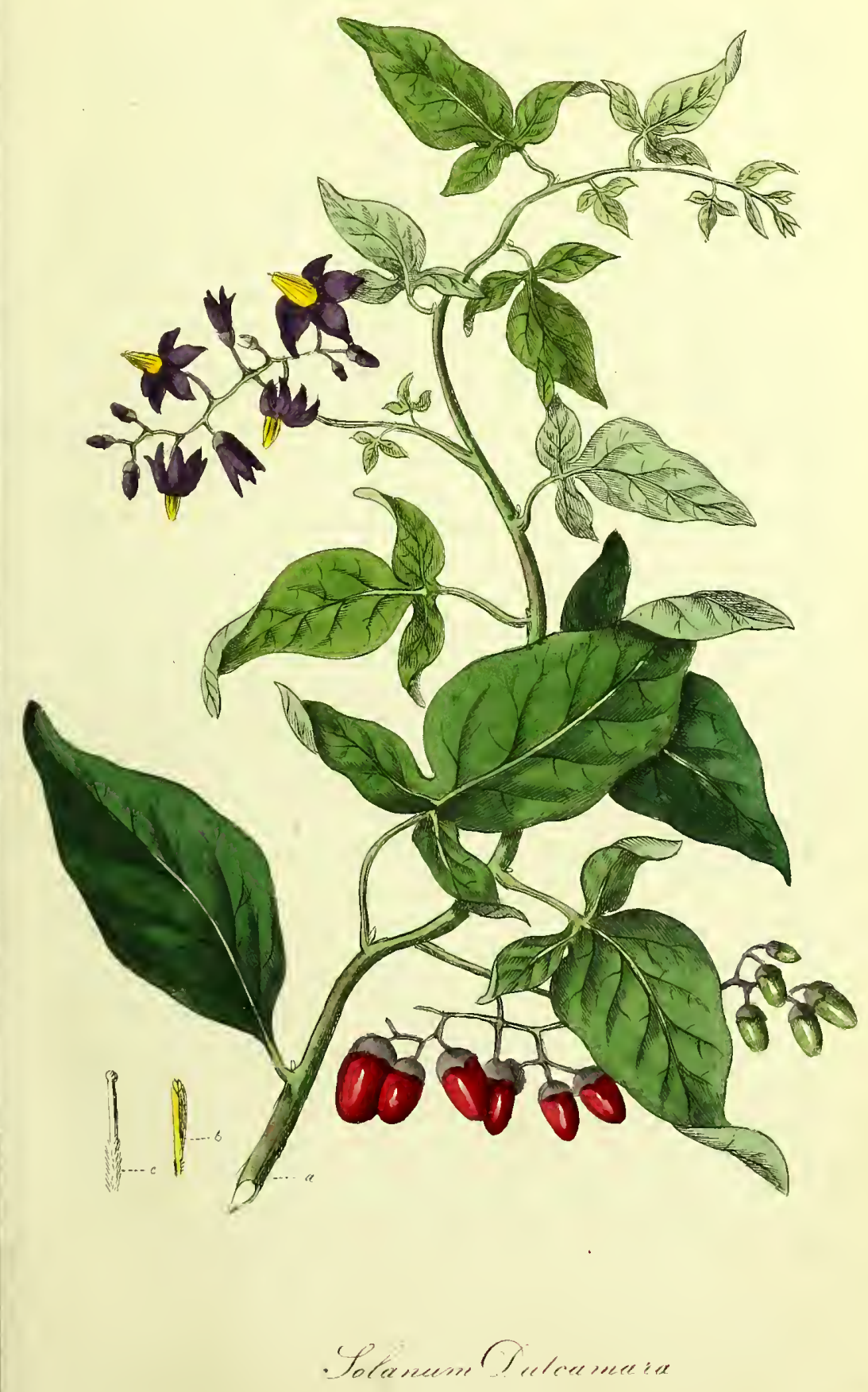



Spec. Char. Stem unarmed, shrub-growing, winding. Superior Leaves halberted. Racemes cymed.

Thus species of Solanum * appears to have derived its specific name from its sensible qualities, which are both bitter and sweet, lience its English name bitter sweet; and its Latin name Dulcamara, is a composition of the words Dulcis sweet, and Amara bitter.

The Dulcamara is a climbing shrub, indigenous to Britain, and found growing in moist hedges, where for support, it attaches itself to the neighbouring bushes, extending its branches from bush to bush, and climbing to the height of five or six feet. The stalk is slender, alternately branched, slightly angular, brittle and hollow, and covered with bark of an ash colour, and that of the young branches is of a purplish hue; the leaves are oval, pointed, and those near the top are halbert shaped, the lower leaves are entire, and of a deep green; the flowers hang in cluster or cyma; the corolla is monopetalous, wheel-shaped, divided into five pointed segments of a bright puirple, $\uparrow$ and the base of each marked with two round greenish spots; the calyx is small, and divided into five blunt segments of a purplish colour; the five filaments are short, and inserted into the tube of the corolla; the anthera are yellow, erect, and unite at their points; the style somewhat longer than the stamina, and crowned by a simple obtuse stigma; the germen is oval, and becomes a roundish bilocular berry, containiug many that yellowish seeds.

This species of Solanum lias been ranked among the narcotic poisons, but from the experiments of M. Dunal, Fages, and Orfila, it does not appear to be possessed of any very active properties. According to the experiments of M. Dunal, the Dulcamara may be given in large doses without any deleterious effects following; he has administered as much as four ounces of the watery extract of this plant to a dog, at one dose; to auother dog he gave one hundred and eighty ripe berries; to a cock fifty berries, but in no one instance were any ill effects produced upon either of the animals. M. Dunal has himself eaten it quantity of the berries without any inconvenience. M. Fages, of Montpellier, has given very large

* The Genus Solanum comprises a numerous tribe, 96 species are enumerated in the the Hort. Cant.

+ Miller says there is a variety, with white blossoms. Vide Gurd, Dict. by P. Milier. 
doses of the watery extract, to several persons, without producing any untoward symptom. From the above it is probable, that the histories of the poisoning by the night-shades, found in the Works of Gmelin and others, belong rather to the fruit of the Atropa Belladonna, which was classed with the Solan un tribe by former botanists ; M. Dunal is of this opinion.* The Solanum Nigrum, S. Villosum, and some other species, appear to possess the same properties as the Dulcamara. On some occasions the fruit of the Dulcanara has produced vomiting, convulsions, and other unpleasant symptoms; when such symptoms arise from taking the fruit, which children will frequently do, no time should be lost in evacuating the stomach by emetics, followed by cathartics, and the usual means rosorted to, where vegetable poisons have been taken.

Medical Properties and Uses. The virtues of the Dulcamara reside chiefly in the twigs, which, on being chewed, are at first bitter, followed by a degree of sweetness; the infusion of the dried twigs is reddislı, intensely bitter, and turns rather brown by green vitriol. $\dagger$ The clinate, and the soil, on which the Dulcamara grows, appear to have great influence on its medicinal properties. The plants which grow in a warm climate and on a dry soil, being more efficacious than those grown in a cold climate, and where the soil is wet. The properties of the plant are also said to be strongest in the Autumn, $\ddagger$ hence it should be gatliered in that season in preference to the Spring. Dulcamara acts upon the animal economy as a stimúlus, exciting the action of the heart and arteries, and is said to increase all the secretions and excretions, hence it has been recommended in a great variety of diseases, by different authors; namely in rheumatism, scrofula, jaundice, dropsy, obstructed menstruation, and many cutaneous diseases, $\S$ particularly in lepra, for whieh it has been recommended as one of the inost effectual remedies, taken internally and applied externally in the form of lotion.T Dulcamara is now, however, little used in this country; the form in which it has been usually prescribed is that of decoction; from one to six ounces of the twigs, boiled in six pints of water to four; dose, three or four onnces,

* Histoire Naturelle, Médicale, et Economique des Solanum, par M. Dunal, 1813, pp. 70, 73, \&c.

+ Gray's Elements of Pharmacy.

‡ Colliqunter stipites vel primo vere vel autumni fine, foliis destituti, tumque et odor saporque insiguiur. Murray Ap. Med. vol. 1, p. 424.

\Per ommia colatoria corporis efficaciam exercent. l. c.

$\oint$ Journ. de Medecine, t. 22. p. 336.

II See Bateman on Cutaneous Diseases, p. 34. 
three times a day; and may be gradually increased to a mueh larger quantity; the extract has been given from five to ten grains for a dose. Off. the twigs. Off. Pp. Decoct. Dulcamara. L.

M. Desfosses, Aprothecary at Besançon, has lately discovered a new alkali in the Solanum Dulcamara, and Solanum Nigrum, which - he named Solanine; M. Desfosses found this alkali most abundant in the berries of the nightshade, (where it exists in the state of malate) and in the leaves of the Dulcamara, but could discover no traces of it in the leaves of the nightshade. To obtain this alkali, M. Desfosses digested the filtered juice of the ripe berries of the Solanum Nigrum, in Ammonia, when a greyish precipitate was formed, which he washed on a filter, and digested in boiling Alcohol; this, by evaporation, gave the salifiable base, in a tolerably pure state; but, if the berrics operated upon were not ripe, the Solanine would be mixed with a ccrtain proportion of the green colouring principle, or Chlorophylle, which lıe found great difficulty in separating.

Properties of Solanine. "Perfectly pure Solanine is in " the form of a white opaque, and sometimes pearly powder; it is " inodorous; its taste is slightly bitter, and nauseous, and its " bitterness is developed by solution in acids, especially in Acetic "Acid. Its salts are incrystallizable, the solutions giving by evapo" ration a gummy transparent mass, which may be easily powdered. "Solanine is insoluble in cold water, and hot water only dissolves " $\frac{1}{8000}$ th part; Alcohol dissolves a small quantity. Its alkaline " properties are slightly manifested by its action on turmeric; it " however restores the blue of turusol paper when reddened by " acids; it unites with acids, even in the cold; and perfectly " neutral solutions may be obtained, if care be used. Like all other “ vegetable alkalies, it is saturated by a very small quantity of acid.', Action of Solanine on the Animal Economy. We have not learnt that Solanine lias yet been prescribed in cases of disease, but wherever the Dulcamara, or Solanum Nigrum, is indicated, it is probable the Solanine would be found useful." Solanine, in doses of two to four grains, when introduced into the stomachs of dogs or cats, excites violent vomiting followed by sleep. Magendie says, eight grains were given to a young cat, which excited violent vomiting, followed by sound sleep for 30 hours: hence

* The Acetate is the only salt that has been tried on man; a quarter of a grain (gr. 205 troy) produces nausea, but no disposition to sleep. Magendie. 
it appears that Solanine, like opium, produces vomiting and sleep; that its emetic properties appear to be more violent than opium, but its narcotic properties much less so.

\section{PAPAVER RHCEAS。 . \\ Corn Rose, or Red Poppy.**}

\section{Class Polyandria. Order Monogynia.}

Nat. Ord. RhaAdes, Linn. PAPAVeracee, Juss.

Gen. Char. Corolla 4-petalled, Calyx 2-leaved. Capsule 1-celled, gaping with pores, under the permanent stigma.

Spec. Cirar. Capsules smooth, globular. Stem hairy, many flowered. Leaves feather-cleft, gashed.

The Red Poppy, or Corn Rose, is an annual indigenons plant, very common on arable land, in most parts of England. This speciest of poppy seldom exceeds two feet in height; the stalk grows upright, branched, round, hispid, and of a purplish colour at the lower part; leaves sessile, forming a kind of sheath at bottom, hispid on both sides, pinnated and jagged; each flower stalk supports a single flower; calyx a perianthium of two leaves, ovate, hispid, hollow, and membraneous on the edges, decidious; corolla, four petals, unequal and spreading, with a black shining spot at the base; stamina numerous, filaments very fine, anthers rounclish and flattened, of a dark purplish coluur, pollen green; germen ovate, style wanting, stigna convex and radiated; seeds numerous and of a dark purple. The Papaver Argemone, Papaver Hybridum, and Papaver Dubium, are native species, and very common in corn fields in many parts of the country; the Papaver Dubium is the most common species of poppy in North Britain. All these varieties bear a great resemblance to the Papaver Rlıeas; hence they are gathered indiscriminately by the dealers, who supply the markets. The Papaver Rhœas may be distinguished from the Hybridum or mule, by the capsules of the latter being furrowed and prickly. The

* In the annexed illustration, Fig. $\alpha$. represents a flower of the natural size. $b$. The germen. $c$. A magnified anther. d. Capsule.

+ Of the Genus Papaver, twelve species are enumerated in the Hort, Cant. 


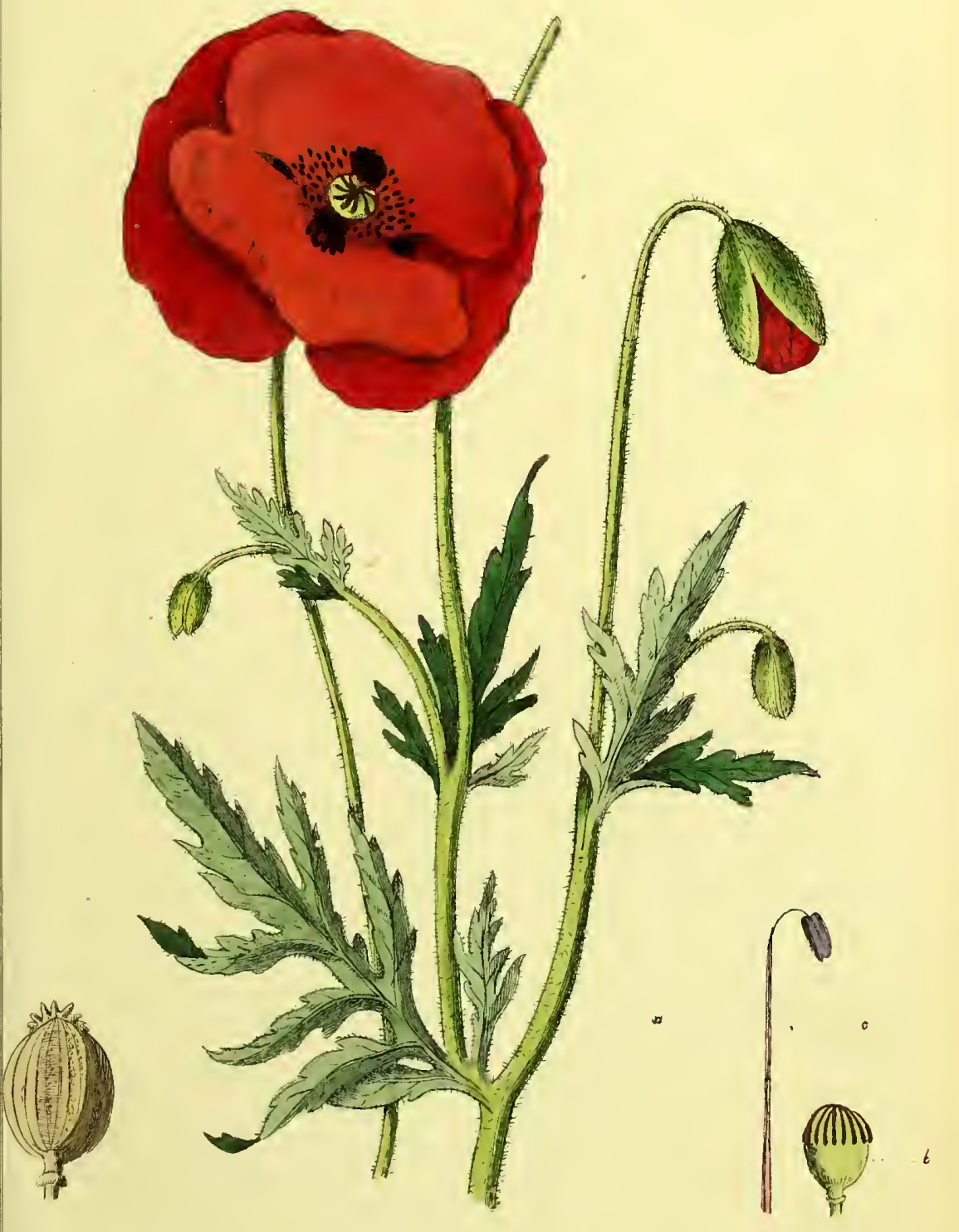

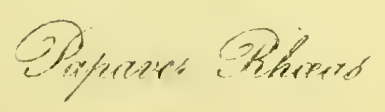





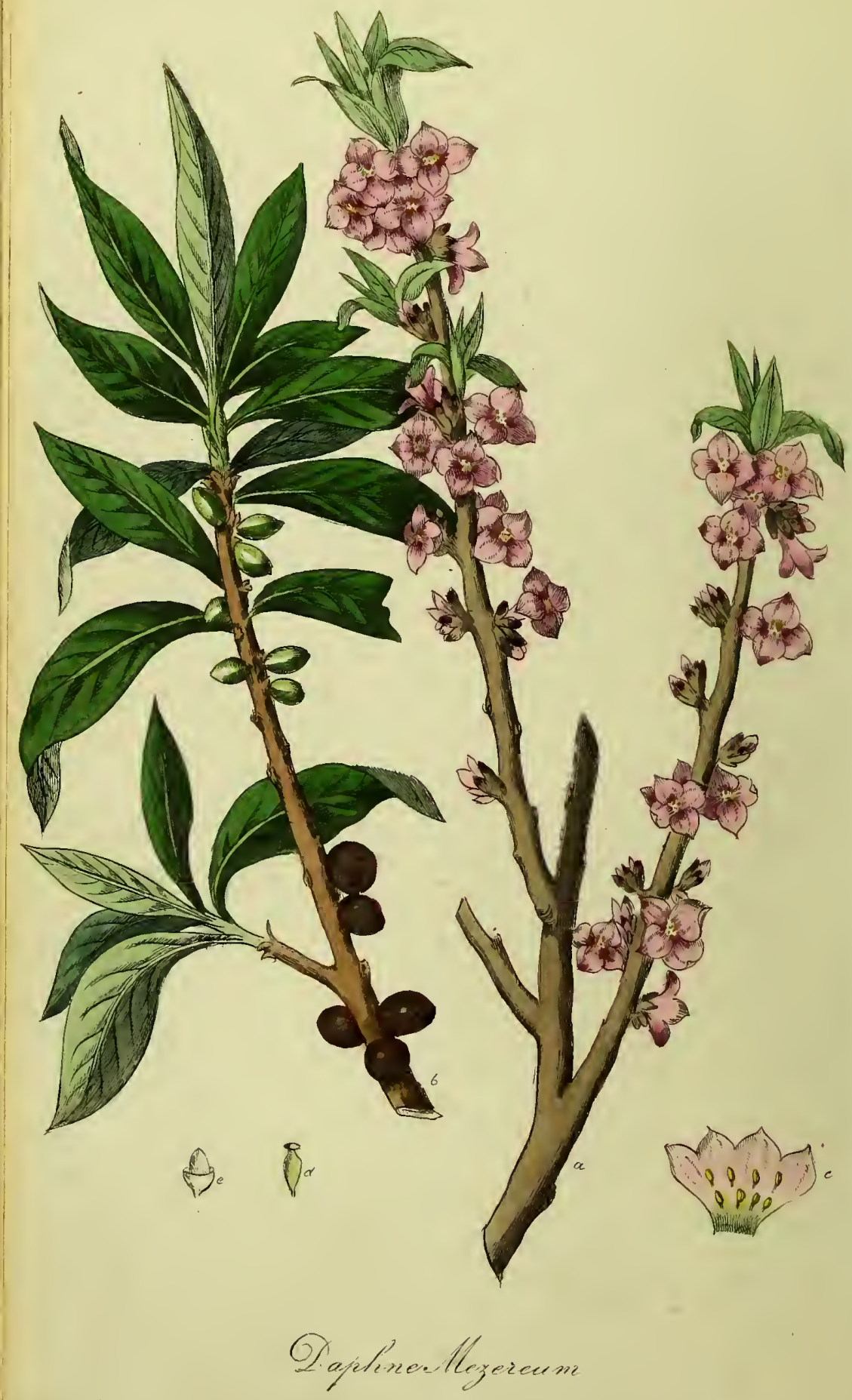


capsules of the Argemone are also prickly and less globular than the Rhœas. The Paparer Dubium bears more resemblance to the Rhœas, than the other species, but may be distinguished by the following characters: the capsules of the Papaver Dubium are oblong, the hairs on the stalks, \&c. are appressed upwards, and the flowers are of a less brilliant colour.

Formerly the red poppy was in more repute than at the present time; a simple water was distilled, and a conserve made from the flowers; also a tincture and syrup; these preparations were considered pectoral and anodyne; but have been long rejected in medical practice; the syrup only, being retained; and that chiefly for the sake of its fine colour; its narcotic properties being very slight.

Off. The Flowers. Off. Pp. Syr. Rhœeados. L. Syr. Pap. Errat. D.

\title{
DAPHNE MEZEREUM.
}

Mewreon, Spurge Olive.†

\section{Class Octandria. Order Monogynia.}

\author{
Nat. Ord. Veprecula, Linn. Thy melee, Juss.
}

Gen. Char. Culyx 0. Corolla 4-cleft, withering, including the stamens. Berry 1-seeded.

Spec. Cinar. Flowers sessile, threefold on the stem. Leaves lanced, deciduous.

OF GENus DaPhNe, fourteen species are known in this country. The Daphute Mezereum is indigenous to Germany and the northern parts of Europe, and found growing in woody situations. It is now ranked by Sir J. E. Smith, and other botanists, among the native shrubs of Britain. $\ddagger$ It lias been loug cultivated in our gardens for its

* The Syr. Rhoeados is more exteusively used than is generally supposed; we learn fron very good authority, that it commonly supplies the pluce of the Syr. Rosac Rub.; and with the addition of a little acid, is very generally substituted for the Syr. Mori of the London Pharmacopoia.

+ In the annexed illusiration, Fig. a. represents a cutting, the flowers of the natural size. $b$. Ditto, the leaves and berries about one-third less than nature. $c$. The corolla cut open to slow the stamina. $d$. The pistillum. e. Pericap and seed.

\# We are told by Miller, " that many years ago the mezereon was discovered " growing in some woods near Andover, from whence several plants were taken," implying, we conclude, that previous to this discovery, it was not known to be indigenous to Britain. (Vide Miller's Gard. Dict.) 
ornamental appearauce. Miller says " 1 here are two distinct varieties of the mezereon; one with peach coloured blossoms, and red berries, the other witl white flowers, succeeded by yellow berries; these are supposed to be accillental varieties from the same seed." The mezereon grows to the height of four or five feet, with a strong woody stem, sending out numerous branches so as to form a large bushy head; it blossoms early in January or February, before the leaves appear, and the berries ripen in $J_{n 1 l y .}$ The leaves are about two inches in length, lanced, smooth, and of a bright green, and placed without order upon the stems; the flowers grow in clusters from the shoots of the former year, they generally grow three or four together from eacl knot or joint; the corolla is monopetalous; open at the top, four-cieft and reflected back; filaments eight, very short; anthere simple, yellow; germen oval, and becomes a scarlet berry, containing one seed; stigma obtuse.

The Genus Daphne [conprises many species, ${ }^{*}$ several of which possess poisonous properties. The Daphne Mezereum ranks with the acrid or irritating poisons. The bark $\uparrow$ of the trunk, branches and roots, contain a very acrid principle, a small quantity, when chewed, exciting an almost insupportable sensation of burning in the mouth and throat. Applied to the skin in its recent state, or infused in vinegar, it will raise blisters. The berries appear to be more acrid than the bark or roots, and liave proved fatal to many children who have incautiously eaten them. Linnæus reports that a young lady, labouring under intermittent fever, died, spitting blood, from having taken twelve berries of the Daphne Mezereum, which had been given with the design of purging her. (Flora Suecica, No. 338.)

The following is related in Vicat, Histoire des Plantes Vénéneuses de la Suisse, p. 140. Solne person having given to an hydropic patient, some wood of the mezereon, the latter was all at once attacked with a diarrhoe, which was continual, and accompanied with insupportable pains; he had also, for six weeks, vomiting, which returned every day with extreme violence, although, during the whole of that time, every proper medicine was had recourse to in order to quiet thenı. From the above account it appears that the Daphne Mezereum, when taken in improper doses, produces

* Fourteen Species are enumerated in the Hort. Cant.

$\dagger$ We are told that the bark of the Daphne Laureola, Spurge Laurel, is generally sold in the market, as mezereon; the qualities of both being the same, we consider the substitation to be of little consequence. 



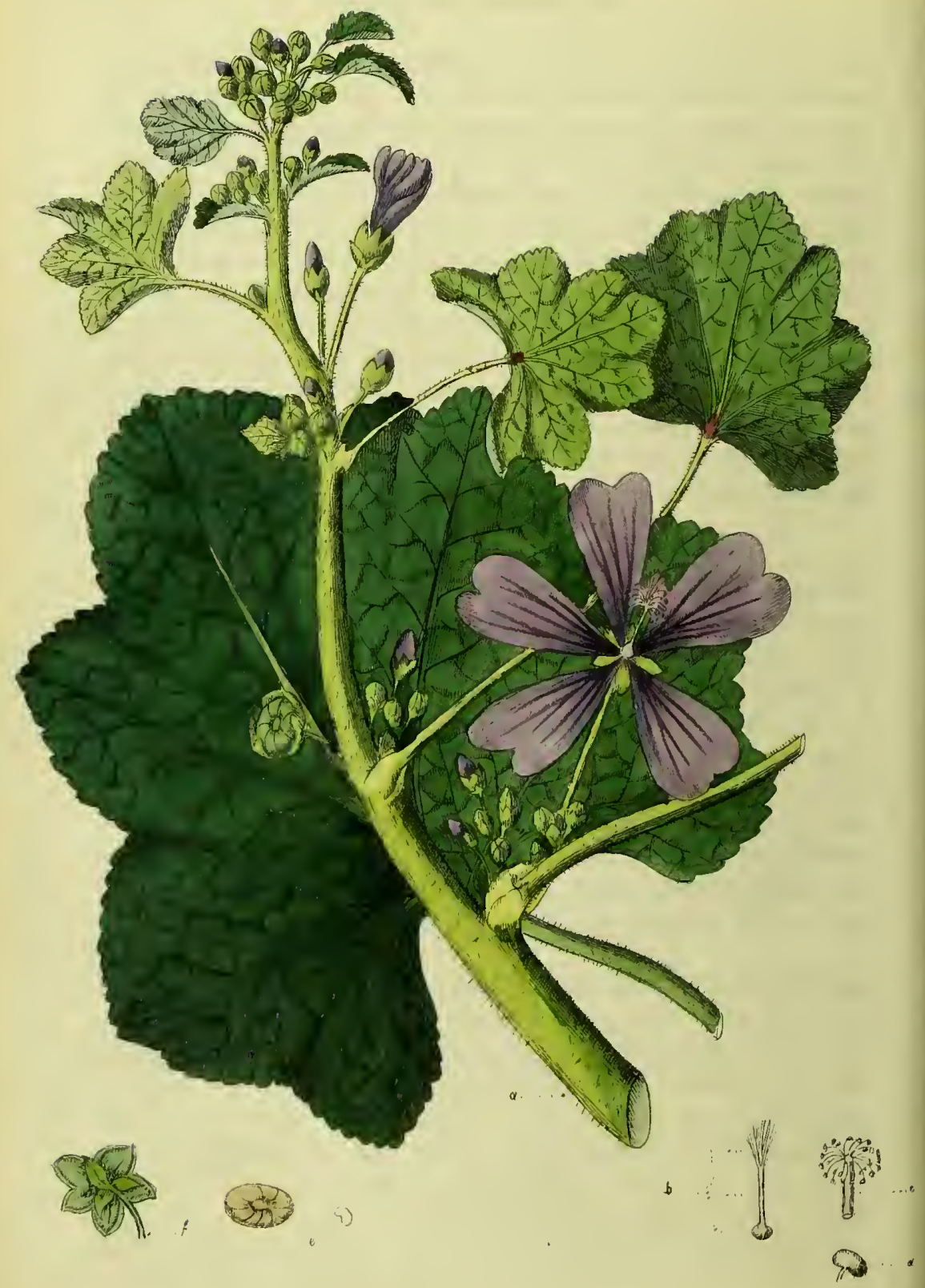

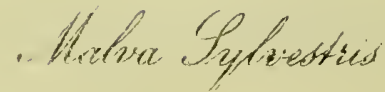


deleterious effects on the animal economy; giving rise to very powerful local inflammation, and sympathetic irritation of the nervous system, to which'cause the fatal symptoms ought to be attributed. The Daphne Gnidium, flax-leaved daphne, commonly called spurgeflax, appears (from the experiments of Orfila and others), to be more deleterious in its effects than the mezereon; three drachms of the former, killed a middle-sized $\operatorname{dog}$ to whom it was given, exciting great infammation throughout the whole alimentary canal.

Medical Properties and Uses. This acrid stimulant operates chiefly by producing perspiration; hence its use in chronic rheumatism, venereal nodes, and various cutaneous affections. Dr. Cullen says it acts upon the urine, giving it a filamentous appearance, and excites perspiration, without remarkably diminishing the strength; that it quickens the pulse in irritable habits, and increases the heat of the body. In the form of decoction it has been given with advantage in some cases of lepra and scrofula; in venereal complaints resisting the use of mercury, it is usually given in the form of the Lisbon diet drink; but Mr. Pearson, of the Lock Hospital, says, that as a remedial agent in the cure of syphilis, or the sequelæ of that disease, he lias seldom found it possessed of any medicinal properties. It is sometimes given in powder, but as it is apt to occasion purging, or vomiting, the powrler should be prescribed in very small doses, 'gradually increased.

Off. The bark of the roots. L. E. D.

Off. Pp. Decoct. Daphnes Mezerei. Ed.

\section{$\longrightarrow$ \\ MALVA SYLVESTRIS.}

Common Mallow.*

Class Monadelphia.-Order Polyandrta.

Nat. Ord. Columifere, Linn. Malvacee, Juss.

Gen. Char. Calyx double, the exterior 3-leaved. Arils most numerous, 1-seeded.

Spec. Char. Stem erect, herbaceous. Leaves seven-lobed, acute. Peduncles and Petioles hairy.

* In the annexed specimen, Fig. $\alpha$. represents a cutting of the natural size of the plant. $b$. The pistillum. c. Stamina. d. A magnified anther. e. Seeds. $f$. Calyx. 
The Genus Malva comprises many species, forty-eight are known and cultivated in England, * the greater number of which are exotic. The Malva Sylvestris is indigenous to Britain, and is one of the most common native plants; it is found in various situations, in pastures, hedgerows, footpaths, amongst rubbish, \&c. The root is perennial, long, thick, whitish, and furnished with many strong fibres; the stem round, hairy and branched, generally upright, and from one to two feet high ; the leares stand on long hairy footstalks, and are divided into five or seven lobes, often marked at the bottom witlı a purplish spot; stipules, two, at the bottom of each footstalk; calyx, a double perialithium, the outer is composed of three and the inner of five oval pointed hairy segments; corolla composed of five heartshaped petals, uniting at the bottom; filaments numerous, uniting into a purplisl tube, unconnected above and bending outwards; anthers kidney-shaped; germen orbicular; style cylindrical; short; stigmata numerous; seeds kidney-shaped, covered with an arillus which opens inwardly.

This species of mallow has been long esteemed for its mucilaginous properties, in which every part of the plant abounds; especially the leaves. Some other native species of mallow, as the Malva Alcea and Malva Rotundifolia, possess nearly similar properties, and the leaves of both (we are told) are collected by the dealers who supply the markets, and sold along with the leaves of the Malva Sylvestris for medicinal purposes. Formerly various species of mallow were eaten as food, $\uparrow$ but in the present epicurean age, even cattle are not fond of it.

Medical Properties and Uses. The Malva Sylvestris, as we have observed, abounds with mucilage, hence it possesses very emollient, pectoral, cooling, and gentle aperient qualities, and is found useful, in lieat of urine, strangury, gravel and gonorrhœa ; also in coughs and hoarseness, roughness of the fauces, \&c. But in the present day, the Malva Sylvestris is but little used, except as a topical application in fomentations, \&c. its internal use being superseded by the Radix Althra. $\neq$ A decoction of the leaves, however with the addition of raisins or prunes, forms a very agreeable drink, in many cases where a bland mucilage is required; and where the Althra is not to be obtained, the leaves of the Malva Sylvestris form an excellent substitute.

Off. The leaves and flowers. Off. Pp. Decoct. Malvæ comp. L.

* Vide Hort. Cant. 10th ed.

† We are told by Tournefort, "The Malva Rotnndifolia, was eaten by the Romans and Egyptians, and that the Chinese mixed the Malva Sylvestris with their food.

¥ "Althea in omnilıus supra dictis efficacior radix." Plin. Nat. Hist. Vol, ii. p. 662. 



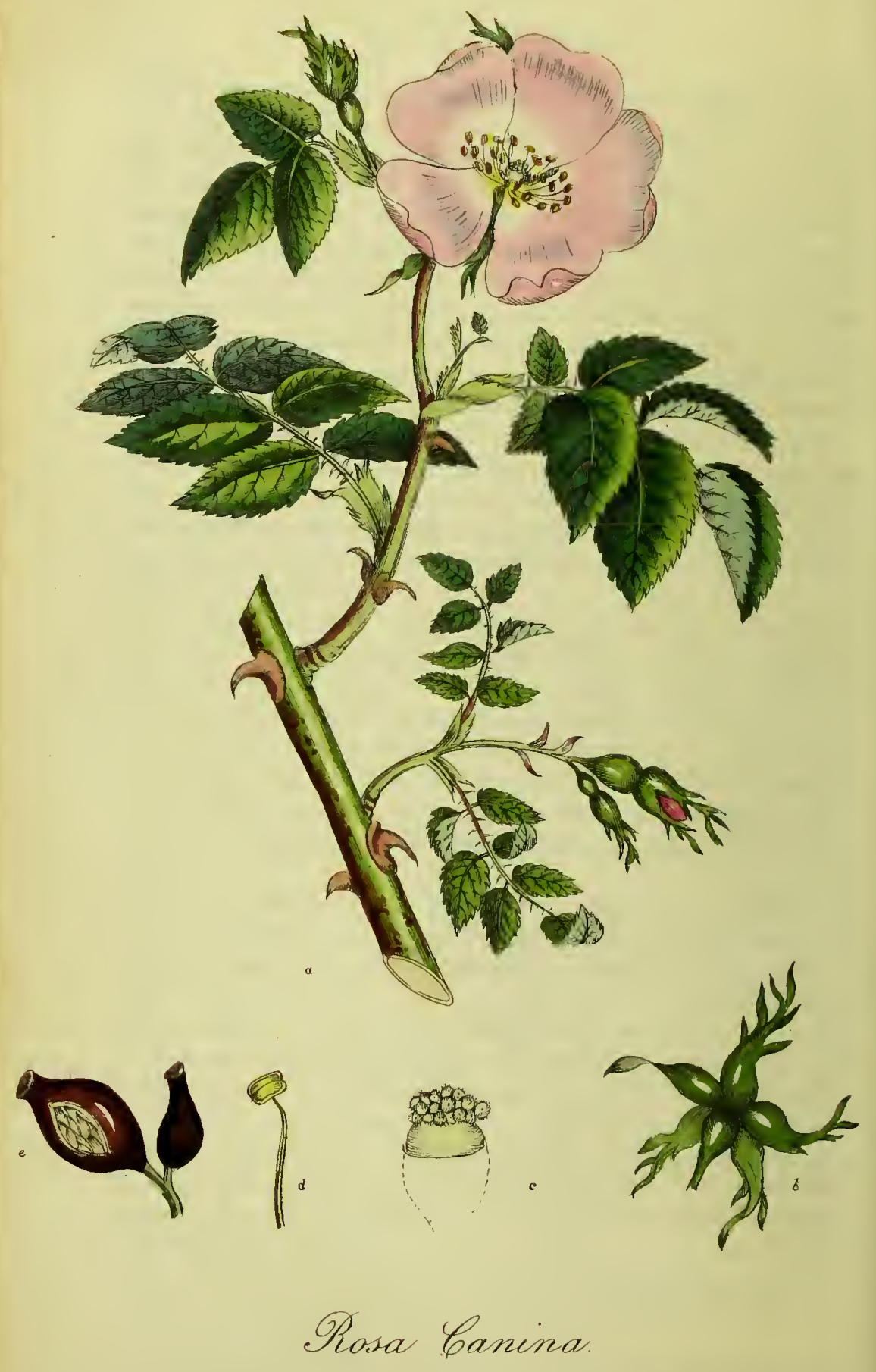




\title{
ROSA CANINA.
}

\author{
Dog Rose.*
}

\section{Class Icosandria.-Order Polygynia.}

Nat. Ord. Senticoser, Linn. Rosee, Juss.

Gen. Char. Petals 5. Calyx pitcher-shaped, 5-cleft, fleshy, contracted in the neck. Seeds numerous, hispid, a sed to the interior side of the calyx.

Spec. Cha r. Gernis egg-shaped. Peduncles smooth. Stem and Petioles prickly.

THE DOG ROSE is a native of Britain, and is commonly found growing in hedge-rows, where it adorns rustic nature with its beautiful blossoms, and perfumes the surrounding atmosphere with its fragrance. There are two or three varieties of this species of rose; one with white, another with pink blossoms; and one with smooth leaves; some botanists have questioued if this last is not a distinct species; $\dagger$ at this time, we believe, it is generally considered as a variety only, of the Rosa Canina. The dog rose grows to the height of eiglit or ten feet, and sends out numerous spreading branclies, studded with prickles : the leaves grow alternate, and are pinnated, consisting generally of seven ovate serrated folioli, the upper sides of which are shining, the midrib prickly; the flowers are terminal, growing several together, on snooth, and round peduncles; corolla composed of five inversely heart-shaped petals; calyx pitclier formed at its base, and separated above into five long expanding divisions, and subdivided into smaller segments; filaments numerous, crowned with ovate anthers; germina numerous, situated within the tube of the calyx; styles filiform, stigmata obtuse and numerous, closely uniting and forming a litlle head; seed vessel a shining scarlet berry of an oval form, with one cavity containing numerous rough seeds.

* Fig. a. Represents a sprig of the natarat size. b. The calyx. c. The pistilla, largely magnitied. $d$. A magnified anther. e. Pericarps, oue of which is cut open to shew the seed.

+ In some parts of Europe, particularly in Austria and Carniolia, the roses are so numerous as to create difficulties in determining the species.

VOL. I. 
On various parts of this rose, there is frequently found a mossy protuberance of a very singular appearance, which is occasioned by an insect, (the Cynips Rosæ of Linnæus;) this substance was formerly used medicinally in calculous diseases, under the name of Bedeguar; * but like many other antiquated remedies of equal efficacy, has with much propriety been long since rejected.

Properties and Uses. The fruit or heps of the various species of dog rose, contain much saccharine matter, and citric acid; when chewed, they have a slight acid taste, and tinge the saliva red; by boiling they become more acid and tender.

Formerly the fruit was considered lithontriptic; and the roots were recommended in liydrophobia and dysentery; + but in modern practice the fruit only is made use of for making a conserve, used chiefly as a vehicle for more active medicines. The heps of the different species of wild rose differ in flavour; and the conserve is prepared indiscriminately from them all, hence the Havour of the conserve varies also; that prepared from the Rosa Avensis, or field rose, has the finest flavour, and forms a very pleasant sweetmeat. It is said that the water distilled from the wild rose is infinitely more fragrant than that distilled from the various species of the Rosa Centifolia, Damacena, \&c. Haller says, "Fragranta ejus olei " omnia alia odoramenta superat, ut inter regia dona sit." We have seen water distilled from several varieties of the wild rose, and can add our testimony in favour of its fragrancy.

Off. The Fruit.

Off. Pp. Conf. Rosæ Can. L. E.

ACONITUM NAPELLUS.

Large Blue Wolfsbane, Monk's-hood, Aconite $\ddagger$

Class Polyandria.-Order Trigynia.

Nat. Ord. Multisiligue, Linn. Ranunculace, Juss.

* Vide Gendornius Cynosbatologia, p. 136, sqq.

† Vide Herman Diss. de Rosa.

\# Fig, a. in the annexed drawing, represents a plant balf the size of the natural specimen from which it'was taken. b. A stamen magnified. c. The three pistilla, attached to the receptacle. $d$. A flower of the natural size, spread open, shewing the two nectaries, \&c. 


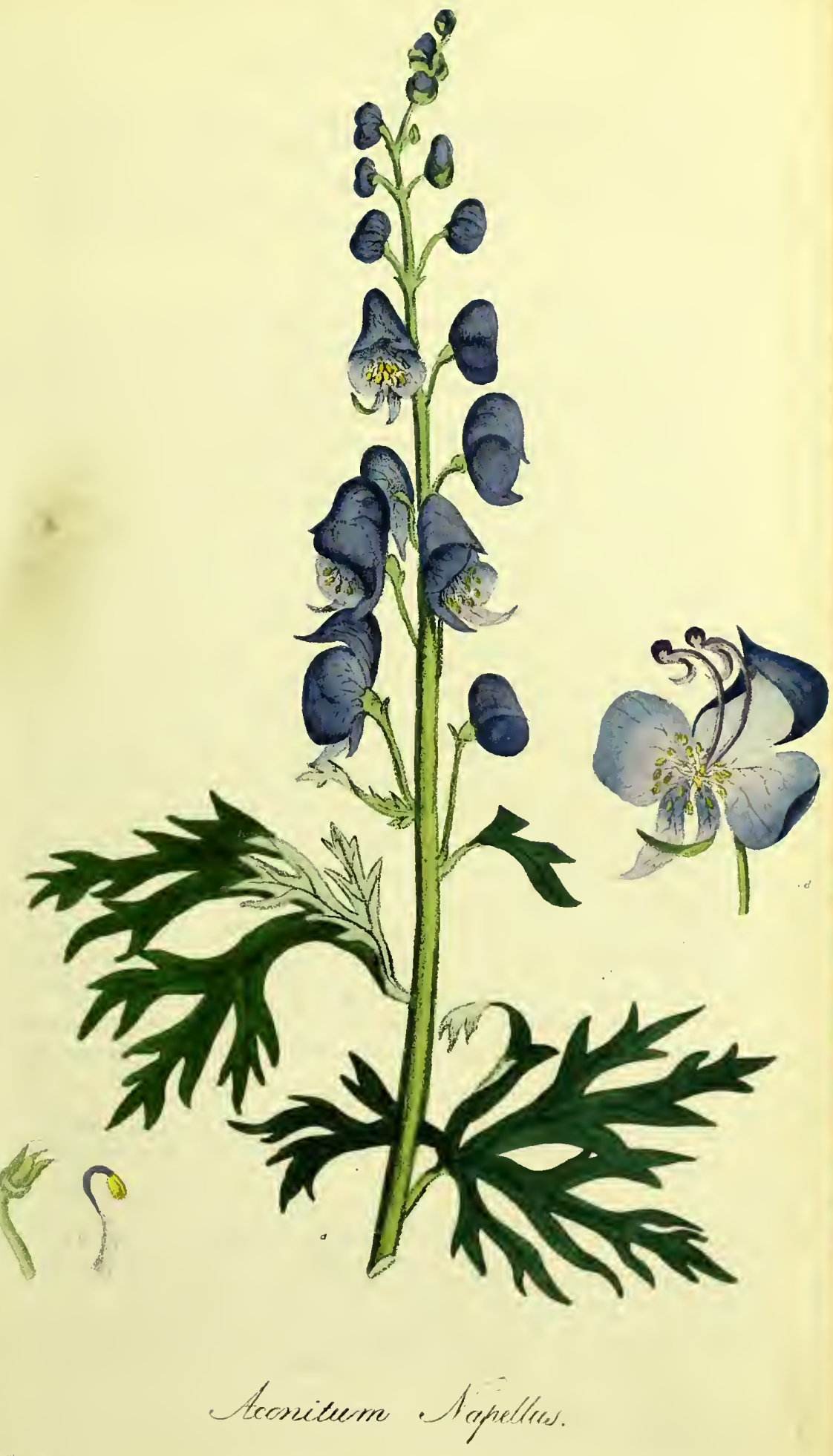



Gen. Cha r. Calyx 0. Pelals 5, the highest arched. Nectaries 2, peduncled, recurved. Siliques 3 or 4.

Spec. Cha R. Divisions of the leaves linear, broader above, scored with a line. Capsules 3.

The AConite is a perennial plant indigenous to the Alps and the mountainous countries of Germany, Austria, and Tartary, now very generally cultivated in our gardens for ornament and medicinal purposes; ${ }^{*}$ it requires a cool shady and moist situation; the wild plant is said to be the most active; by cultivation and luxuriant growth in a rich soil, the medicinal properties become impaired. $\dagger$ The Aconitum Napellus rises to the height of two or more feet; the root is turnip-shaped or fusiform; the stalk is erect, straight, firm and leafy, terminating in a spike of flowers; the leaves are palnated and many cleft, on the upper side of a dark green, the under side whitish, and stand upon large foot-stalks; the upper leaves are almost sessile; the flowers stand singly on the peduncle, and are composed of five purple coloured petals, which enclose two nectaries; the uppermost petal is arched over the two lateral ones, so as to appear helmetshaped or hooded; the pistilla are from three to five; the stamina numerous, crowned with simple roundish antheræ.

Qualities and Properties. The fresh leaves of the aconite have very little smell, but a very acrid taste when chewed; the leaves by drying lose much of their acrimony, and with it, oftentimes much of their virtues. Every part of the fresh plant is strongly poisonous, $\ddagger$ but the root is unquestionably the most powerful, and when chewed, at first imparts a slight sensation of acrimouy, but afterwards, lancinating pains, and swelling of the tongue, accompanied with an insensibility of its apex, and a pungent heat of the lips, mouth and throat; these symptoms are followed with general

- Nineteen species of the Genus Aconitum, are known and cultivated in our botanic gardens. The Aconitum Napellus was first cultivated in Britain in the year $\mathbf{1 5 9 6 .}$

$\dagger$ Ray Hist. Plant. p. 702.

Hort. Cant.

¥ The Aconitum was considered by the ancients to be the most destructive of vegetable productions, as appears from their fanciful derivation of its origin. "Ut ab Hecate " inventum aut ex Cerberi spuma enatum pronunciarent."

The Aconitum Napellus and several other species of aconite bave been frequently eaten by mistake for other plants, and produced fatal eflects. Vide Bacon, Philos. Trans. vol. xxxviii. p. 284. Doeden. Stirp. Pempt. l. iv. p. 442.

A recent case of a family having been poisoned by monkshood is related in No. 167, (for Nov. 1827), of the London Medical Repository, to which we refer our readers. 
tremor and sensation of chilliness. The farina of the anthers if accidentally blown into the eyes, has been known to cause violent pain and swelling; and the juice applied to a wound of the finger, not only produced pain in the hand and arm, but cardialgia, great anxiety, a sense of suffocation, syncupe, $\&$ c. and the wounded part sphacelated before it came to suppuration.*

action of the aconitum Napellus, $\dagger$ on the Animal Econom $、$ The deleterious effects of this plant are produced (like those of most vegetable poisons) by its immediate action upon the uervous sistem; for of the different animals which have been destroyed by it, very few instances are recorded, wherein, upon dissection, traces of organic disease were discovered.

Orfila draws the following conclusions from his experiments on dogs:-1st, that the juice of the leaves of the aconite introduced into the stomach, or rectum, or injected into the cellular texture, produces serious symptoms, followed by death; -2nd, that it acts on the human species as on dogs;-3rd, that being absorbed and carried into the circulation, it acts particularly on the nervous system, and more especially on the brain, producing a kind of mental derangement;-4th, that it likewise causes local irritation capable of producing inflammation more or less violent.

The usual symptoms produced by taking into the stomach a small quantity of the fresh leaves or roots of this vegetable, are dryness of the mouth and throat, with a sense of tightness in it; remarkable debility, sickness, bilious vomiting and catliarsis, convulsive motions of the face, vertign, delirium, dilated pupils and death. $\ddagger$

- Medical Properties and Uses. Störck appears to be the first who gave the wolfsbane internally as a medicine; and since his experiments were published in 1702, the names of many eminent physicians on the continent, as Kaempf, Herz, Juncker, and others, may be added as evidences in favour of its efficacy, it is now very gene-

* Rödder in Alherti Jurisp. Med. t. vi. p. 724.

$\uparrow$ Several other species of aconite, as the Aconitum Cammarum; Aconitum Anthera, and Aconitum Lycoctonum, are more or less poisonous, and produce symptoms nearly similar to those of the Aconitum Napellus.

₹ The root was given by way of experiment to fonr condemned criminals, two at Rome, in the year 1524; and two at Prague, in 1561; of whom two sonn perished, the other two, with great dificulty recovered. Matthinli in Dioscoridis, p. 768.

The following remarkable fact is said to have happened at $S$ weden :-A person having eaten some of the fresh leaves of the Napellns, became maniacal, and the surgeon who was called to his assistance declared, that tbe plant was not the cause of the disorder; and to convince the company that it was perfectly innocent be ate freely of the leaves; but he suffered for his temerity, for soon after lie died in great agony. 
rally, and often successfully employed in Germany, and the Northern parts of Europe, particularly as a remedy for obstinate rheumatism, glandular swelling, venereal nodes, spina ventosa, anchylosis, convulsive disorders, intermittent fevers, \&c. The Aconitum Napellus, when administered with due caution; ${ }^{*}$ acts as a penetrating stimulus, exciting perspiration, and sometimes the urinary discharge; $\dagger$ the diaphoretic operation of the aconite is considerably promoted by the addition of antimonials.

Preparations and Doses. The wolfsbane is usually given in the form of extract, or expressed juice inspissated, or the leaves dried and reduced to powder; in prescribing either of these preparations, we may begin by giving one or two grains, two or three times in the day, gradually increasing the dose according to its effects; Odhelius never prescribed less than two grains of the extract for a dose, which lie repeated tive or six times in twenty-four hours; Dr. Stoll gave it in such extraordinary large quantities, that we must suppose that the virtues of his extract were very much impaired, eitlier by long keeping or in the preparation. In moderate doses, the use of this medicine may be continued for several weeks, or even months, with decided good effects. In preparing the extract, Orfila recommends evaporating the expressed juice in a water bath, as preferable to the common mode, having proved, that it is incomparably more active and certain in its operation than when prepared by any other process.

Kaempf uses the following tincture, in doses of from five to ten minims, increasing the dose gradually to forty.

R Aconit: Sicat $\tilde{3} \mathbf{j}$.

Spt. Vini. R. vj degere per dies septem.

Off. The Leaves.

Off. Pp. Ext. Aconite. L.

Suce. Spiss. Aconiti Napelli. Ed.

* The preparations of the aconite are of very uncertain powers, varying in strength according to the heat employed in their preparation (i. e. the extract and powder, ) bence in beginning with a fresh parcel of either of these preparations, we shonld go back to the smallest dose, and proceed with the same caution as at first.

+ Bergius describes its virtues to be "Pellens, sudorifera, diuretica, suhvertiginosa:" 


\section{HYOSCYAMUS NJGER.}

\section{Black Henbane.*}

\section{Class PeÁtandria.-Order Monog Ynia.}

Nat. Ord. Solane E, Linn. Juss.

Gen. Char. Corolla funnel-shaped, the lobes obtuse. Stamens inclined (or bent). Capsule covered with a lid, 2-celled.

Spec. Char. Leaves sinuate, amplexicaul. Flowers sessile.

THE Genus Hyoscyanus contains several species, most of which are exotic. $†$ The Hyoscyanus Niger is indigenous to Britain, and flowers in July and August, it is a bieunial plant, very common in most parts of the country, and particularly so in the eastern parts of Essex, Suffolk, and Kent; and it is not unfrequently met with in the neighbourhood of London; it is usually found growing on the sides of dry banks, and about old dunghills. The roots of this species of henbane, are fusiform, long, wrinkled, and externally of a brown colour, internally white. The first season (from sowing the seeds) there springs up a few large soft leaves, of the same form as those on the stalks,- the following season, the stem shoots and rises to the height of about two feet, erect, cylindrical, and dividing into two, three, and sometimes more branches; the leaves are placed irregularly or alternately on the stems; are deeply sinuated on the edges and pointed at the extremity, surrounding the stalk at the base; the flowers either emerge from the alæ of the leaves, or form a spike at the top of the branches, are sessile, and mostly grow on one side of the stalk; the calyx is pitcher shaped, 5 cleft and permanent; the corolla is monopetalous, funnel shaped, and divided into 5 obtuse segments of a pale yellowish colour, reticulated at the base with purplish veins; the filaments are inserted into the tube of the corolla; anthers heart-shaped, and of a deep purple colour; the germen is roundish, style tiliform, stigma round; capsule ovate,

\footnotetext{
* Fig. $a$. iu the annesed drawing, represents the upper branches of a plant, the flowers, leaves and capsules a little smaller than nature. $b$. The corolla cut open to shew the stamens. c. Pericarp containing seeds. $d$. The pistil.
}

† Eight species are known and cultivated in England. Vide Hort. Cant. 


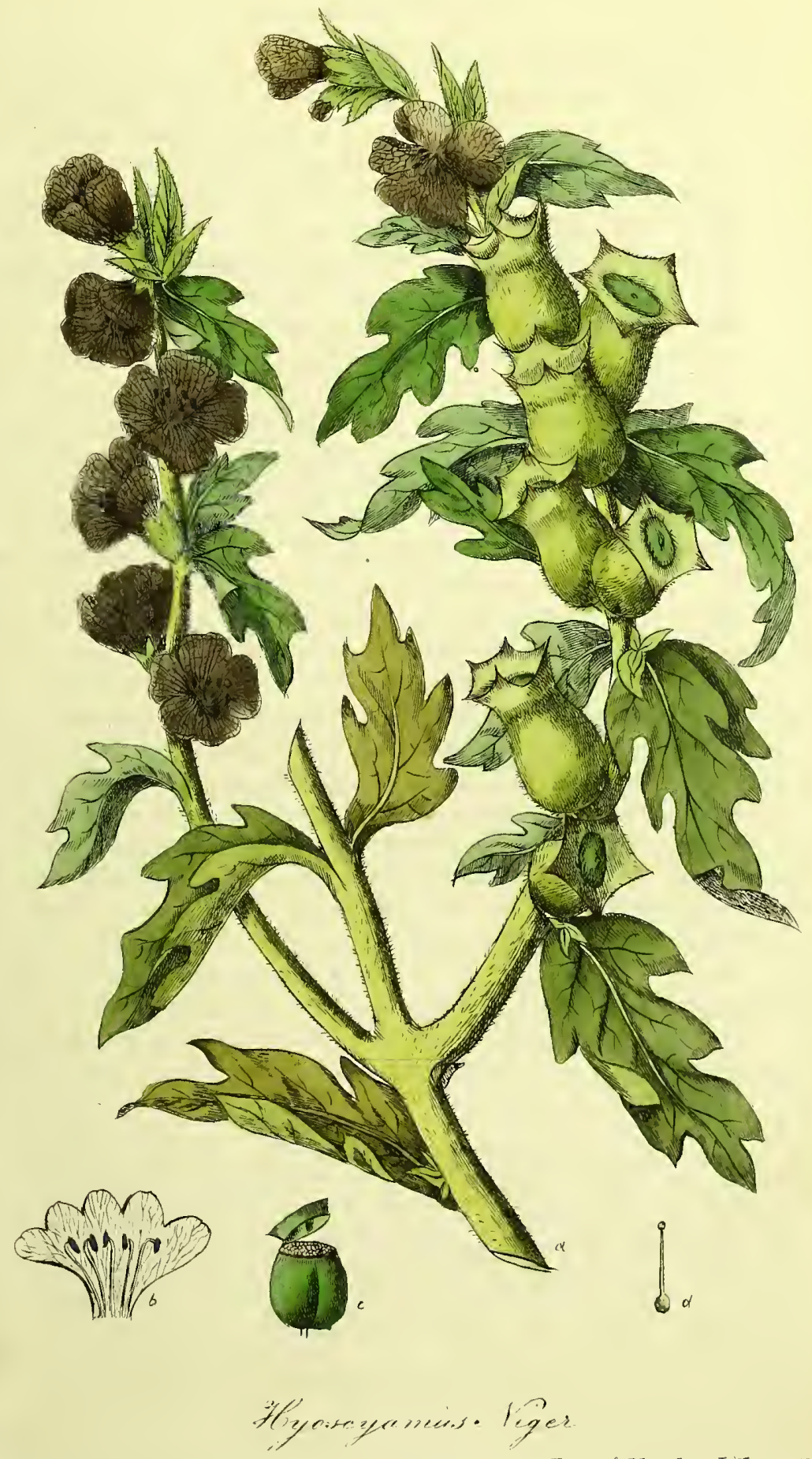

Gprate ded

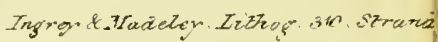
L oxadox, Pab by Callow 8 Vilson, Pnnees St, oho. 

bilocular and opens transversely by a convex lid, and contains numerous small oboval brown seeds; the leaves and stalks are covered with soft liair or down.

Sensible Properties; - Henbane when fresh gathered has a strong disagreeable smell; when bruised or burnt, its smell bears some resemblance to tobacco; taste when chewed, insipid and mtcilaginous; the dried leaves have little taste or smell, the watery infusion is of a pale yellow, with a faint narcotic smell, but very little taste; the yellow colour by the addition of sulphate of iron, is turned to an olive brown; diluted alcolool extracts ail its virtues. The roots, leaves, and seeds possess the same properties, but in different degrees. M. Brandes discovered that the virtues of ben bane, like many other vegetables, depend intirely upon a peculiar alkalied substance, which he named Hyoscyamia."

Deleterious Properties, and Action of Henbane on The Animal Economy. Toxocologists have ranked the black henbane among the narcotic poisons; and from the time of Celsus, and other ancient writers, to the present period, many cases are recorded of the poisonous effects produced by various species of henbane, when taken internally, or applied externally. The usual symptoms following an over-dose of this vegetable, are flushed countenance, loss of speech, delirium, remarkable dilatation of the pupils, convulsions, followed by deatl.. Boerhaave, it is stated, experienced a trembling and intoxication, in consequence of preparing a plaster, in which henbane formed part of the composition. It is related by' Dr. Picard, that a glyster, composed of the decoction of the roots of henbane administered to a lady labouring under an ulcer of the womb, gave rise to the following symptoms; face flushed and bloated, stiffness of the tongue, loss of hearing, stupor and drowsiness, hurried respiration, and loss of motion and numbness of the right arm, leg, and thigh ; and, in fact, almost every symptom characterizing a fit of apoplexy, except stertor and distortion of the mouth. +

* (The seeds of the Hyoscyamus Niger furnished to M. Brandes.-Fixed oil, readily soluble in spirit of wine, 19.6; fixed oil, difficultly soluble in spirit, of wine; 4.6 ; fatty substance, analogous to cetine, 1.4; malate of byoscyamine, with malates of lime and magnesia, and an anmoniacal salt, 6.3 ; incrystallizable sugar, a trace; gum, 1.2 ; bassorine, 2.4 ; fecula, 1.5 ; woody fibre, 2.6 ; phylenmacolle, 3.4 ; soluble albumen, 0.8 ; hard albumen, 3.7 ; malate sulphate (?) and phosphate of potass, 0.4 ; malate of lime, 0.4 ; malate of magnesia, 0.2 ; phosphates of lime and magnesia, 2.4 ; water, 24.1 ; excess, 1.4 ; the ashes contained-carbonate, phosplute, sulpbate (?), and hydrochlorate of potass; carbonate and much phosphate of linze; much selica, manganese and iron, and a very little copper.)

† Traité de Médecine Légale, tom. iv.p. 25, Second Edition. 
Grunwald has seen a decoction of the roots administered as a glyster, give rise to a furious delirium.*

The active properties of henbane, and the effects it produces on the animal economy, vary according to the season of the year, and vigour of the plant, when gathered; Orfila made many experiments to ascertain this; and proves that the roots and leaves are less active in spring, than in the middle of summer, when every part of the plant is fully developed.

From experinents made on dogs, with various preparations of henbane, Orfila draws the following conclusious:-1st, that the different preparations of this plant, produce effects more or less violent according to the active properties of the preparations, these depending upon the full developement of the plaut, ancl the mode of making them; 2nd, that the various preparations of henbane produce nearly the sanie symptonis whether introduced into the stomach, applied to the cellular texture, or injected into the veins; in this last case the effects commence more rapidly and violent, and a very small quantity produces death; $3 \mathrm{rd}$, that they do not produce inflammation of the stomach ; 4 th, that they are absorbed and carried into the circulation, and exert a remarkable action on the nervous system, producing the various symptoms enumerated; 5 th, that they appear to act in the same manner upon the human species as on dogs. 'It is remarkable that goats not only eat this plant with impunity, but seem remarkably fond it.

The black henbane and some other species of the Genus Hyoscyamus have been long known, and prescribed as remedial agents in the cure of disease, but, like most other very active vegetables, had grown into disrepute, probably owing to the many untoward accidents, arising from a want of due caution in prescribing a vegetable possessed of such eiergetic properties, or from disappointments in the effects produced, from the inactive properties of the preparations made use of.

Medical Properties and Uses. We are probably indebted to Dr. Störck, of Vienna, for a revival of this valuable narcotic; he prescribed it with much success in various cases where an anodyne was indicated, and where opium wonld not be adnissible. (It is now deservedly come into general use in this country). Henbane exerts its powers by allaying inordinate action, and mitigating pain, and with this intent it is prescribed in a variety of diseases; henbane

* Grunwald, Ephemer des Eur. de la Nat. an. 9, App. p. 179. 
although a powerful anodyne, is free from the constipating effects of opium, it often acts on the bowels as a gentle aperient; in moderate doses, it generally produces undisturbed sleep, followed by recruited energy of the animal functions. In all spasmodic and many nervous diseases it is givelı with decided benefit; in rheumatism, glandular swellings, induration of the mamma, cancerous and scrofulous swellings and ulceration, the external and internal use of henbane is generally aitculed with the happiest effects. Of late years, the extract of henbane, in solution, has been much used by surgeons, previous to operating for cataract, for dilating the pupils of the eyes; $*$ and in contractions of the iris, a few drops of the solution is dropped in the eyes, or otherwise applied with a camel's-hair pencil. The most powerful effects of this application generally take place in about four hours, and are usually over in ten or twelve; as a topical remedy, the bruised leaves combined with bread-crumb are applied in the form of poultice; in cancerous and other painful ulcers, the dried leaves powdered and sprinkled on the sores, or mixed with simple ung: generally relieve the sufferings, of the patient. The smoke arising from burning the seeds of lienbane, conveycd to carious teeth, is a popular, and often an effectual renedy in toothache. Henbane is generally given in the form of extrací, or inspis. sated juice, and in tincture, the former in doses of one grain, gradually increased to eight, ten, or more for a dose, two or three times a day, the latter in doses from ten to thirty minims. Dr. Cullen says he seldom found any considerable anodyne effects produced from less than eight or ten grains, and often found it necessary to increase the dose to fifteen or twenty, in maniacal cases it has been increased to thirty grains for a dose. In plithisis we have seen it prescribed wilh much advantage in abating the cough and procuring rest. $\dagger$ In spasmodic disease, the Tincture Hyoscyani will often afforl relief where opium fails; we have prescribed it in spasm of the gall ducts, in doses of thirty or forty minims, with immediate relief, when opium in large doses had no effect; in tic-doulorcux we have seen the Ex. tract Hyoscyami afford considerable relief, and in an adult case of acute hydrocephalus, where the patient was suffering the most excruciating torture, we prescribed four grains of the extract at bed-lime, by which, several hours of calnz repose were obtained, the first she had experienced for several days.

* Celsus used lienbane as a collyrimm in inflammation of the eyes.

+ Dr. Donald Munro mentions that a young lady labouring under a deep consumption, took every night, for some months, six grains of the Extract Hyosciami, which procured ber rock, withont heating, or making her uneasy in the pight, as opiates had always done.

VOL. I. 
Off. The Herb and Seeds. Off. Pp. Ext. Hyosciami. L. Ed.

Tinct. Hyosciami. Ed. L. and D.

\section{ALTHAA OFFICINALIS.}

\section{Marsh-mallow.*}

\section{Class Monadelphia.-Order Polyandria.}

Nat. Ord. Columaces, Linn. Malvacee, Juss.

Gen. Char. Calyx double, exterior 9-cleft. Arils very numerous, 1-seeded.

Spec. Char. Leaves simple, downy.

THIs species of Althæa $\uparrow$ is indigenous to Britain, and grows commonly near the sea-shore, and in salt marshes; it is found in great abundance and perfection in the Romney Marshes, in Kent: flowering in the Autumn. The root is perennial, long, tough, white and fibrous; the stalk grows upright, firm, and woolly, somewhat branched towards the top, and rises to the height of three or four feet; the leaves are elliptic and pointed, with a lobe on each side, irregularly serrated, covered with a soft down, and stand upon long round foot-stalks; there are two stipules, narrow, and placed at the base of each leaf-stalk; the calyx, a double perianthium, the exterior consisting of nine, and the interior of five narrow pointed segments; corolla composed of five inversely heart-shaped petals; stamina numerous, united at the base into a cylinder, and terminated by kidney shaped antheræ; germen orbicular, style cylindrical, short, and furnished with numerous long stigmata; seeds numerous, kidneyshaped, placed in a circle, and covered with an arillus.

Properties. Every part of this plant abounds witl mucilage, more especially the roots, a decoctiou of which, yields nearly half the weight of the roots enployed, of a gummy mucilaginous matter, which reddens the infusion of turusole, and "differs from the solu" tion of gum arabic, by not being precipitated, when a solution of

* Fig. a. represents a branch, every part of the natural size. $b$. The calyx. $c$. The stamina. $d$. The pistillum. e. A seed.

+ Eleven species of the Althra tribe are cultivated in our gardens. Hort. Cant. 


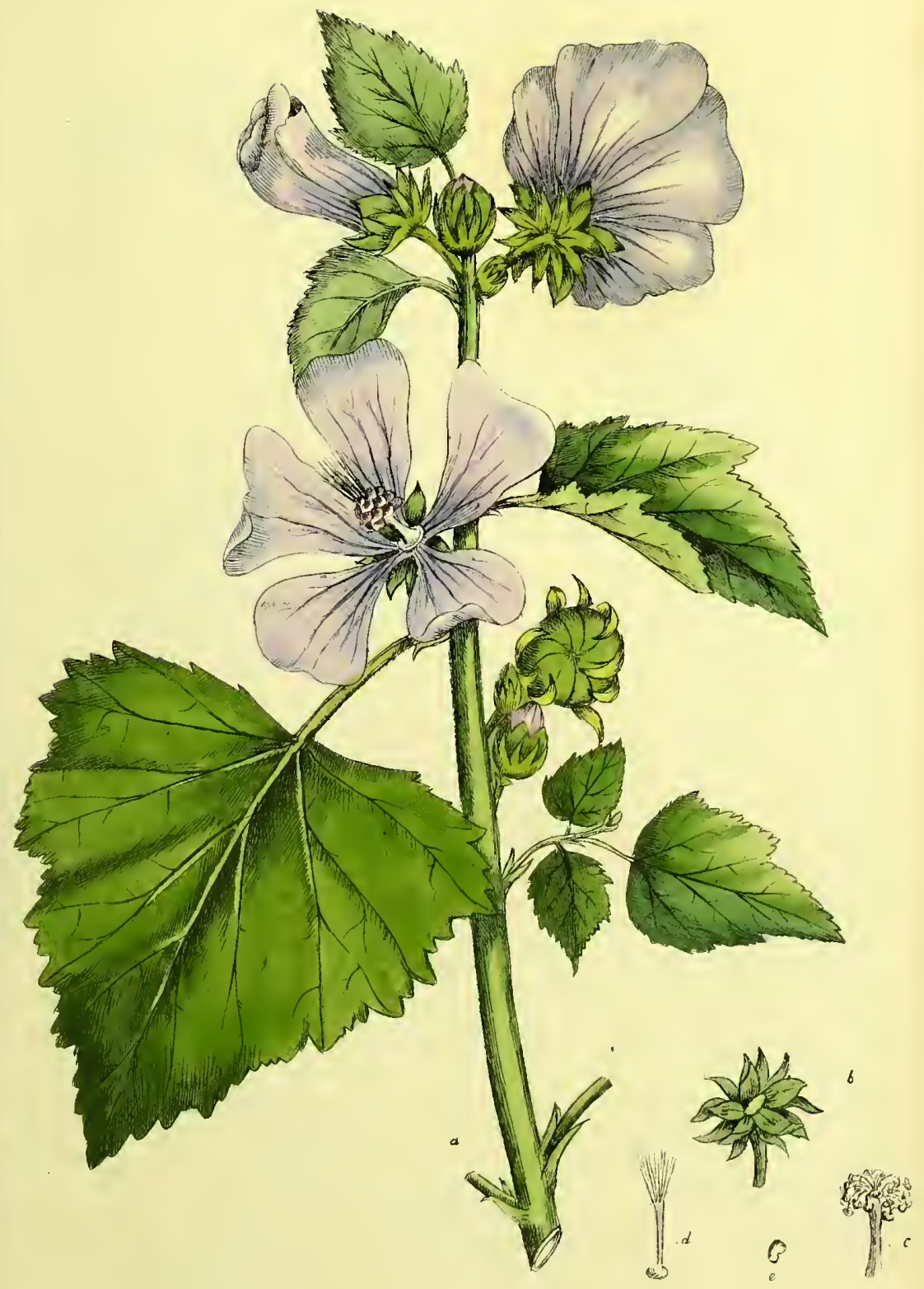

Atthaen Offieirentid. 



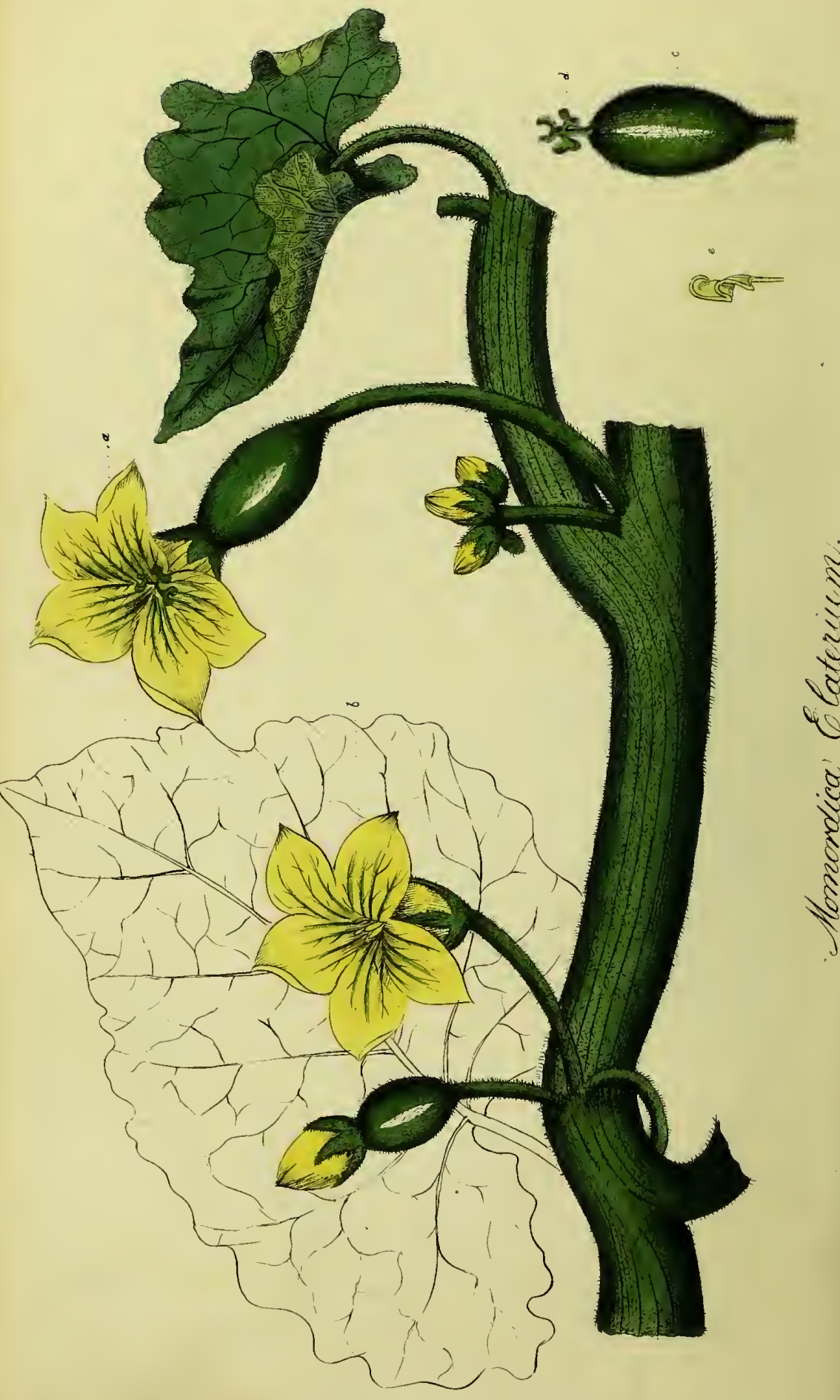


" silica in potasse is poured into it." * The roots are long and, fibrous, seldom exceeding the thickness of a finger ; and when peeled, nearly white; and the whiter they are when dried, the more estimation they are held in. The leaves yield about one-fourth their weight of mucilage, and the flowers and seeds a much smaller proportion.

Medical Properties and Uses. The medical properties of this plant, reside entirely in the mucilaginous matter, hence it is commonly employed for its emollient and demulcent qualities, and few of our indigenous plants possess those qualities in so high a degree; a decoction of the roots, or leaves, forms an excellent drink, for lubricating and relaxing the passages, in nephritic and calculous complaints, strangury, \&c.; also as a demulcent, in pulmonary affections, coughs, and hoarseness, and where the natural mucus of the membranes become sharp and acrid. As a topical remedy, the leaves or roots are used for fomentations, gargles, and enemas. An unguentum is sold under the name of marsh-mallow ointment, mucl esteemed by the vulgar, for its emollient and cooling qualities, and hence it is in great request. A very favourite and fashionable lozenge, called Pâte de Guimauve, vel pasta Althææ, is also prepared from the roots. $\dagger$

Off. The Roots and Leaves.

Off. Pp. Syr. Althææ. L. Ed.

Decoct. Althææ Officinal. Ed.

\section{MOMORDICA ELATERIUM.}

\section{Wild Cucumber.}

\section{Class Moncecia-Order Syngenesia.}

Nat. Ord. CucurbitaceE, Linn. Juss.

Gen. Char, Male Flower. Calyx, 5-cleft. Corolla 5-parted. Filaments 3.

* Gray's Elements of Pharmacy.

+ Pâte de Guimauve, Rad. Althæa, decort. Ziij. water i. gall.; boil to four pints, strain, add gum arab. Ib:s : saceh, alb. Ibij.; evaporate to an extract; then take from the fire, stir it quickly, with the whites of 12 eggs previously beaten to a froth; add, while stirring, aq. flo. aurant. З̌ss. Gray's Supplement, p. 399.

\# In the annexed drawing, Fig. $a_{0}$ represents a female flower, shewing its situation 
Female Flowers. Calyx 5-cleft. Corolla 5-parted. Style 3-cleft. Pume bursting elastically. Spec. Char. Pomes hispid. Tendrils none.

This species of Momordica* is a native of the south of Europe, flowering in June and July; the roots are perennial, but, in this country, seldom survive through the winter; however, when plasted in a warm and dry soil, and the seasons have proved mild, the roots have òccasionally lived through several winters, putting forth their sialts every spring; it lias been cultivated in England since the year 1596. The roots of the Elateriumt are large, long, and Heshy, and send out every sprimg, several thick rough trailing stalks, which divide into many branches (like the common cucumber,) extending several feet each way, but have no tendrils; the leaves are irregularly heart shaped, slight tly serrated, rough, reticulated, veined, of a dark green colour, the under side paler, and stand upon strong petioles; the calyx consists of one leaf, divided into five narrow acute segments; the corolla is monopetalous, and divided into five parts, of a yellow colour, reticulated with green veins; the female flowers are placed above the germen, the style is short and trifid, and each part terminated by gibbous stigmata; in the male flowers, the three styles are short and tapering, two of which have cloven antheræ, the other has a simple one ; the fruit is large, oblong, hairy, and divided into three cells, which contain many flat seeds.

The Elaterium of commerce is the dried juice or feculence of the wild or spurting cucumber, when nearly ripe; obtained as it flows from the fruit when cut, without using any pressure; the juice is let to stand for a few hours, the more liquid part poured off, and the sediment dried by exposing it to the atmosphere. The Elaterium obtained by the above method, is distinguished on the continent by the name of white Elaterium; another kind is prepared by strongly pressing out the juice, and applying heat to evaporate it to a proper consistence ; this extract is known by the name of Elaterium Nigrum;

above the gernen. $b$. A male flower. $c$. A double anthera, $d$. The germen, mounted by the trifid style, each part sustaining an oblong gibbous stigma. We lad not room in our drawing to shew the fruit of its lull size; but the germen represents very perfectly the fruit in miniature.

* Seven species of the Genus Momordica are known and cultivated iu England. Vide Hort. Cant.

† The specific name Elaterium was given this species of cucumber by the Greeks, from tbe violence with which the fruit, when ripe, separates from the stalk, hursts and sheds its seed; from the same callse it has been named Noli me tangere. 
its properties are less active than the former extract. We are told, that half a bushel of the fruit yielded only two drachms of the proper extract, or Elaterium Album, and that forty cucumbers yielded no more than six grains.*

Chemical Properties and Qualities of Elaterium. The sensible qualities of the inspissated juice is not remarkable, either to the taste or smell; when chewed it is slightly bitter, and warms the throat and fauces. The Elaterium Album (as it is called,) is of a pale greenish grey, without smell, dry, brittlc, and powerfully catlartic; the Elateritum Nigrum is of a darker green, and has a resinous appearance. Elaterium is infammable, and readily dissolves in water; spirit of wine dissolves only about one-tenth. According to the analysis of Dr. Paris, Elaterium contains, water 4 parts, extractive 26 , gluten 5 , woody matter 25 , fecula (or starch) 28, elatin and bitter principle 12.

Elatin, or Elatine, Dr. Paris considers to be a new vegetable principle, and describes it to be of a green colour, heavier than water, soft, inflammable, and, when burning, diffusing an aromatic odour; insoluble in water, but readily in alcohol; giving a fine green colour to the spirit. To this vegetable principle (i.e. Elatin) the medicinal properties of Elaterium are due.

Medical Properties and Uses. Evcry part of the Momordica Elaterium is possessed of purgative properties, + but the dried fecula of the fruit (i.e. Elaterium) is the only part now used medicinally. Elaterium possesses properties powerfully cathartic, and was frequently employed as such by the Grcek and Arabian physicians, and its use has since becn much recommended in hydropic cases, by Pauli, Sydenham, Listcr, and utliers. S. Pauli appears to have employed this medicine with great success, yet, from its powerful effects, thinks it should not be used until the milder purgatives have failed; it is undoubtedly onc of the most powerful cathartics in the Materia Medica, and requires to be prescribed with due caution. Elaterium in doses of grss. to gr. iij. generally proves powerfully cathartic. Dr. Woodville says, "The most prudent and effectual " way in which dropsies are now treated by this remedy, is by " repeating it at short intervals in small doses."

Off. The fresh fruit when almost ripe.

Off. Pp. Ext. Elaterii. L.

Elaterium. D.

* Gray's Elements of Pharmacy.

+ Radicum vis catharticum major est quam foliorum, minor vero quam fructaum. Geolf 


\title{
CROTON TIGLIUM.
}

\author{
Purging Croton.*
}

\section{Class Monecia.-Order Monadelphia.}

Nat. Ord. Tricoces, Linn. Euphorbie, Juss.

Gen. Char. Male. Calyx cylindrical, 5-toothed. Corolla of five petals, Slamens ten to fifteen.

Female. Calyx polyphillus. Corolla 0. Styles three, bifid. Capsule trilocular. Seed one.

Spec. Char. Leaves nvate-acuminate, serrate, glabrous. Stem arboreus.

The Croton Tiglium is indigenous to India, Ceylon, Java, China, and other Eastern nations. The Genus Croton contains upwards of ninety species, $\dagger$ of which the Tiglium is the only one possessing purgative qualities. It appears that the natives of the East have for cenluries past been well acquainted with the purgative effects of the.seeds. In Europe, the seeds liave been long known under the names of Gra as a drastic purge.

This species of croton seldom exceeds the height of fifteen feet; the trunk and large branches are covered with a soft bark, of a blackish colour, the younger branches green, with a reddish tinge; the leaves are alternate, ovate-acuminate, serrated, smooth, and of a bright green (having two glands seated on the base), and stand on petioles about one-fourth their length; the flowers are in erect, simple terminating racemes; the calyx, in the male flower, is cylindrical, and five toothed; the corolla is composed of five straw coloured pctals; the stamina from ten to fifteen; in the female flower, the calyx is divided into nany obtuse segments, and reflected under the germen; there is no corolla; the styles are three and bifid; the capsule is trilocular and smooth, and contains three seeds.

Medicinal Properties and Uses. Every part of this tree

* Fig $a$. represents a sprig, shewing the racemes of male and female flowers. b. Female flower. c. Male flower. d. Capsule. e. Seed.

$\uparrow$ Nineteen species are cultivated in Britain. Vide Hort. Cant.

¥ The name Grana Molucca, appears to be derived from the Molucca Islands, from whence the seeds were formerly exported into Europe. 


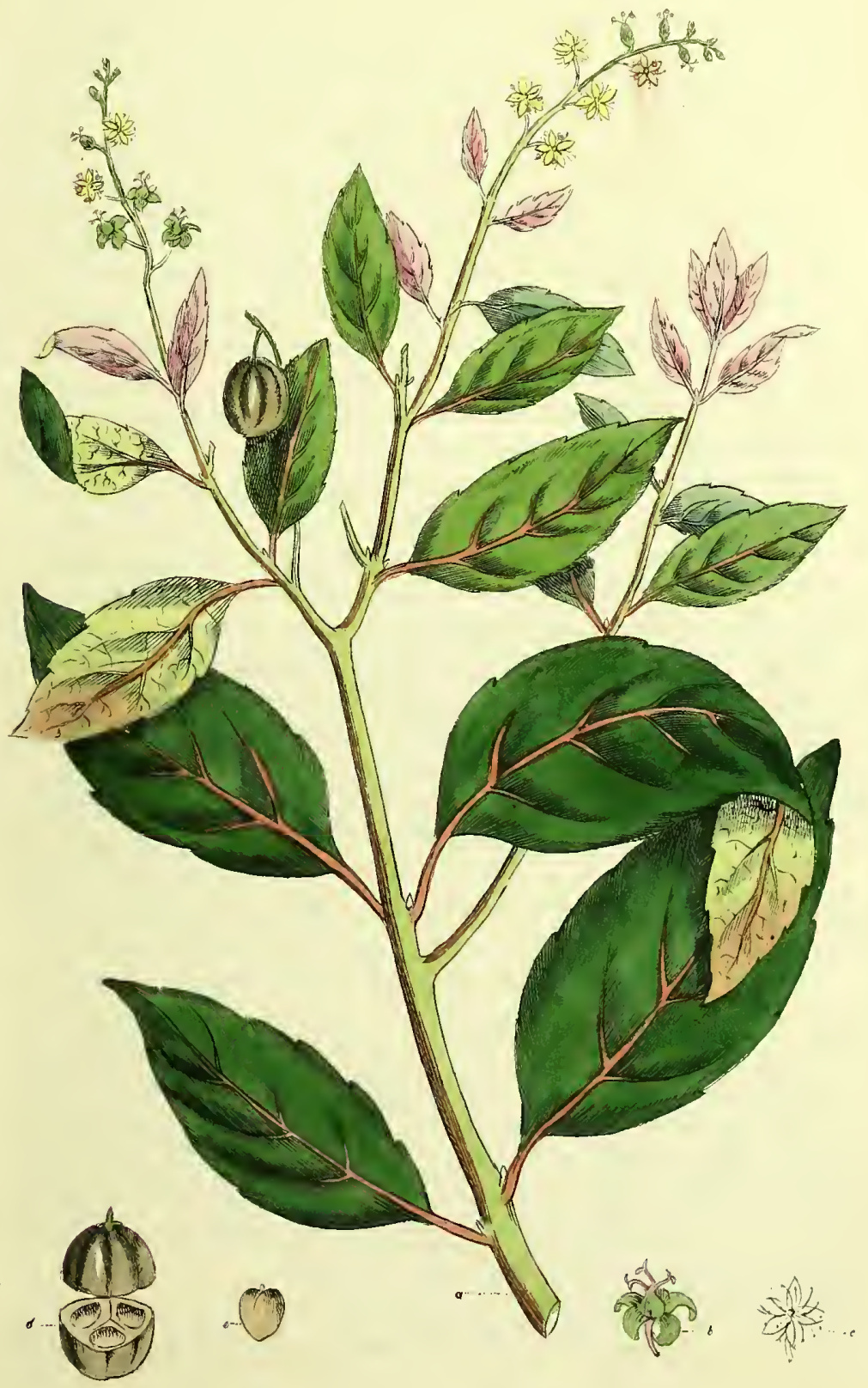

urate del.

$$
\text { Lintrie. \%o Lener }
$$

I oudon. Proibe Callow \& Wilson Prmaes street 

possesses medical properties ;* in the Eastern nations it is valued for its purgative, diaphoretic, and diuretic qualities; the seeds have a nauseous, acrid, burning taste, and purge sharply in doses of one grain ; the roots are likewise powerfully cathartic, and are used in Batavia, and other parts, as a specific for the dropsy; the wood of the trunk and branches, in small doses, acts upon the skin and kidneys, and the leaves in powder are used by the Japanese, as a topical remedy for the bites of serpents.

In this country, the fixed oil, expressed from the seed, has been lately brought into general use, through the exertions of Dr. Conwell : and the valuable scientific aud chemical experiments of Mr. Frost, Dr. Ninmo, and otlıers, have contributed not a little in rescuing a valuable medicine from that oblivion into which it had sunk, $\ddagger$ in consequence of the untoward accidents frequently produced by its use.

The oil of croton is of an orange or deep yellow colour, and of a peculiar smell, sui generis: and of an extremely acrid and pungent taste. The genuine oil, in doses of from one to two minims, proves powerfully catlartic; its effects are generally very rapid, frequently supervening at the expiration of laalf an hour; and in cases of obstinate constipations, when other medicines have failed, it will be found a valuable remedy. Where the oil of commerce is used, the greatest cnution will be required in prescribing it; ill most instances, one minim (or even less, if the oil be genuine) will be found to produce copious evacuations; and we would by no means recommend a repetition of that dose for at least some hours. The safest, and perhaps the best, way of administering the croton oil, is in combination with other aperients, $\S$ to increase their active properties : the following will be found a useful combination-

R. Ol. Tiglii, m. ij.; Pil. Colocynth, $\ni$ ij. Ft. massa et divid. in pilul. decem; from two to three of these pills may be given every two, three, or four liours, if necessary.

* See Dr. Ainslie's Materia Medica of Hindostan.

+ The pnrgative properties of the seeds reside in a fixed oil, which can be separated by expression in the way in which castor, and other fixed oils, are usually obtained.

‡ "The oil of croton, was intrrduced into Europe in the year 1630, and was em" ployed internally with success by several physicians. In 1632, Artus Gyselios "s extolled it in dropsy. In the Herharium Amboinense of Rnmphius, published at "Amsterdam, 1750, by Bermann, a description of the croton is contained; the seeds " of which, says the author, yield on expression an oil, which, when taken in the dose " of one drop in Canary wine, was at that time a conmon purgative."

Appendix to Magendie's Formulary, by $R$. Dunglison, M. D.

One of the best modes of exhibiting the Ol. Tiglii, is in combination with the Ol. Papav. or Ol. Amygd. in the proportion of one drop of the former to an ounce of either of the latter, the mode recommended in Hufeland Journal der practishen Heilkunde, for making artificial castor oil. 
Where patients are incapable of swallowing, a drop or two let fall upon the tongue will, in general, operate powerfully; and a few drops rubbed round the umbelicus, lave produced a purgative effect.*

The experiments of Mr. Frost and Dr. Nimmo go to ascertain the quantum of active matter, in a given quantity of the seeds; and also the purity of the oil, commonly sold as croton oil ; and, from their experiments, it appears that the oil of commerce is usually very much adulterated, and differing in strength nearly ten-fold: the consequence of prescribing a medicine of such unequal powers must be obvious.

- Chemical Propenties and Analysis. According to the experiments of Mr. Frost, one hundred grains of the seeds consist of 32 shell, 68 kernel. " One hundred grains of the seed were digested " in three drachms of sulphuric æther, sp. grav. 71, and afforded " 25 grains of fixed oil. Thirty-two grains of the oil were put into " a Florence cask, containing some alcohol previously digested on " olive oil, to prevent the spirit from dissolving any of the oil of the "Croton Tiglium seed. The mixture was now agitated, and then " passed through a filter containing carbonate of anmonia; the " filtered solution was then evaporated without heat, and yielded"Active matter (soluble in alcolıol and ætlıer) combineel with a. " very small portion of fixed oil $\ldots \ldots \ldots \ldots \ldots \ldots \ldots .6 .5$ grs. "Inert fixed oil ...................... 23.5

32 grs." +

Dr. Nimmo, of Glasgow, has found 100 parts of this oil to consist of 45 per cent. of an acrid purgative principle, soluble in volatile and fixed oils, alcolol and sulphuric rether; and 55 per cent. of a bland oil, (resembling oil of olives,) insoluble in alcolıol.

The croton oil of commerce being very generally adulterated with some of the cheaper fixed oils, Dr. Nimmo has made some experiments for the purpose of detecting this fraud. Dr. Nimmo digested the suspected oil in alcohol, which will dissolve a less proportion, if mixéd with olive oil, and a larger proportion if adulterated with castor oil; but it is evident, the test must fail, if the adulteration were with a combination of both oils.

Off. The oil expressed from seeds.

* Ainslie's Materia Medica.

+ Vide Lancet, vol. ix. 


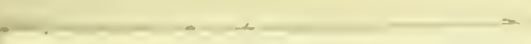

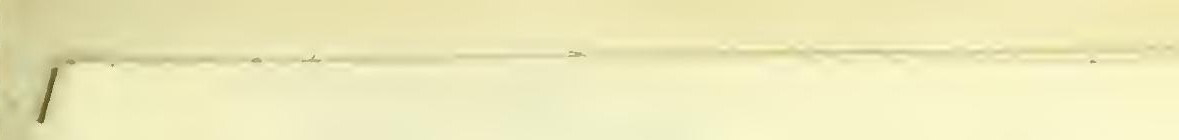




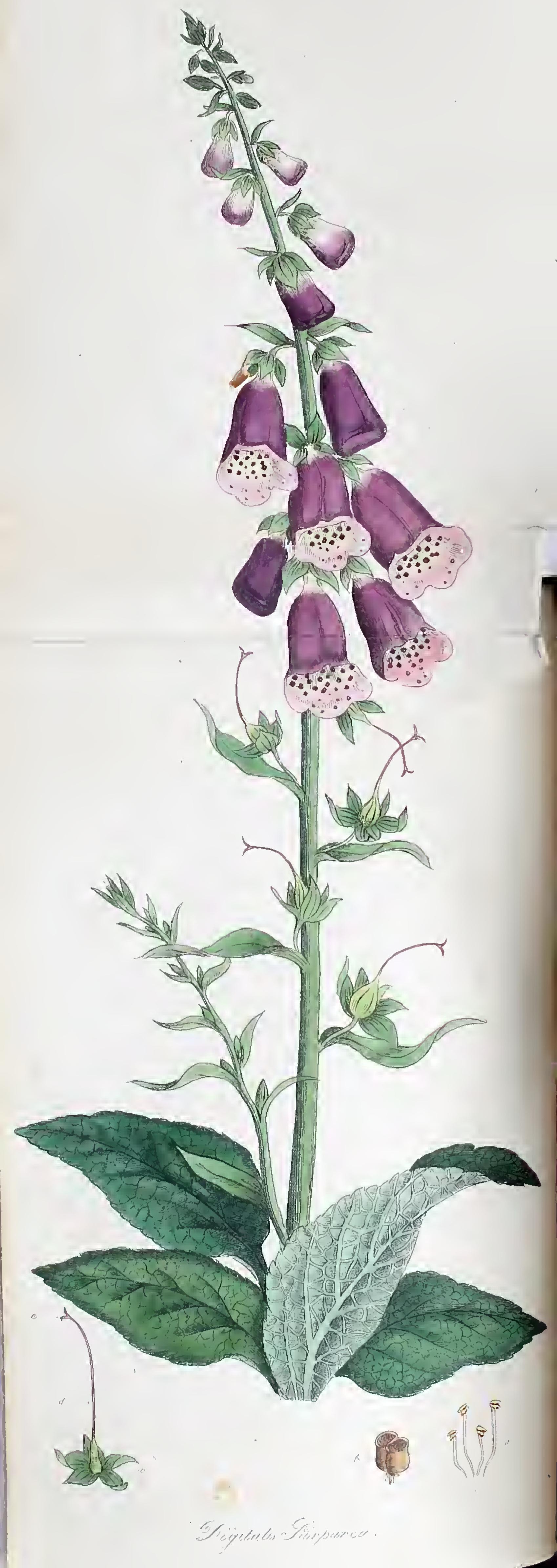




\title{
DIGITALIS PURPUREA.
}

\author{
Fox-glove.*
}

\section{Class Didynamia.-Order Angrospermia.}

Nat. Ord. Luride, Linn. Scrophularie, Juss.

Gen. Char. Calyx 5-parted. Corolla bell-shaped, 5-cleft. Capsules egg-shaped, 2-celled.

Spec. Char. Calyx-leaflets, egg-shaped, acute. Corols obtuse, upper lip intire.

Fuchsius (in his Hist. Stirp. 1542) is the first author who notices fox-glove, from him it received the name of Digitalis, in allusion to the German name Fingerhut, (which signifies a finger stall), from the blossoms resembling the finger of a glove.

The Digitalis Purpurea is a biennial plant, indigenous to these countries ; $\dagger$ it is found on sandy and gravelly soils, on mountains, on elevated banks and hedgerows; it flowers in June and July; the first season it produces only a few large rough oblong leaves; the following spring the flowering stem shoots up, and rises to the height of three or four feet, obscurely angular and leafy, terminating in a spike of purple flowers ; the lower leaves are large, oblong, egg-shaped, serrated, covered with a soft down or hair, and stand on short fleshy footstalks, the upper leaves are much smaller, and spear-shaped; the blossoms are numerous, mostly growing from one side ; the calyx is permanent and deeply cut into five segments; the corolla monopetalous, bell-shaped and bulging, of a purple colour, contracted at the base into a tube, the border divided into four obtuse unequal segments, mottled withiu, resembling small eyes; the filaments are four and crooked, two of which are

* The annexed drawing represents a plant of half the natural size, (taken from nature,) excepting a portion of the lower part of the sten and some large leaves which were removed to allow room to shew the spike of blossoins. Fig. $a$, the stamina. $b$. Capsule. 6. Calyx. $d$. Style supporting the cloren stigna, e.

+ The Genus Digitalis comprises many species, of which the Digitalis Purpurea is the only one indigenous to Britain, eighteen species of Digitalis are cultivated in our botanic gardens. Hort. Cant.

‡ The specific name of Purpurea is ill applied, there being a variety of the Digitalis Purpurea with white fowers, but less common in the wild state than the purple: the purple variety varies also, very much, in depth of colour.

VOL. I. 
short; anthers yellow; pistillum greenish, style simple, stigma cloven, of a pink colour; capsules, egg-shaped, two-celled; each cell containing numerous small angular seeds; the roots are fusiform, fibrous, and knotty.

Sensible and Cuemical Properties. Every part of the fox-glove is possessed of a very nauseous bitter taste, joined with some degree of acrimony, the strength of which varies with the age of the plant, and with the season of the year.* The leaves have but little smell when green, but acquire a slight narcotic smell by drying : the infusion is of a pale olive green, having the taste and odour of the plant; the ce lour of the infusion is rendered darker, by sulphate of iron ; nitrate of silver produces a violet, and muriate of mercury a yellowish precipitate; galls or emetic tarlar do not produce any precipitate. The tincture is rendered nilky by water. $\mathrm{M}$. Bidault de Villiers, who wrote on the medicinal properties of the purple fox-glove, chemically analized six drachms of the dried leaves, the product as follows: " 1st, two drachms, fifty grains of " watery extract; 2 nd, twelve grains of spirituous extract; 3rd, " a peculiar precipitate, eight graiıs, and two drachms fifty grains " of an inert powder, which gave by the action of reagents, six " grains of carbonate of lime, two grains of the oxide of iron, three " grains of sandy quartz, two grains of phosphate of lime, one " grain of sulphate of potass, traces of sulphate, muriate of lime, " and of carbonated alkali; and one grain of charcoal." $t$

The active properties of digitalis appear to depend upon a particular immediate principle or alkali, analogous to that of nany other vegetables. M. Augustus Le Royer, analized a considerable quantity of the purple fox-glove, and obtained from it, a quantity of brown ponderous substance, possessing many of the qualities approximating to a vegetable alkali; to this substance lie gave the name of Digilaline. M. Augustus Le Royer made many experiments with this substance on living animals, the result of which proves it to possess the active qualities of digitalis, in a very concentrated state. A middle sized dog was killed in five minutes by injecting into the jugular vein half an ounce of water containing a grain and a half of digitaline in solution; half a grain of the same

* Withering, who preferred the leaves to any other part of the plant, observes, "These vary greatly in their efficacy at different seasous of the year, and, perhaps, " at different stages of their growth;" and recommends that they should be gathered after the flowering stem bas shot up, and about the time the blossoms are coming forth.

+ Gray's Elements.

‡ Essai sur les Propriétiés Medicinaies de Ia Digitale Pourpréé, par le Docteur Bidault Villiers, 3d. edit. 1.61, Paris, 1812. 
substance, dissolved in two drachms of warm water, being injected into the veins of a cat the animal expired at the expiration of fifteen minutes. Formore particulars on this interesting subject, we refer our readers to a paper on digitaline, (vide Lancet, vol, ii. p. 536.)

action of Fox-glove on the Animal Economy. Since the time of Fuchsius, many authors* have noted the powerful effects produced by fox-glove on the animal frame, and most of them have considered it as possessing very deleterious properties : by modern writers on toxicology it is ranked among the narcotic poisons. Fox-glove in substance, and its various preparations, when administered in large doses, or in small doses frequently repeated, produces violent and distressing sickness and purging; followed by vertigo, dimness of sight, delirium, syncope and death. The effects of fox-glove on the arterial system is generally to diminish the velocity of the circulation in a remarkable degree, although it has sometimes the opposite effect, greatly iucreasing the frequency of the pulse and heat of the body. Orfila, in his general system of toxicology, relates many experiments made upon dogs, and draws the following conclusions from them: $1 \mathrm{st}$, that the powder of fox-glove, its watery and resinous extracts, and its lincture, ought to be regarded as energetic poisons in a certain dose; 2 nd, that all these preparations begin by acting as emetics; $3 \mathrm{rd}$, that the action is much less when introduced into the stoniach, and voniting prevented, than when injected into the jugular vein, or applied to the celiular substance; 4th, that the resinous extract appears to act especially on the heart, or blood-- since this fluid is constantly found coagulated, immediately after death, whenever this extract has been applied to the cellular texture, or introduced into the sfomach; 5th, that the fox-glove acts upon the liuman species as upon dogs.

Treatment. When deleterious symptoms arise from an overdose of fox-glove, (or the plant lias been eaten by mistake) the usual remedies required where narcotic poisons have been taken, should be immediately adıninistered, and for which we refer our readers to our article Lactuca.

Medical Properties and Uses. Digitalis, when administered with due caution, is one of the most valuable of our indigenous plants; when taken into the stomach, its effects are generally to diminish the irritability of the systen,, to retard the velocity of the pulse, and increase the action of the aborbents and urinary discharge.

* Bochaave, Haller, Parkinson, Murray, Gerarde, \&c. Scc. 
Hence it has been recommended in a great variety of diseases; and from its remarkable property of diminishing the velocity of the circulation, it is a valuable and powerful addition to the lancet, in many inflammatory diseases, as we have witnessed in several cases of acute hepatitis and pneumonia, iı active hæmorrhagies and phthisis. In spasmodic asthma, palpitation, and aneurism of the aorta, it produces decidedly good effects. In most anasarcous and dropsical effusions, it isjone of the most powerful diuretics we have: as a topical remedy it has been applied advantageously to scrofulous tumours.

'This active medicine demands great judgment and circumspection in those who administer it, and, as Withering observes, " the doses are not to be repeated too quickly, or an injurious quantity may be taken before any of the signals of forbearance appear." The general rule which he gives, is to stop the exhibition of it as soon as it appears to act, either on the kidneys, the stomach, or the bowels. In diseases accompanied with increased sensibility and irritability, such as phthisis, hæmoptysis, scrofula, \&c. more caution, if possible, is required in the exhibition of this medicine, than in dropsy; hence it should be given in smaller doses. In pulmonary consumption, its virtues have been much over-rated ; in the earlier stages, it generally abates the frequency of the pulse, moderating the hectic heat and cough; but in the last stage of this disease it is rarely admissible, in consequence of its depressing power. Dr. Gregg relates two cases of phthisis, in which it produced a copious ptyalism.

Preparations and Doses. The fox-glove is given in substance, in infusion, and in tincture; alone or in conbination with other medicines. The exsiccated leaves are now generally preferred to the fresh plant.* The dried leaves in powder, may be given from one to three grains, twice a day, or in smaller doses at shorter intervals, so as gradually to remıve many dropsical disorders, without producing any other than mild diuretic effects, and without any interruption to its use, till the cure is completed; in various cases of dropsy many other diuretics níay be advantageously joined with it ; such as spt. æther nit. supertart potasse, acetate of potasse,

* Dr. Witbering preferred the dried leaves to any other preparation, and prescribed tbem to be given in powder or in infusions, and gives the following directions for preparing the powder:- " The leaf-stalk and mid-rib of the leaves shonld be rejected, and " the remaining part should be dried, eitber in the sun-sbine, or on a tin pan or pewter " dish before the fire; if well dried they rub down to a beautiful green powder, care " must be taken tbat the leaves be not scorched in drying, and they should not be " dried more than wbat is requisite to allow of their being readily reduced to powder," As the fox-glove loses much of its active properties by exposure to the light, the leaves or powder sbould be kept carefully covered in a dark place; the bottle containing the tincture sbould likewise be covered with a bladder, so as to exclude the light. 



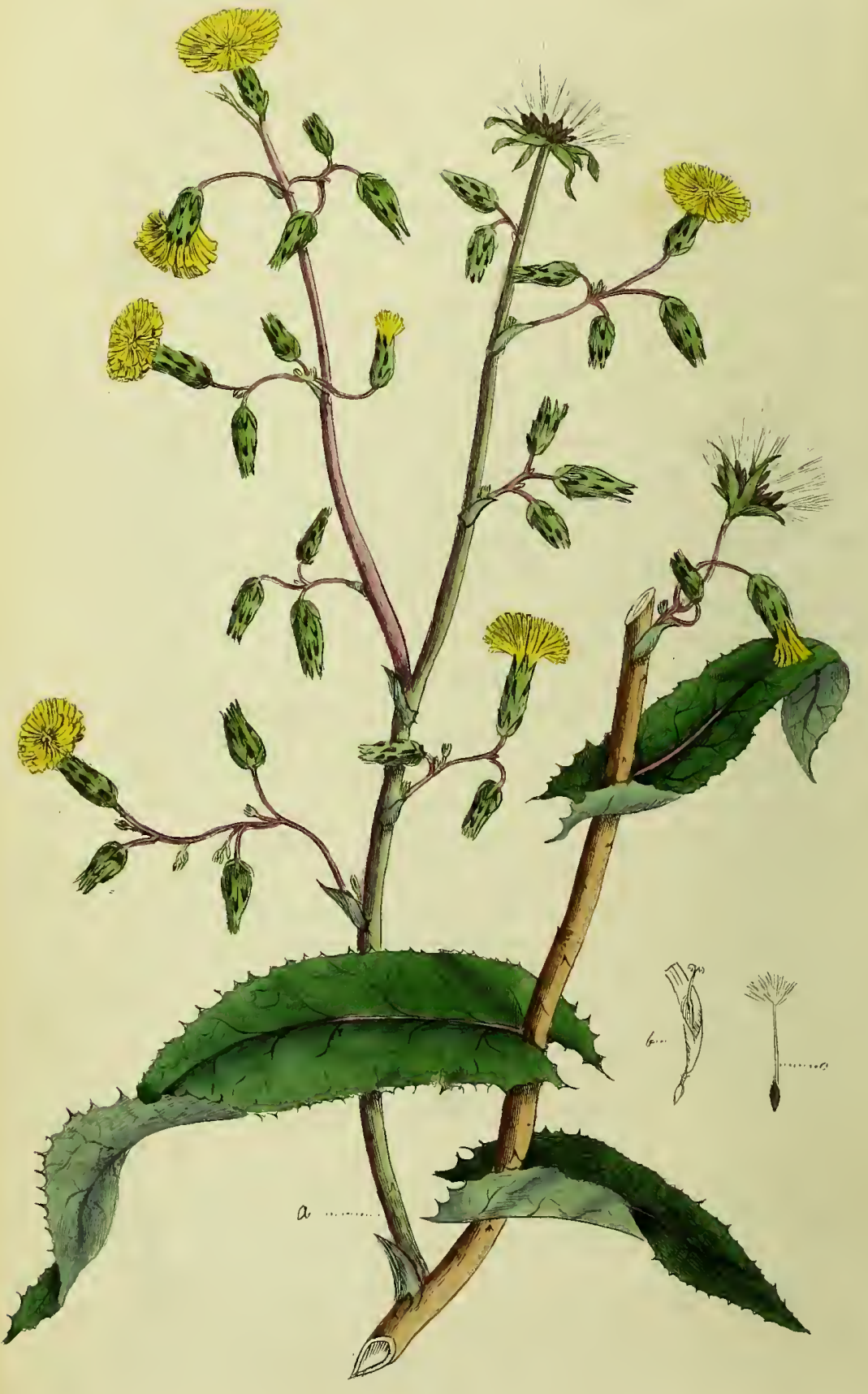

inered dal.

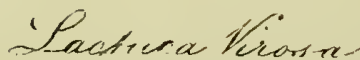

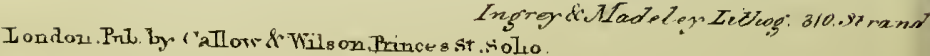


the various preparations of squill, gum ammoniac, \&c. and a small addition of opium is generally useful, particularly if the digitalis purges. The tincture may be generally given in doses of from ten to twenty drops; in some cases of mania, it has been given in much larger doses, sixty or more drops have been given for a dose. The fresh plant is sometimes prescribed in infusion, but where a liquid mediciue is preferred, one drachm of the dried leaves, iufused for four hours in half a pint of boiling water, adding to the strained liquor, an ounce of spt. cinnam., or spt. junip. comp. will be found preferable to an infusion of the fresh leaves; of this infusion, one ounce may be taken, two or three times in a day.

Off. The leaves and seeds.

Off. Pp. Tinct. Digitalis, L. E. D. Decoct. Digitalis, D. Infusum Digitalis, L. E.

\section{LACTUCA VIROSA,}

\section{Strong Scented Lettuce.**}

\section{Class Syngenesia.-O Order EQualis.}

Nat. Ord. Composite Semiflosculose, Linn.

Cichoraces, Juss.

Gen.Char. Receptacle naked. Calyx imbricated, cylindrical, its scales membraneous at their margin. Pappus simple, stipitate. Seeds polished.

Spec. Char. Leaves horizontal, toothed, the keel prickly.

THE generic name given this tribe of plants is supposed to be derived from the juice bearing a great resemblance to milk; the specific name, Virosa, from its possessing deleterious properties.

The Lactuca Virosat is a bienuial plant, growing wild in many parts of Britain; flowering in July and August, delighting in gravelly rubbishy soils: usually found growing on the sides of roads, fields,

* Fig. $a$. represents the superior part of a plant with the flower of the natural size. b. A floret (inagnified.) c. A seed, with its pappus.

+ Fourteen species of the Genus Lactuca are known and cultivated in our botanic gardens. Hort. Cant. 
and about old walls. The stem of this plant is straight, covered with scattered prickles, and seldom exceeds two feet in height; towards the superior part it is furnished with a few branches, which are alternate and slender; the inferior leaves are oblong, anplexical, auriculated at the base, sometimes lobed, unequally dentated and thorny on their upper side; the superior are arrow-shaped and entire, the midrib armed with short spines on the under side; the bracteas are cordate and pointed; the calyx is oblong, pointed, and nearly cylindrical, imbricated, and formed of straight, elongated, pointed, unequal scales, inembraneous on the edges; the flowers are compound, disposed in small clusters; the florets are monopetalous, hermaphrodite, ligulated, and dentated; the filaments are five, anthers united into a cylindrical tube; the germen ovate, style slender, the length of the stamen; stigmata, two and reflected; seeds oblong, compressed, striated, of a dark brown, and crowned by a soft, fleeting pappus.

Every part of this plant contains a viscid, bitter, milky juice, of a very disagreeable smell. In this juice its sensible qualities seem to reside. Dioscorides describes the odour and taste of the juice as nearly agreeing with that of the white poppý, and its effect, according to Haller, are powerfully narcotic; from recent analysis, it is found to contain an alkali analogous to morphia, and on which no doubt its active properties depend.

Action of the Strong Scented Lettuce on the AniMaL EConomy. The strong scented lettuce has been ranked among the narcotic poisons; but from the experiments of Orfila and others, the fresh plant does not seem to be possessed of active properties.* The extract prepared by evaporating the expressed juice, possesses more energetic properties; and in doses of from one to two drachms, invariably proved fatal to $\operatorname{dogs}$, when introduced into the stomach, injected into the jugular vein, or even applied to the cellular texture. $\dagger$

The general symptoms produced were, efforts to vomit, vertigo, slight convulsive movement, great drowsiness, followed by death.

Dissection threw no particular light on the cause of death. The alimentary canal scarcely shewed any appearance of inflammation, and the sanguiferous system presented the usual appearance as in

* A strong dog was made to swallow one pound and a lialf of the fresli leaves of the strong scented lettuce, without experiencing the least inconvenience.

Orfila, vol. ii. p. 159.

+ Vide Orfila on Poisons, vol, ii, p. 160. 
cases of poisoning by narcotics. We have heard, however, that the extract has been given to the extent of half an ounce in the day, without producing any unpleasant symptoms, but we have reason to believe that in those cases it could not have beev good, otherwise we must suppose that the strong scented leftuce was more poisonous to dogs than to man.

Treatment in Case of poisoning. Should deleterious symptoms follow an over dose of this narcotic, either of the recent plant or any of its preparations, no time should be lost in effectually evacuating the stomach, by small and repeated doses of the sulphate of zinc, or copper, followed by cathartics and stimulating clysters; should stupor or much drowsiness attend, the head should be relieved by venesection and cold affusions, blisters and stimulants to the feet; when the poison has been effectually evacuated from the stomach, but not till then, dilnted vegetable acids, may be drank freely, and alternately; with hot tea or coffee.

Medical Properties and Uses. Dr. Collin, of Vienna, was the first who brought the Lactuca Virosa* into repute, he states that in addition to its narcotic properties, it is a powerful diuretic, that it likewise promotes all the secretions, and that by attenuating viscid humours, it removes visceral obstructions; that in recent cases of dropsy proceeding from debility, the extract in doses of from eighteen to thirty grains a day proved sufficient to accomplish a cure, but that in inveterate cases, accompanied with obstructions of the viscera, the quantity of extract was increased to three dracbms; Dr. Collin also states, that he successfully treated nineteen cases of dropsy out of twenty, with the extract of this plant. We are told by Quarint that he never experienced any good effects from its use. The usual mode of exhibiting the Lactuca Virosa, is in the form of extract, prepared by evaporating the expressed juice of the plant to a proper consistence.

The Lactuca Sativa, the Cultivated or Garden LETTUCE. This species of Lettuce as the name inplies, is the cultivated species, so much and so generally esteemed as a salad. Under the name of Sativa, are comprehended the different species and varieties of cos, and cabbage lettuce. As the properties of all these varieties are the same, they may be used indiscriminately for medicinal purposes.

* Observ. Circa Morb. p. 6.

+ Animadv. Pract. p. 188. 
Properties. The garden lettuce, whell young, and at the time it is usually cut for salad, possesses an abundance of a bland, cooling, pellucid fluid; but as the flower stem shoots up, this fluid becomes an opaque, milky juice, of an exceedingly bitter taste, which, by evaporating in the air, and becoming dry, turns brown. According to the analysis of Mr. John, of Berlin, this juice has been found " to " consist of water, caoutchouc as its principle solid constituent, a " trace of resin, a small quantity of bitter extractive, and phosphates, " muriates and sulphates."

From this analysis we are led to infer that it is a very inert substance, as caoutchouc, which he gives as its principal solid constituent, has little or no medicinal properties; we know however that this plant possesses very active properties, which are found to reside in an alkali, analogous to morphia, and which seems to have been overlooked by Mr. John. Indeed the soporific powers of lettuce were known to the ancients; but we are indebted to Dr. Coxe, of Philadelphia, for having first submitted it to the test of experiment, since when, through the perseverance and recommendation of Dr. Duncan, senior, the preparations of lettuce have found a place in two of the British Pharmacopoias.

Mr. Young, surgeon of Ediuburgh, who has taken great pains to bring the various preparations of lettuce to perfection, gives the following, as his process.

Having made an incision in the flowering stem, he collects the juice, as it exudes, on a sponge, from which it is again expressed, and speedily dried by exposure to the atnosphere; to this he gives the name of lettuce opium: it occurs in commerce in round hard masses of a deep-brown colour, with a strong virose smell, and bearing a great resembiance to Turkey opium, but none to an extract: in this way it is now prepared on a very large scale.

It is evident, that by this process of Mr. Young, the virtues of the plant, as an opiate, are obtained in the most natural state; but the great expense of the preparation, has given rise to various attempts to lessen it.

Dr. Probart, we are told, collccts the milky juice, as it exudes from the cut stem, upon pieces of wove cotton, about half a yard square, and from time to time, throws them as they become charged, into a vessel containing a small quantity of water, which when sufficiently impregnated is evaporated by simple exposure in shallow vessels. By this process a very pure extract, free from the caoutchouc, is furnished; but it is still expensive. Dr. Probart further observed, that after the plants have flowered, and the leaves are beginning to assume a yellow hue, the milky juice assumes a concrete 



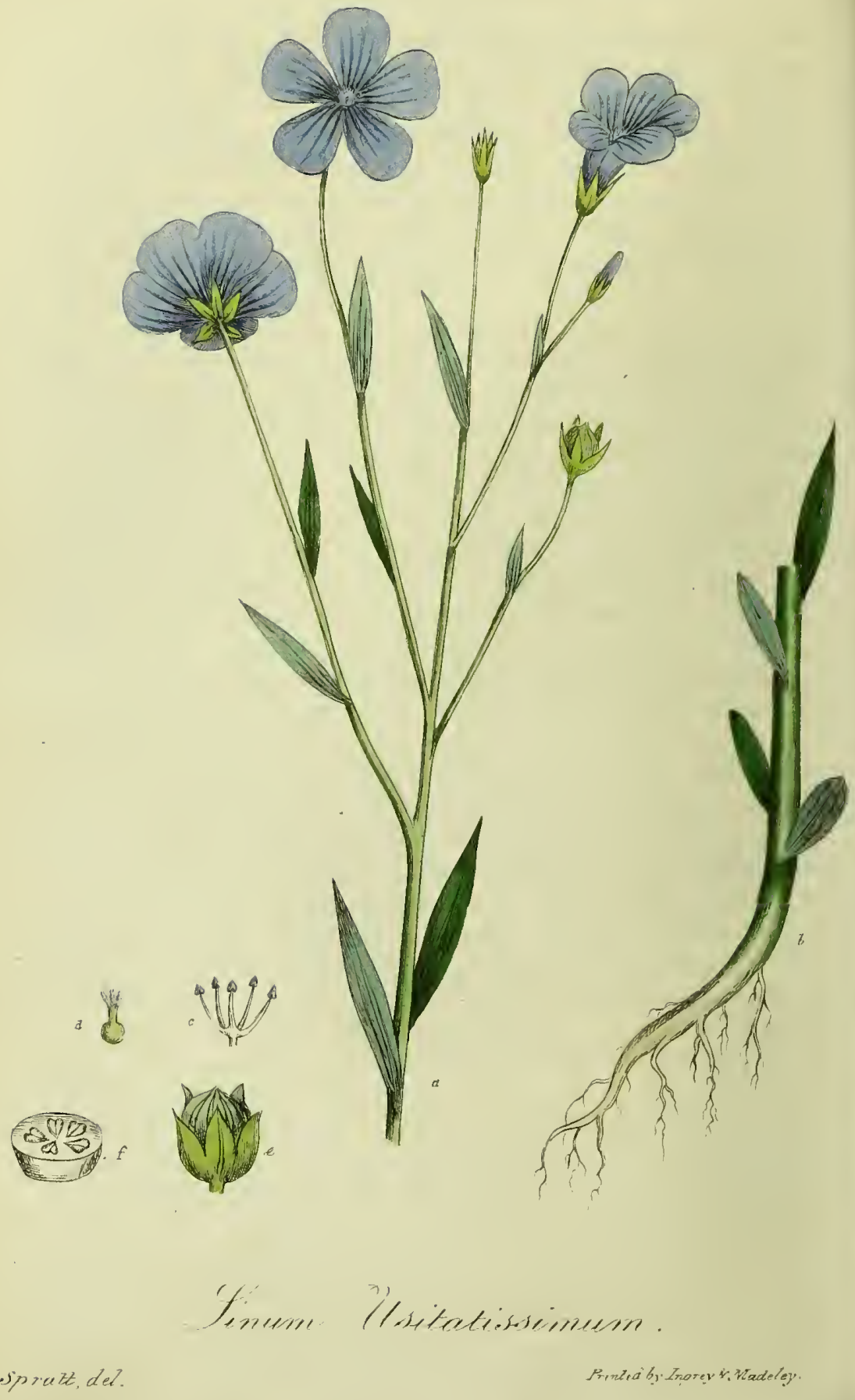

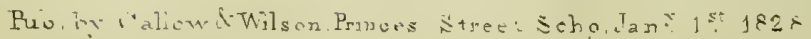


form, and is contained in the bark of the stalk, and in the old leaves. He therefore uses these only, which he macerates in water for twenty-four hours, then boils it for two hours, strains off the decoction, without pressure, and evaporates, first by lieat, and then in shallow dishes; to this he gives the name of Extractum Lactuca Concentratum. He says it is about half the strength of the Lactucarium and obtained at one-sixth of the expense.

In the use of these preparations of lettuce, the practitioner should be aware, that the term, Lactucarium, has been applied to the extract, obtained by different methods, and varying, we sliould imagine, very considerably in its active properties; many give it to what Mr. Young calls Lettuce Opium; Dr. Duncan, senior, uses it for the extract prepared fron the tincture; Dr. Young for the extract obtained by alcohol and water, and Dr. Probart for a watery extract. We have no doubt, however, that when the virtues of this plant become better understood, and more generally known, some formula will be adopted for the preparing its extract or inspissating its juice, so as to present us with a medicine of uniform strength; and when this is the case, we expect to fund it hold a high place among our native medicinal plants. We have seen the Lactucarium prescribed in a number of cases where opium was indicated, and with the happiest effect; acting as a narcotic and anodyne, without the stimulating effects of opium. Indeed, the analysis of the plant leads us to expect such a result, possessing, is it does, the morphine of the opium, without its narcotine. See Papaver Alba.

Off. The Herb.

Off. Pp. Succus spissatus Lactucæ Virosæ. E.

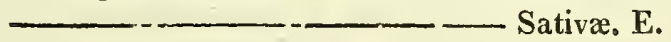

\section{LINUM USITATISSIMUM,}

Common Flax.*

Class Pentandrî.-Order Pentagynia.

Nat. Ord. Gruinales, Linn. Linacee, Juss.

Gen. Char. Calyx 5-leaved. Petals 5. Capsule 5-valved. 10-celled. Seed solitary.

* Fig. a. represents the top of a plant, (shewing the manner of its branching), with the blossoms. b. The lower part of the stem and root. $c$. The calyx and capsule.

VOL. I. 
Spec. Char. Calyxes and Capsules pointed. Petals notched. Leaves lanced, alternate. Stern solitary.

THIS species of Linum is an annual, flowering in June and July, and much cultivated in most parts of Europe, but more particularly in the West. According to the general mode of cultivation, this plant seldom rises above twelve or eighteen inches; but when allowed more roum, and on a rich soil, it will often exceed two or three feet in height.* The roet is annual; the stem erect, round, smooth, and branched towards the top; the branches are simple, alternate, and terminated by the flowers, which are solitary, and of a sky blue; the leaves are lance-shaped, acute, sessile, smooth, glaucous, vertical, and alternately scattered over the stalk and branches; the calyx is divided into five semi-lance-shaped segments, slightly fringed with small hairs; the corolla is composed of five petals, which are obovate, striated, and slightly notched; the filaments are five, tapering, upright, about the length of the calyx, and crowned with simple antheræ; the germen is oval; the five styles are filiform, erect, and of the lengtli of the filaments, and furnished with blunt stigmata ; the capsule is globular, and pointed, divided into tive valves and ten cells; the seeds are solitary, glossy, and of a flattish oval shape.

The Linum Usitatissimum, as the name implies, is the most useful of the Linum tribe, + and the one generally cultivated for the preparation of flax. $\$$

Botanists are not agreed as to whether this species is a native of Britain. Curtis, in his Flora Londinensis, says, "The few species " which we find occasionally among rubbish, and in corn fields, par" ticularly in the neighbourhood of Battersea, have doubtless been " introduced there with the produce of the garden or corn fields." Mr. Hudson, however, speaks of it as a common plant in Dorset and Devon, and entertaius no doubt of its being indigenous. This species of the Linum is generally supposed to have been introduced

d. A section of the pericarp, shewing the cells and seed. e. The stamina. f. The pistillum.

* It is remarked by Haselquist, that in Egypt this plant rises, with a strong stem, to the height of four feet. Resa til hel, Landet. p. 462.

+ Twenty-six species are enumerated in the Hortus Cantabrigiensis.

$\S$ The Linum Perenne, and Linum Bienne, are likewise cultivated for manufacturing of linen. 
into Europe from Egypt; where, in those parts subject to inundations of the Nile, it grows luxuriantly; and we learn from ancient record, that flax was cultivated in Egypt in the time of Moses.* The cultivation of flax in this country, was formerly a very important branch of lusbandry, and, indeed, of lorticulture; for in the earlier stages of society, most families raised it for their own use; this was, doubtless, the means of propagating the seed ; and hence, in the present age, arises the supposition of its being an indigenous plant.

Properties, \&c. The Linum Usitatissimum is chiefly cultivated for the valuable properties of its ligneus principle, or fibre of the stems, which, after due maceration and preparation, form the flax for manufacturing of linen. The seeds, by expression, yield a large proportion of oil, nearly one-sixth, which, when carefully expressed without the application of heat, has no remarkable taste or flavour, and retains its fluidity at the lowest temperature, but it very soon becomes rancid by keeping; the cake remaining after the oil is expressed, contains the farinaceous matter and mucilage, and is denominated oil cake; it is used for the purpose of fattening cattle. The expressed oil is chiefly used as a vehicle by limners, for combining with their pigments, for the general purposes of painting. The husks of the seed contain nearly one-fifth the weight of the whole seeds of mucilage, which may be separated either by boiling or infusion.

Medical Properties and Uses. Liuseed, as a remedial agent, is chiefly valuable for its demulcent and emollient properties. An infusion of the seeds is in general use as a pectoral drink in inflammatory diseases; and particularly useful in gonorrhœa, and nephritic complaints; it is also recommended during the exhibition of corrosive sublimate. The ground seeds, (or what is usually sold for them, the ground cake) is in general use for cataplasms; as, likewise, the whole seeds, which are certainly preferable to the former for the purpose of making poultices. Linseed oil was formerly much used, in combination with lime water, as an application to extensive burns; we have seen much benefit from its use in nuany cases.

Off. The Seed.

Off. Pp. Inf. Lini. Usitatissimi, Ed.

Inf. Liui, comp. Lond.

Ol. Lini. L. E. D.

* Exodus, chap ix. v. 31. 


\section{OXALIS ACETOSELLA.}

\section{Common Wood Sorrel.*}

\section{Class Decandria.-Order Pen'tagynia.}

Nat. Ord. Gruinales, Linn. Gerania, Juss.

Gen. Char. Calyx 5-leaved. Petals connected by the claws.

Capsule 5-cornered, gaping in the angles.

Spec. Char. Scape 1-flowered. Leaves ternate, inversely heart-shaped. Root granulated.

OF the numerous tribe of plants comprised under the genus Oxalis, + two species only are natives of Britain, the Oxalis Acetosella and Corniculata, most of the Oxalis tribe of plants being indigenous to South Afriea. The Oxalis Acetosella is a perennial plant, flowering in April and May; it is very common in the North of England, and is usually found iu woods, moist shady lanes, and hedge-rows; there is a variety of this species of sorrel with white flowers, equally common in many of the southern and western parts of the country.

The root of the Oxalis Acetosella grows horizontal, is granulated, and of a bright red; the leaves are ternate, inversely heart-shaped, of a yellow green, the under side pink, inclining to purple, slightly hirsute, and stand upon long petioles, proceeding from little bulbs, which form a kind of sheath at the botton, the leaf stalks are round, and of a recl colour; the calyx is divided into five obtuse segments, membraneous on their edges, and often spotted witl purple; the flowers grow upon long peduncles; the corolla is composed of five petals, which are connected together by their claws, and affixed by, them to the receptacle; the petals are very slightly crenated, and are either of a white or flesh colıur, streaked with red; the stamens are ten, five of which are shorter than the others; the anthers are yellow and bilocular; the germen is quadrangular; the five styles are slender, and somewhat longer than the stumens, crowned with blunt sligmata; the capsile is pentagonal, inclining to an oval forn, and divided into five cavities, each containing two seeds, inclosed

* Fig. $a$. represents a planî of the satural size. $b$. The pistillun. $c$. The stamina. d. Pericarp. e. The calyx.

+ Sixty-seren are enumerated as being cultivated in our botanic gardens. Hort. Cant. 


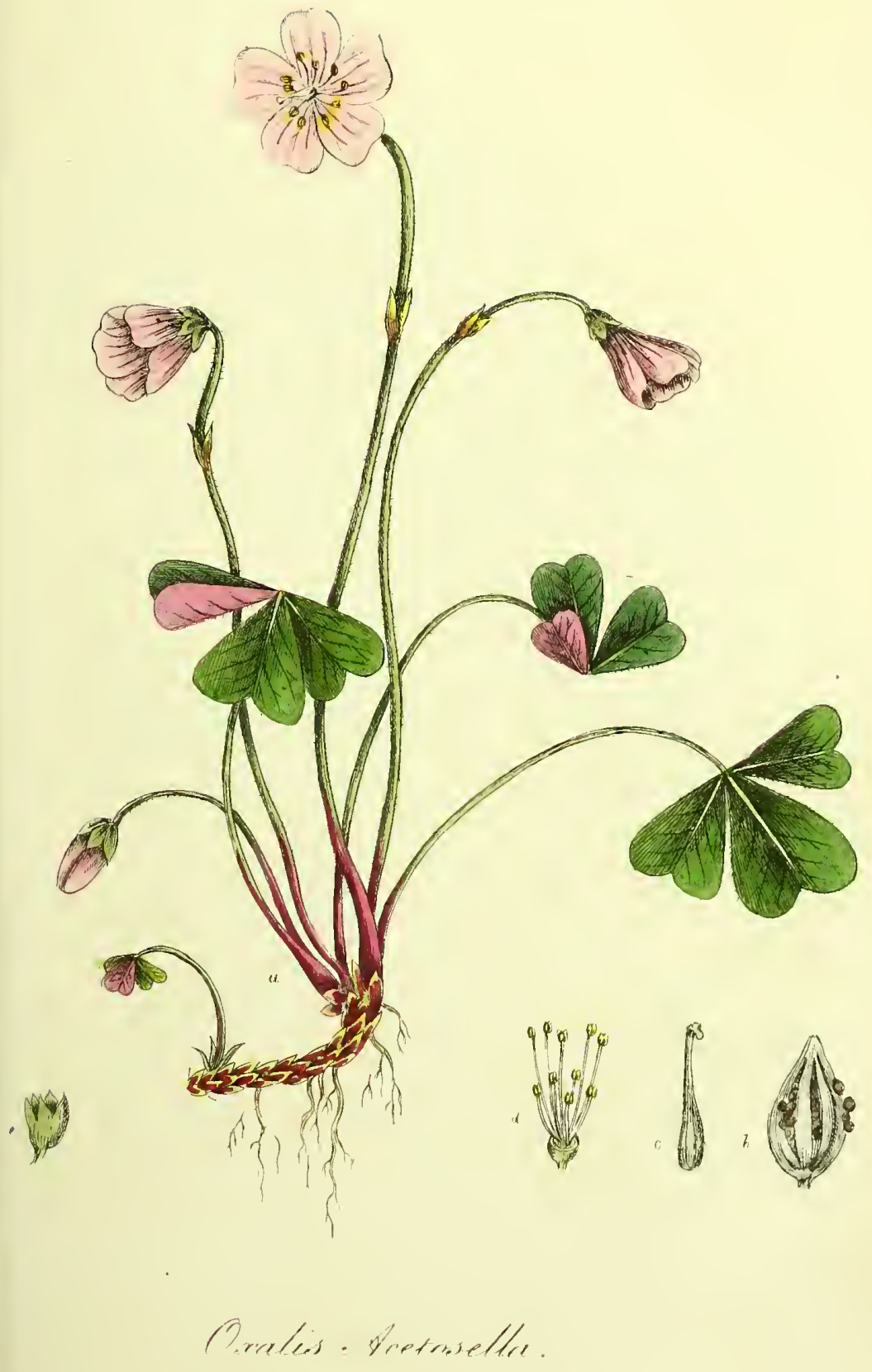

19. iprats del 




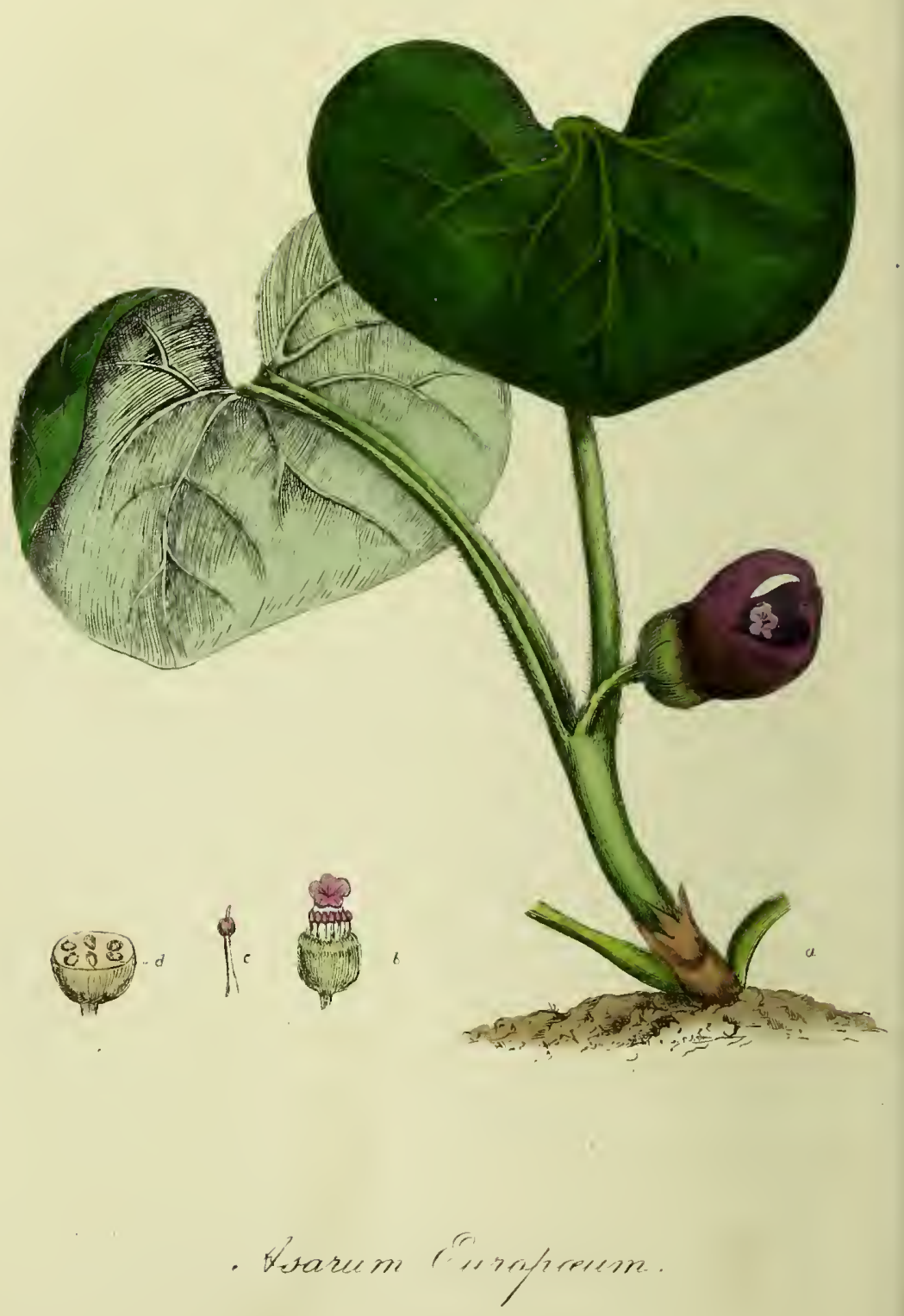


within a shining white elastic arillus, by the bursting of which the seeds are thrown out.

The leaves and stalks of sorrel have an extremely grateful acid taste, but are totally inodorous; the plant loses much of its acidity by drying; the expressed juice when left to settle, and the clear liquor poured off from the feculent matier, evaporated to a certain degree, yields crystals of binoxalate of potasse; twenty pounds of the recent plant is said to yield from two to four ounces of this salt, and the residuary liquor still contains a considerable portion of uncrystallizable acid. The binoxalate of lime has been long sold under the name of essential salt of lemons, $\uparrow$ used for the purposes of bleaching straw, removing iron moulds from linen, \&c.; it also forms a delicate test for detecting the presence of lime in mineral waters.

Medical Properties and Uses. The fresli plant is esteemed antiscorbutic, refrigerant, and diuretic, hence recommended in fevers and inflammatory diseases, to quench thirst asd allay inordinate heat; and for these purposes it is exhibited in infusion, or the leaves bruised and formed into a conserve, and taken ad libitum; the leaves boiled in milk, form a very agreeable acid whey; the salt may also be advantageonsly given wherever vegetable acids are indicated.

Off. The Leaves.

\section{ASARUM EUROP EUM.}

\section{Asarabacca +}

\section{Class Dodecandria.-Order Monogynia.}

Nat. Ord. Sarmentacez, Linn. ARistolochize, Juss. Gen. Char. Calyx 3 or 4-cleft, sitting on the germ. Coroila 0 . Capsule leathery, crowned. Spec. Char. Leaves kidney-shaped, obtuse, two-fold.

* The Oxalis Cornua of the Cape of Good Hope, is said to yield this salt in a much larger quantity.

+ The essential salt of lemon (so called), is not the pare salt of soriel, but a mixture of tivo parts of cream of tartar to one or more of the former.

\$Fig. $a$. plant of the natural size. $b$. The pistillum and stamens. $r$. A single stamen, shewing the attachment of the anther to the side of the filament, d. A section of the pericarp and seeds. 
THIs species of Asarum is indigenous to Britain, but it is an extremely scarce native, and seldom to be found in its wild state. We met with this plant once in the seighbourhood of Matlock, Derbyshire,* and we have been informed it is not uncommon in some parts of Cheshire. We are told by Pliny, that the name of this plant was often confounded by the ancients with that of Baccharis and Nardus, although both the latter plants differ considerably in their appearance from the former; the English name asarabacca is probably derived from Asarum and Baccharis.

The root of the asarabacca is perennial, strong, and fibrous, the leaves rise in pairs immediately from the root, and stand upon long petioles; in form they are kidney-shaped, and of a deep shining green; the flowers are bell-shaped, and arise singly from the base of the leaves upon short peduncles; the calyx is divided at the mouth into three or four pointed segments, which are of a dingy purple, but towards the base inclining to green; there is no corolla; the stamens are twelve; the filaments are about half the length of the calyx, and furnished with oblong antheræ, which are attached to the sides of the filaments; from the germen arises a simple style, supporting a reflected stigma, divided into six radiated parts, the germen becomes a capsule of a leathery texture, divided into six cells, which contain se veral small oblong seeds.

Sensible Properties. The roots of asarabacca are exterually of a greyish brown, internally white; the taste, both of the leaves and roots, is acrid and bitter, and when chewed, they slightly heat the mouth; both leaves and roots have rather a disagreeable, though not a very powerful smell. "An infusion of the leaves is deep red, " tastes rather sharp, and is turned very dark brown by green "vitriol, a greyish sediment falling down." $†$

Medical Properties A v Uses. The root of the asarabacca, in doses of half a drachm or more, almost universally evacuates the stomach both upwards and downwards; from its exciting vomiting so constantly, it has been proposed by Linnæus and others, as a substitute for ipecacuan; it has beell observed, that in very fine powder it invariably acts as an emetic, but that when exhibited in coarse powder, it passes the stomach, and proves cathartic.

Dr. Cullen says, " the root dried, only so much as to allow it to be powdered, will generally answer as a gentle emetic, in doses of

\footnotetext{
* Ray observes, that it is found in some woods in Lancashire.

+ Gray's Elements of Pharmacy.
} 


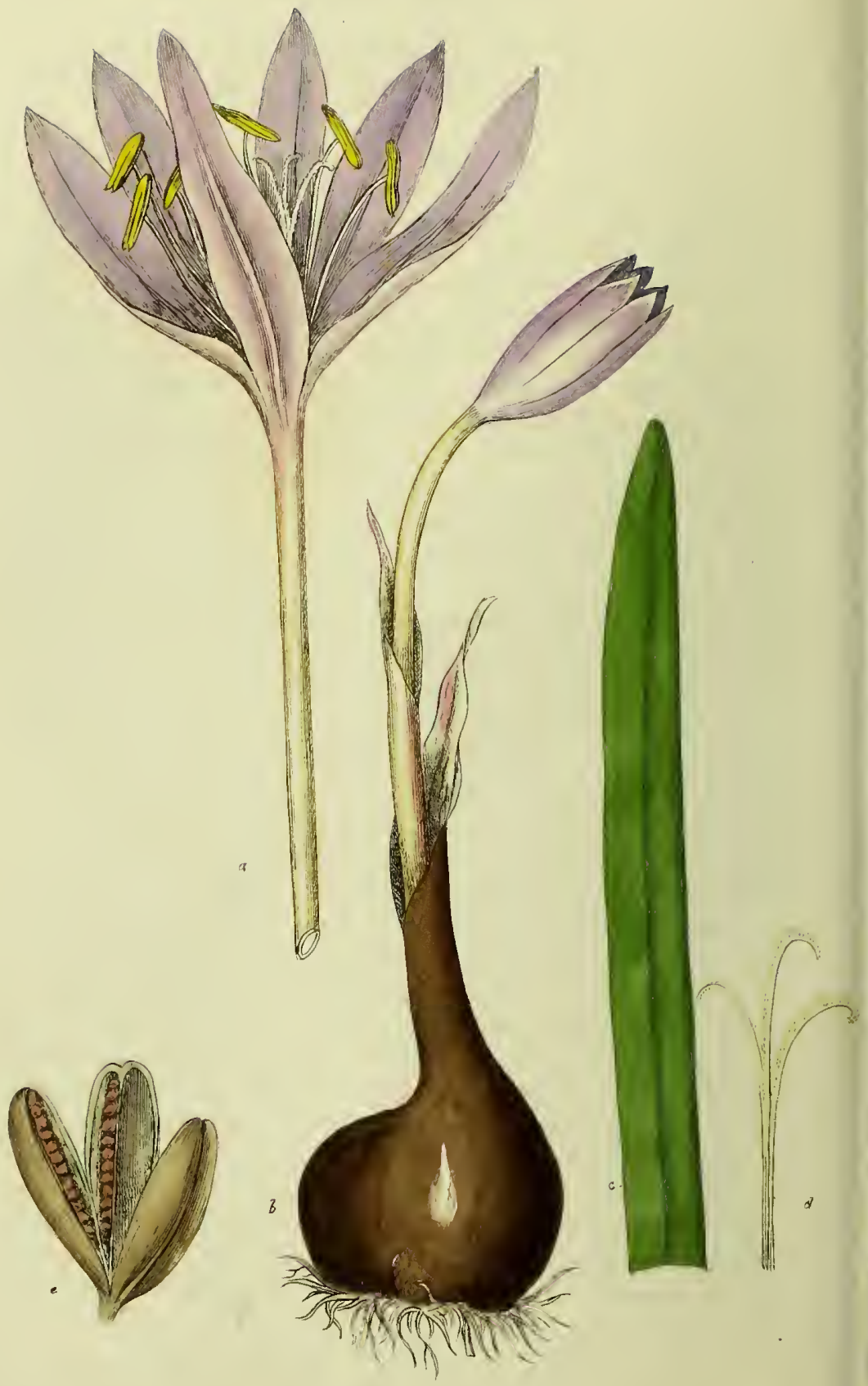

Wispratt del

folchicurn e sutumnate:

Printen bu frardy

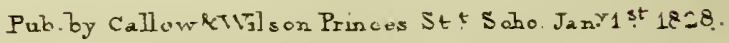


a scruple, and sometimes in less quantities;" in small doses it is said to promote perspiration, urine, and uterine flux.*

By long boiling, the asarabacca loses much of its active properties; the decoction or watery extract having no cathartic or emetic qualities, but retaining the diaphoretic, emmenagogue, and diuretic properties. "It is said, that alcoliolic tinctures possess both the " emetic and cathartic properties of the plant; that the extract " obtained by inspissating these tinctures, actś only by voniting, " and with great mildness." $\dagger$

In modern practice, the Asarum is seldom given internally, as the evacuations expected from its use may be procured with more safety and certainty, by ipecacuan and other medicines.

The asarabacca is now chiefly used as an errhine, and the powdered root or leaves, in the quantity of one or two grains of the former, or of four or five of the latter, generally excite considerable sneezing, accompanied witl a copious discharge of mucus. Hence in those disorders which are likely to be relieved by such a discharge, the asarabacca will be found a powerful medicine; it is said 10 form the chief ingredient in most of the celebrated herb-sluffs.

Off. The Leaves.

Off. Pp. Pulvis Asari Comp. Ed. D.

\section{COLCHICUM AUTUMNALE.}

\section{Meadow Saffron.}

\section{Class Hexandria.-Order Trigynia.}

Nat. Ord. SPathaceE, Linn. Junci, Juss. Gen. Char. Corolla, 6-parted, with a radiated tube. Capsule 3 -lobed.

Spec. Char. Leaves lanced, erect.

The Colchicum autumale is a perenuial plant, indigenous to Britain, and the temperate countries of Europe. In this country

* Vide Ray, Hist. p. 208.

t Dancan's Edinbargh New Dispensatory.

\# Fig. a. (in the annexed drawing) represents a full-blown flower, shewing the stamina and pistilla. $b$. The root. $c$, A leaf, one third of the lower part cut off. $d$. The pistilla. e. The capsule split open. 
it is found growing in moist meadows, and is most abundant in the north and western counties; in sone parts of Warwickshire it is very plentiful, and the provincial name is naked ladies, from the blossoms coming up without leaves. This and several other species of Colchicum, ${ }^{*}$ are cultivated in our gardens for the sake of their beautiful blossoms; by cultivation, and sowing the seed, several varieties are produced, some having double blossoms, and others varying in colour.

The root of this species of Colchicum consists of a solid double succulent bulb, covered with a brown membraneous coat; the flowers which appear in autumn, are large, and of a pale purple or lilac colour, and rise immediately from the root upon a long naked tube; the leaves come out in spring, are numerous, radial, spearshaped, and of unequal breadth; there is no calyx; the corolla is monopetalous, and divided into six lance-shaped erect segments; the stamina are six, filaments tapering, white, and much shorter than the corolla, and furnished with erect pointed yellow antheræ; the germen is lodged at the root, from which issues three slender styles, reflected at the top, and terninated hy simple pointed stigmata; the capsule is lobed, divided into three cells, containing numerous small globular seeds, which ripen the following spring, when the capsule rises above the ground, between the leaves, upon a strong peduncle.

The active properties of Colchicum reside chiefly in the roots; in autumn the old bulbs begin to decay, and new ones to be formed, which are perfected the following spring; about the month of May the young bulbs are in the highest state of perfection, when they should be dug up for medicinal purposes.

Sensible and Chemical Properties, \&c. The sensible qualities of the roots of meadow saffron seem to depend very much upon their age, the season in which they are lug up, and the soil in which they grow; and to these circumstances we would ascribe the contradictory accounts given of their qualities; some asserting the roots to be mild, and void of taste, $\uparrow$ whilst others bear testimony to their great acrimony.† Baron Störck asserts, that on cutting the fresh root into slices, the acrid particles emitted from it irritated the nostrils, fauces, and breast, and that the ends of the fingers with which it had been held, became, for a time, benumbed. "The

* Five species, (four of which are exotic.) Vide Hort, Cant.

+ Haller, Krapf, Kratochvill, âc.

† Ehrmann, Diss. de Colch. Basil, 1772, 5. Murray, App. Med. Vol. v. p. 196. 
" roots, when dried and powdered, are of a light fawn colour, and " bitter taste; the infusion is bitter and pungent ; infused in distilled "vinegar, the liquid becomes bitter, and warm. Starch is also "obtainable from these bulbs." It appears, that the active properties of Colchicum depend upon one of those peculiar principles recently discovered in many vegetables, and denominated alkaloids. We are indebted to MM. Pelletier and Caventon for the discovery of this peculiar substance in the roots of the meadow saffron, to which they gave the name of Veratrine, from having previously discovered a similar substance, possessing the same properties, in the seeds of the Veratrum Sabadilla, and the roots of the Veratrum Album. "The root of the Colchicum, according to MM. Pelletier and “ Caventon, yields on analysis : 1. a fatty matter, composed of oil, "adipocire, and a volatile acid; 2. yellow extractive colouring " matter; 3. acid gallate of veratrine; 4. gum ; 5. fecula, with "inuline and woody fibre. It yields very few ashes." *

Chemical Properties of Veratrine. $\dagger$ Veratrine is scarcely at all soluble in cold water; boiling water dissolves $\frac{1}{10 \overline{0}}$ of its weight, and becomes sensibly acid: it is very soluble in ether and in alcohol. It is insoluble in the alkalies, and soluble in all the vegetable acids. It saturates all the acids, and forms with them incrystallizable salts, which on evaporation take the appearance of gum. The sulphate alone affords rudiments of crystals when its acid is in excess. Nitric acid combines with Veratrine, but if added in excess, especially when concentrated, it does not produce superoxidation, but very rapidly resolves the vegetable substance into its elements, and gives birth to a yellow detonating matter, analogous to the bitter of Welther. Veratrine restores the blue of turnsol paper when reddened by acids. Exposed to the action of heat, it. liquefies at a temperature of $50^{\circ}$ (1220 Fah.) above zero, and has then the appearance of wax: on cooling, it forms an amberlooking mass of a translucent appearance. Distilled on the naked fire, it swells up, becomes decomposed, and produces water, much oil, \&c. A voluminous, carbonaceous mass remains, which, when incinerated, leaves only a very slightly alkaline residuum. Magendie's Formulary.

Action of Colchicum upon the Animal Economy. The meadow saffron when recent and exhibited in large doses, generally

* Magendie's Formulary.

+ For the preparation of Veratrine, we must refer our readers to M. Pelletier's own account.

VoL. $\mathrm{I}$. 
produces violent sickness, vomiting and purging; accompanied with burning pain and heat in the stomach and bowels, colic pains, tenesmus, urgent stranguary, hiccup, and death. It is stated, that two boys, after eating this plant, which they found growing in a meadow, died in great agony ; $*$ and violent symptoms have been produced by taking a few flowers.t The seeds have also the same deleterious effects. When Colchicum, or any of its preparations have been taken in an over dose, post mortem examinations have almost universally discovered some traces of inflammation of the mucous membrane of the bowels.

From the experiments of Magendie it appears that Veratrine, exhibited in small doses, produces the same effects upon men and animals, $\downarrow$ as the plant from which it is prepared.

Medical Properties and Uses. The chief virtues of Colchicum are its diuretic properties; and according to Störck, and many continental practitioners $\S$ it is superior to most other medicines as a diuretic.

From Baron Störck's account of his successful treatment of hydropic disorders in the hospital at Vienna, we should be led to consider it a medicine of superior efficacy ; but we believe that (in this country at least) it is not deserving of those high encomiums that have been lavished upon it. Of late various preparations of Colchicum have been much used in Gout $\|$ and Rheumatism; and we believe, with many practitioners, it lias succeeded in relieving pain, and reducing the inflammatory symptoms ; it is, however, an uncertain renedy, ocasionally operating with extreme violence, as an emetic, cathartic, or dinretic; although with these powerful operations, it generally combines some anodyne effects. Colchicum is usually exhibited in the form of oxymel, prepared by digesting the fresh roots (sliced) in vinegar, straining the liquor, and forming it into a syrup with sugar or honey; ${ }^{* *}$ it is also given in tincture, wine, and powder. $+\uparrow$

* Io. Agricola Ammonias, Medic. berbar. lib. i. p. 90.

+ Garidel, Plantes d'Aix, p. 123.

$\ddagger$ Veratrine, in doses of one or two grains, when injected into the veins, thrown into the pleura or tunica vaginalis of dogs, proves fatal in less than ten minutes, preceded by tetanic convulsions. Magendie.

$\$$ Zack, Plenck, Ebrmann, Krapt, and otbers.

II A saturated vinum Coichici has been reconmended by Sir E. Home as a substitute for the celebrated gout sperific, the Eau Medicinale d'Husson.

** Baron Störck recommends the oxymel in preference to any other preparation.

t+ Mr. Haden, who gives the powdered Colchicum in many inflammatory disorders, " recommends the roots to be cut in thin slices, spread out on perforated trays, and

" dried at a temperature of at least 1300." Obs. on Colchicum. p. 77. 


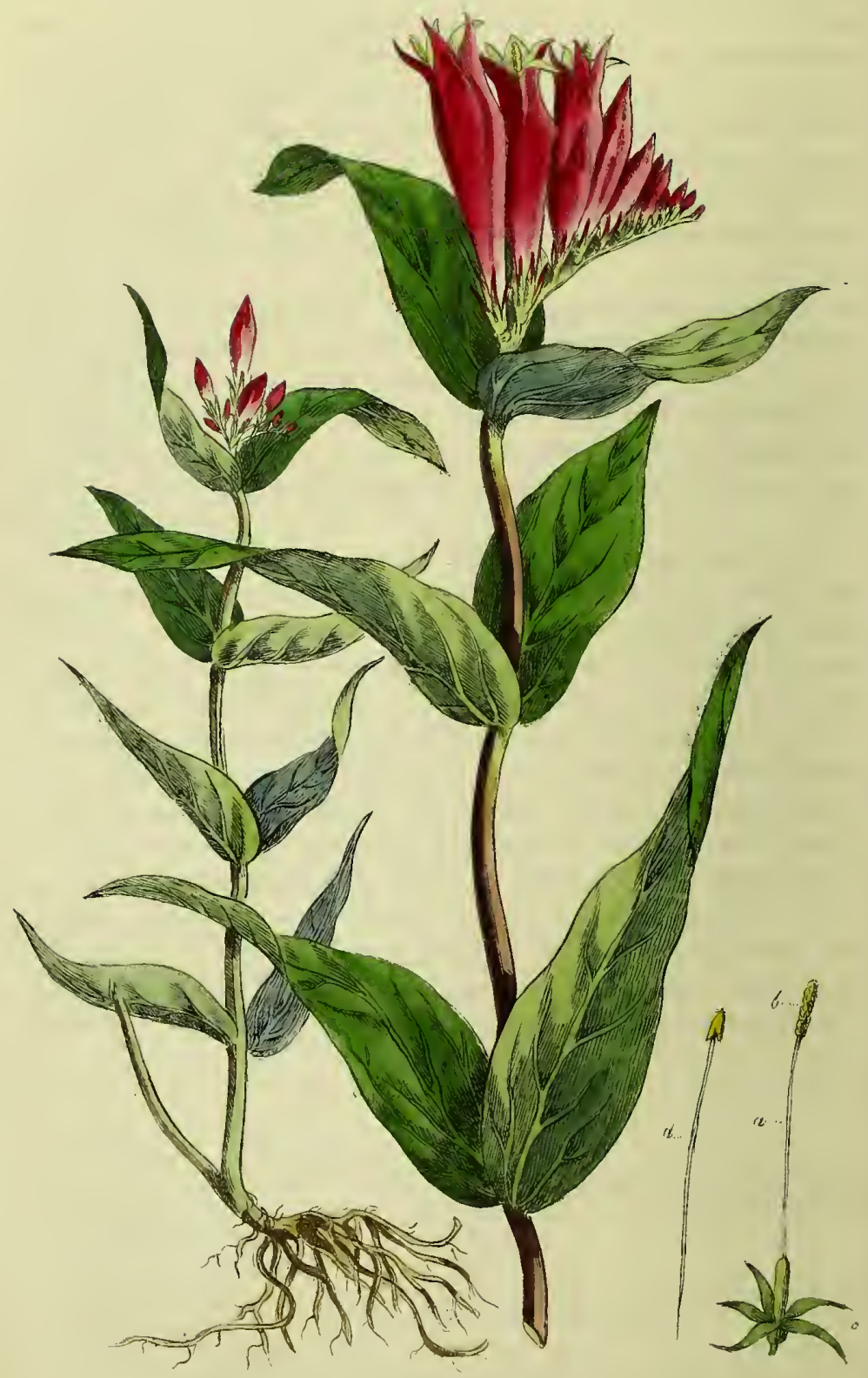

W. Spruathet en Iith

Shigetia Navilandica. 
These preparations of Colchicum (i.e. the oxymel, tincture, and wine) are given in doses of from one to two drachms, and repeated according to circumstances, every four, five, or six hours, until some sensible evacuation takes place, when the dose is diminished or laid aside; the powder is given in doses of from one to five grains.

Off. The Roots and Seed.

Off. Pp. Syr. Colchici Autum. E. Acet. Colchici. L. Oxymel Colchici. D.

\section{SPIGELIA MARILANDICA,}

\section{Carolina Pink.**}

Class Pen'indera.- Order Monugy ina.

Nat. Ord. Stellate, Linn. Gentian正, Juss.

Gen. Char. Corolla funnel-shaped. Capsule double, twocelled. Seeds numerous.

Sprc. Char. Stem four-cornered. Leaves opposite.

THIS species of Spigelia $\dagger$ is a perennial plant, indigenous to North America, flowering in July and August. The Spigelia Marilandica was first cultivated in England in the year 1794, and is now an ornament to most of our botanic gardens. The roots of this plant are unequal, spread horizontally, and send off many slender fibres; from the root proceed several stalks which grow erect, from twelve to eighteen inches high, smooth, obscurely quadrangular, and of a purplish brown colour; the leaves are sessile and oblong, and acute pointed, somewhat undulated, entire, and of a bright green, and stand in pairs upon the stem; the flowers are ranged on one side of the foot stalk, and terminate the stem in a spike; the calyx is fiveparted ; the corolla is monopetalous, funnel-shaped, of a bright crimson, conposed of a long tube, gradually swelling towards the middle,

* Fig. e. represents the top of a plant, the blossoms and leaves a little less than nature. $f$. A young plant half the size of the specimen from which it was drawn. $a$. The style. b. Stigma. c. Calyx. d. A stamen.

+ Two species of the genus Spigelia are known and cultivated in our botanic gardens, the S. Marilandica and S. Anthelmia, the latter of wbich is an annual.

Vide Hort, Cant. 
and divided at the border into five-pointed segments, which are yellow on the inside; the five filaments are about the length of the corolla; the antheræ, halbert-shaped and yellow; gernen, ovate, and placed above the insertion of the corolla; style round and longer than the filaments, stigma long and fringed; seed vessel, a double capsule, two-celled, coutaining many seeds.

The generic name Spigelia, was given to this tribe of plants by Linnæus, in honour of the celebrated botanist Spigelius, who published his first work in 1606. In Carolina, where this species of Spigelia grows naturally, the inhabitants call it indian pink, which is also the popular name given to it in this country.

Qualities and Properties. The roots of indian pink have but little smell and taste, and have beell compared to that of wood rotted by water, ${ }^{*}$ the watery infusion (of the roots and leaves) is of a deep red, rather thick and urucilaginous, with a narcotic smell, and affords a flocculent precipitate by the addition of alcohol, it is not altered by sulphate of iron.

Medical Properties and Uses. The chief virtues of Spigelia are its anthelmintic properties, which were first discovered by the American Indians above a century ago; since which time it has been very generally used in America, and the West India Islands. In this country it was first brought into notice by Drs. Garden and Lining, of Charlestown, Carolina, and it is now in general use as a powerful vermifuge, especially in lumbrici.

The dried root in powder, in drachm doses, will generally purge briskly, and sometimes excite vomiting; but in smaller doses, when taken two or more times in the day, and repeated for several days together, it will occasionally produce giddiness and dimness of sight, followed by convulsions: some allege that it seldom produces any good effects unless it excites purging or vomiting; it is, therefore, frequently combined with some suitable aperient; but we liave seen large quantities of worms expelled without either of those effects being produced. $t$ It is generally recommended to take an emetic previons to beginning a course of the Spigelia; but we have never found this practice necessary; in the remitting fever of clildren, depending upon viscidity of the primæ viæ, the Spigelia has been

* Gray's Elements of Pharmacy.

+ We bave been in the practice of prescribing an infusion of the whole plant (one ounce of the dried plant to one pint of water), in doses of from one to two ounces every morning, for three or four mornings, followed by a dose of inf. sen. or pulv. jalap. which has had invariably the effect of bringing away a considerable quantity of worms. Ed. 



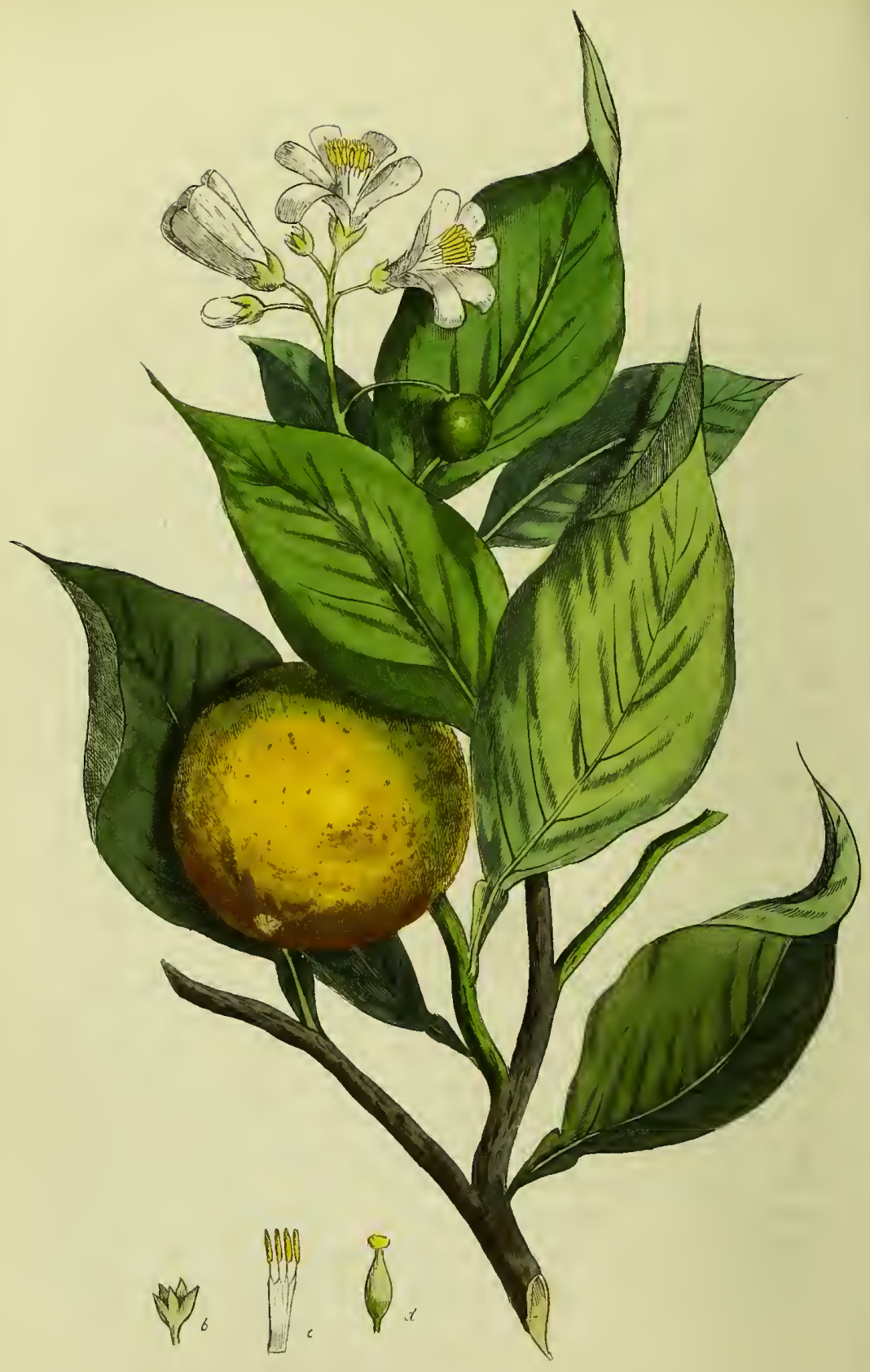

Yiters. Turantriene.

Tizoray \& Madoter Zithog 310.1 
given with much benefit, even when there has been no appearance of worms. The root is usually given in powder, from ten grains to sixty or more for a dose, once or twice in the day; but the infusion is more readily taken by children : should any unpleasant symptoms, as vertigo, dimness of sight, redness and pain in the eyes, or stupor, arise during a course of this medicine, recourse should be had to some warm purgative, which generally in a short time removes every untoward symptom.

Off. The Root.

\section{CITRUS AURANTIUM.}

\section{Seville Orange Tree.*}

\section{Class Polyadelphia.-Order Icosandria.}

Nat. Ord. Pomacee, Linn. Aurantie, Juss.

Gen. Cha R. Calyx 5-cleft. Pelals 5, oblong. Anthers 20, with filaments united in several bundles. Berries, 9-celled.

Spec. Char. Pelioles winged. Leaves pointed. Stem arboreous.

The Orange Tree is supposed to be a native of Asia, but has been long cultivated in all the southern parts of Europe, especially in Spain and Portugal, from which countries, oranges form a very considerable article of export. In England this beautiful evergreen has been 'cultivated since the year 1595. It is said, orange trees were first introduced into England either by Sir Francis Carew, or by Sir Walter Raleigh, in the reigu of Elizabetlı, but whether they brought home plants or seeds is not exactly known, it is probable both were introduced about the same period. Orange trees are now cultivated chiefly as an ornament for the green house, the fruit seldom arriving to any degree of perfection; although many varieties are propagated by the florists, the finest trees are annually imported into England from Italy and Holland. There are several varieties of the Citrus Aurantium produced by cultivation, the chief of which

* Fig. b. Calyx. c. Four stamens united. d. Tistillum. 
are the bitter, known by the name of Seville orange, and the China or sweet orange. Some botanists consider these as distinct species.*

This species of Citrus + rises several feet in height, sending off many branches, the trunk and older branches are covered with a bark of a greyish colour; the leaves are nearly elliptical, pointed, smooth, entire, of a shining green, and stand וpon strong winged footstalks, (which is the distinguishing character of this species of Citrus); the flowers appear early in summer and continue blowing for several montlis; the blossoms arise from the smaller branches upon simple and brancled peduncles; the calyx is divided into five small pointed segments; the corolla is composed of five white, oblong, concave, petals, beset with small glands : stamina about twenty, the filaments are united at their base into three or more distinct portions, the antheræ are yellow and placed vertically upon the top of the filaments; the germen is roundish and superior, the style is cylindrical and terminated by a globular stigma; the fruit a globular berry, divided into nine cells filled with a mucilaginous pulp, and each containiug from two to four seeds.

Sensible Qualities and Properties. The juice of oranges is an agreeable acid, composed of a considerable portion of citric acid, combined with sugar, nucilage and extractive matter; the outer rind of the Seville orange has an agreeable odour, and a bitter taste of the aromatic kind; $\ddagger$ both the taste and odour depend upon the presence of an essential oil which is contained in numerous small vesicles in the cortical part of the rind; the leaves partake of the bitter and aromatic qualities of the rind, but in a less degree; the flowers are highly odoriferous, and an extremely fragrant oil of a red colour is distilled from them, and also from the outer rind of the fruit, and sold under the name of oil or essence of Neroli; this oil or essence is imported into this country from Italy, and is sold at a great price; we are told tliat $2 \mathrm{cwt}$. of the flowers yield only $\mathbf{l ~ o z}$. of oil, $\S$ which is chiefly used as a perfume.\|

Medical Properties and Uses. The bitter, or Seville orange

\footnotetext{
* Vide Miller's Garỏ. Dict. \&c.

+ The genus citrus comprises seven species, including the citron, lime, shaddock,

$\ddagger$ The small unripe fruit dried (vurying in size from a pea to a cherry) are sold under the name of Curaçoa oranges, these are more bitter, but less aromatic than the rind of ripe oranges, and in tincture form a useful stomachic.

§ Gray's Supplement.

H From the high price of the Ol. Neroli, it is frequently counterfeited with oil of Behen, in which orange flowers have been digested.
} 
is the variety retained by the British colleges as officinal; the outer rind is a grateful bitter; but differs from most other bitter substances in containing a portion of aromatic volatile oil, and from the union of these qualities, it proves carminative, warms and strengthens the stomach, and promotes digestion, and lience is prescribed with advantage in weakness of the stomach and other viscera. Orange peel has also been celebrated as a remedy for internittents," but in modern practice it is seldom relied upon, a preference being given to more powerful and certain remedies. On the continent, the leaves and flowers have been held in great estimation as a remedy in convulsive diseases, particularly in epilepsy, $\dagger$ but experience (at least in this country) hás not confirmed their efficacy.

The juice of ripe oranges is a very agreeable acid liquor, and like other vegetable acids quenches the thirst, allays febrile heat, promotes various excretions, and diminishes the action of the sanguiferous system ; lence in inflammatory and febrile diseases the juice of oranges (more especially the China) may be taken ad libitum with much advantage; it has also been prescribed with great success in preventing and curing scurvy. $\ddagger$ We may observe that as the China orange combines more saccharine matter with the acid than the Seville, it is more agreeable to the palate; and as a remedial agent may be taken more freely, but like most other sub-acid fruits, if taken to excess, will produce great clisorder of the stomach and bowels.

Off. The fruit, juice and rind of the fruit, unripe fruit, and distilled water of the flowers.

Off. Pp. Tinct. Cort. Aurant. L.D.

Conf. Cort. Aurant. L.E.D.

Syr. Cort. Aurant. L.E.D.

Aq. Citri Aurant. E.

Infus. Aurant. comp. L.

* Dubeus Medecin des pauvres, p. 285, 399. See also Möhringius Com. Norie 1736, p. 20.

+ Locher, Obs. Pract. p. 47.

$\ddagger$ See Lind on Scurvy, p. 168. 


\section{ROSMARINUS OFFICINALIS.}

\section{Officinal Rosemary.*}

\section{Class Diandria.-Order Monogynia.}

Nat. Ord. Verticillate, Linn. Labiat互, Juss.

Gen. Char. Corolla unequal, upper lip 2-parted.

Filaments long, curved, simple, toothed.

Spec. Char. Leaves sessile.

OF the genus Rosmarinus, two species only are known and cultivated in this country, the Rosmarinus Officinalis, and Rosmarinus Chilensis. There are varieties of both these species of rosemary, one with white striped leaves, denominated silver leaved, this is a variety of the Officinalis, and another with yellow striped leaves called golden rosemary, this latter is a variety of the Rosmarinus Chilensis.t The Rosmarinus Officinalis is a perennial shrub, a native of the south of Europe, growing plentifully in Spain, Italy, and the southern parts of France, where upon the dry rocky soils near the sea $\ddagger$ it thrives luxuriantly.

Rosemary, although indigenous to a warm climate, will bear the ordinary winters of this country in the open air, provided it is planted in a sheltered situation, upon a dry, gravelly, and poor soil ; its cultivation in England is probably of very ancient date, but now cannot be traced beyond the time of Gerarde, or, according to the Hortus Cantabrigiensis, the year 1596. It appears the ancients were well acquainted with this plant, it being mentioned by Galen, Dioscorides and Pliny. The Rosmarinus Otticinalis is an evergreen shrubby plant, and grows to the height of three or four feet, with a strong woody stem, sending out many spreading branches; the leaves are sessile, linear, and reflected on the edges, from one to two-eighths of an inch broad, and from one inch to one inch and a half long, downy on the under side, and of a dark shining green above; the blossoms are of

* Fig. a. represents a sprig of a natural size. b. Calyx. c. The Pistillum. d. A Stamen.

+ Vide Miller's Gard. Dict.

† The generic name Rosmarinus appears to be derived from the Latin " ros dew, and marinns," in allusion to its being indigenous to the sea coast. 


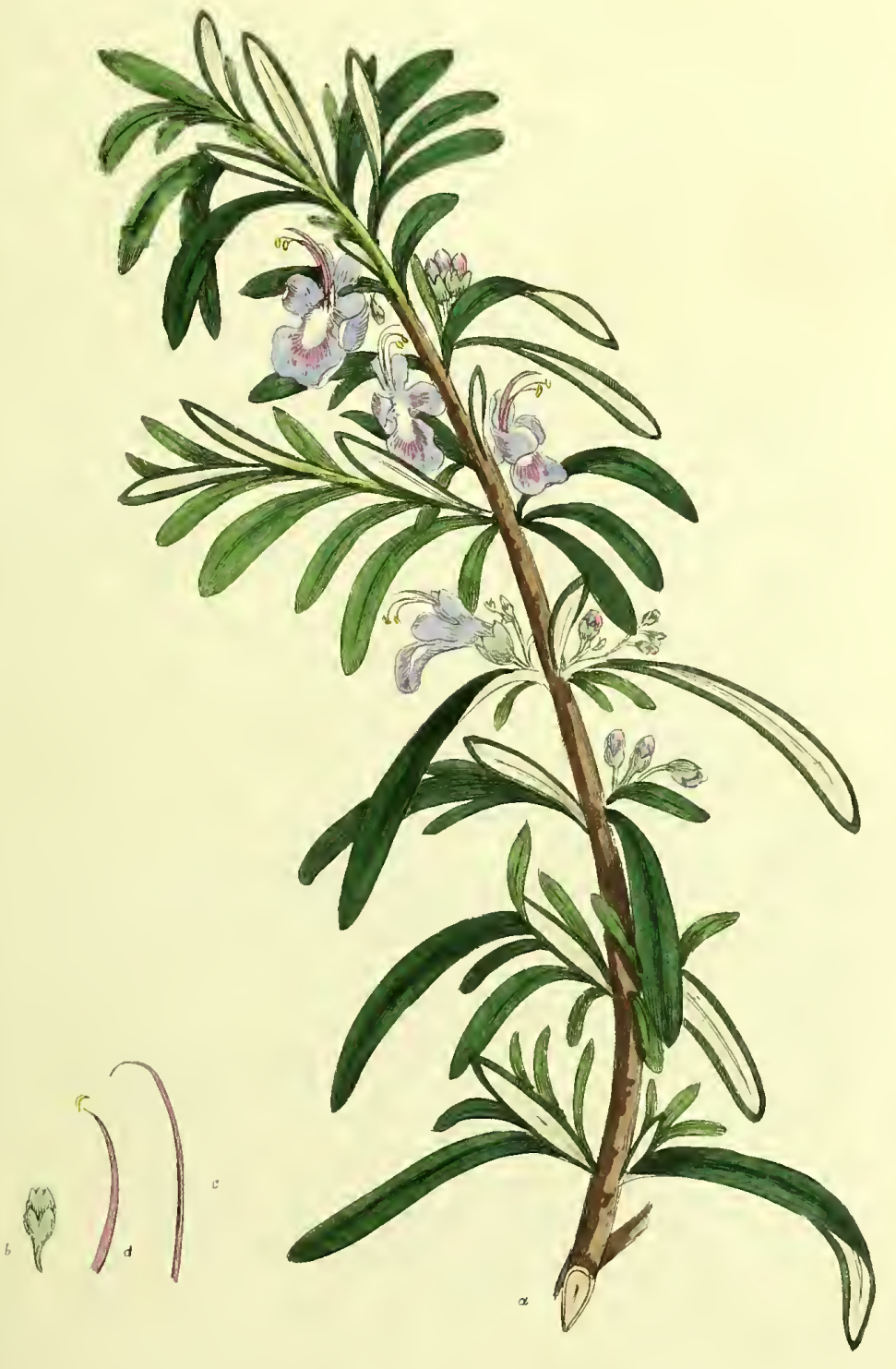

Coommarimes CFifinatios.

if sprate itel

Pub by Callon s wils on Princes St $t^{t}$ oho. Feb? 1 st $^{\text {st }} 1828$. 

a pale purple or lilac, and stand upon short peduncles; the caly $x$ is tubular, compressed at the top and divided into two lips, the upper lip entire, the under one bifid; the corolla is monopetalous, ringent, the lower part tubular, the upper lip erect and bifid, the lower one reflected and cut in three parts, the iniddle division larger and concave; there are two awl shaped stamina, iıclining to the upper lip; the germen is four pointed; the style, the same sliape and length as the stamina; stigma acute; the germen becomes four oval naked seeds, situated at the base of the calyx.

Sensible Qualities and Properies. Rosemary has an agreeable odour, and a warm pungent taste, uearly resembling lavender; the flavour of the flowers is less pungent than that of the leaves and young shoots. Rosemary gives out its virtues completely to rectified spirit, but only partially to water; the leaves and tops distilled with water, yield a thin, light, pale-coloured oil of great fragrancy; 50lbs. of the fresh herb, when in flower, yield nearly $40 z$. This essential oil contains a considerable proportion of camphor, which it deposits in chrystals on long standing. M. Proust has extracted a sixteenth part of camphor from a given quantity of the oil.*

Medical Properties and Uses. The medicinal properties of rosemary (like many other odoriferous plants) depend entirely upon the essential oil it contains. Rosemary acts as a gentle stimulant, sudorifict and cordial; it is useful in nervous headache, lowness of spirits and hysteria; and is supposed to possess emmenagogue propèrties; hencc an infusioh of the leaves and young shoots is drank as tea in chlorosis. Rosemary is not often prescribed but in conjunction with other medicines possessing more active properties; externally, the Spt. Rorism. is used as an einbrocation in rheumatic and other pains; it is also used as a cosmetic, and sold in the shops under the name of Hungary water.

Off. The Herb and Tops.

Off. Pp. Ol. Rorismarini Officinalis, E.I.D.

Spt. Rorismarini Off. E.L.D.

* Ann. de Chimie. tom. iv. p. 179.

+ Oil of Rosemary, in doses of from twenty to sixty drops taken on a lump of loaf sugar when going to bed, excites a copious perspiration for many lours. We have witnessed many cases of both acute and chronic rheumatism greatly relieved by the use of this medicine.

VOL.I. 


\section{ACORUS CALAMUS,}

Sweet Flag.*

\section{Class Hexandria.-Order Monogynia.}

\section{Nat. Ord. Piperite, Limn. Aroinee, Juss.}

Gen. Char. Spadix cylindrical, covered with florets. Córolla six petals, naked. Slyle uone. Capsule 3-celled. Spec. Char. Point of the Scane very lung and leafy.

The Acorus Calamus is a perennial native plant, indigenous also to the northern climates of Europe and India. In England, it is very common in many counties, and is usually found growing in rivers and stagnant waters, producing flowers in May and June. We are told it is very plentiful in the marshy land about Norwich. The root grows horizontal, crooked, fibrous, and pointed, about an inch in thickness, externally of a greenish yellow, interually white, and of a spongy texture; the leaves are long, sword-shaperl, sheathing each other, and often undulated on one side; the flowers are small, numerous, and produced on a spadix or conical spike at the edge of the leaf; there is no calyx; the corolla is composed of six small concave membranous petals, and appears as if truncated; the stamens are six; the filanents thick, and a little longer than the petals, supporting double autheræ; the germen is giblous, oblong, without a style, and terminated by a puinted stigna; the seed vessel is all oblong, triangular capsule, divided into three cells, cuntaining numerous oval secds.

The roots of the Calamus Aromaticus were formerly imported from Asia; but our native species does not appear to be in any respect inferior to the foreign. The roots of the sweet flag were held in much estimation by ancient writers on the Materia Medica, who celebrated their virtues as an aroniatic, and as being possessed of powerful medicinal properties: we are told by Limnzus, that this plant is the only aromatic one indigenous to northeru climates; and from the writings of Dioscorides $t$ and Alpinus, I we learn that the Greeks and Arabians were well acquainted with its virtues.

* Fig. $a$. represents a single petal. b. A magnified stamen. $c$. The pistillum. d. A tower. $e$. The pericarp, cut open to shew the seed.

+ Diosc. lib. i. c. 2.

$\ddagger$ Alpinus, p. 141 . 


$$
A
$$






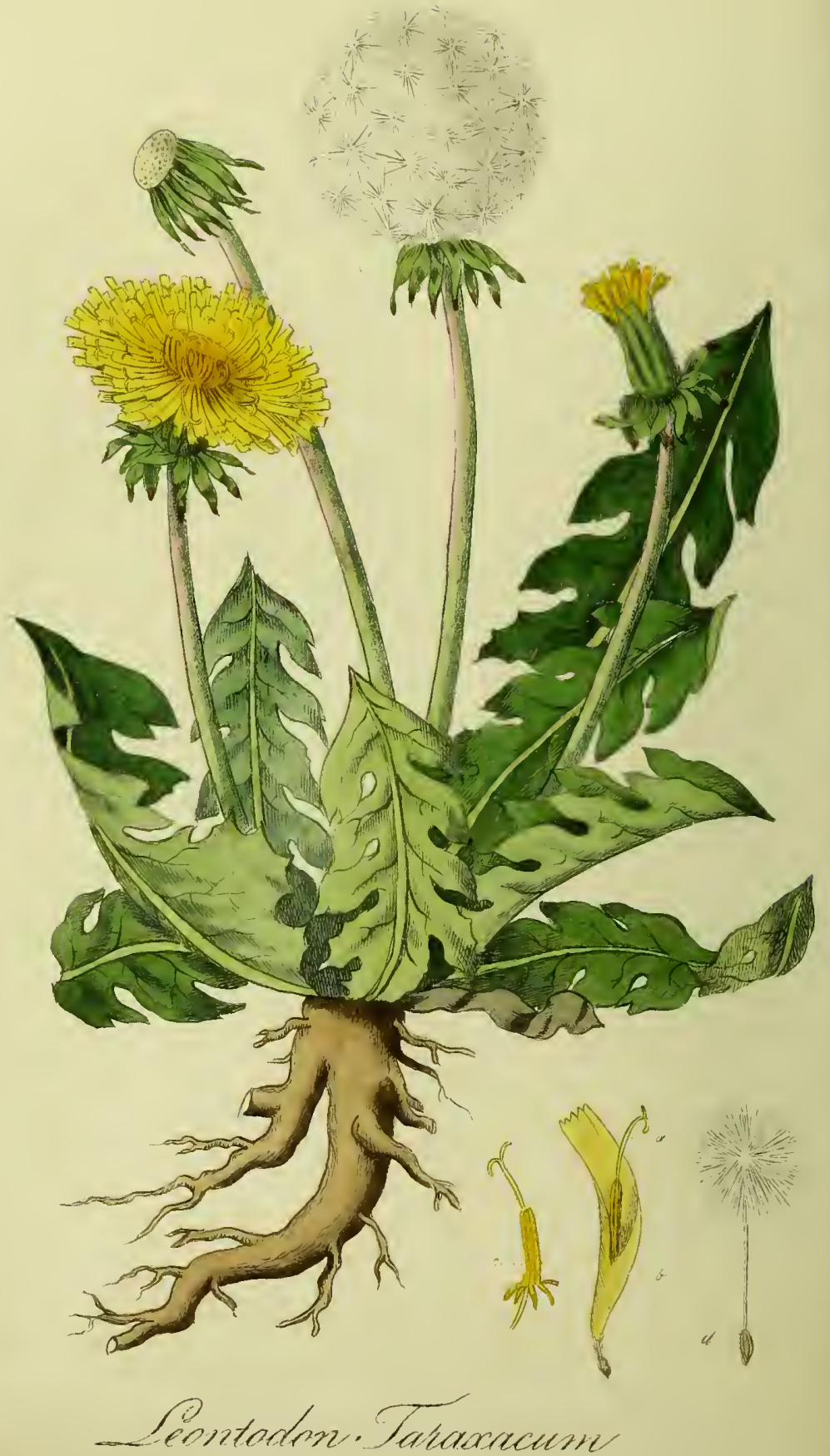


Qualities And Properties. The roots of Acorus Calamus have a moderately strong smell, and a warm aromatic taste, inclining somewhat to bitter, and acrid; these qualities are said to be increased by exciccation. The leaves have a slight fragrant smell resembling the roots, but less powerful. The bitter principle of the roots is extracted best by water, and the aromatic by alcohol: by distillation with water, a small portion of a very fragrant essential oil is obtained; according to Hoffmann, Neumann, and Cartheuser, in the proportion of from one to two scruples from $1 \mathrm{lb}$. of the roots.

From analysis, they are found also to contain extractive, resin, gum, and starch.

Medical Properties and Uses. The sweet flag is seldom prescribed in modern practice. Formerly, it was held in much estimation, and recommended in many diseases, especially in those arising from a vitiated state of the primæ viæ.* Its efficacy in intermittent fevers and scurvy, we believe, does not bear the test of modern experience; and as for its preventive effects against contagion, we leave them to the inhabitants of Constantinople to determine. $\dagger$

As a warm stomachic, gentle bitter and carminative, it may be found useful; and being less heating than the foreign aromatic spices, may be often substituted with advantage for them; when prescribed, the dried root may be given in doses of from one scruple to a drachm.

Off. The Root.

\section{LEONTODON TARAXACUM,}

Common Dandelion. $\ddagger$

\section{Class Syngenesia.-Order Poirygamia Equalis.}

Nat. Ord. Composite, Linn. Cichoracee,Juss.

Gen. Char. Receptacle naked. Calyx double. Pappus stipitate, hairy.

* Mayerne. Pra. Med.

$\dagger$ The roots candied are said to be used in many Eastern countries, and at Constantinople as a preservative against contagion.

$\ddagger$ Fig. $b$. A magnified floret; $a$. the pistillum. $c$. The five united anthers surrounding the style. $d$. A seed. 
Spec. Char. Outer scales of the calyx reflected. Leaves runcinate, glabrous, toothed.

The LeONTodon TARAXacum is one of our common perennial plants, and is to be met with in grass fields, in lanes, and almost every uncultivated spot; the wind wafting the seeds to a great distance there are few places in which this troublesome weed (for as such it is despised) may not be found. The English name given to this species of Leontodon* is a corruption of the French words dent de lion, lion's tooth, a name given to it from the supposed resemblance of the sinuosity of the leaves to the teeth of that animal; the latin name Leontodon has likewise its origin in this resemblance; and the vulgar name given to it in this country doubtless originated from its diuretic properties. The roots are tapering, white, fleshy, and milky within, externally of a yellowish brown; the stems (or scapes) grow erect, round, smooth, tubular, and terminated each by a single flower; the leaves are numerous, and spring from the root, and are deeply divided into sharp lobes, or runcinate; the general calyx is imbricated, oblong, the outer squamæ turning back: the flower, which is composed of a great number of mollopetalous, ligulate, truncated, five-toothed (or quinquedentate) florets; each floret ellclosing five stamens, which unite and form a cylindrical tube; the filaments are capillary and slender; antheræ tubulose; the germen is obovate; style slender, cylindrical, and the length of the corolla, suppporting two revolute stigmata; the receptacle convex, and dotted with little holes; the seeds are oblong, flattisl, striated, and grooved, at the top prickly, of a yellow brown, crowned with a radiated pappus, supported on a short pedicle.

Sensible and Chemical Properties and Qualities. Every part of this plant contains a bitter nilky juice, which is most abundant in the roots; the whole plant is nearly inodorous, its taste gently bitter, combined with sweet, and acrid; from analysis, it is found to contain caoutchouc, glutell, extractive, and a bitter principle. The expressed juice is whitish, and is thought to contain tartaric acid, as it reddens litmus and other vegetable blues. A decoction yields a precipitate with nitrate of silver, nuriate of mercury, sulphate of iron, and acetate of lead.

* T'he genus Leontodon comprises eight or more species, of which the Leontodon Palustre or lividus (Marsh Dandelion) is also a native of Britain ; and may be distinguished from the Taraxacum by the leaves, which are less indented, hy the outer scales of the calyx not being reflected, and by being altogether a smaller plant. 
The roots by drying lose much of their bitterness, and with it their medicinal properties; therefore the recent roots should be preferred. The roots should be taken up previous to the flower stems shooting, as they then contain more of the milky fluid, in which the virtues of the plant reside.

In many parts of the Continent, particularly in France, the leaves of the Taraxacmm are eaten as a salad herb, bcing previously blanched as the gardeners do endive; by this process, the leaves ar edeprived of their bisterness, and are rendered perfectly mild and bland; we are told also that at Gottingen, the poor people roast the roots, and use them as a substitute for coffee.

Medical Properties and Uses. The Dandelion like many of our indigenous plants, has had its rise and fall. Some physicians of great eminence, have extolled it as a valuablc medicine, whilst olhers have looked upon it as a mucilaginous bitter only. Many ycars ago it was a fashionable remedy on the Continent, and subsequently in this country; but it is now rather growing into disreputc.

It certainly possesses mild deobstruent and diuretic properties; but not to that degree to entitle it to the high encomiums which have been lavished upon it by some authors. Boërhaave recommended it for biliary calculi, and esteemed it adequate to resolve obstructions of the viscera; and the late Dr. Pemberton, in his treatise on diseases of the abdominal viscera, strongly recommended it in diseases of the liver, and derangement of the stomach.* By some, it is chiefly valued for its diuretic effects; and by others, for its gentle deobstruent properties: it is probable, the jarring opinions of its virtues ought to be attributed to the preparations made use of. Taraxacum being generally prescribed in the form of extract, a mode of preparation that frequently destroys the most active qualities of vegetables; bencc particular care should be taken in preparing the inspissated juice, or extract; when prescribed in this form, it is usually given in doses of from twenty to thirty grains two or three times in the day; a decoction of the roots, two ounces boiled in one pint and half of water to one pint, with the addition of sulplı, potass. is recommended as a deobstruent in jaundice, and obstructed liver.

In Ireland, a decoction of the leaves, or roots, of this plant, is a popular remedy with the poor iu pulmonary complaints.

Off. The Herb, Root and Leaves.

Off. Pp. Ext. Taraxaei. L.D.

* "I particularly recommend the use of Taraxacum, from which I have seen the most decided advantage, both in incipient scirhus of the liver, and also in several chronic derangements of the stomach." Pemberton. 


\section{HELLEBORUS、NIGER, \\ Black Hellebore, or Christmas Rose.*}

\section{Class Polyandria.-Order Polygynia.}

Nat. Ord. Multisiligue, Linn. Ranunculacee, Juss. Gen. Cha R. Calyx 0. Corolla petals 5 or 6 . Nectaries equal in number to the petals.

Spec. Char. Scape one or two-flowered, nearly naked. Leaves pedate.

Thts species of Helleboret is a native of Austria, and Italy, growing wild on the Appenines; it was unknown in this country until the year 1596, when it was introduced and cultivated by Mr. John Gerarde, when the beauty of its flower, and the time of its appearance, soon obtained for it a place in most of the flower gardens; for if the weather prove sufficiently mild it blossoms soon after Christmas, whence it has obtained the name of the Christmás rose.

The root of this plant is perennial, and is composed of one short, thick stump, knotted, and externally of a black colour; internally whitish; sending off many strong, round fibres, crowned by a large cluster of lobed leaves, consisting each of seven or eight obtuse, fleshy lobes, united to one footstalk, and between the leaves, several thick fleshy flower-stalks, three or four inches high ; the flowerstalks stand erect, round and tapering, and towards the bottom are reddish; the bracteal leaves supply the place of a calyx, and are oval, concave, and generally indented at the top ; the petals of the corolla are five or six, large, roundish, spreading, at first of a white colour, succeeded by reddish tints, and tiually assuming a greenish appearance; the nectaries are generally equal in number to the petals, though sometimes more; tubulated, somewhat compressed, bilabiated, and of a greenish yellow colour: by some botanists these are considered the petals of the flower, and the corolla a calyx: the filaments are white; the antheræ yellow; the germens vary from

* Fig. $a$. The pistilla. b. A magnified stamen. c. A nectary magnified.

$\dagger$ Eight species of the genus Helleborus are known and cultivated in our various botanic gardens. Hort. Cant. 

four to eight, and the capsules or pods, contain many oval, shining, blackish seeds; the leaves are compound, pedated, composed of seven leaflets, and stand upon long radical foot-stalks; each leaflet is elliptical, snooth, thick, and serrated towards the top.

Sensible Qualities. The taste of the fiesh root is acrid and bitter, and of a nauseous smell; its acrimony, Dr. Grew observes, is first felt on the tip of the tongue, and then spreads itself immediately to the middle, without being much perceived in the intermediate part. On chewing the roots for a few minutes the tongue seems benumbed, and affected with a kind of paralytic stupor, as when burnt by eating any thing too hot. The fibres are more acrimonious than the head of the root, whence they issue.* By long keeping, it loses both its sensiole qualities and medicual activity. Orfila ranks the black hellebore among the acrid vegetable poisons: $f$ and gives an account of several experiments made with it on dogs, from which he draws the following conclusions. That the powdered root applied to the cellular texture is rapidly absorbed, carried into the circulation, and gives rise to violent vomitings, and different lesions of the ncrvous system, which the animals speedily sink under, and which seem to bear an analogy to those produced by narcotics. That it acts in the same manner when introduced into the stomach; but its effects are slower and less violent, and it may even happen that those animals are not destroyed which are allowed the power of vomiting, whereas death is the constant result of the application of the powdered root to the cellular texture. That the poisonous property of the Hellebore, resides in that part which is soluble in water. Such are the conclusions drawn by Orfila after sone very careful experiments, and which, in connexion with those of other writers seem sufficient to establish the black hellebore as a certain, though perhaps not a very active poison; many writers, however, consider it a safe and perfectly innoccnt medicine. But it is also to be observed, that sevcral instances are recorded of other plants being mistaken for the one of which we are treating; viz. the Adonis Vernalis; Actæa Spicata ; Helleborus Viridis ; Veratrum Album, or white bellebore; the Aconitum Neomantanum, \&c. The last of these is a very virulent poison; it may be distinguished by its roots being nearly globular, and sending out many very brittle fibres, of a greyish brown colour, about the thickness of a man's finger, and frequentiy divided.

* Dr. Grew on Tastes. Vide Anatomy of Plants, $p, 283$.

+ Orfila, Toxicology. 
Neumann got from $\mathbf{2 8 8 0}$ grains of the root of black hellebore; 380 alcoholic, and 181 watery extract; and inversely, 362 watery, and 181 alcoholic.

Medical Properties and Uses. Black hellebore was highly esteemed among the ancients as a powerful remedy in maniacal disorders; but whether our hellebore be the same species as that said to grow in the island of Anticyra and about Mount Olympus, and so frequently alluded to by the Latin poets, is no easy matter to determine. Orfila supposes the Veratrum Album or white liellebore, a plant of the Monocia urder, to have been the liellebore of the ancients. Tournefort, however, who botanized Mount Olympus and Anticyra, discovered another species, which he supposes to have been the hellebore of Hippocrates, and to which he gave the name of Helleborus Niger Orientalis; it differs from the species here figured by having a large branched stem, the leaf broader, and the flower of a purple hue: it differs also in its effects, for he found that Эi. of the extract, brought on violent spasms. and convulsions. The properties of many plants, however, are known to vary considerably by difference of soil, climate, \&c. In some parts of Germany a species of bjack liellebore has been made use of, which frequently produced violent, and sometimes deleterious effects. It appears to be the kind known here as settlewort, or bastard hellebore. Whatever may liave been the hellebore of the ancients, it was principally for its action as a drastic purge, that it was esteemed as a powerful antimaniacal remedy; at present, it is looked upon chiefly as an alterative, and for this purpose is frequently given in small doses, for promoting the uterine and urinary discharges. It proves a powerful emmenagogue in plethoric habits, where steel is ineffectual, or improper; it is also recommended in dropsies, and some cutaneous diseases, especially Lepra Græcorum.* As a purgative niedicine, it is chiefly used in eases of niania, melancholy, coma, worms, and psora; but its use requires great caution. The watery extract of the rout, as directed by the Colleges, is perhaps one of the best and safest preparations; the irritating power of its active matter being considerably abated by the boiling: of this extract, from gr. x. to Эi. or more may be given for a dose. The tincture is preferred as an alterative and cleobstruent: one tea-spoonful may be considered as a dose. Dr. Duncan recommends the infusion and tincture, as promising to be medicines of more uniform power than the extract.

* By Gesner, Kleim, Milnan, Bacher, \&c. Vide Aretai, Opera, ed. Bö̈rh. p. 136. 


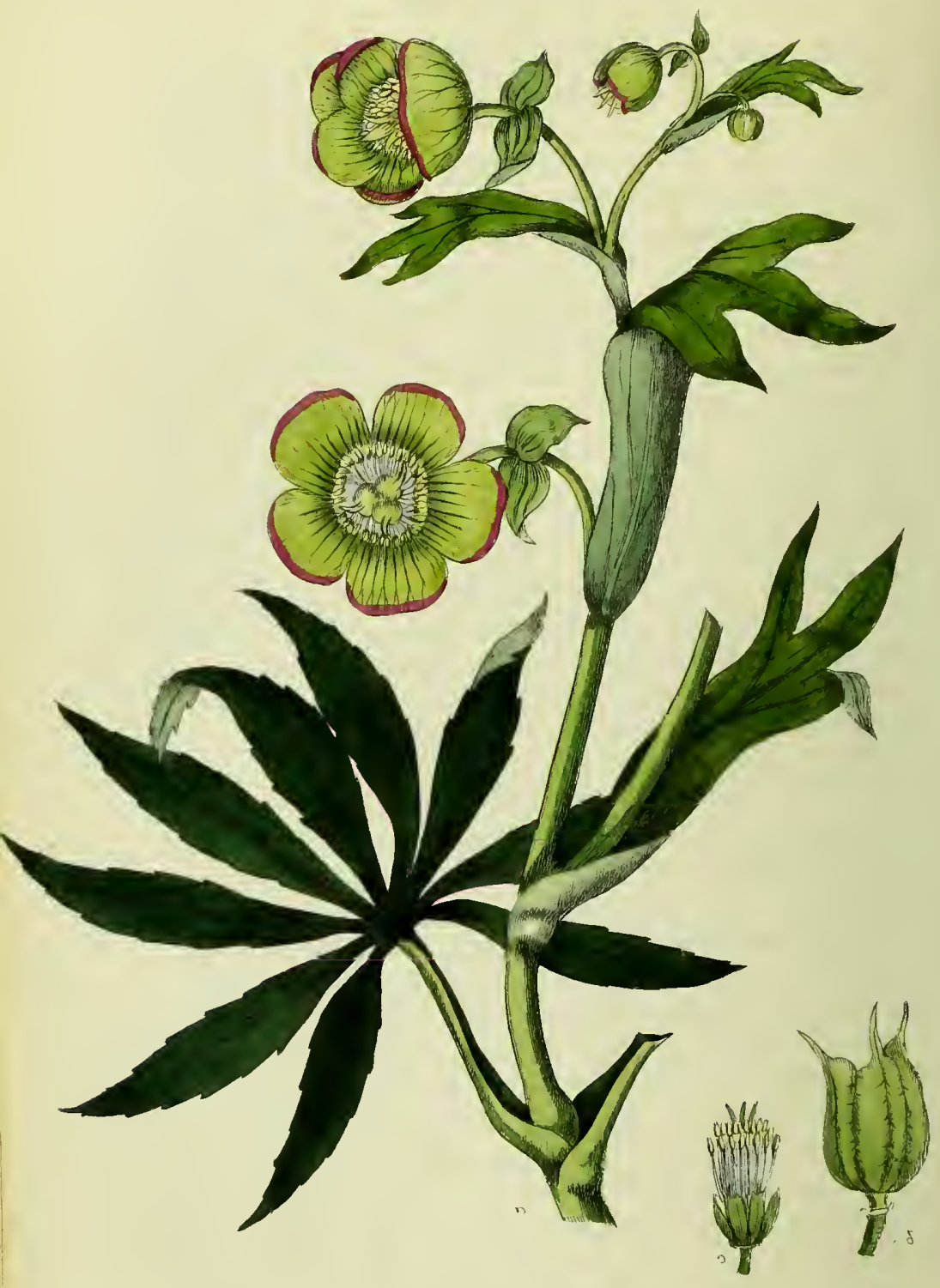

Ylollelinuens Yoridus. 
Off. The Root.

Off. Pp. Extractum Hellebori nigri, E.D. Tinctura Hellebori nigri, L.E.D.

\section{HELLEBORUS FETIDUS.}

\section{Fetid Hellebore, Bear's-foot, or Setter-wort.**}

\section{Class Poliyandra.-Order Polygyin.}

Nat. Ord. Multisiliqua, Linn. Ranunculacez, Juss.

Gen. Char. Calyx 0. Corolla petals 5 or 6 . Nectaries equal in number to the petals.

Spec. Char. Stem many flowered, leafy. Leaves pedate, glabrous. Petals converging.

THus species of hellebore grows wild in many parts of England, flowering early in the spring in mild seasons. It delights in moist shady situations, and in its wild state is most frequently to be met with in woods. Bear's-foot is found in great plenty in many parts of Sussex, Norfolk, and the North of England; it has been long cultivated in our gardens for the sake of its early flowers.

The root of this species of hellebore is small, and beset with a prodigious number of slender dark-coloured fibres; the stem rises to the height of a foot and a half, or more; towards the bottom, it is round, strong, firm, naked, and marked with alternate cicatrices, the vestiges of the former leaves; at the top it divides, and is subdivided into branches, producing many flowers, garnished with scaly leaves, or bracteæ; the leaves are numerous, ind stand upon long foot-stalks, surrounding the niddle of the stem: they are divided, like the preceding species, into simple leaves, which are commonly eight or nine; long, narrow, lanceolated, serrated, and of a dark green colour: the scaly leaves, placed at the ramification of the flower-stems, are smooth, trifid, alternate, and often purplish, but those near the flower, aré. oval and pointed; the flowers are numerous, terminal, pendent, of a roundish shape, and stand upon peduncles, forming a sort of panicle; the petals are generally five, oval, concave; per-

* Fig. a. represents a sprig of the natural size. $b$. The capsule, or pods. $c$. The stamens and nectaries somewhat magnified.

VOL. I. 
sistent, of a pale green colour, their margins usually tinged with purple; the stamina are numerous, the filaments the length of the petals; the anthera white; there are from eight to tcn nectaries, minute, tubular, and placed in a circle situated within the petals; the germens are three, hairy, and shaped like those of the Helleborus Niger, becoming capsules, containing many oval seeds.

Sensible Qualities. The stipulcs and leaves of the recent plant possess a very bitter acrid taste, and when chewed excite excoriation of the month and fauces; the smell is very foetid ; by drying, the acrid quality of the plant is considerably destroyed; vinegar is also said to render it milder.

The foetid hellebore, or bear's-foot, is ranked by most Toxicologists among the irritating poisons; and its action on the animal economy so nearly resembles that of the strong-scented lettuce and black hellebore, already described, that we refer our readers to those articles for the treatment of any untoward symptom arising from an overdose of this acrid substance.*

Medical Properties and Uses. The leaves of this plant have been long employed in this country, as a demestic medicine to expel worms from the alimentary canal. Bisset says, "the great black hellebore, or bear's-foot, is by far the most powerful vermifuge for large round worms of any I have yet experienced." In some parts of York shire, the anthelmintic virtues of this plant are well known, and it is in general use among the common people. One drachm of the green leaves in decoction, or about fifteen grains of the dried leaves in powder, is the usual dose for a child of four or five years of age: the juice of the leaves is also made into a syrup; the bruised leaves being moistened with vinegar previously to pressing out the juice, by which the acrid principle of the plant is corrected, and its tendency to induce vomiting, in some degree prevented: one tea-spoonful of this syrup at bed-time, and one or two in the morning, is the usual dose for children from two to six years. A sufficient dose of the dried leaves generally proves more or less emetic, and of ten acts as an aperient; it is usually repeated for two or three successive mornings; the second dose acts more powerfully than the first, and never fails to expel round worms if there be any lodged in the alimentary tube: it is a remedy, however, which should be used with caution, being so violent in its operation as to have produced in some instances, fatal effects. $\dagger$

Off. The Leaves.

* Vide Vol. i. pp. 39 and 63.

+ Vide Threlkeld's Irish Herbal; and in the Oxford Magazine for March 1769, p. 99, fatal cases are related by John Cook, of Oxford. 



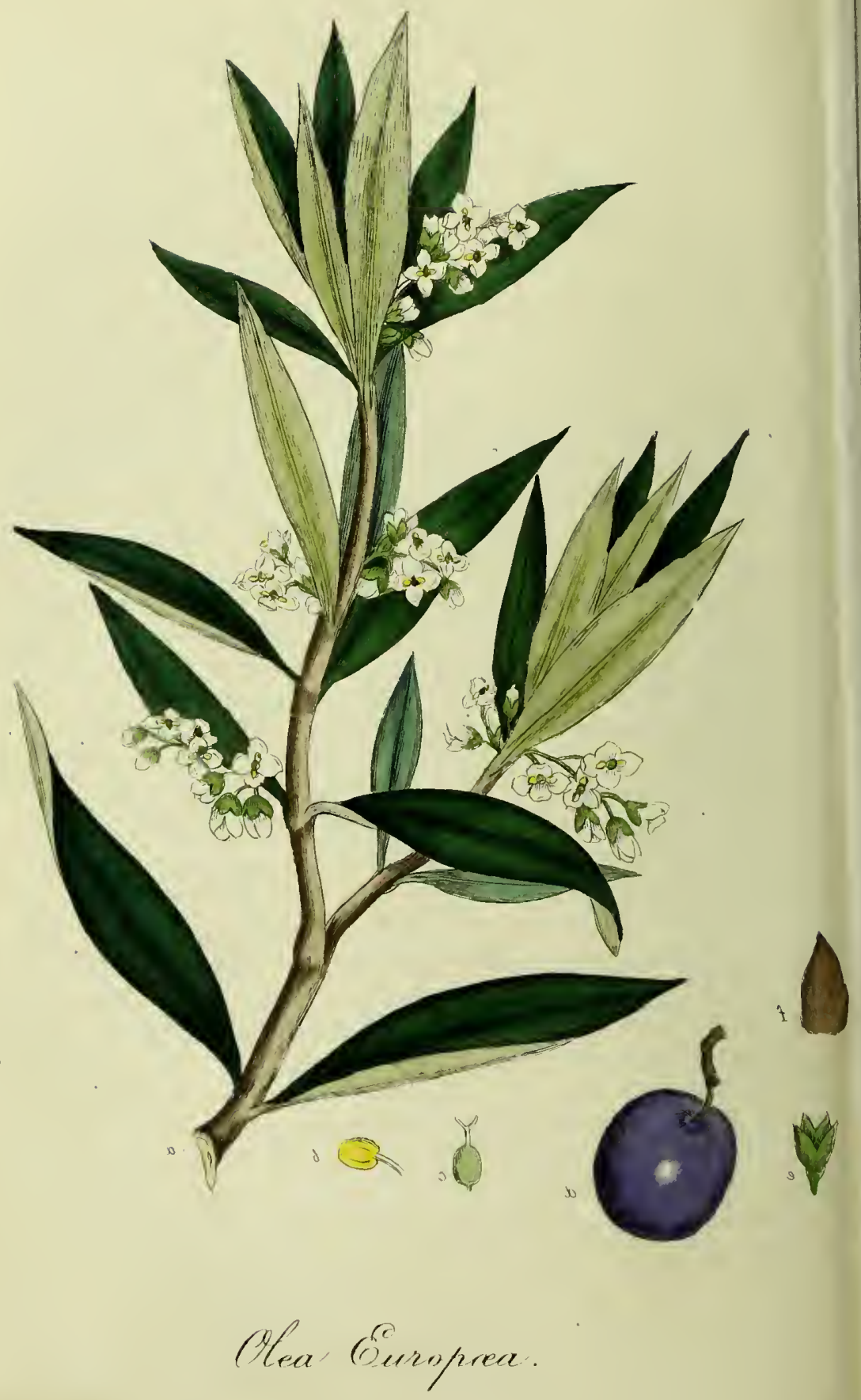

triprait rel

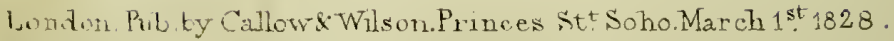




\section{OLEA EUROPAEA.}

\section{The Olive Tree.**}

\section{Class Diandria.-Order Monogynia.}

Nat. Ord. Sepiaria, Linn. Jasminer, Juss.

\section{Gen. Char. Corolla 4-cleft. Segments sub-ovate.} Drupe one seeded.

Spec. Char. Leaves lanceolate, entire, pale underneath. Clusters axillary, dense.

ThIs species $\dagger$ of olive has received its specific name either from its being a native of, or from its extensive cultivation in Europe. It is now ranked among the plants indigenous to the South of Europe; although some botanists have supposed it to be a native of Asia, but from time immemorial naturalized in Europe, where it now grows spontaneously, delighting in a rocky soil.

The olive has been long cultivated in Britain; $t$ we find it mentioned in the Catalogus Plantarum Horti Medici Oxoniensis, published in 1648; and when sufficiently sheltered it bears the cold of onr ordinary winters tolerably well. $§$

This tree usually rises to the lieight of about twenty feet, sending off numerous long branches, covered with a bark of a greyish culour ; the leaves are firm, narrow, lance-shaped, entire, on the upper side of a bright green, beneath whitish, aud stand in pairs upon short footstalks; the flowers are small, white, numerous, and proceed in clusters near the footstalk of the leaves; the calyx is tubular, and divided at the brim into four small, erect, deciduous segments; the corolla is a funnel-shaped petal, consisting of a short tube about the length of the calyx, and divided at the border into four semi-ovate segments; the filaments are two, tapering, opposite, and crowned

* Fig. $a$. represents a cutting of the natural size. b. The ripe fruit. c. The pis. tillum. $d$. A magnified anther. e. The calyx. $f$. The nut.

+ Seven species are enumerated in the Hort. Cant.

$\ddagger$ Since the Year 1570. Hort. Cant.

$\$$ Vide Miller. 
with erect antheræ; the germen is round, and supports a simple short style, furnished with a bifid stigma, each division notched at the apex; the pericarpium is a fruit of the drupous kind, of an oblong or oval shape, (about the size of a sparrow's egg) and containing a nut of the sane form. The olive, as observed, is a native of the South of Europe, and the North of Africa, where it flowers from June until August, it is cultivated with much care in France, Spain, and Italy, for the sake of its fruit, and the oil expressed from that part.

This tree has been greatly celebrated and held in high estimation from the earliest ages, as a bounteous gift of heaven, and in gratitude to the Diety it was formerly exhibited in the religious ceremonies of the Jews. By the Greeks and Romans the olive branch was a symbol of peace, and the emblem has descended even to the present day.

Sensible Properties. Fresh olives have an acrid, bitter, and very disagreeable taste, not altogether unlike that of the outer rind of the green walnut: to make them palatable, and prepare then as an article of luxury for the table, they are first steeped for several days in water, or urore generally in a ley of wood ashes, by which a considerable portion of the bitter matter is extracted; ; after this, they are washed and preserved in a strong pickle of 'common salt and water. In this way they form an important branch of export from the countries that produce them, and a necessary part of every fashionable dessert: the flavour of olives when thus prepared is bland, slightly but agreeably bitter, lıeightening the gout for wine, and tending to prevent its inebriating effects, which latter property is owing to the oil they contain. The small round French olive is the most esteemed for the purposes of the table, and bears a higher price than the Spanish, (which is larger and of an oval form) or even the Italian, though the latter yields the purest oil. The olive for pickling must be pulled some time before it has arrived at maturity.

The fruit of the olive tree yields by expression a considerable quantity of a bland, scentless oil, well known in commerce. To procure this oil, the olives are gathered when fully ripe, but the after mode of preparation varies in different countries, and perliaps it is to this circumstance, as much as to the different quality of the fruit, that we may ascribe the various qualities of the oil which is sold under the name of olive oil. As the tree is not a native of these

* When water only is used, the steeping must be continued much longer. , $E d$. 
countries, it would be useless to give the different methods adopted to obtain the oil ; it is only necessary to observe, that the oil brought from Italy in small flasks, and sold under the name of Florence oil, is by far the purest; though this, as well as the other linds, is frequently adulterăted with oil of poppy seeds, a considerable quantity of which is anmually exported from Holland, to France and Iialy, for this purpose. By exposing olive oil to the freezing temperature its degree of purity can be readily ascertained, for the olive oil freezes, while that of the poppy seeds retains its fluidity; and as oils which freeze with the greatest difficulty have the greatest tendency to become rancid, olive oil is deteriorated by the mixture of poppy oil with it. Good olive oil has a pale yellow colour; with little taste or smell, and shonld congeal at $38^{\bullet}$ Fahrenheit. The best oil, however, becomes rancid by age, particularly if kept in a warm situation or exposed to the air.

Medical Properties and Uses. Oil in some shape enters into the composition of a considerable portion of our food, whether animal or vegetable, and afords much nourishment: with some persons, however, oily substances by not uniting with the colltents of the stomach, frequently occasion ernctatious; this happens especially to those whose stomachs abound with acid in any extraordinary degree." Oil, considered as a medicament, is supposed to correct acrimony, and to lubricate and relax the fibres; it has therefore lieen recommended internally to obviate the effects of varions stimuli which produce irritation and consequent inflammation: hence also it has been prescribed in catarrhal affections, \&c. Olive oil has been effectually used in worm cases; and in nephritic pains, colic, constipation of the bowels, spasms, \&c., it has occasionally been found serviceable. Taken internally also, it operates as a gentle laxative. But it is as an external application that this oil is chiefly resorted to, both alone and in combination with other substances, as camphor, lime-water, spirit of hartshorn, \&c. In this way it has been applied to extensive burns, tumours, \&c.; and to wounds occasioned by the bites and stings of animals and reptiles. See the experiments of Dr. Oliver, related in the Philosophical Transactions, vol. xxxix. p. 310, by which it appears that a man suffered his arm to be bitten by serpents, and waited mutil most violent symptoms ensucd, which were soon removed by applying warm oil of olives to the wounded part; similar experiments were made upon dogs, pigeons, \&c. with equal success. Numerous ex- 
periments of this kind were repeated, with various success, and published in the Mens. de l'Acad. de Sc. 1737. It is to be regretted that the particular species of serpent by which the bites were given has not been mentioned in any of the cases alluded to. Linnæus was much disappointed iu the use of the oil, and says that a woman bitten by the Coluber Chersea, died in great agony, though the oil was liberally administered both internally and externally. We know by experience that the immediate application of oil removes the pain and inflammation occasioned by the sting of wasps and bees. Banniken* has mentioned the successful use of oil in rabies canina, and a further account of its efficacy in that disease was read before the Medical Society of London. + We have seen the best effects produced by the application of equal parts of olive oil and lime water to burns. Oil rubbed over the body has been found by many of great service in dropsy, particularly in ascites; and used in this way, it has been said to be an antidote agaiust contagious fevers, particularly the plague. At Malta it has been remarked that butchers, and others whose vocations lead them to the constant handling of fatty substances, are seldom carried off by the plague.

With regard to the general effects of olive oil, taken internally, we may remark, that although its operation extends over the prima viæ, yet it may reasonably be doubted, that it produces any medicinal effects after it has entered into the sanguiferous system. As all the mild expressed oils of vegetables are nearly of the same nature, Dr. Cullen is of opinion that a preference should be given to the inost fluid; hence the oils of olives and almonds are most commonly directed for use.

The officinal preparations of olive oil are very numerous, as it enters into the composition of many liniments, ointments, plasters, \&c.

\section{CROCUS SATIVUS.}

, Saffron Crocus. +

\section{Class Triandria. Order Monogynia. \\ Nat. Ord. Ensate, Linn. IrIdee, Juss.}

\footnotetext{
* Frank, Journal, T. B. 590, 899.

† Phil. Trans. vol. xlix.p. 46.

$\ddagger$ Fig. a. The pistillam. b. A stamen. c. Capsule. d. A seetion of the capsales.
} 


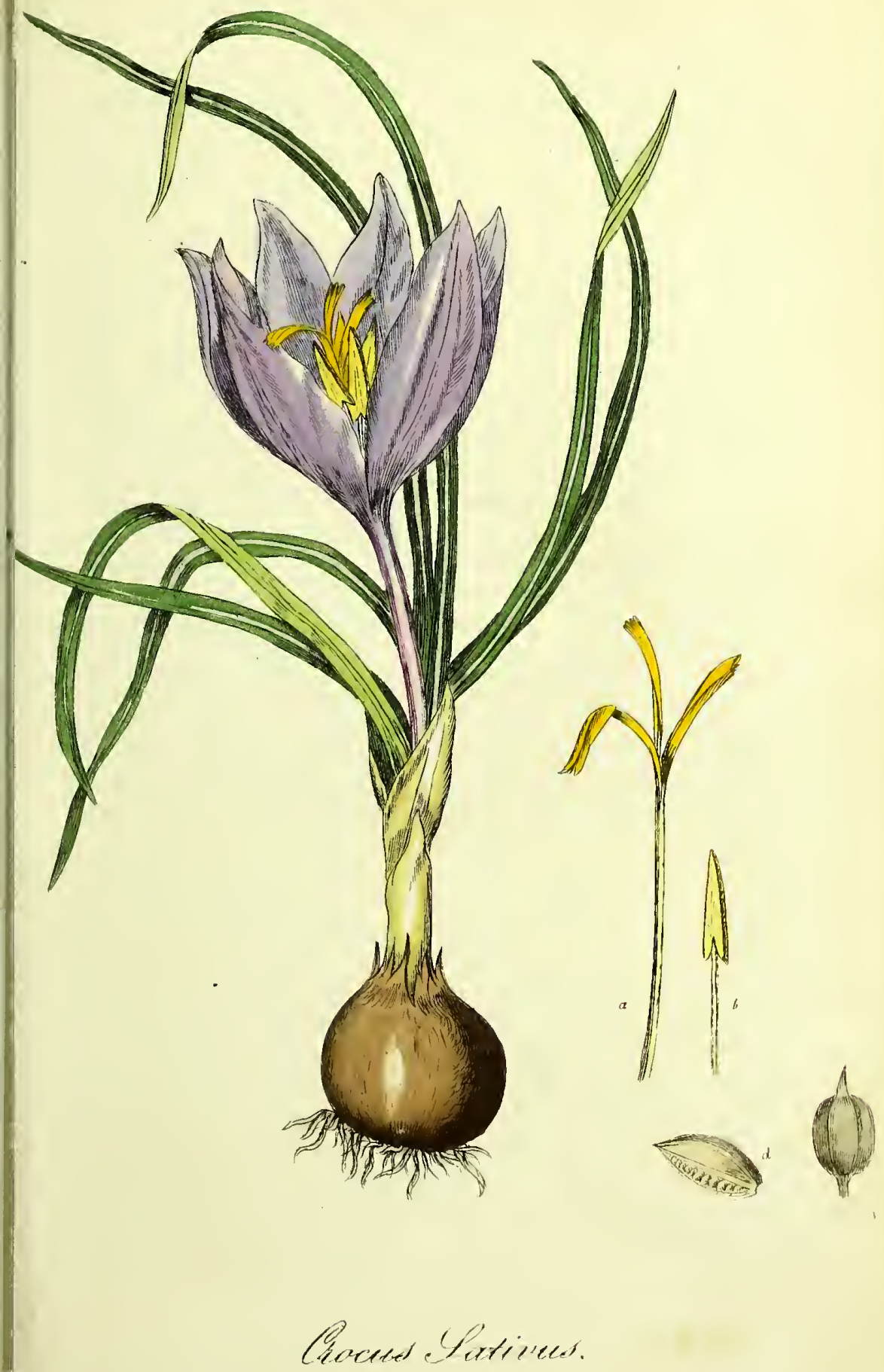



Gen. Char. Corolla six-parted, equal. Stigmata convolute. Spec. Cuar. Spathe of one valve, radical. Corolla with the longest tube.

The Crocus tribe of plants are mostly indigenous to the South of Europe and Asia: eleven species are cultivated in our gardens, chiefly for ornament.* The Crocus Sativus was considered by former botanists as an exotic, nor was it known in the time of Ray, Mi!ler, and many later writers, that this plant was unquestionably a native. of Britain. Modern botanists do not hesitate in ranking this species of Crocus among the indigenous plants of this country; but if it was originally an exotic, it has been long naturalized to our soil, and is now found growing wild in many parts of the country.

The root is bulbous, (perennial) and externally of a brown colour; the leaves are linear, simple, radical, of a rich green, with a white line running through the centre; the flower is large, of a purple colour, inclining to blue or lilac, the tube of which is inclosed at the base, along with the leaves, in the membranous sheath or spathe; the corolla is composed of six petals, elliptical, equal, and turned inward at the edges; the filaments are three, short, tapering, and support long, erect, spear-shaped, yellow antheræ; the germen is ovate or roundish, supporting a slender style, terminated by three long convoluted stigmata, of a golden colour; the capsule is of an oval form, three-lobed, three-celled, and three-valved, and contains many round seeds.

The officinal saffron is composed of the stigmata of the species of Crocus we have been describing, and is prepared for use as follows. In the autumn, the flowers when in full blossom are gathered every morning, the stigmata and top of the style picked from them, and dried in portable kilns constructed for the purpose. The stigmata are spread two or three inches thick upon sheets of white paper, laid over a hair cluth, which is placed npon the kiln, and covered with a blauket; the kiln being heated to a proper degree, the saffron is turned every half hour until sufficiently dried, which usually requires abont twenty-four hours. $\dagger$

The Crocus is chiefly cultivated for the preparation of English saffion in the neighbourhood of Saffron Walden, in Essex, and iı some parts of Cambridgeshire.

* Hort. Cant.

+ Vide Douglas, in Phil. 'Irans. vol. xxxv. p. 566. 
Sensible and Cinemical Properties. Dried saffron has a warm, pungent, and rather bitter taste; when chewed it is tough, but grows soft, and tinges the saliva of a deep yellow; its smell is diffusive and not unpleasant, somewhat aromatic and narcotic. Saffron gives ont the whole of its properties and colour to rectified spirit, wine, vinegar, proof-spirit, and water : about three parts in four are taken up by each of these menstrua. By distillation with water, saffron furnishes a small portion of a very fragrant and purgent oil, of a golden yellow, lieavier than water, with the characteristic smell of saffron in a very considerable degree.* The watery infusion turns purple by the addition of sulphuric acid, which mixture, on being diluted witlı water, deposits a black precipitate; oxymuriatic acid produces a yellow precipitate, the liquid remaining a pale lemon colour.t The soluble matter of saffron is nearly pure extractive, and to it the name of Polychroite lias been given by the French chemists. $f$ Polychroite has been obtained in the form of scales of a reddish yellow colour, deliquescent, of a sweet smell, taste bitter and pungent, like that of saffron, soluble in botlı water and alcohol, which solutions lose their colour by exposure to light; sulphuric acid changes the solution first to blue, then to lilac; and nitric acid to grass green.

Medical Properties and Uses. Saffiron appears to have been well kuown to the ancients, and lield in great estimation as a very powerful medicine.§ Modern physicians, however, do not place much coufidence in its medicinal properties, and, in the present day, it is but little used, except as an adjunct to nore powerful medicines.\| It is generally considered aromatic and cordial, and its effects exhilarating; when given in large doses it is said to produce symptoms of intoxication, mania, and even fatal effects.** It lias been much recommended for removing obstructions of the uterine secretions, but its powers as an emmenagogue we believe to be much over-rated, as well as its diaphoretic properties, and also

* One scruple from four ounces. Gray's Elements.

+ Gray's Elemcants.

‡ Le Grange, Vogel, Bouillon, \&c.

\$ By the Hebrews it was called Carcom; by the Greeks, Korros; by the Arabians, Zahafaran or Zaffaran; by the Latins, Crocus.

II Saffron forms one of the ingredients in the Aromatic Confection, Compound Decoction of Aloes, Pills of Aloes and Myrrh, Componnd Tincture of Aloes, Compound Tincture of Bark, and the Simple and Compound Tinctures of Rhubarb of the London Pharmacopæia.

** Borellus, Hist. et Obs. cent. 4 ; Obs. 35, p. 303 ; Zucat. Lusit. b. c. 



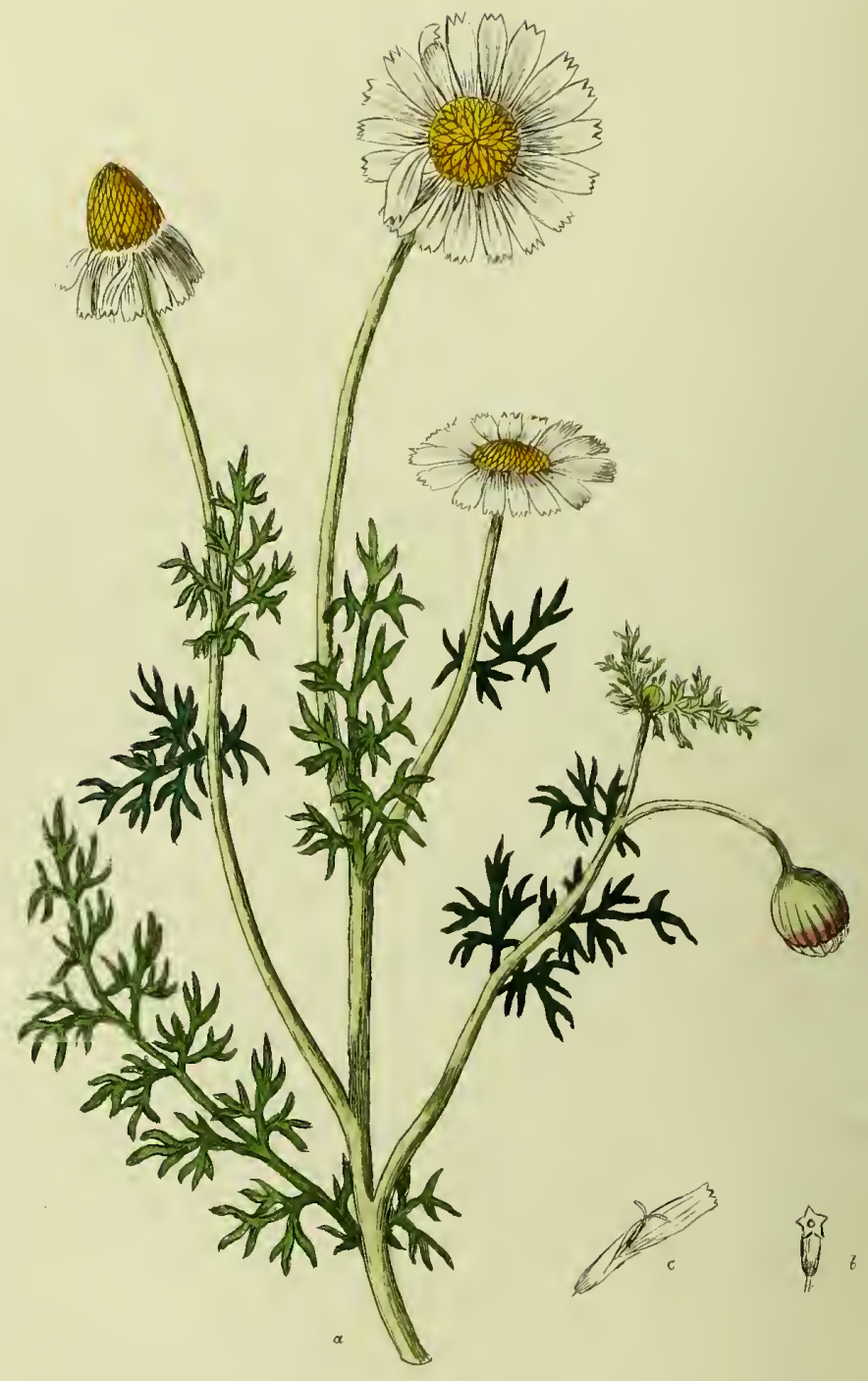

- Inthernis Aolilis. 
its effects in throwing out the various species of exanthemata, and other eruptivc diseases; for these last purposes it still holds its place with the uninformed as an infalliblc medicine.

Off. The summits of the pistils, called Saffron.

Off. Pp. Syrupus Croci, L.

Tinctura Croci, D. E.

\section{ANTHEMIS NOBILIS.}

\section{Chamomile.*}

\section{Class Syngenesia. Order Polygamia Superflua.}

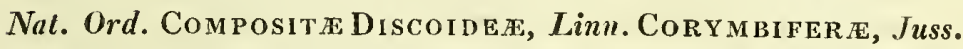
Gen. Cinar. Receptacle chaffy. Pappus none. Calyx hemispherical, nearly equal. Florets of the ray more than five.

SPec. ChaR. Leaves compound pinnate; the divisions linear, acute; rather villous.

The Anthemis Nobilis is a liardy perennial plant, indigenous to Britain, and found in great abundance upon waste lands in the western counties; in its native state it propagates rapidly, by putting out roots from the branclies as they lie on the ground. There is a variety of this speciest of chamomilc with what are usually termed double flowers; $\ddagger$ both sorts are cultivated in large quantities, but the single-flowcred variety is preferred, though not usually kept in the shops.

The roots of clamomile are fibrous and spreading; the stems are many, slender, trailing, branched, and leafy; the leaves are villous, doubly pinnate, of a pale green; the leaflets are small, linear, and usually divided into thrce segments; the flowers are compound, terminal, solitary, and radiated; the calyx is hemispherical, and

* Fig. $a$. represents a plant, the leaves and flowers of the natural size. b. $\Lambda$ magnitied floret of the disk. c. A radial floret (magnified).

+ The genus Anthemis comprises many species, natives of every quarter of the globe; tweuty-six of which are known and cultivated in our botanic gardens. Hort. Cant.

$\ddagger$ Double flowers have the florets of the ray (in compound flowers) redundant, whilst those of the disk are often entirely or nearly extiuct. $E d$.

VOL. I. 
composed of many scales; the florets of the disk are numerous, funnel-shaped, erect, and divided at the top into five segments; the filaments are five; anthers united ; the germen is oblong, supporting a slender style, crowned with a bifid stigma; the florets of the ray are ligulate, and threc-toothed; seeds oblong, naked.

The Matricaria Chamomilla, wild chamonile, or conmon fever-few, (also a native of Britain), is very similar in its general appearance to the Anthemis Nobilis, and is directed for officinal use by most of the foreign pharmacopœias; but the odour of the former is not so fragrant, nor so powerful, nor does it yield so much essential oil as the latter; and as the virtues of chamomile chiefly depend upon its essential oil, it must be preferable to the Matricaria.

Sensible and Chemical Properties. Both the flowers and leaves of chamomile have a powerful and rather grateful odour; its taste is nauseous and very bitter. Chamomile flowers become more grateful by drying, without losing any of their aromatic flavour; and the infusion of the dried flowers is much less nauseous than the fresh plant. Chamomile gives out its flavour (which resides in an essential oil) both to water and alcohol; the distilled water is pretty strongly impregnated with it. On distilling chamomile with water, a small portion of the essential oil separates and rises to the surface; this oil is of a greenish yellow or blue colour, and of a pungent taste, possessing the flavour and odour of the flowers in a concentrated degree.*. The rectified spirit distilled from off a tincture of chamomile, brings over part of the flavour, but leaves a considerable portion behind in the extract; the smell of the spirit is not so powerful as the distilled water, but the taste much more so. $\dagger$ The infusion changes brown by the addition of sulphate of iron. From the analysis of Neumann, the active constituents are an essential oil and bitter extract.

Medical Properties and Uses. The flowers of chamomile have been long held in much estimation for their tonic and stomachic properties, which are chiefly derived from their bitter principle ; and from the essential oil they contain, is derived their active properties as an emmenagogue, antispasmodic, and carmiuative: hence they have been recommended in liysterical affections, colic, suppression of the menses, gout, indigestion, intermittent fevers, \&c.;

* Baumè obtained from 82lbs, of the flowers from 13 to 18 drachms of oil; but from the like quantity of the herb, without the flowers, only half a drachm. See Bergman, Mat. Med.p. 695.

Lewis, Mat, Med. p. 221. 



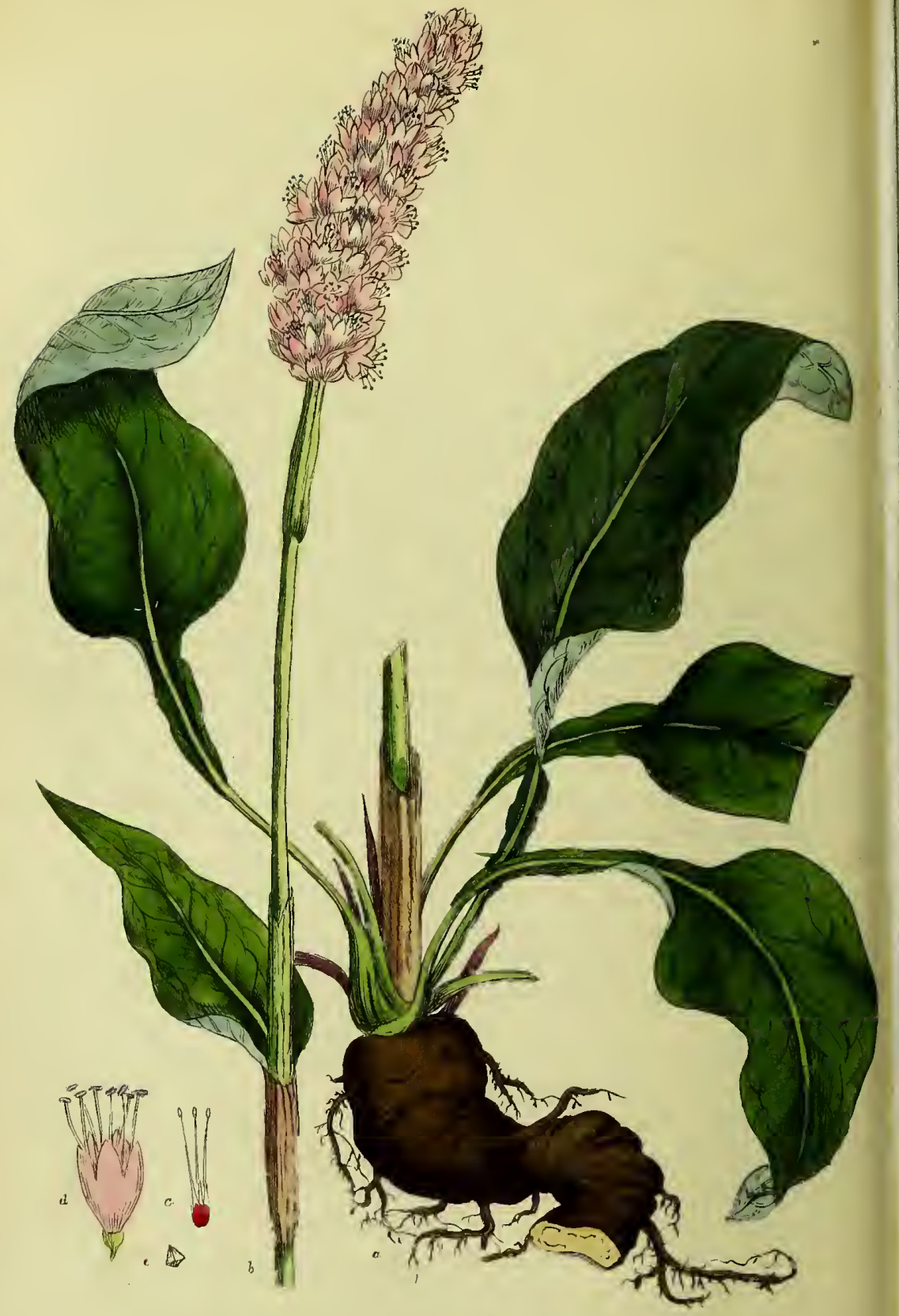

Solygonum Sistorien. 
and we have the testimony of several respectable physicians, that chamomile flowers may be effectually substituted for Peruvian bark, in the cure of intermittent fever." Dr. Cullen says, "I have em. ployed these flowers, and agreeably to the method of Hoffmann, by giving several times, during the intermissions, from half a drachm to a drachm of the flowers in powder, and have cured intermittent fever." Dr. Cullen, however, adds, that he found it necessary to join an opiate or astringent with then, to prcvent their aperient effects, which when considerable, defeated the purpose of preventing a return of the paroxysms. In modern practice, however, chamomile is not often relied upon for the cure of intermittents; as a gentle tonic it is an useful medicine; and with many physicians the infusion of chamomile lias entirely superseded the infusion of gentian, as a stomachic. As a tonic and stomachic, it is usually prescribed in the form of infusion, extract, or powder; when as a carminative, or antispasmodic, the essential oil will be found the most effective. A tepid infusion of the flowers will often excite vomiting, and also promote the action of more powerful emetics. As a topical remedy the flowers are used in decoction, for fomentations, \&c.

Off. The Flowers.

Off. Pp. Decoctum Anthemidis nobilis, E. D. Extractum Anthemidis, L. E. Infusum Anthemidis, L.E. Oleum Anthemidis, L. E.

\section{POLYGONUM BISTORTA,}

\section{Greater Bistort, or Snake-weed.†}

\section{Class Octandria. Order Trigynia.}

Nat. Ord. Holokacee, Linn. P'OLygonea, Juss.

Gen. Char. Calyx 0. Corolla 5-parted, calycine. S ed one, angular, naked.

* Morton, Exercit. 1. de Febr. interm. cap. 6. Iloftmann, Diss. de Præstant. Remediis Domesticis. Heister, Diss. de Medic. Germ. indig. p. 13.

+ Fig $a$. represents the root and radical leaves, the flowering stalk being removed. b. The top of the stem terminating in a spike of flowers of the natural size. c. The pistilla. d. A perfect Dower, magnified. e. Seeds. 
Spec. Char. Stalk perfectly simple, with a rough spike. Leaves ovate, decurrent upon the petiole.

'THIS species of Polygonum* is a perennial plant, indigenous to Britain, and is found growing in moist meadows, in various parts of the country, flowering in May or June; in the North of England it is known by the name of Easter giaut, and used as a pot-herb; Bistort is also frequently met with in the neighbourhood of London, about Battersea, Hampstead, Highgate, \&c. $\dagger$

The root of the Bistort is about the thickuess of a finger, perennial, rugose and crooked, and furnished with numerous small fibres, of a firm texture; externally of a blackish brown, internally of a reddish or flesb colour; the stalk is simple, solid, round, smooth, swelling at the joints, is enclosed by the sheaths of the stipulæ, and rises to about two feet in height; the radical leaves are ovate, inclining to heart-shaped, pointed, and stand upon long winged footstalks; the upper leaves embrace the stem, and are narrower and somewhat undulated; the flowers are of a flesh colour, and stand upon short foot-stalks, and termiuate the stalks in oblong close spikes; the bracteæ, or floral leaves, are membranous, withered, and each encloses two flowers; the corolla (or calyx) is small, tubular, and divided at the brin into five obtuse, concave segments, the base of which contains several small, red, nectarious glands; the filaments are eight, tapering, white, and longer than the corolla; the antheræ are of a purplish colour, lying across the filaments; the germen is triangular, of a deep red; the three styles, the length of the filaments, supporting small round stigmata; the seeds are of a brown colour, triangular, and remarkably glossy.

SENSible QUALities, \&c. Every part of this plant manifests. a considerable degree of stipticity to the taste: it lias no remarkable smell; the root is considered to be one of the most powerful of the vegetable astriugents ; "the infusion is of a pale yellowish red, very stiptic and austere; green vitriol (i.e. sulphate of iron) strikes it black inmediately, and salt of tartar renders it thick. The saturated decoction is of a brown red, opaque, and changes a large proportion of a solution of green vitriol to a violet colour." $\ddagger$ The as-

* Thirty-one species of Polygonum are known and cultivated in our gardens; ten of which are natives of Britain. Hort. Cant.

+ Bistort has been considered to be the Oxylapathum Britannicum, and Limonium of the Ancients. Vide Bauh. Pin. 192, Matth. 946.

$\ddagger$ Gray's Elements. 



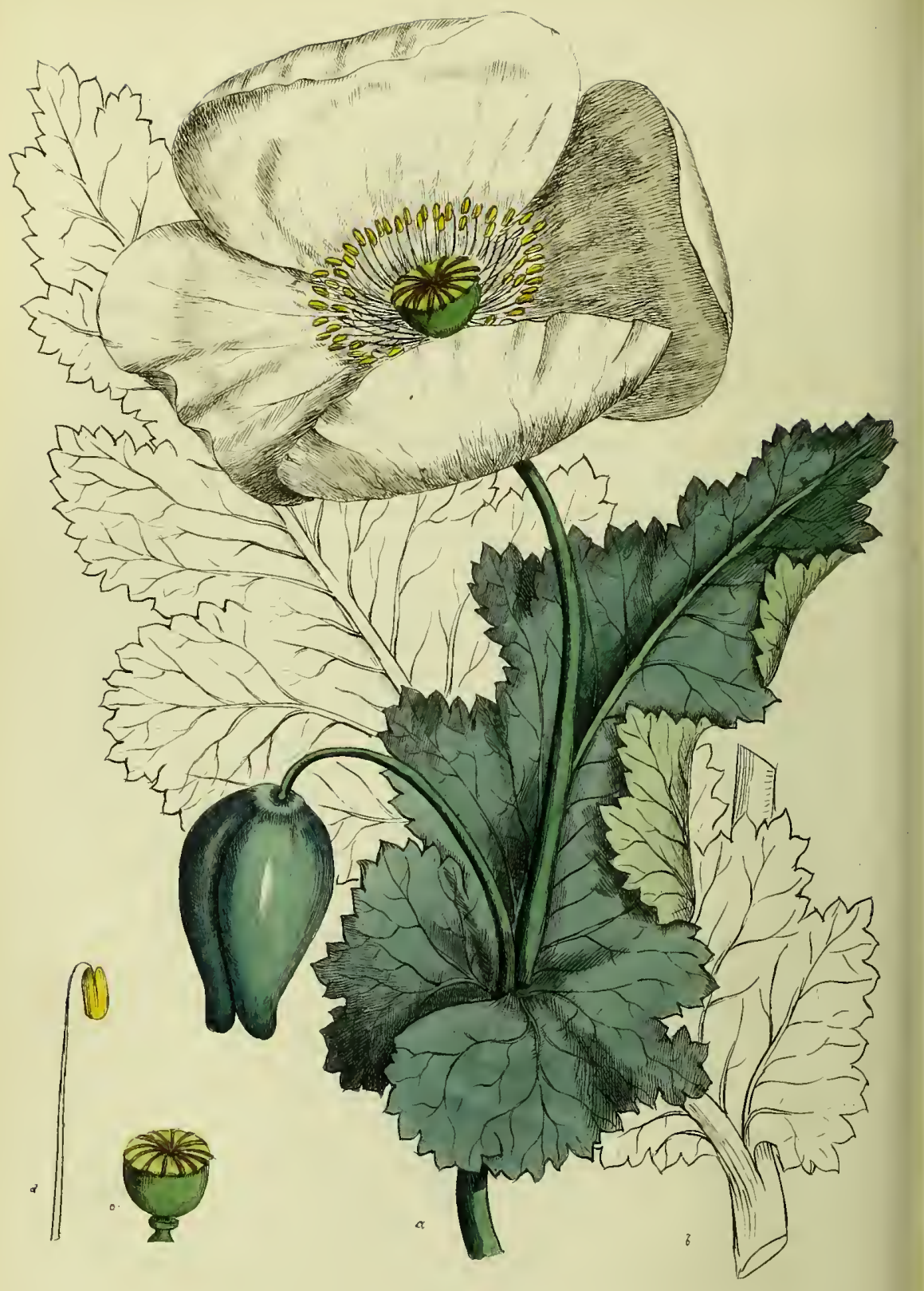

SPRATT,delalithog

Prinzed by Ingrey \& Madeley

Lon don Prtb, by Callow-Wils on Princes St Soho. Mareh 15t. 1828 
tringent matter is totally dissolved both by water and alcohol; the root after the action of either menstrunm remaining insipid.

Medical Properties and Uses. Bistort was formerly held in much repute, and highly extolled for its antiseptic, sudorific, and anti-pestilential virtues; but it does not appear to merit the encomiums bestowed upon it. As an astringent, it posseses vel'y considerable powers; it has been employed in hemorrhages and other immoderate fluxes; it has also been recommended in intermittent fevers; * but in modern praclice it is not often employed, althongh from its powerfully astringent qualities, it equals many of our exotic drugs: but the modern rage for foreign produce lias crept into our dispensatories, and goes nearly to exclude our indigenous plants, whatever valuable propertics they may possess. The root is given in substance from one scruple to one drachun three times a day.

Off. The Roots.

\section{PAPAVER SOMNIFERUM,}

\section{White Poppy.t}

\section{Class Polyandria. Order Monogynia.}

Nat. Ord. Rheanes, Linn. P'apaveracere, Juss.

Gen. Char. Calyx two-leaved. Capsule one cell, opening by pores under the persistent stigma.

Spec. Char. Calyx and Capsule smooth. Leaves incised, embracing the stem.

THis species of poppy is an annual, and although sometimes found wild in this conntry, it is generally considered to be a native of the southern parts of Asia: it has been long cultivated for the capsules and seeds, and also as an ornament in our gardens; many varieties being produced by cullivation with double blossoms, and of various beautiful colours.

* Cullen, Mat. Med. ii. 40.

+ Fig. a. represents the top of a plant, the blossom and bud of the natural size. $b$. The under side of a leaf attached to the stem. $c$. The pistillum, shewing the radiated stigma. $d$. An anther (magnified). 
The root is tapering-and branched; the stalk rises to the height of from three to five or six feet, erect, cylindrical, glaucous, of a pale green colour, and branched towards the top; the leaves are large, alternate, lobed, deeply cut into various segments, and embrace the stem; the flowers are large, terminal, and solitary; the calyx is composed of two smooth, decidunus, ovate, concave segments; the corolla is formed of four large roundish petals, the border somewhat undulated, of a white or purplish colour ; the filaments are numerous, shorter than the corolla, crowned with erect, compressed antlieræ; the germen is roundish, stigma many rayed: capsule of one cell, nearly globular, large, smooth, and filled with very small seed.

Preparation, \&c. Turkey opium is the inspissated juice of the white poppy, and comes to us from the East in solid compact pieces. The best sort are generally covered over with reddish cap. sules, (supposed to be a species of rumex) in which they are packed, the pieces devoid of this covering, are generally considered of an inferior quality. The opium which comes from the East Indies is much inferior to that which comes from Turkey, and may be known by its being of a much less consistence, of a darker colour and having an empyreumatic smell; its taste is likewise more nauseous and less bitter. Opium has also been obtained in this country from the capsules of the poppy, and equal to the best Turkey opium. The Society for Encouraging the Arts awarded Mr. Ball a premium, for his industry in producing some fine specimens of English opium, considered by the best judges to be equal to the finest Turkey opium. Several other persons have produced equally fine specimens, and in considerable quantities. But the variable state of our climate appears to be an obstacle to the general cultivation of this valuable drug, which no precaution or industry can overcome.

Opium is obtained from the capsule of the poppy by making several longitudinal incisions with a knife, having from three to five blades; this operation is usually performed in the evening, and the juice that flows during the night, is collected next morning, by means of iron scrapers, and put in an earthen pot to evaporate to a due consistence in the sun; this operation is performed every day so long as any quantity exudes from the capsules to make it worth collecting;

* The single blossom is generally white; the double ones vary both in depth of shade and colour, beĭng of purple, scarlet, and rariegated hues. Ed. 
when sufficiently inspissated in the sun to form into masses, these are covered with tobacco or poppy leaves. An inferior sort of opium, possessing the property of the genuine opium in a very slight degree, is obtained by evaporating a strong decoction of the stalks, leaves and capsules to a due consistency; this sort is seldom used in this country but for the purpose of adulterating the genuine opium.

Sensible Properties. Opiun when good, is a solid, opaque, tenaceous substance, somewhat brittle, of a dark brown colour, and of a strong heavy smell, and bitter taste; when cut through the surface, it is compact and shining; when broken, the fracture earthy ; not fusible, but the heat of the hand is sufficient to soften it; when dried, reduced to powder with difficulty, unless in the cold ; when powdered, of a light brown; giving but little colour to the saliva when chewed; highly inflammable, burning witlı a white flame: partially soluble in water and alcohol; boiling water dissolves about five ounces out of one pound troy; the watery solution is not decomposed by alcohol. The clear watery solution of Turkey opium yields a precipitate with any of the carbonates of potass or soda, with ammonia, acetate of lead, muriate of mercury, nitrate of silver, sulphates of iron, copper, and zinc; nitrate of mercury, and the infusion of galls. The narcotic properties of opium are impaired by long boiling in water, but nothing rises in distillation with that liquid.

Chemical Properties and Analysis. According to the analysis of the chemists, M. M. Derosne, Sertuerner, and Robiquet, opium is composed of,-1st. a fixed oil ; 2nd. of a matter analogous to eaoutchouc; $3 \mathrm{rd}$. of a vegeto-animal substance not yet investigated; 4th. of mucilage; 5th. of feculent matter; 6th. of resin; 7th. of vegetable fibre; 8 th. of narcotine; 9th. of meconic acid; 10th. of another vegetable acid; and 11 th. of morphine. As the active properties of opium seem to reside in the two newly discovered alkalies, morphine and narcotine, which enter into its composition, we shall speak of each separately; not indeed from experience, as opium in this concentrated form has not, that we know of, as yet been prescribed in this country.

Morphine. This substance does not exist in opium in its pure alkaline state, but united to an acid, to which the name of meconic acid has been given. According to M. Brande, the ultimate elements contained in pure morphine, are- 


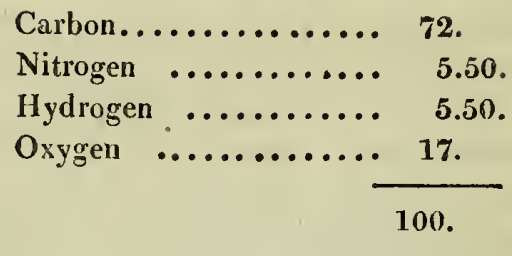

M. Bussy, chemical operator at L'Ecole de Pharmacie, has also found it to contain a small quantity of azote, about oue-twentieth.

M. Robiquet arlopted the following method for obtaining morphine; he boiled a very concentrated solution of opium for fifteen minutes with a small quantity of magnesia, in the proportion of 10 grains of the latter, to llb. of the former; the greyish deposit produced by this operation he collected on a filter, and washed it with cold water. When this precipitate was well dried, he heated it for some time with weak alcohol, at a temperature below boiling. By this process he separated much of the colouring inatter, and a very little morphine. The precipitate he then filtered, and washed by means of a little alcohol; after which, it was strongly boilerl in a large quantity of the same spirit rectified. The liquor being again filtered, while in the state of ebullition, the morphine separates as it cools. The colouring matter is afterwards got rid of by repeated crystallization. Dr. Thomson gives the following, which he considers an easy method of procuring morphine in a state of purity. He precipitates a strong infusion of opium, by means of caustic ammonia; this precipitate he separates by the filter; the infusion is then evaporated to one-sixth its volume, and a new precipitate. obtained by again treating the infusion with caustic ammonia; this precipitate is morphine mixed with colouring matter; when sufficient time has been given for the deposit to form, he separates it by means of the filter, and washes it with cold water. After it is sufficiently drained he sprinkles it with alcohol, which passes through the filter, dissolving and carrying with it a large portion of the colouring matter and a little of the morphine. The remaining morphine is then dissolved in acetic acid, and ally colouring matter removed by ireating the solution with a little ivory black, the mixture being often shaken during twenty-four hours, and then thrown on the filter. The liquid passes through perfectly colourless, and by treating it a third time with the caustic ammonia, the morphine falls down in the form of a white powder. By dissolving this base in alcohol, and allowing the solution to evaporate spontaneously, the morphine is 
obtained in the form of beautiful crystals, each a rectangular foursided prism. These crystals are perfectly white, slightly transparent, entirely devoid of odour, and of an extremely bitter taste. Dr. Thomson obtained from good Turkey opium, nearly three times the quantity of morphine which the same weight of East India opium yielded. Pure morphine is but little soluble, and its narcotic powers are best manifested when it is combined with an acid, the salts of morphine being much more soluble than morphine itself; as already said, it is in combination witl an acid that it is found in opium. Magendie says, "I employed the acetate, the sulphate, and the hydrochlorate of morphine, and found that these salts afford all the advantages which we can expect to meet with in opium, without any of its inconveniences." The acetate of morphine which has been introduced into the Paris Pharmacopœia, is prepared as follows:-.Take four parts of morphine, and of distilled water, eight parts; dilute the morphine in a porcelain vessel, and add acetic acid of the specific gravity 1.075 , until turnsol paper is scarcely tinged red; evaporate the solution, and coutinue the evaporation until the salt may be collected and reduced to powder. Morphine, as well as its acetate, is prescribed in doses of from one-eighth of a grain to a grain. In Paris it is usually administered in the form of a syrup, composed of the acetate and honey.

NaRCotine. The other active ingredient of opium is obtained by exhausting the crude opium in two parts of boiling ether, and repeating the operation five successive times. The solution obtained by this process is then mixed and filtered, and the ether volatilized until the whole is reduced to three-fourtlis. The product consists of two distinct parts; of a saline crust, consisting of narcotine united with an acid ; and of a brown, bitter, acid liquor, also containing narcotine, an acid, and a resin. To obtain the narcotine from this liquor, it must be subjected to evaporation, the residuum treated with boiling water, and the narcotine precipitated from the filtered liquor by ammonia. The narcotine is afterwards to be separated from the resin and caoutchouc, by treating the saline crust in which it is contained with rectified oil of turpentine, and washing the residuum with cold alcohol. This residuum is then dissolved in hot alcohol, and the narcotine precipitated by ammonia. The two precipitates are then dissolved in the least possible quantity of hydrochloric acid, and again precipitated by ammonia. The narcotine thus obtained crystallizes in fine needles or rhonboidal prisms. It has no action on vegetable colours; is without smell or taste, slightly soluble in cold alcohol, while boiling alcohol dissolves VoL. I. 
$\frac{1}{2 \cdot 3}$ of its weight. Hot ether dissolves it freely, and suffers it to crystallize on cooling. According to $\mathbf{M}$. Magendie, a single grain of pure narcotine dissolved in oil, and given to a dog, produced a state of stupor, but very different from sleep, and death generally in twenty-four hours. Narcotine combined with aceti cacid, be found to produce quite a different effect, twenty-four grains having been given to an animal without its perishing. While under its influellce, he says, they are agitated by convulsions, similar to those produced by au over-dose of camphor; the same signs of fright, the same incapability of going forward, the foaming at the mouth, and convulsions of the jaws. The most interesting, and indeed the most important experiment related by Magendie, was the action of the conbined substances, morphine and narcotine, on a dog. He dissolved a grain of each in acetic acid, and introduced the mixture into the pleura of the animal, which soon fell asleep; but lıe says a very remarkable struggle appeared to go on for an liour between the strangulating effects of the narcotine and the anodyne effects of the morphine; at last the animal slept, probably under the sole influence of the morphine. He adds, "may it not be inferred from this experiment, which $I$ have often repeated in various ways and with analogous results, that the variable effects of opium are to be attributed to its containing these two opposite principles?" From these experiments of Magendie, $\mathbf{M}$. Robiquet was tempted to prepare an extract of opium which should be entirely devoid of narcotine. For this purpose, he macerates: bruised opium in cold water, filtrates and evaporates to the consistence of a thick syrup, which he digests in rectified ether, and after frequent shakings, decants the solution; the ether is then separated by distillation. This operation is repeated as long as any crystals of narcotine appear as the residue of the distillation. When these crystals can no longer be discovered, he evaporates the solution to a pilular consistence, which he considers as entirely devoid of narcotine. M. Magendie in recommending this new preparation of opiun to the attention of physicians, says, "I have tried the extract, thus prepared, on animals. Its action appears to be decidedly narcotic, and entirely like that of morphine, only weaker." Mr. Hadell, the able translator of Magendie's work on these new pre- . parations, very properly observes, that "the freedum from narcotine which characterizes the extractum opii (which is aqueous) ought to recommend it to medical men as preferable to the tincture of opium, which contains narcotine in abundance, on account of its being a spirituous solution." We liave ourselves known many persons 
who could not use any other preparation of opium but the watery extract.

ACTION of OPIUM, \&c. Having treated so much at length of the properties of the active ingredients of opium, we shall now notice its action on the living system, in what may be termied its crude state, in which alone it lias ás yet found a place in our Pharmacopœias. This áction hás long been a subject of controversy among the learned of our profession, some ascribing to opium a direct sedative effect and denying that it produces any stimulait effects whatever; while others have as strongly asserted that it is a powerful stimulus, and that its sedative effects are merely the consequence of the previous excitement. We think the recent discoveries of the French chemists must set these controversies at rest, and that the truth is, it acts either as a sedative or a stimulant, according as the patient is under the influence of the morphine or the narcotine. The stimulant effects of opium are most apparent from small doses; which increase the energy of the mind, the frequency of the pulse, and the heat of the body, exciting thirst, and rendering the mouth dry and parched; all the secretions and excretions also are checked, except the cuticular discharge, which is increased; to these effects succeed languor and lassitude. In larger doses the stimulant effects of opium are not so apparent; while the excitability is diminished in a remarkable degree, and confusion of the head, vertigo, and sleep are produced. Should further experience coufirm the experiments of M. Magendie, we shall at last be able to administer opium a a direct sedative, without any of those baneful effects produced by its stimulating properties. The effects of opium in very largé doses are extremely energetic, producing the most violent symptoms, followed by speedy death. The following are among the symptoms which usually follow an everdose of this narcotic; head-aclie, vertigo, delirium, stertorous breathing, stupor or insensibility; a pale and cadaverous countenance, pupils insensible to the impression of light, inuscles of the limbs and trunk in a state of relaxation, lower jaw fallen, skin colder than natural, and death. Many cases are recorded of persons being poisoned by opium and its preparations; and even the external application has not unfrequently produced deleterious effects. It is related that a person died in consequence of having a clyster administered containing four grains of opium, * and an opiate plaster applied to the temples has produced spasms in the mouth and madness. $\dagger$

* Gaubins, Method. Concinn. Form. Lugd. Bat. 1762, p. 420.

+ Monro, Essays and Observ. Phys, aud Lit. vol. iii. p. 297. 
Treatment in cases of Poisoning by Opium. When opium has been taken in an overdose and symptoms of poisoning arise, repeated doses of tartar emetic, or sulphate of zinc, or copper, should be given at intervals till voniting is excited; tickling the throat with a feather, and draughts of infusion of mustard, will assist in stimulating the stomach to action. Solutions of alkaline carbonates decompose opium, and render the morphia iusoluble; with this intention they should be given, and if the person is incapable of swallowing, they should be exhibited through an elastic tube passed down the cesophagus, or by neans of a stomach syphon; or when practicable, the poison itself may be removed by means of the syphon. To counteract its effects, (after as nuch as possible of the poison has been evacuated) stimulants should be given, as the volatile alkali, assafotida, brandy, camphor, and musk; the person should likewise be kept constantly in motion and not allowed to sleep; a blister should be applied to the head, and sinapisms to the feet, as symptoms may indicate; tea, coffee, and lemon juice also may be givell ad libitum.

Medical Uses. Opium, when prescribed with judginent, is perhaps the most valuable article in the Materia Medica. As a sedative, it is in general use to diminish pain; but it is sometimes very difficult to ascertain the quantity requisite to answer the intention: some constitutions being extremely susceptible of very small doses, whilst others require tenfold the quantity to produce any effect. Some persons cannot bear opium in any quantity or under any form, the smallest dose occasioning nausea, head-ache, vertigo, disturbed sleep, or watchfulness; and larger doses producing still more untoward symptoms. When opium is prescribed as a stimulant, small doses frequently repeated will best promote the desired effect. When a sedative is required, to allay spasm or procure sleep, a full dose should be given at once, proportioning the dose to the particular state of the person and the disease.

In many diseases opium is the only medicine that can be given with advantage, especially when spasm is the urgent symptom to be removed; as in the passage of biliary and renal calculi, dysuria from spasm, tetanus, colica pictonum, cholera, pyrosis, \&c. In diarrhœe, after any offending natter has been removed by aperients, opium is given with the best effect; and in dysentery, after the intestines have been freely evacuated, opium will afford much relief in allaying tenesmus and pain. In various stages of syphilis, smallpox, rabies canina, hysteria, dyspepsia, puerperal convulsions, $\&$ c. opium, in conjunction with other medicines, is given with decided 
benefit. Opium has also been given with much benefit in the hot stage of intermittents; and in typhoid fevers, in conjunction with camphor and ether, it is often extremely useful.

Opium is exhibited in a variety of forms, either alone or in combination with other medicines; it is given in substance, in powder, in solution in wine or diluted alcohol; or as described in various chemical preparations. In many cases in which opium is indicated, the stomach is so extremely irritable and disposed to reject whatever is taken, that no liquid will renain down : in these cases, opium in a solid form will frequently be found retainable. But as already said, the recent discoveries here detailed may effect a total revolution in the use of this active substance; this consideration, and the extreme importance of opium as a medicine, have led us to devote more space to the subject, than the limits of our work would otherwise have warranted.

Off. The Capsules, and the concrete juice of the capsules, called $O$ pium.

Off. Pp. Confectio Opii, L.

Decoctum Papaveris, $\mathbf{L}$.

Electuarium Opiatum, E.

Emp. Opii, L. E.

Ext. Opii, L. E. D.

- Papaveris, L. E.

Pil. Opiatæ, E.

— Sapon. c Opio. L.

- e Styrace, D.

Pulvis Cornu usti cum Opio, $\mathrm{L}$.

- Cretæ comp. cum Opio, L.

-_ Opiatus, E.

Syr. Opii, D.

- Papaveris, L. E. D.

'Tinet. Opii, L. E. D.

Camphorata, L. E. D.

Vin, Opii, L. E. 


\section{DELPHINIUM STAPHISAGRIA.}

\section{Palmated Larkspur, Dolphin Flower, or Stavesucre.}

Class, Polyandria,-Order, Trigynia.

Nat. Ord. Multishliquet, Linn. Ranunculacee, Juiss.

Gen. Char. Calyx 0. Petals 5, the upper one spurred. Nectary bifid, horned behind, three-capsuled.

Spec. Char. Nectary 4-leaved, shorter than the petals. Leaves palmate, with the lobes obtuse.

The Delphinium $†$ tribe of plants appears to be nearly allied in habit, and bears a great resemblance to the Aconitum or monk's-hond. Botanists reckon twenty-four species, of which the greater number are perennial, two ouly being biennial; of these, the Staphisagria is one.

The Delphinium Pictum bears a great resemblance to the species here figured, it is the one usually cultivated, and is not unfrequently mistaken for the Staphisagria; but the former may be distinguished from the latter by the length of the spurs, which in the Pictum are considerably larger than in the other; the stem of the Pictum is likewise smooth, and the foot-stalks of the flowers much shorter. The figure here represented, is taken from the one delineated in the Flora Græca, which we believe is almost the only correct representation of the plant. The stem is downy, smooth, erect, simple, purplish, and rises from one to two feet in height; the leaves are palmated, dividing into five or seven lobes, which are ovate or lanceshaped, veined, downy, of the colour of the stem, from which they arise alternately, and àre gradually shorter towards the top of the plant, so as to give the whole a regular conical shape; the flowers, which appear in June, are large, bluish or purplish, stand upon long footstalks, and terminate the stem in an open spike; the corolla is eomposed of five egg-shaped petals, the uppermost of which is extended backwards so as to form a hollow spur, or horn-like pro-

* Fig. a. represents a spike of flowers of the natural size. $b$. The lower part of the stem (from which the spike was cut off) representing the leaf and seed vessel. $c$. The stamens. $d$. Nectary. e. The germens.

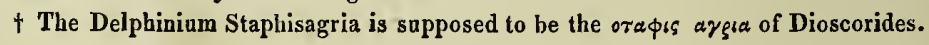




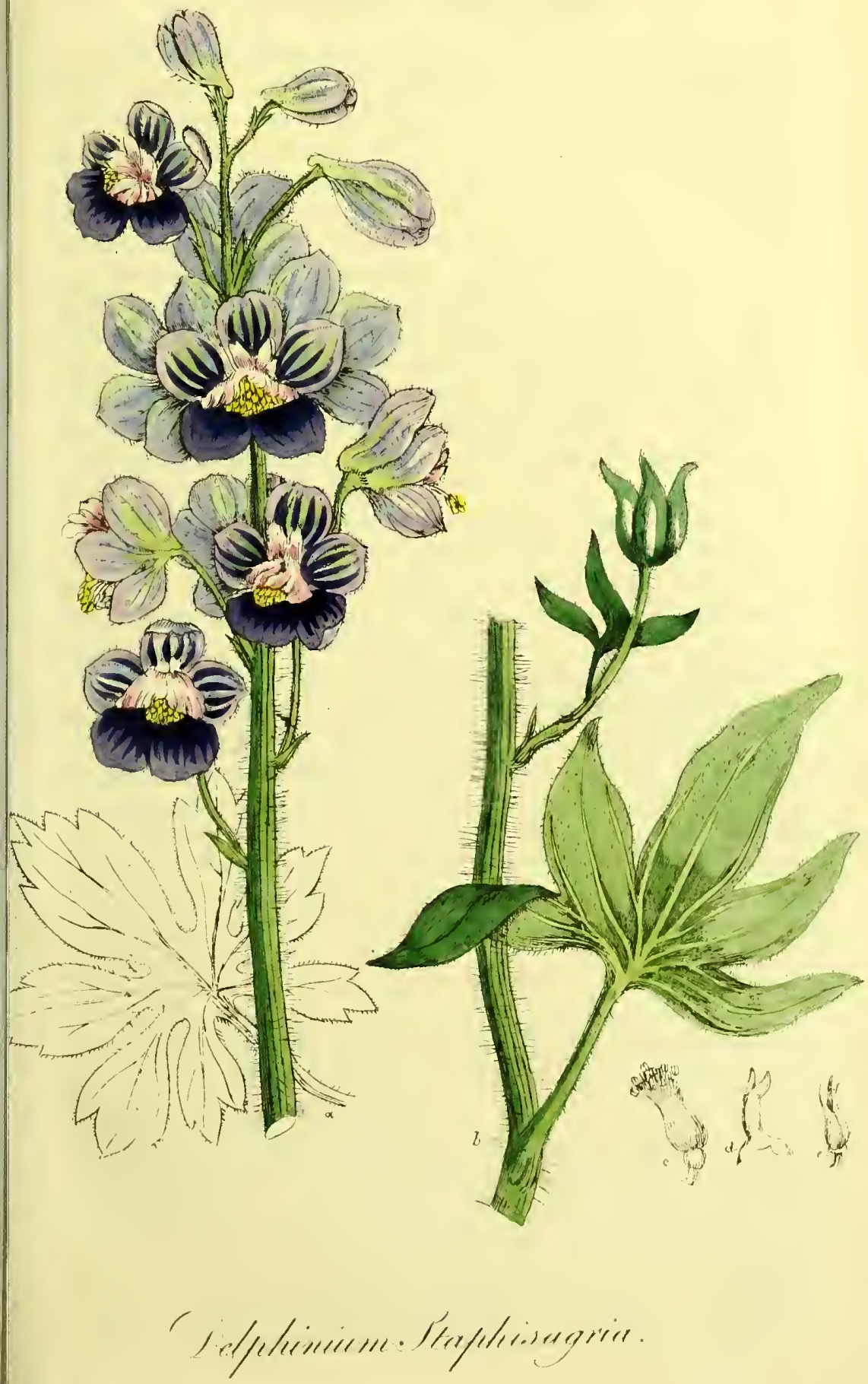


jection, which has given to this plant the English name of larkspur; the nectarinm is sometimes divided into two, but more commonly into four leaves, which are smaller than those of the corolla: the two superior (when there are four,) are narrow, small, erect, and at the base drawn out into spurs, like that of the petal in which they are enclosed, the other two are roundish and plaited at the edges; the filaments are about twenty, short, tapering, and crowned with large yellow antheræ; the germens of this species are three, closely compressing each other, tapering, very downy, and supplied with filiform, short styles, terminated by simple stigmata; the three capsules are straight, tapering, oblong, open internally, and contain many brown, rough, triangular seeds. This plant is a native of the South of Europe; it was cultivated in England in the time of Gerarde, in 1596 ; the seeds, the only part used in medicine, are usually inported from Italy.

Sensible Qualities and Properties. The seeds of stavesacre are rough, of a blackish brown colour externally, and of a pale yellow within; their smell is disagreeable and sonewhat fotid; thẹir taste very bitter, acrị and nauseous; when masticated, they excite a copiou s flow of the saliva.

Chemical Properties. From the analysis of M. Brandes, the seed of stavesacre contains the following constituents: fixed oil, very soluble in spirit of wine, 14.4; fixed oil; sparingly soluble in spirit of wine, 4.8 ; fatty matter, analogous to cetine, 1.4 ; delphine 8.1; gum, with traces of pliosphate of lime, and of a vegetable salt witl a base of lime, 3.15 ; fecula 2.4 ; woody fibre 17.2 ; phyteumacolle, with malate, acetate, sulphate, and hydrochlorate of potass, and salt, with a base of lime, $\mathbf{3 0 . 6 7}$; vegetable albumen 0.5 ; concrete albumen 3.2 ; sulphate of lime, with phosphate of magnesia, 3.62 : water 10 ; excess 1.49 .

Delphinine or Delphine. In 1819 MM. Feneulle and Lassaigne discovered in the seeds of stavesacre a new alkali, to which the name of Delphine was given, from a supposition that the acrid nature of the Delphinium family of plants was owing to the presence of this peculiar principle.

Delphine is prepared by boiling the seeds of stavesacre, previously cleared of their coverings and reduced to a fine paste, in distilled water; strain the decoction and filter it, to which add pure magnesia; boil for a few minutes, and again filter; the residue is to be carefully washed and digested in highly rectified alcolool : on evaporating the alcohol, the delphine is obtained in the form of a finesvlite powder, with some points of crystallization. Delphine is also pre- 
pared by digesting the unbruised seeds in diluted sulphuric acid, and precipitating by ammonia or sub-carbonate of potass; dissolve the precipitate in alcohol, and purify by drawing off the alcohol and re-dissolving in hydrochloric acid, then boil with magnesia; the deposit dissolved in alcohol affords the Delphine in a state of great purity.

Properties of Delphine. " Pure delphine is in the form of a white powder, crystalline when moist, but soon becomes opaque on exposure to the air; it is inodorous, and has a very bitter and acrid taste. Water dissolves so small a quantity of it, that it can only be discovered by the bitterness it communicates. Alcohol and ether dissolve it very readily. The alcoholic solution acts powerfully in turning the syrup of violets green, and restores the blue of turnsol paper when reddened by acids. Delphine forms with the mineral and vegetable acids very soluble neutral salts, the taste of which is very bitter and acrid. Alkalies precipitate it in the form of a white jelly."*

Action of Delphine on Animals. In the experiments of Orfila on dogs, this substance proved fatal in doses of six grains, (gr. 4.92 troy); this effect took place more rapidly when the Delphine was dissolved in weak acetic acid, in which case the animal died in the space of from forty to fifty minutes. Its action appears to be exerted chiefly on the nervous system. When death is not the immediate consequence of its action on the nervous system, it produces local irritation and subsequent inflammation : inflanmation however does not appear to be a necessary consequence of its noxious actiou on the stomach. $\dagger$

We have not learnt that Delphine has been used medicinally, but it is probable that in cases in which stavesacre might be indicated, Delphine would be preferable to any preparation of the plant, presuming that the active properties of the plant reside in this peculiar alkali. $t$

Medical Uses. Stavesacre was employed by the ancients as an emetic and cathartic, in doses of from ten to fifteen grains; $\S$ it was also employed by them as a masticatory, exciting on being chewed, a copious flow of saliva; its deleterious effects however were discovered to be so powerful, that its internal use has been long abandoned. Schultz, by only keeping it in his mouth to relieve the

* Magendie's, Formulary, by Dunglison.

+ Nouveau Journal de Médecine, vol. x. No. 38.

$\ddagger$ As water dissolves a very minute portion only of pure Delphine, the salts of which this alkali forms the base (on account of their solubility) should be employed.

- $\$$ Vide Dioscorid. and Sylvius De Purgant. \&\%. 

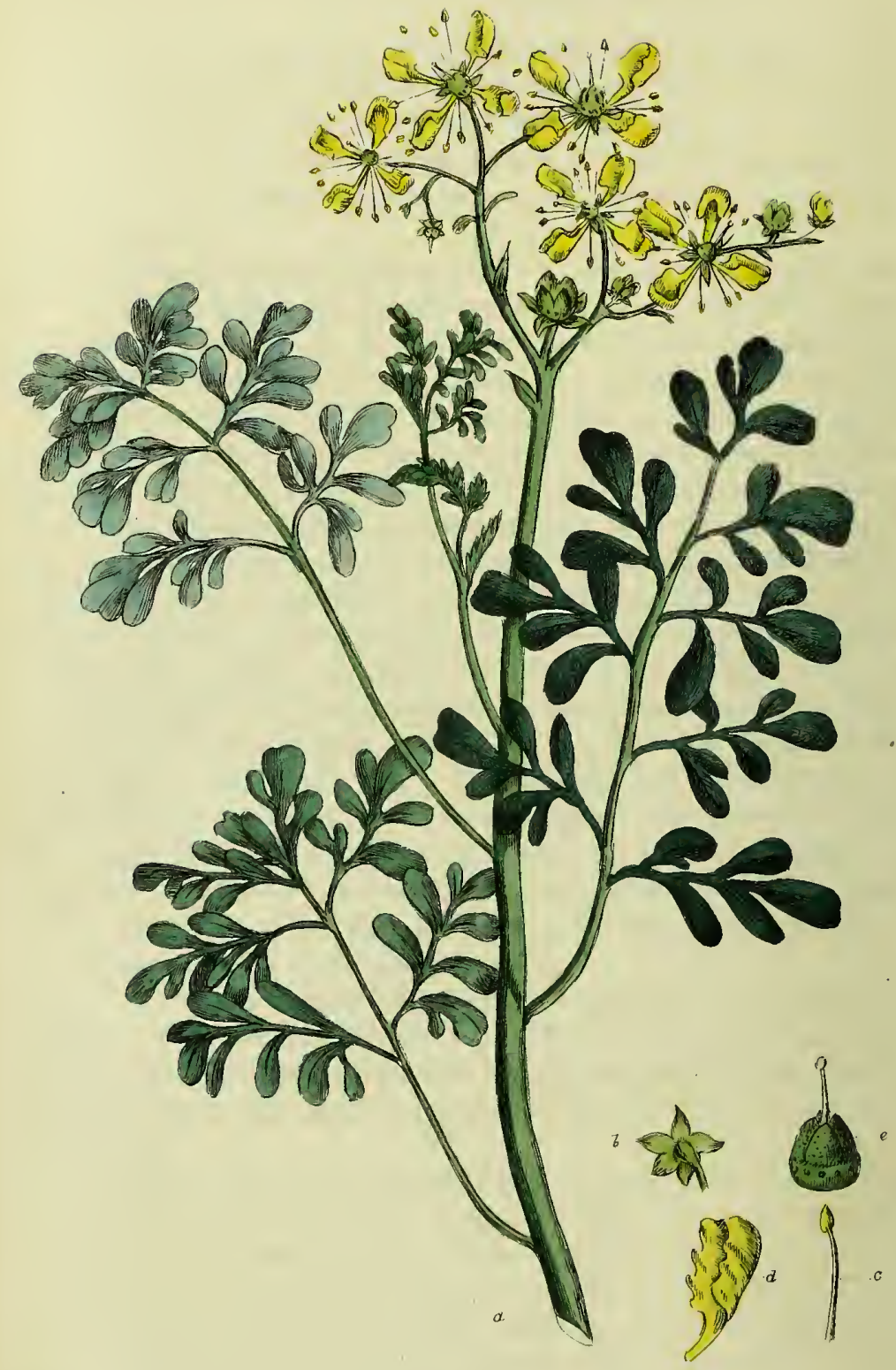
tooth-ache, was for a time deprived of his senses; * and Hillfield relates that a dog by taking five of the seeds, became convulsed and died. $t$ Orfila however tells us, that an ounce of stavesacre reduced to a very fine powder, was introduced into the stomach of a small robust dog, and the oesaphagus tied; yet, though the animal died fifty-four hours after the operation, it experienced neither vertigo nor convulsions. This author concludes that stavesacre is not absorbed, and that its deleterious properties depend on the local irritation it produces, and the sympathetic lesion of the nervous system. He likewise cousider's the part soluble in water as the most active. The use of stavesacre is now confined to external applications in some kinds of cutaneous eruptions, but more especially for destroying lice and otlier insects; its efficacy in this way has obtained for it the names of Herbe aux Poux, and louse-wort.

Off. The Seed.

\section{RUTA GRAVEOLENS.}

\section{Rue. $\neq$}

Class Decandria.-Order Monogynia.

Nat. Ord. Multisiliquæ, Linn. Rutaceæ, Juss。

Gen. Cha R. Calyx, a perianthum, 5-parted. Petals concave. Receptacle girt with ten honey-bearing pores. Capsule 5-lobed.

SPEC. Char. Leaves doubly compound. Lateral flowers 4-cleft.

THrs species of rue is a small shrubby plant, a native of the South of Europe; according to Sweertius, $\|$ it is also a native of

* Vide Mat. Med.p. 435.

+ Diss. de Venen. p. 20.

\# Fig, $a$, represents a cutting of the natural size, $b$. Calyx. c. A stamen magnified. d. A magnified petal. e. The germen magnified.

$\$$ Eight species of rue are cultivated in our botanic gardens. Hort. Cant.

II Sweert. Hort, 24.

VOL. 1. 
Africa ; and was found growing near Iedo in Japan by Thunberg." Rue was introduced into England about the year 1562, and is now cultivated in most gardens, flowering from June to September.

The roots send forth several shrubby stalks, which towards the bottom are strong, woody, and covered with rough grey striated bark : the upper or young branches are smooth, and of a pale green colour ; the leaves are compound, consisting of double sets of irregular pinnæ, which are minutely notched or crenated, of an obversely oval shape, and of a glaucous or bluish green colour; the flowers are numerous, and produced in a branchecl corymbus, on subdividing peduncles; the calyx commonly divides into four, and sometimes into five poiuted leaves; the corolla consists of four, and frequently of five petals, these are hollow or boatshaped, dentated or fringed at the edges, and of a yellow colour; the ten filaments are yellow, tapering, spreading, and generally lodged in the cavity of the petals : the autheræ are yellow and quadrangular; the style short; stigma simple; the germen is large, rough, oval, green, and marked by four longitudinal furrows in the form of a cross; the seeds are angular, rough, and of a blackish colour, contained in a four-celled capsule. The first account we have of the cultivation of rue in Britain is given by Turner, who published his Herbal in 1562 ; it is now common in our gardens, where it is cultivated as an evergreen.

Sensible Properties. Rue has a strong, ungrateful smell, and $a$ hot, bitter, penetrating taste; the leaves are so acrid, that by mere handling they are said to irritate and inflame the skin; the plant in its natural or uncultivated state is supposed to possess these qualities in a more powerful degree. Both water and spirit extract its virtues, the latter more perfectly than the forner. Rue contains a volatile oil, $\uparrow$ which readily congeals, and is obtained in the greatest quantity by distilling the plant with the seeds, half ripe.+ Orfila says that rue exerts a local action, capable of producing more or less of iuflammation, but in general not very severe; the essential oil he says, when introduced into the veins, acts like narcotics, and he thinks it probable that it exerts the same action when introduced into the stomach, but with less energy.

Medical Properties and Uses. Hippocrates commends

* Flor. Japan, p. 180.

+ From the experiments of Beaumé, it appears that the recent plants contain but a very small portion of essential oil: 21 lbs, of leaves yielded one drachm of oil; $10 \mathrm{lbs}$ of the seeds yielded two ounces.

‡ Edinburgh Dispensatory. 



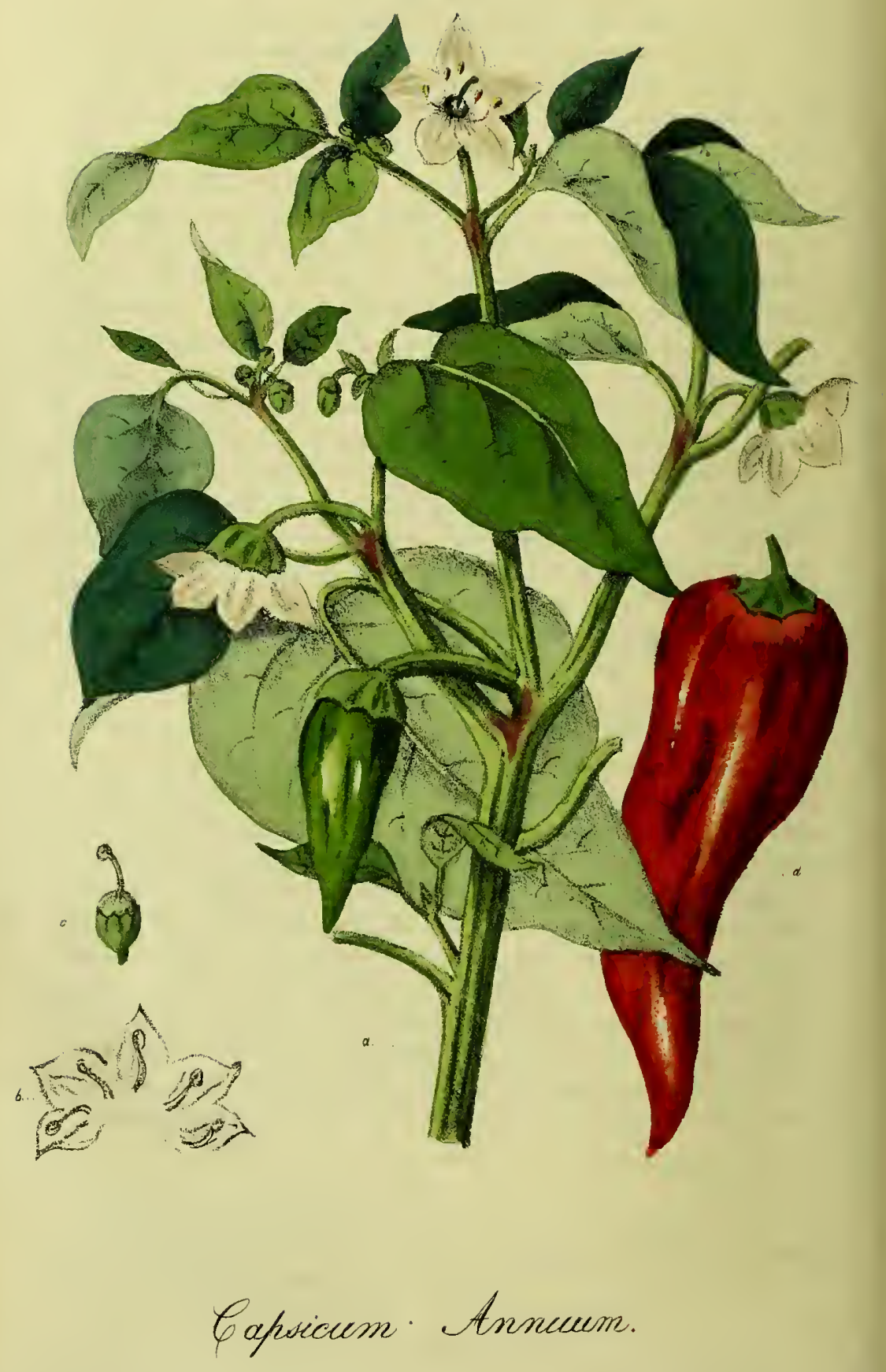

G. Spratt. dei

Lordon Pub. by $C_{s}$ Ilow and Wilron Princes S't Sobo 
this plant as a resolvent and diuretic, and attributes to it the power of resisting the action of contagion and other kinds of poison; with this intention it was used by Mithridates;" this imaginary quality is now however very little credited, though highly extolled by Boerhaave. According to Bergius, it is "alexiteria, pellens, emmenagoga, sudorifera, rubefacieus." It is doubtless a powerful stimulant, and nay be considered like other medicines of the fœtid kind to have deobstruent and antispasmodic powers; and to be peculiarly adapted to phlegmatic habits, or weak, lysterical constitutions, suffering from retarded or obstructed secretions.t Dr. Cullen says, "I have no doubt of its antispasmodic powers. $t$ "

Alibert $\$$ speaks highly of it as a uterine medicine, and says, "Cette plante a un grande action sur le système nerveuse, et particulierement sur le système uterine. Beaucoup de femmes en prennent dans les menstrues laborieuses." The leaves dried and burnt, are used by the natives of India for the purpose of funigating young children suffering from catarrh; and as an external remedy, mixed with arrack, in the first stages of paralytic affections.\|

Rue is given in powder, and in the form of extract, confection, and essential oil. Dose of either of the former, from ten grains to thirty, and of the last from three to five drops.

Off. The Herb, and Leaves.

Off. Pp. Conf. Rutæ, L.

Ext. Ruta, E.

Ol. Rutæ, D.

\section{CAPSICUM ANNUUM.}

\section{Annual Capsicum, Guinea or Cockspur Pepper.**}

\section{Class Pentandria.- Order Monogynia.}

Nat. Ord. Lu RID无, Linn. Solanex, Juss.

* Plin. l. xxviii. c. 8 p. 604.

+ The modern Greeks call this plant by the name of nnyavov $\delta$ vadss, and consider it a valuable medicine in epilepsy.

$\ddagger$ Cullen, Mat. Med. vol. ii. p. 365.

Nouveaux Elémens de Thérapeatique, vol. ii. p. 550.

II Ainslie's Materia Indica, vol, i. p. 351.

** Fig. a. represents a cutting, the leaf blossoms, and young fruit of the natural size. $b$. The corolla spread open to shew the five stamens, $c$. The pistillum. d. A ripe pod. 
Gen: Char. Corolla wheel-shaped. Berry juice-less, with 2 cells.

Spec. Char. Stem herbaceous. Peduncles solitary. Fruit oblong.

ThIs species of Capsicum is a native of "South America and the East Indies; it is cultivated in large quantities in the West Indies for making cayenne pepper, \&c.. It appears to have been introduced into this country about the year 1596. Guinea pepper, as its specific name implies, is an annual plant, frequently reared in our gardens for culinary purposes, and for the beauty of its pods; there are two varieties of this species, one with red and the other with yellow pods, but they differ in no other respect, tireir properties being the same. The stem of this plant is somewliat angular, smootl, crooked, much branched, and rises to the height of from two to four feet; the leaves are elluptical or ovate, pointed, veined, smooth, entire, of a dark green, and stand upon long footstalks in irregular order; on the stems; the flowers are solitary, and proceed from the axillæ of the leaves upon long footstalks; the calyx is persistent, angular, tubular, and divided into five segments; the corolla is monopetalous, of a yellowish white colonr, wheel-shaped, consisting of a short tube, divided at the limb into five segments, which are spreading, pointed and plaited; the five filaments are shorter than the corolla; the anthera are oblong and yellow; the germen is ovate; style slender, a little longer than the filaments, and terminated by a blunt stigma; the frait is a long pointed pendulous pod, at first of a fine shining green, changing as it ripens to a bright scarlet or deep yellow; it is filled with a dry pulpy mass, and many small, flat, kidney-shaped seeds.

Sensible Qualities and Chemical Properties. The various species of Capsicum have a spicy aromatic smell; their taste is extremely hut and pungent, a very small quantity when chewed, exciting that burning sensation, which is vulgarly expressed by having the mouth on fire, and which continues for a long time.

The principle on which the pungency depends, is soluble botl in water and alcohol, is not volatile, reddeus infusion of, turnsol; and is precipitated by nitrate of silver, muriate of mercury, acetate of lead, sulphate of zinc, sulphate of copper, carbonate of potass, alum, and ammonia; but not by the mineral acids.

* Nine species of capsicum are known and cultivated. Hort. Cant. 
Spirit of wine extracts the acrid and pungent principle, but when distilled off, the spirit passes over deprived of this principle, leaving an acid orange-coloured resinous substance, which lias lately been considered as a vegetable alkati (named Capsicine); this substance is readily soluble in water, and extremely acrid.

C.Ayenne Pepper. This substance, as it comes to us from the West Indies, is a mixture of many different species of Capsicum, but chiefly the pods of the Capsicum Frutescens, (a shrubby plant) commonly knowı by the niames of Barbary or bird's-eye pepper, which is the hottest species of Capsicum ; ${ }^{*}$ to this, muriate of soda is always added. The cayenne pepper of commerce clianges infusion of turnsol to a beautiful green; this is owing to the muriate of soda, or red oxide of lead, which is said to be sometimes mixed with it also.†

Economical Uses, \&c, Cayenne pepper is in general use as a condiment, and when taken with moderation, is perhaps preferable to the Eastern spices; it prevents flatulence from vegetable food, and promotes digestion; although taken to excess, it is supposed to produce visceral obstructions.

In hot climates, particularly the West Indies $\ddagger$ and some parts of Spanish America, capsicum is eaten both with animal and vegetable food, in very large quantities; in Peru especially, it enters so abundantly into their sauces, that to a person unaccustomed to it, their taste is intolerably lot.

Medical Properties and Uses. Capsicum as a medicine, is one of the nost simple and powerful stimulants we possess, its action not being followed by any narcotic effects; hence, in all diseases where a strong stimulant is indicated, we may expect decided benefit from its use ; it has been found a powerful remedy in the Cynanche Maligna, taken interually and used also as a gargle. In loss of speech arising from paralysis of the tongue, a gargle composed of capsicum, and used several times a day, has been prescribed with decided success. $\S$ Bergius says that in obstinate agues, taken immediately before the cold stage was coming on, it has

* This species of capsicum, called by the English, Chillie, is cultivated in every part of India on account of the pod, or rather pod-like berry, and is much used by the natives as a warm seasoner. In the island of Ceylon there are varieties of the Capsicam Frutescens, red, yellow, and black.-Ainslie's Materia Indica, vol. i. p. 306. et seq.

+ Red lead may be detected, by digesting a portion of the cayenne in acetic acid, to which add sulphuret of ammonia, which will produce a dark coloured precipitate if lead be present. $E d$.

$\ddagger$ Vide Brown's Jamaica, p. 176.

$\$$ Vide Case by F. Bassett.-Lancet, vol ii. p. 29. 
prevented a return of the fit.* Many of the West India practitioners strongly recommend it in the advanced stages of yellow fever, and direct it to be given in the form of pill, + in doses of three grains, repeated every two or three hours. In tropical fevers attended witls delirium or coma, the application of cataplasms coniposed of capsicum to the feet, has been altended with good effects.

Capsicum forms a good adjunct to mercury to prevent the griping which frequently attends the taking of that mineral. In dropsy, and other diseases where chalybeates are indicated, the addition of a small portion of capsicum has been strongly recommended. Dose of the tincture from ten to thirty drops; the powder. from three to ten grains.

Off. The Fruit or Berry.

Off. Pp. Tinctura Capsici, L. D.

LAVANDULA SPICA.

Lavender, or Spike Lavender.\$

Class Didynamia.-Order Gymnospermia.

Nat. Ord. Verticillate, Linn. Labiate, Juss.

Gen. Cha R. Calyx ovate, slightly toothed, supported by a bractea. Corolla resupine. Stamens within the tube.

Spec. Char. Leaves linear-lanceolate, spike interrupted, naked at the summit.

The Lavandula Spica grows spontaneously in many of the southern parts of Europe, and was introduced into England prior to the year 1568; it is now in general cultivation for the sake of its flowers, the fragrance of which is a favourite with most people; it flowers from June to September. All the species of lavender known

* Mat. Med.p. 144.

$\dagger$ Capsicum when given in the form of pills, should be well coated with dough or wafer, to prevent the burning sensation which it would otberwise excite in the mouth and throat. $-E d$.

¥ Fig. $a$. and $b$. represent a sprig of the natural size. $c$. The germen supporting the style and stigma. d. A flower magnified, and cut open to show the stamens. e. A bractea. $f$. The calyx. 


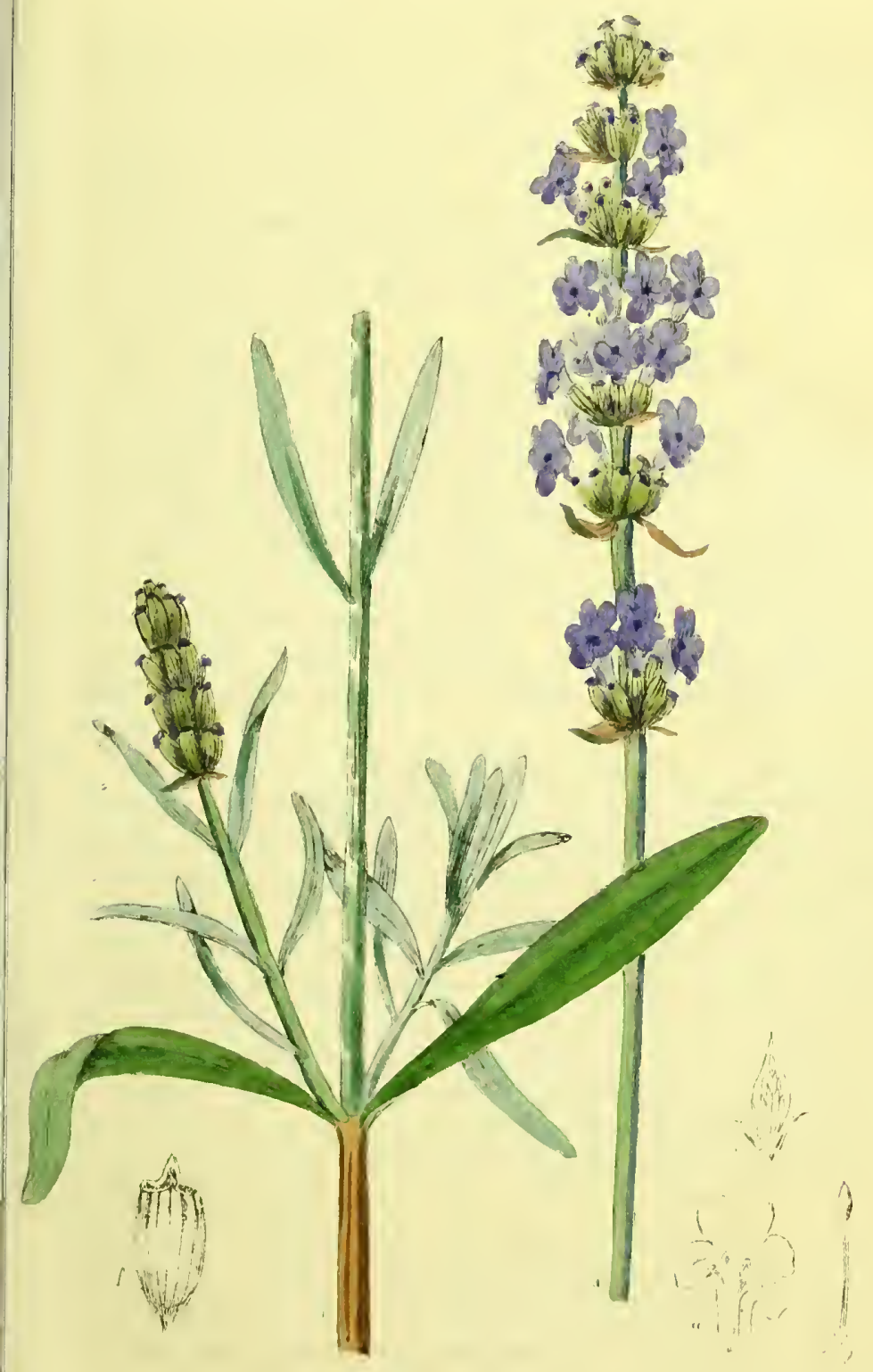

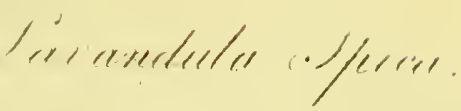



are natives of southern climates; ${ }^{*}$ two of these are in general cultivation in this country, the Lavandula Spica, (broad-leaved lavender) and Lavandula Angustifolia (narrow-leaved): these two by some botanists are considered as varieties only, but Miller $\dagger$ and others class them as distinct species.

The Lavandula Spica is a perennial shrubby plant, much branched, and rising to the height of four or five feet; the younger branches and shoots are of a pale green, but the old woody part of the stem is brown and rough.

The leaves are numerous, linear, long, narrow, entire, sessile, and of a whitislı green colour; the flowers form terminating spikes upon the young shoots, of a bright purplish colour, and consist of interrupted whorls; the calyx is ovate, and supported by a bractea; the corolla consists of a cylindrical tube, divided at the mouth into two lips, the uppermost of which is the largest, and divided into two segments, the lower is trifid, and expands downwards; the filaments are four, enclosed within the tube of the corolla, and support small simple antlieræ; the germen is composed of four naked seeds, from which rises a slender style, supporting a bilobed stigma.

Sensible and Chemical Properties. The flowers of lavender have a strong fragrant smell, the leaves are weaker and less grateful ; the taste of both leaves and flowers is somewhat bitter, aromatic and pungent, heating the mouth when chewed. An infusion of the flowers is fragrant, of a reddish colour, and grows black with sulphate of iron; alcohol extracts the qualities of lavender completely; by distillation in water, the leaves yield a small quantity of essential oil; the flowers a much larger proportion, 15lb. yielding nearly 5 oz. of a very fragrant oil, of a greenish yellow. The foreign oil of lavender, or true oil of spike, is distilled from the tops of a different species or variety, by a quick fire. It is said, that a few drops of the oil of lavender rubbed on the binding of books prevent their becoming mouldy. $f$

Medical Properties and Uses. Lavender has been an officinal plant a very considerable time, although we have no certain account given of it by the ancients. The medicinal virtues of lavender reside entirely in its essential oil, which experience proves to be a gentle stimulant of the aromatic kind. Dr. Cullen observes,

* Nine species are enumerated in the Hort. Cant.

+ Vide Gardener's Dict.

‡ Gray's Elements. 
that among the plants entitled cephalics, lavender has perhaps the best title to it; and whether applied externally, or given internally, it is a powerful stimulant to the nervous system.*

Bergius speaks highly of it, and says, "Virtus, nervina, resolvens, tonica, emmenagoga." Lavender is now however chiefly used as a perfume, being seldom prescribed but in combination with other medicines. A mixture of one part of oil of lavender, and three parts of turpentine, or rectified spirit, was formerly a very celebrated application to old sprains, indolent tumours, diseased joints, \&c. It was sold under the name of oil of spilse, and still holds its reputation with the uninformed.

Off. The flowering Spikes.

Off. Pp. Oleum Lavandulæ, L. E. D.

Spiritus Lavandulæ, L. E. D.

Composit. L. E. D.

\section{ARTEMISIA ABSINTHIUM.}

\section{Common Wormwood.*}

\section{Class Syngenesia.-Order Polygamia Superfuna.}

Nat. Ord. Composita Discoideæ, Linn. Corymbifere, Juss.

Gen. Cha R. Receptacle either hairy or naked. Pappus none. Caly $x$ imbricated, with rounded converging scales. Florets of the ray, none.

Spec. Char. Leaves compound, multifid, Flowers sub-globose, pendulous. Receptacle villous.

THE genus Artemisia comprises nearly fifty species, $₫$ natives of almost every country in Europe, and of Asia. Of the four officinal species, three are indigenous to Britain.

* Mat. Med.p. 513.

+ In the annexed drawing, fig. $a$. represents the calyx magnified. b. A magnified corolla spread open to shew the insertion of the stamens. c. A perfect floret magnified. d. The pistillum magnified.

$\ddagger$ According to the Hort. Cant. forty-eight species are cultivated in the various botanic gardens. 
The Artemisia Absinthium is a perennial plant, a native of Britain; in its wild state it is usually fornd growing on waste rubbishy soils, near the sides of roads, and in rocky places; in the neighbourhood of London it is pretty largely cultivated for medicinal and other purposes.*

The root of this plant is woody, branched, and at the lower part fibrous; the stems rise to the height of one or two feet, erect, branched, striated, and leafy; the leaves are compound, and divided into many obtuse segments, the lower leaves are bipinnate, the upper ones digitated or pinnatifid, and stand upon short fontstalks; the leaves and stems are covered with a very soft silky down; the flowers are hemisplerical, drooping, of a yellow colour, and grow in racemes, placed alternately upon the branches-each flower is accompanied by oblong bracteas; the calyx is imbricated, and composed of many oval scales; the florets of the disk are numerous, perfect, and divided into five segments, those of the radius less numerous and destitute of stamens; the filaments in the perfect flowers are five; the anthers are united and form a five-toothed tube; the germen supports a long recurved style, crowned with a cloven stigma; the seeds are obovate, naked, and placed upon a convex villous receptacle.

This species of Artemisia is supposed to be the Absinthium Ponticuin of Dioscorides and Pliny. It is one of the principal herbaceous bitters, and it is said, communicates a bitter taste to the flesh and milk of cows and sheep that feed upon it. $\dagger$

Sensible Qualities, Chemical Properties, \&c. The leaves of wormwond, when recent, have a powerful and (to most people) a very disagreeable smell; the taste is intensely bitter; the flowers are less bitter, and somewhat aromatic; and the roots are warm and aromatic, without the bitterness of either of the former. Both water and spirit extract its virtues, and in distillation with the former it yields a dark green essential oil, in the proportion of from six to ten drachms from $25 \mathrm{lbs}$. of the herb, with the smell and flavour of the plant. The watery infusion is of an olive colour, and turws black with the addition of sulphate of zinc or iron. Wormwood by analysis has yielded 66 per cent. of a vegetable acid combined with potass,

* The leaves and tops of wormwood were formerly much used in the brewing of malt liquor, and when infused in ale, formed the favorite liquor called purl. We are told thut the distilfers of whiskey nse them in place of hops. $E d$.

- + Linn. Flora Suec. n. 735.

vox. I. 
14.8 resin, 15.4 of uncombined acid, 3.7 muriate of potass, the ashes being chiefly carbonate of lime.

Medical Propertes and Uses. The properties of wormwood are chiefly derived from its bitter quality, hence its use as a stomachic and tonic; formerly it was held in great esteem : Boerhaave, Linnæus, Haller, and others, speak of its good effects in a variety of diseases, viz. intermittents, hypochondriasis, obstruction of the liver and spleen, gout,* calculi, scurvy, \&c. In the words of Bergius, its viriues are " antiputredinosa, antacida, anthelminthica, resolvens, tonica, stomachica;" but in modern practice chamonile and gentian have almost entirely supplanted the use of this plant, it being now seldom employed. A decoction of the leaves and tops is used as an antiseptic fomentation; the essential oil possesses the virtues of the plant, is stimulating, and has been used with success as an antispasmodic and anthelnintic; the extract possesses the property of a simple bitter only, hence it may be prescribed where bitters are indicated.

Off. The Leaves and Tops.
Off. Pp. Ext. Absinthii, D.

\section{ARTEMISIA MARITIMA.}

\section{Sea Wormwood.}

\section{Procumbent before flowering.}

Spec. Char. Leaves pinnatifid, downy. Racemes drooping. Flowers oblong. Receptacle naked.

THIs species of wormwood is a pereinial native plant, growing plentifully in salt marshes and on the sea shore, and flowering in August and September.

The root is spreading and fibrous; the stems are procumbent, about a foot in height, branched, and leafy; the leaves are numerous, irregularly divided into many narrow linear segments; both the leaves and stems are covered with a very soft cotton-like substance, communicating to the whole plant a whitish appearance; the flowers are

* Wormwood formed one of the principal ingredients in the Portland powder, once celebrated for the cure of gout. 


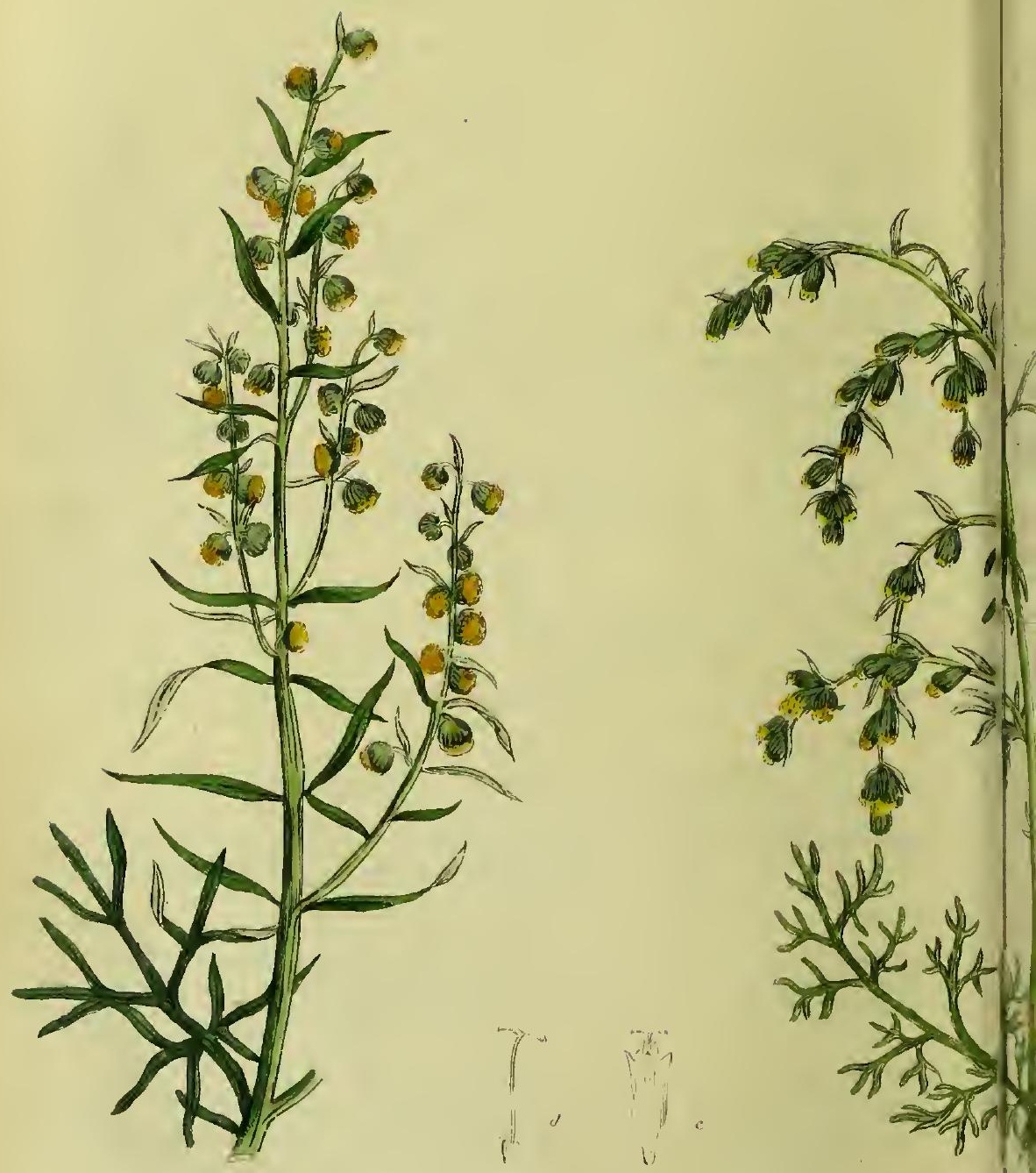

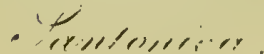



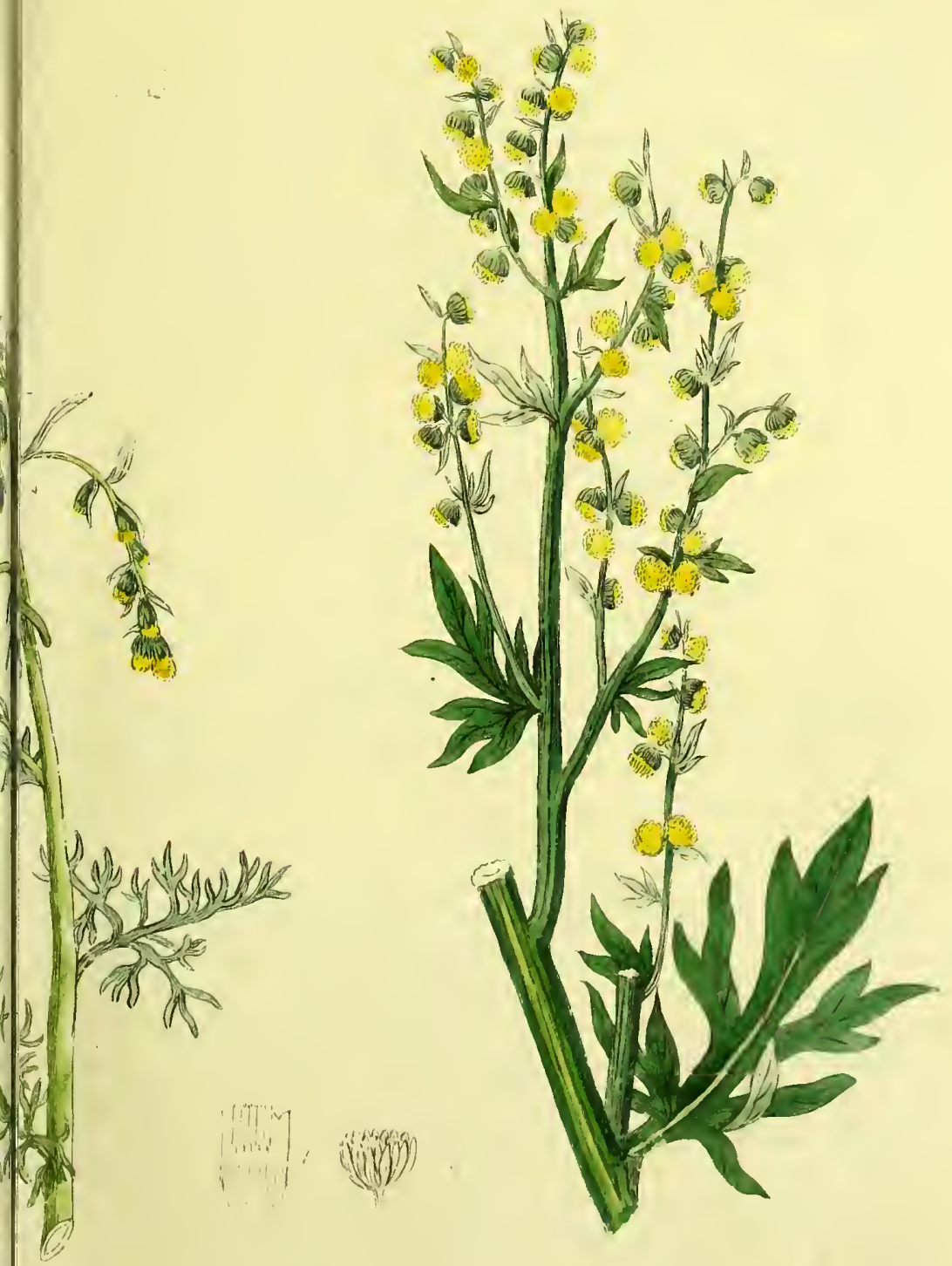

- Il:milllirien. 

placed in unilateral racemes, are oblong, drooping, and of a yellow colour; the calyx is composed of many roundish scales, the outer. ones of which are woolly; the florets, in their structure resemble those of the Absinthium; the receptacle is naked.

- Qualities, Medical Properties and Uses. The sensible qualities of this plant resemble (though much less powerful) those of common wormwood; and as its virtues depend upon these qualities, it must be considered a medicine of little efficacy. Sea wormwood in its taste is more aromatic, and its bitter quality less nauseons than common wornwood; as such, where a slight tonic is indicated, it may often supply the place of the latter.

Off. The Tops.

\section{ARTEMISIA SANTONICA.}

\section{Tartarian Southernwood.}

\section{Procumbent before Flowering.}

Spec. Char. Stem Leaves pinnate, linear, multifid. Branches undivided. Spikes 1-ranked, reflexed. Flowers composed of five florets.

ThIs species of Artemisia is a hardy perennial shrub, flowering from September to November. It is a native of Siberia, Tartary and Persia, and was cultivated in England previous to $\mathbf{1 7 6 8 .}$

The stem rises to the height of two or more feet, erect, and branched; both stem and branches are somewhat hoary; the flowers terminate the stem and branches in spikes or racemes, and stand upon short footstalks; the flowers are of a brownish yellow colour, and in their structure resemble those of the common wormwood; the receptacle is naked.

The seeds of this plant (the officinal part) are imported from the Levant, and sold under the name of worm-seed; these seeds are usually mixed with bits of stalk and the scales of the calyxes; they are also often adulterated with the seeds of other plants. The genuine seeds are small, smooth, oblong, and of a greenish yellow colour, and are said to be not only the produce of the Artemisia San- 
tonica, but also of various other species of the same genus, as the Artemisia Judaica, Austriaca, \&c.

: Qualities, Medical Properties, \&c. The sensible and chemical properties of this plant resemble those of the Absinthium already described. The seeds have a very hitter and somewhat acrid taste, a strong disagreeable smell, and are heating and stimulating: these seeds lave been long employed as an anthelmintic, and have been considered a very effectual remedy for the expulsion of lumbrici. They are given to children, finely powdered, in doses of from ten to thirty grains, and to adults in double the quantity, combined with syrup, honey, or treacle: this quantity is usially taken two or three times a day, occasionally interposing a cathartic; or they are conjoined from the first with jalap, calomel, rhubarb, or sulphate of iron: Formerly the seeds were considered to be emmenagogue, but are now never employed but as a vermifuge.

Off. The Seeds.

\section{ARTEMISIA ABROTANUM.}

\section{Common Southernwood.*}

\section{SHRUBBY ERECT.}

Spec. Cha R. Leaves setaceous, pinnatifid. Stem very branching, shrubby.

THis species of Artemisia is called by the Greeks Aßpozovov, a name supposed to be given to it from its extreme bitterness. Southernwood is a perennial shrub, a native of France, Spain, Italy, Carniola, China, and other southern climates. In England it was first cultivated by Gerarde, about the year 1596, and its great fragrance has obtained for it a place in most gardens. Although it bears the cold of our variable winters, it seldom flowers in this country.

The roots of this plant are woody and fibrous; the stalk rises to the height of two or three feet, shrubby, covered with a smooth brown bark, and sends out numerous branches; the leaves are nume-

- This plant being well known, and never employed in modern practioe, we have not thought it necessary to give a figure of it. 


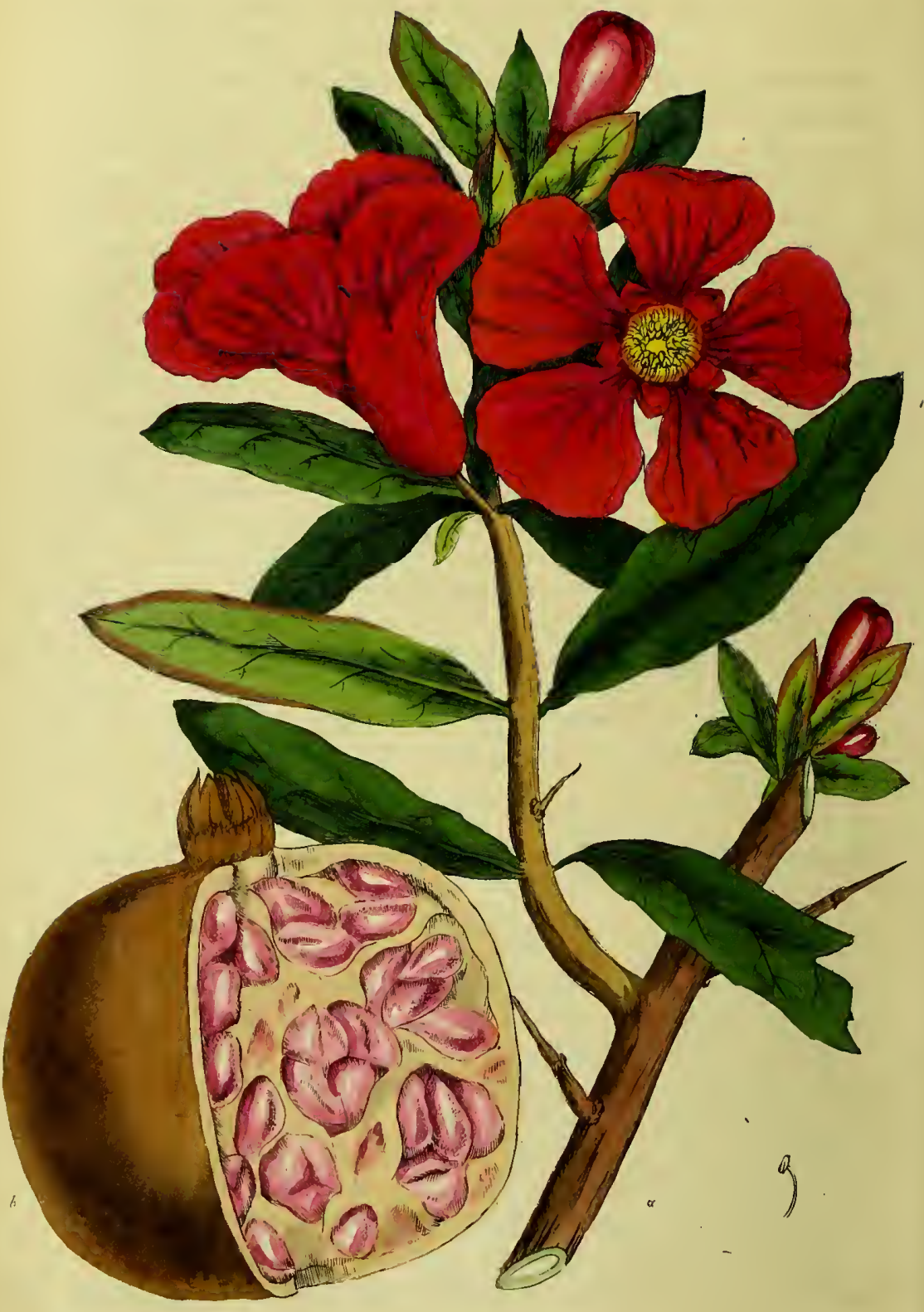

Senceder. Girmereterne:

Printed by Irgroy \&Madeley.

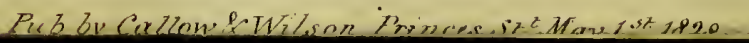


rous, tomentose, doubly and irregularly pinnate, and supported upon long footstalks; the pinnæ are linear, long, narrow, entire, concave on the upper surface, and convex beneath; the flowers are small, of a yellowish colour, grow in close spikes, terminating the branches, and in their structure resemble those of the Artemisia Absinthium; the seeds are solitary and naked.

Qualities and Chemical Properties. The leaves and tops have a very powerful and, to most persons, a very agreeable odour; the taste is bitter, pungent and nauseous. These qualities are extracted both by water and spirit; to the latter, they give a very beautiful green colour ; the watery infusion is of a brown colour, and turns black by the addition of sulphate of iron. In distillation with water, they yield a small quantity of essential oil of a yellow colour :* viz. five or six pounds about oue drachm of oil.

Off. The Leaves.

\section{PUNICA GRANATUM.}

\section{Pomegranate Tree.†}

\section{Class Icosandra.-Order Monogynia. Nat. Ord. Ром асев, Linn. Myrte, Juss.}

Gen. Char. Calyx 5-cleft, superior. Petals 5. Pome manycelled, many seeded.

SpEc. Cha Leaves lanceolate. Slem arboreous.

This species of Punica, according to Dierbach, $\ddagger$ is the $\pi 00 \varepsilon \varepsilon \delta \eta$ of Hippocrates. It is a native of Persia, Barbary, Arabia, and Japan, and also of the southern part of Europe; in the East and West Indies it is now much cultivated, and in the latter country produces fruit of the finest quality. We are informed by Olivier, in

* The medical properties of this plant agree so nearly with those of the other species of Artemisia, and it is now so seldom prescribed, that we think it annecessary to swell onr pages with an enomeration of its supposed virtues. $E d$.

$\dagger$ Fig. $a$. represents the leaves and flowers of the atural size. $b$. The frnit cut open to shew the pulp. c. An anther somewhat magnified.

$\ddagger$ Vide Dierbach's Materia Medica of Hippocrates, c. iv. 
his Travels in the Ottoman Empire,* that the finest pomegranates in Turkey are those of Ghemlek. The Greek writers, it appears, were well acquainted with the pomegranate: Celsus valued the fruit as a stomachic, and Pliny speaks of the flowers called Balaustium, " medicinis idoneus, et tingentibus vestibus, quarum color inde nomen accepit;" and also tells us that the fruit was sold in the neighbourhood of Carthage. + The pomegranate was first cultivated in England about the year 1596, and now forms an ornamental tree in many of our gardens; it is cultivated chiefly for the beauty of its flowers, the fruit seldom arriving to perfection.

This small tree rises to the height of about fifteen or eighteen feet, it is covered with a bark of a brown colour, and divided into many small branclies, which are armed with spines; the leaves are oblong or lance-shaped, pointed at both ends, veined, of a deep green, wavy, entire, about three inches long, and half an inch broad, sessile or placed upon very short footstalks; the flowers are large, of a rich scarlet colour, and proceed from the end of the young branches; the calyx is bell-shaped, thick, fleshy, and of a deep red colour, and divided at the extremity into five pointed segments; the corolla is composed of five large roundish wrinkled petals, of a scarlet colour, with narrow claws, by which they are inserted into the calyx; the stamens are numerous, filaments short, bent inwards, and inserted in to the tube of the calyx, and supporting yellow antheræ; the germen is inferior, roundish, and supports a simple style the length of the filaments, terminated by a globular stigma; the fruit is about the size of an orange, and crowned with the segments of the calyx, the rind is thick and tough, externally of a reddish brown, internally yellow, filled with a rose coloured succulent pulp, enclosed in a transparent cellular membrane; the seeds are numerous, oblong and angular, each enveloped in a separate portion of the pulp. The pomegranate tree flowers from June to September.

Qualities and Chemical Properties. The juice contained in the succulent pulp of the fruit is mucilaginous and slightly acid, hence refreshing, and calculated to quench thirst; the flowers are inodorous, and gently stiptic ; the outer rind of the fruit is very stiptic to the taste; with water it yields nearly half its weight of a very austere extract, but gives out very little of its astringent matter to alcohol. The infusion of the rind is of a deep red, thick, and gluti-

* Vol. i. p. 9.

† Pliny, lib. 13, ch. xix. p. 197. 
nous; coagulating into a fine red jelly on adding spirit of wine, and growing black and also glutinous with sulphate of iron.

Medical Properties and Uses. The fruit of the pomegranate is not in general use in this country, although the powerfully astringent quality of the rind might, we think, entitle it to be more generally employed. The juice and pulp may be taken ad libitum to quench thirst and abate febrile heat, and form an excellent substitute where oranges are indicated. We are told by Dr. Ainslie,* " that the Hindoo doctors prescribe it, combined with saffron, when the body is preternaturally heated." The bark of the fruit, as well as the flowers, are useful astringents. Dr. Cullen observes, that " the strong stiptic taste of the bark, and the black colour it strikes with green vitriol, shew sufficiently its astringent power. I have frequently found it particularly useful in gargles, in diarrhœea, and in external applications." The flowers are also gently astringent, and may be given as well as the rind, where astringent medicines are indicated. The bark of the root has of late years been successfully employed as a powerful vermifuge for destroying the tape-worm. Dr. Ainslie says, "The efficacy of the bark of the root of the pomegranate tree, as a renedy for the tape-worm, is now well established in India. It is given in decoction, prepared with two ounces of the fresh bark, boiled in a pint and a half of water till but three quarters of a pint remain; of this, wlien cold, a wine-glassful may be drank every half hour till the whole is taken. This quantity occasionally sickens the stomach a little, but seldom fails to destroy the worm, which is soon after passed." $\dagger$ It lias also been successfully employed by several physicians on the Continent. Dr. A. Duncan says, "I also made some trials of it, on the supposition that it was the astringent principle which acted chemically upon the gelatinous body of the worm, and the result was promising; but the introduction of the oil of turpentine superseded the necessity of prosecnting the experiment."

Off. The Bark of the Fruit, and the Flowers, called Balaustines.

* Materia Indica, vol. i. p. 322.

+ Ibid, vol. ii. p. 175. 


\section{DAUCUS CAROTA.}

\section{Wild Carrot.*}

\section{Class Pentandria.-- Order Digynia.}

Nat. Ord. Umbellat e, Linn. Umbellifere, Juss.

Gen. Char. Flower:s separated. Petals inversely heartshaped, unequal. Fruit hispid.

Spec. Cha R. Stem bristly. Leaves tripinnate. Leaflets pinnatifid, with linear-lanceolate acute segments. Involucre nearly as long as the rays of the umbel. Fruit bristly.

The Daucus Carotat is a native biennial plant, flowering in June and July, and generally found growing by the sides of fields and pastures; thriving best on light chalky and gravelly soils : provincially it is called bird's nest, or bee's nest, from the resemblance . the umbels form as they approach to maturity, to a bird's nest.

The root of the wild carrot is spindle-shaped, fleshy, externally of a yellowish colour, (the roots of the cultivated species, which by most botanists is reckoned a variety only of the wild, is so well known as to need no description); the wild carrot rises to the height of about two feet, erect, round, hairy, furrowed, and branched; the leaves are alternate, bipinnate, and stand upon broad footstalks, hairy, especially on the under side, and of a dark green; the umbels terminate the branclies, are composed of several radii, and form a flat surface at the top while in flower, but as the seeds ripen, the external rays become incurved and drawn logether, which renders the inner surface of the umbel hollow, giving the character of a bird's nest, (hence the provincial nanue) the partial umbels are similar to those of the general: the general involucre consists of many pinnatifid leaves shorter than the umbel, the partial ones undivided or 3-cleft; the corolla is composed of five unequal petals ; the five filaments are capillary and furnished with simple antheræ; the germen is small and supports two reflected styles, crowned by

* Fig. $a$. represents a cutting with the umbel in flowers. b. In seed. c. 'Phe top part of a root. $d$. A magnified blossom. e. The germen. $f$. A.ripe seed:

+ Nine species of the Genus Daucus are known and cultivated. Hort. Cant. 


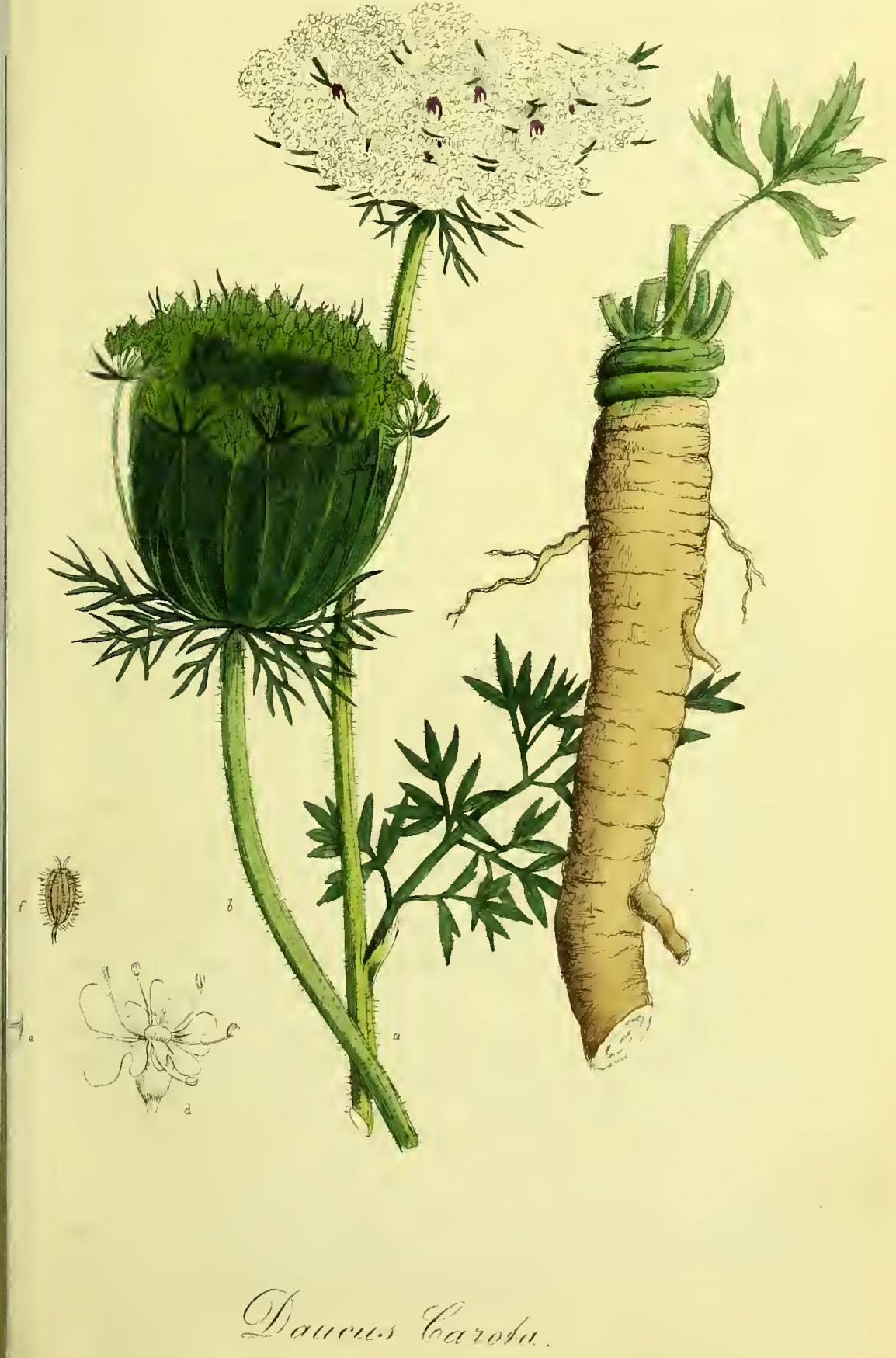



blunt stigmata; the seeds are in pairs, ovate, convex, rough on one side and covered with strong bristles and flat on the other.

Various species of the Daucus have been held in great esteem as an article of food and medicine, by ancient and modern writers; both Pliny and Celsus speak of the carrot, and the $\sigma \tau \alpha \Phi U \lambda$ ivos ar $\% 105$ of Dioscorides is supposed to be the Dancus Carota of the moderns. Although most botanists consider the cultivated carrot to be a variety only of our wild native species, and have endeavoured to improve the latter by various modes of cultivation, yet they do not appear to have succeeded in producing equally edible roots from the seeds of the wild species, as from the cultivated variety: it is therefore, not improbable, but that we are indebted to some exotic species for our edible carrot. * We are told by Pliny, (book xxv. c. 9), that in his days the finest roots were those of Candia and Achaia.

Sensible and Chemical Properties. The seeds of the wild carrot have a slight aromatic smell, and a warın aromatic, and somewhat bitter and acrid taste. Water digested on the seeds, becomes impregnated with their odour, but takes up little of their taste ; on distillation with water, the whole of the odour and aromatic warmth of the seed becomes elevated, and when large quantities are submitted to the process, a small portion of essential oil of a yellowish colour is obtained, of a moderately pungent. taste, and smelling strongly of the carrot. Alcohol extracts the whole of their virtues by digestion.

Medical Properties and Uses. The seeds of the wild carrot possess the aromatic and carminative qualities, common to most of the umbelliferous plants; lience they have been long esteemed and recommended in flatulent colic, obstructed menstruation, calculous complaints, \&c. but they have been chiefly celebrated for their diuretic powers, although Dr. Cullen says, "We have seen the Sem. Dauci employed in calculous cases, in considerable quantities and for a length of time, but never found its diuretic powers anywise remarkable." $\dagger$ The seeds however are now but little used; as a topical remedy, the roots of the garden carrot beaten into a pulp, form an excellent application to cancerous and other ill-conditioned

* It was the opinion of Miller, that they were different species. Vide Gardener's Dict. Art, Daucus. The Cultivation of carrots is so simple, and so well known to every person possessing a spot of garden ground, that we presame it quite unnecessary to swell our pages with a particular description of it. Ed.

+ Mat. Med. vol. ii. p. 552.

VOL. I. 
ulcers, relieving pain and abating the foetid smell.* As an article of diet carrots may be considered wholesome, seldom disagreeing with those who eat them in moderation, and from the large portion of saccharine matter they contain afford much nourishment; $\uparrow$ carrots when eaten raw, or not sufficiently boiled to be tender, are certainly of difficult digestion, and as indigestible substances were thought to be pernicious to worms, raw carrot was formerly a popular remedy, and was given to children as a vermifuge:

Off. The Seeds of the wild, and the Roots of the garden carrot.

\title{
INULA HELENIUM,
}

\author{
Elecampane. $\ddagger$
}

Class Syngenesia.-Order Polygamia Superflua.

Nat. Ord. Composite Discoides, Linn. CORYMiBIfERE, Juss.

Gen. Char. Receptacle naked. Pappus simple. Calyx imbricated. Anthers with two bristles at the base.

Spec. Cha R. Leaves ovate, rugged, clasping the stem, tomentose beneath. Calyx scales ovate, leary.

TwENTY-six species of the genus Inula are cultivated in our botanic gardens; $\S$ the Inula Helenium is indigenous to Britain, although rarely to be met with in its wild state. Elecampane is also

*. The use of the carrot poultice was first discovered by Salzur.

See Journal de Medicine, t. 24, p. 68.

+ "'l'he Arabians place carrots among their Mohelyyat, (Aphrodisiaca), a proof that they never could have sapposed them to be iudigestihle, which they have been by some reckoned; the fact is, that when well boiled, they are of peculiarly easy digestion, and very nutritious." Ainslie's Materia Indica, vol. i. p. 57.

$\$$ Fig. $a$. represents a branch of the natural size. b. Florets of the disk. c. A perfect floret. $d$. A floret with the corolla removed to shew the anthers. $e$. A floret of the radius. $f$. The anthers spread open.

Hort. Cant. 


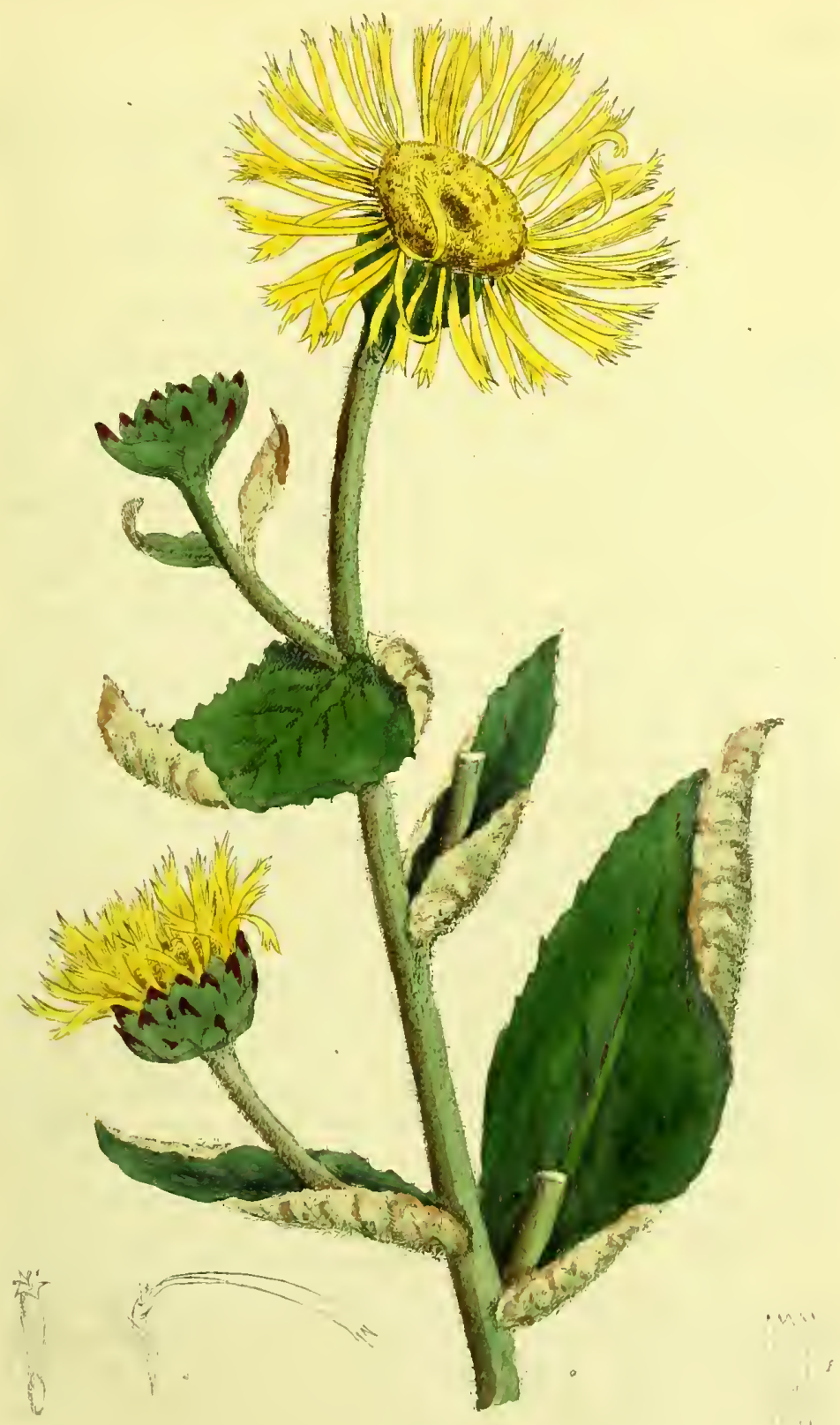

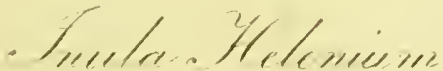



a native of many parts of Europe and Japall, but whether our native species is the same noticed by. Pliny and Dioscorides remains in doubt.* Inula is also mentioned by Horace,-

\section{Erucas virides, inulas ego primus amaras, \\ Monstravi incoquere.-Sat. viii. v. 51. \\ quûm rapula plenus \\ Atque acidas mavult inulas.-Sat. ii. v. 44.}

The anclents entertained a high opinion of this plant, and esteemed it a medicine of great efficacy in the cure of many diseases, which modern experience however does not confirm. Elecampane is a perennial plant, delighting in moist meadows and pastures; it has been occasionally met with in several parts of the east, west, and northern counties, viz.-in Essex, Norfolk, Sussex, Bedfordshire, Cornwall, Surrey, \&c.

The root is large, thick, fusiform and brancherl, externally brown or grey, internally whitish; the stalk grows upright, round, striater, branched, solid, and downy, and rises to the height of three or four feet; the leaves are ovate, serrated, crowded with reticular veins; mid-rib strong and fleshy; upper'surface of a deep green, under side downy; the stem-leaves are sessile and clasping, the radical ones are very large, and stand upon footstalks; the flowers are compound, large, terminal, and of a deep yellow; the calyx is composed of several rows of strong imbricated ovate segments; the corolla is composed of numerous florets, those occupying the disk are of a regular tubular form, divided at the brim into five equal segments, and are hernaphrodite; each containing five stamens; the anthers united, so as to form a hollow cylinder (and furnislied with bristles at their base); germen oblong, style slender, stigma bifid, the florets of the radius are female, at the lower part tubular, the upper ligulated, and cut into three narrow pointed segments; the style cloven, supporting an obtuse stigma; germen oblong; seeds solitary, striated, quadrangular, and furnished with a simple down; the receptacle flat and reticulated.

Sensible and Chemical Properties. The leaves, and more particularly the root, in their recent state, possess a somewhat strong, rancid, pungent, and glutinous taste, succeeded by an aromatic bitterness; the cdour of the roots when recent is both foetid and aromatic; these qualities are improved by drying; the former

* It is probable that elecampane is the Hclenium foliis Verbasci of Dioscorides.Vide lib. i. chap. 27. 
being diminished, and the latter increased by the process. Both water and alcohol extract its virtues, the latter better than the former; an essential oil rises in distillation with water, and concretes upon the surface in white flakes; this oil possesses the flavour and odonr of the plant, which qualities it soon loses by keeping. According to Funke's analysis, the root, have been found to contain "1. a crystallizable volatile oil; 2 . a peculiar fecula; 3 . an extractive matter; 4 . free acetic acid; 5. crustallizable resin ; 6 . albumen; 7. fibrous matter. The ashes contain carbonates of lime and of magnesia, silica, and a trace of iron." *

Inulin. Mr. Rose discovered in the roots of elecampane a peculiar matter, bearing some analogy to starch, t to this the name of Inulin has beeu given. Inulin is a white pulverulent substance, insoluble in alcohol and cold water, but readily dissolves in hot water, from which on cooling, the Inulin is precipitated in the form of a white powder; when thrown on lout coals it melts and burns with the smell of calomel, when heated with nitric acid it yields oxalic acid. We have not learnt that Inulin has been given internally, or that its action on the animal economy has beell ascertained.

Medical Properties and Uses. The root of elecampane is gently stimulating, and from its possessing this quality has been recommended in a variety of diseases, as in cachexy, colica Pictonum, dyspepsia, pulmonary complaints, and uterine obstructions, \&c. Dr. Cullen observes-" we lave no satistactory evidence of its medicinal powers," $\ddagger$ and it is now seldon prescrited. We are informed however, that it is frequently made use of to adulterate ipecacuanha. With farriers and others also who prescribe for cattle, it is in general use as a cordial; probably its effects may be more powerful on cattle than on man. Dose of the root in powder, from one scruple to one drachm.

Off. The Roots.

* Edinburgh New Dispensatory.

+ The same peculiar substance has been discovered in the roots of many other regetables in considerable quantities; as in the roots of pellitory, by M. Grutin, in the roots of colchicum, by M. M. Pelletier and Caventou, and in the roots of the Jerusalem artichoke, by M. Braconnot.

‡ Cullen's Mat. Med. vol. ii. p, 459. 



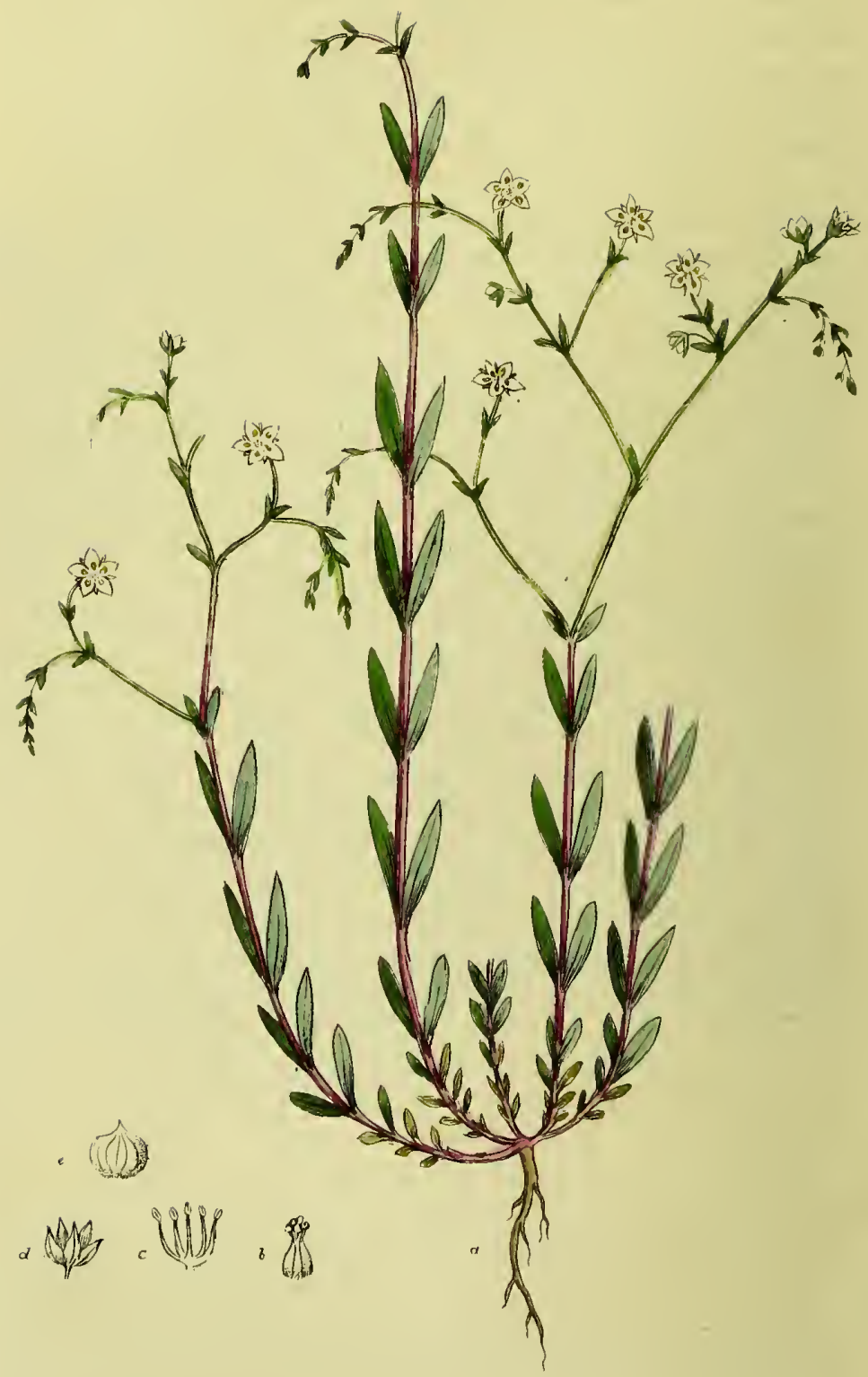

Linum Cathartiaum. 


\section{LINUM CATHARTICUM.}

\section{Purging Flax, or Mill Mountain.*}

\section{Class Pentandria. Order Pentagynia.}

Nat. Ord. Gruinales, Linn. Linace兂, Juss.

Gen. Char. Calyx 5-leaved. Pelals 5. Capsule 5-valved, 10-celled. Seerl solitary.

Spec. Char. Leaves opposite, obovate, lanceolate. Stem dichotomous. Pelals acute.

THIs species of flax is an annual, indigenous to Britain, and is found in various situations, delighting in light chalky soils; it is commonly met with npon dry barren hills, and in pastures.

The root of the mountain flax is small, tapering and woody, and sends ont several slender, smonth, straight stems, which rise to the height of six or eight inches, and are branched towards the top; the leaves are small, smooth, lanceolate, elliptical, and stand opposite in pairs, those lowards the lower part 0 . the stems are rounded at the extrenity; the flowers are small, white, and stand upon long footstalks at the end of the branches; the calyx is composed of five permanent lanceolate leaves, serrated and one-ribbed; the petals are ovate, pointed, slightly united at the base; the germen is ovate, triangular, and crowned with yellow stigmas; the filaments are ranged in a circle rouıd the germen, and support yellow antheræ; the capsule is globular, about the size of a pea, ten-valved and ten-celled, each cell enclosing an oblong, glossy, pointed seed.

Qualities and Chemical Properties. Purging flax has rather a warm and bitter taste, its smell is somewhat faint and unpleasant, it gives out the whole of its virtues to water. The watery infusion of the plant resembles in colour that of tea, is very bitter, and turns black by the addition of sulphate of iron. The ethereal tincture is green, and when evaporated in water, leaves a bitter green resin, and the water contains an extractive matter.

Medical l'roperties and Uses. The medical properties of this plant are entirely confined to its aperient effects. An infusion of

* Fig. a. represents a plant of the natural size. $b$. The pistilla magnified. $c$. The stamens magnified. $d$. The calyx magnified. e. The capsule magnified. 
a handful of the recent plant, or of two or three ounces of the dried, in doses of three or four ounces, will generally act as a gentle aperient, unattended with any griping; or one drachim of the dried plant in powder, will usually produce the same effect. But the use of this plant, like many more of indigenous growth, is now neglected, being seldom employed but as a domestic remedy; and the present rage for the new chemical preparations, will probably expunge from our pharmacopœias many more of our valuable native plauts.

Off. The Herb.

\section{SALVIA OFFICINALIS.}

\section{Garden Sage.*}

Class Diandria.-Order Monogynia.

Nat. Ord. Verticillate, Linn. Labiate, Juss.

Gen. Char. Corolla unequal. Filaments affixed transversely by the middle.

Spec. Cha R. Leaves ovate, lanced, intire, finely crenated. Flowers spiked. Segments of Calyx acute.

The genus Salvia comprises upwards of eighty species, $\uparrow$ natives of every quarter of the globe, and of every climate. 'The Salvia Officinalis is a perennial plant, indigenous to the south of Europe, and was first cultivated in this country by Gerarde, previous to the year 1597: it has now a place in most of our kitchen gardens. There are several varicties of this species of sage, viz. the greater or common sage, the small or narrow leaved, (commonly called sage of virtue,) and another with variegated leaves; these appear to have been accidental varieties, produced from seed, or sone other circumstance in their culture.

The root is long and fibrous; the stem rises to about two feet in height, firm, square, and branched; the leaves are of an oblong,

* Fig. a. represents a spike of flowers of the natural size. b. A cutting (in outline) with the young branches. $c$. The pistil. $d$. The stamens. $e$. The calyx.

+ Hort. Caut. 


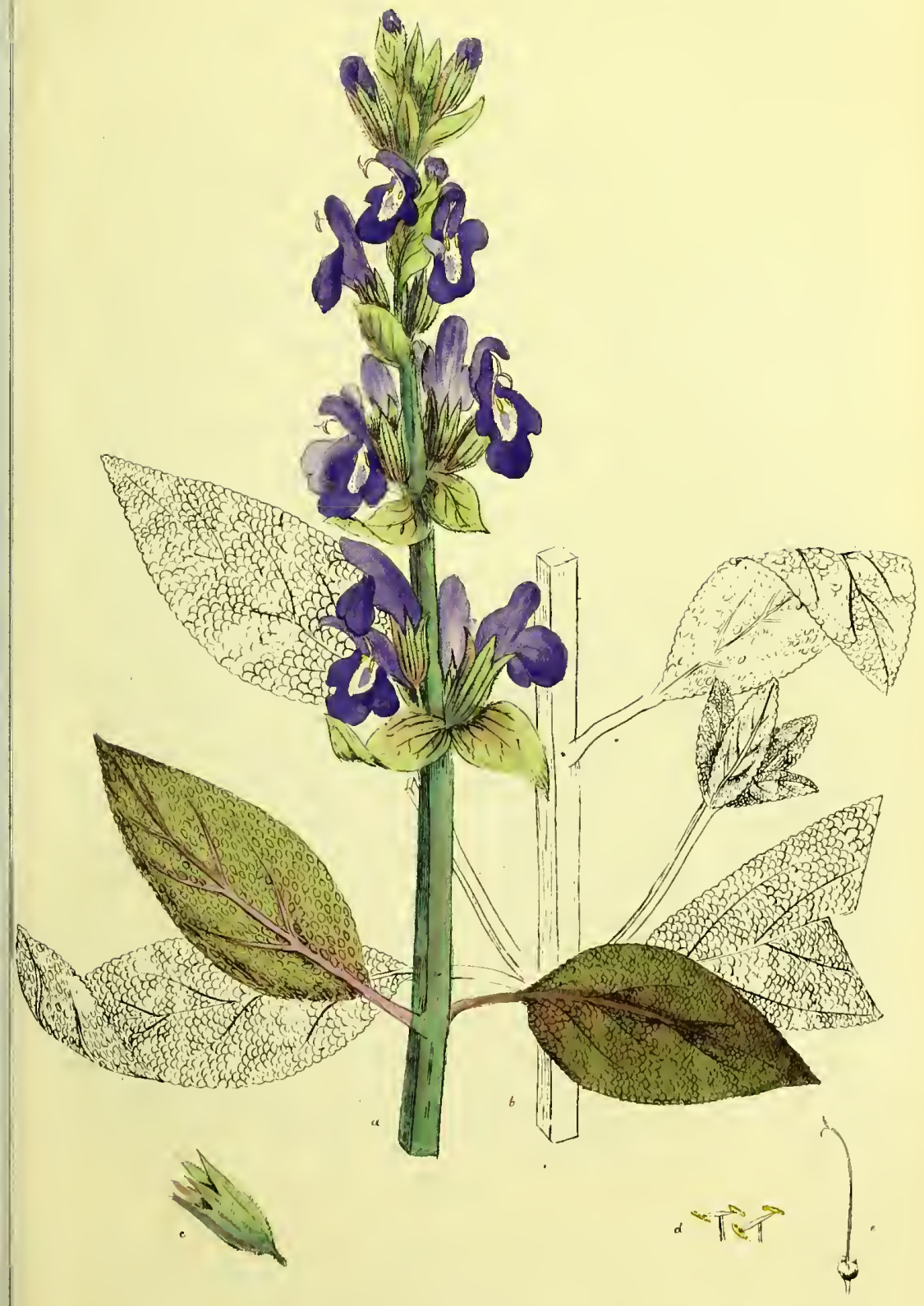



ovate form, entire, rough, and finely crenated, often of a reddish or purplish tinge, are produced in pairs, and stand upon long footstalks; the flowers are of a bluish purple, and terminate the branches in long spikes; the corolla is monopetalous, tubnlar, and divided at the extremity into two lips, the upper one entire and concave; the lower lip divides into three obtuse lobes, the niddle one of which is the largest; the calyx is tubnlar, of a reddish colour, striated, and divided into acute segments; the two filaments are sliorl, and are affixed transversely by the middle on the top of the rudiments of two others; the antheræ are large and yellow; the style is filiform, of a blue colonr, and supports a bifid stigma; the seeds are four in number, naked, and placed at the botton of the calyx. It flowers in June and July.

This species of sage is called by the Greeks $E \lambda \varepsilon \lambda เ \sigma$ D a $\propto$ os, from the brown or parched colour of the leaves. There is found occasionally on the Salvia Officinalis, a peculiar excrescence or gall apple, and we are told by Virey, ${ }^{*}$ that this is eaten at Constantinople by the Turks.

Sensible Properties, \&c. The odour of sage is strong, and of a peculiar fragrancy; its taste is warm, aromatic, and somewhat bitter, with a slight degree of astringency. Both water and spirit extract these qualities, but the latter inore perfectly than the former.

Medical Properties and Uses. Sage, as possessing aromatic and bitter qualities, is in its effects gently stimulating, tonic, and carminative; hence it is serviceable in sone cases of debility of the stomach and nervous systen. Formerly it was celebrated as a medicine of great efficacy in obstructions of the menstrual flux, fluor albus, rheunatism, paralysis, $\& c$.; $\uparrow$ but in the present day no confi. dence whatever is placed in it as a medicine of much efficacy, and it is chiefly prescribed as a gentle sudorific, $t$ and as a diluting drink in febrile disorders; for these purposes, an infusion of the fresh or dried herb, may be taken ad libitum; it forms a very grateful drink, and the addition of a little lemon acid renders it still more agreeable. The infusion is also used as a gargle in cases of sore throat, either alone, or with the addition of honey and vinegar.

\section{Off. The Leaves.}

* Vide Histoire Naturelle des Médicamens.

+ Vide Murray's Ap. Med. vol. ii.

$\ddagger$ We are inclined to think, that the sudorific effects it is supposed to possess, are shiefly to be attributed to the aqueous flaid. $-E d$. 


\section{TUSSILAGO FARFARA.}

\section{Colt's-foot.*}

\section{Class Syngenesia.-Order Polygamia.}

\section{Nat. Ord. Composite Discoide质, Linn. CORYMBIFER E, Juss.}

Gen. Char. Receptacle naked. Pappus simple. Calyx scales equal, submembranaceous.

Spec. Char. Scape 1-flowered, scaly. Leaves cordate, angular, toothed.

THIS species of Tussilago + is a perennial plant, a native of Britain and many parts of Europe, and grows in moist shady situations, flowering in March and April.

The root is long, round, tapering, creeping, and sends off many small short fibres; the stalks are furrowed, downy, simple, six or eight inches high, beset with several scaly leaves of a brownish pink colour, and closely embracing the stem; the leaves are obtusely heart-shaped, angular, irregularly indented, above of a bright green colour, beneatlı white, downy, and stand upon long roundish radical footstalks; the flowers, which appear some time before the leaves, are compound, large and yellow; the florets in the dișk are hermaphrodite, tubular, cut into five obtuse segments, which curl outwardly; stamens five, very short, united into a tube, but separated and pointed at the apices; germen short; style filiform, longer than the stamina ; stigma round. The florets in tlie circumference are female ; tubular at the base, limb large and linear; germen oblong; stigma bifid: seed oblong, and of a pale brown colour, crowned with a silky down.

Sensible Qualities, Medical Properties and Uses. The sensible and medical properties of this plant are very inconsiderable:

* Fig. $a$. represents two plants of the natural size, with portions of the root removed, b. A seed. c. A floret of the disk. d. A floret of the ray. e. A floret of the disk magnified, and cut open to shew the pistil and anthers.

+ Fifteen species of the genus Tussilago are cultivated in our botanic gardens.Hort. Cant. 


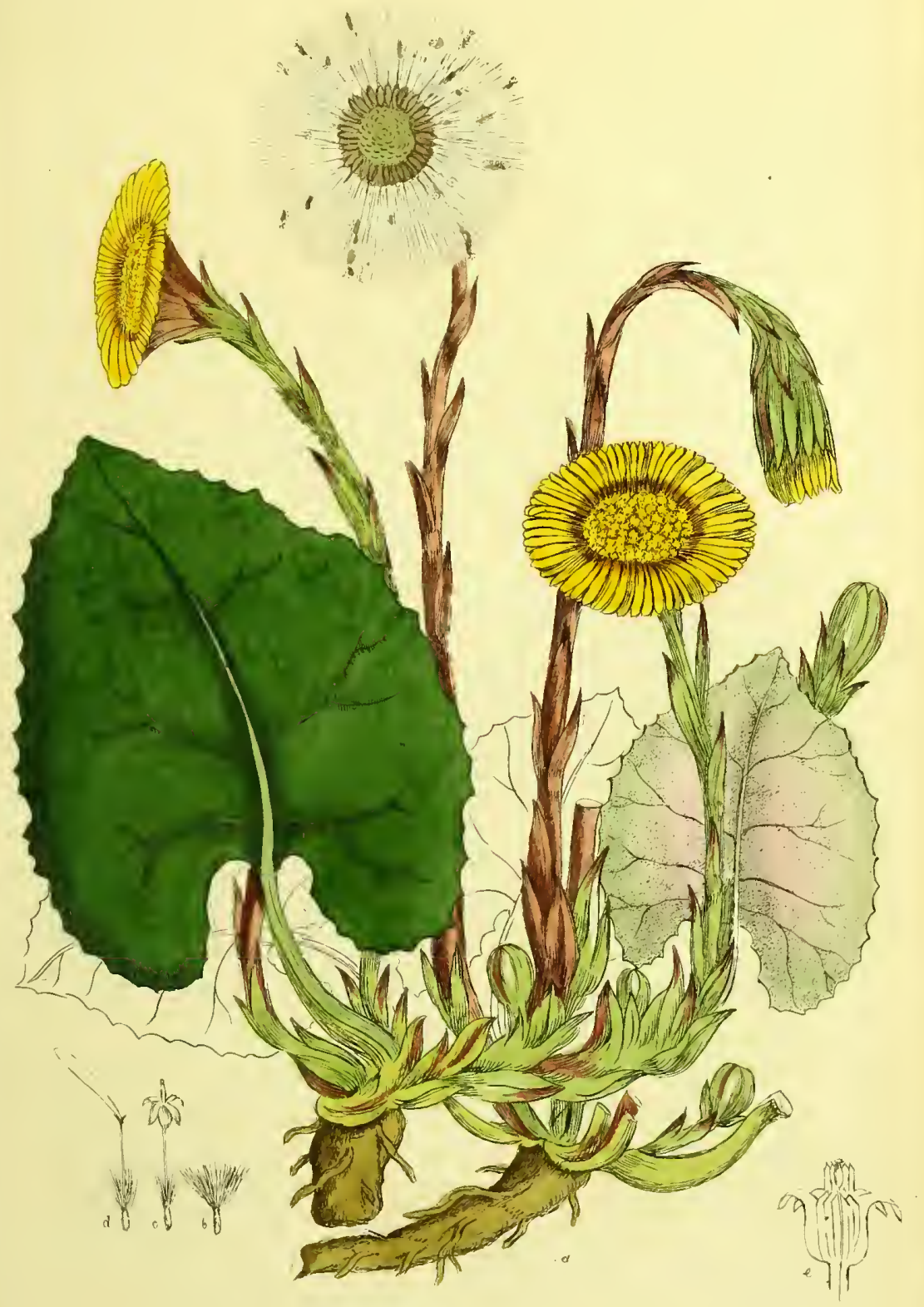

Frusiteryo cayfair 



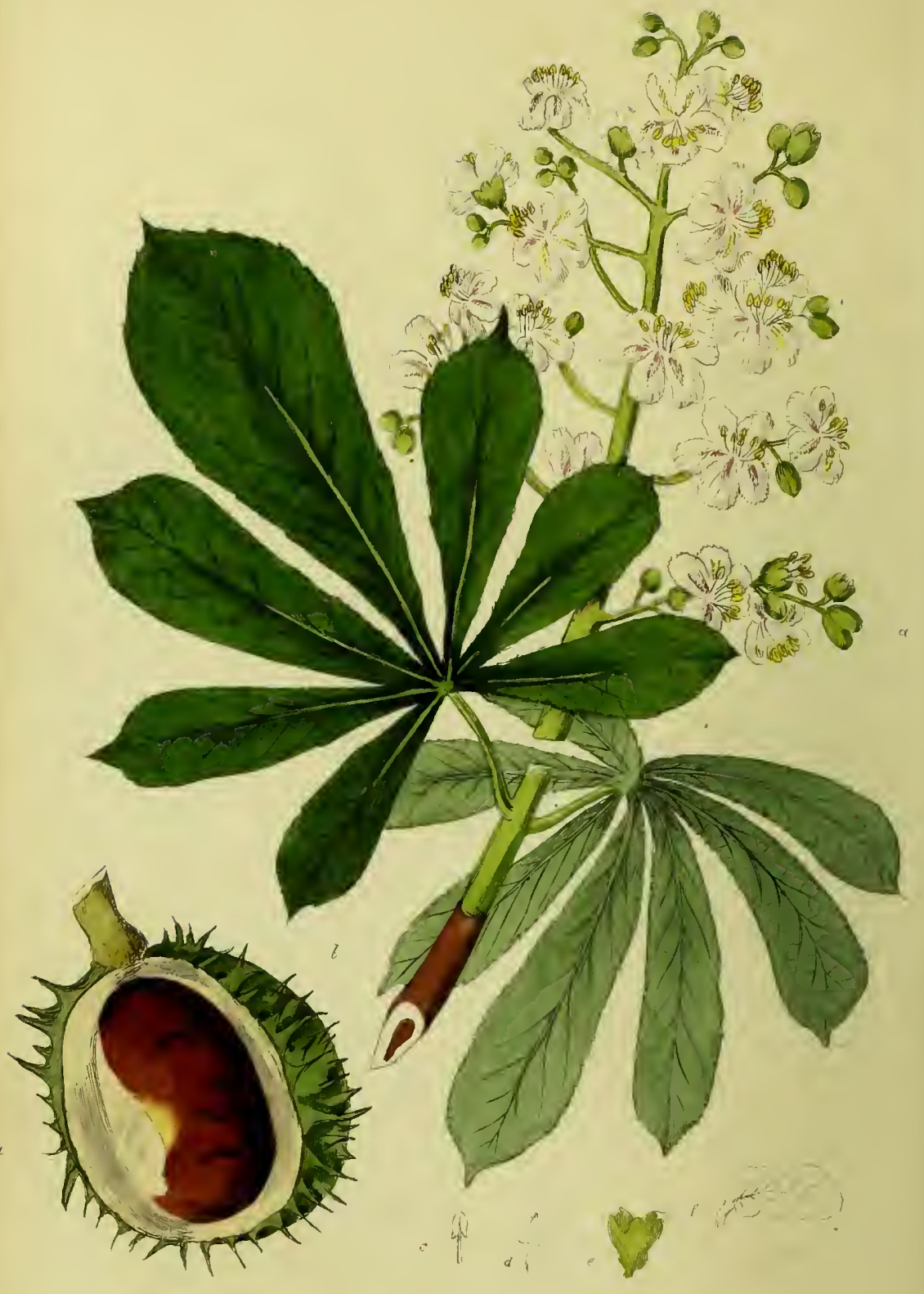

Speott del et litheg

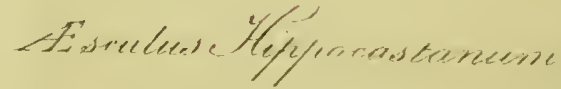


it has a rough mucilaginous taste, but no remarkable smell; it possesses some demulcent, and perhaps pectoral properties, and hence it has been recommended, but we believe with very little effect, in coughs, phthisis, asthma, \&c. in which cases it is usually taken boiled upon milk: every part of the plant has been medicinally used as a demulcent, but more particularly the leaves and Howers; the former are the principal ingredient in the botanical herb-tobacco. The smoking of this plant has been recommended by Dioscorides, Galen, Pliny, and even Boyle.*

Off. The Herb and Flowers.

\section{ESCULUS HIPPOCASTANUM,}

\section{Common Horse Chesnut. $\uparrow$}

\section{Class Heptandria.-Order Monogynia.}

Nat. Ord. Trinilate, Linn. Acera, Juss.

Gen. Cha R. Calyx 1-leaved, 5-toothed, swelled out. Corolla four or five unequally coloured petals inserted into the calyx. Capsule 3-celled.

Spec. Char. Theares digitate, with seven leaflets. Corolla 5-petalled. Capsules prickly.

MatThrolus appears to be the first author who described the horse chesnut. $\neq$ This species of Esculus is a native of the northern parts of Asia, and was first introduced into Europe about the middle of the sixteenth century; in the time of Clusius only one tree was known at Vienna, which being too young to bear fruit, $ई n u t s$ were

* "Et adhac hodie plebs in Suecia instar tabaci contra tussim sagit," Lin. Flor. Suec. p. 289.; and under the direction of Pling it was very successful, "in singulos haustus passum gustandum est." I.ib. xxvi. c. 6. p. 561.

$\uparrow$ Fig. $a$. in the drawing represents a cutting, the leaves mach reduced in size. $b$. The top of a spike of flowers of the natural size, c. A stamen. $d$. The pistillum. $e$. The calgx. $f$. A petal. g. The fruit.

$\ddagger$ Epist. Medicinal. Op. Omn. p. 101, 125.

$\oint$ Murray App. Med, vol.iv. p. 93.

VOL. I. 
obtained from Constantinople; soon after, the tree was very generally cultivated throughout Europe.

This species* of chesnut is of very rapid growth, rises to a great height, and sends out numerous large spreading branches; the bark of the stem and branches is rough and of a brown colour; the leaves are large and composed of seven spatulate-shaped leaflets, which are pointer, serrated, ribbed, and of a dark green colour; the centre leaflet is the largest, and the lateral ones on each side gradually decrease in size; the flowers (which are produced early in May) stand on short peduncles, and terminate the branches in large conical erect spikes; the calyx is monopetalous, bell-shaped, and divided at the niargin into five blunt segments; the corolla is composed of five spreading petals, which are slightly waved at the borders, and inserted into the calyx by narrow claws; the petals are white, with a yellow or pink spot just above the claw; the filaments are awl-shaped, curved, about the length of the petals, and support oblong, double antliers; the germen is cylindrical; style short, stigma pointed; the fruit is a roundish three-celled, three-valved capsule, generally containing two subglobular nuts; externally the capsule is armed with short spines.

The horse chesnut was first cultivated in England by Mr. John Tradescant, in the year 1633 ; $\dagger$ it is now common in most parts of the country, and forms one of the most ornamental trees il our parks and pleasure grounds.

Economical Uses, \&c. The wood is of little value, being soft, and falling rapidly to decay. The fruit is eaten by oxen, deer, sheep and goats; horses, it is said, devour it greedily, and are also said to have been cured by it of pulmonary affections; hence this tree derived its name. When the fruit is made use of for the purpose of fattening cattle (especially sheep) it has been the practice to steep the nuts in caustic alkali, which destroys their bitterness; afterwards to wash them in water, and then boil them till they form a paste. In France and Switzerland they are used for the purpose of washing and bleaching linens, and also for cleaning woollen cloths. From the farinaceous matter which they contain, very excellent starch has been made; the bark has been made use of for dying yellow.

Qualities and Chemical Properties. Both the bark and fruit are nearly inodorous, and the taste bitter and astringent, with

* The Genus $\not$ Esculus comprises eight species. Hort, Cant.

+ Woodville. 



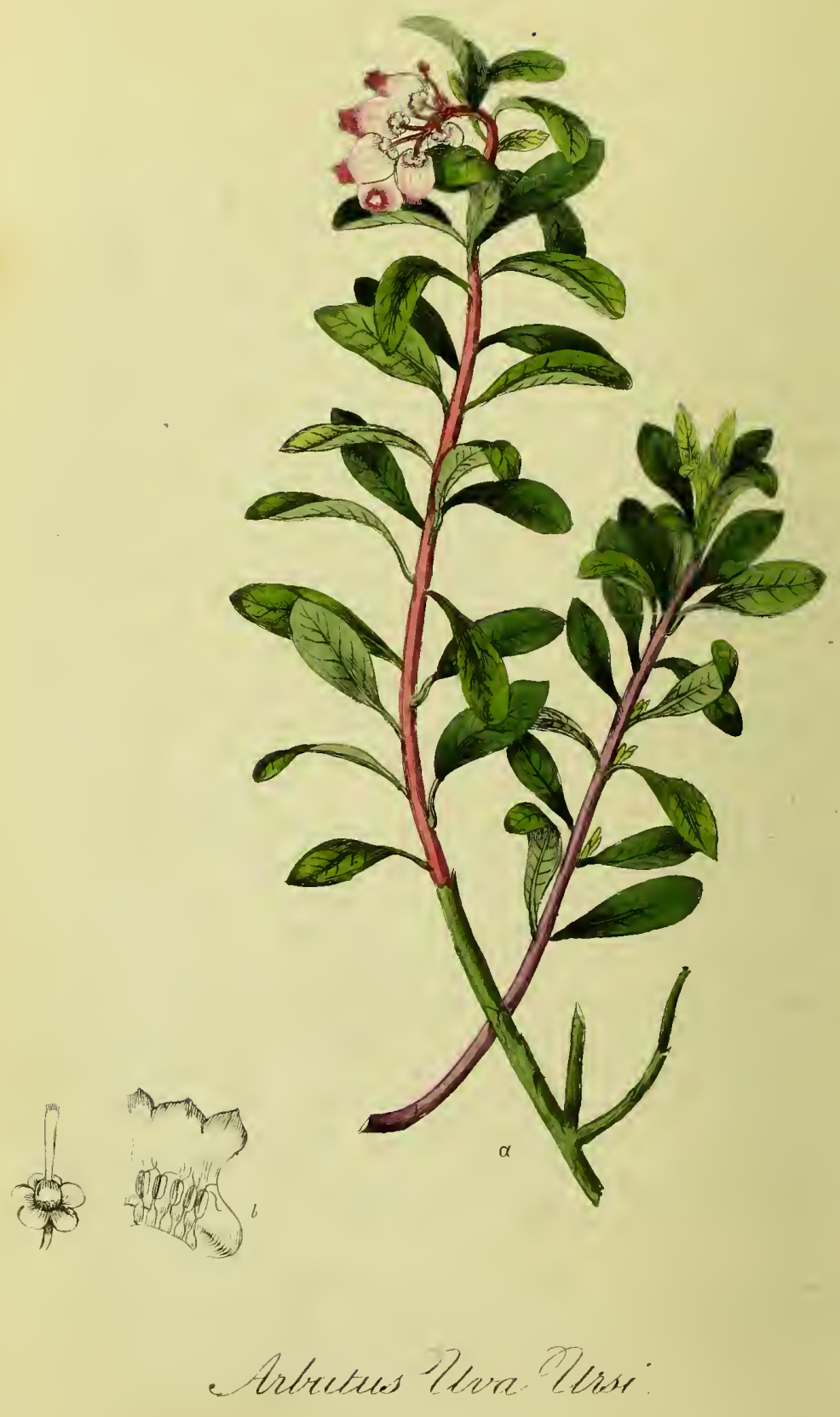

W. Spratt. del, at lithog 
a very slight aromatic flavour. Both water and diluted alcohol extract these qualities. The infusion of the bark deposits dark coloured precipitates with the addition of the sulphates of zinc or iron; the superacetate of lead and oxymuriate of mercury produce white precipitates. M. Cargoneri has lately obtained from the Æsculus Hippocastanum, (by a process analogous to that for the preparation of cinchonine and quinine) an alkaline principle, to which he has given the name of Esculine: this principle is supposed to contain all the febrifuge virtues for which the Æsculus has been celebrated.

Medical Properties and Uses. The bark of this tree has been strongly recommended by Zaunuckelli and some other continental physicians, as a valuable remedy for intermittent and other fevers ; but the experience of the profession in this country does not confirm the high encomiums bestowed upon it by their continental brethren. It is nevertheless deserving of further trial, having also been applied externally with some success in gangrene. The bark is given in powder in doses of from one to four scruples, which may be repeated three, four, or six times in the twenty-four hours; some prefer a decoction of an ounce and a half to a pint of water, of which two ounces is a proper dose, or from five to ten grains of the extract in an ounce of cinnamon water.

Off. The Bark.

\section{ARBUTUS UVA URSI.}

Whortleberry, Red-berried Trailing Arbutus.*

\section{Class Decandria.-Order Monogynia.}

Nat. Ord. Bicornes, Linn. Ericineæ, Juss.

Gen. Char. Calyx 5-parted. Corolla ovate, pellucid at the base. Berry 5-celled.

Spec. Char. Stem procumbent. Leaves entire.

* Fig. a. represents two cuttings of the natural size. $b$. A section of the corolla cut open, and largely magnified to shew the situation of the anthers. $c$. The pistillum and calyx. 
THIS species* of Arbutus is a small evergreen shrub, indigenous to Britain, and found wild on the sand hills in Scotland. It is also a native of almost every cuuntry of Europe, and of many parts of America.

The root is perennial, long, branched, and fibrous; the stems are about a foot in height, woody, procumbent, spreading, and but seldom branched; the leaves are sessile, oblong, obtuse and narrower at the base, somewhat thick, smooth, of a shining green, and thickly surround the upper part of the stems; the flowers, which appear in May and June, terminate the stems in clusters, upon short peduncles; the calyx is small, and divided at the brim into five obtuse segments; the corolla is monopetalous, of a pinkish or flesh colour, tubular, oval, contracted, and divided at the brim into five small reflected segments; the ten filaments are short, downy, tapering, and support erect antheræ; the germen is oval, and placed above the insertion of the corolla, style tapering, a little longer than the filaments, and supporting a simple stigna; the fruit is a round pulpy red berry.

Sensible Qualities, Properties, \&c.-The leaves of bearberry have no smell when recent, but when dried have a smell resembling that of good hay; the taste is slightly bitter, and somewhat astringent. The sapid matter of the leaves seems to depend more upon the presence of a gummy than a resinous principle, as its virtues are more perfectly extracted by watery than spirituous menstrua. $\dagger$ The powder of the dried leaves is of a light brown; the watery extract is bitter and astringent, of a darkish brown, and in smell resembling that of the extract of dandelion, or honey. The watery infusion of the leaves is of a yellowish colour, and instantly turns black by the addition of a small quantity of sulphate of iron. "Four ounces of the leaves gave twelve drachms of extract, and the residuum yielded four scruples of resinous extract, with spirit of wine. They contain tannin, bitter extractive, gallic acid, and some resin." $\ddagger$ The leaves are used in Russia for tanning leather, they are also used for dying a brown colonr.

Medical Properties and Uses. The virtues of this plant reside entirely in its astringent properties; hence it las been recommended both by ancient and modern writers in various diseases

* Five species of the Genus Arbatus are cultivated in our botanic gardens.

Hort. Cant.

+ Murray's App. Med. vol. ii. p. 58.

$\ddagger$ Gray's Elements. 



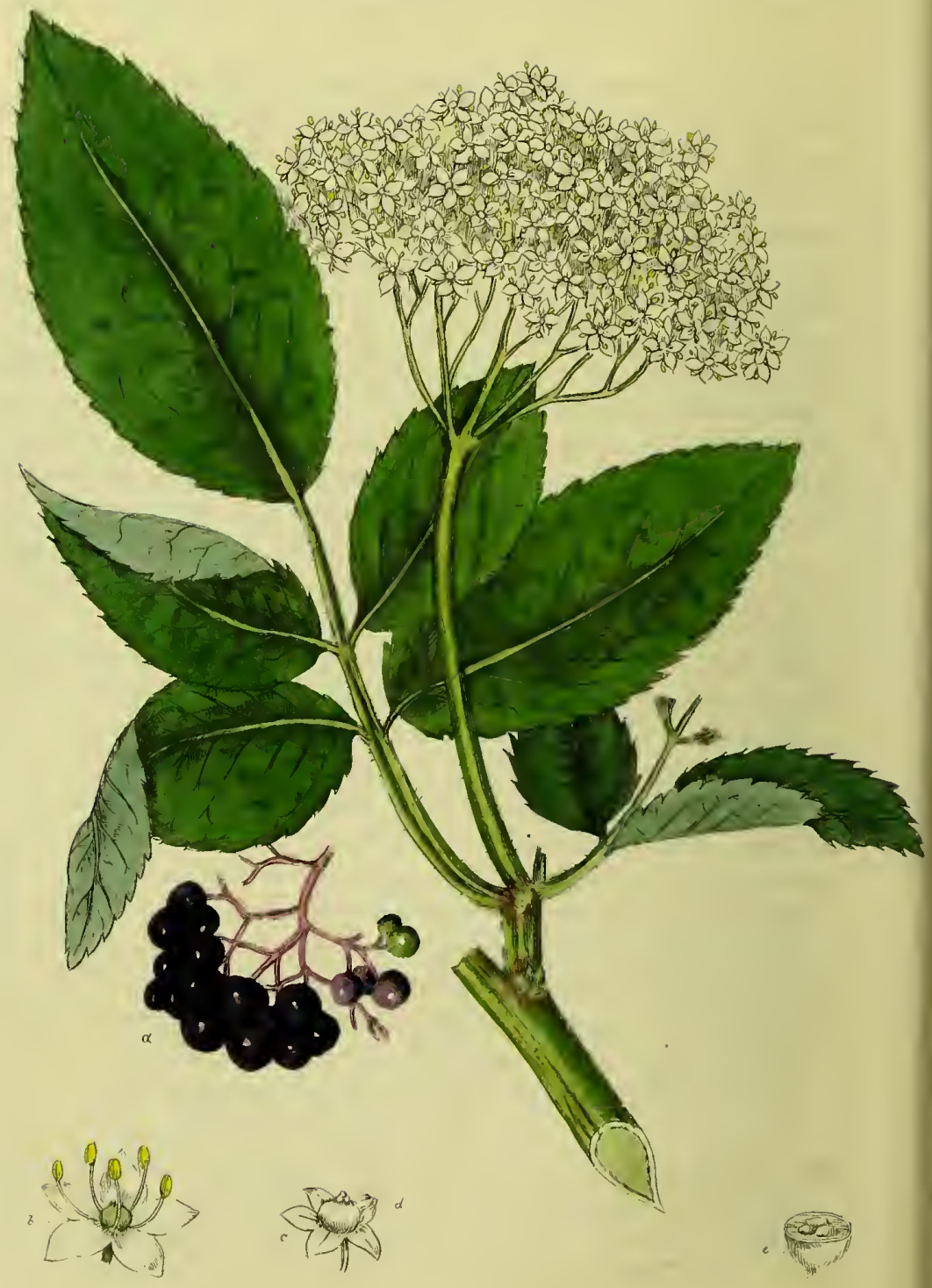

- Sirmelersusese tégine. 
depending upon laxity of particular organs, viz. in fluor albus, menorrhagia, diabetes, diarrlœa, dysentery, \&c. and also debility of the system in general; but in modern practice, it has been chiefly prescribed in calculous and nephritic affections," and it often relieves the dyspeptic symptoms attendant on those disorders. It has likewise been recommended in disorders of the lungs. Uva Ursi is usually given in powder, $(i$. $e$. the leaves carefully dried and powdered) in doses of from lialf a scruple to one drachm, once in six or eight hours or oftener.

Off. The Leaves.

\section{SAMBUCUS NIGRA. \\ Common, or Black Elder.†}

\section{Class Pentandria.-Order Trigynia.}

Nat. Ord. Dumose, Linn. CaPrifoliaces, Juss.

Gen. Char. Calyx 5-parted. Corolla 5-cleft. Berry 3-seeded.

Spec. Cha R. Cymes 5-parted. Stem woody, tree-like.

OF the genus Sambucus, five species are known, $\ddagger$ two of which are indigenous to Britain, the Sambucus Nigra and Ebulus; the former is common in most parts of England; it is generally found growing in hedge-rows, and will thrive in almost any soil or situation. The stem is shrubby, and of ten rises to the lieight of from twelve to sixteen or more feet, and much branched towards the top; both stem and branches are covered with a whitish bark; the wood is tough, hard, and contains a considerable portion of medullary matter (pith) in the centre; the leaves are pinnated, consisting of two or three pair of leaflets, with an odd one at the end; the leaflets are oval, veined, smooth, and deeply serrated; the flowers are small,

* Drs. Barton, Bourne, De Haen, and others, strongly recommend it in ulcerations of the kidneys and bladder; also in gleet.

+ Fig. $a$. in the annexed drawing represents a portion of a bunch of ripe berries. $b$. A magnified flower. $c$. and $d_{0}$. The calyx and pistilla magnified. e. $\Lambda$ berry cat open to shew the seed.

$\ddagger$ Hort. Cant. 
white, and grow in large flat umbels; the calyx is permanent, divided into five segments, and placed above the germen; the corolla is monopetalous, wheel-shaped, and divided into five obtuse and somewhat convex segments; the five filaments are about the length of the corolla, tapering, spreading, and support roundish yellow antheræ; the germen is oval, and furnished with a prominent gland, which supports three blunt stigmata; the fruit is a small round succulent berry, containing three seeds, and when ripe of a deep purplish or black colour. The common elder, flowers in May and its fruit ripens in September. There are two varieties of the Sambucus Nigra, one with variegated leaves, and another with white berries ;' it has been doubted by some botanists, if this last is not a distinct species, the lobes of the leaves being much less, and but slightly serrated compared to the black elder; we have raised many trees from the seeds of the white elder berries, which have invariably produced white berries, and also the distinguishing characters of the leaves.

The London markets are annually supplied with large quantities of the fruit for medicinal and domestic purposes; which is not however the produce of the black elder only, but also of the Sambucus Ebulus, or dwarf elder; it being a common practice with those persons who supply the markets, to mix the fruit of the latter with that of the former ; this fraud is of no consequence, as the fruit of both possess the same medicinal properties, and may be readily distinguished; the former staining the finger a red colour, and the latter the colour of a withered leaf.

Sensible Qualities, \&c. The plant has an unpleasant and somewhat narcotic smell, and a disagreeable bitter taste; the berries when ripe are sweetish, and contain malic acid.

The flowers have a bitterish and mucilaginous taste, and an agreeable and somewhat aromatic smell : these qualities are communicated to water, spirit, and oil ; in distillation with water, a small quantity of a butyraceous essential oil separates, having the smell and flavour of the flowers.

We are told by Withering, if fruit trees and many vegetables, (viz. cabbages, \&c.) which are subject to blight from insects, are whipped with the green leaves and branches of elder, the insects will not attack them.* The berries are said to be very deleterious to poultry, and the flowers also to peacocks. +

* Phil. Trans, vol, Ixii. p. 348.

† Linn. Flor, Suec. p. 79. 



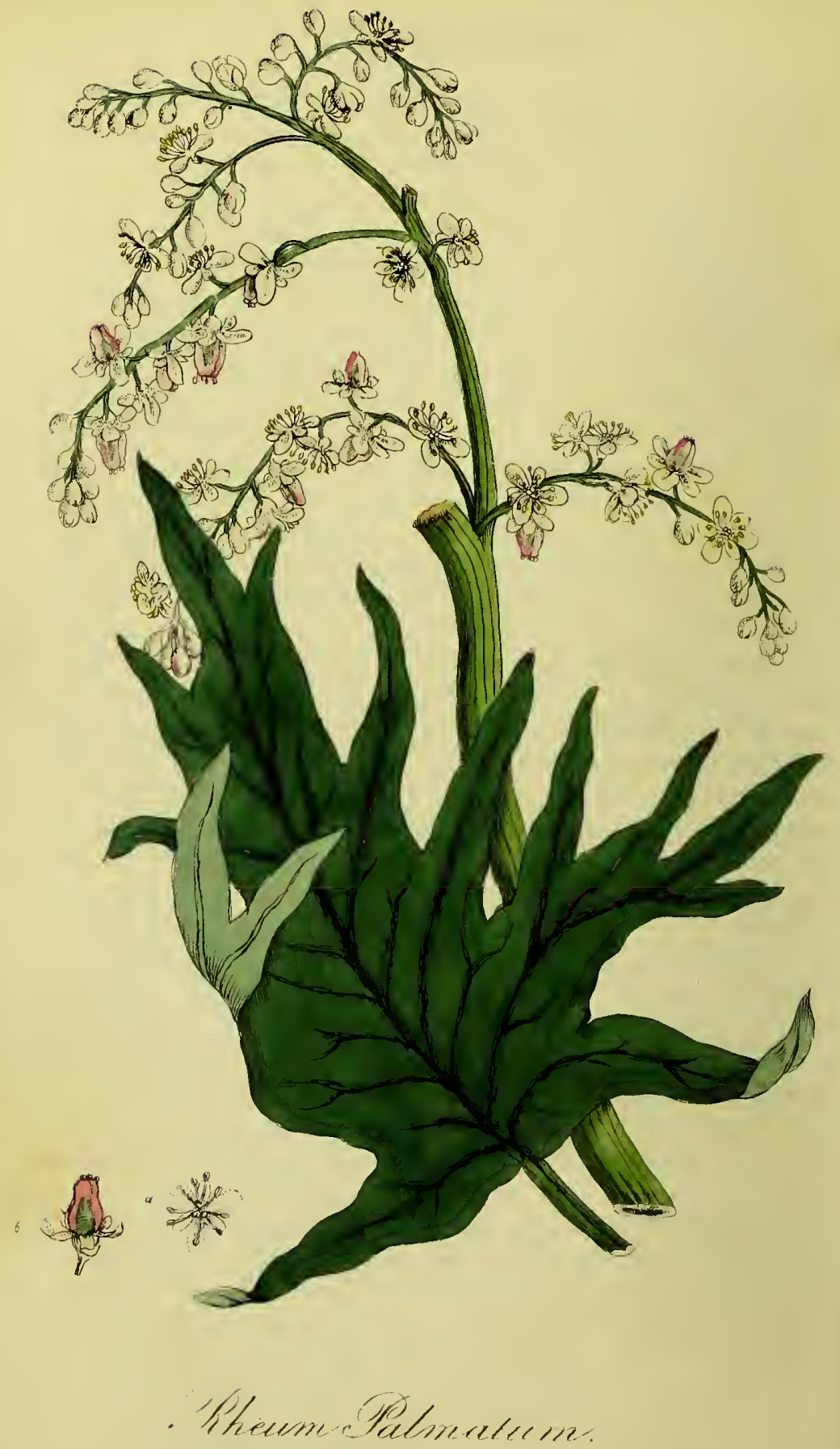


Medical Properties and Uses. Although the medicinal properties of elder are not inconsiderable, it is but seldom prescribed in the present day. Both Boerlaave and Sydenham* recommended it in a variety of diseases; and the latter prescribed it as a powerful remedy for the cure of dropsy; a strong decoction of the inner bark proving botlı emetic and cathartic, and upon these evacuations its utility depends. An infusion of the young leaves is said to prove so violently cathartic, as to be deservedly accounted unsafe. The expressed juice of the berries, in doses of half an ounce or more, acts as a gentle aperient, and in smaller doses has proved an efficacious deobstruent; an infusion of the inner green bark of the trunk in wine is given for the same purposes. The inspissated juice or rob dissolved in water, with the addition of nitrate of potass, or liq. ammon. acet. proves an excellent febrifuge and diaphoretic, and is at the same time somewhat laxative. As an external application, an ointment prepared with the flowers is considered cooling and emollient.

Off. The Flowers.

Off. Pp. Succus spissatus Sambuci Nigræ, E.

Unguentum Sambuci, L. D.

\section{RHEUM PALMATUM.}

\section{Palmated Rhubarb. $†$}

\section{Class EnNeANdria.-Order Trigynia.}

Nat. Ord. Oleracee, Linn. Polygonee, Juss.

Gen. Char. Calyx 0. Corolla monopetalous, six-cleft. Filaments nine, inserted into the corolla. Germen short, scarcely any style. Stigma three. Seed one, large, threesided.

Spec. Char. Leaves palmate, pointed.

IT might at first appear strange, that so little should be known of the history of a plant which has so long formed an important article of commerce, and which has, for such a series of years, been received

* Oper. p. 49

+ Fig, $a$, represents a perfect flower. b. A seed. 
in all the European Pharmacopœias as a safe and useful remedy; but so ignorant are we of it, even at this day, that the particular species of Rheum which constitutes the rhubarb of commerce, continues a matter of dispute and uncertainty. Two causes may be assigned for our want of information on this head; the one is, that the countries from whence the roots are brought to us, and where the plant is indigenous, are not very accessible to European travellers, and another reason is, the probability that the rhubarb of commerce is the produce of different species of Rheum. In the London and Edinburgh Pharmacopœias we have the Rheum Palmatum, (the plant here figured) while the Dublin College considers the Rheum Undulatum as the true rhubarb. We may consider the palmated rhubarb, and perhaps most of the other species, as uatives of Asiatic Russia, and the more southern parts of European Russia, growing in the meridian of from $45 \circ$ to $35^{\circ}$ north latitude, but at a considerable elevation, which sufficiently accounts for its bearing the winter of more northern climates; hence it is found in Siberia, but whether indigenous to the soil or not, appears doubtful. Professor Pallas, who resided for several years in the Crimea, thinks that the rhubarb of commerce is obtained indiscriminately from the Rheum Undulatum, Palmatum and Compactum, but more especially from the first : he further states, that in Bukharia the palmated rhubarb is unknown, and that the Bukharians consider the Compactum as the true species. M. Sievers, an apothecary, was sent by the Empress Catharine II. into Tartary, on purpose to obtain the true rhubarb plant; but after travelling for several years in the countries contiguous to that from whence the rhubarb is brought, he was of opinion that the botanical characters of the plant were still unknown, excepting that it was said not to grow to a great size, and to have round leaves, toothed at the edges, with almost spinous points. It appears to us, however, that M. Siever's might have been spared these many years of travel, unless her Inperial Majesty had previously decided which species of rhubarb she would be pleased to consider the true, a point, as we have observed, by no means decided even at this day; and as without a knowledge of the plants that furnish the roots with which we are supplied, and submitting the latter to the test of examination, we do not see how the matter can be cleared up, if, as we suppose, by true rhubarb be meant the best.

The roots of the palmated rhubarb, when they have attained their full growth, are large, thick, and branched, externally brown, within of a deep yellow colour; the stem grows erect to the lieight of six 
or seven feet, it is round, hollow, jointed, and branched at the top; the lower leaves are very large, palmated, as the name implies, acuminate and rugged : they stand upon long smooth footstalks, channelled the whole length, grooved above, and rounded at the edges, with ferruginous dots; the leaves become smaller towards the summit of the plant; the blossoms appear in the early part of summer: they consist of a number of small white monopetalous flowers, surrounding the stem, and collected at the extremity of the branches into a kind of spike; the $\operatorname{limb}$ of the corolla is divided into six obtuse segments; filaments nine, inserted into the corolla, and supporting oblong anthers; the germen is short, triangular, with scarcely any style, and supports three reflected stigmas; this germen becomes a triangular seell, acute, with membranaceous margins. Linnæus says, "Genus hocce licet ad Rumicem proxime accedat, ab eo tamen distinctissimum esse, ex dictis patet."*

The Rhubarb of commerce is commonly distinguished by the names of Turkey and East India Rhubarb; both names extremely inapplicable, as the former is brought by the Bukharians from the Chinese town of Sini, in the neighbourbood of which it grows on a chain of lofty mountains, and the latter we receive direct from Canton in China. There is likewise a distinction made in what is called Turkey rhubarb, into Russian and Chinese, though they both come from the same place. The Russian is always better and cleaner than the Chinese, froun the great care taken in examining it by order of the government : for this purpose a qualified person is sent to Kiachta on the Russian frontier, who receives it from the Bukharians, when the bad is immediately burnt, and the best parcels sent to Moscow and St. Petersburgh, carefully packed.

Different authors have ascribed different periods for the taking up of the roots for drying; according to Pallas, the Tartars take them up in April and May, Forster + says they are dug up in winter, and Bell in autumn. The roots being thoroughly cleaned from the earth by washing and the smaller branches removed, are cut transversely iuto moderate sized pieces; these are placed on tables, and frequently turned during the first days, until the viscid yellow juice that exudes is absorbed by the root, and incorporated with its substance. When this juice has ceased to exude holes are made in the pieces, through which they are slung, and then hung up to

- Linn. Genera Plantaram.

+ History of Voyages to the North.

voL, 1 . 
dry, exposed to a free current of air, but shaded from the sun; in about three months they are sufficiently dry for packing.

Various species of rhubarb have been long cultivated in this country; in 1629, Mr. Parkinson first cultivated the Rleum Raphonticum; and the Rheum Undulatum was shortly afterwards introduced: in 1762, the seeds of the Rheum Palmatum were procured from Russia, and the plant was cultivated at Cambridge and Edinburgh ; and since that time, this species and the Rheum Undulatum, have been extensively propagated by gardeners, both for medicinal and culinary purposes; the Rheum Undulatum is most generally preferred and used for the latter purpose. The cultivation of this plaut is by no means difficult; the seeds are sown in spring, in a light soil, and next spring the plants are transplanted out at the distance of three feet from each other; during the summer season the ground must be frequently hoed, to keep it clear from weeds, and that the soil may be kept loose about the plant; before winter, the earth should be thrown up round the plant, by which means the root is preserved from the action of the cold atmosphere; the third year the plants begin to flower, but the root will be strengthened by nipping off the buds as they appear, and not allowing them to proceed to fructification; at the end of six or seven years, the roots may be taken up for use. The process directed for preparing them for the market is as follows:- they are first to be washed in a large quantity of water, and the fibres and small roots cut off; they are then to be well brushed in fresh water, and cut into pieces of a proper size; the brown bark being rasped off, they are again thrown into freslı water for three or four hours, when they throw out a great quantity of gummy matter; they are then taken out, and allowed to drip for some hours, during which they exude a white transparent gummy matter, resembling jelly. This process being over, they are put into a stove, heated, to $120^{\circ}$ or $130^{\circ}$, till dry; when perfectly dry, the wrinkles unst be rasped out, and the pieces thus dressed are put into a barrel, and rolled about for the space of lialf an hour, when they get covered with a fine powder, formed by their attrition. Baumé says that rhubarb, prepared in this way, has not only the appearance of foreign rhubarb, but that it could be immediately powdered; four ounces of French rhubarb yielded to him 1644 grains of extract; and the same quantity of foreign rhubarb, 1500 grains. We do not, however, mean to propound this as the best mode of preparation, as it may require some further experience before this is ascertained. The chief peculiarity in the foregoing process of Baumé, is the steeping the roots in water 
after they are cleaned, by which means they are deprived of a quantity of gummy matter; without this precaution, he says, even when apparently perfectly dry, they cannot be reduced to powder, but become pasty under the pestle until they are two years old, and even then the powder is apt to concrete into lumps. Twenty-five pounds of the recent root give only about $8 \mathrm{lbs}$. of the dry. The leaf stalks of rhubarb are the part of the plant used for culinary purposes; they contain a pleasant acid, and when made into tarts, are not unlike quinces in their flavour.

Sensible and Chemical Properties; Analysis, \&c. The best rhubarb, known by the name of Turkey, comes to us in small pieces, each perforated with a hole in the middle, by which it has been strung for dring; it should have a clear yellow colour, be dry, solid, compact, and moderately lieavy; brittle, and when recently broken, appearing marked with yellow or reddish veins mixed with white; easily pulverizable, and forming a powder of a fine bright yellow, having a peculiar, nauseous, aromatic smell, and a bitterish, somewliat astringent taste, feeling gritty under the teeth, and colouring the saliva; the larger pieces should be broken, in the choosing of rhubarb, to ascertain that they are not decayed within. The rhubarb brought from Canton is heavier, harder, and more compact, seldom perforated with holes, and either in long pieces, or with two flat sides; it is less aromatic, and appears to lave been prepared with less care.

According to the analysis of Messrs. Brande, Henry, Sclirauder, and others, rhubarb coutains more or less of the following constituents; gum, starch, extractive, resin, albumen, lignum, oxalate of lime, phosphate of lime, malate of lime, and water.

The principal constitueut of rhubarb is extractive matter, soluble in alcohol and water; it also contains a volatile odorons matter, on which its peculiar smell, and activity as a purge depend; for when dissipated by age, or by any preparation to which it has been subjected, the powers of the medicine are destroyed; it likewise contains some tannin, which resides entirely in the dark coloured veins, and to which we may ascribe the astringent property of rhubarb already noticed.

Medical Properties and Uses. Rhubarb is a mild and safe aperient, operating without violence, and peculiarly useful for pregnant women, or children; in some people however it occasions griping, and very generally, after its purgative effects have ceased, renders the habit costive; its great bulk is a further objection to its use as an aperient remedy, the usual dose for an adult being half a 
drachm, and even this quantity will frequently fail to produce a sufficient evacuation. It is in its tonic power we consider the chief virtues of rhubarb to reside; and in this respect it is peculiarly applicable for young children, strengthening the stomach, correcting acidity, and promoting digestion. We have seen children in the most delicate state of health improve rapidly from the use of rhubarb, from three to five grains being given every morning: perhaps for adults, the tincture would be the better mode of administering it; of this, from one to three drachms may be taken. In diarrhoa arising from impaired digestion, rhubarb, in combination with more active purgatives, will be found useful; and in flatulency we have known the best effects from the use of powders, composed of rhubarb, magnesia, and cinnamon or ginger. Sir E. Home has recommended the external application of powdered rhubarb to indolent ulcers:

With respect to the relative virtues of the British and foreign rhubarb, as well as of the different species of the latter, we scarcely know what to say; experience shews that there is the greatest difference in the rhubarb of commerce brought from abroad; but, as we before observed, while we remain ignorant of the particular species which is supplied to us, no experiments can be instituted to ascertain their relative virtues. From several experiments that have been made, it would appear that British rhubarb is not quite so active a purgative as the best of foreign growth, while it is vastly superior to a great proportion of that imported; and we have no doubt, that by proper care in the cultivation, it will soon become equal to any now supplied us from abroad.

$\begin{array}{ll}\text { Off. } & \text { The Roots. } \\ \text { Off. Pp. } & \text { Extractum Rhei, L. } \\ \text { Infusum Rhei, L. E. } \\ \text { Pilulæ Rhei Compositæ, E. } \\ \text { Tinctura Rhei, L. E. D. } \\ \\ \end{array}$





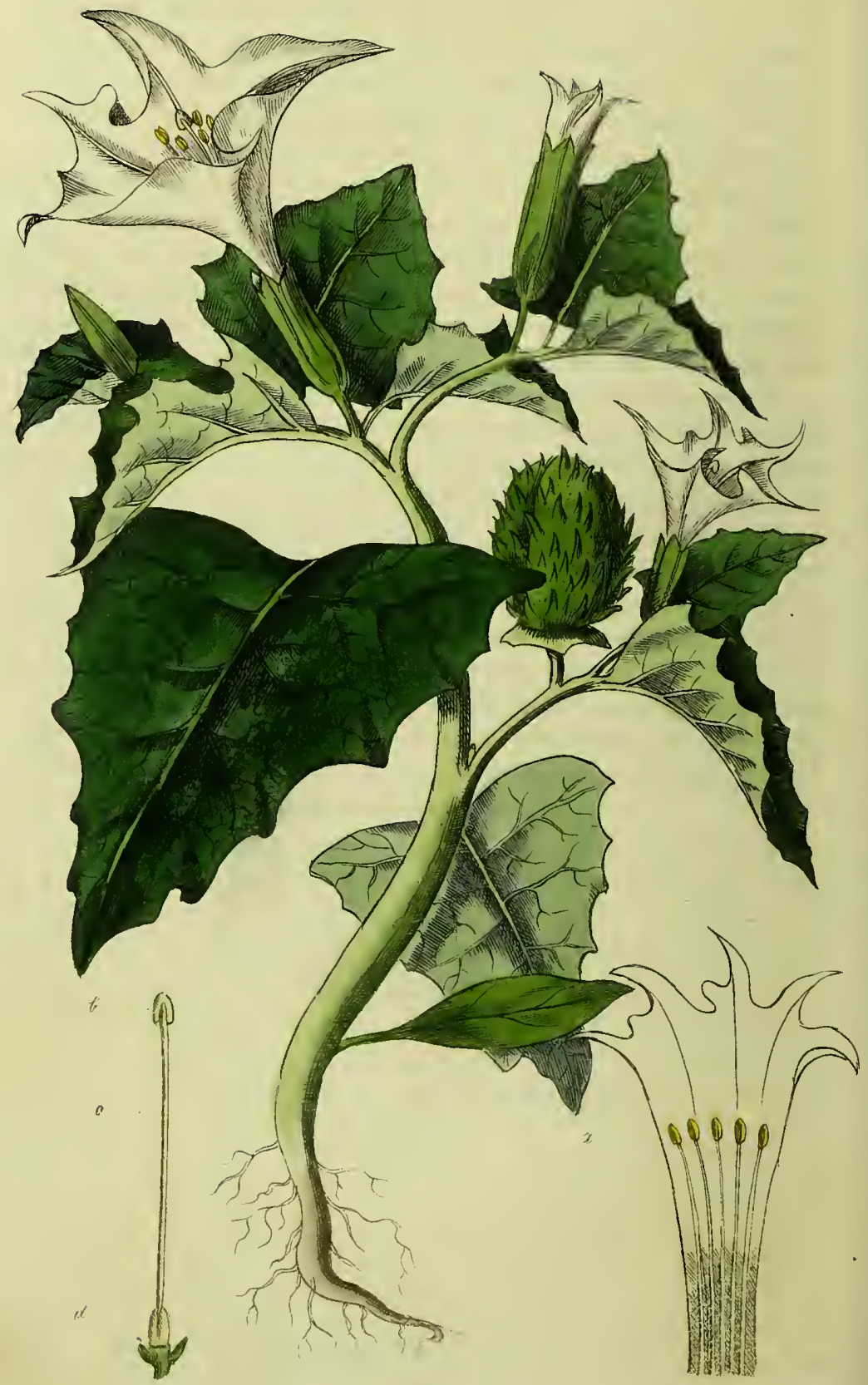

Dawra Strannnium. 


\section{DATURA STRAMONIUM.}

\section{Thorn Apple.*}

\section{Class Pentandria,-Order Monogynia.}

Nat. Ord. Luride, Iinn. Solanem, Juss.

Gen. Char. Calyx a perianth, monophyllous, tubular, 5-cleft, deciduous. Corolla monopetalous, funnel-shaped, plaited, pentangular. Capsule 2-celled, 4-valved, seated on the base of the calyx. Seeds numerous, kidney-shaped.

Spec. Cha R. Pericarps thorny, erect, ovate. Leaves ovate, smooth.

There is every reason to believe that the Dature, of which there are eight species, are all originally natives of the new world, from whence they have been introduced into England; the Datura Stramonium however is the only species which is found to grow wild in this country; the seeds are said to have been first introduced about the year 1597, when the plant was known under the name of the thorny apple of Peru. In some parts of America the ground is so over-run with this plant, and from the number of its seeds it is so difficult to be eradicated, that it las obtained the name of the Jamestown weed; and in many counties in this country, the thorn apple is found as a troublesorne weed in almost every garden. It is an annual plant, and seems to delight in rich warm soils; hence it is usually found about dunglills, and in gardens which are highly manured. A species of the Datura, (Datura Arborea) has long been an ornament of our hot-houses, where the beauty of its large white trumpet-shaped flower renders it truly conspicuous: it is a native of the warmer climates of America, requires the stove, and if heated to a sufficient degree, rises to the height of several feet, growing in an arborescent form.

The thorn apple rises with an herbaceous stem to the height of two or three feet ; the root is white, branched, woody, and fibrous ; the stem is erect, strong, round, hollow, of a pale green colour, branching luxuriantly, and having the branches widely extended on every side; the leaves are of a dark green on their upper surface,

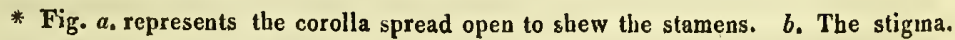
c. The style. $d$. The germen. 
somewhat paler beneath, sessile, large, egg-shaped, irregularly angulated, pointed, and spring from the divisions of the stem and branches on loug cylindrical footstalks; the flower consists of one large funnel-shaped petal, rising on a short footstalk from the divisions of the branches, having a long tube, and a spreading, pentagonal limb, of a pure white, but occasionally having a tinge of purple or violet; at night the upper leaves rise up and enclose the flowers; the filaments are five, awl-shaped; the anthers are of a bright yellow, oblong, flat, leart-shaped; the style, rising from an egg-shaped germen, is erect, filiform, the length of the stamens, and supports an obtuse bi-lobed stigma; the fruit is a roundish capsule, of a dark green colour, as large as a middling-sized apple, and closely beset with sharp spines; it contains two cells and four valves.

Sensible Properties. Every part of the Stramonium, and indeed of every species of Datura which has come under our observation, has a strong disagreeable smell, a taste bitter and nauseous, imparting a green tinge to the saliva whell chewed: most of the animals of this country refuse to eat it.

Action of Stramonium on. The Animal Economy. Every part of this plant is a strong narcotic poison, producing. vertigo, torpor, delirium, loss of memory, excessive thirst, paralysis of the limbs, dilatation of the pupils, and death. Dr. Barton mentions the cases of two British soldiers who ate of it by nistake; one became furious, and ran about like a marlman, and the other died with symptoms of genuime tetanus. Beverly, in his History of Virginia, meutions some extraordinary effects produced by the eating of this plant, but they liave too inuch the air of fabulous narration, or, at least, of the traveller's privilege of enbellishment, to be recorded liere. Dr. Rush gives the case of a child between three and four years old, who, having eaten some of the seeds, was seized with violent fever, delirium, tremors in the limbs, and a géneral eruption on the skin, accompanied with considerable swelling and inflanımation: by repeated emetics and purgatives, the symptoms were alleviated, and the child ultimately recovered. According to the experiments of Orfila, who classes the Datura Stramonium among the narcotico-acrid poisons, the effects produced by the use of it are entirely analogous to those produced by Belladonna; the Datura, lowever, appears to excite more strongly the brain; and to produce a more violent general action.* Haller opened the

* Orfila, Toxicology. 
body of a woman who had taken the seed of this plant through mistake; the cortical substance of the brain was full of blood, and there were some hard clots in the cavities of the cranium. It is worthy of remark, that many of the most active vegetable poisons belong to the class and order, Pentandria, Monogynia, forming for the most part the natural order, Luridæ of Linnæus, viz. the Tobacco, Henbane, Belladonna, Strychnus, Solanum, \&c. The remedies to be used in case of poisoning by the thorn apple, are similar to those recommended for the Belladonna, and other vegetable poisons of this class.

Chemical Properties, \&c. The active principle of the Stramonium resides in an extractive matter, which is imparted to water and alcohol, but more readily to the former than the latter; the watery infusion is of a pale yellow colour, which becomes deeper by the addition of alkalies : the muriate of tin produces a copious precipitate, which is the extractive matter. Brandes has succeeded in extracting from the seeds (which appear to contain the most active principles of the plant) an alkaline principle, to which he has given the name of Daturine; it contains the whole of the poisonous matter in a highly concentrated state, and even its vapour is exceedingly deleterious.

Medical Prỏperties and Uses. Dr. Störck of Vienna we believe to have been the first European physician who tried the Stramonium as a remedial measure, and, as he states, with considerable success in mania and melancholy; Dr. Barton also recommends it as a medicine of great efficacy, and by the Swedish physicians it has beeu very extensively used in cases of mania and epilepsy. In tic douloureux Stramonium has likewise been found serviceable, in moderate doses frequently repeated; we may observe however, that it does not appear to us a remedy calculated to conquer the disease, but that its action is like that of other powerful anodynes in allaying pain and irritation. In spasmodic asthma, the leaves of more than one species of Datura are said to have afforded relief, by smoking them in the manner of tobacco; and Professor Bigelow gives some remarkable cases in confirmation of this assertion. On the whole, we should consider Stramonium as a very powerful, but dangerous, narcotic and anodyne, and that its action as such must be somewhat similar to that of the other vegetable narcotics, but of greater power. In extreme cases the use of it might be justified, but we think some further knowledge of its properties, at least in this country, is requisite to establish it as a remedial measure. In ordinary cases, where anodynes are 
indicated, we should prefer the Henbane, or Digitalis, as remedies which have not been found to produce those alarming symptoms that have so frequently followed the use of Stramonium.

We have next to consider the mode of administering it, and here we may remark, that, reasoning by analogy, we should conclude the system might be so habituated to the nse of Stramonium, like the other narcotics, as to bear a dose, which under other circumstances, must prove fatal. Tlre inspissated juice of the leaves has been most commonly used, and of this a quarter of a grain is considered a sufficient dose at first. Dr. Barton gives it in powder, beginning with doses of three or four grains, and increasing them in a few days to fifteen or twenty. In a case where it was exhibited to the extent of thirty grains, it dilated the pupil of one eye, and produced paralysis in the eyelids, which was removed by a blister. A tincture made from the seeds has also been used. As an external application, an ointinent prepared from the leaves, has been found to give ease in hæmorrhoids and in inflammation; and, according to Plenck, the fresh leaves bruised, soften hard and inflamed tumours, and discuss tumours from indurated milk in the breasts of nurses.

Off. The Leaves.

Off. Pp. Extract. Stramonii, L.

\section{CASSIA SENNA.}

Senna, or Egyptian Cassia.*

Class Decandria.-Order Monogynia.

Nät. Ord. LomentaCEE, Linn. LEguminos E, Juss.

Gen. Cha R. Calyx 5-leaved. Petals 5. Anthers 3, superior, barren; the three lower ones beaked.

Spec. Char. Leaflets in five or six pairs, lanceolate equal; a gland above the base of the petioles.

* Fig. a. represents a branch, the leaves and flowers of the natural size. $b$. The seed pods. . c. The calyz. d. A stamen. e. The pistillum. $f$. A seed. 

SENNA is an annual plant, a native of Asia, and grows spontaneously in Egypi, Syria, and some parts of $\Lambda$ rabia, especially about Mocha; it is cultivated in some of the West India Islands, and also in the soutl of France. Senna was first cultivated in England ahout the year 1640; but the temperature of our climate is too cold for this tender exotic, which will not produce flowers unless the seeds are sown in a good hot-bell."

This species of Senna rises to the height of about two feet; the stem is rather woody, erect, and branching; the leaves grow alternate, are doubly pinnate, smooth, flat, and furnished at their base with two narrow, pointed stipules; each leaf is composed of from five to six pair of leaflets, about an inch long, and about one fourth the breadtlı; the leaflets are oval, pointed, exitire, sessile, and of a yellow green colour; the flowers grow in luose axillary racemes, towards the upper part of the stems; the calyx is monophyllous, five toothed: the teeth are obtuse, somewhat concave, and deciduous; the corolla consists of five, roundish, entire, concave petals, the three lower ones the largest; the filaments are ten, the three inferior longer than the others; the anther's are large and curved; germen cylindrical; style sliort, incurved, and supports obtuse stigmata; the fruit is an ovate, membranous legume, with, foliaceous appendages, marked $n$ ith transverse striæ; bivalve, with six or bine cells, and divided by very thin iransverse partitions, each containing one heart-shaped, oblong seed.

Three sorts of Senna are imported and sold in the English markets, under the names of Alexandrian, Tripolian, and East Indian; + the first is the produce of Egypt, called in Nubia guebelly, where it grows wild; this is the pointed-leaved Senna, which, when carefully dried, has a faint, rather sickly odour, and a slightly bitter, sweetish, and nauseous taste. This sort of Senna is the most purgative, and is rendered still more so by the leaves of the coronilla emerus, and periploca græca, with which it is frequently adulterated; these however may be detected by being larger and more pointed than the true Senna. The Tripolian is a variety of the Alexandriall. We are told by Dr. Ainslie that the East India

* The Senna of cormerce consists of the leaves of several varieties of this plant; that known by the name of Alexandrian Senna has derived its name from the port of Alexandria, the great mart for the exportation of Senna from Egypt, Arabia, \&c.

+ This last, according to Lemaire Lisancourt, is the produce of a species of Senna which grows on the west coast of Africa, near Sierra Leone, and over the country of Senegambia; and to which he has given the name of Cassia Elongata. $\boldsymbol{E} d$.

VOL.I. 
Senna is not the actual produce of the Indian dominions, "but a product of Arabia, either of Arabia Felix, (about Mocho), or from a more northern part of that country, the territory of Abuarish. It is ${ }_{x}$ in fact, the sharp-pointed-leaved Senna, the cassia lanceolata of Forskāl, which he distinguishes, foliis 5-jugis, lanceolatis, æequalibus, and tells us that it is common at Surdud, and near Mor." * From an examination of various samples of Senna, we are led to believe that the Senna of commerce is chiefly the produce of two species, viz. the Cassia Obovata, and the Cassia Lanceolata: these species are both natives of Egypt, and the neighbouring countries. It is said, that at Cairo, the traders mix these two sorts in various proportions, and also adulterate the mixture with a certain quantity of the leaves of argel; and it appears that the European traders adulterate it a second tinic, by the admixture of the leaves of a species of the Collutea, (bladder Senna).

Sensible and Chemical Properties. The Egyptian Senna has a faint, and somewhat sickly smell, taste bitter, slightly aromatic, and rather nauseous; the infusion is of a deep reddish brown colour, and is not clianged by the sulphate of iron: by boiling, it becomes thick and mucilaginous, the extraclive principle absorbing oxygen from the air ; the extract, of which Senna yields about onethird its weight, is black and glutinous. The alcoholic tincture is of a deep green, and is rendered milky by adding water. The leaves of Senna have been analyzed by MM. Lassaigne and Fenuelle; and in addition to mucilage, extractive, resin, saline matter, chlorophylle, greasy oil, volatile oil, albumen, and bitter principle, they discovered a peculiar salifiable matter, of a very cathartic property ; this they consider the purgative principle of Senna, and have givelı it the name of Cathartin. ' Cathartin is of a reddish yellow colour, uncrystallizable, deliquescent, of a peculiar smell, and nauseous bitter taste; soluble in both water and alcohol in all proportions, but insoluble in ether.

Medical Properties and Uses. The Cathartic properties of Senna being very considerable, it may be considered one of our most useful purgatives; when given in proper doses it generally produces the desired effect, without creating that disturbance of the bowels which many of our stronger catilartics frequently do : the

* Materia Indica, vol. ii. p. 249.

+ For the preparation of Catbarlin, we must refer our reader to M. Lassaigne's own aosount, in the Anuales de Chimie, xvi. p. 20. Ed. 
griping which it sometimes occasions may be readily prevented, by the addition of some warm carminative, viz. coriander, cardamoms ginger, cinnamon, \&c. : the former of which is recommended by Dr. Cullen to disguise the nauseous flavour, which is unfortunately a great objection to its use. Seuna is given in substance, $(i . e$. the leaves dried and powdered), in doses of from 30 to 60 grains, and also in infusion, in the form of electuary, and in 'tincture. The infusion is the preferable form of administering this drug, as it contains the whole of the active properties of the plant, and may be conveniently combined with soluble tartar, sulphate of potass, Epsom salts, \&c." The tincture of Senna is recommenled in flatulent complaints, cholic, and atonic gout; and is an active purgative and stomachic, in that debilitated and torpid state of the bowels produced by the intemperate nse of spirituous liquors; the dose of the tincture. is from half an ounce to one or two ounces.

$\begin{array}{ll}\text { Off. } & \text { The Leaves. } \\ \text { Off. Pp. } & \text { Confectio Seunæ, L. E. D. } \\ & \text { Extractum Sennæ, E. } \\ & \text { Infusum Senıæ Comp. L. E. D. } \\ & \text { Pulvis Senıæ Compositus, L. } \\ & \text { Syrupus Sennæ, D. } \\ & \text { Tinctura Sennæ, L. E. D. } \\ & \text { Tinctura Sennæ Composita, E. }\end{array}$

* Under one of these forms it is the popular medicine kuown by the name of black draught. The infusion of Senza is best prepared by pouring six ounces of boiling water upon from four to eight drachms of Seana, and letting it stand till cold. $E d$. 


\section{ATROPA BELLADONNA.}

Deadly Nightshade.*

\section{Class Pentandria.-OOrder Monogynia.}

Nat. Ord. Luri De, Linn. Solanácee, Jiss.

Gen. Char. Corolla bell-shaped. Stamens distant. Berry globular, 2-celled.

Speo. Char. Stem herbaceous. Leaves ovate, entire.

The Atropa Belladonnat is indigenous to Britain and the South of Europe; it is sometimes cultivated in our gardens; in its native state we commonly meet with it in shady lanes, on the borders of woods, on the sides of ditclies, amongst limestone, rubbish, and where the ground is rich from manure. We have not often met with it in the neighbourhood of London; and according to Stokes, Woodward, Ballard, and others, it is found growing very luxuriantly amongst the Mines of Furness Abbey, in the vicinity of Norwich, Hardwick Park, Derbyshire, the banks of Dudley Castle, \&c. it is also very common in many parts of Hertfordshire.

Deadly nightshade rises with an herbaceous stem to the height of two or three and often four feet, much branched and crowded with leaves; the stem is annual, round, slightly pubescent, and of a purplish tint; the leaves are of unequal size, and grow in pairs, standing upon short foot-stalks; in shape, ovate, pointed at the extremities, somewhat soft, and of a lively green colour; the flowers are drooping and stand solitary upon longish peduncles; the calyx is persistent and deeply divided into five segments; the corolla is bell-shaped, mouopetalous, and of a dusky purple colour, but towards the base inclining to yellow; the five stamens are shorter than the corolla, and support roundish anthers; the germen is spherical, supporting a long style crowned with a two-lobed stigma; the fruit is a pulpy berry, (enclosing many seeds,) at first green,

* Fig. a. represents a sprig, the leaves, flowers and fruit of the natural size. b. A stamen. c. The calyx and pistillum. d. A section of the pericarpium. c: Seeds. t Of the genos Atropa four species are known and cultivated. Hort. Cant. 

changing to red as it advances to maturity, and when ripe of a jet black, staining paper of a durable purple.* The Belladonna flowers in June and July, and the fruit ripens the latter end of Summer.

Deadly nightshade has been long known for its baneful effects on men and animals. Both ancient and modern history furnishes many instances of the fatal consequences arising from the use of it, either by accident or design. $\dagger$ Notwithstanding its deleterious properties, it has been very extensively employed in ancient and modern practice; few, if any, vegetables possess properties so active and powerful as this. The active properties of the Belladonna reside in every part of the plant, although the leaves are generally preferred for medicinal purposes. The Belladonna acts upon the animal economy as a powerful narcotic, and in an over-dose causes intoxication, maduess, and death.

Symptoms of Poisoning by the Belladonna. Dryness of the mouth and throat, great thirst, trembling of the tongue, difficulty of sivallowing, fruitless efforts to vomit, swelling of the face, dilated pupils, slow and feeble pulse; vertigo, convulsions, coma, and death succeed. The body after death enters rapidly into the putrefactive state.

Treatment in Case of Poisoning by the Belladonna. When any of the above symptoms arise, and it is known, or suspecterl, that the fruit or any part of the obnoxious plant has been taken, no time should be lost in immediately cleansing the stomach from the poison, by exhibiting from ten to twenty grains of the sulphate of zinc or copper, dissolved in warm water, and repeated at short intervals, until the stomach is completely evacuated; then, and not till then, we should have recourse to potent draughts of vinegar, or any other vegetable acid and water, followed by powerful cathartics, and stimulating clysters to clear the bowels Should symptoms

* It is said the Italian ladies use the juice of these berries in their compositions for painting the cheeks; hence the derivation of the word Belladonna, which in the Italian language signifies beautiful woman. *

t Above one hundred and fifty soldiers were poisoned by the herries of the Belladonna, which they gathered at Pirna, near Dresden.

Jutrnal de Sedillet, Decembre, 1813, p. 36.1.

In Buchanan's History of Scollaud it is recorded, that the army of Sweno when be invaded that country, was destroyed by the Scots, who mixed the juice of the Belladonna with wine, with which they supplied the Danes during a trace; this so intoxicated the latter that the Scots fell npon them in their sleep, and destroyed the greater part of them. 
of paralysis, convulsions, or coma appear, the usual remedies in such cases should be immediately resorted to.

Sensible Properties. The leaves of deadly nightshade when recent have a slight and somewhat disagreeable smell, their taste is nauseous, and slightly acrid; the infusion is not altered by the sulphate of iron.

Chemical Properties. According to the analysis of Messrs. Brandes and Vauquelin, the Atropa Belladonna yields the following constituents:-wax, 0.7 ; resiuous chlorophylle, 5.84; acid malate of Atropise, 1.51 ; gum, 8.03 ; fecula, 1.25 ; woody fibre, 13.7; phyteumacolle, 6.9 ; a matter analagous to osmazôme, with malate of atropine, oxalate, hydrochlorate, and sulphate of potass, 16.05; soluble albumen, 4.7 ; hard albumen, 6 ; ammoniacal salts and acetates, malate of atropine, oxalate, malate, sulphate, hydrochlorate, and nitrate of potass; oxalate, malate (?) and phospliate of linee, aud malate and phospliate of magnesia, 7.47 ; water, $25.8 ;$ loss, 2.05 . The ashes contain oxide of copper.

ATROPIŃE. This salifiable substance was discovered by $M$. Brandes in the Atropa Belladonna, and from the result of his experiments he considers the active properties of Belladonna to reside in this peculiar substance.

To obtain this principle M. Brandes boiled two pounds of the dried leares of the Alropa Belladonna in a sufficient quantity of water, pressed out the decoction, and boiled the leaves again in water; the decoctions were mixed, and some sulphuric acid was added, in order to throw down the albumen and similar bodies; the solution was thus rendered thinner, and passed more readily through the filter. The decoction was next supersaturated with potass, by which he obtained a precipitate, weighing, after haviug been washed with pure water and dried, eighty-nine grains. It consisted of small crystals, from which, by solution in acids, and precipitation by alkalies, atropine was obtained in a state of purity.* Or atropine may be obtained by digesting the decoction of the herb of the Atropa Belladonna with magnesia, boiling the precipitate in alcohol, and filtering; the atropine crystallizes on cooling, in needles, or colourless, translucent, shining prisms. $†$

Properties of Atropine. According to M. Brandes, atropine is almost insoluble in water; soluble in both hot and cold

* Ure's Chemical Dictiouary. Art. Atropia.

† Chimie Organique, par Leopold Gmelin.. Edition de Virey, p. 898. 
alcohol, but much more readily int the former; perfectly so in æther and oil; with the aeids, it forms nentral crystallizable salts. A tropine when perfectly pure, is in the form of white or colourless transparent crystals.

Action of Atropine on the Animal Economy. When M. Brandes was experimenting on this alkali he was obliged to desist, in consequence of the violent head-ach, pain in the back, giddiness, and nausea, which the vapour of atropine oecasioned; it had indeed so injurions an effect upon his health that he has entirely abstained from any further experiments, and no one has hitherto repeased them. He once tasterl a small quantity of the sulphate of alropine; the taste was not bitter, but merely saline; there soon followed howcver, violent head-ache, shaking in the limbs, alternate sensations of heat and cold, oppression of the chest, diffieulty of breathing, and dininished circulation of the blood. The violence of these symptoms ceased in half an hour. Even the vaponr of the various salts of atropine produces vertigo. When exposed for a long time to the vapour from a solution of the nitrate, phosphate, or sulphate of atropine, the pupils of the eyes bceome dilated. This occurred frequently to M. Brandes; and when he tasted the salt of alropine, the dilatation followed to so great a degree, that it persisted for twelve hours, and was not influenced by the different shades of light.*

Medical Uses, \&c. The Belladonna, besiles its narcotic properties, when exhibited in small doses promotes all the excretions. From a vegetable possessed of properties so energetie and powerful as this, we may expect a remedial agent proportionably active, and when arlministered with judgment and care, we shall be seldom disappointed in our expectatious.

This medicine should be preseribed in doses, suited to the effects we wish to promote; in small and repeated doses it operates on the nerves, kidneys, intestines, or skin; thereby proving sedative, diuretic, aperient, or surlorific; lence it becomes beneficial in a variety of diseases. If given in larger doses and without promoting any of the excretions, it may be absorbed in excess and injurious affects will follow. The Atropa Belladonna from the time of Galen to the present period has been recommended for the cure of a great

* Vide Ure's Dictionary of Clienistry, and the Formulary of New Remedies, by F. Iaden, p. 120 and 121. 
variety of diseases, as in rabies canina,* mania, chincough, + amaurosis, ophthalmia, $\ddagger$ inflammation, gout, plague, and many febrile diseases; as a topical remedy the Ext. Bellad. combined with some unguent or cerate, in the form of plaister, has readily removed rheu matic and venereal pains; in open cancer applied in the form of powder, decoction, or unguent it greatly palliates the most distressing symptoms. According to historical authorities we find that the early stages of schirrus and cancer $\S$ are in many instances completely cured by the external and internal use of this medicine; and modern practice confirms the superiority of the Belladouna to most other medicines in these diseases; in tic douloureux $\|$ and tetanus, it has been used with success, in the form of lotion in conjunction with its internal exhibition. In tedious and long protracted labours, arising from rigidity of the os and cervix uteri, and in puerperal convulsion, Dr. Conquest, M. Chaussier, and others, approve of the application of a small quantity of extract of the Belladonna to the os and cervix uteri, which has been attended with decided benefit, in subduing the spasmodic constriction of those parts.

As the Belladonna requires the greatest caution in using, we shall transcribe the words of a modern author on this subject, who says : "Let me repeat nly caution to those who attempt the use of this medicine, to commence the administering of it, whether internally or. externally, always in small doses or applications, and afterwards gradually increasing them; if the least unfavourable effects should arise, the prescription should be laid aside imnediately; but if all go on favourably, it ought to be increased gradually and prudently, until the desired effect be obtained; of course, there will not then arise any reason to increase it, as long as the same effect continues." वा

* Manch, Mayerne, Buckholz and Richter, were very successfal in ouring rabies canina, after their patients had been attacked with convalsions, loatbing of food, drink, \&c.

+ Raison on the Atropa Belladonna in hooping-cough.

London Med. Repository, vol. vi. p. 77-Bordu Ditto, vol. xv. p. 509.

$\$$ Mr. Blackett on the Use of the Atropa Belladonna.

$\$$ Galen, Lambergen, Callen, Degner, and others, speak in high terms of the Atropa Belladonna in the cure of these diseases; Jancker mentions two cases cured with it, and strongly recommends its use.

II Account of two cases of Tic Doloureux cured hy the external use of the Belladonna, by Henry. London Medical and Physical Journal, vol, xliii. p. 474.

I Essay on the use of the Atropa Belladonna, by P. C. Blackett, p. 40 and 41. 



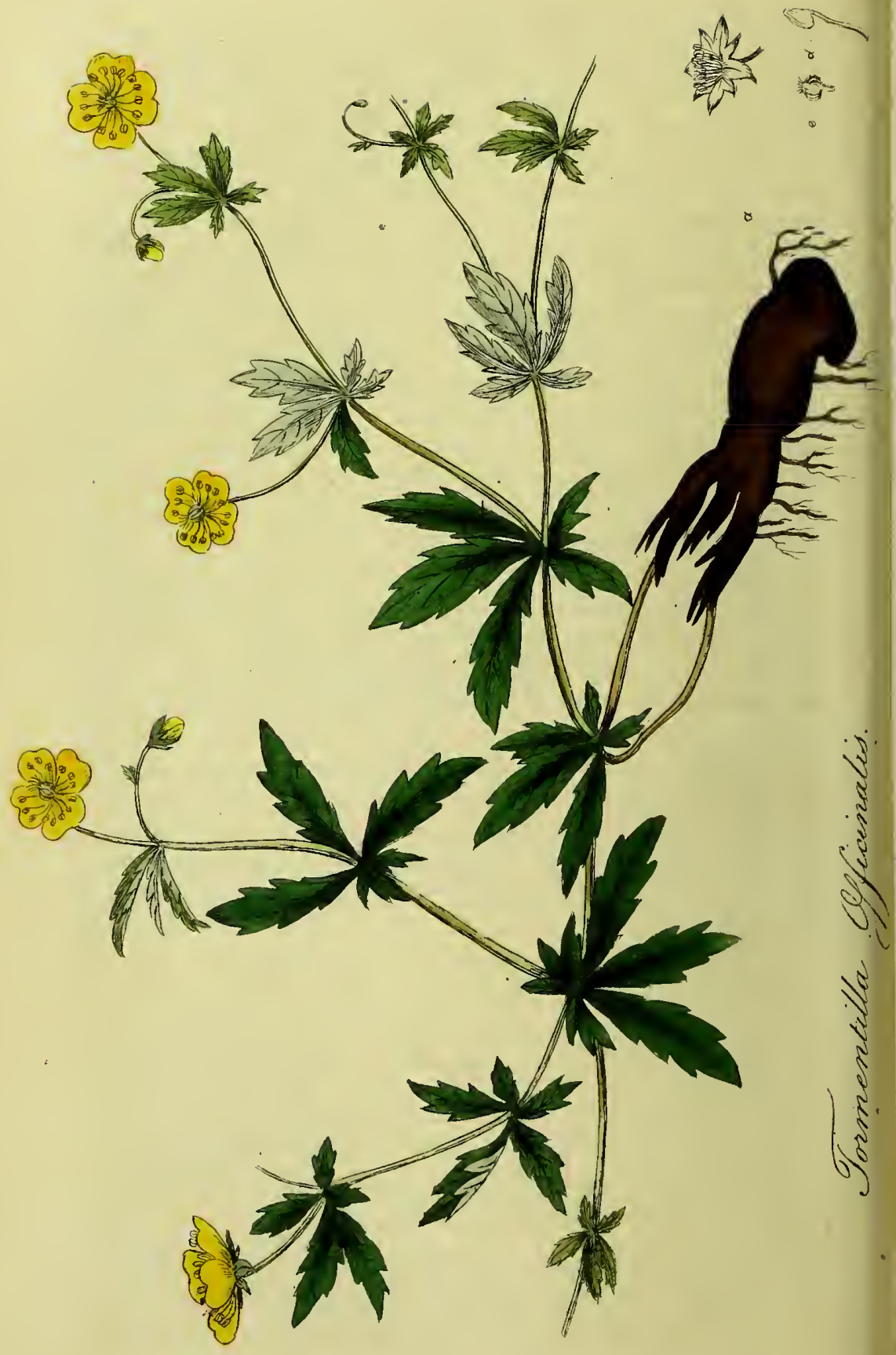


Application of the Belladonna. Internally the leaves and roots have been given, from a quarter of a grain to four or five, in the form of pills, powder or extract; it has also beell exhibited in the forms of tincture,* and infusion; topically the leaves have been applied in their recent state, or formed into a poultice; the dried leaves have also been applied in the form of powder. The extract diluted with four or six times its weight of simple unguent, or from ten to thirty grains of the extract, dissolved in eight ounces of water, form excellent exterual applications.

Off. The Leaves.

Off. Pp. Extract. Belladonnæ, L.

\section{TORMENTILLA ERECTA.}

Common Tormentil, or Septfoil. $\uparrow$

\section{Class Icosandria, - Order Polygynia.}

Nal, Ord. Senticose, Linn. Rosacea, Juss.

Gen. Char. Calyx eight-cleft, alternate divisions smaller. Corolla 4-petalled. Seeds 8, roundish, naked, enclosed in the calyx.

SPEC. Char. Stem somewhat erect, branched. Leaves ternate, sessile.

THis species of Tormentilla, as also another, the Tormentilla Reptans, is iudigenous to Great Britain ; growing on dry, heathy grounds, and by the road sides. Linnaus says, "Genus hoc artificiale magis quam naturale esse, ipse agnosco, et qui illud conjungit cum pracedenti, (Potentilla) vix ervat." $\ddagger$

- Mr. Blackett recommends the following tincture, which he has used with very great success:- "To ten fluid drachms of the expressed juice of the leaves, add sixteen ounces of proof spirit, allow to macerate for twenty-one days, and strain for use."

The above we think one of the best preparations of Belladonna, being admirably snited for the gradnal increase of this powerful medicine.-Ed.

† Fig. a. A plant of the natural size. $b$. The calyx and stamina. C. $\Lambda$ seed. d. A stamen, magnified. e. The pistilla.

$\ddagger$ Linn. Genera Plantarum.

VOL. I. 
The common tormentil is perennial; the root is crooked and knotty, externally of a blackish or dark brown colour, and reddish within, it sends out a number of long slender stalks, which grow erect, to the height of ten or twelve inches, branching towards the top ; the leaves are sessile, proceeding from the joint, and consist of seven long, narrow leaflets, three of which are larger than the rest, somewhat liairy, of a dark green on their upper surface, but palebeneath ; the flowers are small, solitary, of a bright yellow colour, and consist of four petals, obversely heart-shaped, flat, spreading, and standing upon long, slender, axillary stalks; the calyx is hairy, and cut as we have said, into eight segments; the germens are eight, gathered into a little head, and each supporting a thread-shaped style, inserted in the side of the germen, and crowned with an obtuse stigma ; the seeds are oblong, obtusely acuninated, and lodged within the calyx. This plant flowers in June: it is distinguished from the Tormeutilla Reptans by its sessile leaves, its smaller petals, and more erect sten.

Sensible Properties. The root of tormentil has an austere, styptic taste, with a slightly aromatic flavour; its active principle appears to be tannin, which it contains in a very great degree, and which it readily yields to boiling water.*

Medical Properties. The root of tormentil is a pleasant and efficacious astringent, to which use it is now entirely confined, although it was formerly prescribed for various conplaints, as the plague, malignant fevers, syphilis, \&c.; it may possibly possess some antiseptic properties, which would render it a useful remedy. in fevers, where such medicines are indicated. It has been recommended by Dr. Thompson in diarrhoa in consumptive patients, and has been a favourite domestic remedy with the peasantry of many countries, in dysentery; with the faculty of these countries it appears to have gone out of fashion, though we think unjustly, for as the resin it contains is very inconsiderable, it seems particularly adapted in those cases where heating and stimulating medicines of this class are less proper. Dr. Cullen thinks "it has been justly commended for every virtue that is competent to astringents;" and says, "I myself have had several instances of its virtues in this respect; and particularly $I$ have found it, both by itself and as joined with gentian, cure intermittent fevers ; but it nust be given in substance and in large quantities." +

* The root of tormentil has been substituted for oak bark, in the tanning of skins for leather, and it is said the process has been perfected in less time than when oak bark was used.

† Cullen, Mat. Med. vol, ii. p. 36. 
Rutty recommends it in these words:- " Ulcera vetera et putrida, sanat vino vel aqua decocta collutione et inspersu. In vino cocta optime deterget et roborat, in ulceribus scorbuticis oris, gutturis, et faucium ac in gingivis dissolutis, sanguinem stillantibus. Decocta ad appetitum deperditum maxime valet, tonum ventriculi restituens, et sordes ejus abstergens. Non est vegetabile quod in fluxionibus alvi efficacius sit. In dysenteria epidemica quidam, in ore tenent ad præcavendum contagium. In fluxu sanguinis, floure albo, et mictu involuntario valet." *

As an antiseptic, its external application lias been recommended to ill-conditioned ulcers; and it has been found serviceable as a gargle, in ulcerations of the mouth and fauces. It may be given either in substance or decoction; the latter is the more general way of administering it : of the former, from 3 ss. to $3 \mathrm{i}$. of the powdered root may be given; in decoction the following formula may be used: $\frac{1}{2} \mathrm{oz}$. of the root powdered, boiled in $3 \mathrm{lb}$. of water to $2 \mathrm{lb}$.; to which add, towards the end, cinnamon $3 \mathrm{i}$; d dose $2 \mathrm{oz}$. three or four times a day. It gives out its astringency both to water and spirits, but most perfectly to the latter. The extracts obtained by inspissation, are intensely styptic, particularly from the spirituous infusion. It enters into but one officinal preparation, the Pulvis crete composilus.

Off. The Root.

\section{GUAIACUM OFFICINALE. Guaiacum $\uparrow$}

\section{Class Decandria.-Order Monogynia. Nat. Ord. Gruinales, Linn. Rutaces, Juss.}

Gen. Char. Calyx 5-cleft, unequal. Petals 5, inserted on the calyx. Capsule angled, 3 or 5-celled.

Spec. Char. Leaflet two-paired, obtuse.

This treet is a native of the West India Islands, and the warmer parts of America; by a MS. of Sir Hans Sloane, in the British

* Rutty, Mat. Med. p. 521.

+ Fig. $a$. The pericarpium. $b$. The pistillum.

\# Linnæus describes three species of the Guaiacum, viz. Officinale, Sanctum and Afrum, but later botanists cousider the Sanctum to be a variety of the Officinale. 
Museum, it appears to have been first cultivated in this country by the Duchess of Beaufort, in 1699. About the year 1508 the wood was first used in Spain for the cure of syphilis; in $\mathbf{1 5 1 7}$ its use was extended to Italy, and soon after to Germany. This tree grows to the height of thirty or forty feet, and to the circumference of from three to five, sending out many large knotty branches, which divide into numerous sub-divisions; the wood is extremely compact, brittle, and heavier than water; the bark is thin, of an asl colour, and variegated with greenish or purplish spots, streaked, and marked with fissures; the leaves are pinnated, consisting of from two to four pairs of pinnæ, which are of an inversely oval shape, smooth, veined, of a bright green, and stand upon short petioles; the flowers are produced in clusters, and stand upon long peduncles, which spring from the divisions of the smaller branches; the calyx is deciduous, and composed of five concave, oblong, unequal leaves; the petals are five, concave, elliptical, and of a deep blue colour; the stamina are erect, somewhat villous, tapering from the base, and crowned by yellow hooked antheræ; the germen is oval and angular ; the style is short and tapering, and supports a simple pointer stigma; the seeds are solitary, and of an oblong form.

The wood of this tree is in great demand for various articles of turnery ware, being much admired for the beauty of its colour. It is imported in large blocks, of from four to fire cwt. each; the outer part is of a pale yellow, the heart of dark blackish brown, more or less tinted with green.

Sensible Properties, \&c. Guaiacum wood has scarcely any smell unless heated, when it gives out a pleasant aromatic odour; when swallowed in a state of minute division it excites considerable burning and acrimony between the palate and fauces. Its pungency resides in a resinous matter, which is entirely extracted by digestion in rectified spirits, and partially by boiling water; the bark is less resinous than the wood. The quantity of solid extract obtained by rectified spirits amounts to about $\frac{1}{4}$ the weight of the wood; by water scarcely $\frac{1}{6}$ is obtained.

The gum guaiacum is obtained by different processes : as by wounding the bark in different parts of the body of the tree, when it exudes copiously, though gradually; when a quantity is found accumulated, and hardened by exposure to the suu, it is gathered and packed in sniall kegs for exportation; it is likewise procured by sawing the wood into billets, about three feet long, which are then bored longitudinally, and one end of the billet being placed on the fire, the gum exudes at the other, and is collected in a calabash. The 
guaiacum tree also yields a spontaneous exudation from the bark, which is called the native gum ; this is brought to us in small irregular pieces, of a bright semi-pellucid appearance, and differs from the former, in being mucl purer.

Chemical Properties. Guaiacum is of a friable texture, of a dark greenish colour, ${ }^{*}$ and sometimes of a reddish hue: it has a pungent acrid taste, but little or no smell unless heated; it contains more resin than the watery extract of the wood, and more gummy matter than the spirituous extract. Alcolıd forms, with guaiacum, a deep brown-coloured solution; which is rendered milky by the addition of water, and precipitated pale green, by the muriatic and sulphuric acids, and brown by the nitric. $\dagger$ Guaiacum is soluble in fifteen parts of solution of potass, and in thirty-eight of ammonia ; it differs from the resins, in the change of colour produced on it by air and light, in the action of the acids, and in not forming tannin when heated with nitric acid; it gives a blue colour to vegetable matters containing gluten, and to the mucilage of gum arabic and nilk.

Medical Properties and Uses. The wood, gim, bark, fruit, and even the flowers of this tree, have been found to possess medicinal qualities, but it is only the wood and resin which are now in general use in Europe; the efficacy of the former, depending entirely on the quantity of resinous matter it contains. The bark containing less resinous matter than the wood, and is not so powerful a medicine, though in a recent state strongly cathartic; the fruit is purgative, and for medicinal use, far exceeds the bark; a decoction has been known to cure the venereal disease, and even the yaws in their advanced stage, without the use of mercury; the flowers are laxative, and in Jamaica, are commonly given to children in the form of syrup, which in appearance much resembles that of violets. $\ddagger$

Guaiacum was first introdnced into Europe as a remedy for the venereal disease, and was used in Spain so early as 1508 ; the great

* According to Dr. Wollaston, this green colour is produced by the action of air and light, which is effected by the most refrangible rays ; and in the refrangible rays it is disoxidized, and the jellow colour returns.

+ Sulphuric acid dissolves gum guaiacum; the solution is a fine claret colour, and on adding water lets fall a lilac precipitate. Nitric acid dissolves it : much nitric vapour is emitted, and on distillation oxalic acid is formed ; dilute nitric acid only changes it into a brown resin. Spirit of salt dissolves a small portion; this solution is brown : by distillation it yielded 5.5 per cent, of acidulous water ; 24.5 of thick brown oil ; 30 of a fine oil ; 30.5 of charcoal, and 9.5 of gas ; chiefly carbonic acid gas, and carburetted hydrogen. Gray's Elements, p. 271.

\$ Long's History of Jamaica,-Des Marchais Voyage en Guinée et Caycnne. 
success attending its administration brought it into such repute that it sold for a very high price; but it did not continue to maintain its reputation, being generally found to fail where the disease was inveterate, and it was at length superseded by mercury. The general virtues of guaiacum are those of a warm stimulating medicine, strengthening the stomach, and other viscera; exciting a sense of warmth, and a dryness of the mouth, with thirst ; it increases the heat of the body, and quickens the circulation ; if the patient be kept warm it acts as a diaphoretic; if exposed freely to the air as a diuretic. Dr. Cullen supposes it to be, like the balsams and turpentine, very diffusing in the system, stinulating the extreme vessels, and to this property attributes its power in chronic rheumatism, and cutaneous disorders : this opinion accords with Murray's. We have frequently conjoined it with bark and steel, and found it eninently useful as an alterative.

The wood is always exhibited in decoction : the resin is exhibited either in substance, made into pills, or suspended in water, in the form of emulsion, with mucilage or yoke of egg ; in this way from ten grains to thirty of the resin may be taken, or it is given in solution in alcohol : about half an ounce of the tincture, with two or three ounces of water, is a sudorific dose for an adult. The resin is also conveniently made into pills, with nucilage of gum arabic; the ammoniated tincture is given in doses of from one to two drachms.

Off. The Wood and Resin.

Off. Pp. Decoctum Guaiaci Compositum, E.

Mistura Guaiaci, L

Tinctura Guaiaci, L. E. D.

Guaiaci Ammoniata, L. E. D. 


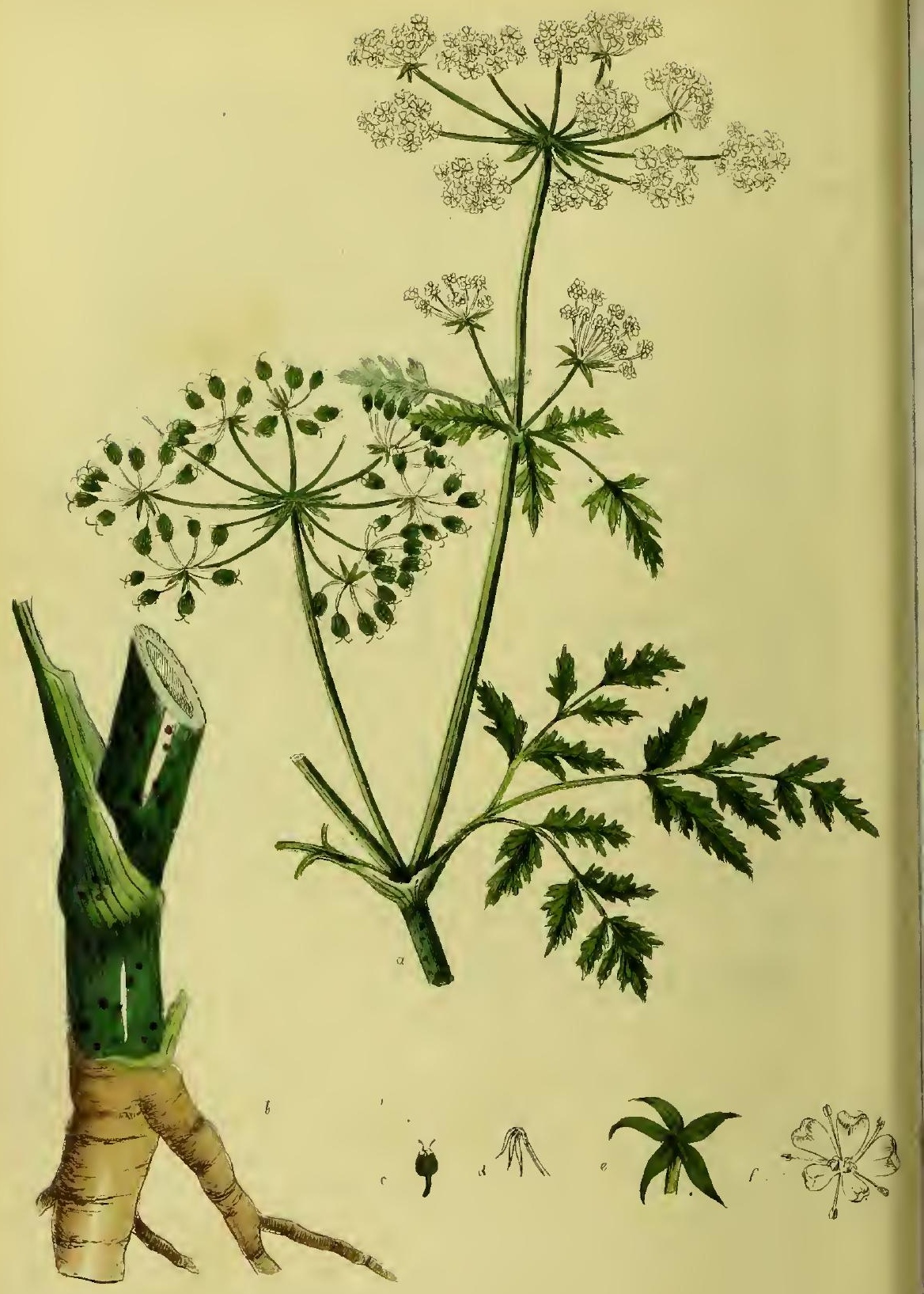

Goniem . Harulatum.

W. Sprati. del. et tithyy. 


\section{CONIUM MACULATUM, Common, Greater, or Spotted Hemlock.*}

\section{Class Pentandria.-Order Digynia.}

Nat. Ord. Umbellate, Linn. Umbellifere, Juss.

Gen. Char. Involucella 3-leaved, placed all of one side. Petals heart-shaped. Fruit nearly globular, 5rribbed and furrowed; the ribs crenate.

Spec. Char. Stem smooth and spotted. Seeds striated.

The Conium Maculatum $\dagger$ is a biennial, umbelliferous plant, indigenous to Britain, and many parts of Europe ; it is very common in many parts of England, and is usually found growing on the shady sides of fields, under hedges, and where the ground is cool and moist; it often rises to the height of several feet, flowering in June and July; and soon after the seeds ripen, the leaves and the stalks wither.

As there are several other plants which bear a very great resemblance to hemlock, some of which are very virulent poisons, it requires much circunspection in those who gather it for medicinal purposes, and attention to its distinguishing characters. The roots are long and tapering, the thickness of a finger, in form resembling a young carrot, the colour of a parsnip, and contains when young a milky fluid; the stalk is smooth, shining, hollow, and sprinkled with reddish purple spots, and much branclied; the leaves are large, supported on long thick footstalks, the lower ends of which embrace the stems; the leaves are compound, and very inuch resemble those of parsley, (which has given rise to many fatal accidents); the leaflets are small, sessile, lancet-shaped, and notched; the umbels are terminal, and compound; the general involucrum is composed of from three to seven leaflets, which are reflected and membranous towards the base; the invollucellun is composed of

* Fig. a. represents a sprig of the natural size, shewing the flower and fruit. $\quad b$. The lower part of the stem and root. c. A seed. $d$. The involucella. e. The involucrum $f$. A flower magnified.

T The Maculatum is the only species of Conium that is a valive of Britain, three exotic species of Coniunı are cultivaled in our botanic gardens. 
three lanceolate leaves, which are disposed on the internal side of the umbel; the flowers are composed of five unequal heart-shaped petals, which turn inward; the germen is situated under the flower, and support two reflexed styles, which are permanent; the stigmata obtuse; the staniens are five, and support roundish anthers; the seeds are flat on one side, and hemispherical on the other, with five serrated ribs; the character of the seeds, the polished and spotted stalks, together with the peculiar nauseous foetid smell, particularly when rubbed between the fingers, will serve to distinguish it from all other plants.*

Hemlock has been long knowu as a powerful narcotic poison, and many cases are recorded of the fatal consequences arising from eating the leaves or roots. Sir Astley Cooper says, "the effects of this poison are known rather from history, than from any recent observations which have been made with respect to it. The Greeks were in the habit of putting to death, by this poison, persons who had forfeited their lives to their country, and it was by this poison that Socrates was destroyed." But whether this species of hemlock was really the poison usually administered at the Athenian executions is not quite clear; Dioscorides only proves it to have beell one of the umbelliferæ; Linnæus, Lamarck, and otler botanists, believed the juice of the Conium Maculatum to be the poison used by the Grecians; Haller supposed it to be the Cicuta Virosa, + but the word Cicuta with the ancients seemed not indicative of any particular species of plants, but of poisonous vegetables in general. $\ddagger$

EFfects of Hemlock on the Animal Economy. Hemlock, when taken in an overdose, gives rise to all the symptoms produced by other narcotic poisons, viz. sickness, anxiety, vertigo, delirium, dilatations of the pupils, stupor, convulsions, \&c. A soldier who bad eaten of some broth for his supper, in which the leaves of hemlock liad been put, soon fell into a profound sleep, his respiration became extremely difficult, pulse hard, small, and slow, to $\mathbf{3 0}$ pulsatious in a minute; the face bluish, and distended with blood; the extremities became cold, and he died three hours after taking the

* Hemlock may be distinguished from the Chœrophyllum Sylvestre, (wild chervil or cow-parsley) to which it bears a very great resemblance, by the stems of the latter being furrowed, and hairy, and without spots. Tbe Conium Bulbosum bas a spotted stem, but its swelled joints and rough seeds distinguish it from bemlock.

† The Cicuta Virosa, or water cowbane, is a very virulent poison, considerably more energetic than the hemlock, to whicb it bears some resemblance; it is indigenous to Britsin, and found in marshy situations. Ed.

† Vide Plin. Hist. Nat, iv. 14. 
broth. * An instance of its fatal effects in this country, is related by Dr. Watson in the Philosophical Transactions, in which it is fully ascertained by him, that two Dutch soldiers, at Waltham Abbey, were killed in a very short tine by eating this plant.

For the treatment of persons suffering under the influence of this poison, we refer our readers to the article Atropa Belladonna, page 133.

Sensible and Chemical Properties. Hemlock leaves, when fresh, have a disagreeable odour, compared by some to the smell of mice, or the urine of a cat; taste bitter and nauseous; both these qualities are much diminislıed by drying. $t$ The infusion is limpid and thin, with a slight smell of the plant, the sulphate of iron produces no change. The expressed juice evaporated to the consistence of an extract, is bitter, foetid, and somewhat salt; in summer, saline crystals separate from it. Ether and diluted alcholool extract all the medicinal properties of the plant. We are told by Dr. Paris, the medicinal properties reside " in a resinous element, which may be obtained in an insulated form, by evaporating an ethereal tincture made with the leaves on the surface of water. It has a rich dark green colour, and contains the peculiar odour and taste of hemlock in perfection. A dose of half a grain will produce vertigo and headache. It may be distinguished by the name of Conein." According to the analysis of Schrader, hemlork contains the following constituents:- - уuнuy calract, resin, albumen, green frecula, extractive, and also various earthy and alkaline salts. Various sentiments prevail respecting the qualities of the Root of hemlock, some asserting that it is highly acrimonious, whilst others maintain that it is perfectly mild, and devoid of all deleterious properties. Störck says that the milky juice is so extremely acrid and deleterious, that a small drop or two applied to his tongue, produced great pain and swelling of that organ, and for some time deprived lim of the power of speech. The following instances are in direct opposition to Baron Störck. Ray relates, in the Philosophical Transactions, vol. xix, p. 684, that Mr. Petiver ate half an ounce of the root, and that Mr. Henly swallowed three or four ounces, without experiencing any remarkable effect. Mr. Curtis says, "Mr. Alchorne assures ine that be has tasted the root in every season of the year, and in most parts

* Journal de Medicine, tom. xxviii. p. 107.

$\uparrow$ Hemlock should be gathered when in full flower, at which time its peculiar smell is most powerful, and its properties most energetic; the leaves should be picked from their footstalks, and immediately dried before a fire, and when powdered should be kept in close vessels, and carefully excluded from the light. $E d$.

VOL, I. 
of our island, without finding any material difference." * From these discordant sentiments, we must draw the conclusion, that the qualities of the roots of hemlock must materially depend upon the soil in which it grows, the season of the year, and the maturity of the plant.

Medical Properties and Uses. The chief virtues of hemlock consist in its anodyne properties; in many diseases where opium would, be improper, it will be found to mitigate pain and procure rest. Hemlock has beell strongly recommended by Baron Störck, $\nmid$ as a remedy for the cure of scirrlius and cancer, but experience teaches us, that a! though it often relieves the pain for a time, and the discharges become more mild, these effects are not lasting, hence it is now looked upon as a palliative only in those disorders. Hemlock was in general use with the Greek and Arabian physicians, as an external reniedy for ulcers, tumours, cutaneous eruptions, $\angle c$., and they believed it to have the power "frangere stimulum venereum." Bergius however, recommends its interual use for disorders of the opposite nature ; as a topical remedy, it is frequently used in the form of poultice to discuss scrofulous tumours, and often with good effect, but Dr. Cullen says "I have not at any time observed that it disposed scrofulous ulcers to heal. $\S$ It is also found a useful remedy for many other disorters, viz. in tic douloureux, passage of biliary calculi, hooping cough, pulmonary disorders, chronic rheumatism, \| \&c. The best form of administering bemlock is in powder, beginning with one or two grains, gradually increased to sixty or more; this quantity may be given twice or oftener in the day, according to circumstances; it is also frequently prescribed in the form of extract, but this latter is an uncertain remedy, from the careless manner in which it is usually prepared; the extract is given from three or four grains to one scruple or more.

Off: The Leaves, and Seed.

Off. Pp. Extractum Conii Maculati, L. E. D. Tinctura Conii Maculati, E.

* Curtis's Flora Londinensis.

† Baron Störck appears to have been the first physician who brought hemlock into repute, as a medicine possessing extraordinary efficacy.

$\ddagger$ Bergius Mat. Med. p. 195.

$\$$ Cullen's First Lines,

II We are told by pr. Withering, that he found it particularly usefal in chronic, rheumatisı. Vide Bot, Arr. 2nd edit. p. 280. 


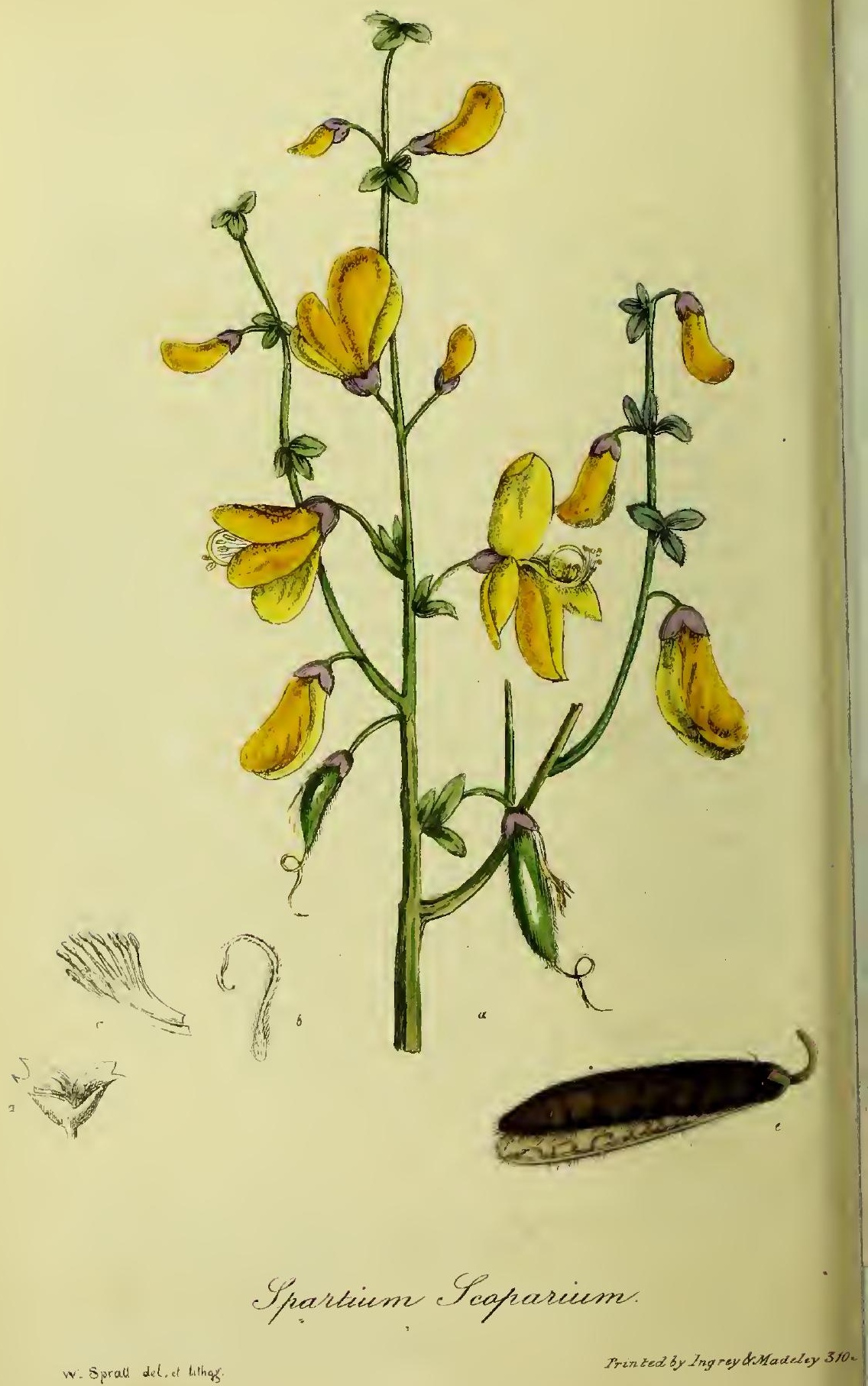

Pub by Cazzon \& Wilson Princas SE Soho. 1828 


\section{SPARTIUM SCOPARIUM.}

\section{Common Broom.*}

\section{Class Diadelphia. Order Degcandria. \\ Nat. Ord. Papizion acere, Linn. Juss.}

Gen. Char. Filaments united into a tube at the base. Stigma linear, hairy. Legume flat.

Spec. Cha R. Leaves ternate, or solitary. Branches angular, unarmed. Legume many seeded, fringed.

THIs species of Spartium + is an indigenous shrub, flowering in May and June, and grows plentifully on dry, sandy soils, in many parts of the country; it is a large bushy shrub, rising to the height of five or six feet, with numerous straight, slender, angular branclues, covered with a light brown bark; the young twigs are green; the leaves are small, downy, divided into three oval leaflets, and stand upon short footstalks; the flowers are of papilionaceous form, large, numerous, and of a briglit yellow; the calyx is of a purplish colour, tubular, bilabiate and notcherl; the corolla is composed of five petals; the standard is inversely heart-shaped and reflexed; the two wings are ovate-oblong, convex, and united to the filaments; the keel is composed of two lanceolate oblong petals, and connected together at the lower margin by soft hairs; the tell filaments are of unequal length, united at the base so as to form a tube; the anthers are oblong, and of a deep yellow; the germen is oblong, flat, hairy, and supports a slender style crowned with an oblong stigma; the legume is flat, and contains many small flat shining seeds.

Sensible Properties. The tops and leaves of broom have a bitter and somewhat nauseous taste and a disagreable odour, these qualities are imparted by infusion both to water and spirit.

Medical Properties and Uses. The leaves and tops of broom have been long held in much estimation for their diuretic and purgative qualities, and have been successfully employed in dropsy. $\downarrow$

* Fig. $a$. represents a cutting of the natural size. b. The pistillam. c. The stamens. $d$. The calyx. $e$. The pericarpium.

+ There are above twenty species of the genus Spartium cultivated in our botanic gardens, of which the Scoparium and Alpinum are the only two that are natives of Britain. Ed.

‡ See Linnæus, Bergias, Sydenham, \&c. 
We are told by Dr. Cullen, that many dropsical disorders have been cured by taking a decoction of this plant; one ounce of the fresh plant may be boiled in a pound of water till half is consumed, and of this two or three spoonsful may be taken every hour, till it operates upon the bowels; this quantity may be repeated every day, or every second day, until some decided effect is produced. Sydenham prescribed the ashes of broom tops, * and on his authority they were formerly much used, and, as it appears, with much success. Dr. Monro also confirmed their efficacy, and prescribed them in doses of from twenty to thirty grains, three times a day. But as the efficacy of these ashes must, doubtless, depend entirely upon the alkaline salt they contain, and not in the least upon the vegetable from which they are obtained, they are now out of repute, small doses of the carbonate of potass being found equally efficacious. The seeds and flowers are said to be emetic and cathartic, we are told however, by Dr. Woodville, that " the evidence upon which this rests, is not wholly to be relied upon, as the former, when roasted, have been used as a substitute for coffee, and the latter employed as a pickle."

Off. The Tops and Seeds.

Off. Pp. Extractum Genisiæ, D.

\section{CEPHAËLIS IPECACUANNA.}

\section{Ipecacuan.†}

\section{Class Pentandria.-Order Monogynia.}

Nat. Ord. Aggregater, Linn. Rubracere, Juss.

Gen. Char. Flowers in an involucred head. Corolla tubular. Stigma 2-parted. Berry 2-seeded. Receptacle chaffy.

Spec. Char. Stem ascending, somewhat shrubby, sarmentous. Leaves ovate, lanceolate, somewhat pubescent. Leaflets a little heart-shaped. Corolla 5-cleft, chaffy. Bracteas large.

* Opera, p. 497.

+ Fig. a. The germen. b. A flower magnified. c. An imbifloral bractea. d. A berry of the natural size. 


$$
14
$$





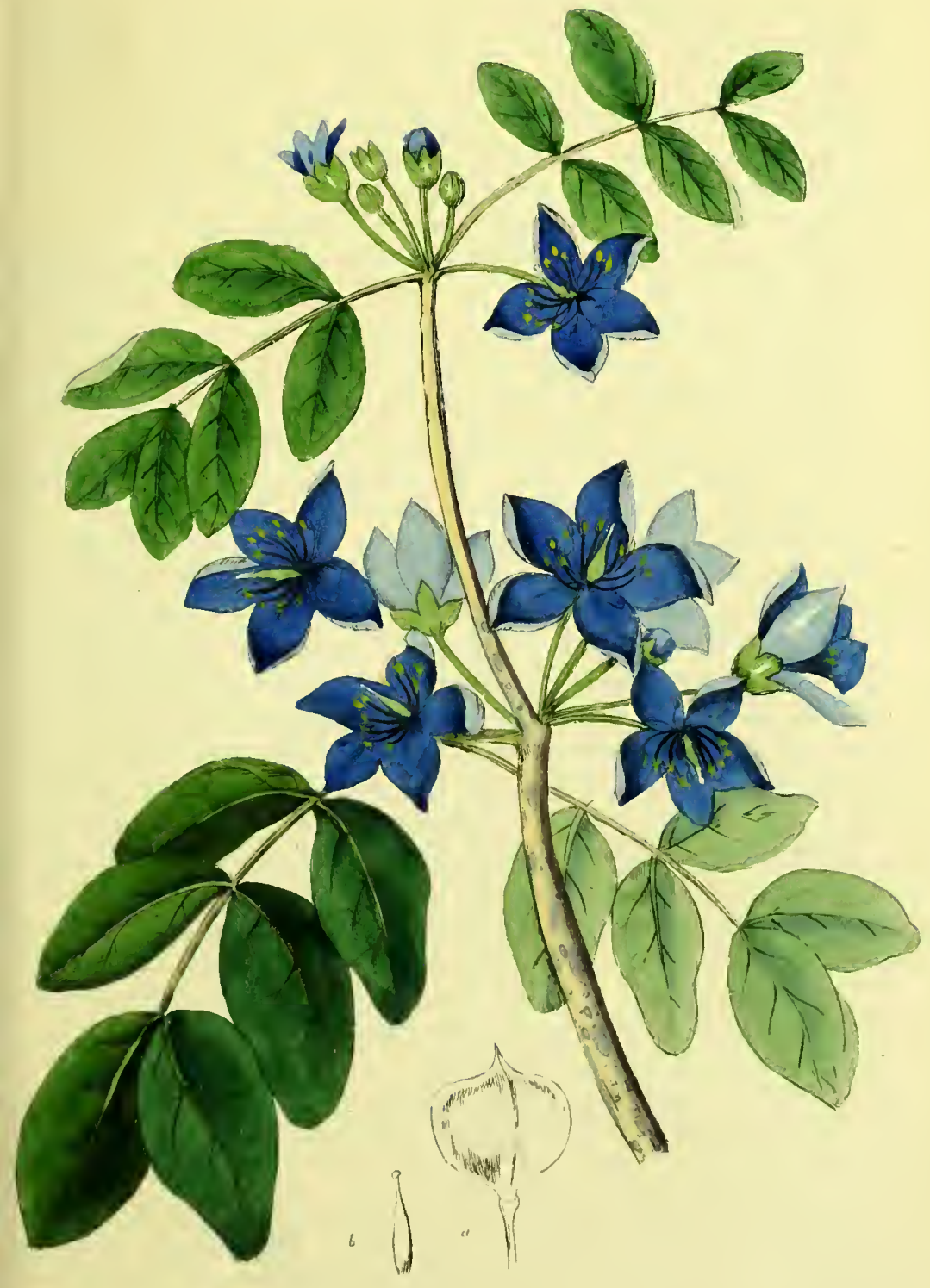



The Cephaflis Ipecacuanha is a perennial plant, a native of South America, and flowers in the months of December, January, February and March. It is found growing in moist slady situations in the forests of Brazil, particularly in the provinces of Pernambuco, Rio Janeiro, Mariannia and Paulensia. In the language of South America, ipecacuan signifies vomiling root, lience it is applied to the roots of various plants that have the property of exciting vomiting; from this circumstance has arisen the confusion which for a long period prevailed, concerning the specific plaint which furnished the officinal roots. According to Professor Brotero's description, * the plant which furnishes the roots of commerce, (i. e. the gray and brown Ipecacuaula) is the Callicocca Ipecacuanha; but Willdenow having united the genus Callicocca with that of the Cephaëlis, the species in question is now referred to the latter.

The Cephälis Ipecacuanha is a low plant, rising to the height of from six to nine inches; it has a simple or somewhat branched root, furnished with a few small short radicals ; the root is three or four inches in length, and two or three lines in diameter, it is of a roundish form, and bent in different directions, externally brown, and annulated with numerous prominent, rough, unequal ridges; the stem is procumbent at the base, about the thickness of a small quill, round, smooth, of a brownish colour, the lower part leafless and somewhat knotty, but leafy toward the upper part, and somewhat pubescent; after the first year it throws out a few knotty runners, which take root at the distance of eight or ten inches, and send up new stems : the leaves are three or four inclies long, ovate, pointed at both ends, of a deep greell on the upper surface, pale, downy, and veined on the under side, they stand almost sessile and opposite; the lower leaves are caducous, so that not more than six or eight remain on the upper part of the stem when it flowers : at the base of each pair of leaves, are placed a pair of stipules deeply cut into awl-shaped sections, they are withering, and embrace the stem; the flowers terminate the stems, and are aggregated into a solitary head, on a ronnd downy footstalk, somewhat drooping, and encompassed by a fourleaved involucre; the florets are from fifteen to twenty-four in number, interspersed with small bracteas, which are sessile, entire, ovate, or obtusely lanceolate, and pubescent; the calyx is very small, superior, persistent, and divided into five acute-segments; the corolla is monopetalous, the border shorter than the tube, and divided

* Vide 'Iransactions of the Linuæan Society, vol. vi.

VOL. I. 
into five ovate, acute, recurved segments; the filaments are short, capillary, inserted into the upper part of the tube, and support long, linear, erect anthers; the germen inferior, ovate, supporting a filiform style, terminated by two obtuse stigmas the length of the authers; the germen becomes a one-celled berry of a reddish purple colour, changing to black as it ripens, and containing two oval seeds.

It appears that ipecacuan was long used by the natives of America as an emetic, before its introduction into Europe. Michael Tristam, a native of Brazil, was the first who wrote on its virtues; he was followed by Piso, who in his Natural History of Brazil, in the year 1618, fully described its uses, and introduced it into Europe ; but it was little used previous to the year 1700. In 1672 it was introduced into France by a French physician of the name of Le Gras; but'it did not attract much notice till the year 1686, when Helvetius (who was patronized by Lewis XIV.) made known its use as a remedy in dysenteric disorders.

Sensible Qualities, Properties, \&c. There are three varieties of the root found in the shops:-1. the common brown ipecacuan which grows in Brazil, and is exported from Rio Janeiro to Portugal; its colour varies with different tiats of grey or brown, but it is characterized by being contorted, wrinkled, and unequal in thickness, having a thick bark deeply fissured transversely, covering a very small central wood, so as to give the idea of a number of rings strung upon a thread. This is the root of the Cephaëlis. 2. The black or striated ipecacuan which is a native of Peru, and is exported from Carthagena to Cadiz; it is black within and without, fusiform, articulated, striated, and not annulated. This is the root of the Psycotria Emetica. 3. The white ipecacuan, called Amylaceous by M. Merat.* This species is the root of the Richardsonia Brasiliensis, and is described by M. Gorney as of a dirty white, which turns brown by drying; it is three or more inches long, and from four to six lines thick, variously contorted, with transverse annular rugosities; the bark is white internally and softish; the wood is lıard, white, and fine as a thread. $\dagger$

The root of ipecacuan is inodorous, but when powdered it has a faint disagreeable smell; the taste is bitter, nauseous, and slightly

* Duncan's Edinburgh New Dispensatory, 11th edit.

+ Besides these three species, the name of ipecacuan is given to various roots possessing emetic propertics, as some species of Cynanchum, Asclepias, Euphorbia, Dorstenia, and Voila. The comparative strength of each depending upon the quantity of emetine it contains. $-E d$. 
acrid. The emetic properties are destroyed by boiling; both water and spirit take up the emetic quality, but the latter more completely than the former.

Chemical Properties, Analysis, \&c. We are indebted to MM. Majendie and Pelletier* for the discovery of the emetic principle in ipecacuan ; from their experiments it appears, the active property resides in a peculiar principle, or vegetable alkali, which M. Pelletier has obtained in an isolated state. To this substance they have given the name of emetine: to obtain it, they digested ipecacuan root, first in ether and then in alcohol; evaporated the alcoholic infusion to dryness, dissolved the residue in water, and dropped in acetate of lead; the precipitate was then washed, diffused in water, and decomposed by a current of sulphureted hydrogen gas. Sulphuret of lead falls to the bottom and the emetine remains in solution; by evaporating the water, the latter is obtained.

Emetine. This substance, obtained according to the above process, is in the form of transparent brownish red scalcs. It has no smell, but a bitter acrid taste; at a heat somewhat above that of boiling water, it is resolved into carbonic acid, oil, and vinegar; it affords no ammonia; it is soluble in both water and alcohol, but not in ether, and uncrystallizable. It is precipitated by a protonitrate of mercury and corrosive sublimate, but not by tartar emetic.

Pure Emetine. The emetine obtained by the process we have described is not pure, but MM. Pelletier and Dumas by further chemical researches obtained this substance in a completely isolated state.

To obtain pure emetine, the powder of ipecacuan is digested in water with calcined magnesia; the deposit is throwil on a filter, carefully washed with cold water, and dried. The emetine is then taken up by alcohol. It inay afterwards be combined with an acid, and the salt purified with animal charcoal; when the emetine is once more thrown down by magnesia, alcolol redissolves it in a colourless state. Emetine thus obtained is of a yellowish white, and pulverulent. The only effect of air is to colour it slightly. It is little soluble in cold water, and sonewhat more so in hot. It fuses about $122^{\circ}$. F.; and is very soluble in alcohol, but not in ether or oils. It is highly alkaline, though acids saturated with it do not afford crystallizable

* Vide Ann. de Chim. et de Phys. iv. 172. 
compounds. Gallic acid and nut galls seem to alter it, by forming very abundant white precipitates. Subacetate of lead has no effect on it, though it precipitates the coloured (or impure) emetine, which has, according to Majendie, only one-third the activity on the animal frame of the pure substance. Its constituents are carbon 64.57; azote 4.00 ; hydrogen $\mathbf{7 . 7 7}$; oxygen $\mathbf{2 2 . 9 5 . * " ~}$

Action of the Coloured Emetine on the Animal Sxstem. This substance given to dogs and cats, to the extent of from half a grain to two or three grains, produced vomiting, followed sometimes by long protracted sleep; but when given to a greater extent, such as ten grains, it produced upon dogs repeated voniting, accompanied by stupor, in which the animal, instead of recovering, as in the other case, commonly died in the course of twenty-four hours. On opening the body, the cause of death was discovered to be a violent inflammation of the pulmonary tissue, and of the mucous membrane of the intestinal canal, from the cardia to the anus-phenomena very analogous to those described by our author, in a separate memoir on the action of tartar emetic. The same effects are produced, whether the emetine be injected into the jugular vein, or simply absorbed from any part of the body.

Two grains taken on an empty stomach, gave rise to protracted vomiting, followed by a marked disposition to sleep. Sometimes a quarter of a grain will be sufficient to excite nausea and vomiting. In cases of disease, the action of this substance is perfectly analogous. It both vomits and purges, but acts beneficially in catarrbal affections, particularly tlose of a chronic kind. $\dagger$

Action of Pure Emetine on the Animal System. It is the same as that of the coloured, but much more powerful. Two grains are sufficient to kill a large dog. M. Magendie saw vomiting produced by $\frac{1}{16}$ of a grain in a man aged 85 , in whom however vomiting was easily excited.

Medicinal Employment of IMPURE OR Coloured EMEtine. The cases in which emetine may be given are the same as those in which ipecacuan is indicated. To procure vomiting, dissolve four grains, and give it in divided doses. If the whole quantity were administered together, the vomiting thereby excited would expel it at once frotn the stomach, without producing any other effect.

* Annales de Chim. et Phys. vol. xxiv.; and Ure's Chemical Dictionary.

† See Recherches Chimiques, et Physiologiques sur l'Ipecacuan, par MM. Majendie et Pelletier.-Paris, 1817. 
M. Majendie used the following formula :-

EMETINE MIXTURE.

Take of Emetine,
$\begin{aligned} & 4 \text { grains, } \\ & \text { Weak orange flower water, } \\ & \text { Syrup of orange flower, }\end{aligned} \quad{ }^{\frac{1}{2}}$ once.

Mix. Five gros + to be taken every half hour.

In chronic pulmonary catarrhs, hooping cough, obstinate diarrhoas, \&c. Majendie substituted the following lozenges for the common ipecacuan preparations.

\author{
PECTORAL LOZENGES OF EMETINE. \\ Take of Sugar, \\ 4 onces, \\ Coloured emetine, \\ 32 grains. \\ Mix.
}

The above mixture may be coloured with a little carmine (in order to distinguish it from similar preparations of ipecacuan) and divided into lozenges of nine grains each, one of which may be given every hour; more frequent exhibition will excite nausea. To excite vomiting by this preparation, the quantity of sugar should be reduced one half, and the lozenge should consist of eighteen grains. One of these is an enetic dose for a child, and three or four will readily excite vomiting in adults.

Pure Emetine.-M. Majendie used the following formula for this powerful substance:-

Sugar, 4 onces,

Pure Emetine 8 grains made into lozenges of 9 grains each.

To produce vomiting, one grain of pure emetine, previously dissolved either in a little acetic or sulphuric acid, may be mixed in soma drink; or the following may be adopted:-

EMETIC MIXTURE OF PURE EMETINE.

Take of infusion of lime flowers, 3 onces,

Pure enetine dissolved in a sufficient quantity of acetic acid, Syrup of marshmallow, 1 grain, 1 once.

Mix. Dose. Five gros every quarter of an hour till vomiting is produced.

Medical Properties and Uses of Ipecacuan. Ipecacuan, when taken into the stomach in large doses, excites

* The once is equal to 1 f. $340 \mathrm{M}$. English measure.

+ Equal to five fluid drachms and a lalf English measure. Vide Houlton's Translation of Majendie's Formulary. 
nausea and vomiting; in smaller doses its effects are expectorant and diaphoretic, and in very small quantities it gently sti. mulates the stomach, and gives ellergy to the digestive organs, increasing the appetite and pronıting digestion. Dr. A. T. Thomson justly observes, "as an emetic it is mild, safe, and certain in its operation; but it is a mistake, that when given in laryer doses than are necessary, it does not operate more violently, but only in a shorter space of time. It does not act so quickly as many other emetic substances; but it evacuates completely the contents of the stomach, and does not so much weaken it as antimonial emetics." Its secondary effects seem to depend upon the sympathy of other parts with the stomach, and in this way we presume it acts as a diaphoretic, expectorant and antispasmodic, and also in cliecking hæmorrbages. Ipecacuanha is givell in a great variety of diseases, and when properly administered generally proves serviceable; at the commencement of intermittent and continued fevers, when given in an emetic dose it frequently cuts short the disease. At the commencement of many inflammatory diseases, when the inflummation does not run very high, its effects are to cut short the disease; hence it is given in inflanmation of the pharyux, larynx and trachea, also in rheumatism, bubo, swelled testicle, cynanche tonsillaris, purulent ophthalmy, abscess, and in every case where we wish to evacuate the stomach. Its good effects, when exhibited in small doses, in dysentery and chronic diarrhœa are so decided, that formerly it was esteemed a specific in those diseases; the good effects, however, seem to depend upon its producing a steady determination of the peristaltic motion of the intestives downwards, and also by the nausea which is kept up, diminishing the arterial excitement and determining to the surface. In this way also, (by lessening the force of the circulation) its beneficial effects in uterine and pulmonary hamorrlages may be accounted for. The sudorific effects of ipeeacuan are considerably increased by its combination with opium, and in this way it is exhibited in almost every case in which we wish to promote perspiration, particularly in acute rheumatism, dropsy, and arthritic affections. It is given in exanthematous diseases when the eruption is disposed to recede, and in mally other cutaneous diseases. In very small doses its expectorant powers have been found exceedingly useful in the early stage of phthisis, catarrhal affectious, and in pneumonia after the free use of the lancet. Ipecacuan is exhibited in substance, or infused in wine or water. To excite vomiting, the dose of this powder is from 15 to 30 grains; the vinous infusion is given in doses of from one to two ounces, 



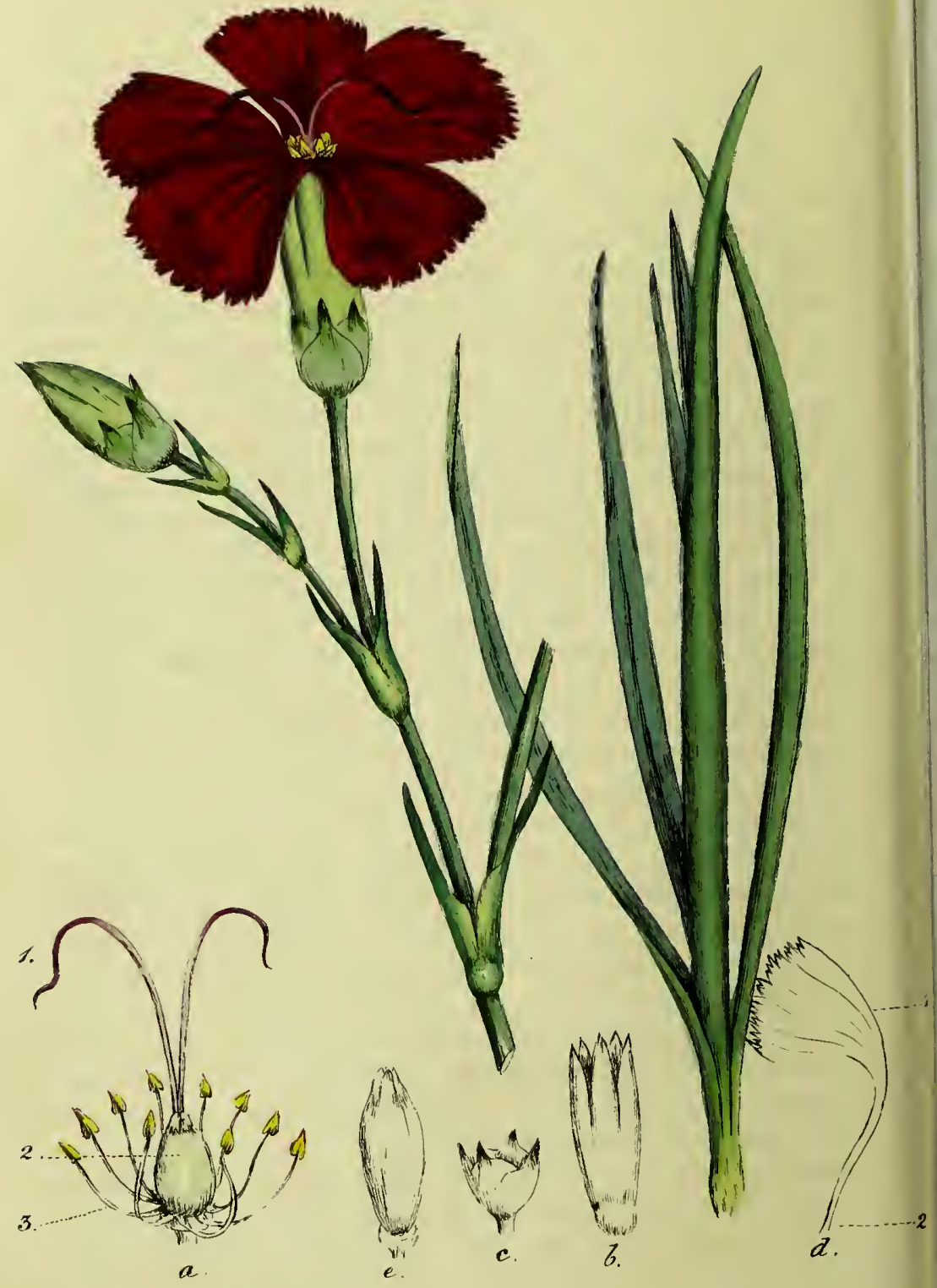

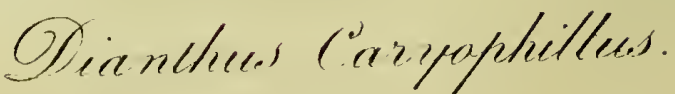


when its emetic effects are required. The watery infusion is made by macerating one drachm in three or four ounces of boiling water, and filtering the infusion, one or two ounces of which may be taken every half hour till emetic effects are produced, which are promoted by taking at intervals copious draughts of warm diluents. To excite sudorific and expectorant effects, it is exlibited in doses of from one to three grains, generally in the form of bolus or pill.

Ipecacuan checks the narcotic effects of opium, and by some has been considered one of its best antidotes. Dr. A. T. 'Thomson, however, says, "We do not agree in opinion with those who think that it is to be relied upon as an antidote against the deleterious effects of opium, its emetic effects being too slow, and checked by the opium." The best antidote when ipecacuan, or any of the preparations of emetine have been iaken in an over dose, is an infusion of galls, which instantly destroys its combination.

Off. The Root.

Off. Pp. Pulvis Ipecacuanhæ Compositus, L. D.

Vinunı Ipecacuanhæ, L. E. D.*

\section{DIANTHUS CARYOPHYLLUS. Clove Gillyflower, Clove Pink, or Carnation. $\uparrow$}

Cless Decandria.- Order Digynia.

Nat. Ord. CAR YOPHYLLE⿸, Linn. Juss.

Gen. Char. Calyx cylindrical, one-leaved, with four scales at the base. Petals 5, with claws. Capsule cylindrical, one-celled.

Sipec. Char. Flowers solitary. Caly.x scales sub-ovate, very short. Petals serrated.

This species of Dianthus $\ddagger$ is a native of Italy; it is also indigenous to Britain, having been found wild in many parts of the

* The Vinum Ipecacanba however of the London College is a weak tincture, $-\boldsymbol{E} d$.

† Fig. r. represents the stamina and pistilla._- T. The styles, 2. The germen, 3. The stamens. b. The calyx. c. The scales, d. A petal.-1. The limb, 2. The claw. e. The pericarp.

$\ddagger$ According to the Hort. Cant. fifty species of Dianthus, natives of every country and olime, are cultivated in our botanic gardens. 
country; according to Ray and Hudson, it was formerly very common in the neighbourhood of Rochester, Sandown, Deal, \&c. and is now occasionally met with in the crevices of-rocks and old walls.

The clove pink now forms an ornament in almost every garden, being generally admired both for its colour and fragrance; by the aid of cultivation, many beautiful and double varieties are produced, the most luxuriant of which are known by the name of caruations. The specific name, Caryophyllus, given to this species of Dianthus, appears to be derived from its odour, which greatly resembles that of the clove spice. The root is perennial; the stems are slender, upright, smooth, branched and jointed, of a glaucous green colour, and rise from one to two feet in height; the leaves of the young shoots are numerous, smooth, linear, entire and pointed; those on the stems are short, linear, and placed in pairs at the joints; the flowers stand singly at the extremities of the branches, and are of a deep crimson colour; the calyx is cylindrical, tubular, and five-cleft; the base is surrounded with four ovate, pointed squamæ; the corolla is composed of five petals, the limbs of which are rounded, scolloped, and fringed; the claws are long, narrow, and attached to the common receptacle; the ten filaments are longer than the calyx, tapering, and furnisher with oblong compressed anthers; the germen is oval, the two styles slender and longer than the filaments, and crowned with pointed stigmas, which curl outward ; the capsule is cylindrical, and contains many roundish seeds.

Sensible Qualities, Properties, and Uses, \&c. The flowers of the clove pink have an agreeable aromatic smell, resembling the clove spice; their taste is bitter and slightly astringent; they impart these qualities both to water and spirit, and either by infusion or distillation. The medicinal properties of the flowers (the only part used in pharmacy) are very inconsiderable; former writers on the Materia Medica supposed them to possess power over the nervous system, and therefore recommended them in many nervous diseases, in palpitations of the heart, convulsions, tremours, \&c. Modern practice however does not confirm the encomiums bestowed upon thein, and the flowers are' now valued only for their sensible qualities; the officinal preparation is esteemed as an useful adjunct only; as such it is used to disguise the taste of unpalatable medicines, and to give a fine colour where it is wanting.

Off. The Flowers.

Off. Pp. Syrupus Caryophylli Rubri, D. 


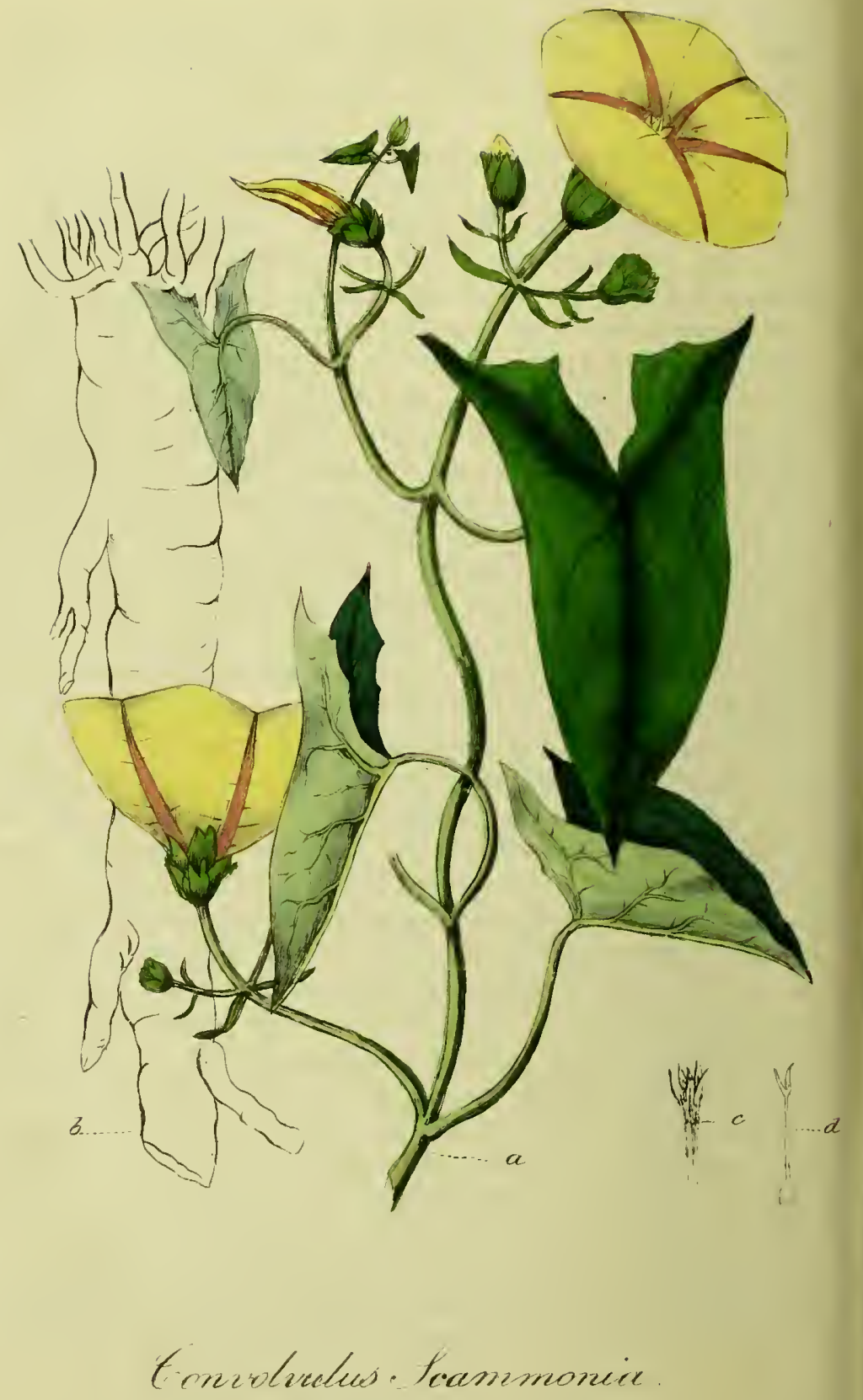

II. Sorale del. ateter 


\title{
CONVOLVULUS SCAMMONIA.
}

\author{
Syrian Bindweed, or Scammony. *
}

\section{Class Pentandria.-Order Monogynia.}

Nat. Ord. Campanacee, Linn. Convolvuli, Juss.

Gen. Char. Calyx, a perianthum, five-cleft. Corolla nonopetalous, bell-shaped, plaited, Stigma 2. Capsule two or three-celled, each cell containing two or three seeds. Spec. Char. Leaves sagittate, the posterior margins with a tooth. Footstalks cylindrical, long, mostly three-flowered.

The Convolvulus is so universally known, and so easily distinguishable, from the shape of its flowers, as scarcely to require any general description; we shall only observe, that the species are very numerous, amounting to no less than one huudred and twenty, some of which are to be found in almost every country, and every climate of the habitable world, though by far the greater part are indigenous to the warmer latitudes, from whence many of them have been introduced into our gardens and green-houses. $\uparrow$

The scaminony Convolvulus is a climbing perennial plant, growing in Syria, Mysia, and Cappadocia, particularly in the neighbourhood of Antioch and Aleppo; it is also to be met with in Tripoli, and we believe some other of the more eastern Barbary States. It was first cultivated in England by Gerarde, in $\mathbf{1 5 9 7 .}$ The root of this plant is from three to four feet long, and from nine to twelve inches in circumference, covered witl bark of a light grey colour; tapering, branched towards the bottom, and containing, when fresh, a milky juice, in which the medical virtues of the plant reside; the stalks are numerous, slender, twining, and spread themselves on the ground, or, if supported, climb to the height of fifteen or twenty feet; the leaves are arrow-shaped, smootl, of a bright green colour, and stand upon long foot-stalks; the flowers

* Fig. $a$. represents a cutting, the leaves, flowers, \&c. of the natural size. $b$. The top portion of a small root. $c$. The stamina. $d$. The pistiliam.

Thirty-nine species.-Hort. Cant.

voL. I. 
are funnel-shaped, yellowish, plicated, and, according to Doctor Russell, placed in pairs upon the peduncles; the calyx is double, consisting of four emarginated leaflets in each row; the bracteas are awl-shaped, spreading renote from the flower; the capsule is three, and sometimes four-celled, containing seeds of a pyramidical shape.

The scammony of the pharmacopœias is a gummy resin, being the concrete juice of the roots. In the first vol. of the Medical Observations and Inquiries, we learn the following method of procuring the officinal scammony, as communicated by Dr. Russell. "Having cleared away the earth from about the root, the top is cut off in an oblique direction, about two inches below where the stalks-spring from it. Under the most depending part of the slope they fix a shell, or some other convenient receptacle, into which the nilky juice gradually flows. It is left there about twelve hours, which time is sufficient for drawing off the whole juice; this, however, is in small quantity, each root affording but a very few drachms. This juice from the several roots is put together into some proper vessel, where in a little time it grows hard."

Scammony is brought to us from Aleppo aud Sniyrna; that which comes from the latter place, is less valued than the former; it is said to be more ponderous, and of a deeper colour; the colour however affords us no test of the goodness of the drug, which depends entirely on the purity of the concrete.* Its principal constituent is resin, and proof spirit is the best neenstruum for it.

Sensible Properties, \&c. Genuine scammony, at least the best scammony of the shops, which comes to us from Aleppo, is obtained in light, spongy masses, having a heavy disagreeable smell, very much resembling decayed cheese; of a shining ashcolour; texture friable, and easily reduced to powder; when powdered of a light grey or whitish colour; taste bitterish, somewhat acrid, and extremely nauseous to most palates. The Snyrna scammony is in more compact, ponterous pieces, having less smell, not so friable, and more difficult to: pulverize; it contains sand and other. impurities. Scammony may be best clrosen by the fracture and the smell.

According to Vogel and other chemists, 100 parts of Aleppo

* The Jews who trafic in scammony, make a practice of buying it while yet soft, and adulterating it by mixing with it ashes, sand, and whatever other ingredient bost answers their purpose. 
scammony consist of 60 resin, 35 insoluble matter, 3 gum and 2 extract. Water dissolves about one-fourth of scammony, the solution is of a greenish grey and opaque; alcohol dissolves about twothirds, and ether about one-fifth.

Medical Properties. Scammony appears to have been well known to the Greek and Arabian physicians, * and was not only employed by them internally as a purgative, but likewise as an external remedy for tumours, scabies, tinea, \&c. Hoffman entertained an opinion that it was a dangerous medicine, $\uparrow$ but since Boerhaave's time it lias justly been cousidered a safe though a stimulating cathartic. Like other resinous purgatives, it is uncertain in its operation, which may be occasioned by the natural mucus of the intestines defending them from the action of the stimulant, or perlıaps in most instances from the impurity of the drug. For ourselves we have never found it fail in its operation, and we lave long been in the habit of prescribing it for children witlout experiencing any bad results. As an adjunct to other aperient medicines we consider it truly valuable, and it is in this way we would recommend its use. $t$

There are several officinal preparations into which scammony enters; of these we consider the Extract. Colocyuthidis Comp. and the Pílulæ Colocynthidis Comp. as the best. The Confectio Scammoneæ is likewise a very good preparation, in doses of from $\exists i$ to $3 \hat{B}$ we have never found it fail of operation. Dr. Russell administered the dried root in decoction, and found it a pleasant and mild cathartic; no other part of the plant seems to possess any mediciual quality.

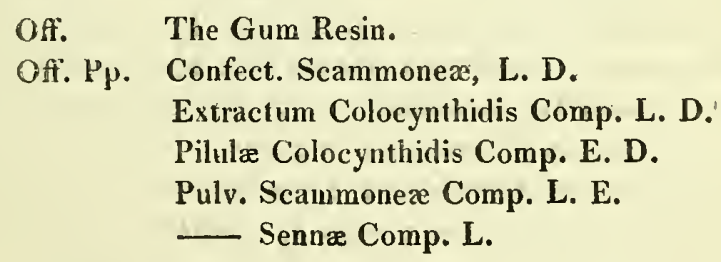

* Hippocrates, Dioscorides, Aëtius, Mesue, \&c.

† Ego numquam in praxi mea in usu babui, nec in posterum habebo: me semper ab istiusmodi veneris colliquativis abstinens.-Hoff. in Schrod. p. 543.

$\ddagger$ Orfila, after several experiments, found the concrete juice of scammony not innoxious. 


\section{VIOLA ODORATA.}

Sweet Violet.*

\section{Class Pentandria.-Order Monogynia.}

Nat. Ord. Campanaces, Linn. Cisti, Juss.

Gren. Char. Calyx 5-cleft. Corolla 5-petalled, irregular, the upper petal spurred at the base. Anthers cohering. Capsule 3-valved, 1-celled.

Spec. Char. Stem none. Scyons creeping. Leaves heartshaped, smooth as well as the footstalks. Calyx obtuse.

The genus Viola comprises a great number of species, more than forty of which are cultivated in our botanic gardens; these are chiefly natives of Europe and North America. The Viola Odorata is a perennial plant, indigenous to Britain, and very common to most parts of the country; in its wild state, it is usually met with on banks, under shady hedges, and in moist cool pldces, where it perfumes the atmosphere with its fragrant odour, the sweetuess of which has obtained for it the specific name of Odorata. This species of violet flowers in March, and continues blowing for many weeks; it has no stem, and rapidly increases by runuers, which send out fibrous radicles; the leaves rise upon long petioles, they are heart-shaped, serrated, smooth on the upper surface, slightly wrinkled, and of a dark green colour; the flowers stand a little higher than the leaves, upon long channelled footstalks, about the middle of which are placed a pair of small lanceolate bracteas; the calyx is composed of five oblong acute pointed leaves; the flowers are drooping, of a peculiar purple colour; the corolla is composed of five unequal petals, the two lateral of which are opposite and somewhat bearded at the base, the posterior one is slightly keeled, and has a horned nectarium; the stamens are five, almost sessile, aud terminate in a membranous expansiou, that covers the upper part of the germen; the germen is roundish, and curved with a falcated pistil.

\footnotetext{
* Fig. a. The stamina. $b$. The pistillum. c. The calyx. $d$. The pericarpium. e. A seed. t Hort. Cant.
} 


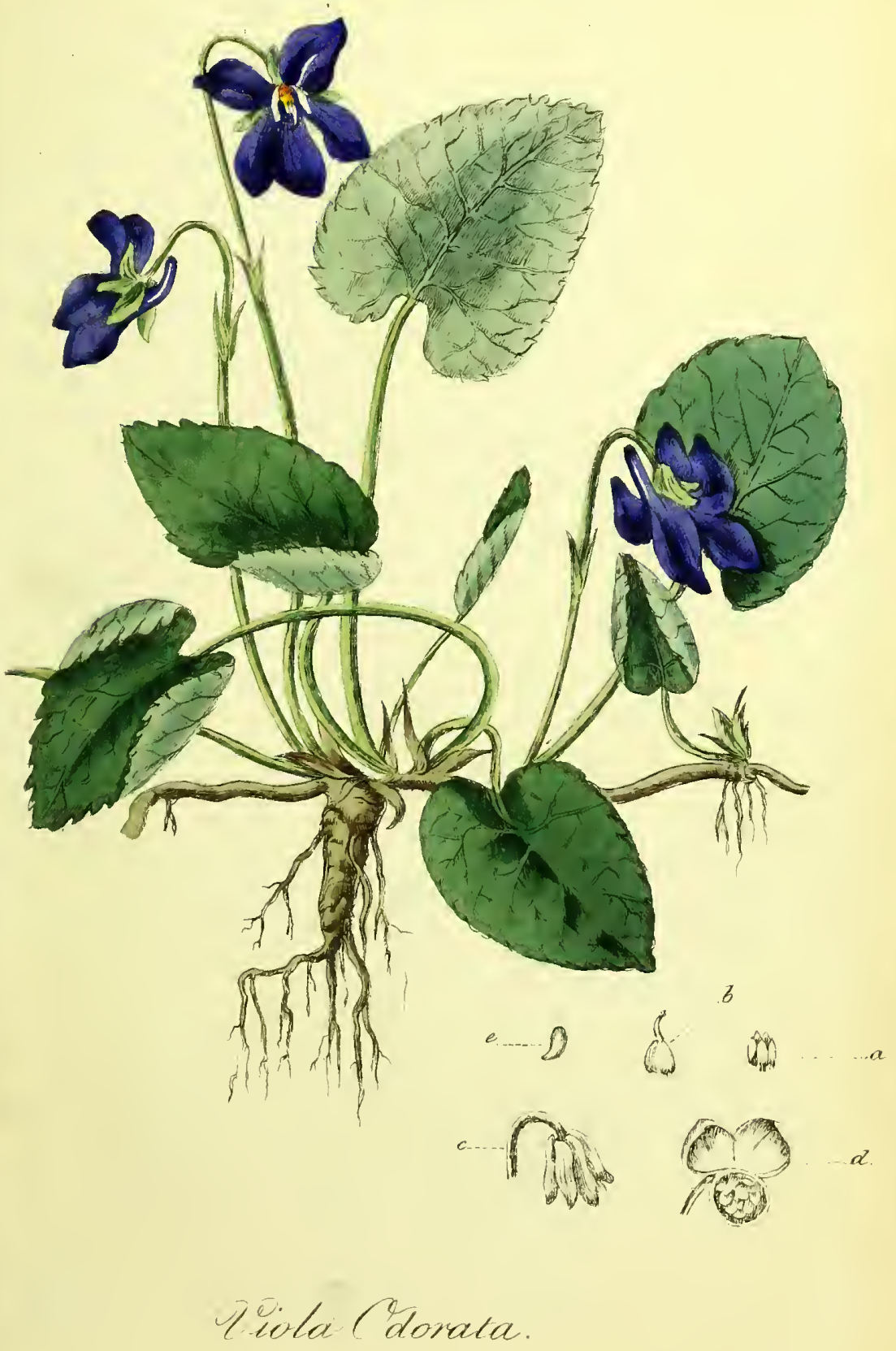



-

$\therefore \quad=$

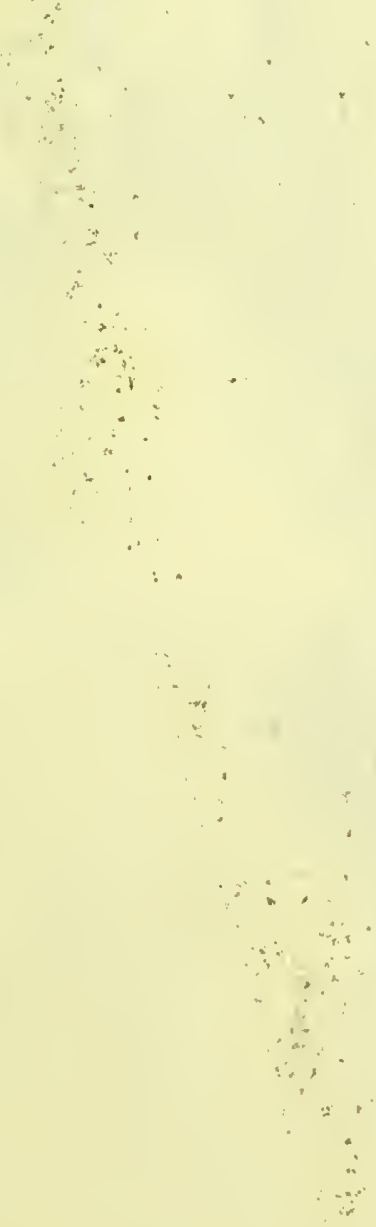

$\therefore$ 


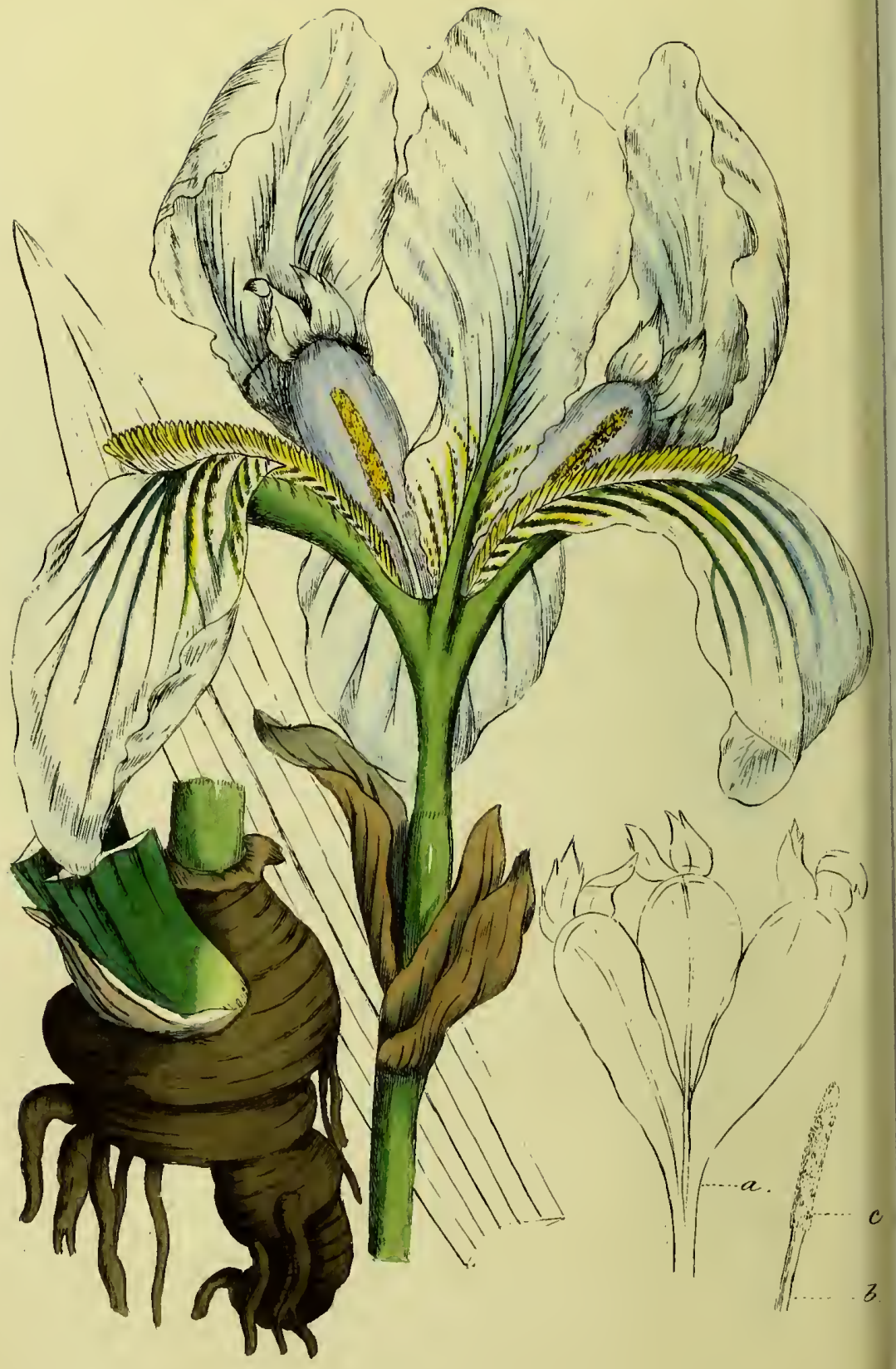

- Ires oftorrintina. 
Sensible and Chemical Properties. Violets have a tolerably powerful odour, which to most persons is extremely fragrant; their taste is slightly bitter; these qualities, and also their colour, they inupart to boiling water. From the analysis of M. Boullay, violets contain an alkaline principle of considerable activity, and, from the experiments of Orfila, even powerfully poisonous; this principle resides in every part of the plant, but more particularly in the roots; it is acrid and bitter, and excites vomiting in small quantities." M. Boullay proposes it should be named Violine, indigenous emetine, or emetine of the violet. It is procured in the same manner as emetine from ipecacuanla, for which process we refer our readers to that article.

Medical Properties and Uses. The officinal part of the violet, i.e. the flowers, contains but very slight medicinal properties, their effects being gently aperient; as such, the syrup is sometimes prescribed for young children, either alone or in combination with oil of almonds. The flowers of violets are chiefly valued as a delicate test for detecing the presence of uncombined acids and alkalies, the former of which, cliange the watery infusion or syrup, (which is blue) to red, and the latter to green.

$\begin{array}{ll}\text { Off. } & \text { The Flowers. } \\ \text { Off. Pp. Syrupus Violæ, E. D. }\end{array}$

IRIS FLORENTINA.

Florentine Iris. $\uparrow$

Class Triandria.-Order Monogynia.

Nat. Ord. Ensate, Linn. IrIdes, Juss.

Gen. Char. Calyx 0. Corolla 6-parted; alternate petals, reflected. Germen oblong beneath the receptacle. Stignia large and petal-like. Capsule oblong, 3-celled, 3-valved.

Spec. Char. Corolla bearded. Leaves sword-shaped, smooth, and shorter than the scape, which is mostly two-flowered.

* The roots of most species of the violet are possessed of emetic properties, and aro sold and substituted for those of Ipecacianha. $E d$.

$\dagger$ Fig. $a$. The pistillum. b. A stamen. c. The anther. 
The Florentine Iris is a perennial plant, a native of Italy and the South of Europe, but from the beauty of its flowers, which appear early in May, it has been long naturalized in the gardens of Britain; it was first cultivated by Gerarde, at the end of the sixteenth century. The root of this plant is thick, tuberous, knobbet ; externally of a dark brown colour, and of a dirty white within ; from the lower part of the root it sends off a number of fibres which leave a round indentation, or shade on the tuberous root; the leaves are swordshaped, sheathing, and of a yellowish green colour, rising from the root; the flower stems are erect, simple, cylindrical, rising about two or three feet high, and each bearing two or three flowers: the flowers are large, erect, protruded from a sheath, or spatha, of two valves; the three outer petals of the corolla are larger than the inner ones, thick and fleshy near the base, and bearded within with white hairs tipped with yellow, which are the nectarium of the flower; the inner petals are narrower, of a bluish white, with thick greenish claws; the capsule contains many flat brown seeds; the filaments of the stamina are terminated by a number of long, pale yellow anthers.

Sensible and Medical Properties. As the flowers of this plant are an ornament in the garden, so is the root an almost indispensable requisite at a fashionable toilet, under the name of orris root, a substance so well known as almost to render description unnecessary, but we are quite at a loss to know low it came to find a place in the Materia Medica. It has indeed been saill to possess hydragigue and purgative properties, and may like many other remedies no longer in use have liad its fashionable reign, but that day has long passed by, at least in these countries. As a perfume, orris root is still in vogue among the fair sex, and serious consequences are said to have arisen from the immoderate use of it in this way. Dr. Aumont, of Paris, relates a case of two young ladies having become paralytic from putting a quantity of it into their hair at bed-time; the effects produced were somewhat similar to those which are consequent upon the internal use of cantharides. The fresh root has an acrid, bitter taste; exciting, when cheived, a pungent heat in the mouth : by drying, most of this acrimony is destroyed, and the taste becomes mildly bitter, and somewhat aromatic, imparting at the same time, all agreeable odour resenbling violets. It is to be observed, however, that the roots propagaled in England, have few of the properties of those which grow in Italy, which country supplies us with the orris root of commerce; the powdered root enters in to the composition of many of the fashionable tooth powders, and is an agreeable addition to other substances used for this purpose. 



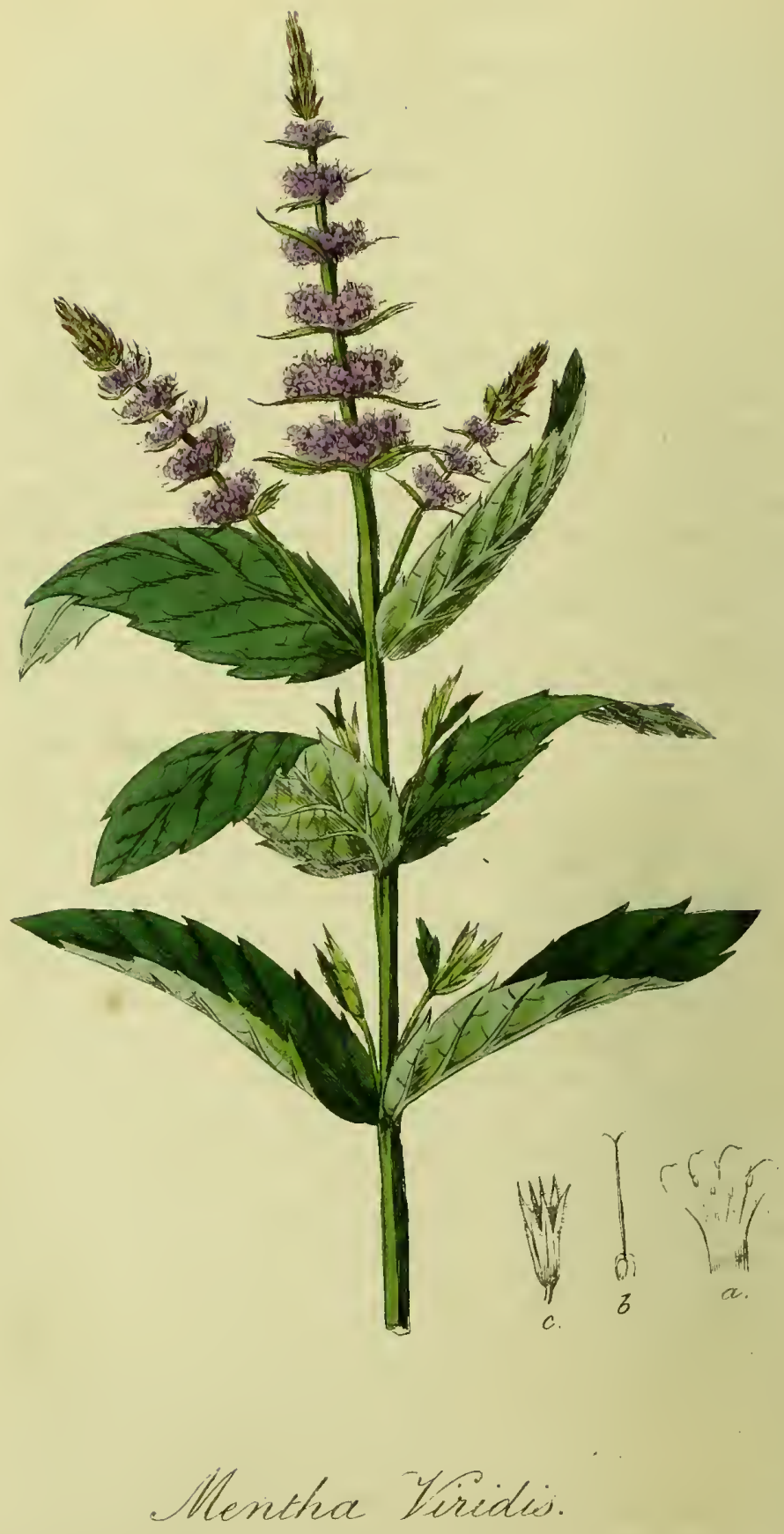

If Spraze del et lizz.

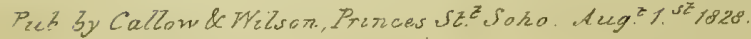




\section{MENTHA VIRIDIS.}

Spearmint.

\section{Class, Didrnamia, - Order Gymnospermia.}

Nat. Ord. Verticillate, Linn. Labiath, Juss.

Gen. Char. Corolla not quite equal, 4-lobed. Stamens erect, spreading.

Spec. Cha R. Spikes interrupted. Leares sessile, lanceolate, acute, naked. Bracteas bristle-shaped, somewhat hairy, and also the teeth of the calyx. Peduncles smooth.

THE genus Mentha comprises more than thirty species, of which twenty-three are indigenous to Britain; of these several are largely cultivated for medicinal and culinary purposes, viz. spearmint, peppermint and penny-royal. The Mentha Viridis is a hardy perennial, towering the latter end of July or beginning of August; in its native state it delights in a cool marshy suil, and has been found in many parts of the country: many years ago, it was found by Hudson on the banks of the Thames and Avon, but it is now rarely nut with. The root is fibrous and creeping, and sends up stems that rise to the height of two and often three feet, erect, branched, angular, and often of a purplish tint; the leaves, when full grown, are from two to three inches long, and from one to one and a half broad, lanceolate, somewhat hairy on the under side, placed nearly sessile, and stand opposite on the stem and branches; the fiowers terminate the stems and branches in long panicled acute spikes, the whorls of which stand a little remote from each other, and are furnished with narrow, lanceolate bracteas; the peduncles are smooth and polished; the calyx is bell-shaped, divided into five acute segments; the corolla is funtel-shaped, and of a pale purple colour; the stamens are shorter than the corolla, crowned with roundish anthers; the germen is four-lobed, style filiform, stigma bifid; the seeds are four, small, and often abortive.

Qualities, Properties, Uses, \&c. Spearmint has an aromatic and somewhat bitter taste, its smell is fragrant; in distillation witl water it yields a considerable portion of essential oil, of a pale 
greenish colour; the distilled water and spirituous tincture are aromatic; the watery infusion is of a reddish yellow colour, which changes to a blackish green by the addition of sulphate of iron.

The medicinal properties are very inconsiderable; it is slightly aromatic and carminative, and chiefly used in the form of the distilled water as a vehicle for more active medicine; the infusion of the herb forms a cooling drink in febrile disorders. This species of mint is in general use as a culinary pot-herb. The essential oil combined with from three to six parts of rectified spirit forms the essence of mint, used for flavouring sauces, \&c. where the fresh herb cannot be procured.

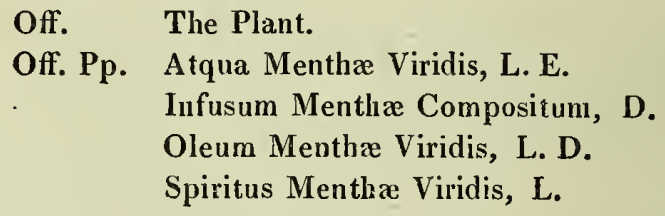

Off. The Plant.

Off. Pp. Atqua Menthæ Viridis, L. E.

Infusum Menthæ Compositum, D.

Oleum Menthæ Viridis, L. D.

Spiritus Mentha Viridis, L.

\section{MENTHA PIPERITA.}

\section{Peppermint.*}

\section{Class Didynamia.-Order Gymnospermia.}

Nat. Ord. Vertichllate, Linn., Labiate, Juss.

Gen. Char. Corolla not quite equal, 4-lobed. Stamens erect, spreading.

Spec. Char. Spikes blunt, interrupted below. Leaves ovate, petioled. Stamens shorter than the corolla.

PePPERMint is an indigenous plant, but like the spearmint it is rather a rare native; in its wild state it is usually found in moist places, hence it is occasionally met with on the banks of rivers: but for medicinal purposes, it is cultivated in large quantities in the

Fig. $a$, represents the corolla magnified, and cut open to shew the stamina. $b$. The pistillam. c. The calyx. 


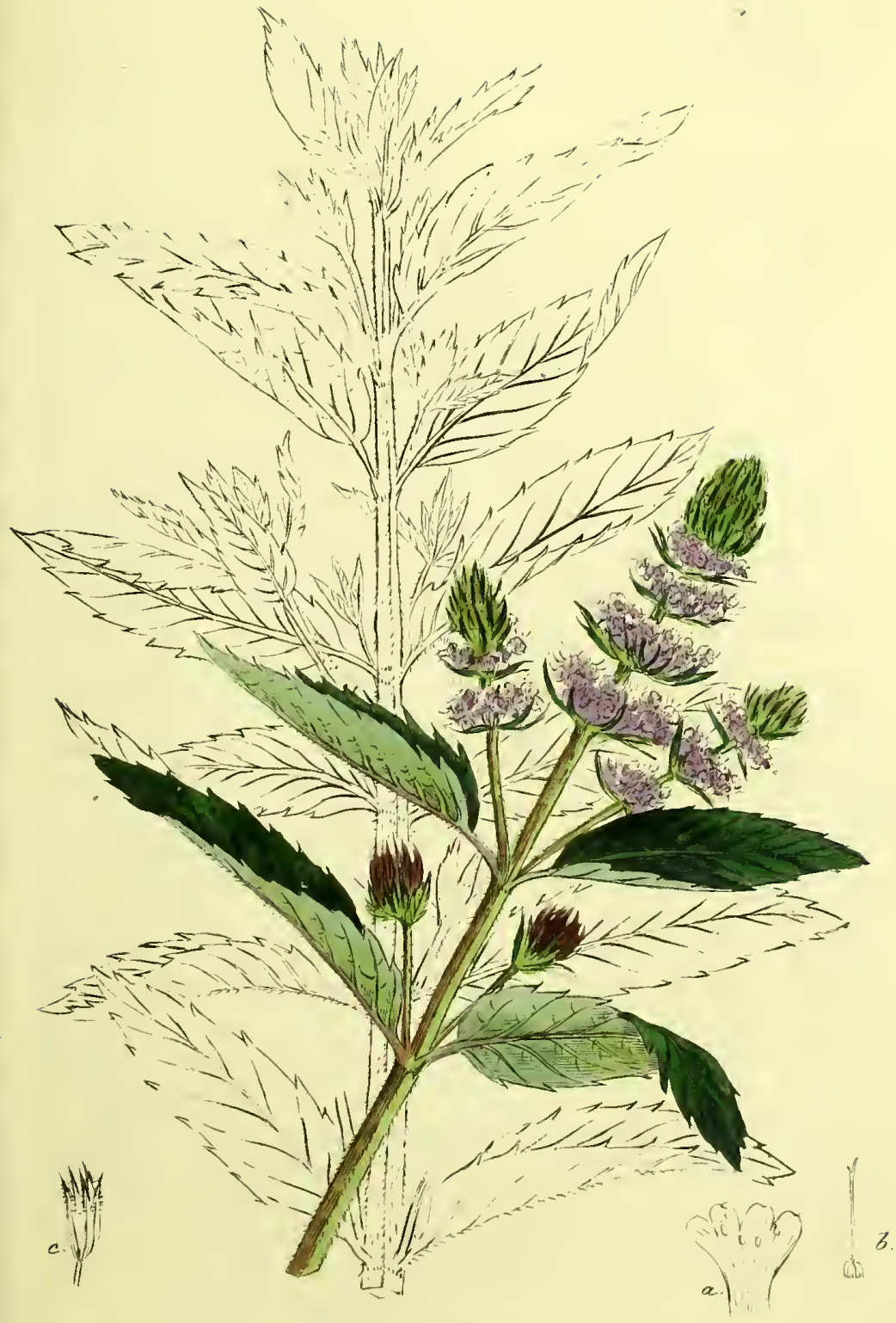

Menthacifierita. 

neighbourhood of London. It flowers from the latter end of July to September. Peppermint bears a great resemblance to spearmint, for which it has been often mistaken, but may be distinguished from the latter by the leaves being much broader, and liaving short footstalks, whereas in the latter the leaves are narrower, and stand almost sessile on the stems.

The root of peppermint is creeping and fibrous; the stems rise to the height of from two to three feet, in form quadrangular, often of a purplish colour, somewhat hairy, and branched; the leaves stand opposite on short footstalks, and vary both in length and breadth, are ovate, acute, serrated, of a dark green on the upper surface, the under side is pale, and the mid-rib studded with short lairs; the flowers terminate the stem and branches in solitary interrupted bluntish spikes, the lowest whorls are more distant, and sometimes form smaller spikes; the bracteas are lanceolate and fringed; the flower-sialks vary, being generally perfectly smooth, but occasionally slightly hirsute; the calyx is slender, and divided into five acute segments, which are fringed, and of a deep purplish colour; the corolla is funnel-shaped, of a purple colour; the filaments are awlshaped; the germen is superior, four-lobed, and supports a slender style, longer than the corolla, crowned with a bifid stigma.

Sensible Qualities, \&c. Peppermint has a fragrant smell, slightly approaching to that of camphor; taste lot and aromatic, exciting first a sensation of heat in the mouth, which is succeeded by a coldness; both smell and taste are increased by exsiccation. The watery infusion of the plant is of a reddish colour, which grows brown by the addition of sulphate of iron; by distillation with water, it vields a considerable quantity of essential oil, of a very pungent fiery taste, and smelling strongly of the plant. This essential oil contains a considerable proportion of camphor; it is soluble in spirit of wine, and in the proportion of one part of the former, to eight or tell of the latter, forms the essence of peppermint, often used for making extempore peppermint water.

Medical Uses, \&c. Peppermint is the most powerful of the mints, and from its hot and pungent qualities, proves an excellent carminative and stimulant; hence it is in general use in all flatulent disorders, to obviate nausea and griping; it is also much used as a vehicle for other medicines, to disguise tlıeir taste and smell.

Off. The Plant.

Off. Pp. Aqua Menthæ Piperitæ, L. E. D.

Oleum Menthæ Piperitæ, L. E. D.

Spiritus Menthæ Piperitæ, L.E.

VOL. I. 


\section{MENTHA PULEGIUM,}

\section{Penny Royal.*}

\section{Class Didynamia.-Order Gymnospermia.}

Nat. Ord. Verticillate, Linn. Labiate, Juss.

Gen. Char. Corolla not quite equal, four-lobed-Stamens erect, spreading.

Spec. Char. Flowers whorled. Leaves ovate. Stem prostrate. Flower-stalks and Calyx downy.

Penny Royal is a native species of mint, and much oftener met with in its wild state than either peppermint or spearmint; it is usually found in moist places on comnons and heaths; it flowers the latter end of August and September. There are two or three varieties of penuy royal cultivated in our gardens; these chiefly differ from the wild species in the form of the leaf, which is longer and narrower than in our native species, they also rise to a greater height, but possess the same qualities as the indigenous; as such they are generally used for domestic and medicinal purposes. The root is creeping, and puts fortl numerous, slender, bluntly quadrangular stems, which are procumbent at the lower part, and rise to the height of eight or nine inclies, the upper part is somewhat downy; the leaves are about an inch in length, ovate, obtuse, unequally serratell and stand on short footstalks; the under surface is slightly hairy; the whorls are axillary, and supported on short peduncles; the flowers are numerous, and stand on short downy purplish stalks; the calyx is nearly cylindrical, five-cleft, strongly furrowed, and downy, the segments of which are unequal, pointed, and fringed; the corolla is longer than the calyx, of a pale lilac or purple colour, $\dagger$ externally hairy; the stamens are erect and longer than the corolla; the germen is four-cleft, and supports a slender siyle, crowned with a bifid stigma; the germen becomes four naked seeds.

* Fig $a$. represents a plant of the natural size. b. A perfect flower, (magnified). c. The calyx. $d$. The pistillum.

+ There is a variety oocasionally met with which has white lowers. $E d$. 


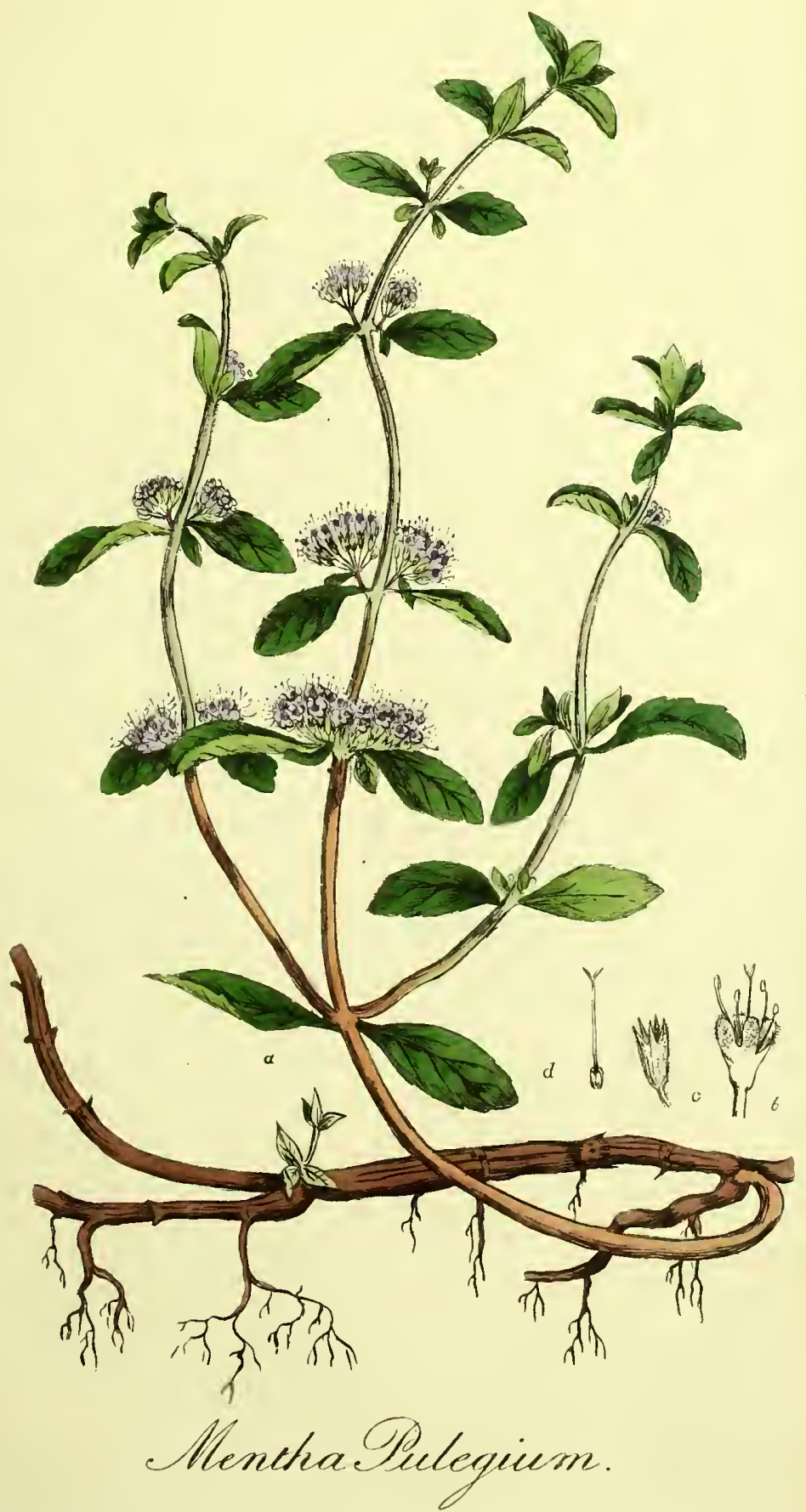





\section{.}




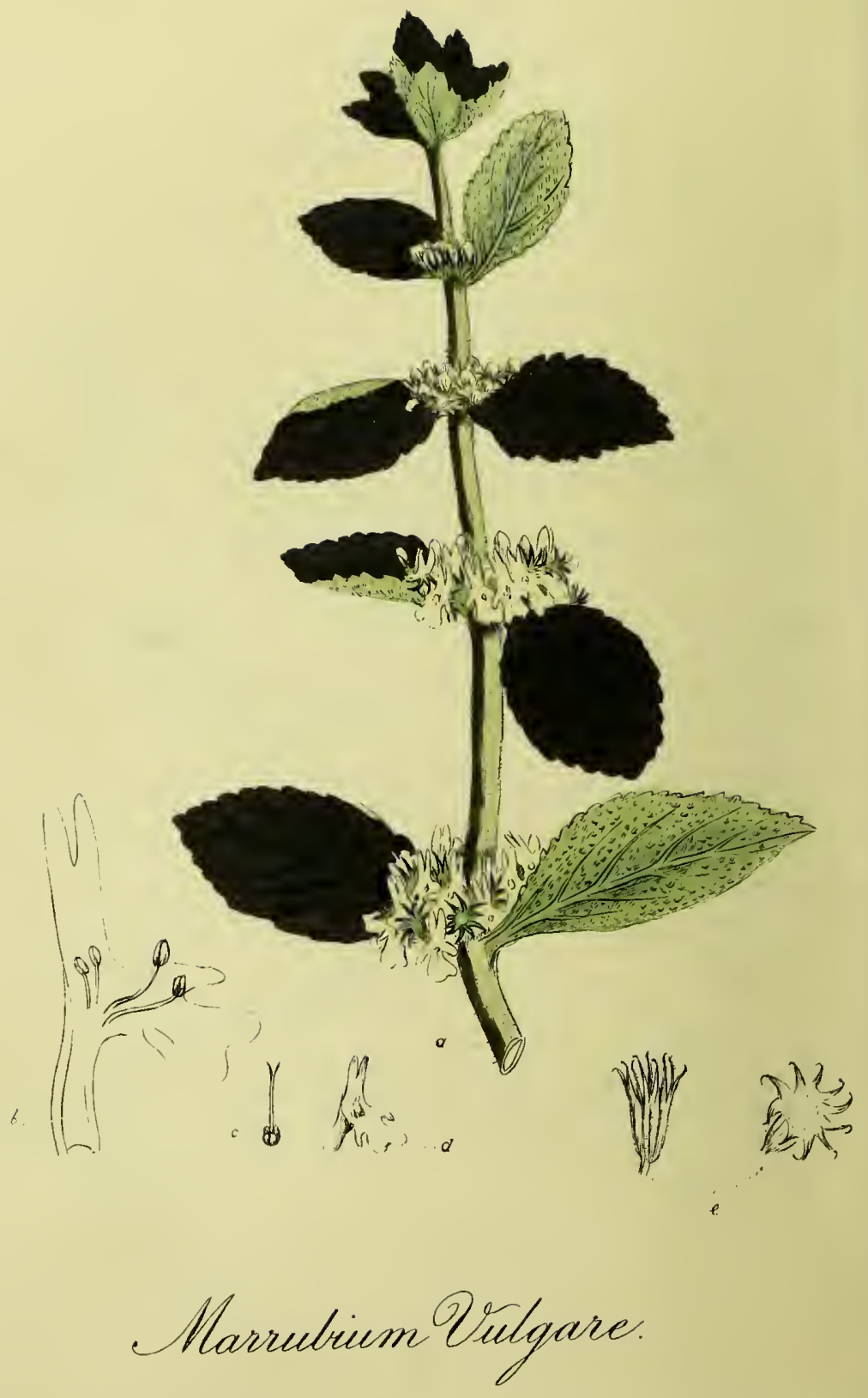

W. Spratz del eE $Z$ zZZ Pub.by callow \& Wilson Princes St. Soho. Sept" fst 1828 . 
Sensible Qualities, \&c. Penny royal lias a strong, spirituous, and somewhat disagreeable smell; its raste is strong, sweetish, and slightly acrid, when ehewed it heats the tongue and fauces. The watery infusion is of a yellowish colour, strong scented with a slight spirituous taste: sulphate of iron instantly turns it black. Penny royal by distillation, either with water or spirit, gives out both its smell and taste. By distillation with water it yields a considerable quantity of essential oil of a reddish yellow colour, with the smell and taste of the herb in a concentrated degree, the oil contains a small portion of camphor.

Medical Properties, \&c. Penny royal in the present day is chiefly employed as a domestic medicine by the uninformed, who greatly esteem it in uterine obstruction.* Formerly it was supposed to possess emmenagogue properties, but it is now disregarded by the profession; it is both carminative and stimulant, like the other mints, but its disagreeable flavour causes it seldom to be employed as such.

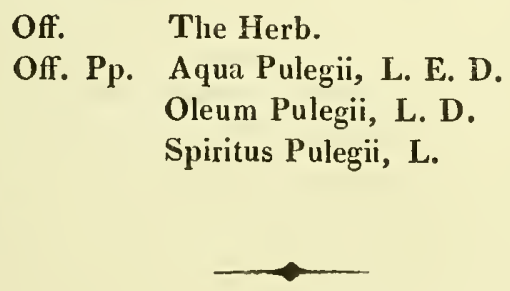

\section{MARRUBIUM VULGARE.}

Common or White Horehound.†

Class Didynamia.-Order Gymnospermia. Nat. Ord. Verticillate, Linn. Labiate, Juss.

* The distilled water, sold in the shops under the name of hysteric water, is a favourite mediciue with the vulgar in obstruction of the menses and hysterical disorders.

† Fig. $a$ represents the top of a plant of the natural size. $b$. The corolla magnificd, and cut open to shew the anthers. c. The pistillum. d. The corolla. e. Two views of the culyx. 
Gen. Char. Calyx monophyllous, salver-shaped, rigid, tentoothed, and channelled. Corolla monopetalous, gaping, upper lip erect, bifid, linear.

Spec. Char. Teeth of the calyx bristly, hooked.

The Marrubium Vulgare* is a perennial plant, growing wild on road-sides, and among rubbish, and flowering in July. The root is furnished with numerous fibres; the stalks are upright, strong, square, hairy or downy, and rise about a foot and a half in height; the leaves are roundish or oblong, deeply serrated, veined, wrinkled, loary, and stand in pairs upon thick broad footstalks; the flowers are white, and produced in whorls at the footstalks of the leaves; the calyx is tubular, scored, and divided at the mouth into ten narrow segments which are hooked at the end ; the corolla consists of a cylindrical tube, opening at the mouth into two lips; the upper lip is narrow, and cloven or uotched; the under lip is broader, and divided into three segments, the centre one being broad and slightly scolioped at the cnd; the lateral segments are spear-shaped and short; the filaments arc supplied witl simple anthers which are concealed in the tube; a sleuder style issucs from the germen, furnished with a cloven stigma; the seeds are of an oblong shape.

Sensible and Chemical Properties. The leaves of this plant have a strong but not disagrceable smell, and a rough bitter taste; the odlour is ncarly lost by long keeping. The flowers likewise in some degree partake of the smell and taste of the leaves, but are not nearly so powerful: the latter is the only part used medicinally. The infusion reldens the tincture of litmus, gives a deep green olive precipitate with sulphate of iron, a brown with nitrate of silver, and a pale yellow with muriate of mercury; but acetate and superacetate of lead do not affect it. The active principles of horehound, therefore, appear to be bitter extractive, volatile oil, aud gallic acid.

Medicinal Properties. Marrubium was mucl esteemed by the ancients for its extraordinary effect in removing disorders of the lungs, and obstructions of the abdominal viscera : $\dagger$ taken in considcrable quantities it is said to act as an aperient; but its virtues, if it possess any, do not appear to be clearly ascertained. It has

* Mpartoy Dioscorides. According to Lemery, the name is derived from the Hebrew word Marrob, which means a bitter juice.

† Dioscorides, lib. iii. c. 119. See also Pliny, lib, xx. c. 22. 


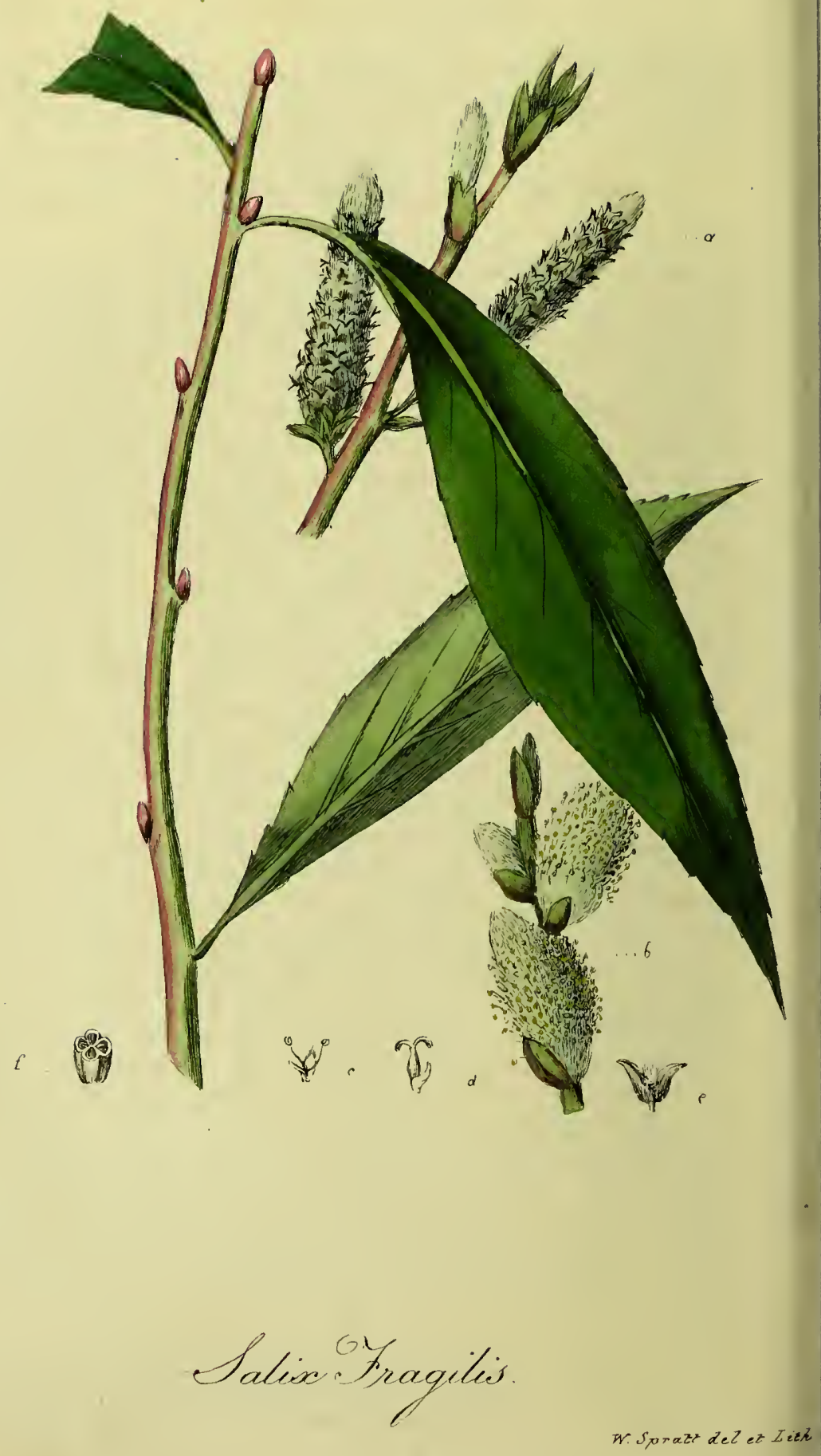

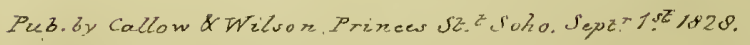


chiefly been employed in humoral asthmas, obstinate coughs, and pulmonary consumption; in the latter case we have seen it given in infusion, in conjunction with decoction of Iceland moss, as a diet driuk, for a cousiderable time; whether the patient derived benefit from it or not it is difficult to say, we can only state as the result of the disorder, that she died.* Instances are also mentioned of its successful use in scirrhous affections of the liver, jaundice, cachexia, and menstrual suppressions. $\dagger$ Bergius says, virtus, tonica, emmenagoga, diuretica; usus, cachexia, obmensium, hysterica, asthma pituilosum. It is now seldom prescribed, but maintains its popularity among the poorer class, by whom it is still a favourite remedy for cough. Cullen says, "it has had the reputation of a pectoral, but in many trials its virtues in that way have not been observed, and in several cases it has been judged hurtful: for its use in asthma and phthisis, and for its power in resolving induration of the liver, I consider the authorities of Forrestus, Zacutus Lusitanious, and Chomel, to be very insufficient; and the events they have ascribed to it to be very improbable." $\ddagger$

It is usually given in infusion: the expressed juice, and leaves dried and powdered, have also been employed; and we believe it to be so innocent that in any way it may be taken ad libitum. There is no officinal preparation of Marrubium.

Off. The Leaves.

\section{SALIX FRAGILIS.}

\section{Crack Willow.}

\section{Class Diqeia.-Order DiandRia.}

Nat. Ord. A ment ACER, Linn. Juss.

* Dr. A. T. Thomson however says, "we have seen decided advantage from its exhibition in phthisis."

+ Vide Celsus, lib. iii. cap, 22.

\$ Mat. Med, vol. ii. p. 155.

$\$$ Fig. a. represents the top of a brancl, with female flowers or catkins. b. Male flowers or catkins. c. A single male flower a little magnified, composed of the two stamina and calyx. d. A single female flower composed of the pistillum and calyx. e. A magnified anther, cut open to shew the four cells. $f$. The seed vessel. 
Gen. Char. Male-Amentum cylindrical. Calyx, a scale.

Corolla, 0. Gland of the base, nectariferous.

Female-Amentum cylindrical. Calyx, a scale.

Corolla 0. Style, bifid. Capsule one-celled, two-valved. Seeds downy.

Spec. Char. Leaves serrated, smooth, ovate, lanceolate. Petioles furnished with glandular teeth.

The Willow is a well known tree, and the species of it found in these countries are very numerous, more than fifty being indigenous to Britain. The one under consideration grows to a considerable height, sending off large branches, and is covered with a wrinkled bark of a grey colour; the leaves are long, narrow, and lance-shaped, standing upon foot-stalks, which are furnished with glandular teeth; the fructification is borne on that peculiar description of calyx called an amentum, or catkin; there is no flower, properly so called, the parts of fructification being limited to the stumina, pistillum, and nectarium; the stamina and pistillum, or male and female flowers, are seated upon different trees, which is the distinguishing mark of the class Diœcia, and they are accordingly called male trees, or female trees; the calyx, or common catkin of the male flower, is oblong, imbricated, enclosed by an involucrum, or common calyx, formed of a bud, and consistiag of scales, which are oblong, flat, expanding, and unifloral; the nectarium is a small, cylindrical, truncated gland, containing honey, and placed in the centre of the flower; the filaments are two, (whence the order Diandria is designated) straight, filiform, longer than the calyx, and furnished with double antheræ of four cells. In the female flower, the scaly catkin resembles that of the male; the germen is eggshaped and tapering, so as to leave no distinct style, and is longer than the scales; the stigmata are two, bifid and erect; the capsule is ovate, one-celled, and furnished with two valves, which roll back; the seeds are numerous, egg-shaped, very small, and crowned with a simple hairy pappus : the flowers appear in April and May. This tree is distinguished from the other species of willow by the readiness with which it breaks at the last year's shoot upon being slightly struck with the finger; hence the name fragilis. Besides the above, some other species of willow are used medicinally, viz. the Salix Alba, (white willow) this species is indigenous, flowers in April 
and May, and is found growing in woods and moist places; and the Salix Caprea, (round leaved) is also indigenous and flowers in April.

Sensible and Chemical Qualities and Properties. The dried bark is inodorous, bitfer and austere. "The bark of the white willow only has been chemically examined; but as the other two species agree with it in their sensille qualities, it is probable that they agree also in other respects. Water extracts its virtues and affords a decoction of a reddish colour, which is precipitated by a solution of isinglass, the carbonates of potass and of ammonia, and by lime water, which throws down a precipitate, at first blue, and afterwards buff-coloured; sulphate of iron also produces a dark green precipitate. The watery extract is reddish, brittle, has a bitter taste, and does not deliquesce. Digested in alcohol this bark affords a greenish yellow tincture, which water renders turbid. When evaporated the extract is of a bright yellow colour, bitter, melts at a moderate heat, and emits an aromatic odour. The constituents therefore of white willow bark, and probably of the two other species also, are tannin, bitter resin, extractive, and gluten."

Medical Properties, \&c. The bark of the branches of this, and most of the other willows, is powerfully astringent; and hence most of them have been considered as good substitutes for Peruvian bark : upon trial they have been found to stop the paroxysms of intermittent fever, but in points of efficacy they are not to be compared to Peruvian bark, neither do they, like the latter, contain any cinchonin. We should be inclined to consider the willow barks as mere tonic and astringent medicines. As sucl they have been administered with success in some cases of debility, dyspepsia, and pulmonary hamorrliage; and we are told by Dr. A. T. Thomson, that in phthisis and hectic fever, they have apparently been more serviceable than the cinchona. The dose of the powdered bark is from thirty to sixty grains, or it may be given in the form of decoction, either alone or combined with aromatics.

Off. The Bark.

* Vide Med. Comment. vol. v. p. 298. Phil. Trans, vol, liii. p. 195. Gerlard Mat, MIed. p. 301. With Bergius it did not succeed, he says, "Ego hunc corticem in febribus internittentibus iterum iterumque exhibui, sed irrito conatu." 


\section{ORIGANUM VULGARE.}

\section{Common Marjoram.*}

\section{Class Didynamia.-Order Gymnospermia.}

Nat. Ord. Verticillate, Linn. Labiate, Juss.

Gen. Char. Strobile four-cornered, spiked, collecting the calyxes. Corolla monopetalous, gaping.

Spec. Char. Spikes somewhat round. Panicles conglomerate. Bractea ovate, longer than the calyx.

The Common Marjoram is a perennial plant, growing wild in many parts of Britain, especially on dry chalky hills, or gravelly soils, and flowering in July and August. The root is creeping, and beset with numerous slender fibres; the stem is erect, square, purplish, downy, producing opposite branches, and rising about a foot and a half iu height; the leaves are ovate, pointed, somewhat indented at the ediges, smooth above, beneath downy, of a deep yellow green, and stand upon footstalks in pairs, at the joints; the flowers. are numerous, terminal, of a pale purplish colour, and stand in panicles or clusters; the bracteas or floral leaves are oval, sessile, and of a brownish red colour; the partial calyx is tubular, and divided at the brim into five segments, fringed at the edges; the corolla consists of a funnel-shaped tube, longer than the calyx, divided at the limb into two lips, the uppermost of which is erect, bifid, obtuse; the lower lip is trifid, blunt, and spreading; filaments of a purple colour, and furnished with a double anther; the germen is divided into four parts, from the centre of which rises a filiform style, crowned with a bifid stigma reflected ; seeds four, eggshaper, and lodged in the bottom of the calyx.

From the above description it will be seen that the Origanum agrees with Marrubium in most of its botanical characters, belonging as they do to the same class and order; and it may be well here to remark, that the plants belonging to this class have througliout many striking points of resemblance, and seem to form a true natural class;

* Fig. $a$. represents a sprig of the natural size. $b$. A flower magnified to shew the stamina, \&c. c. The calyx and bractea, magnified. $d$. The pistillum maguified. 


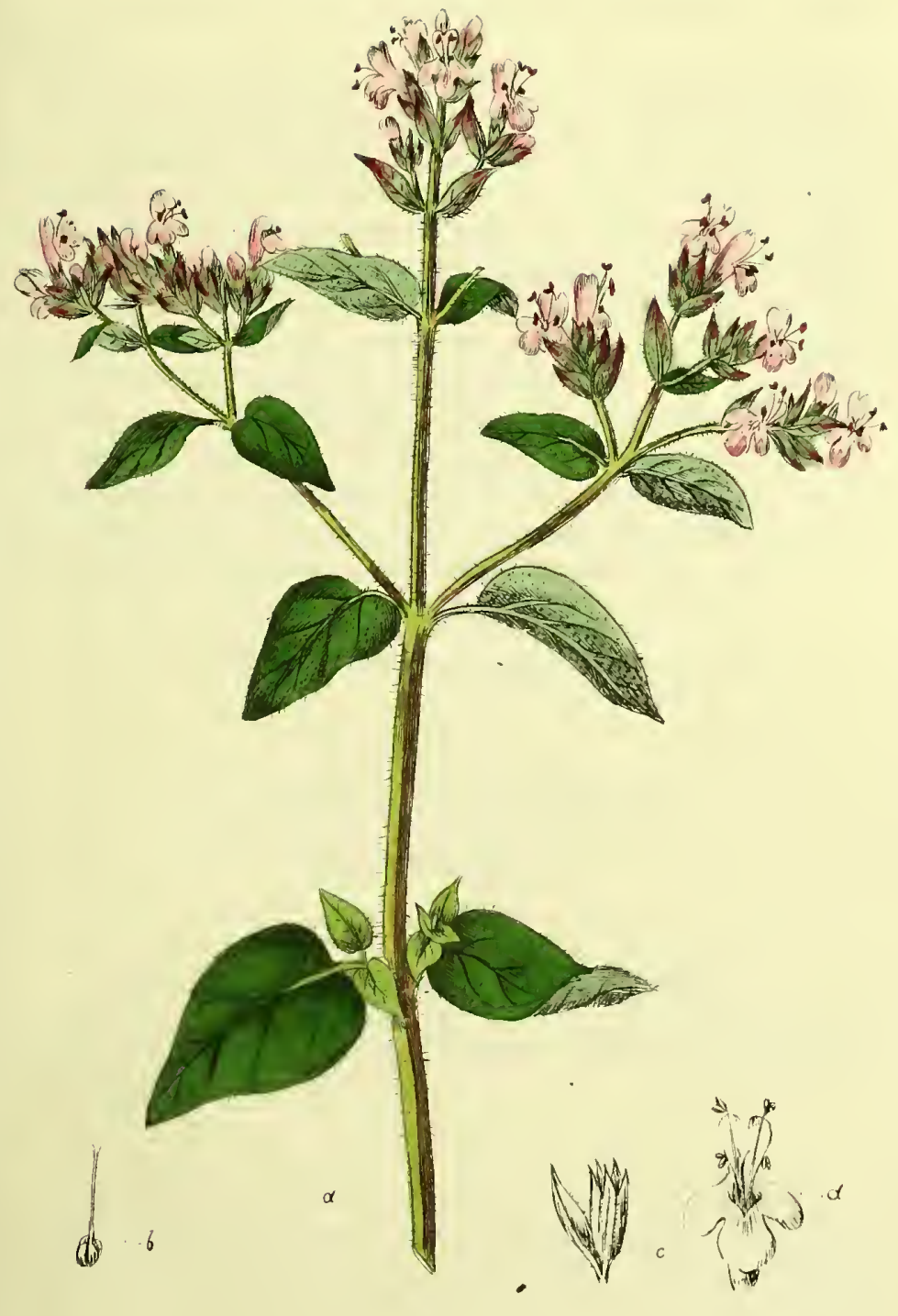

Qriganum L/ilyare.

W.Sprall del el Luch. 

the class may at once be known-from having labiate or gaping blossoms.

Senjible and Menical Properties. Wild marjoram has an agreeable aromatic smell, approaching to that of the sweet or garden marjoram, and a warm pungent.taste, much resembling thyme, to which it is likewise thought to be more nearly allied in its medicinal qualities, than to any other of the Verticillatæ, and therefore deemed to be emmenagogue, tonic, stomachic, \&c.; these effects however are commonly ascribed to all the herbs of this natural tribe, which possess unconımon aromatic and stimulant powers. Distilled with water it yields a moderate quantity of a very acrid, penetrating oil, which has been much used for easing the pain of carious teeth. An infusion of the dried leaves forms a very grateful drink; the fresh leaves are also used externally for fomentations, \&c. We arc told by Withering, that the tops of this plant dye purple, and are much used by the country people for that purpose.

Off. The Leaves.

Off. Pp. Oleum Origani, L. D.

\section{ORIGANUM MAJORANA.}

Sweet Marjoram.

Class, Order, and Gen. Char, as the last.

Spec. Char. Leaves ovate, obtuse. Spikes roundish, compact, pubescent.

Tuis species of Origanum is an annual plant, a native of Syria and Portugal, but cultivated in our gardens, chiefly for culinary purposes. Being scarcely ever used medicinally, (although the Edinburgh and Dublin colleges have retained it in their pharmacopoias) we have not thought it necessary to give a drawing of it.

The stalks are numerous, square, woody, branclied, and rise to about twelve or eighteen inches in height; the leaves are ovate, obtuse, entire, and downy, of a pale green, and stand in pairs upon short peduncles; the flowers are small, white, and appear successively between the bracteas, which are numerous, and form round

vOL $I_{\text {. }}$

$2 \mathrm{~A}$ 
compact terminal spikes. The other parts of fructification agree with those of the Origanum Vulgare.

The sensible qualities and virtues of this plant nearly resemble those of the common marjoram, and it is therefore unnecessary to enumerate them: it is more fragrant than the latter, hence it has been chosen by the colleges as an ingredient in the Pulvis Asari Comp. the only officiual preparation into which it enters.

Off. The Herb.

\section{GRATIOLA OFFICINALIS.}

Hedge Hyssop.*

\section{Class Diandria.-Order Monogynia.}

Nat. Ord. Personate, Linn. Scrophularie, Juss. Gen. Char. Corolla irregular, reversed. Stamens two, sterile. Capsule 2-celled. C'alyx 7-leaved, the two exterior leaves spreading.

Spec. Char. Leaves lanced, serrated. Flowers peduncléd.

THREE species of Gratiola $\uparrow$ are cultivated in our botanic gardens, of which the Officinalis of the dispensatories forms one. This is a perennial plant, a native of the South of Europe, and usually found in moist pastures, flowering in June and July. It was first introduced into England about the year 1568 . In 1775 Kostryewski wrote upon the virtues of hedge hyssop, since which time its properties have been nore duly appreciated.

The root of this plant is creeping, cylindrical, white, jointed, and furnished with many slender fibres; from the root rise many erect, round, smooth stems, to about twelre or eighteen inches in height;

* Fig. $a$. represents a plant of the natural size. $b$. The pistillam magnified. c. The corolla magnified, and cut open to shew the anthers.

+ The name of Gratiola is derived from gratia deo, an appellation given to this plant from its supposed extraordinary virtues.

$\ddagger$ Dissert. de Gratiola, Viennx, 1775. 


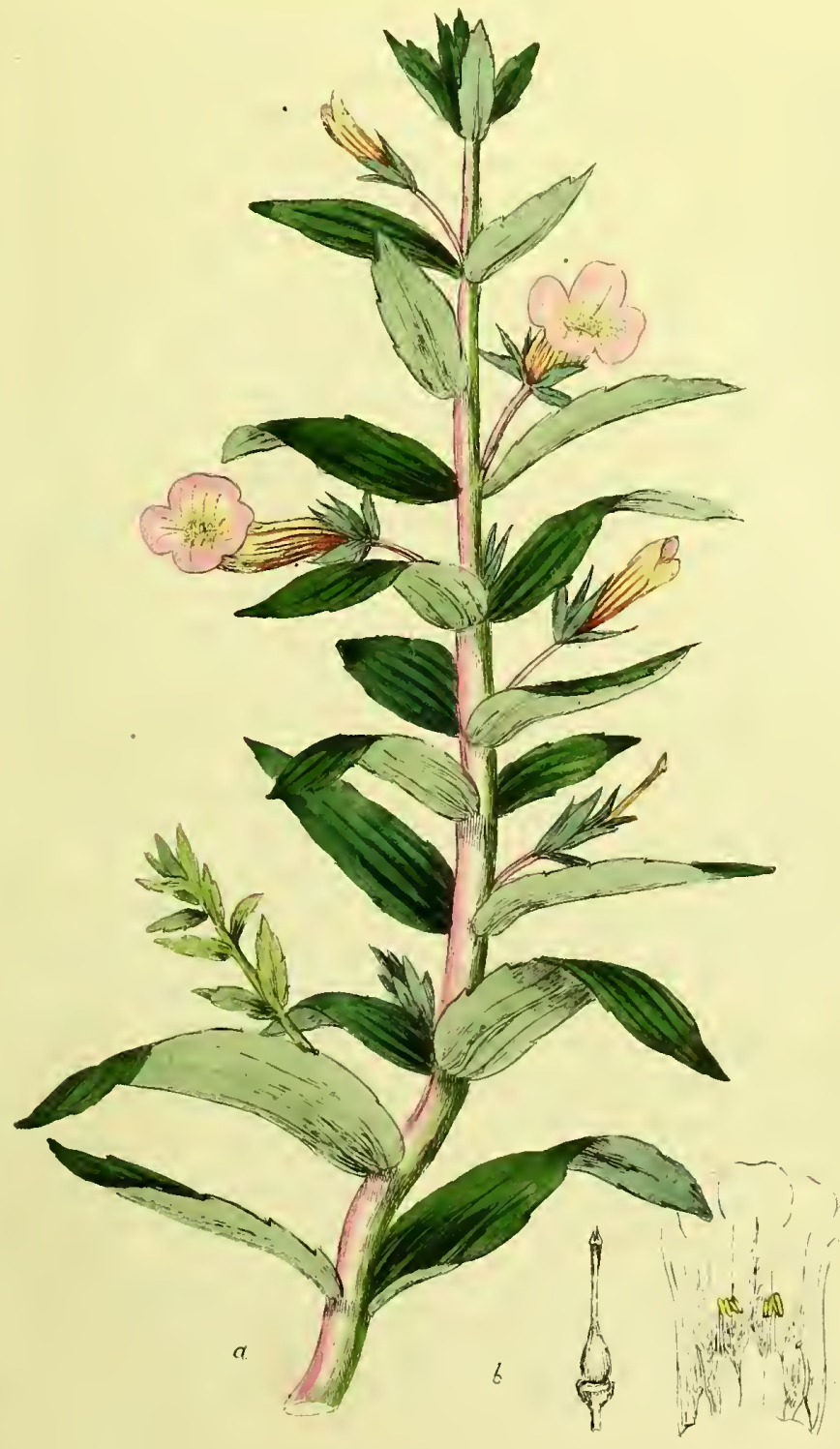

Gratiola Officinalis.

W Sprate ded. et Lithog. 

the leaves are numerous, sessile, lance-shaped, from one to two inches long, about half an inch broad, pointed, serrated towards the extremities, and stand opposite in pairs; the flowers are axillary, solitary, and stand on slender peduncles, nearly an inch in leugth, and of a red colour; the calyx consists of five or six elliptical pointed segments; the corolla is tubular, and divided at the limb into four obtuse irregular segnents of a pale purplish colour; the tube is yellow streaked witl red; the filaments are four, two only of which are furnished with anthers; the two supporting the anthers are shorter than the others, and are inserted ahont the middle of the tube of the corolla; the germen is ovate; style slender, tapering, and erect; stigma divicled; the germen becomes an ovate pointed, bilocular capısile, which contains many small seeds.

Sensible and Chemical Properties. Hedge hyssop is nearly inodorons, its taste is very bitter and nauseous; boiling water extracts these qualities more perfectly than spirit; the watery infusion is of a yellowish colour which changes to an olive brown by the addition of sulphate of iron, without occasioning any precipitate. "When sulphuric acill is added to the unstrained infusion, it emits, the odcur of lamariuds; and when the infusion is filtered and slowly evaporated, spicular cristals are formed, which appear to be tartaric acid." From the analysis of Vanquelin, the expressed juice contains in a state of solution, 1 . a peculiar bitter resinous matter; ${ }^{*}$ 2. a small quantity of animal matter; 3. a brown gumny matter; 4. muriate of sorla.

Porsonous Effecrs. Gratiola when taken in an over-dose produces very energetic effects on the animal economy, exciting violent vomiting and hypercatharsis. From the experiments of Orfila we learn that a few drachms of the watery extract introduced into the stomach of a strong dog occasioned its death within twentyfour hours, and that iventy-eight grains of the same extract injected into the jugular vein of a middle sized robust dog, occasioned some giddiness, the animal became insensible, and expired two hours after the injection; and M. Bouvin asserts that an injection of the decoction being administered to a female produced great irritation of the sexual organs.

Medical Properties and Uses. Gratiola in moderate doses acts as a powerful cathartic and emetic, $\uparrow$ but as it is very un-

- This matter is named by Vauquelin resinoid; it is soluble in alcohol, and contains the active and purgative properties of the plant.

+ We are told by Boerhaare that it in general produces vomiting. Vide Hist. Pl. Hort. L. B.,Bergius Mat. Med, p. 26. 
certain in its effects it requires great caution, and on this account it is thought by some to be a medicine adapted only to vigorous and robust constitutions. In small doses it acts upon the kidneys and produces diuretic effects. Formerly it was held in great estimation on the continent, and the German physicians extolled it in dropsy, mania, lues venerea, jaundice, $\& c_{0}$; * it lias also been prescribed with success in visceral obstructions and scrofulous affections. ${ }^{\prime}$ In this country however it is but seldom prescribed, although from its active qualities we think it may be deserving of more extensive use. It is given either in the form of infusion, made with half an ounce of dried herb to a pint of boiling water, of which, half an ounce to an ounce may be taken three times a day; or in powder, in doses of from fifteen to thirty grains two or three times in the twenty-four hours.

Off. The Herb.

\section{ACACIA VERA.}

Egyptian Gum-Arabic Acacia, or Egyptian Thorn.

\section{Class Polygamia.-Order Monecia.}

Nat. Ord. Lomentaces, Linn. Leguminose, Juss.

Gen. Char. Hermaph. Calyx 5-toothed. Corolla 5-cleft, or formed of five petals. Stamens 4-100. Pistil 1. Legume bivalve.

Male. Calyx 5-toothed. Corolla 5-cleft, or formed of five petals. Stamens 4-100.

Spec. Char. Spines stipulary, in pairs, linear, awl-shaped. Leaves doubly pinnate: first division, of five or six pair; second, of many pairs. Common Stalk glandular. Heads axillary, about three together. Legume necklace-like, nearly flat, smooth.

* Vide Dissert. de Gratiola. Víennæ, 1775.

+ Hufeland uber die Natur, \&c. der Scrofula.

¥ Fig. $\alpha$ represents part of the legume, or seed-pod. 


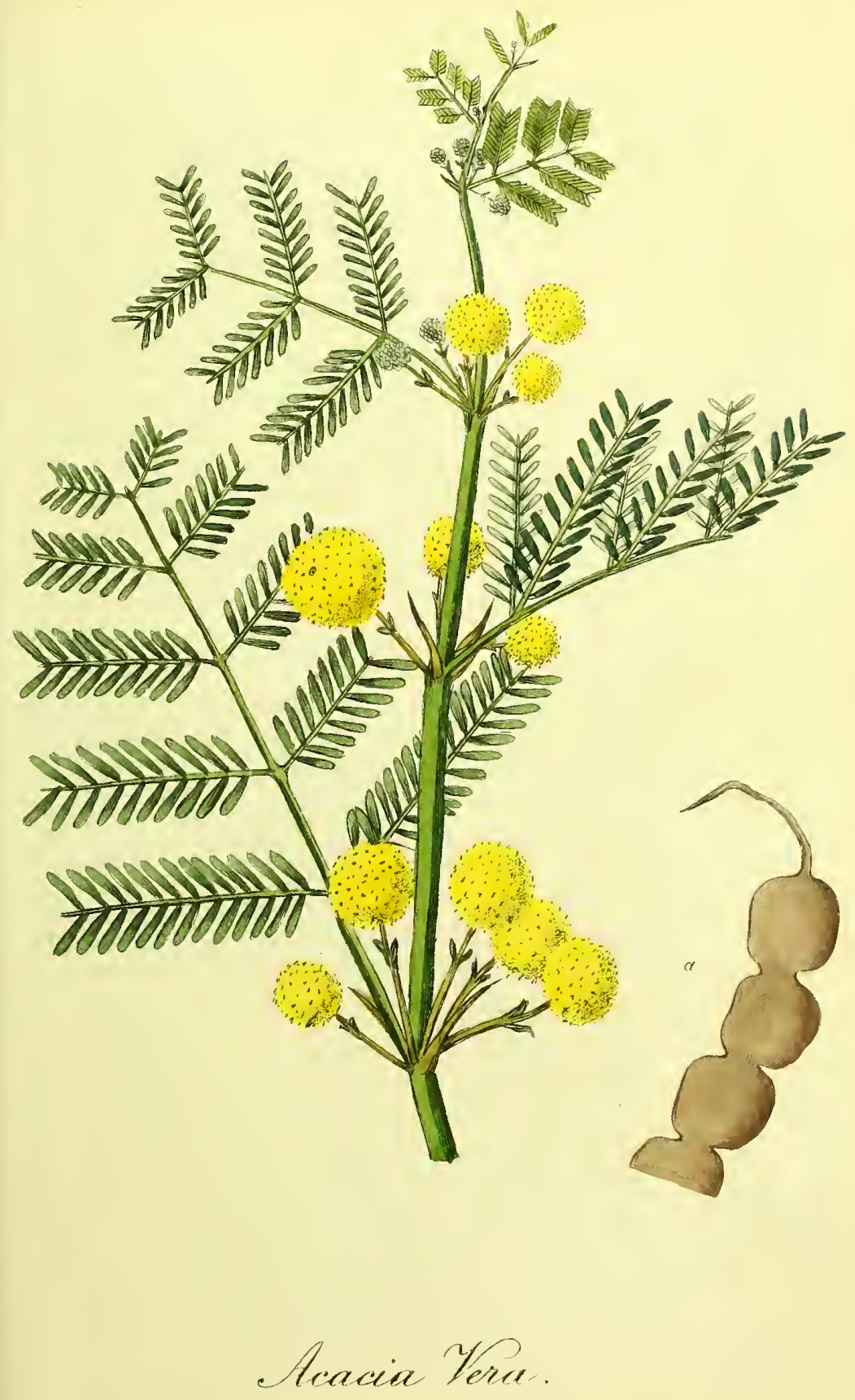

W. Sprutt, del ex Letre. 

THE ACACIĀE were formerly a subdivision of the genus Mimosa of Lisnæus, who says, "Mimosæ legumen articulatum; folia veluti sensitiva. Acaciæ legumen cylindraceum; folia non moventia se à vactu." * But Willdenow has established the Acaciāe as a distinct genus. In their general appearance the Acaciāe and Mimosāe bear a strong resemblance to each other, and perhaps the division of them may be considered rather an artificial than a uatural arrangement; the species of both are very numerous, and many of them have long formed some of the greatest ornaments of our green houses. We may further observe, that the Mimosàe and Acaciāe are to be found geserally throughout the warm regions of Asia, Africa, and the Islands in the Sonth Seas; and that they all, more or less, exude a gummy matter, similar to the gum arabic of commerce.

The Acacia Vera (Mimosa Nilotica of Linneus) is a native of the sandy parts of Arabia Petræa and Egypt, flowering in July: it appears to have been sometime known to our English botanists, and was cultivated by Gerarde at the end of the sixteenth, or beginning of the sevellteenth century. 'The greatest quantity of pure gum arabic is furnished by this tree, but as we before observed, a similar gum may be obtained from all the species of the Minosa and Acacia; and from many other trees also, as the Swieleuia febrifuga, Melia azadirachta, the Terminalias, and even the cherry and plum trees of Europe. Dr. Ainslie says there are several gunis which resemble the true gum arabic, or that of the Acacia Vera, which grows in almost every part of Africa; but, perhaps none of them comes nearer to it than the VullumPisin, or gum of the Feronia Elephantum of Roxburgh, (or what is called the wood-apple tree) and which is commonly ised for medicinal purposes by all the practitioners of Lower India. What is termed the Baul tree, in Bengal, (Acacia Arabica of Willdenow) also furuishes a great deal of gum, which is employed in place of gum arabic; it would appear to be the same tree that Dr. Wittman, in his travels, ( $p, 231$ ) mentions as yielding much gum arabic in Turkey. We learn from Niebliur $\dagger$ that a considerable quantity of gum arabic is produced in the neighbourhood of Mount Sinai, and brought for exportation to Alexandria. In Morocco, $\neq$ a great deal of it is procured, especially about Rasel-wed and Bledhummer, in the province of $A b d a$, where the tree is called Attaleh.

\footnotetext{
* Species Plantarum.

+ Niebhur's Travels, vol. i. p. 99\%

† See Jackson's Account of Morocco, p. 83.
} 
Dioscorides was certainly well acquainted with the tree of which we are treating ; and the accounts left by Alpinus, and other subsequent naturalists, leave no doubt on the subject. It is worthy of remark, that the barks of all the trees which furnish this kind of gum are highly astringent; and in India and other places, they are employed in tanning. Although the Acaciāe and Mimosāe grow in great abundance over the vast extent of Africa, yet gum arabic is obtained chiefly from those trees that are situated near the equatorial regions, and we are told, that in Lower Egypt the solar heat is never sufficiently intense to produce it.

This species of Acacia rises several feet in height; the stem is covered with a grey smooth bark; on the younger branches the bark is yellowish green, with a reddish or purplish tinge; the leaves are placed alternately, they are bipinnate and composed of several pairs of opposite pinnæ; the leaflets are numerous, in pairs, linear, and of a bright green colour; at the base of the leaves are two long, spreading, awl-shaped spines, furnished with a small glandular swelling below; the flowers are collected together so as to assume a globular form, and stand upon slender foot-stalks, which proceed from axilla of the leaves; a small distance below each head of flowers is placed a pair of small ovate bracteas; the calyx is small, bell-shaped, and divided into five segments; the corolla consists of five narrow yellow segments; the stamens are numerous; the filaments are thread-like, capillary and support roundish yellow antliers; the germen is cnnical; the style slender, and crowned with a simple stigna; the fruit is a smooth pod or legume, four or five inches long, nearly flat, of a pale yellowish brown colour, and contracted into orbicular portions.

The gum exudes in a liquid state from the bark of the trunk and branches of the tree in a similar manner to the gum which is often produced upon cherry trees, \&c. in this country; by exposure to the air it soon acquires solidity and harduess. In Senegal the gum begins to flow when the tree first opens its flowers, ${ }^{*}$ and continues during the rainy season until the month of December, when it is collected for the first time; another collection is made in the month of March from incisions in the bark, which the extreme dryness of the air at that time is said to render necessary. $\dagger$

There are two kinds of gum found in the shops, and sold promis-

* Adamson, Mem. de l'Acad. de Science de Paris 177, 3. p. 8.

† Demanet, Noavelle Hist. de l'Afrique Françoise, tom. is p. 56. 
cuously: gum arabic, which comes from Barbary and the Levant, by way of the Mediterranean, and East India gum. In Egypt and A rabia it was formerly the custom to pack this gum in skins, but it is now usually imported into England in large casks.

The best gum arabic consists of roundish transparent tears, colourless, or of a very pale yellow, or anber colour; it has a shining fracture, without smell or taste, and is perfectly soluble in water; the pieces which are most transparent and colourless are sometimes selected from the rest, and sold for about double the price, under the name of picked gum. The large, rough, and reddish, or brownish gum, is said to be produced by a different species of tree, but the Arabian and Egyptian gum is conmonly intermixed with pieces of this kind. The East India gum is darker coloured than gum arabic, and not so soluble in water.

Sensible and Miedical Properties. By exposure to heat, gum arabic softens and swells, but does not melt; it emits air bubbles, blackens, and finally, when nearly reduced to charcoal, burns with a low blue flame. After the gum is consumed, there remains a small quantity of white ashes, composed chiefly of the carbonates of lime and potash. The vegetable acids dissolve this gum without alteration, the strong acids decompose it. Chlorine, according to the experiments of Vanquelin, converts gum into nitric acid; if nitric acid be slightly heated on gum till it has dissolved it, and a little nitrous gas is exhaled, the solution, on cooling, deposits saclactic acid. Malic acid is formed at the same time, and if the heat be continued, the gum is at last converted into oxalic acid, developing no less than three acids by the action of nitric acid on the gum.

According to Vanquelin, gum contains traces of iron, and he conjectures that the lime which it contains is usually combined with acetic or malic acid. Berzelius analysed it by burning it along with chlorate of potash, and gives the following as the result.* -

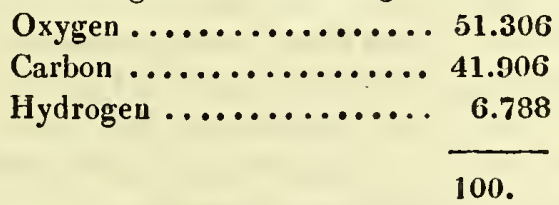

Gum arabic is insoluble in spirits, oil, and ether; but readily dissolves in twice its weight of boiling water, forming a simple mucilage,

* Thomson's Chemistry, vol.iv. p. 36. 
which may be used for many purposes connected with pharmacy, and the other arts. By means of this mucilage we suspend in' water various substances which could not otherwise be diffused in that fluid, as in the Mistura Cretæe, \&c. ; it also renders oily, resinous and pinguedinous substances miscible with water, and forms an useful cement for many domestic purposes. In the arts, this gum is very extensively used by calico printers, and in the preparation of crayons and water colours for drawing it is an indispensible ingredient. Of the medical properties of gum arabic little need be said, like other vegetable mucilages, it may be considered nutritious, and we are told that in miany parts of Africa and India it forms an important article of diet, mixed with milk, rice, \&c. In the province of Guzerat, in India, the poor inhabitants use gum as a common article of food.

In medicine this gum is chiefly used as a vehicle for the exhibition of other medicines; taken internally, it has been considered a de-? mulcent, and has been prescribed in dysentery, stranguary, sore throat, \&c. Dr. Cullen is of opinion that this mucilage as an internal demulcent can be of no service beyond the alimentary canal. "II common practice," he says, "hardly more than a few ounces are given in one day, and what that can give of a mucilaginous quality. to many pounds of serosity I leave my intelligent reader to judge." He observes, that the drinking of two pounds additional of aqueous liquor would be of more service than four ounces of gum árabic without this additional drink. By the native doctors of India, the bark of the gum arabic tree is considered a powerful tonic, and an infusion of it is prescribed in cases requiring medicine of this description, in the quantity of three or four ounces twice in the day. It is supposed to be particularly indicated in the extreme languor and sinking, consequent on the bite of certain snakes, and which are sometimes accompanied with spitting of blood, and roiding it by urine.*

Otf. The Gum. Gum Arabic.

Off. Pp. Emulsio Acaciæ Arabicæ, E. Arabicæ, $D$.

Mucilago Acaciæ Arabicæ, L. E. D. Trochisci Gummosi, E.

* Materia Medica, vol. ii. p. 142. 



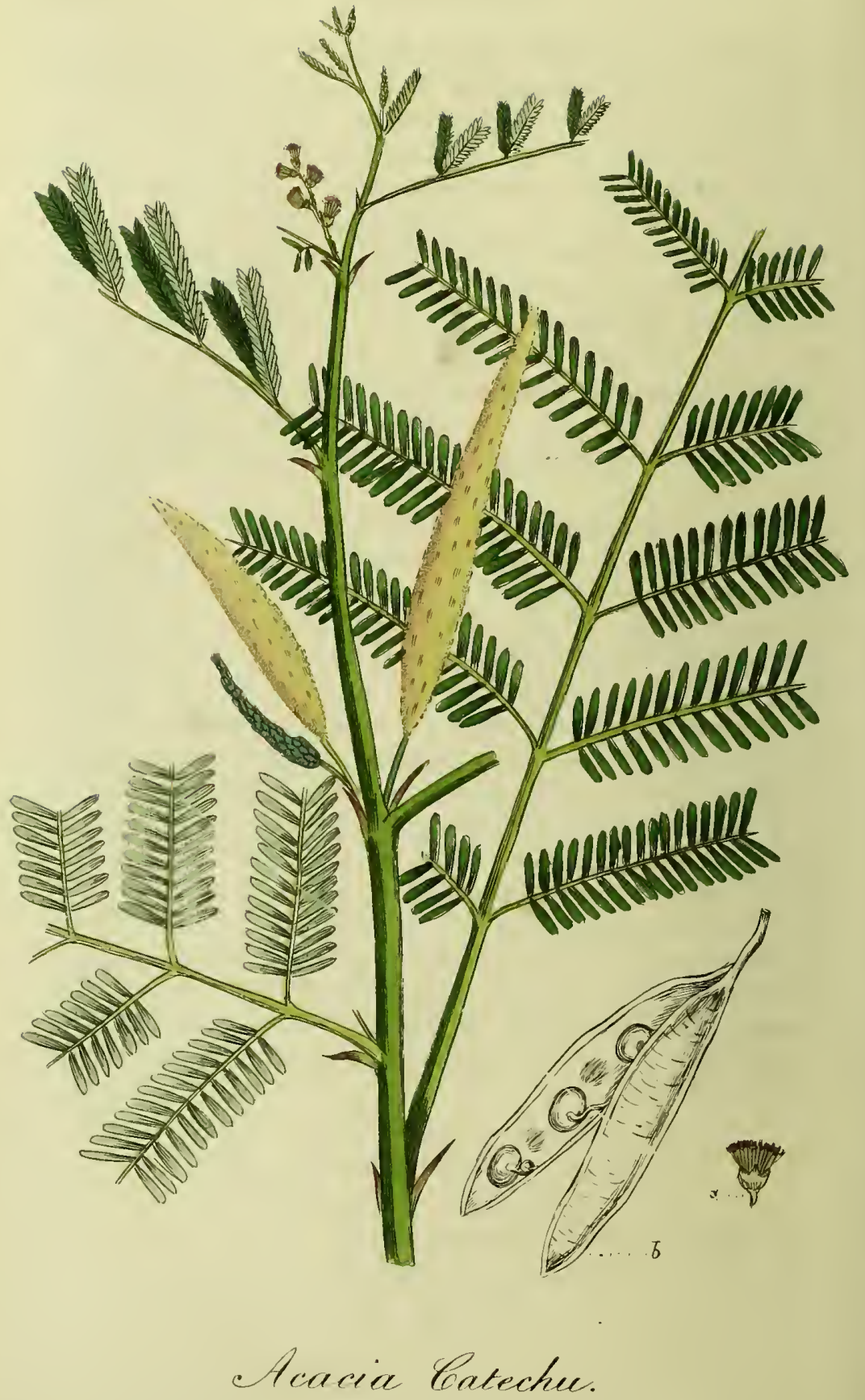

WSprazz deZ. ez Lizh. 


\section{ACACIA CATECHU. \\ Catechu, or Medicinal Acacia.*}

\section{Class Polygamia.-Order Monacia.}

Nat. Ord. Lomentaceæ, Linn. Leguminose, Juss.

Gen. Char. Hermaph. Calyx five-toothed. Corolla fivecleft, or formed of five petals. Stamens 4-100. Pistil 1. Legume bivalve.

Male. Calyx five-toothed. Corolla five-cleft, or formed of five petals. Stamens 4-100.

Spec. Char. Spines stipulary, hooked, in pairs. Leaves hairy, bipinnate; first division of ten or twelve pairs; second of many pairs; with a gland at each extremity of the foot-stalk. Spikes cylindrical, axillary, two or three together.

THrs, like the preceding species of Acacia, formerly belonged to the genus Mimosa of Linnæus, and was with it removed to the new genus Acacia. The Indian drug which is the produce of this tree, has been long known by the name of Terra Japonica, a name which was originally given to it, from a supposition that it was a mineral production of the Island of Japan; and though it was soon discovered by chemical analysis, to be of vegetable origin, neither the plant from which it was obtained, nor the process of preparing it, were sufficiently ascertained, for nearly a century after it had been in general use in Europe. Writers on the Materia Medica very generally, from the time of Clusius, considered the Catechu to be extracted from the seeds of a nut, the produce of a species of palm, (Areca or beetle nut); and in both the editions of the Materia Medica of Linnæus, he refers the drug to the "Areca Catechu, frondibus pinnatis, foliolis replicatis oppositis præmorsis." We are told, however, by Mr. Kerr, Assistant Surgeon to the Civil Hospital in Bengal, who was the first to describe the tree, that in the province of Bahar,

* Fig. $a$. Male flower. $b$. The legume.

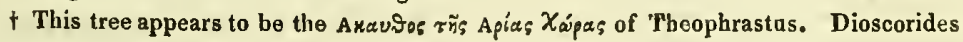
also mentions it. 
where the Terra Japonica is manufactured, the price of the Areca nut exceeds that of Catechu; but he thinks it probable, that where this nut is in great plenty, they may perhaps join some of the fruit in making the extract, to answer a double purpose; for the most general use made of both in the country, is to chew them as Europeans do tobacco. Herbert de Jager asserts that Catechu is not extracied from one tree only, but from almost all the species of Acaciāe whose bark is astringent and reddish, and from many other plants, which, by boiling, yield a juice of the same nature.* There are two sorts of Catechu now exported from India to England, a pale kind from Bengal, and another of a yellowish brown colour from Bonbay; the first being the produce of Canara, the latter of Bahar. $†$

This species of Acacia is a large shrub, or tree, and grows to the height of from ten to twenty feet, and to twelve or fifteen inches in diameter; the trunk and older branches are covered with a thick, rough, feruginous bark; the branches, when young, are somewhat downy; the older branches are beset with numerous pairs of small recurved spines, originating in the stipulas; the leaves are placed alternately on the younger branches, and are composed of from fifteen to thirty pair of pinnæ, about two inches long, each having many (often forty or more pairs) leaflets, which are hardly a quarter of an inch in length, linear, covered with short hairs, and of a pale green colour; the common petiole is often furnished with a few recurved prickles, and a small gland is placed at the base of each pair of pinnæ; the flowers are hermaphrodite and male, and arise from the axillæ of the leaves in close spikes, three or four inches long; the flowers are of a pale yellow, stalked, and hairy; the calyx is tubular, hairy, and five-toothed; the corolla is about twice the length of the calyx, monopetalous, and divided at the limb into five pointed segments; the filaments are nunerous, capillary, double the length of the corolla, and united at the base with the germen, and support roundish anthers; the germen is ovate; the style is slender, and crowned with a simple stigma; the fruit is a smooth lance-shaped legume, three or four inches long, and less than one broad, with an undulated smooth margin, containing six or eight roundish flat seeds. Preparation of Catechu. "After felling the trees, the

* Vide Misc. Nat. Car, Dec. 2, Ann. 4, Obs. 3, and Dec. 2, Ann. 3, p. 8.

+ Dr. Fothergill's Works, vol. ii. p. 296. Also Dr. Buchanan's Journey through Canara, \&c. vol. iii. p. 177. 
exterior white part of the wood is cut off; the interior coloured wood is cut into chips, which is put into a narrow-mouthed unglazed earthen pot, pouring water upon them till the whole is covered; when this is half evaporated by boiling, the decoction, without straining, is poured into a flat earthen pot, and boiled to one-third part; this is set in a cool place for one day, and afterwards evaporated by the heat of the sun, stirring it several times in a day; when it is reduced to a considerable thickness, it is spread upon a mat or cloth, which has been previously covered with the ashes of cow dung; this mass is divided into square pieces by a string, and completely dried by turning them frequently in the sun, until they are fit for sale." "This extract is called cutt by the natives of India, by the English cutch, and by different authors Terra Japonica, catechu,* khaath, cate, cachou, \&c. \&c."

"In making the extract, the pale brown wood is preferred, as it produces the fine whitish extract; the darker the wood is, the blacker the extract, and of less value." There are two kinds of extract inet with in commerce, one which comes from Bengal, and the other from Bombay.

Sensible Qualities and Chemical Properties. Catechu, in its purest state, is a dry pulverable substance, which does not deliquesce, or apparently cliange by exposure to the air : outwardly it is of a reddish colour, internally of a shining brown, (more or less dark) tinged witl a reddish hue; its specific gravity varies from $\mathbf{1 . 3 9}$ to 1.28 ; to the taste it is sweet and mucilaginous, accompanied with a considerable degree of astringency. It dissolves almost entirely in water; alcohol dissolves about $\frac{7}{8}$ of the pure mass, the residue is an almost insipid mucilaginous substance. It is also soluble in vinegar. It softens when heated, and then takes fire from a flaming body, and burns away with a somewhat grateful smell. The watery solution is of a deep red brown, highly astringent to the taste, but has no perceptible smell; it slightly reddens litmus paper, and forms an insoIuble elastic precipitate with gelatin, and green, dark blue or black precipitates with iron. The watery infusion is copiously precipitated by the sulphuric and muriatic acids, by solutions of lime, of strontia and of barytes. The carbonates of magnesia, of soda, of potash, and of ammonia, added to a solution of catechu, deprives it of the power of precipitating gelatine, which is restored by the addition of

* This name is said to be compounded of two Oriental words, cate which signifies a tree, and clue juice. 
acids. According to the analysis of Mr. Davy, 200 grains of. Bengal Catechu gave tanuin, 97 ; peculiar extractive matter, 73 ; mucilage, 16 ; residual matter, chiefly sand and calcareous earth, 14. Another sample of Bumbay Catechu gave tannin, 109 ; mucilage, 13 ; peculiar extractive matter, 68 ; residual matter as the former, 10.

Medical Properties and Uses. Catechu, as being powerfully astringent, is very generally employed in all cases requiring medicines of this class. Formerly it was supposed to possess considerable antiseptic qualities, and was employed successfully both by Huxham and Sir John Pringle, * in cases where a putrid or dissolved state of the blood prevailed. As an astringent, it is particularly useful in diarrhœe, chronic dysentery, lımorrhoidal and uterine hæmorrhages, \&cc, ; and may be givcn alone, or in conjunction with the bitter and aromatic barks. As a topical remedy, it is often successfully employed in the form of gargle, in relaxations of the fauces, ulcers, aphthre in the mouth, relaxed uvula, $+\& c$.; the usual dose is from ten to sixty grains of the substance in powder. Dose of the tincture from one to three or four drachms.

Off. The Extract of the Wood.

Off. Pp. Electuariun Catechı Compositım, E. D. Infusum Catechu, L. E. Tinctura Catechu, L. E.

\section{S'T Y RAX OFFICINALE.} The Officinal Storax Tree. $\ddagger$

\section{Class Decandria.-Order Monogynia.}

Nat. Ord. Bicornes, Linn. Guaiacine, Juss.

Gen. Char. Calyx inferior, pitcher-shaped. Corolla funnelshaped. Stigma simple. Drupe coriaceous, two-seeded.

Spec. Char. Leaves ovate, rather blunt, entire, downy beneath. Clusters simple, of few flowers.

* Vide Diseases of the Army, App. Exp. 10.

+ Dr. Thomson recommends the slow solution of a small piece of catechu in the moutb, as " a certain remedy for the troublesome cough induced by a relaxed uvula, hanging into, and irritating the glottis."

$\ddagger$ Fig. $a$. The pistillum. $b$. The stamens, $c$. The fruit. 


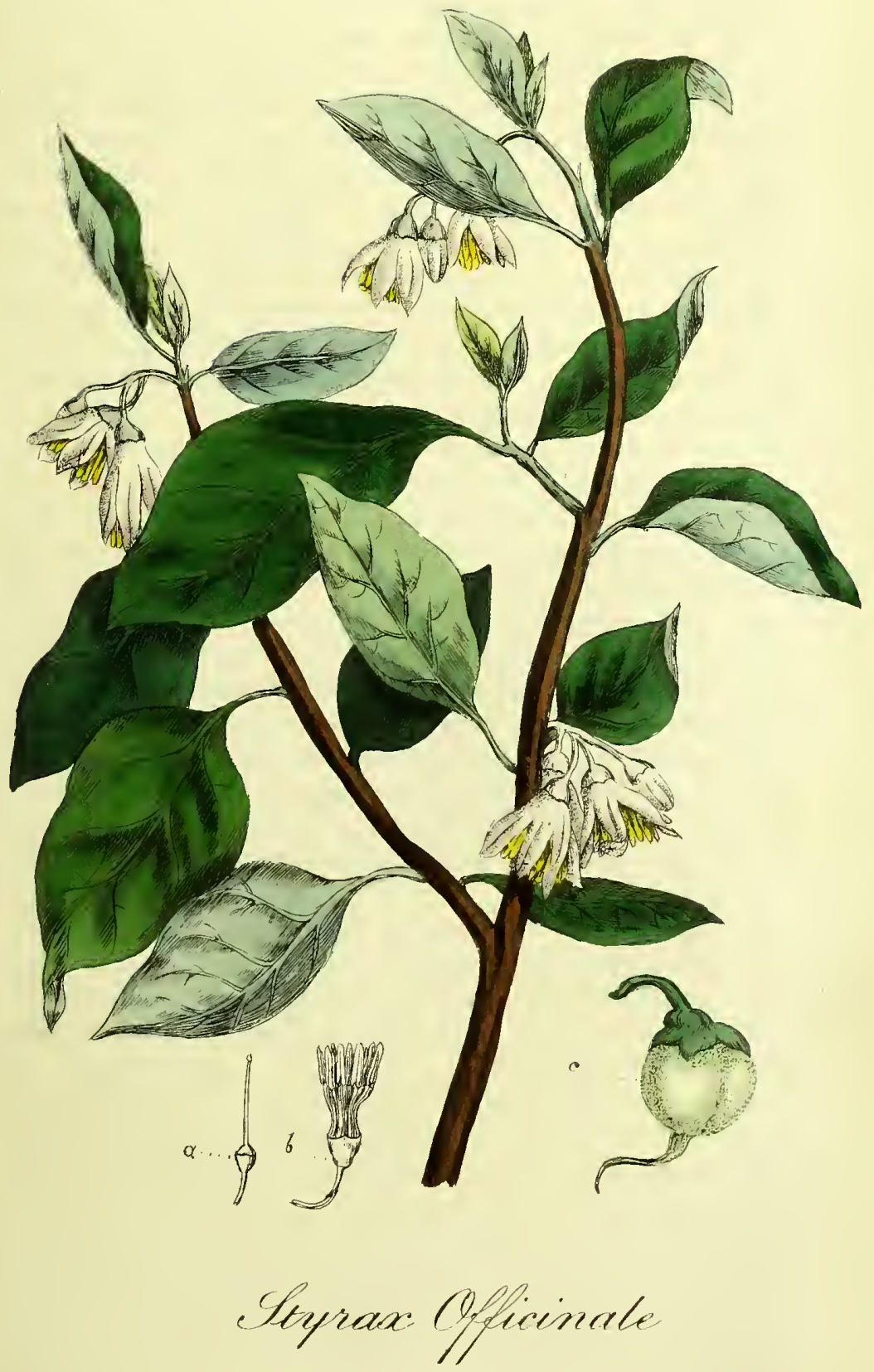

Eed by Irgrey Madeley 3io. Szrand.

IV Spratz det et $Z$ zech

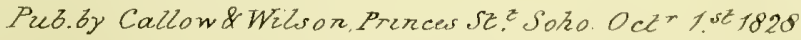



THis tree, (the $\Sigma$ tupa\} of Dioscorides) we inagine, was originally confined to Syria and the Levant, from whence it was introduced into Italy, and the south of France, where it may now be considered naturalized; but the resinous drug which it produces, is only to be obtained in perfection from the trees growing in Asiatic Turkey. It was first cultivated in England by Gerarde, about the year 1590, but it is by no means a common tree to meet with in our gardens, nor does the climate of England appear to favour its growth. The storax issues in a fluid state from incisions made in the bark of the trunk, or branclies of the tree, and as it was formerly the custom to collect and export this balsam in reeds, it obtained the name of Styrax Calamita, under which name it is noticed by Galen.

This species of storax seldom exceeds the height of from fifteen to twenty feet. The branches are irregular, alternate, round, leafy, and, when young, somewhat downy; the leaves are deciduous, petiolate, and arise alternately on the branches; their form is ovate or elliptical, entire, and somewhat pointed, of a fine smooth shining green on the upper surface, and covered with hoary stellated down on the under; the flowers terminate the young lateral shoots, and grow in small clusters, containing from two to five or six flowers each; the calyx is white and downy; the corolla is monopetalous, white, funnelshaped, and divided at the limb into five deep, oblong, obtuse pointed segments ; the filaments are ten, and placerl in a regular circle; the anthers are yellow, erect, and oblong; the germen is oval, and supports a slender style, crowned with a simple stigma; the fruit is a pulpy pericarp, containing one or two nuts, of an oval compressed form, concave on one side, and convex on the other. The flowers appear in May and June.

Sensible and Chemical Properties. There are two kinds of storax met with in the shops; the best, at least the purest, is in compact masses of a red or yellowish colour, interspersed with whitish tears; it has a very fragrant odour, and a bitter, somewhat pungent, aromatic taste; it readily melts with a gentle heat. The common storax is in larger masses, much lighter, and bears very little resemblance to the former. It is in fact a composition of the pure balsam and saw dust, the ingredients being in greater or less relative proportions, according to the honesty, or rather dishonesty of the manufacturer. It is purified by dissolving it in rectified spirits, and straining; the spirit is then distilled off by a gentle heat, until the balsam has acquired a proper consistence. When thus purified, it possesses more fragrance, and is by many preferred to the former kind, which we niay conclude, has in most instances undergone some

VOL. I.

$2 \mathrm{c}$ 
process of adulteration; for it is very rare to meet with the storax of commerce in a state of purity. In selecting it, we should choose it of a reddish-brown colour; ratlier soft, unctuous to the touch; brittle and friable, and of a fragrant smell: indeed we consider the smell the best test of its purity; this it derives from the benzoic acid it contains, and its virtues, in every respect, may be considered to arise from, and be proportioned to the quantity of this ingredient, which enters into its composition.* Rectified spirit readily dissolves storax, which may be inspissated to a solid consistence, as clirected above for the purification of it, without sustaining any loss of its sensible properties. Common storax infused in water, imparts to the menstruum a good yellow colour, some sliare of its smell, and a slight balsamic taste; it gives a considerable impregnation to water by distillation, and strongly diffuses its fragrance to water when heated, though it scarcely yields any essential oil. The pure resin, distilled without addition, yields aloug with an empyreumatic oil, a portion of bellzoic acid. Storax appears to be a natural combination of resin with benzoic acid; the proportion varying according to the purity of the drug, and perhaps the soil, clinate, and culture of the tree, from whence it lias been obtained. $\dagger$

Medical Properties and Uses. As the medical properties of storax'are entirely dependant on the benzoic acid which enters into its composition, and as this latter is so readily obtained in a state -of purity, the compound substance may well bc considered, as it is by most practitioners, an useless article in the Materia Medica; it was formerly prescribed for asthna, and chronic affections of the trachea, but as we slall have oceasion to treat further of this acid, when noticing the Styrax Benzoin, we shall for the present dismiss the subject.

$$
\begin{array}{ll}
\text { Off. } & \text { The Balsam } \\
\text { Off. Pp. } & \begin{array}{l}
\text { Pilulæ e Styrace, D. } \\
\text { Styrax Purificata, D. } \\
\text { Tinct. Benzoini Comp. L. }
\end{array}
\end{array}
$$

\footnotetext{
* Storax enters into the composition of the incense which is burned on the altars of Roman Catholic Chapels, and some other places of worship.

+ Another substance under the name of storax, or liquid amber, is known in commerce; it is a liquid balsam, distinct from the storax of the Pharmacopøias, and is said to be obtained from a tree growing in the Southern States of North America.
} 


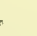




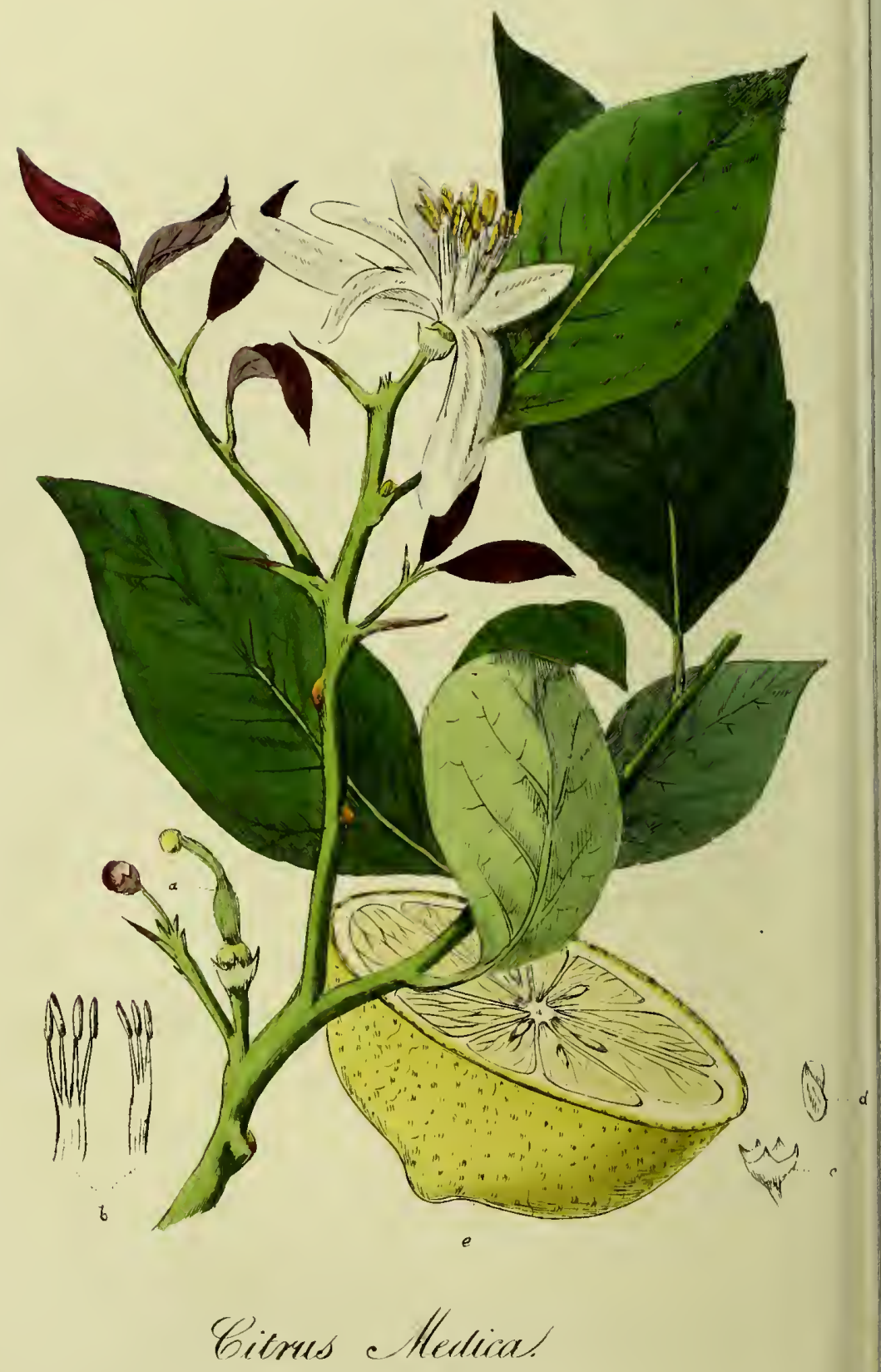

Punted by Ingrey \&uadely no strand

W spratt det et lut

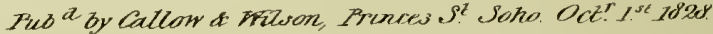




\title{
CITRUS MEDICA.
}

\author{
The Lemon Tree.*
}

\section{Class Polyadelphia.-Order Icosandria.}

Nat. Ord. Ромасеж, Linn, Aurantiæ, Juss.

Gen. Char. Calyx 5-cleft. Petals 5, oblong. Anthers 20, with filaments united into several bundles. Berries 9-celled. Spec. Char. Petioles linear.

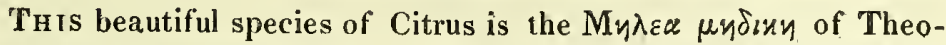
phrastus and Dioscorides : it is a native of Assyria and Persia, from whence it was brought to Greece, and afterwards to Italy, $\dagger$ and successively propagated in other parts of southern Europe, and the West India Islands, where it is now in general cultivation. The orange and lemon is now extensively cultivated throughout Spain, Portugal, and the islands iu the Atlantic belonging to these countries, from which places, England and the North of Europe are supplied. The fruit for exportation is pulled while yet green, rolled separately in paper, and packed in boxes; it is seldom perfectly ripe for some time after it comes to this country.

In England, this beautiful evergreen forms one of the greatest ornaments in our greeı houses; it was first cultivated in the Oxford Botanic Garden about the year 1648. $\ddagger$ The lemon tree in this country may be propagated, and the most approved varieties continued, by budding or inarching them on stocks raised from seed; as the younger trees however are annually imported from Spain, Italy, and Portugal, this method is seldom practised. 'The lemon tree is remarkable for its fertility, so much so, that in Italy it is proverbial. We are told, a wager was laid in 1812, by Signor Antonio Georgeri, of Massa, with the Marchese Calani, of Spezia, that at Cresullo, half

* Fig. $a$. The pistillum. b. T'wo separate parcels of stamens. c. The calyx. d. A seed. $e$. A section of the fruit.

t Paladins is supposed to have introduced the lemon tree into Italy, although this has been doubted by some writers, but as the cultivation of this tree is not noticed by writers prior to Pliny, it is evident it could not bave been propagated there long before his time.

\# Vide IIort. Kewensis. 
a mile from Massa, there was a lemon tree which would mature thas year 14,000 lemons. It exceeded the quantity.*

The lemon tree is of small growth, $\uparrow$ sending off numerous branches covered with a greyish bark; in appearance it so much resembles the' orange tree that at some little distance they are not easily distinguished. The leaves are alternate and somewhat larger than those of the latter, slightly indented at the edges, and without those winged appendages at the footstalk which constitute the specific character of the orange; their form is nearly elliptical, entire, pointed, and of a shining green colour, from three to four inches long, and two broad; the flowers (which continue to bloom most part of the summer) are large, simple, and stand on branched peduncles; the calyx is saucershaped, and divided into five pointed segments; the corolla is composed of five oblong concave petals, which are white on the inner side, and of a purplish tint on the outer; the stamens are about twenty; the filaments are united at their base into three or four distinct portions; the anthers are yellow, and placed vertically upon the top of the filaments; the germen is roundish and superior; the style is cylindrical, and terminated by a globular stigma; the fruit is an ovate berry, with a prominent apex,-externally rough, punctured, and of a pale yellow colour; internally divided into seven or nine cells, filled with a mucilaginous extremely acid pulp, each cell containing from two to four seeds; the rind is double; the exterior part thin, and cliefly made up of a great number of vesicles filied with a very fragrant oil; the interior is thicker and whiter than the former, and coriaceous.

Sensible Properties, \&c. The exterior rind of the lemon. is a grateful aronatic bitter; it is less hot than orange peel; its aromatic flavour and smell is derived from a volatile essential oil, a small quantity of which it yields in distillation with water; this oil is considerably acrid, and when the fruit is fresh, will often blister the mouth and skin by simply pressing it out of the rind upon the parts; this oil is extremely light, almost colourless, and in smell. nearly as agreeable as the fresh peel; it is frequently used as a perfume, and is generally brought to us from the South of Europe, under the name of essence of lemon. The flavour of the lemon peel is more perishable than that of the orange, but does not rise so

* Lander's Conversations, vol, i. p. 122.

+ In this country it seldom rises higher than from five to ten feet, bat in the Sonth of Europe it attains the height of fifteen, or even more. 
readily with spirit of wine; for a spirituons extract made from lemon peel retains its aromatic taste and smell in much greater perfection, than an extract prepared in the same manner from orange peel. The juice of the lemon is a sharp, grateful acid, analogous to that of oranges, from which it only differs in containing more citric acid, and less syrup. The simple expressed juice will not keep, on account of the syrup, extractive, mucilage and water, which cause it to ferment, and hence many modes have been recommended for preserving it for use. In the navy, it has been mixed with a fifth or a sixth part of brandy, or rum, and in this way has been kept for more than two years without undergoing any change,* but this is not pure lemon juice. Perlaps the best node of preserving it for a long period, is the plan reconmended to bring it to a highly concentrated state; this is done by repeatedly exposing it to a sufficient degree of cold to congeal the aqueous and mucilaginous plarts; after a crust of ice is formed, the juice is poured into another vessel, and by repeating the process several times, the remaining juice becomes highly concentrated, and will keep for many years without undergoing any change; it is proper to observe, however, that the lemon being the produce of the warmer climates, there may be a difficnlty in submitting it to this process previously to exportation. In the West Indies, v. here a considerable quantity of this acid is prepared for the use of the navy, under the name of lime juice, being obtained from the lime (Citrus Lima,) it is customary to boil the juice, and to allow the feculent matter to subside as it cools; it is then strained off into casks, and a small quantity of sulphuric acid added; in this way it is imported, and keeps good for a considerable time. $\dagger$

Pure citric acid, commonly called salt of lemon, is best obtained by saturating boiling lemon juice with powdered chalk, on which the saline compond falls to the bottom and leaves the mucilage suspended in the fluid, which must be decanted off and the precipitate washed till quite clean; then add a quantity of sulphuric acid, equal to the chalk in weight, and diluted with ten parts of water, and boil it for a few minutes, on which the sulphuric acid combines with the chalk, and leaves the citric acid dissolved in the fluid. If this fluid be evaporated to the consistence of a syrull, the pure citric acid

* Forster's Voyage, p, 638.

+ Lemon joice may also be evaporated by the heat of the sun, till it forms a solid salt; in which state it was brought from Jamaica, and found extremely gratefal to the taste, and $\ni i$ dissolved in a quantity of water equal to tbe juice of a lemon, was rendered of the same degree of acidity.-See Percival's Phil. Med. and Exp. Essays, p. 219. 
will appear in thin needle-like crysta!s, assuming the form of rhomboidal prisms; these crystals suffer no change from exposure to the air, and have an exceedingly acid taste. When sufficiently heated, they melt, swell, and emit fumes, and are partly sublimed, unchanged, and partly decomposed; water at the ordinary temperature dissolves one half its weight of this acid, at $212^{\circ}$ twice its weight; the solution undergoes spontaneous decomposition very slowly; sulphuric acid elears it, and forms vinegar; nitric acid converts it into oxalic and acetic acids. Citric acid being more costly than tartaric, is occasionally adulterated with it.

Medical Properties and Uses. The rind of the lemon being similar in its properties to that of the orange, may be employed with the same inteution, and in the same manner, in the making of stomachic tinctures and infusions. Lemon juice is a powerful and agreeable antiseptic: Dr. Wright says its powers are much increased by saturating it with muriate of soda, (cummon salt) and this mixture he recommends as possessing great efficacy in dysentary, remittent fever, putrid sore throat, \&c. Lemon juice is one of the most powerful antiscorbutics among the vegetable acids, and with this view has long been used in the British navy, when the crews are at sea and eonfined to the use of salt provisions. We have even kuown scorbutic sores to be washed with it with good effect, and perhaps its application in this way might be found sepviceable with other ill-conditioned sores. Scorbutic gums are much benefited by washing the mouth with it. But the most general use to which lenoon juice is applied medicinally, is in combination with the alkalies which it neutralizes. These mixtures are almost universally given to fever patients, and are found extremely grateful ; allaying thirst and febrile heat, and promoting diaphoresis; the most common mixture of this kind is a solution of the carbonate of soda in water, (four draclims to eight ounces of water) an ounce of which, with half an ounce of lemon juice may be frequently taken in the course of the day : on the mixture of the acid and the alkaline solution, a considerable effervescence takes place, occasioned by the acid combining with the soda, and expelling the carbonic acid gas; it is best to take it during this effervescence, particularly if there is any sickness of the stomach, which will be relieved by the carbonic acid gas, and these effervescent mixtures are not unfrequently given merely to allay sickness : one ounce of lemon juice will generally be found sufficient to saturate a drachm of the alkali. The carbonate of potass is sumetimes used instead of the soda; and sometimes also a solution of the carbonate of ammonia in water. The crystals may 



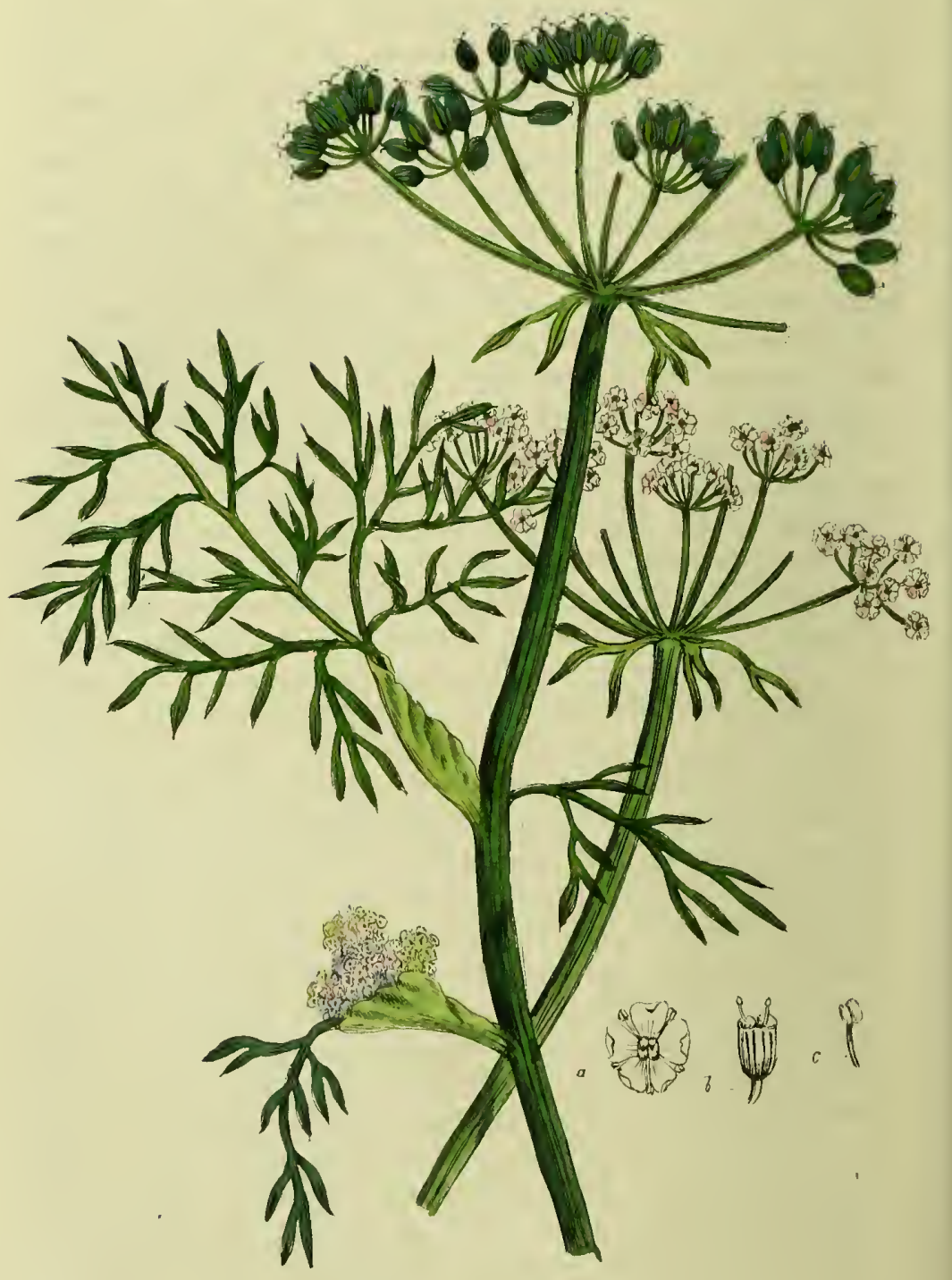

Carum Carui:

W. Spratt d el. ez.Ziz 
in every instance be substituted for the recent juice. Lemon juice is also an ingredient in many pleasant refrigerant drinks, which are of great use in allaying febrile heat and thirst; the most common of these is the well known beverage, lemonade. The essential oil of the rind is added to some plasters and ointments for the sake of its odour.

Off. The Fruit.

Off. Pp. Aqua Citri Medicæ, E. D.

Oleum Citri Medicæ, L. E. D.

Syrupus Citri Medica, L. E. D.

\section{A R U M C R U I.}

Common Carraway.*

\section{Class. Pentandria. Order Digynia.}

Nat. Ord. UMBELLIFERE, Linn.

Grin. Char. Involucre one-leafed. Petals inversely heartshaped. Fruit elliptical, oblong, with equi-distant ribs; interstices convex and striated. Calyx 0 , or very minute.

Spec. Char. Stem branched. Partial Involucres none.

The Carum Carui, or Kuбtopos opzis of Dioscorides, is an umbelliferous biennial plant, a native of Europe, and has been found wild in many parts of Britain, particularly in some of the rich meadows in Lincolnshire and Yorkshire. It is now ranked by many botanists among our indigenous plants. This species of carraway is cultivated in large quantities for culinary and medicinal purposes, particularly for the former. By cultivation the seeds are said to be larger, more aromatic, and more oily than those of the wild plant. The plant Howers in June, and the seeds ripen in August and September.

. The root is spindle-shaped, long and thick; the stem rises to the height of from two to three or four feet, erect, round, channelled, branched, and leafy; the lower leaves are eight or ten inches long,

* Fig. a. Magnified flower. b. The germen and styles magnified. c. A stamen. 
bipinnate, and sub-divided into numerous fine segments, which are narrow, linear and pointed; the leaves which grow upon the stem are smaller and stand opposite, one sessile, and the other on a dilated membranous edged foot-stalk; the flowers are white or pale flesh colour, and grow in umbels, which terminate the stem and branches; the general umbel usually consists of ten radii, and is furnished with a one-leafed involucre, divided into from three to five narrow segments; the partial involucrum resembles the general one, both of which are often deficient; the partial is sometimes entirely wanting ; the calyx is very minute, or altogether wanting; the corolla is composed of five (nearly equal) roundish petals, whicl are very small and inflexed; the five filaments are about the length of the petals, slender, and support small round two-lobed anthers; the germen is inferior, ovate, two-lobed, and support two short capillary, simple stigmas; the germen becomes two ovate, bent, striated, brown, naked seeds, of an oblong form, marked with three dorsal, and two marginal lines.

Sensible Qualities, Properties, \&c, Carraway seeds are spicy and pungent to the taste; their smell is aromatic. The distilled water is spicy, and strongly impregnated witl the scent of the seed. Spirit of wine carries over in distillation more of the flavour of the seeds, but less of the scent than water. By distillation with water, 6lb. of unbruised seed yield 4 ounces and a half of pale yellow oil, having the smell of the seed, and the taste, but much more pungent.

Medićal Properties and Uses. The medicinal properties of carraway depend upon its sensible qualities, hence it is considered stomachic and carminative, and is ofter employed in flatulent colic, and other complaints requiring warm aromatic medicines. It is also of ten used as an adjunct, to cover the taste of unpleasant medicines, and to prevent them from griping. Carraway seeds are used very largely for culinary purposes, and we are told the ground seeds are used by the Tartars as a stimulant food, either in the form of gruel or bread, to enable them to bear fatiguing journies. Carraway seeds are not often given in substance, but may be taken, either whole or bruised, to the extent of from one to two drachms. The essential or volatile oil is given in doses of from one to five drops. The distilled spirit from $\xi i$ to $z i j$. Carraway seeds enter into the composition of the compound tinctures of cardamom and senna.

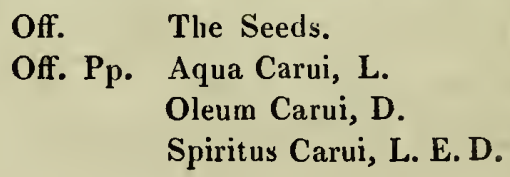




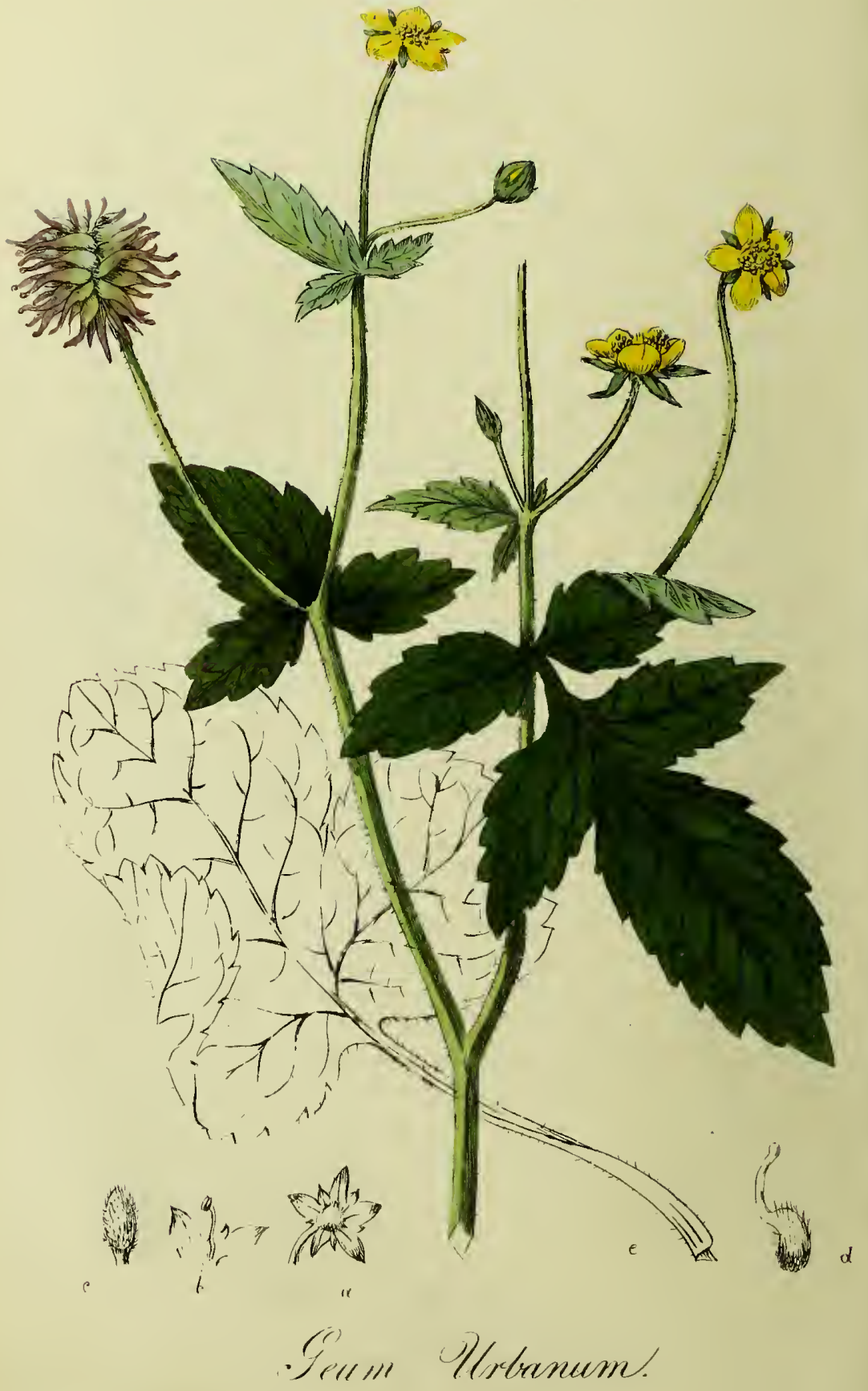

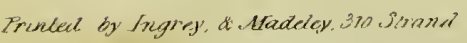

W Spratt del at Lith

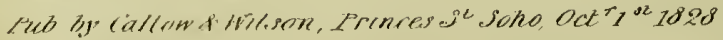




\section{GEUM URBANUM.}

\section{Common Avens, or Herb Bennet.*}

\section{Class Icosandria-Order Polygy ina.} Nat. Ord. Senticose, Linn. Rosacea, Juss.

Gen. Char. Calyx 10-cleft, inferior. Corolla 5-petalled. Seeds with a bent awn. Receptacle cylindrical.

Spec. Char. Flowers nearly erect. Awns naked. Leaves ternate. Radical ones lyrato-pinnate.

The Geum Urbanum is a perennial plant, indigenous to Britain, and most other parts of Europe. It is a very common plant in many of our counties, and is generally found in woods and other shady situations, where it flowers through the greater part of the summer months.

The root of this plant is woody, fibrous, and of a brown colour ; the stem grows erect, is rough, covered with minute hairs, and somewhat angular, branched towards the top, and rises to the height of about two feet; the leaves vary, the lower ones stand on long channelled foot-stalks, in form interruptedly pinnate and lyrate, the terminal leaf the largest, rounded, and frequently three-lobed; the cauline leaves are sessile, wedge-shaped and trifid; the whole irregularly toothed, serrated and hairy; the flowers are terminal, solitary, and stand on long hairy peduncles; the calyx is inferior, permanent, formed of one leaf, divided into ten acute segments, which are alternately large and small ; the corolla is composed of five bright yellow petals, which are roundish, and attached by their claws to the rim of the calyx; the filaments are numerous, awl-shaped, shorter than the corolla, and support roundish yellow anthers; the germens are ovate, hairy and compressed into an orbicular head; the styles are jointed about the middle, and support simple stigmas; the seeds are

* Fig. a. The calyx. b. A stamen magnified, attached to part of the calyx. c. A radical leaf. d. A pistil magnified. 
numerous, compressed together, ovate, downy, and each seed tipped with a long rigid awn of a purple colour, terminating in a small sharp hook.

Sensible Qualities and Properties, \&c. The root has an aromatic, and gently astringent taste, and a fragrant aromatic odour, approaching to that of cloves; especially when produced upon a warm and dry soil. It gives out its astringent principle both to water and spirit, its aromatic part most perfectly to the latter. On distillation with water, it yields a small quantity of a very fragrant concrete volatile oil. The watery infusion (which is red) turns black by the addition of sulphate of iron, and gives a copious precipitate with gelatin.

The virtues of the root (the only part used in medicine) are said to be increased by cultivation, and the large roots are preferred to the smaller fibres; they should be dug up in the spring, whell the leaves begin to appear, and dried in the air, but not with a strong heat, as the flavour would thus be dissipated, and the virtues diminished.

Medical Properties and Uses. The root of the avens was formerly held in much estimation, particularly on the continent, where it has been considered of great efficacy in obstinate intermittents. Many of the German Physicians* advance numerous instances of its successful exhibition, after the Peruvian bark had failed; it was also held in great esteem in diarrhœa and dysentery. In this country we believe it has been rarely employed, although, as a general tonic and astringent, it possesses considerable power.

We are told that a tincture of this root, four ounces to a quart of brandy, digested in a sand heat, and given to the quantity of half an ounce, or more, two, three, or four times a day, seldom fails to cure agues. It may also be given in powder, decoction, or electuary, in the proportion in which Peruvian bark is commonly employed.

Avens when employed as a gentle tonic in dysentery, flatulent colic, chronic diarrhœas, or cases of debility, is usually given in the form of decoction; made by boiling one ounce or more of the dried roots in a pint of water for ten or fifteen minutes. Dose one or two ounces three or four times in the day.

Off. The Root.

* Buckhave, Aaskow, Callisen, Bang, and others. 


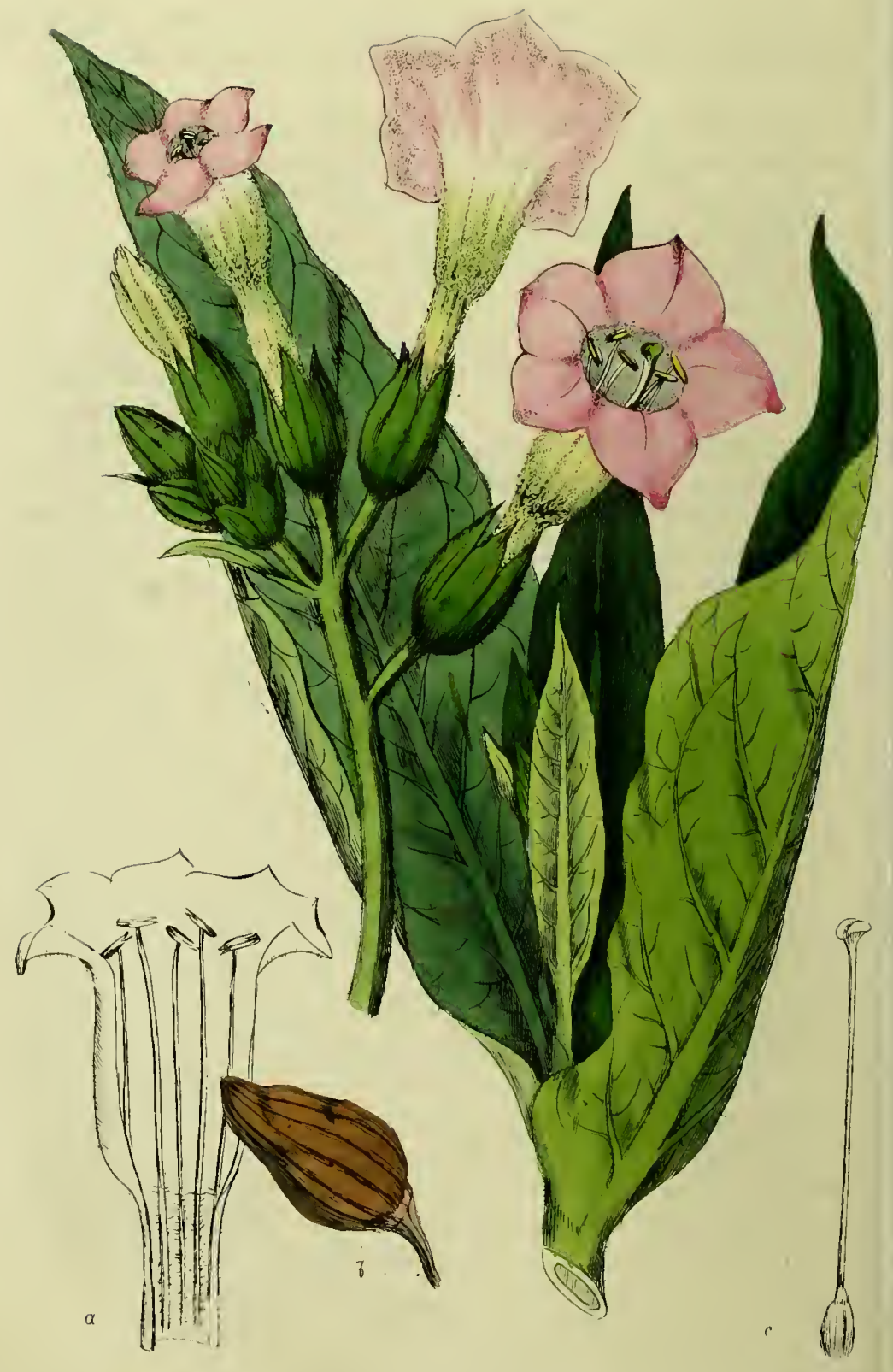

Nicotiana Jabacurn. 


\title{
NICOTIANA TABACUM.
}

\author{
Tobacco**
}

\section{Class Pentandria.-Order Monogynia.}

Nat. Ord. Luride, Linn. Solanèr, Juss.

Gen. Char. Calyx monophyllus, egg-shaped, 5-cleft. Corolla funnel-shaped, margin spreading, plaited. Slamens inclined. Germen egg-shaped. Seeds numerous, kidneyshaped, rough.

Spec. Char. Leaves lanceolate, sessile, decurrent.

TOBACCo is an annual plant, a native of North America, and was first brought into Europe about the middle of the sixteenth century. According to Humboldt, the first tobacco was brought from Yucatan, and the cultivation of it was sonn introduced into the southern states of Europe, particularly Portugal. It would appear that the first use which was made of this plant, and the only one to which it was applied by the natives of the countries wherein it grew, was to smoke it; the snuffing and chewing of tobacco are, comparatively speaking, nodern refinements. $t$ Several attempts were made, after the introduction of the plant into Europe, to abolish the use of it : in England, Switzerland, and Russia, it was denounced, and the use of it prohibited under severe penalties; experience, however, has shewn that these attempts to controul the rising taste of the day were wholly unavailing, and it is even probable, such is the perverseness of human nature, that the interdict only served to increase the rlesire to attain this loathsome weed. It does indeed appear strange that a plant so noxious in its qualities, so offensive in its smell, and so acrid and disagreeable in its taste, should so rapidly have grown into public favour, not only among the civilized of Europe, but even among savage tribes, where it lias become known: the natives of Guinea, and the Gold Coast, seek for it with

* Fig. a. The corolla cut open to shew the stamens. b. The pericarp. c. The pistillum.

+ The introduction into Eugland of the custom of smoking is ascribed to Sir Walter Raleigh. 
avidity ; it is with them one of the most useful articles of barter, and indeed we scarcely know a people among. whom tobacco has been once introduced, who have not ever after had a desire for it. It has now become a most important article of commerce to Europe and America, and by the imposition of leavy duties on tlie importation, a considerable source of revenue to England and other states; an event which certainly was not contemplated by the governments of those countries when they sought to discourage the use of it.

We are not certain of the precise period when the tobacco plant was first introduced into England, * but we know that it was very extensively cultivated, particularly in the northern counties, until the rising importance of our American colonies induced the legislature to pass an act, cominonly known by the name of the Virginia Act, by which the home cultivation was interdicted, with a view of encouraging what was then the most important branch of American commerce. After the loss of these colonies, heavy duties were imposed on the importation of tobacco, and by the increased consumption, these duties became such an important branch of the reveuue, that the prohibition to home cultivation was continued. Holland is the country in Europe where tobacco is now most extensively grown, and it is not a little remarkable, that this plant seems to flourish equally wherever it is planted, and to have in a manner neither. country or climate peculiarly its own. The best imported tobacco is from the state of Virginia, in North America; but whether its greater excellence is attributable to the soil, the clinate, better cultivation, an improved method of preparing it for market, or lastly, to a better species or variety being indigenous to that territory, we must confess ourselves ignorant.

Botanical Description. The rout of tobacco is fibrous, branchy, white, and of a strong acrid taste; the stalk rises from four to five feet high, is strong, cylindrical, about the thickness of the thumb, slightly hairy, and full of marrow; the leaves are large, oval, lanceolated, sessile, and even prolonged upon the stock on each side of their insertion, particularly the lower ones; their summit is acute, edges slightly undulated, surface hairy, ribs large, and very apparent; colour of a yellowish green; the flowers grow in a pannicle, at the extremity of the branches; calyx monophyllous, in the shape of a cup, cut into five segments, acute, and slightly hairy; corolla monopetalous, funnel-shaped; tube of the corolla, of a pale green, expanding into a limb, the colour of which varies from purple

- It appears from Lobel, that this plant was cultivated in Britain previously to the year 1570 . 
to the most delicate rose colour, * opening like a cup, and having five divisions, equally short, and pointed; the filaments the length of the corolla, seated close to the stigma before fecundation, forming a kind of crown, but receding when this organ bas been fecundated; they are surmounted by oblong, compressed authers; germen oval, supporting a long slender style, terminated by a roundish, bilobed stigma; calpsule ovate, conical, grooved with four streaks, with two cells, opening at the top in four parts, corresponding with the grooves, and coutaining a great number of small kidney-shaped seeds. Its time of flowering varies according to the climate it grows in; in its native soil it flowers about $\mathbf{J u l y}$, but with us it is somewhat later, and continues in blossom until late in September.

Sensible Properties. Every part of this plant is clammy and fotid; its other sensible properties, so far as regards smell, taste, $\&$ c. are so universally known as to render any description here unnecessary. We need only remark that its taste is much more acrid, and its smell more pungent in the dry than in the recent state.

Chemical Properties. The active constituent of tobacco is an essential oil, for by long boiling, the decoction and extract become almost inert; by distillation an oil is obtained so active, that small animals are almost immediately killed by being wounded with a needle dipped in it. Vauquelin has also discovererl a peculiar acrid volatile principle, to which he has given the name of Nicotin; it is soluble both in water and alcohol, has the peculiar smell of tobacco, and acts powerfully as a sternutatory. Besides these, tobacco contains albumen, mucilage, extractive matter, and a bitter principle.

Deleterious Effects of Tobacco. Orfila classes this plant among the Narcotico-Acrid Poisons, and gives a number of experiments made with it upon dogs and otler animals; from these it appears, that whether introduced into the stomach (in the form of suuff) or applied to the cellular texture, it proved equally fatal. The two following experiments were made by Dr. Macartney, of Trinity College, Dublin; a few drops of the essential oil of tobacco were applied upon the surface of the encephalon of a rabbit, after the upper part of the cranium and a portion of the brain had been raised, half an lour after the animal had not experienced any re-

* We have seen a beautiful variety of this plant, in which the whole of the corolla was of a bright piuk.-Ed.

VOL. I. 
markable symptoms; it was then killed by putting two drops of the same oil upon the tongue. About half a scruple of the same oil was introduced into the hemispheres of the brain of another rabbit, which had not produced any effect thirty minutes after; the animal was instantly killed by applying three drops of it to the tongue.

A woman applied to the heads of three children, who had the tinea, a liniment prepared of snuff and butter, soon after they experienced vertigo, violent vomiting, and fainting; they had profuse sweats, and during twenty-four hours they walked as if they were drunk.* A person fell into a state of somnolency, and died apoplectic, from having taken by the nose too great a quantity of snuff. $\dagger \mathbf{A}$ decoction of the leaves applied to parts affected with the itch, produced violent vomitings and convulsions. The celebrated Santeuil died in great agony, in consequence of having drauk a glass of wine in which some Spanish sunff had been put. But it would be needless to insist further on the deleterious effects of tobacco, since we believe it is generally admitted to be one of the most active, and certain vegetable poisons with which we are acquainted; $;$ we sliall only mention two cases which came under our own observation.Some young marines, six we believe in all, wishiug to get discharged from the service, betook themselves to chew tobacco, to which they had before been unaccustomed, allowing some of the juice occasionally to pass into the stoniach; the effects were soon visible, though no person suspected the cause; they became pale and emaciated, and had constant nausea; in a few days it was necessary to send them to the hospital, where at length tley disclosed their secret on finding themselves reduced to so dangerous a state. The result was, that one of them died, and the others were with difficulty recovered. Within these few days, the writer of this article liad a full growu viper, which he kept in a jar of water, where for two days it was perfectly lively ; wishing to destroy the reptile, he prepared a tolerably strong infusion of tobacco, on pouring a small quautity of it into the water, the creature made the most violent exertions to escape, but in a short time seemed to lose all its vivacity, reniaining coiled up and motionless, and on the addition of a snaall quantity more of the infusion, it died in less than an hour. We

* Ephemer. des Cur. de la Nature.

+ Ibid.

\$ The oil of tobacco applied to a wound, is said by Redi, to be as fatal as the poison of a viper. See Experiment. Natural. p. 8, 50, 315. 
have invariably found tobacco the most effectual thing for banishing and destroying moths and other insects, and if furniture in which bugs are lodged is sprinkled with snuff, or some of the leaves strewed about, they will soon disappear; indeed, it has always appeared to us, that tobacco is much more fatal to animals than to man, and that it is the latter alone who, by force of habit, can habituate his constitution to use it with impunity.

From his own experiments Orfila draws the following ccnclusions:- Ist. That tobacco, whether whole or reduced to powder, is endued witl energetic poisonous properties; 2nd. That its active part resides in that portion which is soluble in water, and that it is absorbed and carried into the circulation; 3rd. That its deleterious effects appear to depend on an especial action upon the nervous system; and that it produces a general tremor, which is seldom observed when other poisons are taken; $4 \mathrm{th}$. That it is much more active when injected into the anus than when it is applied to the cellular texture, or introduced into the stomach; 5 th. That besides its other phenomena, it is capable of producing an inflammation nore or less violest; 6th. That the empyreumatic oil does not act directly on the brain, or trunks of the nerves, but that it direets its action to the nervous system in a manner not easy to determine.

Mr. Brodie was formerly of opinion that the infusion of tobacco, when injected into the rectum, acterl primarily on the heart, by being carried into the circulation; but after some very satisfactory experiments he relinquished this belief, and agreed with Orfila, that its action on the hear is through the mediun of the nervous system.

To us it las always appeared that tobacco was endued with two distinct principles, an acrid and a narcotic principle, and that it would affect the system in one way or the other, according to the manner of its application; it is likewise worthy of remark, that the use of tobacco in one way will not liabituate the system to the use of it in another; the greatest smoker would not be able to chew tobacco without nausea, vertigo, and otler distressing symptoms being produced; and vice versa, a pinch of snuff will frequently produce giddiness in persons accustomed to smoke all their lives; but liabit can never reconcile the constitution to the reception of tobacco into the stomach.

In case of tobacco being taken into the stomach, the treatment should be the same as in the case of opium or other powerful narcotics; active emetics, friction, $\&$ c. should be speedily resorted to. 
Medical Properties and Uses. From what we have already said, the medical properties of tobacco will be easily understood; the great difficulty is the management of so energetic a remedy. Dr. Fowler, we believe, has used it more extensively than any other physician, and recommends the infusion in cases of dropsy and dysuria, taken in such small doses as to have little effect on the stomach; the following is his method of preparing it ; to one ounce of the dried leaves he adds a pound of boiling water, and macerates for one hour, in a close vessel placed in a sand bath; fourteen ounces of this infusion are pressed out, and wher cool, two ounces of rectified spirits of wine are added, the better to preserve it. From eighty to two hundred drops are given for a dose.

The very energetic action of tobacco on the muscular system has naturally pointed it out as an antispasmodic, and in this way it has been advantageously employed in colic, ileus, strangulaterl hernia, suppression of urine, \&c.; by the injection into the rectum of the smoke, or the infusion, the latter is now more generally employed, but it is right to add, that death has been frequently produced by the use of it, and we should therefore pronounce it a remedy only to be resorted to in extreme cases. Sir A. Cooper recounmends a reduced quantity, half a pint, of the infusion to be first injected, and repeated, if necessary, at intervals. We have once or twice seen good effects produced by an injection of the smoke in obstinate constipation of the bowels, but in more instances we have found it produce the most distressing and alarming symptoms, without any corresponding good result.

Dr. Cullen says, we have employed tobacco in various cases of dropsy, but with very little success; sniall doses having very little effect, and large ones exciting such severe sickness, and even vomiting, as to make it a very inconvenient remedy. Dr. C. employed both the infusion and decoction.

Smoking has been much recommended as a means of guarding against contagion, but many facts are related which prove the inutility of the practice. Dr. Cullen says, we cannot suppose that tobacco contains an antidote against any contagion, or that it has any antiseptic power; but it is very probable that this and other narcotics, by diminishing sensibility, may render men less liable to contagion, and by rendering the mind less active and anxious, it may also render men less liable to fear, which has so often the power of exciting the activity of contagion.

From the effects of tobacco as an antispasmodic, it is probable that it might be advantageously used in cases of tetanus; we are not 
aware that it has been as yet tried in this disease.* Dr. Cullen observes, that in smoking, part of the smoke must necessarily pass into thelungs, and that its narcotic power applied there often relieves spasmodic asthma; by its stimulant power also it sometimes promotes expectoration, and proves useful in catarrhal or pituitous difficulty of breathing. A watery extract of tobacco, in the dose of two or three grains, has also been recommended for clironic catarrh. As an errhine and sternutatory, the effects of tobacco are sufficiently known; snuff, by exciting a considerable discharge of mucous from the nose, has in many instances relieved lead-ache, tooth-ache, and ophthalmia, but very bad effects have frequently resulted from the immoderate use of it. Dr. Cullen says, he has found all the symptoms of dyspepsia produced by it, and particularly pains of the stomach.

The practice of chewing tobacco, produces nearly the same effects as smoking; it also occasions a greater waste of saliva, and the effect of this in weakening digestion, and impairing the tone of the stomach, will sufficiently account for the pale and emaciated appearance which so frequently attends the use of it.

As an external application evell tobacco must be considered not altogether a safe remedy; instances of this we have already recorded.

Off. The Leaves.

Off. Pp. Infusum Tabaci, L.

Vinum Tabaci, E.

* Since the preceding observation was written, our attention has been directed to an interesting communication on the subject to which it relates, by $\mathrm{Dr}$. James O'Beirne, of Dublin, by which we learn that tobacco has already been einployed in the treatment of tetanas, in this country, and with success. It bas also, we are informed, been so . employed in the West Indies. For Dr. O'Beirne's Paper, vide Dublin Hospital Reports, vol, iii, 1822. 


\section{CONVOLVULUS JALAPA.}

\section{Mexican Jalap, or Bindweed.*}

\section{Class Pentandria.-Order Monog Ynia.}

Nat. Ord. Campanacez, Linn. Convolvuli, Juss.

Gen. Char. Corolla bell-shaped, plaited. Stigmas 2. Capsule 2 or 3-celled, each cell containing two seeds.

Spec. Char. Leaves ovate, somewhat cordate, obtuse, obsoletely repand, villous underneath. Peduncles 1-flowered.

TuE plant which furnishes this useful drug belongs to the numerous family of the Convolvuli; this particular species is a native of Mexico and Vera Cruz; it was first discovered by the Spaniards, in the neighbourhood of Xalapa, between Vera Cruz and Mexico, and from hence has derived its specific name, the pronunciation of the Spanish $X$ being nearly similar to our $J$. This plant grows in great abundance on the eastern side of the Cordillera of Anahuac, under the $19^{\circ}$ of northern latitude, and at no great elevation; consequently subject to the powerful heat of that climate. In Europe it has not been found to thrive, unless constantly kept in a stove; it has, however, been for some years cultivated in the botanic garden of Charlestown, in the United States, and in the stoves at Paris; $\uparrow$ a plant may likewise be seen in the botanic garden at Chelsea. $\ddagger$ Dr. Houston appears to have been the first who introduced this plant into Europe, in 1710, and its value as a purgative remedy was soon appreciated. At present, between two and three hundred thousand pounds of the root are exported annually from Vera Cruz.

The root is large, of an irregular oblong form, externally of a whitish brown colour, internally white and lactescent; the stems

* Fig. $a$. the pistillum. $b$. The anthers united to the lower part of the corolla.

$\uparrow$ A root of jalap, which was carried by Michaux, jun. in 1803, from the botanic garden of Charlestown to Paris, and planted in the garden of the Museum of Natural History, where it now grows, weighed forty-seven pounds and three quarters.

Memoires de l'Institut, tom, vi. p. 387.

$\ddagger$ It was first cultivated in England in 1668 . 



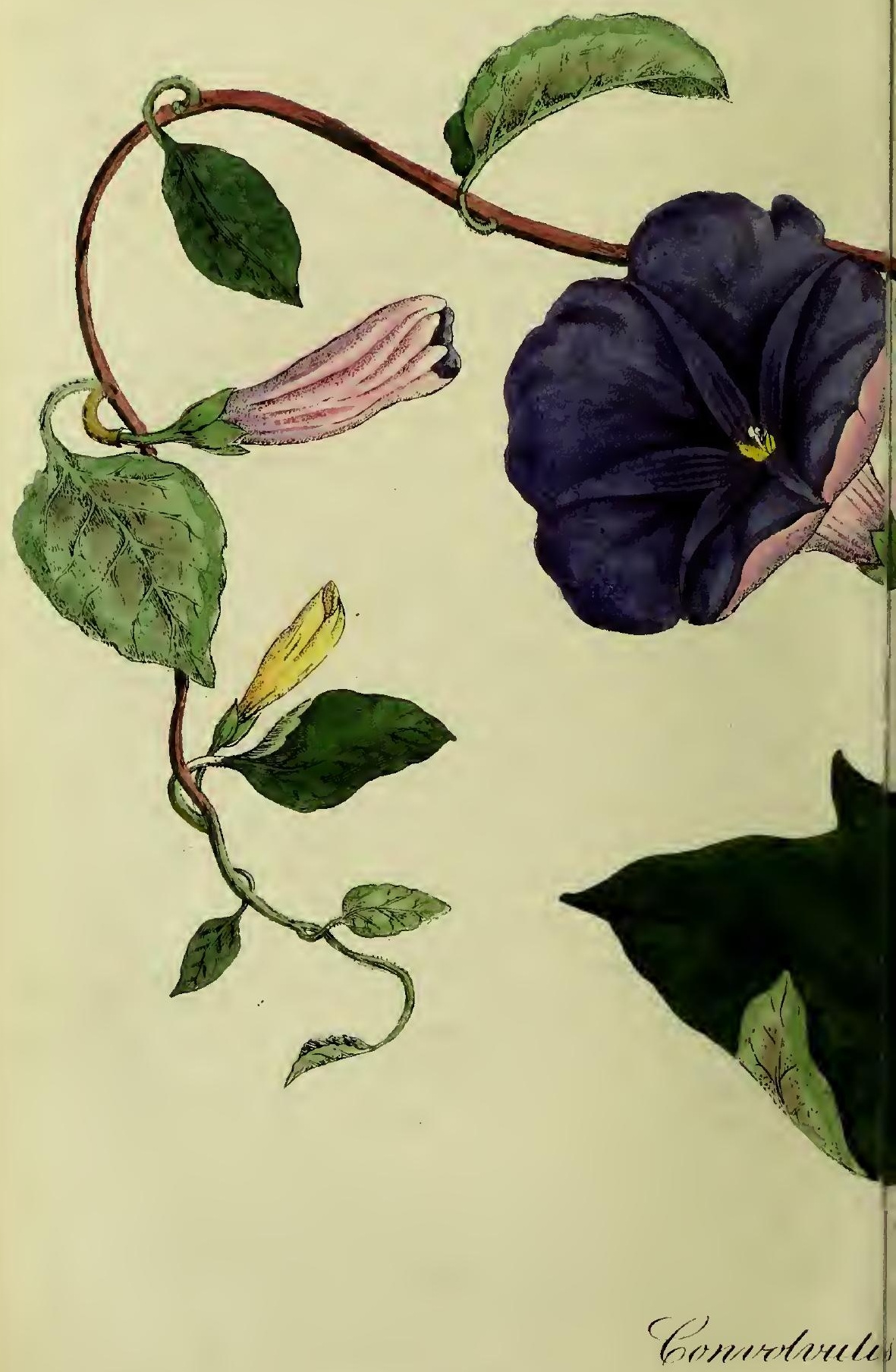

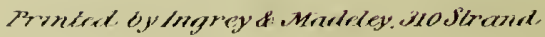

Tub' by Callow का Whas l 


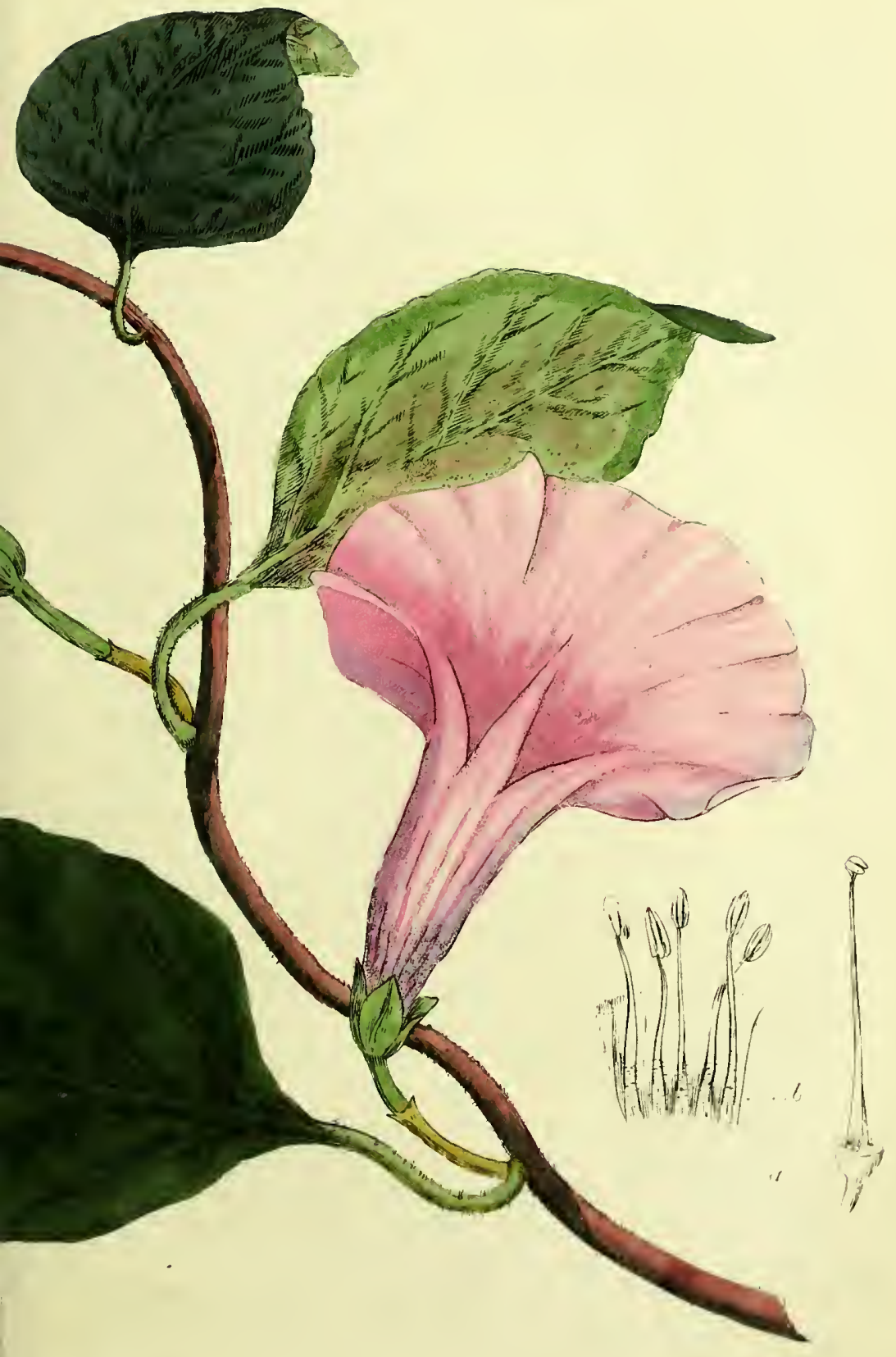

ofalerper:

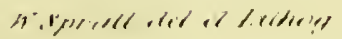

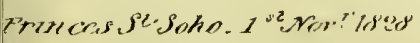



sire numerous, slender, herbaceous, climbing, and twine round other bodies for support, and rise to the height of eight, ten, or more feet; the leaves are petioled, serrated, smooth on the upper surface and hoary underneath, but vary in shape; the lower leaves are generally heart-shaped or lobed; the upper ones oblong and acute; the flowers are large, and stand upon short axillary peduncles, each peduncle bearing one or more flowers; the calyx consists of five oval concave leaves; the corolla is monopetalous, bell-shaped, plaited and entire, of a pink or rose externally, and a deep purple within; the filaments are slender, and vary a little in length, the base of the filaments are covered with short purple hair, and inserted into the corolla; the antliers are large, oblong, tapering, and of a yellow colour; the germen is oval, the style slender, stigma roundish and two-lobed.

Sensible and Chemical Properties. The root of jalap as imported is in the form of transverse slices, or in round lumps, vhich are covered with a wrinkled bark, of a blackish colour; internally they are of a dark grey, marked with darker or blackish stripes. Jalap is heavy, hard, and solid; its smell is somewhat nauseous, and its taste nauseous and acrid; when swallowed it affects the throat with a sense of heat, and occasions a copious discharge of saliva; when powdered it has a yellowish colour. The constituents of jalap are resin, extract, starch, and woody fibre, the proportion of which, vary in different varieties of the root.

Slices of briony root are said to be frequently mixed with those of jalap, but these may be readily distinguished (by the careful examination of each separate piece) by their whiter colour and less compact texture.

Medical Properties and Uses. Jalapine, this is a new vegeto-alkaline principle lately discovered in the root of jalap, by Mr. Hume, jun., of Long Acre. Of its action on man and animals, we are unacquainted, not having learnt that any experiments have been yet instituted to ascertain its effects. Mr. Hume considers that one ounce of jalap will, on careful treatment, afford about five grains of this substance. Mr. Hume's process is as follows; coarsely powdered jalap is macerated for twelve or fourteen days in strong acetic acid; a highly-coloured tincture is thus obtained, which, when filtered, is super-saturated with ammonia, and the mixture violently sliakelı; a sabulous deposit rapidly falls, and a few crystals form on the sides of the vessel. The deposit and crystals are collected and washed with distilled water, again dissolved in a small quantity of concentrated acetic acid, and re-precipitated by 
ammonia, added in excess, which throws down the Jalapine in small, white, acicular crystals.

Chemical Properties of Jalapine. Jalapine is without any perceptible smell or taste, and seems to be heavier than morphina, quinina, or other substances of this class; it is scarcely soluble in cold water, and only to a small extent in hot; ether has no effect upon it; alcohol is its proper solvent. Very little trouble is requisite to purify Jalapine from extractive or colouring matter, for which it appears to have but a slight affinity.

Medical Properties and Uses. Jalap is an active and, in general, a safe and effectual purgative, seldom occasioning nausea or much griping; in doses of about half a drachm, it generally produces copious evacuation. In some constitutions, particularly those of a bilious and hypochondriacal habit, jalap will sometimes produce considerable griping; in these cases it seldom operates with due effect as a cathartic. It is notwithstanding a safe and useful inedicine, and may be commodiously combined with other aperients. Jalap may be prescribed in almost every disorder requiring copious and speedy evacuations, and when given with due caution, we shall seldom be disappointed. The watery extract, nuade according to the Dublin Pharmacopœia, is a very mild, and almost universal aperient, hence well adapted for weak constitutions and children. The alcoholic extract (whicl is almost pure resin) is a very uncertain cathartic, and in general occasions most violent griping, and other distressing symptoms; it is best given in combination, $i . e$. triturated with sugar or oil, so as to form an emulsion, when it operates with more certainty and much less violence. Jalap' also produces very considerable diuretic effects, at the same time it acts upon the bowels; and we are told that the part of the jalap remaining after the separation of the resin, yields to water an extract, which has no effect as a cathartic, but operates powerfully by urine.

$$
\begin{array}{ll}
\text { Off. } & \text { The Root. } \\
\text { Off. Pp. Extractuin Jalapæ, L. E. D. } \\
\text { Pulvis Jalapæ Comp. E. } \\
\text { Tinctura Jalapæ, L. E. D. }
\end{array}
$$




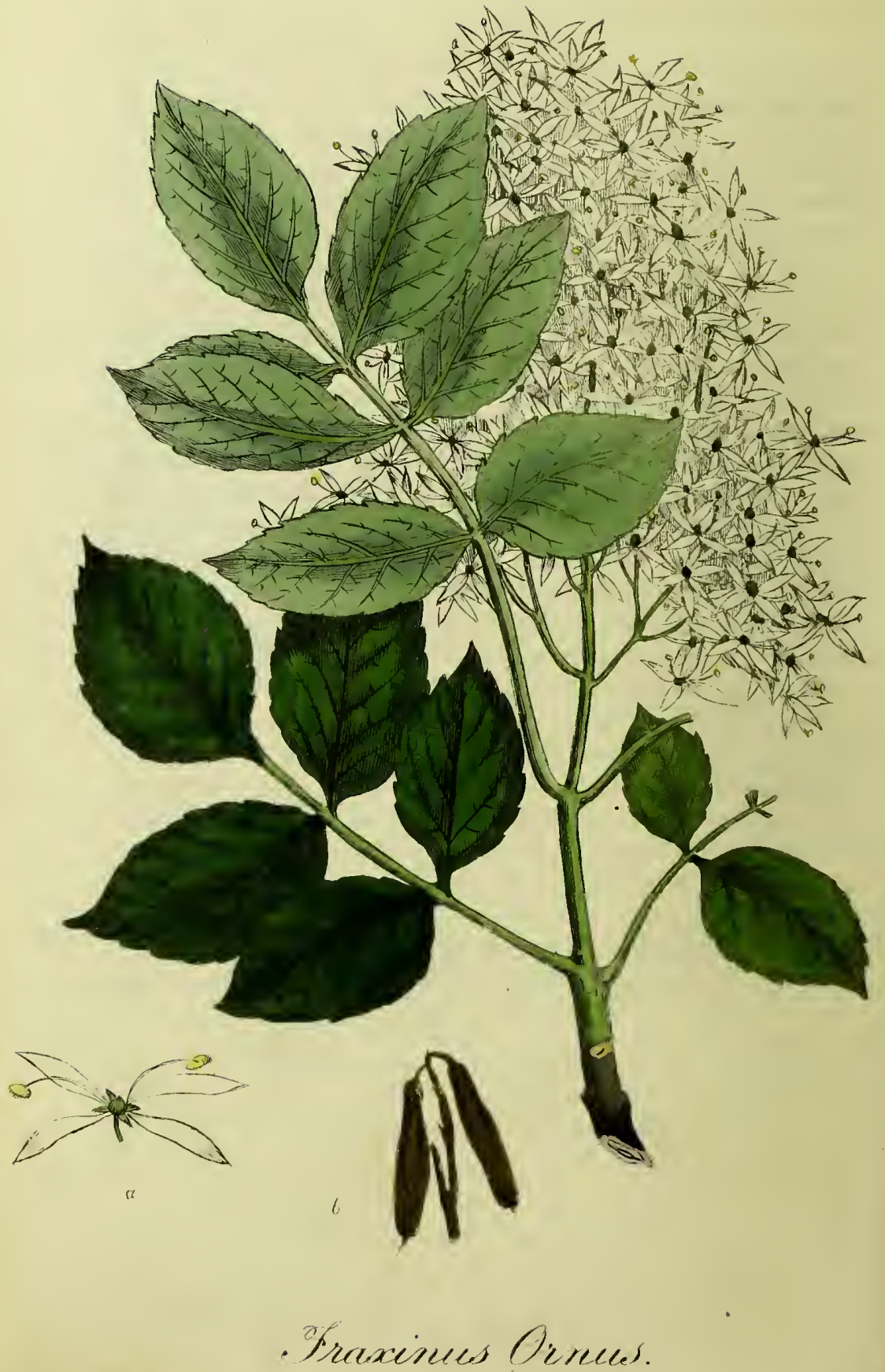

W.Spratl del. et. Wh. 


\section{FRAXINUS ORNUS.}

\section{Manna, or Flowering Ash.*}

\section{Class Polygamia.-Order Digeia.}

Nat. Ord. Seprarie, Linn. Jasminee, Juss.

Gen. Char. Hermaph. Calyx 0, or four-parted. Corolla 0, or four-petaled. Stamens 2. Pistil 1. Capsule 1-seeded, lanceolate.

Female. Pistil 1, lanceolate.

Spec. Char. Leaflets elliptic, oblong, pointed, bluntly serrated. Flowers with a corolla.

The Manna, or flowering ash, was first introduced into England, about the year 1730, + and now adorns many of the gardens of this country; it greatly resembles our common ash, but does not rise so high. This species of ash is a native of the southern parts of Europe, and grows abunclantly in Sicily, Calabria, and Greece; it appears to thrive best in high rocky situations, being found to grow very luxuriantly on the lofty nountains of Garganus, $\uparrow$ and many of the high rocky mountains in Greece.

This tree is very much branched, and covered with a smooth bark of a greyish colour; the leaves (which are produced on the young shoots) are somewhat smaller than those of our connon asli; they stand upon long channelled footstalks, are pinnate, opposite, and consist of several pair of pinnæ, with a terminal one; the pinnæ are placed opposite, of an oval or oblong, pointed at both ends, serrated, veined, and of a bright green colour; the flowers are produced in branched spikes, or panicles, at the extremities of the branches; the calyx is four-parted, the segments of which are ovate; the corolla is of a pale yellowish colour, and consists of four oblong, linear pointed petals; the two filaments are spreading, and support long furrowed

* Fig. $a$. a flower magnified. $b$. The capsules.

+ Hort. Cant.

‡ Vide Phil. Trans. vol, Ix. p. 234.

VOL. I. 
erect anthers; the germen is oval, compressed, and supports a short cylindrical style, crowned with a notched stigma; the capsule is long, flat, and membranous, and contains a single, flat, pointed, dark brown seed. This is not the only species of ash which produces mauna.

Sensible and Chemical Properties. The best Calabrian, or what is called the flake manua of commerce, is in oblong, liglit, friable pieces, of a whitish, or pale yellow colour, and somewhat transparent; its taste is sweet, accompanied with a peculiar nauseous flavour, which it leaves upon the tongue. Manna liquefies in moist air; dissolves perfectly in water, and also in alcohol, when assisted by heat. The alcoholic solution, when slowly evaporated, gradually deposits five-eigliths of the manna, of a tine white colour, somewliat crystalline, light and spongy. The precipitate thus obtained, is probably pure manna; it instantly melts upon the tongue, and has an agreeable sweet taste, without any of the nauseousness of nalına. By further evaporation, one-fourth more is obtained, but less fine than the former, by contiuuing the evaporation, a thick extract is fornied, which can scarcely be reduced to dryness; this extract, which amounts to about one-eighth of the manna operated' upon, consists chiefly of foreign bodies, and to these, or sonie of them, manna owes its nauseous flavour. According to Fourcroy, when a solution of manna is clarified with the whites of eggs, and sufficiently concentrated, crystals of sugar may be obtained from it; but with Dr. Thomson, the experiment did not succeed; its crystals were always acicular, and with more difficulty formed.

According to the experiments of Vauquelin and Fourcroy, the manna of commerce consists of four different ingredients; 1 . pure manna; 2. a small quantity of common sugar; 3 . a yellow matter, with a nauseous odour, (to which probably the unpleasant flavour, and purgative qualities of manua is owing); 4. a little mucilage. The proportion of these several substauces depends, in some measure, on the purity of the manna operated upon. The pure crystalline manna usually constitutes three-fourths of the whole mass.

Manna, when digested in nitric acid, yields both oxalic and saclactic acids, in this it differs from sugar which yields oxalic acid only.

Although the Fraxinus Ornus produces the greatest quantity, and the finest manna, it is by no means to be considered as a substance peculiar to this tree; for not only is it obtained from the Fraxinus Rotundifolia and Excelsior, particularly in Sicily, but many other trees and shrubs of different families are known, in certain seasons and 
situations, to emit a sweet juice, which concretes on exposure to the air, and which may be considered a kind of manna. The principal European trees known to produce this substance, in different climates and seasons, are the larch, the orange, the walnut, the willow and the mulberry.* Near Khounsar in Persia it is obtained from some species of oak; and also from oaks growing between Merdin and Diarbekir. $\uparrow$ The Cistus Landaniferus in some parts of Spain produces manna, which in its recent state has no purgative quality, and is eaten, it is said, by the shepherds. I In Sicily the three species of Fraxinus we have mentioned, are regularly cultivated for the purpose of procuring manna, and for this purpose they are planted on the declivity of a hill with an eastern aspect; after ten years growth, the trees first begin to yield the manna, but they require to be much older before they afford it in any quantity. At Briauçon, in France, manua is said to be collected from all kinds of shrubs, and it is remarked, that those seasons which produce it in the greatest abundance, the trees never thrive, and frequently die the following winter.

A curious and interesting question here arises; is the manna a peculiar secretion belonging to some particular tribes of plants, as the camphor is; or is it an exudation of some part of t!e nutritive juices which belong to plants generally, as part of their vegetative system? It was the opinion of the aucients, that manna was some extraneous substance foreign to the tree; a deposition, and not an exudation, and they considered the best and purest manna to be what was deposited on the leaves. This latter belief it is said still obtains in some parts of Italy, $\S$ and the Sicilian custom of giving to their manila trees an eastern aspect, would seem to be derived from ancient habit, founded on this opinion. We will explain this:-in Spain, Italy, and all the other coasts bordering on the Mediterranean Sea, there is with easterly winds a dense, damp, gummy atmosphere; the effect of this wind upon vegetation is very remarkable; the leaves, and every other part of the trees and plants, acquire a clammy feel, as if they had been washed over with a solution of gum; or saccharine matter; this substance may even be taken off on the

* Haller, Stirp. Helv. N. 1624.

+ Otter, Voyage en Turquie et en Perse, vol. ii. p. 264.

‡ Vide Dillon's Travels through Spain, p. 127.

$\$$ And yet it is diflicult to recoucile such an opinion with the manner of obtaining the manna, which will be hereafter described. 
finger, and when applied to the tongue has a sweetish taste. Whether this may ever be accumulated in sufficient quantities to be collected as manna, we cannot pretend to say; * or whether the exudation of the manna, which is evidently distinct from the deposition we have noticed, is itself a diseased state of the plant, consequent on the easterly wind, and, therefore, concurrent witl the other appearance alluded to, and perhaps for this reason confounded with it, is more than we can determine. If this clammy deposition was confined to vegetation, we might readily conceive that it was, in the first instance, exuded from the plants, and carried up by the heat of the sun in the form of a vapour, to be again deposited after the sun had withdrawn its influence; but wood, cloth, paper, leather, and, in fact, every other substance which is exposed to the action of the atmosphere, presents a similar appearance. The like effects, though in a much less degree, may frequently be seen to attend the east wind in our own climate. On the whole, the production of manna may be consilered a subject worthy of further investigation, as leading to a better knowledge of vegetable physiology, a science which has not hitherto been sufficiently attended to.

Dr. Fothergill supposes the manna spoken of by the ancient Greek writers, to be portions of Olibanum, broken off in the conveyance, and still called manna of frankiucense.

Mauna is a spontaneous exudation, which, when concreted into granules, is known in the market as " manna in the tear." To obtain it more copiously, incisions are made in the bark; the best season for this process is a little before the dog-days commence, when the weather is dry and serene; these incisions are first made in the lower part of the trunk, and extended upwards, at the distance of an incl, until they reach the branches, confining them to one side of the tree, the other side being reserved for the following year, when it undergoes the same treatment; these incisions are about a span in

* The manna of the wilderness, mentioned in the book of Exodus, has been supposed by some authors to bave been a deposition on the leaves of the trees, which fell off spontaneously: other authors consider it to have been the produce of insects.

Major Macdonald Kinneir, in his Geographical Mesnoir of Persia, speaks of a sort of manna, which the Persians call Guz, that is supposed to be prodnced by small red insects, which swarm under the leaves of particular trees. According to Mr. Hnnter, the Guz projects from the abdomen of the animal, in appearance like a tail, or bunch of feathers; these animals are found on certain trees in Persia and Armenia, swarming in millions, and generating this substance until it gets loug, and drops on the leaves, caking ou them, and resembling beautiful hees wax. 
length, and two inches wide. The juice, which is thick and white, immediately begins to flow, and gradually hardens on the bark; in eight days it acquires the consistence and appearance with which it is seen here, when it is collected and packed for sale. Sometimes it flows in such abundance from these incisions as to run on the ground, by which it becomes mixed with various impurities. Manna is distinguished into different kinds; viz. manna in the tear, canulated and flaky manna, and common brown manid; these varieties seem rather to depend upon the relative purity of the substance, than from any essential difference in it. When the juice transudes very slowly the manna is always drier, more transparent and pure, and consequently of more value; but when it flows very copiously, it concretes into a coarse, brown unctuous mass. Houel, who tasted the manna when flowing from the tree, found it mucl more bitter than in its concrete siate.

Medical Properties and Uses. It is supposed that the Arabian physicians were the first who used manua medicinally, and that by them it was introduced into the other eastern countries. It is a mild aperient, and was formerly much used, but it is now seldom administered, except in combination with senua, salts, or other purgatives, more to cover their taste than to aid their operation; it is a mild and innocent laxative for young children, though it sometimes produces griping, and in this respect, its effects are analogous to honey; from $3 \mathrm{i}$ to $\zeta$ ss may be given dissolved in water, or what is better, gruel or decoction of pearl barley; for an adult, from one to two ounces will be required, and this alone will sufficiently account for its being discarded as a purgative remedy.

Off. The Concrcte Juice, called Manna. 


\section{VALERIANA OFFICINALIS.}

\section{Great Wild Valerian.*}

\section{Class Triandria.-Order Monogynia. \\ Nat. Ord. Aggregatæ, Linn. Dipsacee, Juss.}

Gen. Char. Corolla monopetalous 5-cleft, gibbous at the base. Seed 1, crowned with a feathery radiating pappus.

Spec. Char. Stamens three. Leaves all pinnate. Leaflets lanceolate, serrate, nearly equal.

Valerian is supposed to be the $\Phi_{8}$ of Dioscorides and Galen, and the species under consideration, the Officinalis of Linnzus, is the $\mathrm{Va}$ leriana Sylvestris Major Montana of Bauhin. The great wild valerian is a perennial native plant, very common in the southern parts of Britain, flowering from June to August. It is found in various situations, on dry heaths, and high mountainous pastures, on the banks of rivers, ditches, and other wet and marshy situations; and the appearance of the plant (and also its sensible qualities) vary, according to the situation in which it is produced. $\dagger$

The root of this plant consists of a great number of long, slender, dusky brown fibres, which unite at their origin and form one head; the stem rises erect to the height of from two to four feet, hollow, smooth, channelled and branched; the leaves vary on different parts of the plant, those on the stem are placed in pairs upon short broad sheaths, they are composed of from five to ten pair of elliptical, serrated pinnæ, termiuated by an odd leaflet, which is the largest; the radical leaves are the largest, and stand upon long footstalks; the floral leaves, or bracteas, are lanceolate and pointed; the flowers white, or of a purplish colour, and terminate the stem and branches in large bunches, or corymbs; the calyx is ouly a narrow rim, which

* Fig. b. a flower magnified. c. An anther. d. The pistillum. e. A seed,

+ In the northern parts of the kingdom it is found on more elevated situations and drier ground, where it becomes, in every respect, smaller and more hairy.

Curtis, Flora Londinensis. 


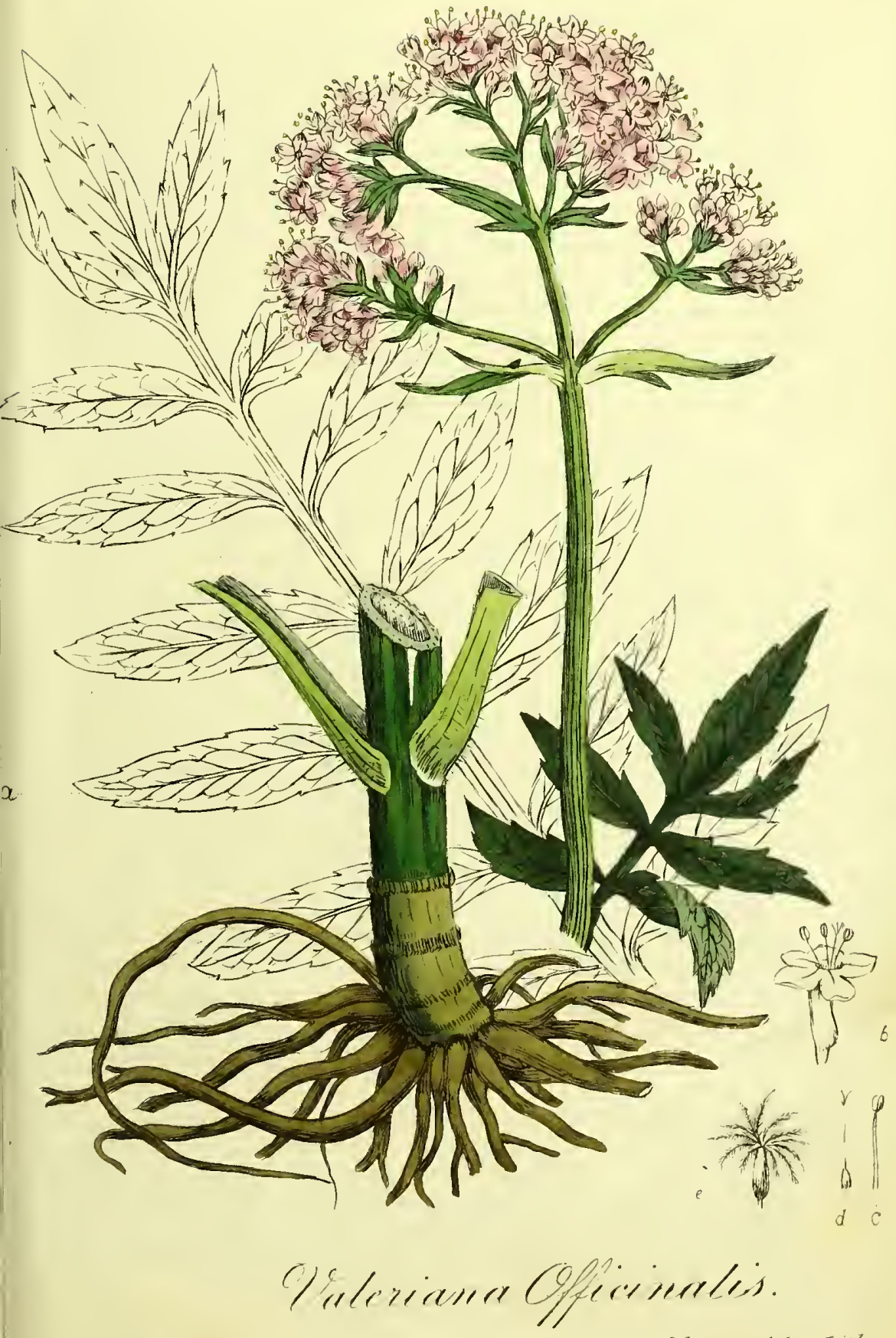

Th. Sorerte del et Lith 

expands as the seed matures; the corolla is tubular, swelling towards the base, and divided at the limb into five obtuse segments; the stamens are three; the filaments tapering, longer than the corolla, and support oblong yellow anthers; the germen is inferior, and supports a slender style, shorter than the filaments; stigma trifid and bearded; the capsule is crowned with a fcathery pappus of tcn rays, and contains one seed.

It is doubted by some botanists if the Valeriana of Dioscorides and Galen, is the same plant as our indigenous species. Dr Sibthorp, in his tour through Greece, ascertained the plant of the ancients to be a distinct species; this plant has been figured and described by him, in his Flora Græca, under the name of Valeriana Dioscoridis; * but we think it probable that the varieties and species of this plant may be so far changed by climate and soil, as to lose their specific characters, lience arises the difficulty in ascertaining the particular species so much celebrated by the Greek writers.

The roots of the wild plant, which grow upon a calcareous soil, are said to be preferable to those of the cultivated; they should be dug up for use in the antumn, when the leaves are decaying, or in the spring before the leaves expand, and carefully dried and preserved in a dry place.

Sensible and Chemical Properties. The leaves of valerian have scarcely any smell, but a somewliat saltish taste; the roots have a bitter and acrid taste, and a strong penetrating odour. $\dagger$ The watery infusion is of a deep red, and turns black with a sulphate of iron. By distillation with water, a small quantity of volatile oil comes over, of greenish-white colour, very light and liquid, having the smell and taste of camphor; by exposure to light it becomes yellow; a small portion of nitric acid converts it into resin, and a larger proportion into oxalic acid. The expressed juice of the root contains starch, extractive and gum; the root when deprived of the juice, consists chiefly of woody fibre, combined with a portion of black coloured resin. $\neq$ Valerian root gives out its qualities both to alcohol and boiling water, and also to solution of pure alkalies.

* Sibthorp, Flora Græca, p. 24-33.

† The smell of Valerian is said to be very delightful to cats; rats also are equally fond of it, and rat-catchers employ it to allure them.

¥ Thomson's Chemistry, 5th edit. vol. iv. p. 225. Annales de Clim. vol, Ixx. p. 95 . 
Medical Properties and Uses. Valerian has been long esteemed as a medicine of considerable efficacy; by Dioscorides and Galen it is mentioned as an aromatic and diuretic. 'It has, however, been chiefly valued for its good effects in nervous diseases, particularly in epilepsy. Its powers as an antispasmodic was first discovered by Fabricius Columna, who cured himself of epilepsy by the roots of this plant; and its efficacy in this and other spasmodic diseases, is supported by the testimony of Haller, Sylvius, Marchant, Sauvages, and others. Dr. Cullen says, its power as an antispasmodic, is very well established; it has likewise been given with advantage in hysteria, hemi-crania, \&c., and also in intermittents, combined with cinchona; and we are told by Dr. A. T. Thomson, that he found it exceedingly serviceable in hypochondriasis.

In nervous disorders, proceeding from debility, and in hysterical complaints, it is particularly useful; it is sometimes given to procure sleep in fevers, when opium fails. As the virtues of valerian depend entirely on the volatile oil it contains, it never should be exhibited either in the form of extract or decoction. The root when carefully dried and powdered, is the most efficacious preparation, and may be administered in doses of from one scruple to one draclim, to which may be added a few grains of mace, ${ }^{*}$ two or three. times, or oftener in twenty-four hours. The dose of the spirituous and ammoniated tinctures is from $3 i$ to $3 \mathrm{ij}$

Off. The Root.

Off. Pp. Extractum Valerianæ, D.

Infusum Valerianæ, D.

Tinctura Valerianæ, L. D.

- Valerianæ Ammoniata, L. E.D.

* Mace is generally considered the best corrector of the unpleasant flavour of valerian. 


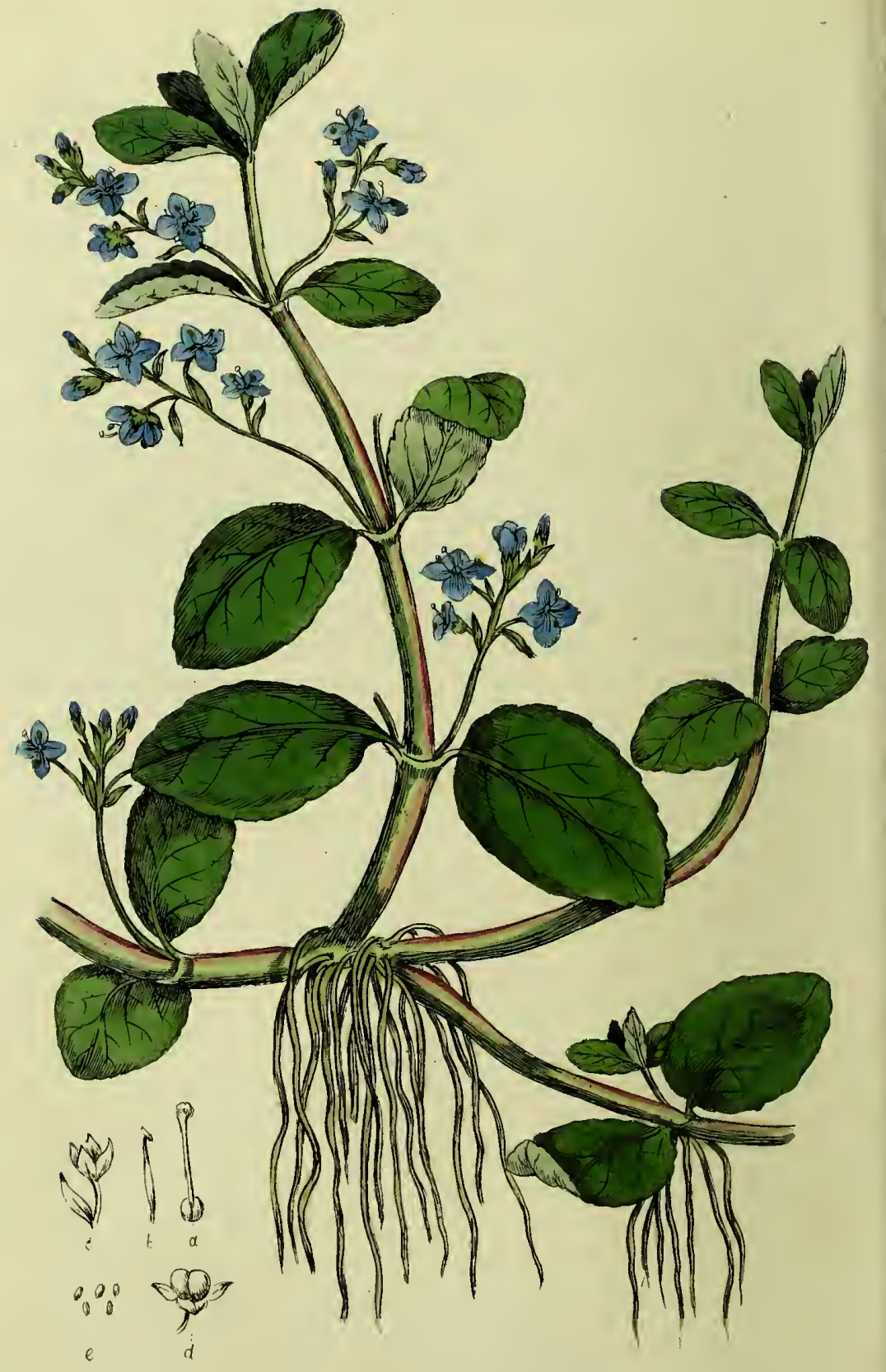

Deronica. OBnccalunga. 


\title{
VERONICA BECCABUNGA.
}

\section{Broad-leaved Brook-lime.*}

\section{Class Diandria. Order Monogynia.}

Nat. Ord. Personate, Linn. Pedicularis, Juss.

Gen. Char. Corolla border four-cleft, with the lowest segment narrower. Capsule two-celled, with corymbose racemes.

\author{
Spec. Char. Racemes lateral. Leaves ovate, flat. Stem \\ creeping.
}

THIS species of Veronica, $\uparrow$ has probably derived its specific name from the Flemish beck-pungen, (mouth smart) and its English name, from its being constantly found growing in brooks and muddy waters. Brook-lime is an indigenous perennial plant, flowering in June and July. It is common in most parts of Britain: in the north of England and in Scotland, (where it is often eaten like watercresses) it is known by the name of water purple.

The roots issue from the joints of the stems, and consist of numerous, long, simple fibres; the stens are succulent, of a reddish colour, round, thick, smooth, shining, brancled, and leafy; the leaves are opposite, ovate, obtuse, serrated, somewhat fleshy, punctured, of a pale green colour, and stand upon short petioles; the flowers grow in opposite clusters from the axilla of the leaves, and supported on delicate peduncles; the calyx is a periantheum, divided into four acute segments, slorter than the corolla ; the corolla is monopetalous, somewhat wheel-shaped, the brim of which is of a beautiful sky blue colour, striped at the bottom witl veins of a deeper hue, and divided into four obtuse segments, the lowermost of which is narrower than the others; the tube is white; the filaments are somewhat longer than the style, and support blueish coloured anthers, the pollen of which is white; the germen is roundish, double; the seed

* Eig. $a$. the pistillum. b. An anther. c. The calyx. d. The capsule e. Seeds. t The Genus Veronica comprise numerous species, sixty-eight are enamerated in the Hortus Cantabrigensis.

VOL.I. 
vessel is a fiattened cloven capsule, of two cavities and four valves, containing several oval brown seeds; the style is thickest at the top, and crowned with a stignia, forming a little head.

Sensible Properties. Brook-lime is without smell, its taste is herbaceous, and when chewed, slightly bitter and astringent; the leaves contain a volatile acrid principle, vegetable albumen, and sulphate of lime; the expressed juice reddens the infusion of turnsol and other vegetable blues in a slight degree.

Medical Properties and Uses. The virtues of brook-lime are very inconsiderable, formerly it was in great repute as an antiscorbutic, and with the uninformed it is still held in much estimation; in moderu practice. however, as a remedial agent, it is almost totally. disregarded : it is justly observed by a writer in the Materia Medica,* that to produce any good effects it must be eatell as food; and we presume it may be taken ad libilum. Although it continues green throughout the year, it is supposed to be most active in the spring.

Off. The Herb.

\section{MELALEUCA CAJUPUTI. \\ Lesser Cajeput Tree.†}

\section{Class Polyadelphia.-Order Icosandria.}

Nat. Ord. Hesperide e, Linn. MYRTr, Juss.

Gen. Char. Calyx 5-parted, semi-superior. Corolla 5 petaled. Stamens (about 45 ) very long conjoined in five bodies. Style single. Capsule 3-celled. Seeds numerous.

Spec. Char. Branchlets pendulous. Leaves alternate, short petioled, narrow-lanceolate, three and five-ribbed. Spikes terminal and axillary, comose, villous. Bracteas lanceolate, three-flowered.

* Lewis.

+ We have (by permission) copied our drawing from the one published by the Medico Botanical Society of London, the only one we believe in print. The Editors of the Flora Medica take this opportunity of returning their thanks to the Directors and Secretary of the Botanical Society for their liberal assistance in supplying them with the means of making drawings from rare and beautiful specimens of exotic plants.

Fig. a. a flower magnified. b. and c. Capsule and seed. $d$. The pistillum. 


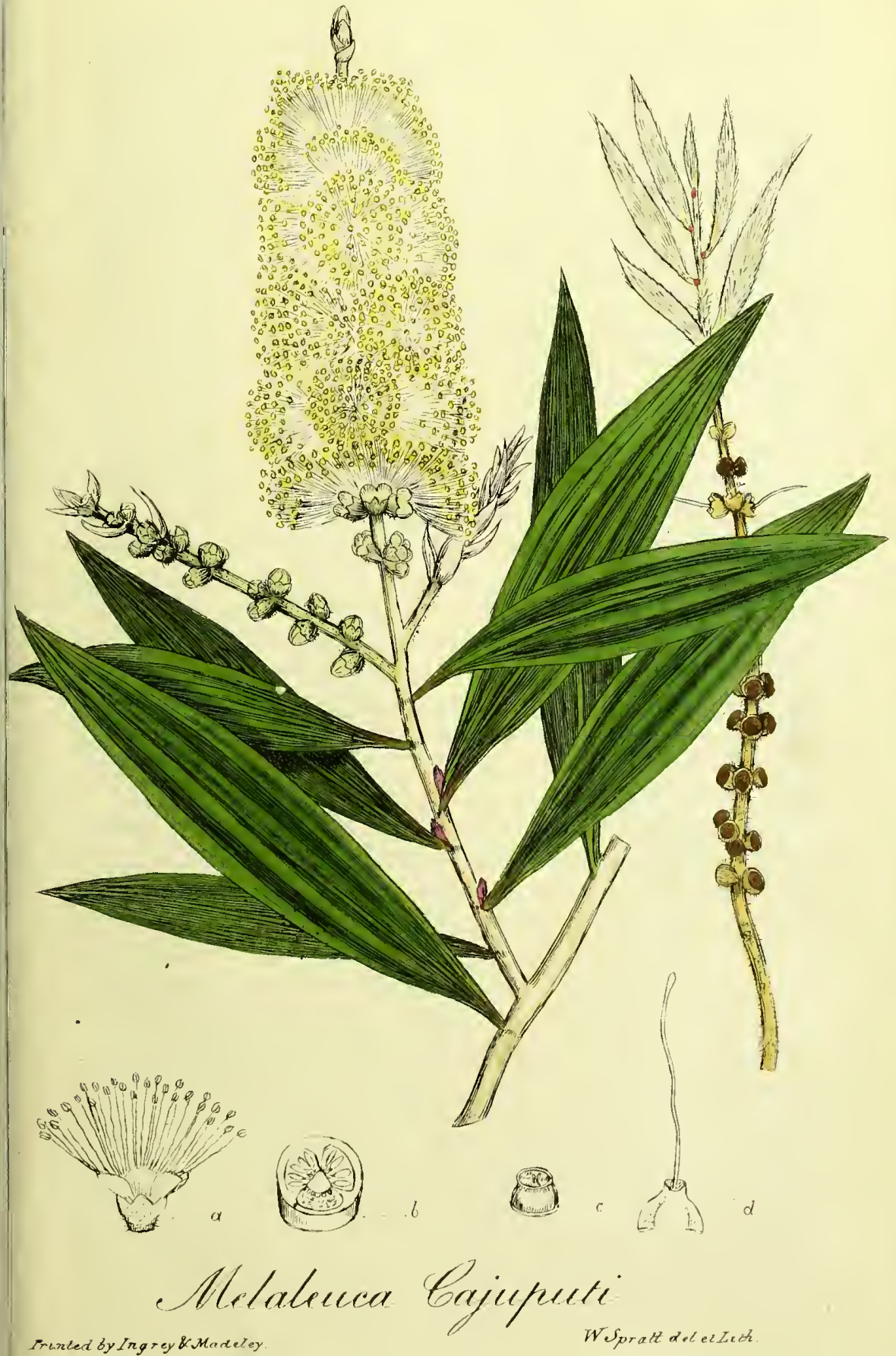

Pub by Callow \& Wilson, Prences St Soho Wov" 1 st 1828 

This elegant, useful, and small tree is a native of the Molucea Islands, and it is from its leaves that the valuable medicine called Cajuputi Oil is obtained.

The following account we transcribe from the Transactions of the Medico-Botanical Society of London, from the description furnished to the Society by Thomas Henry Colebrooke, Esq., F.R.S. froin the MS. of Dr. Roxburgh :- " During my absence at the Cape of Good Hope, on account of bad health, in 1798, Dr. John Fleming had charge of the Botanic Garden; at the same time, Mr. Smith, the nurseryman, was employed on the Molucca Islands, collecting plants for the garden, consequently an excellent time for obtaining growing plants of the trees; Dr. Fleming, therefore, gave Mr. Smith strict orders to be very careful to get the proper sort, (two or three being mentioned by Rumphius) from which the best oil was obtained. This commission, Mr. S. executed to our satisfaction; many thriving plants having been sent to the garden by the close of the year, where they grow freely; and in six or seven years they began to blossom at various times of the year, which they have hitherto continued to do, and to ripen their seeds perfectly. From them numerous plants have been reared, and not only distributed over many parts of the continent of India, but sent to varions other quarters of the world. It is from the original young trees, now (1811) thirteen years old, that the following description and accompanying figur are taken."

The trunk is tolerably erect, but crooked, and slender for the age of the trees; the bark is of a very light or whitish ash colour, soft, thick, and spongy, pretty smooth on the surface, and the exterior lamina peels off from time to time in thin flakes, like the birch tree; and the interior bark may be separated into numerous lamina, like the leaves of a book; branches scattered, with slender twigs, often drooping as completely as in the weeping willow; they are round and smooth; young shoots sericeous; height of the young tree when thirteen years old, about twenty feet, and the thickest part of the trunk not nore than a man's leg, including the bark, which is three quarters of an inch thick; the leaves are alternate, and project in every direction, short petioled, narrow, lanceolate ; while young sericeous; when full grown, smooth, deep green, three and five uerved, sometimes slightly falcate; entire length, from three to five inches, and from half to three quarters of an inch broad; on being bruised they smell strong of the substance they yield, yet the cells which contain this aromatic fluid are scarce visible in the fresh leaves; the spikes are terminal, and from the extreme axils, downy; 
while in young flowers, there is only a scaly cone at the apex, which soon advances into a leafy branchlet; bracteas solitary, lanceolate, sericeous, three-flowered, caducoul; flowers tern, sessile, small, white, inodorous; calyx urceolate, semi-superior, sericeous, margin of five semi-lunar deciduous segments; petals five, orbicular, short-clawed, white, greatly longer than the segments of the calyx; filaments from thirty to forty, united into five portions at the base, three or four times longer than the petals, and with them inserted into the large villous, five-lobed rim of the calyx, alternate, with its segments; anthers ovate-cordate, with a yellow gland on the apex; germen ovate, united to the calyx, three-celled; with numerous ovula in each, attached to an elevated receptacle in the inner and lower angle of each cell; style rather longer than the stamina; stigma obscurely three-lobed; capsule completely enveloped in the thick fleshy gibbous permanent tube of the permanent calyx, three-lobed, three-celled, three-valved; valves thin, hard, and elastic, opening from the apex; partitions contrary; receptacles triangular, thin, flat, lodged in the inner and lower angle of the cell; seeds numerous, regularly wedge-shaped.

This species of Melaleuca may be cultivated either by seed or root, when by the latter, slender pieces of the root are cut into small bits, and laid horizontally in the earth, (this is done in the rainy season) when they readily produce plants.

The beautiful green essential oil of commerce, known by the name of cajuput oil, was supposed to be the produce of the Melaleuca Leucadendron; but it appears from the specimens of the tree yielding the true Cajuputi, sent home by Mr. Christopher Smith, that the species is different, and referable to Table 17th of Rumphius's Herbarium Amboinense, (vol. ii.) and not to that author's Arbor $A l b a, 16$. After a careful examination of specimens in Sir Joseph Bankes's, and other collections, by Dr. Maton, and in those of the Linnæan Herbarium, by Dr. Smith, we are authorized to consider the tree which yields the above oil as a new species, and from the name of its medicinal product, those gentlenıen have agreed to give it the appellation of Melaleuca Cajuputi.*

- This species of Melaleuca appears to have got its specific name from its colour, Cajuputi, or Kayu-puti, in the Malay language, signifying white wood, and hence its appellation, as given to it by Rumphins, Arbor Alba; it is also known in the Malay countries under the names of Galant, Daun, Kitsjil, \&co.

Ainslie, Materia Indica, vol. i. p. 261. 
Qualities. The oil of cajuputi, as it is brouglit to us, has a very powerful odour, resembling a mixture of camphor and oil of turpentine, but gradually becomes more fragrant; the taste is pungent, like that of camphor. It is transparent, and of a beautiful bluish green colour; when dropped on the surface of water, it diffuses itself over it, and very rapidly and completely evaporates: this is said to be a test of its purity ; when ignited, it burns rapidly without leaving any residue. When pure, it is entirely soluble in alcohol, and partly so in water. Its green colour is said by some to be derived from the copper flasks in which it is imported, but by others this is denied.*

The oil is obtained by distillation from the dried leaves. In the Island of Banda large quantities are thus prepared, and sent to Holland in copper flasks, from whence it is imported into this country.

Medical Properties and Uses. Cajuputi oil, like other aromatic oils, is highly stimulating. In doses of a few drops it produces copious perspiration, hence it is efficaciously given in chronic rheumatism. In hysteria, flatulent colic, palsy, epilepsy, and other nervous and spasmodic diseases, it has been given with good effect. As a topical remedly, when diluted with olive or almond oil, it is employed for restoring vigour after luxations and spasms, and for easing violent pain in gouty and rheumatic cases; when put into carious teeth it lulls the pain. Dr. A. T. Thomson says, "We have seen much benefit derived from rubbing it on the temples; in defective vision from a weakened state of the eyes." When given internally, the dose is from one to three or four drops on a lump of sugar.

Off. The Essential Oil.

* We are told by Mr. Brande, that none of the samples which he examined contained copper. 


\section{ARUM MACULATUM, Common Arum, or Cuckow-pint.*}

\section{Class Mongcia.-O Order Polyandria.}

Nat. Ord. Piperite, Linn. Aroidee, Juss.

Gen. Char. Spathe 1-leaved, cowled. Corolla 0. Spadix naked above. Stamens in the middle. Germens below.

Spec. Char. Stem" none. Leaves radical, hastate, entire. Spadix club-shaped.

Thrs species of Arum is the Apov $\mu \dot{\varepsilon} \gamma \varkappa$ of Hippocrates; it is a perennial indigenous plant, and, as Mr. Curtis very justly remarks. in his Flora Londinensis, " Botanists who have noticed the history of this plant wẹll know that it appears under two very different: forms in the spring and autumn; but the generality of people are not aware, that the naked cluster of scarlet berries, so conspicuous in the hedges at the close of summer, is the produce of what are. usually, called loxds and ladies, which attract the notice of children in the spring, and which are observable under most shady hedges."

The rooț is tuberous, sending forth on every side numerous fibres, about the size of a large nutmeg, externally of a brownish colour, internally white and fleshy; the leaves are. radical, and stand upon long grooved petioles, in number seldom more than three or four from each root: they are arrow-shaped, four or five inches long, and two or more broad, of a deep shining green, often spotted with brown or black; the flower stem is a simple erect scape, from eight to ten inches high, olscurely channelled, and terminated by the spathe, which is erect, bellied, pointed above, of a pale green colour, frequently spotted, covering the fruit till it is nearly ripe, when it withers; the spadix is club-shaped, obtuse, of a deep purple or whitish green colour: on the lower part are situated

* Plate 1. Fig. a. represents the leaves as they appear in the spring. b. The root.

Plate 2. Fig. a. The spathe. $b$. The spadix. 1 and 2 , represent the nectaries. 3. The anthers. 4. The germens. c. The fruit. 


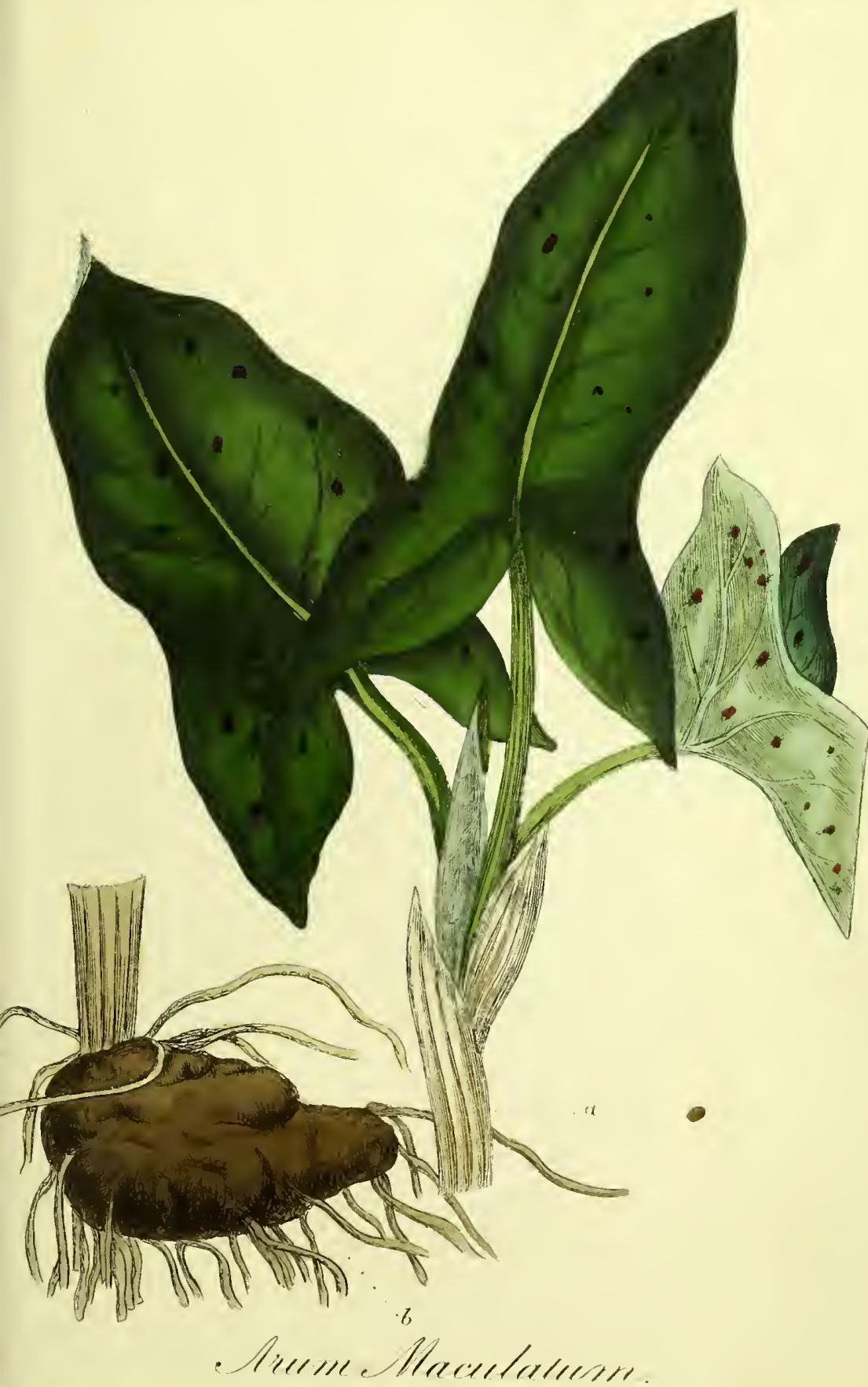

Wiprost del ae Lick 

Plate 2.

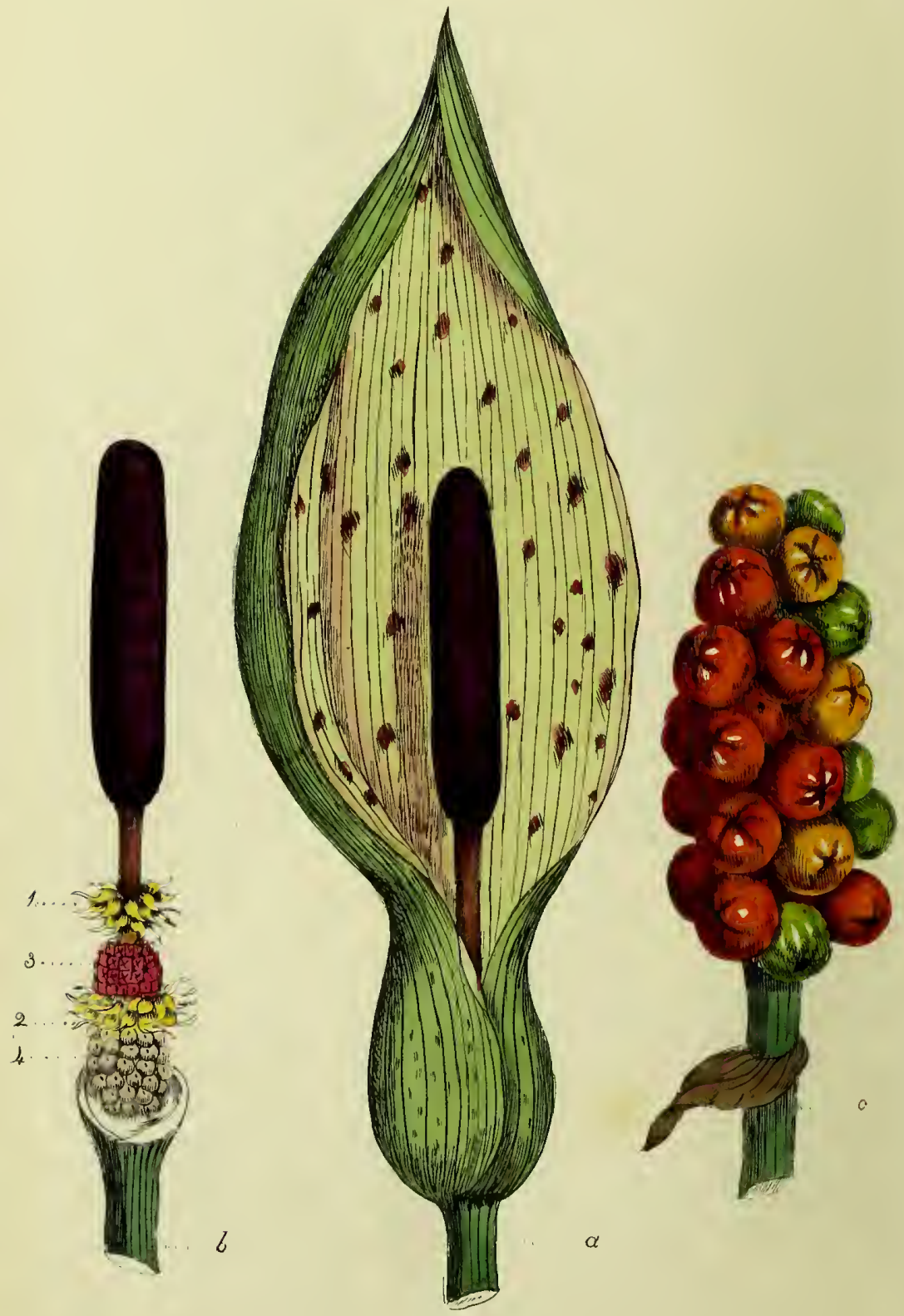

- Auern. Macudatienn.

Tr. Snt azz dez ezLith 
numerous roundish germens, above these are placed many nectaries, which are divided into two circles, between which are placed numerous sessile anthers, (vide plate 2 , fig. $b$.) ; the berries are succulent, of a bright scarlet colour when ripc, and correspond in uumber to the germens : cach berry contains two or more hard seeds.

The root of the Arum Maculatum, in its recent state, is allowed by most authors to be extremely acrimonious, but this quality is totally dissipated by drying, when it becomes edible, and affords nourishment sonewhat similar to sago or salop.* The roots of Arum, when collected for medicinal purposes,' should be dug up in autumn, when the leaves are withered : this season is recommended by Lewis, Bergius, and other writers on the Materia Medica. When so collected and carefully packed in sand, they will keep fresh, and retain their virtues for twelve months.

Qualities. The fresh root is inodorous; when cliewed, it excites a burning, pricking sellsation in the moutl and tongue, which continues for many hours, accompanicd with great thirst; these effects are removed by oily fluids, and milk. The root, sliced and rubbed on the skin, excoriates or raises blisters. The acrimonious quality of the roots is entirely dissipated by drying, or by bruising and washing them in water. The recent expressed juice reddens vegetable blues, and by analysis has been found to contain malate of lime.†

Poisonous Effects of Arum Maculatum. The following is related by Bulliard - "The three children of a woodman ate of the leaves of this plant: they were seized with horrible convulsions. Assistance was procured for them too late; it was impossible to make the two youngest swallow any thing; they were bled without success; clysters were given them, which produced no effect ; they died, one at the expiration of twelve days, another at the cnd of sixteen. The other child was able to swallow, although with considerable pain ; the tongue was so swelled that it filled the whole cavity of the mouth, but deglutition became free after being bled. The clild was made to drink milk, warm water, and an abundance of olive oil. A diarrhœa

- Many of the Arum genus have mild roots, viz. the Aram Esculentum, Arum Colcasia, and Arum Sayittifolium, \&c. These are eaten by the iuhabitants in the hot countries where they grow naturally, and some of them are cultivated, and the leaves boiled and eaten as greens. We are told by Mr. Loudon, in his Encyclopedia of Gardeving, tha in the Isle of Portlaud, the roots of the spotted Arum are collected and sent to Loudon, where they are sold as Portland Sago, $-E d$.

+ Aun, de Chimie, xxxv. 153. 
came on, which appeared to save the child; it was pretty well restored in a short space of time, but always preserved a very great degree of leanness." *

Medical Properties and Uses. Arum root in its recent state is a very powerful stimulant, and when taken internally it is expectorant, diaphoretic, and/cathartic. By Bergius it is extolled as a never failing remedy for cephalæa sympathica. It has been recommended in intermittents, which are said to have yielded to its use ; and also in rheumatic cases, chlorotic and cachetic disorders; but the active property of Arum being of a very perishable quality, it is difficult to procure it in a state to be depended upon, from which cause it is now seldom employed.

The dose of the recent root is from ten to twenty grains, given three or four times a day; to sheath its acrimony it should be combined with milk or sone mucilaginous drink, as linseed tea, barley water, or mucilage of gum acacia.

Off. The recent Root.

\section{ANCHUSA TINCTORIA.}

\section{Dyer's Burgloss, or Alkanet. $\uparrow$}

\section{Class Pentandria. - Order Monogynia.}

Nat. Ord. Asperifolie, Linn. Boraginez, Juss.

Gen. Char. Corolla funnel-shaped, the throat closed with. arches. Seed engraved at the base.

Spec. Crar. Stem and Leaves hairy. Leaves lance-shaped, obtuse. Stamens shorter than the corolla.

THE ancients believed that this tribe of plants had the power of choking and destroying serpents, from whence originated the Greek

* Histoire des Plantes Vénéneuses de la France, p. 84.

+ Fig. a. the calyx. b. Represents the corolla, cut open to shew the situation of the stamina. c. The pistillum. 


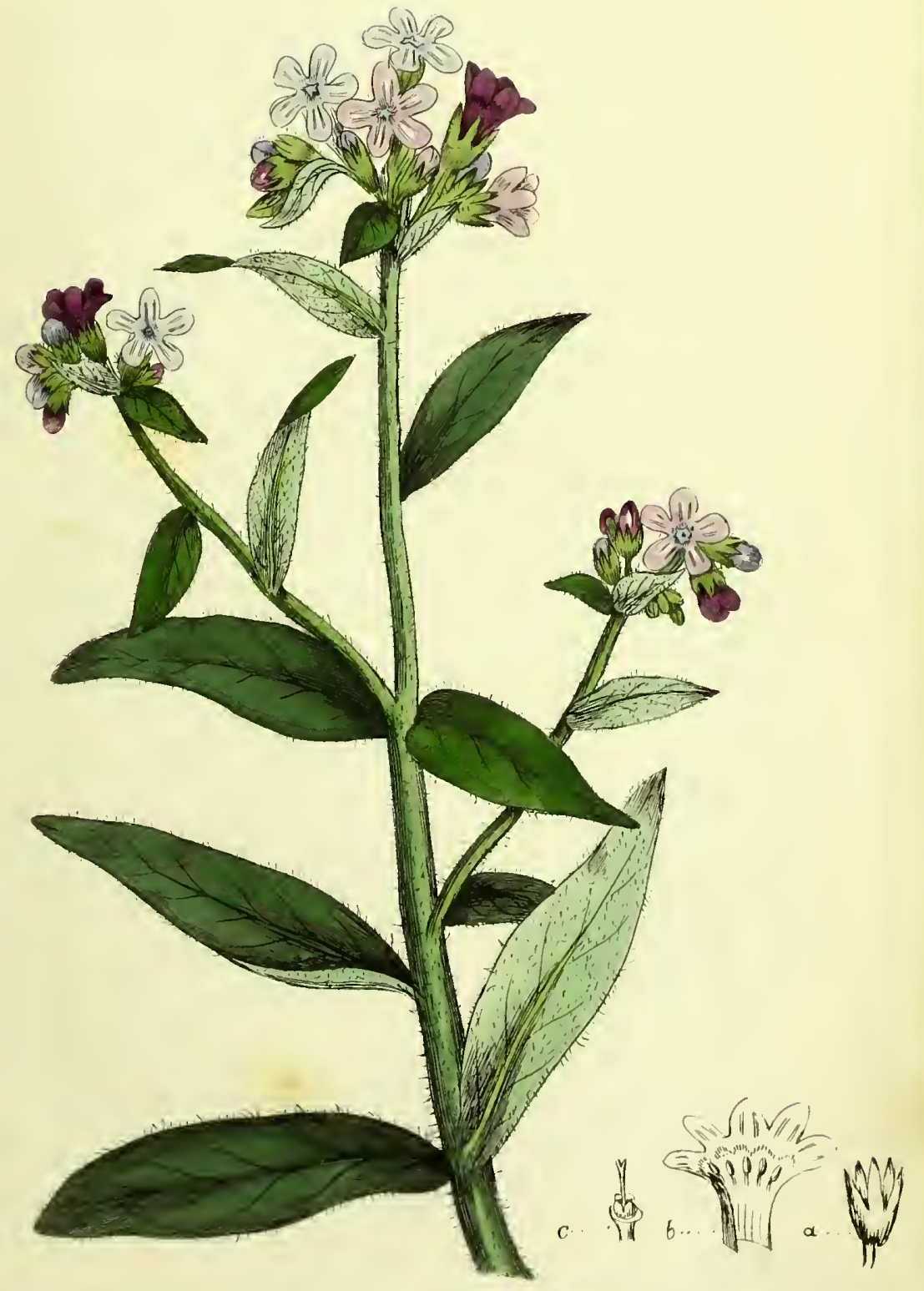

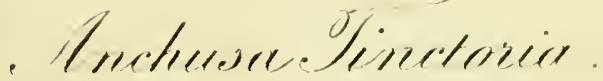





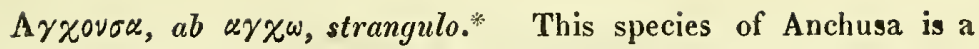
native of Montpellier, where it is cultivated in great abundance. It was introduced into Britain about the year 1596, $\uparrow$ and cultivated by Mr. J. Sutherland in the year $1683 ; \ddagger$ it now forms an ornament in many of our gardens, but in this country the roots do not acquire the beautiful red colour of the foreign plants, on which their chief value depends.

The root is perennial, long, round, fibrous, internally whitish, and covered externally witl a dark purplish red coloured bark; the stem rises from eighteen to twenty-four inches in lieight, is round, rough, hairy, and branched; the leaves grow alternate, are long, lanceolate, obtuse, hairy, and stand sessile on the stens; the flowers vary in colour from a purplish to a red, and terminate the branches in close clusters; the calyx is persistent, and divided into five oblong, erect segments; the corolla is monopetalous, funnelshaped, consisting of a cylindrical tube, (equal in length to the calyx); the limb is divided into five blunt segments, and closed at the centre by five small scaly leaflets; the filaments are shorter than the tube of the corolla, and furnished with simple anthers; the germens are four; the style is filiform, about the length of the filaments, and supports an obtuse notched stigma; the seeds are four, of an irregular form, and lodged within the calyx. This species of alkanet flowers from June until October.

Qualities, \&c. The fresh root lias a faint odour, which it loses entirely by drying; its taste is somewhat astringent and bitter when fresh, but the dried root is insipid. To water, (either hot or cold) this root gives only a brownish hue; to alcohol, ether, spirit of turpentine, oils and fat, it imparts a fine deep red colour; the watery infusion turns black by the addition of sulphate of iron, and a copious dark coloured precipitate is thrown down from the infusion by the sulphate of zinc.

Medical Properties and Uses. Formerly the alkanet root was recomnended as an useful astringent in many diseases, but it is now totally disregarded, and the chief use to which it is applied is for colouring oils and ungueuts; it is also used by cabinet makers for staining mahogany and other wood.

Off. The Roots.

* Vide Bod. in Theophrast. p. 835.

+ Hort. Cant.

$\$$ Sutherland's Hort. Edin. 24, No.7. 


\section{GENTIANA LUTEA.}

\section{Gentian.*}

\section{Class Pentanoria.-Order Digynia.}

Nat. Ord. Rotacee, Linn. Gentiane, Juss.

Gen. Char. Corolla monopetalous. Capsule two-valved, one-celled; with 2 longitudinal receptacles.

Spec. Char. Corolla mostly five-parted, wheel-shaped, surrounding the stems. Calyxes spathy.

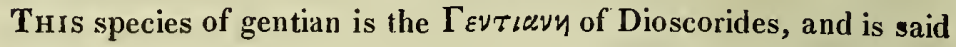
to have been named after Gentius, king of Illyria, who first discovered its medicinal properties, one hundred and sixty-seven years before the birth of Christ. This plant is a native of the Alps and mountainous parts of Germany, it is also found in North America, and according to the Hortus Kewensis, was first cultivated in Britain in the time of Gerarde; the gentian of the shops is supplied by Germany and Switzerland.

This root is perennial, long, cylindrical, externally brown, internally yellowish; the flower stem is strong, smooth, erect, tapering, and rises two or three feet in height ; the leaves which proceed from the lower part of the stem, are spear-shaped, large, entire, ribbed, sessile, and pointed; those on the upper part are concave, smouth, egg-shaped, and of a pale or yellowish green colour, and have five large veins on the back of each; the flowers are large, yellow, produced in whorls, and stand upon strong peduncles; the corolla is divided to its base into five or more long, narrow, spreading elliptical segments; the filaments vary in number from five to eight; they are shorter than the corolla, and furnished with long erect anthers; the germen is long, conical, without a style, and supplied with two reflected stigmata; the capsule is conical, one-celled, and divided into two valves containing numerous small seeds; it flowers in June and July.

Sensible Properties. The root, the only part of the plant used in medicine, has little or no smell, but an extremely bitter

* Fig. $a$. The pistillum, $b$. The anther. 


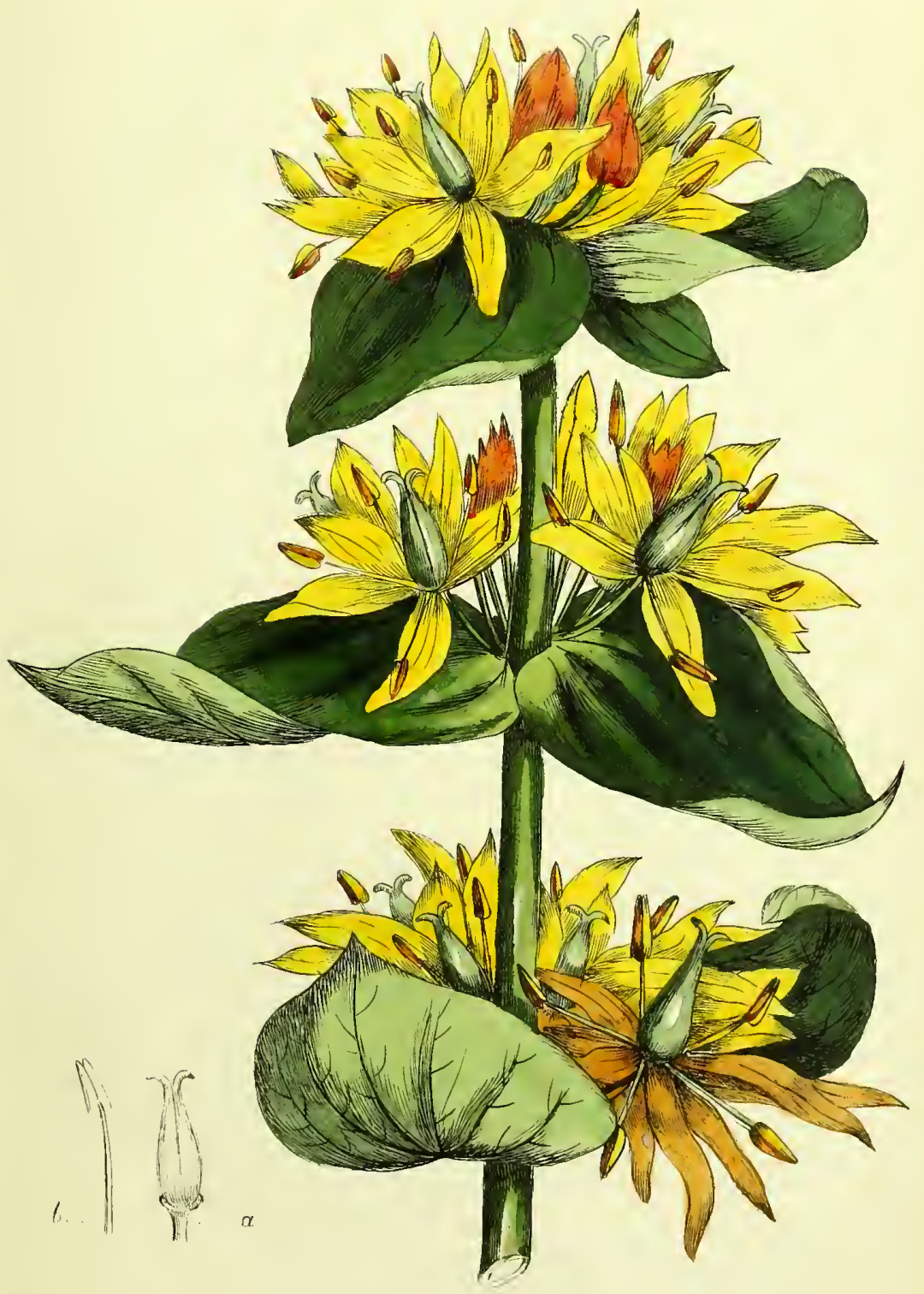

Gentiana Litea. 

taste; not so nauseous as the aloe, nor so aromatic as the chamomile. The bitter principle is extracted by aqueous, vinous, and spirituous menstrua; but in a less degree by the former than the latter. Nenmann however got from 960 grains, 390 alcoholic, and afterwards 210 insipid watery extract; and inversely, 540 watery, and only 20 alcoholic. Lewis notwithstanding says that the extract prepared from the watery infusion, is less bitter than that made from the spirituous tincture.*

Medical Properties, and Uses. Gentian possessing as it does the general virtues of bitters in an eminent degree, without the astringency which characterises some of them, has long been in general use as a tonic and stomachic; besides these properties it acts upon dead animal matter as an antiseptic, and hence has been administered in putrid fever, and other diseases where antiseptic medicines arc indicated; it is likewise considered anthelmintic, emmenagogue, and febrifuge. We are told by Dr. Cullen, that gentian joined with an equal quantity of galls or tormentilla, constantly succeeded in curing intermittents, if given in sufficient quantity. This effect we would be inclined to attribute to its tonic properties, and in dyspeptic complaints, and others arising from debility of the stomach, we can safely recommend the use of gentian, though, as we shall elsewhere have occasion to notice, many practitioners now prefer the different preparations of chamomile, where the organs of digestion are conccrned. As a simple bitter, gentian is rendcred morc grateful by the addition of an aromatic to the infusion, which is the nost general, and perhaps the best form in which it is administered ; for this purpose the Cort. Aurantii is commonly employed.

There are fifty-three species of gentian, and the ronts of some of the other species are said to be equally bitter, and arc indeed preferred by some to the Gentiana Lutea, viz. the Gentiana Purpurea, Asclepiadea, Campestris, Amerilla, \&c. Some years ago, a poisonous root was discovered amoug the gentian brought to London, the use of which occasioned violent disorders, and in some instances deatl. This root may be distinguished from the gentian, by its being internally of a white colour, and devoid of bitterness.

Gentianine. Messrs. Henry and Caventon lave lately discovered a peculiar principle in the roots of gentian, to which they have given the namc of Gentiauine. This substance is yellow, inodorous, possessing very strongly the aromatic bitter taste of the

* Lewis's Materia Medica, p. 320. 
gentian, which is much increased by solution in an acid. It is highly soluble in ether and in alcohol, and separates by spontaneous evaporation in the form of very small yellow crystalline needles. It is much less soluble in cold water, which nevertheless it renders exceedingly bitter; in boiling water it is more readily dissolved. . Diluted alkalies deepen its colour very much, and dissolve rather more of it than water will alone. Acids diminish its yellow colour in a very remarkable manner. With sulphuric and phosphoric acids, the solution is almost colourless; but yellowish with the weaker acids, such as the acetic. Concentrated sulphuric acid carbonizes it, and destroys its bitterness. Exposed in a glass tube to the heat of boiling mercury, Gentianine sublimes in the form of small yellow crystalline needles, and is partially decomposed. It has no sensible effect on turnsol, either when blue or reddened by acids, being apparently neutral.

M. Magendie has ascertained by experiment that this substance is not possessed of any poisonous qualities, several grains injected into the veins producing no effect. He himself swallowed two grains dissolved in alcohol, and was merely sensible of the extreme bitter taste, and a slight sensation of heat in the stomach.

Gentianine has been medicinally employed in the forms of tincture and syrup; and in this way it may be substituted for all purposes, instead of the root in substance, or the various preparations usually made use of.*

Off. The Root.

Off. Pp. Ext. Gentianæ, L. D. E.

Inf. Gent. Comp. L. D. E.

Tinct. Gent. Comp. L. E. D.

Tinct. Rhei cum Gent. E.

Vinum Gent. Comp. E.

* Tincture of Gentianine,

Take of Alcohol at $\mathbf{2 4}^{\circ}, 1$ once.

Gentianine, 5 grains. Mix.

Syrup of Gentianine,

Take of Simple Syrup, 1 livre.

Gentianine, 16 grains. Mix.

Magendie's Formulary. 



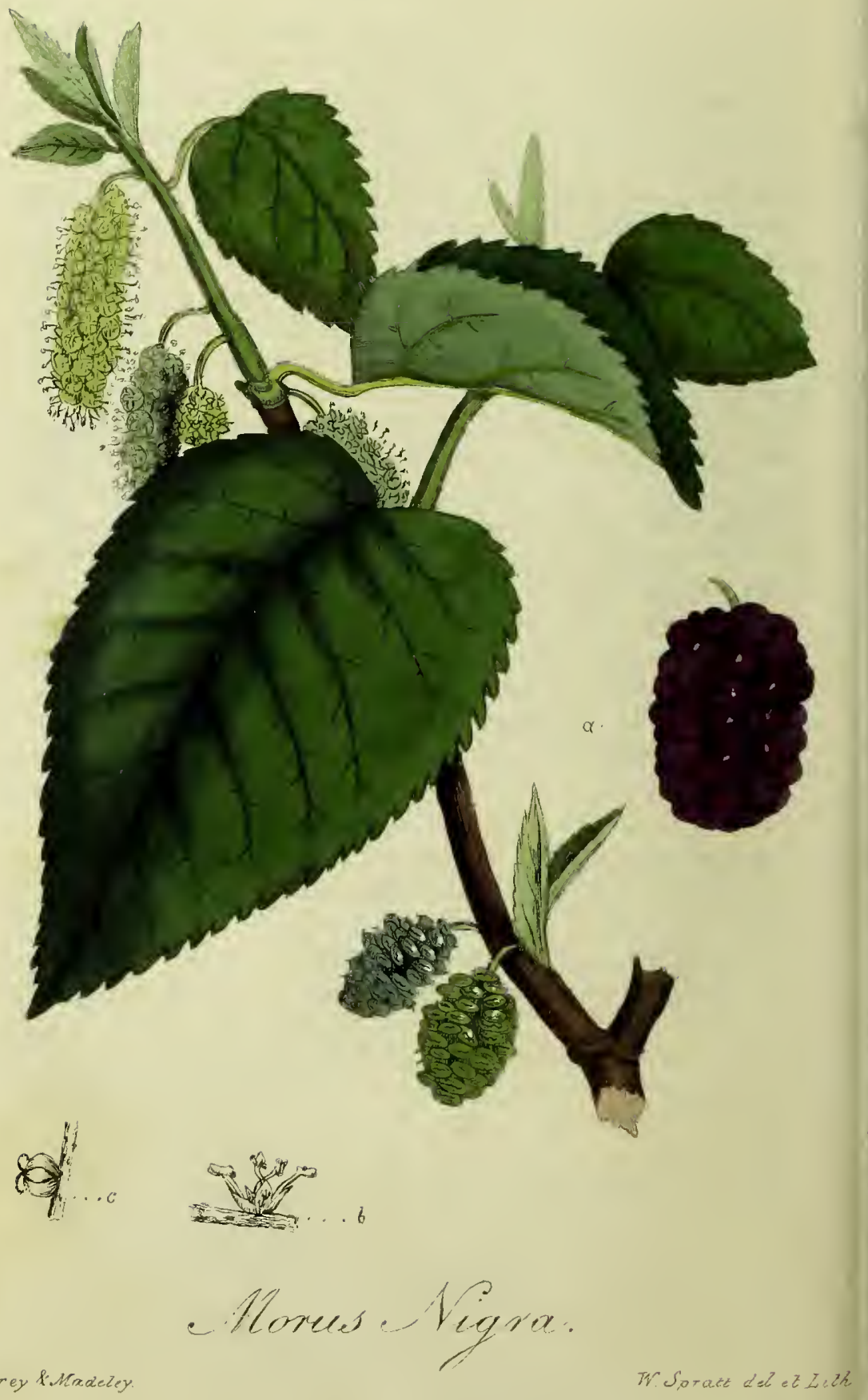




\section{MORUS NIGRA. \\ Common Mulberry Tree.**}

\section{Class Monacia.-Order Tetrandria.}

Nai. Ord. Scabride, Linn. Urtic艮, Juss.

Gen. Char. Male. Calyx 4-parted. Corolla 0. Female. Calyx 4-leaved. Corolla 0. Styles 2. Seed solitary, invested witl the pulpy calyx.

Spec. Char. Leaves heart-shaped, scabrous above, villose underneath.

THIs species of Mulberry is a native of Persia, whence it was brought to Italy, where it became naturalized, and has gradually spread over Europe. It was first introduced into Eng' nd in the year 1596, and is now abuudantly cultivated in most $p_{c}$ 'ts of the country. The flowers are produced in June, and the fruit s ripe in August or September.

This tree rises to the height of about thirty feet, much branched, and covered with a brownish grey bark; the leaves are numerous, cordate, serrated, veined, from three to fonr inclies long, and nearly the same breadth: rough on the upper surface, of a deep green, paler and villous underneath, and stand upon short footstalks; both the male and female flowers are produced upon the same tree; the male flowers are in close roundish catkins, composed of caducous florets, each floret consists of a calyx divided into four, oval, concave, erect segments : inclosing four filaments supporting simple anthers; the female flower's consist of a roundish germen, inclosed in a calyx, resembling that of the male, bearing two retlexed styles, crowned with simple stigmas; the fruit is a large succulent, compound berry, composed of a number of acini, each containing a single seed, and attached to the common peduncle.

There are several species of mulberries, $\dagger$ of which the Morus Alba, a native of China, is much cultivated for the purpose of

* Fig. $\boldsymbol{a}$. The fruit. $b$. The male flower. $c$. The female fower.

+ Five species are cultivated in our botanic gardens, natives of China, Tartary, Italy, North America, and the West Indies. Hort. Cant.

VOL. I. 
feeding silk worms. The Japanese manufacture paper from the inner bark of one species.

QUALITIEs. Mulberries have but little smell, a sweet sub-acid taste, colour the saliva dark violet, and yield rather more than half their weight of a fine reddish juice, which contains tartaric acid, mucus, and jelly.

Medical Properties and Uses. The fruit is cooling and laxative, and like other sub-acid fruits allays thirst, and proves very grateful in most febrile disorders. As a medicine it is seldom prescribed but in the form of the ofticinal preparation, Syrupus Mori, which is chiefly used for the purpose of disguising unpalatable medicines, and giving a finer colour to others. As an article of diet when eaten too freely it is apt to disorder the bowels and produce diarrhœa,

Off. The Fruit.

Off. Pp. Syrupus Mori, L.

\section{COCHLEARIA OFFICINALIS.}

Common Scurvy Grass.*

Class Tetradynamia.-Order Siliculosa.

Nat. Ord. Siliquose, Linn. Crucifere, Juss.

Gen. Char. Silicle emarginate, turgid, rugged; with gibbous, obtuse valves.

Spec. CHAR. Radical Leaves heart-shaped. Stem Leaves oblong, somewhat serrated.

This tribe of plants has derived its generic name from the fancied resemblance of the radical leaves to an old-fashioned spoon. The Cochlearia Officinalis is found growing naturally on the mountains of Scotland and the north of England, but more commonly about the sea shore of those countries, and of Holland. It is culti-

* Fig. a. The anthers. b. The germen. c. A petal. . 


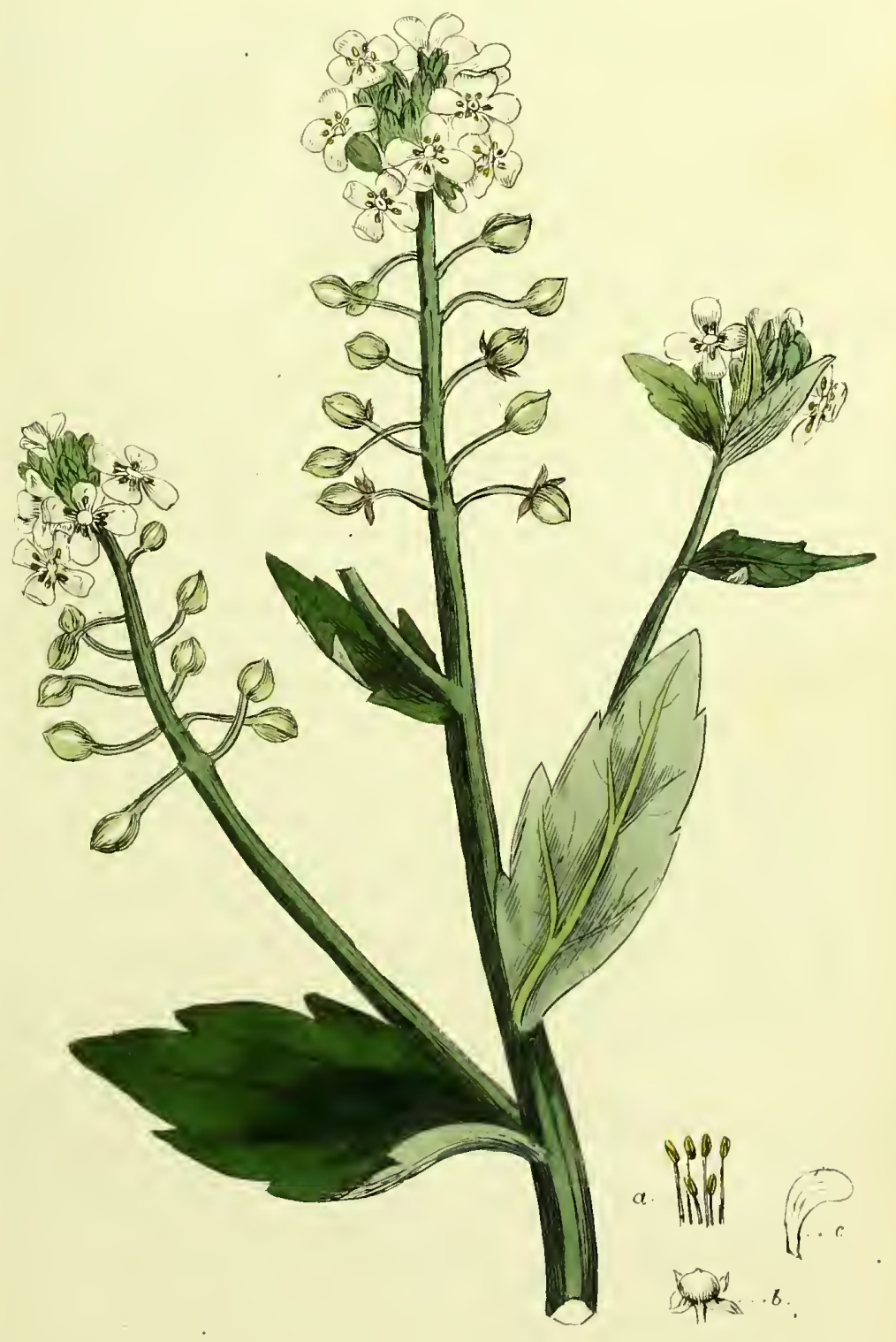

Cochterivia Coffecieralis.

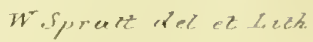



vated for use in the gardens near London, where it differs in no respect from the plants which grow in their native soil. It flowers in April and May.

The root is perennial, fibrous, and usually produces several upright, branching, angular stems, rising from six inclies to a foot in height; the radical leaves are heart or kilney-shaped, hollowed like a spoon, fleshy, succulent, and standing upon long footstalks; the stem leaves are alternate, rlomboidal, blunt, and dentated on each side : towards the top the leaves are sessile, or embracing the stem, but towards the bottom they frequently stand upon sliort, broad footstalks; the calyx consists of four leaflets, which are oval, blunt, concave, gaping, deciduous, and whitisl at the margins; the flowers are cruciform, and stand upon short peduncles in thick clusters, which terminate the branches; the petals are four, white, oval, spreading, and twice the length of the calyx; the filaments, four long and two short, are greenish, tapering, and crowned with yellow anthers; it has no style, and the germen becomes a small roundish, compressed pod, having two celis, divided by a thin partition, in each of which are lodged four or five roundish, rough seeds.

Sensible Properties. This plant has an unpleasant smell, and a warm, acrid, bitter taste; its active principle yields by maceration to both watery and spirituous menstrua, and appears to be of a very volatile nature, the peculiar penetrating pungency totally exhaling in the exsication of the herb, and in the evaporation of the liquors. Its principal virtue resides in an essential oil, obtained by distillation; this oil is so heavy as to sink in water, but of great volatility, subtility, and penetration; one drop dissolved in spirits, or received on sugar, communicates the smell and taste of the plant to a quart of wine or spirits.*

Medical Properties. Scurvy grass is antiseptic, attenuant, aperient, diuretic, and is said to remove obstructions of the viscera, and remoter glands, without irritatiug or heating the system. It is considered the most effectual of all-the antiscorbutic plants; we have the testimony uot only of physicians, but of navigators, in confirmation of this opinion, and it has been noticed that this plant grows most abundantly in those high latitudes where scurvy is most prevalent. Foster found it in great plenty in the islands of the South Sea. A remarkably volatile and pungent spirit, known by the

* Lewis's Materia Medica. 
name of Spiritus Antiscorbuticus, sive, Mixtura Simplex Antiscorbutica, Drawizii,* was found by Werlhofi an useful remedy in paralysis, and other diseases requiring active and powerful stimulants. $\dagger$ Dr. Cullen observes, that the distilled spirit of scurvy grass may probably be improved by the addition of volatile acid of tartar, as in the Spiritus Antiscorbuticus Drawizii, and in this state may be an useful stimulant in paralytic cases. It may also be employed as a diuretic; but as an antiscorbutic, neither this, nor the conserve, promises so much benefit as the fresh plant, eaten as a salad, or the expressed juice in its pure unmixed state. The sensible qualities of this plant are sufficiently powerful to warrant a belief in many of the virtues that are ascribed to it.

Off. The Plant.

Off. Pp. Spiritus Raphani Comp. D.

\section{COCHLEARIA ARMORACIA.}

\section{Horse Radish.}

\section{Class, Order, Nat. Ord. and Gen. Char.} as the preceding species.

Spec. Char. Radical Leaves lance-shaped, notched. Stem Leaves jagged.

THIs plant is the Raphanus Rusticanus of former Pharmacopocias. The root is perennial, long, tapering, white; the stalk is round, erect, branched, smooth, and rises two or three feet in height; the radical leaves are very large, lance-shaped, scolloped at the edges, and stand on strong foot stalks : those of the stalk are inuch smaller, narrow, and often divided at the edges; the flowers are white,

* Fit ex spirita Tartari et spirita 'Cochlearix, quibus Vitriolum, ad rubedinem calcinatum, irrorátur, succedente digestione et destillatione. Murray, Ap. Med. vol, ii: p. 426.

+ Opera, 278. Mat. Med. 241.

$\ddagger$ This plant being so well known, we think it unnecessary to give a figure of it, 
numerous, and terminate the branches in thick clusters; the calyx is composed of four leaves which are egg-shaped, concave, opening, and deciduons; the corolla consists of four inversely egg-shaped petals, which expand in opposite directions and form a cross; they are twice the size of the calyx, and are inserted by narrow claws; the filaments are six, tapering, the two opposite ones shorter than the other four, and all furnisled with blunt compressed anthers; the germen is heart-shaped, supporting a simple style, which is short, permanent, and furnished with an obtuse stigma; the capsule is hcart-shaped, turgid, slightly notched at the end, and furnished with the style; it is divided into two cells, each containing about four seeds.

This plant is frequently found growing wild in many parts of England, particularly about river sides and other moist places. It flowers in May and Junc, but rarely perfects its seeds in this country, which would lead us to think that it is not indigenous. For medicinal and culiury purposes it is cultivated in our gardens.

Sensible Properties. The root of this plant affects the organs both of taste and smell with a quick, penetrating pungency; nevertheless it contains in certain vessels, a sweet juice which sometimes exudes in little drops upon the surface. Its pungent matter is of a very volatile nature, being totally dissipated in drying, and carried off in evaporation, or distillation by water or rectified spirit. As the pungency exhales, the sweet matter of the root becomes more sensible, though this also is in a great mcasure dissipated or destroyed: if kept in a cool place covered with sand, it retains its pungency for a considerable time. By infusion or distillation, it impregnates both water and spirit very strongly with its active matter; in distillation with water, it yields a small quantity of an exceedingly penetrating and pungent essential oil.

Medical Properties. The root of this plant is an extremcly powerful stimulant, whether it be applied externally, or taken internally; taken in to the stomach it stimulates and promotes digestion, and hence its use as a condiment; it likewise proves stimulant to the nervous system, and is therefore useful in palsy; if taken in a large quantity it heats the whole body, and hence it is often useful in chronic rheumatism, Bergius exhibited it by cutting it in small pieces, without bruising, and ordered it to be swallowed, without chewing, to the quantity of a table-spoonful. It has frequently been of service in some kinds of scurvy and other clironic disorders, supposed to proceed from a vicidity of the juices, or obstructions of the excretory ducts. The active matter of horse radish carried 
into the blood vessels passes readily into the kidney, and proves a powerful diuretic; it has accordingly been recommended by Sydenham in dropsies, particularly those which sometimes follow intermittent fevers. One drachm of the fresh root scraped down, infused for two hours in four ounces of water, and made into a syrup, of which a tea-spoonful or two is to be swallowed leisurely, and repeated two or three times, we have found often very effectual in renoving that hoarseness which proceeds from an interruption of the secretion of mucus. Infused in water, and taken witl a large draught of warm water it proves emetic; and may either be thus employed alone, or to assist the operation of other emetics, when narcotic poisons have been takeu into the stomach. Externally applied it readily inflames the skin and proves rubefacient, and if the application be long continued it raises blisters. We are told by Dr. Withering that an infusion of horse radish makes one of the safest and best cosmetics.

Off. The Root.

Off. Pp. Infusum Armoraciæ Compositus, L. Spiritus Armoraciæ Compositus, L. _- Raphani Compositus, D.

END OF THE FIRST VOLUME. 



$1829-F$ Vol. I 
